

\section{Subtle Agroecologies}




\title{
Advances in Agroecology
}

\author{
Series Editor: \\ Stephen R. Gliessman \\ University of California, Santa Cruz, California
}

Land Use Intensification

Effects on Agriculture, Biodiversity, and Ecological Processes

Edited by David Lindenmayer, Saul Cunningham, and Andrew Young

Agroecology, Ecosystems, and Sustainability

Edited by Noureddine Benkeblia

Agroecology

A Transdisciplinary, Participatory and Action-oriented Approach

Edited by V. Ernesto Méndez, Christopher M. Bacon, Roseann Cohen, and Stephen R. Gliessman

Energy in Agroecosystems

A Tool for Assessing Sustainability

Gloria I. Guzmán Casado and Manuel González de Molina

Agroecology in China

Science, Practice, and Sustainable Management

Edited by Luo Shiming and Stephen R. Gliessman

Climate Change and Crop Production

Foundations for Agroecosystem Resilience

Edited by Noureddine Benkeblia

Environmental Resilience and Food Law

Agrobiodiversity and Agroecology

Edited by Gabriela Steier and Alberto Giulio Cianci

Political Agroecology: Advancing the Transition to Sustainable Food Systems

Manuel González de Molina, Paulo F. Petersen, Francisco Garrido Peña, and

Francisco R. Caporal

Urban Agroecology

Interdisciplinary Research and Future Directions

Edited by Monika Egerer and Hamutahl Cohen

Subtle Agroecologies

Farming with the Hidden Half of Nature

Edited by Julia Wright and Nicholas Parrott

Food System Transparency

Law, Science and Policy of Food and Agriculture

Edited by Gabriela Steier and Adam Friedlander

For more information about this series, please visit https://www.crcpress.com/Advances-inAgroecology/book-series/CRCADVAGROECO 


\title{
Subtle Agroecologies \\ Farming With the Hidden Half of Nature
}

\author{
Edited by \\ Julia Wright \\ Contributed by \\ Nicholas Parrott
}

\section{CRC Press}


First edition published 2021

by CRC Press

6000 Broken Sound Parkway NW, Suite 300, Boca Raton, FL 33487-2742

and by CRC Press

2 Park Square, Milton Park, Abingdon, Oxon, OX14 4RN

(C) 2021 Taylor \& Francis Group, LLC

CRC Press is an imprint of Taylor \& Francis Group, LLC

Reasonable efforts have been made to publish reliable data and information, but the author and publisher cannot assume responsibility for the validity of all materials or the consequences of their use. The authors and publishers have attempted to trace the copyright holders of all material reproduced in this publication and apologise to copyright holders if permission to publish in this form has not been obtained. If any copyright material has not been acknowledged, please write and let us know so we may rectify in any future reprint.

Except as permitted under U.S. Copyright Law, no part of this book may be reprinted, reproduced, transmitted or utilised in any form by any electronic, mechanical or other means, now known or hereafter invented, including photocopying, microfilming and recording, or in any information storage or retrieval system, without written permission from the publishers.

For permission to photocopy or use material electronically from this work, access www.copyright.com or contact the Copyright Clearance Center, Inc. (CCC), 222 Rosewood Drive, Danvers, MA 01923, 978-750-8400. For works that are not available on CCC, please contact mpkbookspermissions@tandf.co.uk

Trademark notice: Product or corporate names may be trademarks or registered trademarks and are used only for identification and explanation without intent to infringe.

ISBN: 9781138339811 (hbk)

ISBN: 9780367768874 (pbk)

ISBN: 9780429440939 (ebk)

DOI: $10.1201 / 9780429440939$

Typeset in Times

by codeMantra 
This book is dedicated to Hugh Lovel (1947-2020) pioneer of quantum agriculture and a gentle soul 


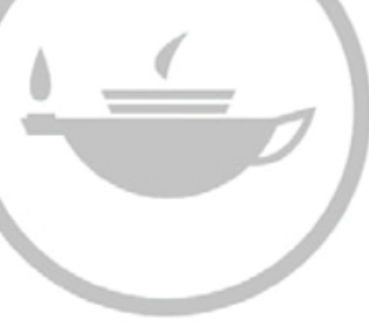

Taylor \& Francis Taylor \& Francis Group http://taylorandfrancis.com 


\section{Contents}

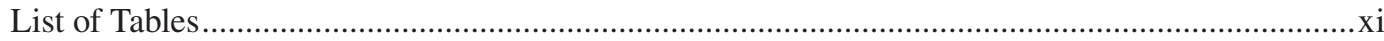

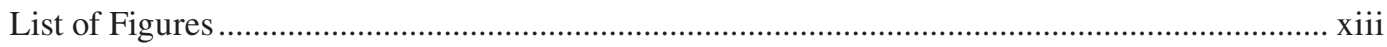

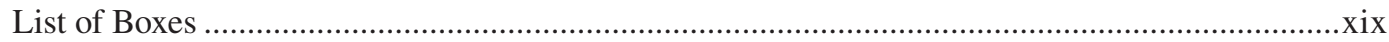

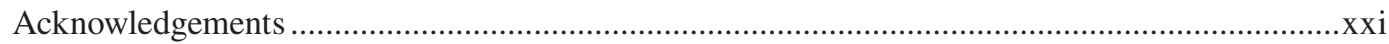

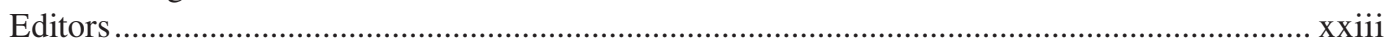

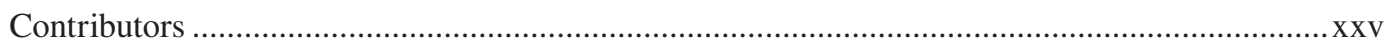

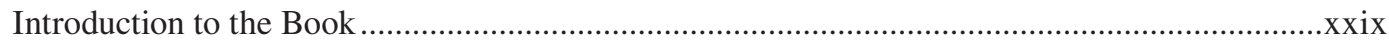

Julia Wright

\section{SECTION 1 Transformative Epistemological, Philosophical and Theoretical Frameworks}

Chapter 1 Re-Enchanting Agriculture: Farming with the Hidden Half of Nature 3

Julia Wright

Chapter 2 From the Mainstreaming of Western Science to the Co-Evolution of Different Sciences: Addressing Cognitive Injustice

Bertus Haverkort

Chapter 3 Conversations with Nature Spirits: The Political Ecology of Power and

Progress in Rural Zimbabwe

Georgina McAllister and Mike Zeddy Chikukwa

Chapter 4 The Forgotten Ground: Recollecting the Primordial Harmony. 49 Joseph Milne

Chapter 5 Humans Are Humus: Using Eco-Psychology to Highlight the Language of Dualism and the Promise of the Non-Dual.

Travis Cox

Chapter 6 A New Science from a Historical Figure: Goethe as Holistic Scientist..... .71 Isis Brook

Chapter 7 From Quantum Biology Towards Quantum Consciousness 81 Jack Tuszyński

Chapter 8 Healing Our Relationship with Gaia through a New Thrivability Paradigm 89 Anneloes Smitsman and Jude Currivan 


\section{SECTION 2 The Intersection of Wave-Based Science and Agriculture}

Chapter 9 Electromagnetic Fields Mitigate Adverse Effects of Environmental

Stresses in Plants 101

Angel De Souza-Torres

Chapter 10 Practical Uses of the Method of Epigenetic Regulation of Protein Synthesis in the Agricultural Field. 111

Victor Prévost, Michel Duhamel, Pedro Ferrandiz, and Joël Sternheimer

Chapter 11 Astronomical Rhythms in Biodynamic Agriculture:

A Brazilian Case Study on the Yield and Quality of

Daucus carota L. under Biodynamic Management.

Pedro Jovchelevich

Chapter 12 Electromagnetic Parameters Related to Plants and Their Microbiomes

Ed Moerman

Chapter 13 Homeopathy Applied to Agriculture: Theoretical and Practical

Considerations with Examples from Brazil 145

Pedro Boff, Rovier Verdi, and Leonardo Felipe Faedo

Chapter 14 Effect of Low-Power Laser Biotechnology Pretreatment on Shooting and Initial Growth of White Mulberry and Sugarcane under Flood Stress 155

Sergio Rodríguez Rodríguez, Eduardo Ortega Delgado, Juan José Silva Pupo, Alexander Álvarez Fonseca, Medardo Ángel Ulloa Enríquez,

and Luis Enrique Arias Basulto

Chapter 15 Fluorescence Excitation Spectroscopy (FES) to Evaluate the Farming

System's Impact on Food Quality 167

Jenifer Wohlers, Peter Stolz, Gudrun Mende, and Jürgen Strube (in Memoriam)

Chapter 16 Picturing Vitality, the Crystallisation Fingerprint Method 179 Paul Doesburg 


\section{SECTION 3 In Search of More Embodied Methodologies}

Chapter 17 Calibrating the Body: Embodied Research Strategies for Attuning to Subtle Information

Eline Kieft

Chapter 18 The Art of Food Rituals as a Practice in Sympoiethics. 203 Miche Fabre Lewin and Flora Gathorne-Hardy

Chapter 19 The Systemic Constellations Method Applied to Agriculture. 219 Melissa Roussopoulos

Chapter 20 Engaging in the Goethean Method: An Approach for Understanding the Farm?. 229

Isis Brook

Chapter 21 Intuitive Farming: Heart-Based Decisions for Harmony in Agricultural Ecosystems 239

Saskia G. von Diest

Chapter 22 An Investigation of Sustainable Yogic Agriculture as a Mind-Matter

Farming Approach 247

Janus Bojesen Jensen

\section{SECTION 4 Voices from the Field}

Chapter 23 The Etheric Realms as a Foundation for Exploring the Use of Radionics with the Biodynamic Preparations

Hugh Lovel

Chapter 24 The Subtle Life of the Bee and Its Importance for Humanity 269 Sabrina Menestrina

Chapter 25 Exploring a Dynamic Role for Water in Agriculture 279 Simon Charter

Chapter 26 Land Whispering: Practical Applications of Consciousness and Subtle Energy Awareness in Agriculture 293

Patrick MacManaway 
Chapter 27 Rediscovering Ancient Pathways for Regenerative Agriculture 305 Charles Massy

Chapter 28 Experiences with the Metaphysics of Nature 315 Michael J. Roads 


\section{List of Tables}

TABLE 0.1 Some Subtle Agroecological Practices (with corresponding chapter numbers in brackets). xxvii

TABLE 1.1 Comparison of Modernist with Indigenous Worldviews of Nature and of Farming........9

TABLE 9.1 Examples of Effects of Electromagnetic Fields of Plants Sown under Abiotic Stress Conditions . 102

TABLE 9.2 Examples of Effects of Electromagnetic Fields of Plants Sown under Biotic Stress Conditions 106

TABLE 10.1 Evaluation Methods Used for Each of the Four Cases 113

TABLE 11.1 Deviations from the Trend Curve (\%) of Fresh Mass of Roots (FMR) and Leaves (FML) and Dry Mass of Roots (DMR) of Carrots, According to the Different Lunar Rhythms, in 2005 and 2006. 128

TABLE 12.1 Reduction and Oxidation in Relation to Plant Growth. 134

TABLE 12.2 Range of Currents and Potential between Ground and Stem Base in Different Types of Trees or Plants . 135

TABLE 13.1 Materia Medica for Some Farm Crops 150

TABLE 14.1 Mean Values of Foliar Bud Length $(\mathrm{cm})$ and Root Aerenchyma Area (in $\mu \mathrm{m}^{2}$ ) in Mulberry Seedlings, Acorazonada Variety, Treated with Laser for 10 Seconds and Evaluated under Flood (F) and Non-Flooded Stress (NF) in the Substrate, and the Control (No Laser Treatment and No Excess Moisture) .... 160

TABLE 14.2 Mean Values of Foliar Shoot Length $(\mathrm{cm})$ and Root Aerenchyma Area (in $\mu \mathrm{m}^{2}$ ) in Sugarcane Seedlings, Variety C90-469, Treated with Laser for 10 Seconds and Evaluated under Flood (F) and Non-Flooded Stress (NF) in the Substrate, and the Control (No Laser Treatment and No Excess Moisture) .... 161

TABLE 20.1 The Four Stage Goethean Approach and Related Human Faculties and Elements.. 236

TABLE 22.1 Affirmations Used by SYA Farmers at Specific Farming Events. 249

TABLE 22.2 Trial of Bread Wheat over One Season, Comparing (a) SYA, (b) Organic and (c) Non-Organic Methods of Agriculture 251

TABLE 22.3 Key Quantitative and Qualitative Benefits of SYA, as Described by Farmers...... 253 


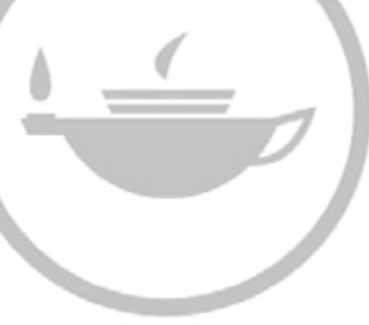

Taylor \& Francis Taylor \& Francis Group http://taylorandfrancis.com 


\section{List of Figures}

FIGURE 1.1 The conceptual frameworks of (a) industrial, (b) agroecological and

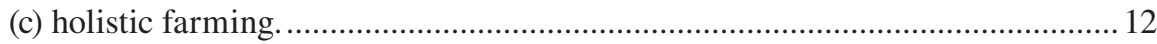

FIGURE 2.1 The three worlds in indigenous sciences and their interactions..........................26

FIGURE 2.2 Creating an enabling environment for endogenous development.

(Source: Haverkort et al., 2003: 250.)................................................................28

FIGURE 2.3 Ritual in a rice field in Sri Lanka. (Photo credit: author's own.) .........................28

FIGURE 2.4 Agnihotra ceremony, India. (Photo credit: author's own.) .................................2 29

FIGURE 2.5 Pacha Mama ritual in the Andes. (Photo credit: author's own.) ...........................30

FIGURE 2.6 Ceremony to seek ancestral support in Zimbabwe. (Photo credit: author's own.) ... 30

FIGURE 2.7 Consultation with the ancestors prior to adopting a new technology, Ghana.

(Photo credit: author's own.) ….............................................................................. 31

FIGURE 2.8 Group of farmers burying cow horns, Staffordshire, UK. (Photo credit:

Alysoun Barrett Bolger.) 31

FIGURE 2.9 Scenario 1: marginalisation: suppression, substitution and selective inclusion. ...34

FIGURE 2.10 Scenario 2: complementarity and co-evolution of different sciences.................... 35

FIGURE 10.1 (a) Evolution of Esca-related mortality rate before and after genodic use.

(b) Esca-related mortality rate before and after genodic use.

FIGURE 10.2 Evolution of the Esca mortality rate compared to the average historical mortality rate ( $N=91$ plots), 1,209,020 vine stocks on 260 ha total, CI 99\%...... 116

FIGURE 10.3 (a-e) Comparison of the evolution of Esca with and without genodic treatment.

FIGURE 10.4 Number of mildew blotches on grapes, on each plot of five vines, as a function of the distance from the broadcasting device.

FIGURE 10.5 (a) Change in percentage of second-grade endives as a function of duration of exposure. (b) Evolution of endive yield as a function of exposure time. 118

FIGURE 10.6 Virus expression as a function of distance from the delivery device (where compliant signifies healthy).

FIGURE 11.1 Fresh mass of roots and leaves (kg, Y-axis) for the different dates of sowing (X-axis) in 2005.

FIGURE 11.2 The per cent deviation from the trend line of the fresh root and leaf mass and dry mass of roots (Y-axis) for the different sowing dates (X-axis) in 2005 .

FIGURE 11.3 The per cent deviation from the trend line of the fresh mass of roots and leaves and dry mass of roots (Y-axis) for the different sowing dates (X-axis) in 2006.

FIGURE 12.1 Phase angle: alternating current (red line) lags $90^{\circ}$ behind alternating voltage (blue line). 
FIGURE 12.2 Resistance-capacitance (RC) circuits according to the revised model: $(\mathrm{a}, \mathrm{c})$ diagrams of barley plants with five root tips, $(b, d)$ electrical equivalent networks of the root systems showing the location of the RC components, (a,b) RC circuits for a completely submerged root system and (c,d) RC circuits for a partly submerged root system. The sub-circuit that largely determines the capacitance is ringed to emphasise its importance.

Note that the individual RC components can have different values.

FIGURE 12.3 Correlation between gram dry root weight per plant (X-axis) and phase angle (Y-axis).

FIGURE 12.4 Simple LCR meter (a) and voltmeter (b) used for measurements of cucumber plants in pots. (c) The grounding probe and (d) a crocodile clamp on a needle inserted into the stem at the plant base.

FIGURE 13.1 Levels of coherence/similarities to help select what needs to be healed. (Adapted from Manzalini and Galeazzi, 2019)

FIGURE 14.1 Percentage of vegetative bud breaks in mulberry, variety Acorazonada, produced by the effect of two laser treatments (10 and 20 seconds) plus the control (graph a), assessed at 15 and 30 days from the initiation of treatments (graph b), and the combination of the two (graph c). Different letters indicate significant differences at $p<0.05$ using Tukey's test.

FIGURE 14.2 Percentage of vegetative bud break in sugarcane, variety C90-469, produced by the effect of two laser treatments (10 and 20 seconds) plus the control (graph a), assessed at 15 and 30 days from the initiation of treatments (graph b), and the combination of the two (graph c). Different letters indicate significant differences at $p<0.05$ using Tukey's test.

FIGURE 14.3 Histological cross section. (a) Mulberry root, Acorazonada variety, with laser application for 10 seconds in conditions of excess water; (b) mulberry root, Acorazonada variety, with no application of laser rays in conditions of excess water; (c) sugarcane root, variety C90-469, with laser application for 10 seconds in conditions of excess water; and (d) sugarcane root, variety C90-469, with no application of laser rays in conditions of excess water. 161

FIGURE 15.1 Schematic overview of the FES measuring apparatus with $90^{\circ}$ position between excitation illumination and emission detection by photomultipliers.

The time sequence between excitation and emission is regulated by shutters. ... 169

FIGURE 15.2 Schematic illustration of the excitation and measuring interval and a characteristic declining curve of the delayed emission. Mw1 indicates the short-time emission, and R40 indicates the long-term emission. 169

FIGURE 15.3 Differences between the wheat samples collected over 6 (O2 and K2) and 8 years (D2 and $\mathrm{M})$, on the basis of mean values per year and farming system (standardised by year of harvest). Whiskers indicate standard error of the mean. D2=biodynamic; $\mathrm{O} 2=$ organic; $\mathrm{K} 2=$ conventional (manure + mineral); $\mathrm{M}=$ mineral fertilisation only.

FIGURE 15.4 R40yellow/blue of whole apples and their seeds at different maturation stages. Whiskers indicate standard error of the mean. An increasing divergence of the induced emission of whole apples and their kernels during maturation was observed, these being indicated on the figure by the crossing of the lines. 
FIGURE 15.5 R40yellow/blue of whole apples from different growing conditions (light intensity and application of biodynamic preparations).

FIGURE 15.6 Fluorescence excitation spectrum of different kinds of samples: emission of leaves (dried crushed nettle leaves), of seeds (whole wheat kernels) and of citric acid. (Derived from Strube and Stolz, 2001a.)

FIGURE 15.7 Emission intensity (R40yellow) of fermented whole cocoa beans from a cultivation trial. Whiskers indicate standard error of the mean.

FIGURE 15.8 Differences between conventional and organic farming in cocoa beans in the relative emission intensity of R40yellow/blue.

FIGURE 16.1 Product-specific crystallisation patterns of barley (left), tomato (middle) and white cabbage (right).

FIGURE 16.2 Crystallisation patterns of the effect of milk processing: raw unprocessed milk (left) and the same sample after homogenisation at 50 bar (right).. 181

FIGURE 16.3 Crystallisation patterns of different ripening stages of vine tomatoes: unripe, little structure and condensed patterns (left); ripe, structure and cohesion (middle); and overripe, loss of structure and cohesion (right).

FIGURE 16.4 Crystallisation patterns of fresh (left) and aged carrot juice (right, after 7 days of storage at $4^{\circ} \mathrm{C}$ ).

FIGURE 16.5 Enlarged details of crystallisation patterns of a wheat aging series. Left: fresh extract; middle: extract stored for 3 days at $4^{\circ} \mathrm{C}$; and right: extract stored for 12 days at $4^{\circ} \mathrm{C}$

FIGURE 16.6 Crystallisation patterns of 12-day-aged wheat extract originating from a long-term DOC field study (FiBL, CH). Photos bottom: whole images; and top: enlarged details. Biodynamic wheat (left), organic wheat (middle) and conventional wheat (right). (Images: J. Fritz, Uni Bonn, Germany.). 185

FIGURE 18.1 Buddha resisting the temptation of Mara. (Image credit: Exotic India Art.) ......204

FIGURE 18.2 FieldTable prepared for participant diners. (Image credit: Eva van Niekerk.) ...208

FIGURE 18.3 Participants walking up the farm track to the entrance of the field. (Image credit: Eva van Niekerk.)..................................................................208

FIGURE 18.4 The field shrine to FieldTable. (Image credit: Eva van Niekerk.).....................209

FIGURE 18.5 Being in silence to encounter the genius loci, the grazing cattle and the table of food. (Image credit: Eva van Niekerk.)

FIGURE 18.6 Reading FieldTable menu of dishes from the season's bounty. (Image credit: Eva van Niekerk.)

FIGURE 18.7 A plate of locally and naturally grown 'bare awakening food' composed of: poached asparagus; brochettes of biltong, pickled beetroot and horseradish paste; marinated kohlrabi; broad beans with freshly made mayonnaise; salted lemon chard; fermented cabbage; butternut squash puree with oregano; grilled red spring onions; raw whole carrot and boiled egg in shell. (Image credit: Eva van Niekerk.).

FIGURE 18.8 Participants conversing at FieldTable. (Image credit: Eva van Niekerk.) 
FIGURE 18.9 A young farmer sharing his passions and aspirations for change.

(Image credit: Eva van Niekerk.).

FIGURE 18.10 Tasting rosemary-infused water. (Image credit: Eva van Niekerk.)

FIGURE 18.11 Breaking bread as a gesture of companionship. (Image credit:

Eva van Niekerk.).

FIGURE 18.12 Soil Shrine making visible examples of natural methods for increasing soil fertility through composting foodwaste and growing clover as a nitrogenfixing plant. The sprigs of rosemary call us into remembrance. (Image credit: Eva van Niekerk.)

FIGURE 18.13 Leftover food emptied into a bokashi bin. This Japanese fermentation method prepares foodwaste to become a natural fertiliser for soil regeneration. (Image credit: Eva van Niekerk.).

FIGURE 18.14 At the end of the meal, participants write about their experiences of FieldTable and reflect on how their hunger has been satisfied. (Image credit: Eva van Niekerk.). 214

FIGURE 18.15 FieldTable was set up and completed in a day. (Image credit: Touchstones.)... 214

FIGURE 18.16 FieldTable manifests in 2016 as a convivial, local and agroecological narrative to counter the 1976 Union Carbide advert promising synthetic and genetically modified solutions to world hunger. (Image credit: Eva van Niekerk.). 215

FIGURE 22.1 Bar chart showing yield $(\mathrm{kg} / \mathrm{ha})$ of wheat grain and stover from SYA, organic and non-organic treatments. (Adapted from Pandey et al. (2015).)...... 252

FIGURE 23.1 The author in a field of maize undersown with soybeans with radionically applied biodynamic preparations and no other fertility inputs, in metre wide beds spaded into the soil food web. (Photo credit: Hugh Lovel).....

FIGURE 23.2 Field Broadcaster (left) and radionic instrument with cards (right). (Photo credit: author's own.) 265

FIGURE 24.1 'VITA NOVA' (New Life) by Julia Artico, Villa Maser, Treviso, Italy. ........... 276

FIGURE 25.1 Spiral vortex geometry. (After Edwards, 2006.) 281

FIGURE 25.2 Spiral vortex. (Photo courtesy of Institute of Flow Science, Wilkens et al., 2005.)

FIGURE 25.3 Spiral vortex in free water, viewed from above. (Photo credit: Simon Charter.) 283

FIGURE 25.4 Ring vortex, smoke in air. (Photo credit: stock image from pinterest.com.) ....283

FIGURE 25.5 Ring vortex viewed from the side, made using marker dye in water, pushed in a slow pulse from the tube below. (Photo credit: by kind permission Andreas Wilkens, Institute of Flow Sciences, Herrischried, Germany, www.stroemungsinstitut.de.)

FIGURE 25.6 Water falling into a pool by Leonardo da Vinci, circa 1511. Original drawing held in the Royal Library Windsor (no 12660). (Reproduction courtesy Royal Collection Trust/(C Her Majesty Queen Elizabeth II 2020.) .... 284 
FIGURE 25.7 Collapsing ring vortex in water, seen end-on, as it slowly encounters a perpendicular glass wall. Top left shows the almost undisturbed toroidal ring, which changes through the forms to the bottom right where the form is beginning to disperse. (Photo credit: by kind permission of the Institute of Flow Science. Wilkens et al., 2005.)

FIGURE 25.8 Rhythmic pattern of alternating vortices (also known as the Kármán vortex street). (Photo credit: Simon Charter.) 286

FIGURE 25.9 'Malmo' Flowform Design by John Wilkes, Nigel Wells and Nick Weidmann. (Photo credit: Imke Naudascher.)..... 288

FIGURE 25.10 'Vortex’ Flowform Design, by John Wilkes, Nick Weidmann and Michael Monzies. (Photo credit: Simon Charter.)..........................................289

FIGURE 26.1 Brussels sprouts eaten by dragon in Scotland..............................................296

FIGURE 26.2 Cancerous burls on spruce trees in Vermont. ..................................................297

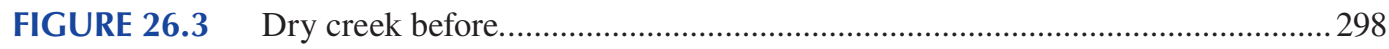

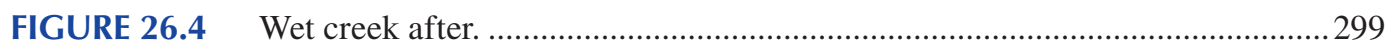




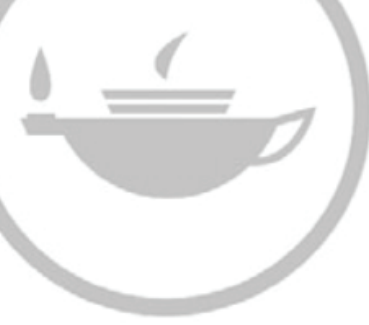

Taylor \& Francis Taylor \& Francis Group http://taylorandfrancis.com 


\section{List of Boxes}

BOX 1.1 Two Examples of Farming Practice Based on Indigenous Ontologies....................... 13

BOX 2.1 Different Worldviews, Ways of Learning and Ways of Knowing ..............................24

BOX 12.1 Explanation of the Usefulness of Different Electrical Parameters (Northolt et al., 2004: 56) ................................................................................... 139

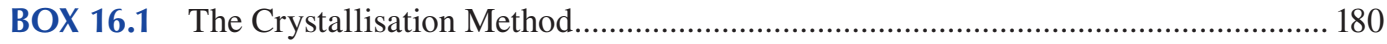




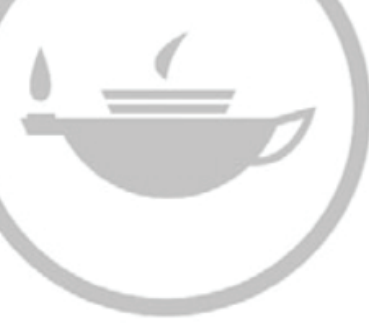

Taylor \& Francis Taylor \& Francis Group http://taylorandfrancis.com 


\section{Acknowledgements}

It was Alice Oven of Taylor \& Francis who made this book happen, through her proactive commissioning. The concept itself had already been brewing for a few years, and many people are integral to its development, including Michael Roads for awaking so many people to the metaphysics of nature, Hugh Lovel and Henk Kieft for their impetus on quantum agriculture, several colleagues and friends for enjoyable conceptual explorations, and all the inspiring practitioners from around the world. The international lockdown of 2020 provided the spaciousness for the book's completion.

A big thank you to all the contributors to this book; your courage and trust is appreciated. Also to Nick Parrott who stepped in to support the editing process; even so the first editor is responsible for the concept and directive content of the book.

Finally, thank you to Michel Pimbert, Director of the Centre for Agroecology, Water and Resilience at Coventry University, who has charmingly created a safe space in academia from which this offering emerges. 


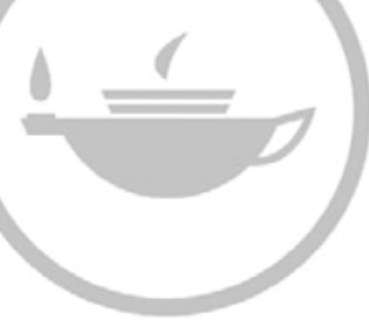

Taylor \& Francis Taylor \& Francis Group http://taylorandfrancis.com 


\section{Editors}

Julia Wright has a background in international research and development, seeking to integrate ecological (organic and permaculture) thinking into conventional agricultural systems and organisations, including in humanitarian settings. After studying at Trinity St David (University of Wales), Silsoe College (Cranfield University) and Wye College (London University), she worked for some years in South America before undertaking a $\mathrm{PhD}$ at Wageningen University, The Netherlands, on the coping strategies of the Cuban farming sector during the country's period of food and fuel shortages in the 1990s, resulting in the Earthscan publication Sustainable Agriculture and Food Security in an Era of Oil Scarcity: Lessons from Cuba (2009). Returning to the UK in 2003 to lead the International Programme of the organic NGO Garden Organic (formerly the Henry Doubleday Research Association), in 2011 she was involved in establishing the Centre for Agroecology, Water and Resilience at Coventry University, where she has since been developing a research programme in the applied discipline of Subtle Agroecologies.

Dr Nicholas Parrott has been a freelance English-language editor since 2002, providing support to non-native English-speaking academics and NGOs for the publishing of books, articles, reports and doctoral theses on sustainability, agroecology and rural development. Prior to this, he was a research associate at the universities of Aberystwyth and Cardiff, and a European Parliamentary candidate for the UK Green Party. He has lived and worked in Wageningen, the Netherlands, and Brussels, Belgium, and is now based in Hendaye, south-west France. One of his most important works is The Real Green Revolution: Organic and Agroecological Farming in the South (Parrot and Marsden, 2002), which has been translated into multiple languages. His company has clients from around 20 different countries (www.TextualHealing.eu). 


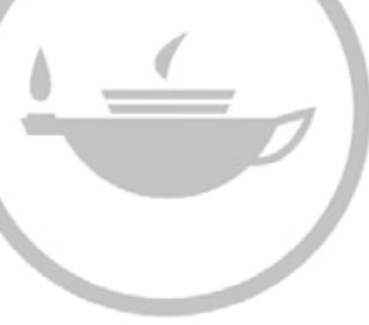

Taylor \& Francis Taylor \& Francis Group http://taylorandfrancis.com 


\section{Contributors}

\author{
Alexander Álvarez Fonseca \\ Center for Research, Services and \\ Environmental Technologies \\ Research Agricultural Institute 'Jorge Dimitrov' \\ Bayamo, Cuba

\section{Luis Enrique Arias Basulto} \\ Department of Agricultural Production \\ Faculty of Agricultural Science \\ Plant Biotechnology Study Center \\ University of Granma \\ Bayamo, Cuba

\section{Pedro Boff} \\ Laboratory of Homeopathy and Plant Health of \\ Lages Experimental Station \\ Agricultural Research and Rural Extension \\ Agency of Santa Catarina State (EPAGRI), \\ Brazil \\ and \\ Interdisciplinary Post-graduate School \\ University of Planalto Catarinense \\ Lages, SC, Brazil
}

\section{Janus Bojesen Jensen}

Centre for Agroecology, Water and Resilience

Coventry University

Coventry, United Kingdom

\section{Isis Brook}

Crossfields Learning

Crossfields Institute

Stroud, United Kingdom

\section{Simon Charter}

Ebb and Flow Ltd

Nailsworth

United Kingdom

\section{Mike Zeddy Chikukwa}

Chikukwa Ecological Land Use Community Trust (CELUCT)

Chimanimani, Zimbabwe

\section{Travis Cox}

Naropa University

Boulder, Colorado, USA

\section{Jude Currivan}

WholeWorld-View

\section{Saskia G. von Diest}

Department of Conservation Ecology and Entomology

Stellenbosch University

Stellenbosch, South Africa

\section{Paul Doesburg}

Society for Cancer Research

Hiscia Research Institute

Arlesheim, Switzerland

\section{Michel Duhamel}

Genodics SAS

Paris, France

\section{Miche Fabre Lewin}

Centre for Agroecology, Water and Resilience

Coventry University

Coventry, United Kingdom

\section{Leonardo Felipe Faedo}

Agroveterinary Science Centre

Santa Catarina State University

Lages, SC, Brazil

and

Centre for Agroecology, Water and Resilience

Coventry University

Coventry, United Kingdom

\section{Pedro Ferrandiz}

Genodics SAS

Paris, France

\section{Flora Gathorne-Hardy}

Centre for Agroecology, Water and Resilience

Coventry University

Coventry, United Kingdom

\section{Bertus Haverkort}

the Netherlands 


\section{Pedro Jovchelevich}

Brazilian Association of Biodynamic Agriculture

Brazil

\section{Eline Kieft}

Clover Trail

Winchester Institute for Contemplative

Education and Practice (WICEP),

University of Winchester

Winchester, United Kingdom

and

Centre for Agroecology \& Water Resilience (CAWR)

Coventry University

Coventry United Kingdom

\section{Hugh Lovel}

USA

\section{Patrick MacManaway}

United Kingdom

\section{Charles Massy}

Fenner School of Environment and Society

Australian National University

Canberra, Australia

\section{Georgina McAllister}

Centre for Agroecology, Water and Resilience

Coventry University

Coventry, United Kingdom

\section{Gudrun Mende}

Forschungsinstitut KWALIS gGmbH

Dipperz, Germany

\section{Sabrina Menestrina}

Anthroposophical Veterinary Medicine, Medical Section, the Goetheanum

Dornach, Switzerland

\section{Joseph Milne}

University of Kent

Canterbury, United Kingdom
Ed Moerman

R\&D Agronomic Development

Koppert Biological Systems

Berkel en Rodenrijs, the Netherlands

\section{Eduardo Ortega Delgado}

Faculty of Biology

Laboratory of Plant Physiology

University of Havana

Havana, Cuba

Victor Prévost

Genodics SAS

Paris, France

\section{Michael J. Roads}

Australia

\section{Sergio Rodríguez Rodríguez}

Faculty of Agricultural Science

Plant Biotechnology Study Center

University of Granma

Bayamo, Cuba

\section{Melissa Roussopoulos}

Independent Researcher

Forgotten Connections

United Kingdom

\section{Juan José Silva Pupo}

Faculty of Agricultural Science

Plant Biotechnology Study Center

University of Granma

Bayamo, Cuba

\section{Anneloes Smitsman \\ EARTHwise Centre}

\section{Joël Sternheimer}

Réseau Associatif de Chercheurs Indépendants (RAChI)

Université Européenne de la Recherche

Paris, France

\section{Angel De Souza-Torres}

Faculty of Technical Sciences

Department of Physics and Mathematics

Granma University

Granma, Cuba 


\section{Peter Stolz}

Forschungsinstitut KWALIS gGmbH

Dipperz, Germany

\section{Jack Tuszyński}

Department of Oncology

University of Alberta

Edmonton, Canada

and

Department of Physics

University of Alberta

Edmonton, Canada

and

DIMEAS

Politecnico di Torino

Torino, Italy
Medardo Ángel Ulloa Enríquez

Technical University of Cotopaxi

Latacunga, Ecuador

\section{Rovier Verdi}

Agroveterinary Science Centre

Santa Catarina State University

Lages, SC, Brazil

and

Centre for Agroecology, Water and Resilience

Coventry University

Coventry, United Kingdom

Jenifer Wohlers

Forschungsinstitut KWALIS gGmbH

Dipperz, Germany 


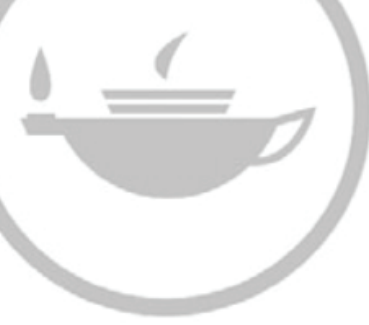

Taylor \& Francis Taylor \& Francis Group http://taylorandfrancis.com 


\title{
Introduction to the Book
}

\author{
Julia Wright
}

If you talk to animals, they will talk with you

and you will know each other.

If you do not talk to them you will not know them

and what you do not know you will fear.

What one fears one destroys.*

\section{THE NATURE OF THE INVISIBLE: RECONCILING SCIENCE AND SPIRITUALITY}

This book examines the principles and practices of farming and food systems from the perspective that half of life is not visible to us. Everything that we know (and do not know) about the physical world has an invisible, subtle counterpart that has been scarcely considered in the farming practices or research of modernist cultures. Subtle Agroecologies is not a farming system in itself, but superimposes a non-material dimension upon existing, materially based agroecological farming systems.

By visible, we are talking about that which is physical and material, things that can be observed and measured. Seeing the world chiefly as matter, and also as operating according to mechanical laws, is characteristic of the Newtonian - Cartesian philosophical paradigm of sixteenth- and seventeenth-century Europe. Yet even during this period, philosophers and scientists were continuing to hold, explore and debate a range of other theories and beliefs of a non-material nature. Newton himself, for example, held deep theological interests covering alchemy, spirituality and lost Biblical works (Chambers, 2018), and historian John Brooke provides a fascinating account of how the development of the secular-material perspective held by modernist societies today was more a factor of politics and power than of being arrived at through scientific study (Brooke, 1991).

So what do we mean by invisible or non-material? It is that which we cannot see or initially perceive with our five basic senses, a dimension that may be described in secular terms as involving vibrational energy, consciousness, ether, sentience/intelligence and/or electromagnetic or sound waves/frequencies. Research advances continue to open up a broader and deeper understanding of this dimension, including through the disciplines of quantum mechanics, consciousness and phenomenological studies, bioelectromagnetics, chronobiology, sonochemistry, neuroscience and transpersonal psychology. Meanwhile, our lives are increasingly facilitated by the technological applications of such advances.

Independent of scientific advances is the belief in, and experience of, invisible realms and phenomena, ranging from the non-allopathic, energy-based medical systems and the practices of mindfulness and martial arts, to the innate societal recognition of human intuition and premonition. The majority of the world's cultures continue to regard the invisible dimension as a matter of course, and may perceive it as a spirit realm and/or involving subtle forces or entities (Berkes, 1999; Peat, 2005). Even in Western Europe where such a worldview appears not to be the norm and where such beliefs - and corresponding behaviours and practices - are commonly adopted from other cultures, relevant indigenous, place-based traditions are being reclaimed and revived, some having been forced to go underground during certain periods in history (see, e.g., Arlow and Adam, 2011; Marrable, 2019; Timmons, 2006; Uzzell, 2019).

\footnotetext{
* 'My Heart Soars' from The Best of Chief Dan George, copyright 2004 by Hancock House Publishers Ltd., ISBN 978-088839-544-3, used with permissions - www.hancockhouse.com.
} 
Following this, the concept of Subtle Agroecologies holds two ontological perspectives that diverge from the secular-materialistic worldview. One is the basic existence of an invisible dimension to nature. The second concerns the nature of this dimension, as potentially involving not only light- and sound wave-based and magnetic field-based phenomena - some of which we now have the technology to capture and measure - but also more ethereal aspects of consciousness and/or spirit. The term spirit is variously interpreted, and here it is defined as a vital principle or animating force within all living things which is inextricably linked to consciousness (Smith, 2020). Also known as panpsychism - the view that everything has a mind - soul (Bruntrup and Jaskolla, 2017) - this definition of spirit holds resonance across indigenous cultures. Returning to Brooke's historical review of the relationship between science and spirituality, any conflicts between the two have, he reminds us, been overplayed and are simply a relatively recent development of Western Europe, instigated by political, social and economic factors (Brooke, 1991). This book takes an open minded approach to explore these concepts in the field of agriculture.

\section{INTRODUCING THIS BOOK: THE CHALLENGES OF TRANSDISCIPLINARY AND ONTOLOGICAL DIVERSITY}

Agriculture as a philosophy is eminently positioned to explore a range of existential questions relating to who we are, why we are here and the nature of reality, all grounded in the practicalities of farming. In his examination of mankind's sense of the sacred, Gregory Bateson argues that our spiritual sense arises from the recognition that we are part of nature and part of a creative wholeness and that it is only through this recognition that we may avoid ecological disaster (Bateson, 1987). Deep interaction with nature through the practice of farming provides the opportunity for this recognition to arise, and at the same time farming holds some of the keys to averting such disaster. For example, evidence from the organic farming sector shows that one does not have to hold sympathetic beliefs in order to start implementing more ecologically based farming practices, yet such practice may cause one's beliefs to change (Hall and Mogyorody, 2001).

This book could have taken many philosophical directions and it is beyond the physical scope of one volume to comprehensively cover such a vast subject. Instead, the book makes a solid contribution through the presentation of a collection of curated essays or chapters, to serve as both a foundation stone and inspiration for subsequent research on the invisible dimension of agriculture. Each contributor to the book has written a stand-alone chapter, and contributing to this book does not mean that she or he ascribes to any or all of the other contributions, coming as they do from a range of different perspectives. The contributors span 12 countries across 5 continents, comprising Australia, Brazil, Canada, Cuba, France, Germany, the Netherlands, South Africa, Switzerland, the UK, the USA and Zimbabwe. Care has been taken to include contributions not only from experienced researchers but also from early-career and doctoral scholars.

Sustainable farming requires the farmer to be a Jack- or Jill-of-all-trades, holding knowledge in many subject areas, and the main challenge of this book has been to manage this multi- and transdisciplinary nature and the resulting content. Transdisciplinarity in the research context works both between and across the disciplines, as well as beyond them (Pimbert, 2018). This book therefore encompasses academic and industry contributors from the natural and social sciences as well as the arts and humanities. In terms of going beyond the formal academy, the Agricultural Knowledge System serves as a useful epistemological framework to identify the agricultural knowledge sources as well as the knowledge processes, flows and interactions between all stakeholders involved farmers and their households and communities, as well as researchers, advisors, enterprises, NGOs and so on (EIP-AGRI, 2018). Science takes just one seat around this table; it is the farmers and growers, and others in their communities, who are the real experts of, and decision-makers about, their own agroecosystems based on local agroclimatic and sociocultural conditions. This book suggests that farmers and others working close to the land are also the interlocutors with another source of knowledge: the hidden half of nature. Nature as a primary knowledge source has yet to be 
included in Agricultural and Ecological Knowledge Systems frameworks. Yet sourcing knowledge and making sense of it, for the farmer, may involve not only standard reasoning, experiencing, sensory perceiving and communicating with other humans, but also, as we will see, conscious intention, intuition, direct knowing or communication with the other-than-human.

This transdisciplinary context, and the fact that many of the topics explored in this book have not yet been widely researched, has necessitated extending the range of book contributors beyond the formal research academy. The knowledge holders include skilled practitioners or practitionerresearchers who are quite literally operating in the field, and their non-academic contributions in this book provide very different ontological perspectives or lenses through which the concept of Subtle Agroecologies may be approached.

In this book, the challenges of multidisciplinarity and ontological diversity rested to a large extent with the contributors themselves. With such a broad potential readership, they were required to write as if for the layperson rather than for others in their particular discipline, and this necessitated setting aside discipline-specific terminology or an assumed prior knowledge of the subject. In some instances, the setting aside of ontologically-specific terminology was also required. Therefore, some of what is communicated in these pages may be simplified versions of what contributors would share amongst their own peer groups.

\section{BOOK OVERVIEW: A CONTRIBUTION OF PHILOSOPHIES, TECHNOLOGIES, METHODOLOGIES AND PRACTICE}

The book's content is organised into four clusters or sections. The first section is dedicated to providing a range of philosophical and theoretical perspectives as a 'way in' to this subject. The second section demonstrates existing, pioneering, commercial, largely wave-based applications in agriculture. The third explores innovative and appropriate methodologies for researching and working with the hidden half of nature, whilst the fourth and final section is dedicated to the non-academic voices of practitioners who are working directly in agriculture and associated fields.

\section{Section 1: Transformative Epistemological, Philosophical and Theoretical Frameworks}

This section, and the whole book, kicks off with a provocative look at what may be behind the secular materialistic approach of the agricultural sector (Chapter 1, Wright). Drawing from the works of two contemporary scholars of neurobiology and psychology, the chapter explores how Western European culture and society may be a product of a left hemisphere-dominant brain and how this irregularity, along with the widespread denigration of the feminine, may be both the cause and hold the keys to a way out of - the current industrial, secular-materialist paradigm, a way out that would necessarily include the revival and reclaiming of whole-brain, indigenous worldviews. Through a critical examination of modernist, ecologically-based farming movements, it deduces that to date, their science and taught practice also stems from this paradigm. The chapter introduces the concept of Subtle Agroecologies as a means of re-enchanting or reviving ecologically-based agriculture and argues that through its application, we might not only desist from harming nature but might also be better equipped to co-create more harmonious farming futures.

Chapter 2 (Haverkort) takes forward the issue of indigenous knowledge and worldviews though the lens of the need for cognitive justice. It asserts that local ways of knowing are expressions of science on their own, being based on a specific worldview, methodology of learning, epistemology and values of their own knowledge community. Identifying the commonality amongst these worldviews of three dimensions - the spiritual, social and material - it provides examples of the spiritual dimension of agricultural systems from different cultures. The chapter suggests that a constructive combination of a diversity of sciences holds greater potential to address the multifaceted problems 
the world is facing than a sole reliance on mainstream science and concludes by outlining how inter-science cooperation may function. Chapter 3 (McAllister and Chikukwa) continues with the critique of developmentalism, structured as a series of musings between a community activist and a political ecologist in Zimbabwe's Eastern Highlands. Lamenting the erosion of bio-cultural diversity, knowledge and social connection through colonial interventions since the end of the nineteenth century, it suggests how farming approaches that reconnect people to one another and their landscape are being undermined by coercive power relations and sometimes violent environments. Yet throughout this persists the community knowledge of the spirits that inhabit the natural world, the ancestors and the sacred places, and the need to preserve and maintain relationships with these. In particular, the relationship between mermaids and the recent devastating cyclones is discussed, demonstrating the striking coexistence of different worldviews.

Chapter 4 (Milne) turns to a thoughtful philosophical reflection on reconnecting with the ancient sense of nature as originally intuited in cosmological myths and later with the rise of Greek philosophy. It demonstrates how the rational and the ethical were once always connected, and that these provided a society with its sense of being part of nature and of the greater cosmic order. Focusing on the example of ownership and right use of property, it traces the rise of natural law in the Middle Ages and how the emergence of the mechanistic vision of nature in the seventeenth century led to Western society losing its participatory relationship with nature, with the consequences of commercial exploitation and environmental abuse. It concludes on a positive note with the reminder that all people have an innate sense of the whole and a moral call to live in harmony with nature. Chapter 5 (Cox) takes the example of soil to explore non-dualism from an eco-psychology perspective. This chapter suggests that the current move in the environmental humanities to develop a fuller picture of human relationships to soil will be thwarted if it doesn't overtly challenge the assumptions of modern dualistic culture. Building on previous works that discuss human relationships to both 'inner soil' and 'outer soil', it proposes eco-psychology as a framework not only to highlight the problematic assumptions that inform many modern perspectives about soil, but also to provide an alternative way forward which includes, simultaneously, acknowledging soil on its own terms, encouraging human relationships with soil and understanding humans as soil. It concludes by proposing three non-dualistic frameworks for consideration: eco-feminism, Buddhism and indigenous perspectives. Similarly, calling for a new kind of science and perspective for seeing the world, Chapter 6 (Brook) proposes the alternative scientific methodology of Johann Wolfgang von Goethe, which countered both the prevailing vitalism and mechanistic ways of seeing the world which dominated the science of his time (1749-1832). This chapter explains how Goethe's approach was of an informed holism that did not reject science but aimed to direct its path towards a more sensitive appreciation of the generative power of nature, which he called a 'delicate empiricism'. Using human faculties such as imagination and intuition, Goethe's approach could inform new ways of engaging with the environment, such as through agroecology. The link between Goethe and Rudolf Steiner (the initiator of biodynamic agriculture) and phenomenology is explained, and the chapter also introduces the work of cytogeneticist Barbara McClintock (discoverer of the transposition of genes). Shifting to methodology in the hard natural sciences, Chapter 7 (Tuszyński) brings the quantum perspective to the table. It presents a historical overview of the development and application of quantum physics methodology to various fields of science beyond physics, especially biology and consciousness, and explains how, in recent years, individual biological phenomena such as photosynthesis and bird navigation have been experimentally and theoretically analysed using quantum methods, building the conceptual foundations for quantum biology. Quantum concepts have also been employed to explain metabolism and how processes scale with body size and with each other. The chapter explains how several proposals, especially the Orch OR hypothesis, have been put forth in an effort to introduce a scientific basis to the theory of consciousness, and discusses the merits and potential extensions of these approaches. The final chapter in this section (Chapter 8, Smitsman and Currivan) rounds up by proposing a way to heal our relationship with Gaia by offering a wholeworldview that addresses the many fragmented perspectives of our world and life and offers a more unified understanding of what has now become the greatest existential challenge our species has ever faced 
at this scale. The wholeworld-view is explored through the study of infodynamics, which focuses on informational patterns and content that reveal deeper implicit dimensions that inform and underlie our manifest physical world. The chapter ends with an exploration of the infodynamics of living systems as thrivability systems, and how this can be applied to the design principles and processes for developing the agroecological farming systems of tomorrow.

\section{Section 2: The Intersection of Wave-Based Science and Agriculture}

This section comprises eight chapters that draw chiefly from empirical studies in the applied natural sciences, about techniques and technologies that are in commercial practice in the agri-food sector. It starts with a review of the mitigating effects of electromagnetic fields on plants sown under environmental stress conditions in Cuba (Chapter 9, De Souza-Torres). Focusing on static and alternating magnetic fields and pulsed fields in the range of extremely low frequencies, it shows how they exhibit a mitigating effect on key impact factors including drought, salinity, ultraviolet light, heavy metal toxicity, high temperatures, pathogens, bacteria, fungi and viruses. They do this by improving seed vigour, plant growth, water relations, photosynthesis, accumulation of biomass and concentration of defence secondary metabolites, and reducing free radicals and oxidative stress due to the activation of plant defence mechanisms. Shifting to the impact of sound waves on plant growth, Chapter 10 (Prévost et al.) explains how the emission of acoustic waves of a quantum nature during gene expression in living organisms may be predicted through the discipline of genodics. Using this approach and without the use of any other inputs, it describes experiments and treatments undertaken in France to address grapevine trunk diseases in viticulture, and in particular Esca, a destructive disease of the woody tissues of grapevine, as well as bacterial and virus diseases in market gardening. The results of some of these treatment projects on vines, endives and courgettes are provided, indicating a significant reduction in the impact of pathogens on agricultural production, and confirming the reliability of the method as a no-input treatment for plant pathologies for a more rational agriculture. Chapter 11 (Jovchelevich) moves to Brazil and skywards to consider the influence of astronomical rhythms on the yield and quality of carrot roots sown on different dates under biodynamic management. It commences by providing examples of the use of ethno-astronomy in the South, as well as selected scientific research on the influence of the moon on plants and animals including in biodynamic agriculture. Field trials were carried out over two periods on a biodynamic farm in Botucatu, São Paulo State, and the effects associated with planting at specific lunar positions were measured by the deviations from the trend curve. Although several characteristics were evaluated, dry root mass was the only one that, in the contrast between averages, showed significant results in the two periods of the experiment and suggested that sowing during the synodic new phase produced better results than sowing during other lunar phases. Returning to electromagnetic parameters, Chapter 12 (Moerman) presents a snapshot of the work that scientists have undertaken on electromagnetic phenomena in plants. It gives a brief explanation of the measurable electric parameters and which of those look the most promising to expand the growers' toolbox for monitoring plant growth and to provide better information to support decisions. It also discusses bioelectric methods that can help with simple and cheap comparisons of product health quality. These methods help to change the notion that plant growth is only about physiology, yet more in-depth and systematic work is needed. The chapter concludes by reflecting on the lack of commercial breakthroughs in this sector.

Research on agro-homeopathy (Chapter 13, Boff et al.) is included in this section because its working principle appears to involve the action of electromagnetic waves. Providing an integrated account of the nature, effectiveness and potential of homeopathy for sustainable agriculture, it commences with an overview of the science of homeopathy and the art of healing throughout history. It then looks at homeopathic preparations and their modes of action, addressing controversial issues through the scientific literature. The contribution of homeopathy to sustainable agricultural systems is reviewed, including for family farmers, animals and plants, with practical examples from Brazil. 
The case is made for the inclusion of homeopathy in the debate on, and practice of, agroecology and its social commitment, providing further insights into the multifunctional character of agriculture. Chapter 14 (Rodríguez Rodríguez et al.) presents research on the effects of the use of low-power laser pretreatment on shooting and initial growth of mulberry and sugarcane crops under flood stress. These two crops are commercially important in Cuba, and many areas where they are grown are prone to flooding which can have damaging impacts in the early stages of plant growth. In a completely random design, cuttings of both species with two different laser exposure times (10 and 20 seconds) were evaluated after 15 and 30 days. After 30 days, shoots that were exposed to a laser for 10 seconds were placed in flooded and non-flooded substrates. The results indicated that exposure of the shoots for 10 seconds to the laser beams gave the best results in terms of the number of buds sprouted, and in flooding conditions caused a greater elongation of the bud and increased the spongy plant tissue. These results indicate the potential for producing a physical method of seed priming on an industrial scale. Also concerning light frequencies, Chapter 15 (Wohlers et al.) explores how to evaluate a farming system's impact on food quality using the method of Fluorescence-ExcitationSpectroscopy (FES). This technique analyses the emission of light from a sample in order to provide biochemical information, and thus may be used as a measurement in food quality assessments. The chapter presents the historical background of the development of the methodology based on previous research into mitogenetic radiation and biophotons, and also a description of the measurement devices. Food produce grown under organic, biodynamic and conventional farming systems are compared from three scientifically controlled field experiments (wheat in Switzerland, cocoa beans in Bolivia and apples in the Netherlands). The results are used to explain the epistemology and the specific quality criteria which may be evaluated by FES, including product-specific or species-specific emission spectra, expression of specific maturation, plant development stages, organisational performance, and aspects of the integrity of the plant and its resilience to stay healthy. Finally in this section, Chapter 16 (Doesburg) also explores food quality, in this case through the crystallisation fingerprint method which is concerned with vitality through an organism's ability to self-organise and form signature patterns. Although not directly wave-based, this approach manages to capture the somewhat elusive nature of vitality and is being applied in commercial practice. The method of copper chloride crystallisation with additives is based on the generation and subsequent evaluation of dendritic crystallisation patterns (i.e. 'fingerprints'), which emerge when an aqueous cupric chloride solution is crystallised on a glass plate in the presence of a water-soluble additive (the sample). Existing research demonstrates the potential of this method to study the effect of food processing, the livestock feeding regime and farming system in a broad range of agricultural products. Trained panels have been able to correctly assign encoded samples to the farming system from which they came (conventional, organic, biodynamic) based on the degree of decomposition perceived in the crystallisation patterns. Conceptually, this relates to estimating the sample's degree of self-organisation in the sense of 'resilience' (its elasticity or capacity to cope with challenges) in response to the controlled ageing of the sample.

Overall, these exceptional examples and their impacts draw attention to how little investment or effort has yet been made into exploring and mainstreaming such benign applications in the food and farming sector.

\section{Section 3: In Search of More Embodied Methodologies}

This section turns to the social sciences and humanities to explore a range of more embodied methods for connecting with the hidden half of nature. Chapter 17 (Kieft) dives straight in by examining the means by which the body can be used as a research instrument in order to attune to subtle information. Assuming an animist perspective in which everything in nature is imbued with a spark of life, soul or consciousness, it proposes ways to educate the body in order to perceive such 'intangible' aspects of the natural world. Divided into three parts, the chapter first 
discusses the existence of different forms of information all around us, then examines views on exchange between the human body and environment and subsequently articulates the necessity of widening our epistemology beyond cognition to include other ways of knowing and learning through immersion, feeling and intuition. Finally, it offers a practical approach for reawakening a multi-levelled literacy that includes body, heart, mind, consciousness, and intuition, movement and nature, in order to empower people who work with nature on a daily basis. Chapter 18 (Fabre Lewin and Gathorne-Hardy) considers the art of ritual as a means of creatively unfolding life with each other and the planet - which it terms sympoiethics - through the inextricable connection between nature and culture. It develops a case study of a participatory food ritual that took place in South Africa, as an emergent process with local communities, energies and the otherthan-human. This performative event engaged participants in interdependent exchanges with the living food cycle by making visible the life-giving connections between humans and the sentient Earth. This chapter explores how, within the context of agroecological food cultures, the ritual offered a safe and convivial haven to attend to social, ecological and food justice issues. It concludes by suggesting that the recovery of food rituals may stimulate transitions towards new approaches, responsibilities and actions that foster an ethics of care in the everyday. The next chapter, Chapter 19 (Roussopoulos), considers another method, that of Systemic Constellations, and how it may be applied to agriculture. It charts the evolution of the method through to the early 2000s, when practitioners began to address questions about human/ecological systems. A series of case studies illustrate this form of Constellations, known as Nature Constellations (NCs), and explore the conundrums it raises. Research indicates that NCs can access accurate information about the animals and plants within ecosystems, effectively becoming a form of two-way interspecies communication, and can also generate creative solutions not easily reached through more linear methods. Further, the approach is in itself a unique form of research into agroecosystems, capable of adding to agricultural knowledge.

The history of Goethean inquiry has already been explored in the first section of this book, and the next chapter, Chapter 20 (Brook), applies this method as an approach for understanding the farm. The Goethean method is presented in an accessible series of practical steps towards a deeper relationship to any aspect of the farm. At the heart of this method, human faculties such as imagination and intuition may be developed in a disciplined way that allows them to play an insightful role in a holistic understanding of the land and of ourselves. For agroecology, the Goethean method can give a fresh view of land and how it can be worked with - what its needs are and how to enter into collaboration with it. The chapter concludes by stressing that this need not replace other forms of exploration but may accompany them for a fuller understanding of the being that we collaborate with when we engage with land. Chapter 21 (von Diest) takes up the subject of intuition as a means for better on-farm decision-making. It provides evidence that many farmers rely on intuition for practical decisions, often preferring this to technology-based decision support tools. The chapter explores the practical benefits of intuitive farming as well as the methods available for developing intuition. These methods highlight the importance of personal development and the transformative potential of this approach on the farmer. The final chapter in this section (Chapter 22, Bojesen Jensen) investigates Sustainable Yogic Agriculture (SYA), a farming approach from India that is based on a combination of physical and metaphysical (mind-matter) practices. The chapter provides an overview of SYA, its meditation-based and physical methods and possible effects and then discusses its potential for uptake, taking into consideration research evidence on the mind-matter relationship. Evidence indicates the positive effects of using SYA not only on farm performance but also on social dimensions. The chapter concludes that, the core SYA technique is simple and low cost, and as such may be particularly appropriate for organic and agroecological smallholder farmers worldwide.

This section has emphasised the potential of the human being as sensory instrument, a communicator with nature and a conscious influencer of both research and practice. 


\section{Section 4: Voices from the Field}

This final section steps outside of the formal research academy to showcase voices from the field: individual practitioners who have ploughed their own furrows to explore humans' relationship with nature including for the purpose of agriculture. Coming from a variety of non-mainstream worldviews, they provide examples of the practical, positive impacts of subtle agroecological phenomena and techniques on the physical-material dimension of agriculture and related fields, as well as describing their own unique journeys outside of the mainstream academic or industry pathways.

Chapter 23 (Lovel) considers the etheric realms as a foundation for exploring the use of radionics with the biodynamic preparations. It weaves a story that starts with an overview of the advance of Western science, from Kant's empirical realism through to the emergence of quantum theory and how this tends to support Goethe's concept of subjective reality. It explains how Scottish physician Maxwell developed the concept of an ether as an extremely fine stationary field which supports the propagation of light and electromagnetic frequencies, a concept which hasn't since been disproved. This provides a backdrop for relating the author's own learning experiences when developing his market garden, during which he took up the practice of applying biodynamic preparations as well as the concept of the soil food web. The chapter explains how the author's experiments with radionics - a technology based on the wave or etheric aspect of nature - have enabled him to be more efficient and effective through applying the biodynamic preparations as wave patterns. In this sense, according to the author, the farm can be viewed as a living organism that breathes and grows in cycles to become increasingly alive and coherent within its boundaries.

Chapter 24 (Menestrina) delves into the subtle life of the bee and its importance for the proper functioning of ecosystems. It explains how poor breeding practices, as well as agrochemical and electromagnetic pollution, have weakened their health status. The chapter stresses that we need to re-learn about bees: their intricate life, their social organisation and their role as biological indicators of the dangers facing humanity. It also advocates new approaches to bee-friendly beekeeping and for everyone to help create a bee-friendly world, because the needs of bees are increasingly understood as being aligned to our needs. Chapter 25 (Charter) considers another essential part of nature and agriculture, in the form of the dynamic role of water. It seeks to make sense of some unconventional ways of working with water in agricultural practice, in particular the rhythmic stirring or 'dynamisation' used in biodynamic farming, but also other methods used to support animal, plant and soil life. To do so, it examines the basis for understanding the healthy development or 'forming' in living organisms and then looks closely at the way water forms itself in flow. Whether exploring from the conceptual perspective of projective geometry or a perceptual perspective of Goethean observation, the same principles are arrived at of the spiritual working in the physical, perceptible world. Dynamisation is examined in terms of water's changing relationships to its spatial environment, and the movement of water induced in Flowform vessels is also explored and their use within agriculture is discussed. Questions are raised regarding research into life processes and the reproducibility of results.

Chapter 26 (MacManaway) explores the practice of land whispering as the practical application of consciousness and subtle energy awareness in agriculture. The author explains how he was raised with an understanding that all of nature is, at source, a vibrational, interactive intelligence, with our physical, experiential world being a reflection and expression of that vibrational content and tone. The chapter discusses and provides examples of five modalities: communication with the 'spirit realms'; understanding earth meridians; engaging with elemental consciousness; engaging with nature spirit consciousness; and healing and renewal of residual human energies. Following this, Chapter 27 (Massy) reflects from a farmer's perspective on a farm training event held by the previous author (MacManaway). The author compares the material in the course with his own experiences, those of other farmers in Australia, and the worldviews of Australian indigenous communities, reflecting on subtle energy, its uses in the 
form of geomancy or dowsing, the use of field towers and broadcasters and indigenous totems and nature spirits. The final chapter in this section, and in the book, Chapter 28 (Roads), offers thoughtful anecdotes on experiencing the metaphysics of agriculture. The author explains how he learned many of the deeper insights of Nature whilst farming in Tasmania, based on his understanding that all space and matter is energy, all energy is information, and this energy is consciousness. The chapter describes some of the author's metaphysical experiences as a dairy farmer in Tasmania, and then a beef producer, after which he went on to become an organic farming consultant. He explains how the farmer is the very matrix of the land being farmed and that every thought and emotion stirs the holistic energy of the farm, affecting everything from the micro-organic life in the soil, every plant that grows and all the livestock, with farmers therefore having the greatest responsibility of anyone.

\section{WHAT NEXT? OUTSTANDING SUBJECT AREAS FOR RESEARCH}

This collection of works provides some intense coverage of a relatively small number of thematic areas, whereas the scope of the hidden half of nature is, to all intents, limitless. Nevertheless, five salient subject areas are highlighted here, that arose as patterns through the chapters and that require more attention than was possible in this book. These subject areas are as follows:

- a more in-depth understanding of the identified subtle agroecological practices, including their impacts,

- perspectives and writings on subtle practices from indigenous authors,

- the theoretical and conceptual underpinnings and mechanics of Subtle Agroecologies,

- an exploration of Rudolf Steiner's cosmological framework in relation to both indigenous epistemologies and quantum science, and finally,

- the potential impact of practising Subtle Agroecologies on the human practitioner.

First and foremost - given that Subtle Agroecologies is grounded in the practice of farming - each of the subtle techniques suggested in Chapter 1 requires exploring in more detail. Almost all of these techniques have been touched upon in this book and are provided in Table 0.1 along with the chapter numbers in brackets.

The use of feng shui and of plant psychoactives are included in this list but are not mentioned in the book. The 4,000-year-old practice of feng shui seeks to establish harmony between people and nature, and as an umbrella term it involves several of the other techniques listed, including sacred geometry, dowsing and astrology (Teather and Chow, 2000). The use of plant psychoactives is also included here as a technique to facilitate communication with the other-than-human. It was, and still is, widely used in indigenous cultures (Armijos et al., 2014) and is going through a revival in modernist ones (Apud, 2017).

These subtle techniques can and should be explored from the practical perspective of their physical-material effects on, and interactions with, food and farming systems, as demonstrated by the contributions in Section 2. They can also help to deepen our understanding of phenomena that we cannot see. Chapter 24, for example, refers to research exploring how the flowers of a plant use sound vibrations to detect and respond to pollinator bees in their vicinity, and in Chapter 12 we learn how electrons influence the direction of plant growth as well as influencing plant geometry. Some negative impacts of industrial agriculture also show up at subtle levels. In Chapter 16, for example, copper chloride crystallisation images reveal that heavy doses of synthetic fertilisers prevent the crop from fully developing into the mature adult stage which results in it becoming more susceptible to disease and more limited in the extent to which it forms the nutrients and aromas that affect our taste perception. Both Chapters 23 and 24 allude to the disruptive impacts of electromagnetic wave pollution on living organisms, with Chapter 23 linking this to disorganisational forces in the etheric realm, an area that has been scarcely recognised, let alone researched. 


\section{TABLE 0.1}

\section{Some Subtle Agroecological Practices (with corresponding chapter numbers in brackets)}

Agro-homeopathy (13)

Astronomy/Planting calendar (11)

Bio-electromagnetism $(9,12$, Eco-alchemy (23)

14, 15)

Feng shui/geomancy

Love (28)

Prayer/intention $(22,26)$

Ritual (18)

Teacher plants/ psychoactives

\author{
Interspecies communication (19, 26, 27, 28) Intuition/direct knowing (17, 20, 21, 26, 28) \\ Mantras/chanting (22) \\ Radionics (23) \\ Sacred geometry $(13,16,23,25)$
}

Water dynamisation (25)

\author{
Biodynamic preparations $(1,23)$ \\ Dowsing $(26,27)$ \\ Paramagnetism $(1,27)$ \\ Resonances (26) \\ Sound/ultrasound (10)
}

Yet the impact of subtle techniques on both material and invisible dimensions of the farming and food system is only part of their reason for being. As Wohlers et al. explain in Chapter 15, 'Research also shows that the use of biodynamic preparations may result in enhanced product quality... The term "may" is used here rather than "does" because the biodynamic preparations do not work like standard industrial inputs, such as nitrogen fertiliser, and thus should not be compared to or treated as such. The preparations enhance quality in the way that is appropriate for each given situation; they encourage growth and enable other possibilities without forcing the plant'. This implies that the impact of these techniques is situation-specific, and in addition may also be dependent on the presence of the human being involved, as is stressed by Boff et al. in relation to homeopathy (Chapter 13) and Charter in terms of the challenges of replicating trials of subtle influences of living things (Chapter 25). By limiting our choice of research objects to phenomena that can be replicated in trials, and by not considering the potential interference of the research subject, we are limiting both the scope of the research and our understanding of reality. Following this, two further functions of the application of subtle techniques are suggested, firstly to enable the development and refining of specific abilities and faculties of the human being, including awareness and intuition (as described in Chapters 17, 21 and 22), and secondly to bring holistic balance and harmony to the agroecosystem, one that is so valued by indigenous cultures (Chapters 1, 2 and 4).

Inherent in the above is the need for more involvement and contributions on subtle farming techniques from indigenous writers themselves (Chapter 3 goes some way towards this through a co-authored dialogue on the indigenous practices of communities in Chikukwa, Zimbabwe). There is a gap in the literature, and Chapter 1 explains how much of this knowledge has historically been passed down through oral rather than written tradition. Chapter 1 also describes how such practices have multiple functions and may not necessarily relate solely to agriculture, such as the Indian tradition of Panchakavya, a concoction of animal products that not only has proven benefits as a biofertiliser, as a biopesticide and for restoring soil fertility, but also has medicinal applications and is used in ceremonies and rituals (Ramprasad, 2012). Moreover, food acquisition in indigenous cultures is not solely dependent on settled agriculture, and indigenous authors have tended to explore their cosmologies and epistemologies in relation to nature and the environment rather than directly to agriculture. From New Mexico, Cajete (2000) is an exception, describing gardening, farming and hunting activities as including prayer, ritual, negotiations with nature spirits, totemic relationship with animals, and the importance of a sense of place, as well as more material activities including advanced plant breeding and knowledge of herbal medicines. He explains, 'The Native garden involved a deep understanding of "practiced" relationship. Therefore, Native gardens were as much a mythic-spiritual-cultural-aesthetic expression of tribal participation and relationship with nature as was Native art, architecture and ceremonialisation. The technology of Native farming was only one dimension of such practiced relationship' (2000: 131). 
Moving on from farming practice, another subject area requiring more attention is the theoretical and conceptual underpinnings and mechanics of Subtle Agroecologies. In this book, Chapter 7 makes a valiant contribution from the perspective of quantum biology and relationship to quantum consciousness, identifying some of the unexplained features of consciousness as including free will or intuitive processes, the subjective flow of time, and non-locality including paranormal connections from human to human or to non-human. Some of these unknowns are addressed in other works on unified theories of life (e.g. Capra, 2016; Currivan and Laszlo, 2017; Wan Ho, 2008). In particular, Blackfoot Physics (Peat, 2005) explores the interface between quantum science and indigenous cosmologies and epistemologies. A theoretical physicist, Peat discusses sacred mathematics, time, sacred vibrations and indigenous science amongst other issues. Applying these concepts to the agricultural context would advance our understanding of what is at play and in particular our handling of consciousness, and would provide indications of how we might otherwise conduct research if mechanistic criteria, such as the previously discussed challenges around reproducibility and replicability, are inappropriate in the context of subtle agroecological techniques.

The work of Rudolf Steiner and the biodynamic farming method that he founded run like a thread throughout this book, from both an epistemological and a practical perspective. This is unsurprising given that, as Chapter 1 explains, biodynamic agriculture is the chief modernist farming approach to work out of a cosmology that embraces the invisible dimension and advocates the practice of subtle farming techniques. That Steiner shares a similar worldview with indigenous cultures has been noted by other authors such as Marti (2018) and Klocek (2013). A novel contribution to this subject area would be an exploration of Steiner's cosmological framework in relation to indigenous epistemologies, to quantum science and to consciousness studies. For example, Steiner's worldview encompasses an etheric realm, one that he identified as a subtle area existing between the physical and spiritual from whence emerges the formative forces of life that enable coherence (Marti, 2018). The concept of ether has existed since Greek times as material that fills the region of the universe above the terrestrial sphere (Lloyd, 1968), and was explored by Scottish physicist James Maxwell (1831-1879) as an extremely fine stationary field which supports the propagation of light and electromagnetic waves. Chapter 23 points out that whilst Maxwell's theory of a universal fixed etheric field was disproved, the notion of an ether has not been, and several chapters in this book refer to formative forces or system's coherence. A deeper understanding of ether in relation to agriculture would be a crucial component in advancing Subtle Agroecologies.

The final subject area requiring further exploration is the potential impact on the human practitioner of practising Subtle Agroecologies. The physical, mental and emotional health benefits of simply being in nature are well documented (Buzzell et al., 2009; Kellert, 2008; Lackey et al., 2019) as are of being physically active through food growing (Schmutz et al., 2014). Practising Subtle Agroecologies may do more than add to these benefits, through the impacts of developing soft skills around deep listening and observation, meditation, intuition and a heightened mental and bodily awareness, as many of the chapters in Sections 3 and 4 elucidate. Chapter 22, for example, points to the spiritual, physiological, psychological and emotional benefits provided by (on-farm) meditation. Looking to other texts, in order to fully utilise the biodynamic farming methods, Klocek (2013) asserts the need for constant self-development, as well as a continually deepening relationship with the whole of nature including plants, animals and the weather. Biodynamic practitioner and Jungian analyst Patricia Damery echoes this view, describing the similarities between Jungian analysis and biodynamic agriculture, and the new consciousness that both offer for the physical world and for the development of thinking. Damery (2011: 114) explains:

Biodynamics has offered me an alternative, developed way to incorporate spirit into our farming practices, to temper our overly rational agriculture driven by profit and efficiency with a conscious holding of feminine relatedness to that which is not human. For me, the forum Biodynamic farming has afforded has also been a natural and necessary next step in my own path of individuation. 
Cajete's aforementioned description of Native gardening and farming as a 'practised relationship' also reflects this dynamic, co-evolving process between human and nature.

Might this increase in conscious awareness, in being more 'in touch' with our thoughts, feelings and intuitive processes, as well as being more connected to and experiencing more of nature's sentience, fundamentally transform us at the systemic level of our inner selves and thus our own worldviews, which in turn would reflect in transformed beliefs and behaviours around nature, food and farming? One scholar who has spent her life exploring such virtuous cycles, through developing frameworks for personal and social change, is ecological systems theorist Joanna Macy. In her essay The Greening of the Self (2009), Macy explores the profound shift in identification that takes place when we extend our limited sense of self to encompass the things and beings of the natural world we depend on. Macy contends that, through inner work that faces head on the reality of the destruction of our biosphere and that explores more of the experiential, phenomenal world, we are moved beyond the separate ego and are lifted onto another systemic level that recognises the interconnectedness of all things. Then, she suggests, it becomes in our natural self-interest to interact in harmony with nature, rather than for moralistic, altruistic or regulatory reasons. Is this the promise that Subtle Agroecologies might hold?

\section{IN CONCLUSION: RESEARCH TO RECLAIM THE INVISIBLE}

This book lays a foundation stone for the discipline of Subtle Agroecologies, a nexus of indigenous epistemologies, multidisciplinary advances in wave-based and ethereal studies, and the science and practice of sustainable agriculture. As discussed in Chapter 1, Subtle Agroecologies is not then a farming system in itself, but superimposes a non-material dimension upon existing, materially based agroecological farming systems. Research into Subtle Agroecologies may be described as the systematic study of the nature of the invisible world as it relates to the practice of agriculture, through adapting and innovating with research methods and in particular with those of a more embodied nature. Such research may take a reductionist, single-gaze focus on, for example, increasing crop and livestock yields or reducing the incidence of pests and diseases, or a wide-angled vision of simultaneous, multiple factors and concerns, all based on an ethics of care and with the overall purpose of bringing and maintaining balance and harmony. Such research is an open-minded inquiry, its grounding being the lived experiences of humans working on, and with, the land over several thousand years to the present.

By reclaiming and reinterpreting the perennial relationship between humans and nature, the implications, if followed through, are paradigm shifting and would, it is suggested, enable a coevolution of the farm with the farmer. They would not only herald a new wave of more sustainable farming techniques based on, for example, electromagnetic and sound wave technologies, but could also change our whole relationship with nature to one of real collaboration rather than control. By working with subtle, vibrational fields, becoming more adept at embodied methods of research and practice, and communicating with nature, we may move towards the healing of ourselves as well as of the planet.

\section{REFERENCES}

Apud, I. (2017) Science, spirituality and ayahuasca: The problem of consciousness and spiritual ontologies in the academy. Zygon, 52(1): 100-123.

Arlow, R. and Adam, W. (2011) The druid network. Ecclesiastical Law Journal, 13(1): 127-128.

Armijos, C., Cota, I. and González, S. (2014). Traditional medicine applied by the Saraguro yachakkuna: A preliminary approach to the use of sacred and psychoactive plant species in the southern region of Ecuador. Journal of Ethnobiology and Ethnomedicine, 10(1): 26.

Bateson, G. (1987) Angels Fear: An Investigation into the Nature and Meaning of the Sacred. London: Rider. Berkes, F. (1999) Sacred Ecology. Abingdon: Taylor \& Francis.

Brooke, J.H. (1991) Science and Religion, Some Historical Perspectives. Cambridge: Cambridge University Press. 
Bruntrup, G. and Jaskolla, L. (2017) Panpsychism: Contemporary Perspectives. New York: Oxford University Press.

Buzzell, L., Chalquist, C., Orr, D.W., Roszak, T., Gomes, M.E. Macy, J., Andrews, C. and McKibben, B. (2009) Ecotherapy: Healing with Nature in Mind. Berkeley, CA: Counterpoint Press.

Cajete, G. (2000) Native Science, Natural Laws of Interdependence. Santa Fe, NM: Clear Light Publishing.

Capra, F. (2016) The Systems View of Life: A Unifying Vision. Cambridge: Cambridge University Press.

Chambers, J. (2018) The Metaphysical World of Isaac Newton: Alchemy, Prophecy and the Search for Lost Knowledge. Rochester, VT: Destiny Books.

Currivan, J. and Laszlo, E. (2017) The Cosmic Hologram: In-Formation at the Center of Creation. Rochester, VT: Inner Traditions.

Damery, P. (2011) The enclosed garden: Underlying principles of Jungian analysis and biodynamic agriculture. Culture and Psyche, 5(2): 102-116.

EIP-AGRI (2018) Agricultural Knowledge and Innovation Systems: Stimulating Creativity and Learning. EIP-AGRI Brochure Agricultural Knowledge and Innovation Systems. European Commission, https:// ec.europa.eu/eip/agriculture/sites/agri-eip/files/eip-agri_brochure_knowledge_systems_2018_en_web. pdf (accessed September 5th 2020).

Hall, A. and Mogyorody, V. (2001) Organic farmers in Ontario: An examination of the conventionalisation argument. Sociologia Ruralis, 41(4): 400-422.

Kellert, S.R. (2008) Biophilia. Encyclopedia of Ecology, 4: 247-251.

Klocek, D. (2013) Sacred Agriculture, the Alchemy of Biodynamics. Great Barrington, MA: Lindisfarne Books.

Lackey, N.Q., Tysor, D.A., McNay, D., Joyner, L., Baker, K.H. and Hodge, C. (2019) Mental health benefits of nature-based recreation: a systematic review. Annals of Leisure Research. DOI: 10.1080/11745398.2019.1655459.

Lloyd, G.E.R. (1968) Aristotle: The Growth and Structure of his Thought. Cambridge: Cambridge University Press.

Macy, J. (2009) The greening of the self. In Buzzell, L. and Chalquist, C. (eds), Ecotherapy: Healing with Nature in Mind, pp. 238-245. Berkeley, CA: Counterpoint Press.

Marrable, T. (2019) Becoming shamanic: How do people talk about their experiences of finding shamanism as a spiritual practice? The Future of the Study of Religious and Spiritual Experience: 50th Anniversary of the Religious Experience Research Centre. 1st-3rd July 2019, Lampeter Campus, University of Trinity St David. Compilation of Abstracts. P.16.

Marti, E. (2018) The Etheric: Broadening Science through Anthroposophy, Volume 2: The World of Formative Forces. Forest Row: Temple Lodge.

Peat, F.D. (2005) Blackfoot Physics: A Journey into the Native American Universe. Boston, MA: Weiser Books.

Pimbert, M. (2018) Democratising knowledge and ways of knowing for food sovereignty, agroecology and biocultural diversity. In Pimbert, M. (ed), Agroecology and Biocultural Diversity: Constructing and Contesting Knowledge, pp. 1-65. London: Earthscan, Routledge, Taylor \& Francis.

Ramprasad, V. (2012) Manure, soil and the Vedic literature: Agricultural knowledge and practice on the Indian Subcontinent over the last two millennia, Chapter 12. In Jones, R. (ed), Manure Matters: Historical, Archaeological and Ethnographic Perspectives, 173-181. Abingdon: Taylor \& Francis Group.

Schmutz, U., Lennartsson, M., Williams, S., Devereaux, M. and Davies, G. (2014) The Benefits of Gardening and Food Growing for Health and Wellbeing. Coventry: Garden Organic. DOI: 10.13140/RG.2.1.3703.5289.

Smith, T. (2020) The common consent argument for the existence of nature spirits. Australasian Journal of Philosophy, 98(2): 334-348.

Teather, E.K. and Chow, C.S. (2000) The geographer and the Fengshui Practitioner: So close and yet so far apart? Australian Geographer, 31(3): 309-332.

Timmons, S. (2006) Witchcraft and rebellion in late seventeenth-century Devon. Journal of Early Modern History, 10(4): 297-330.

Uzzell, J. (2019) Gods, wights and ancestors: The varieties of pagan religious experience at ancient sacred sites. The Future of the Study of Religious and Spiritual Experience: 50th Anniversary of the Religious Experience Research Centre. 1st-3rd July 2019, Lampeter Campus, University of Trinity St David. Compilation of Abstracts. P.10.

Wan Ho, M. (2008) The Rainbow and the Worm: The Physics of Organisms. Singapore: World Scientific Publishing Co. 


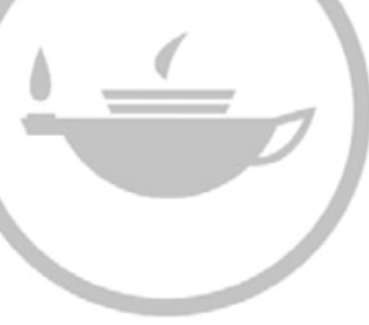

Taylor \& Francis Taylor \& Francis Group http://taylorandfrancis.com 


\section{Section 1}

Transformative Epistemological, Philosophical and Theoretical Frameworks 


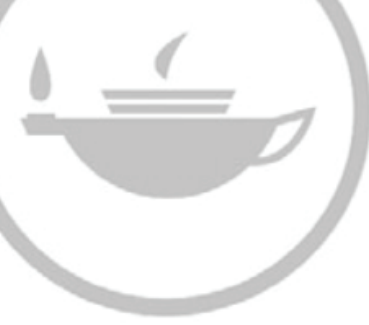

Taylor \& Francis Taylor \& Francis Group http://taylorandfrancis.com 


\title{
1 Re-Enchanting Agriculture Farming with the Hidden Half of Nature
}

\author{
Julia Wright \\ Coventry University
}

\section{CONTENTS}

Prelude: Something Happened in a Hot Tent in Telangana ....................................................... 3

Introduction: The Stranglehold of the Industrial Worldview ....................................................... 4

Towards Understanding the Cognitive Factors behind the Industrial Worldview........................... 6

The Blind Spot of Contemporary, Ecologically Based Farming Systems ..................................... 8

Harmony and Balance: The Indigenous Relationship of People, Land and Nature..................... 8

Do Ecologically Based Farming Systems Fully Embrace Indigenous Praxis?........................... 10

Introducing Subtle Agroecologies: Farming with the Hidden Half of Nature ............................... 12

The State-of-the Art of Subtle Agroecologies .......................................................................... 13

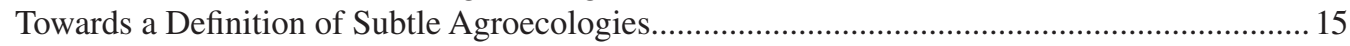

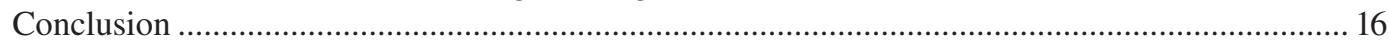

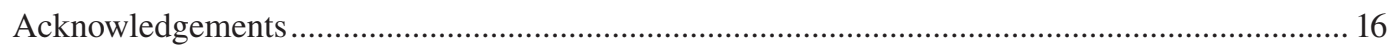

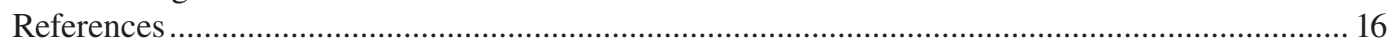

\section{PRELUDE: SOMETHING HAPPENED IN A HOT TENT IN TELANGANA}

It looked unlikely that anyone was going to come to the workshop. Buses had jolted us for three hours from the conference centre in Hyderabad to a farm in the Telangana hinterland, land that was dry and dusty those November days and adjacent to a river where signs warned to 'beware of crocodiles'. Now all were busy pitching their tents and queuing for some late lunch that hot afternoon. Thus was the transition from the first formal part of the 13th International Permaculture Conference, in India, at which government ministers and keynote speakers had held forth, to the more informal and interactive, tented Convergence, and we were all tired and drowsy. A volunteer led me to the tent where I was scheduled to give the workshop one of seven rectangular structures arranged in a semicircle to one side of the encampment and adorned with deep gold and purple bunting. It wasn't only the heat and fatigue that were serving as potential deterrents. 'Quantum-inspired agriculture: is it time for permaculturalists to embrace the invisible?' was the title of the workshop, and I was mindful that (the late) Bill Mollison, the co-founder of permaculture, had stressed many times, and most vehemently, that belief systems, or 'woo-woo' as he and many practitioners put it, should be kept out of permaculture.

As I have often been accused of lacking that set of credulity, mystification, modern myth and hogwash that passes today for New Age Spirituality, I cheerfully plead guilty. Unqualified belief, of any breed, dis-empowers any individuals by restricting their information. Thus, permaculture is not biodynamics, nor does it deal in fairies, devas, elves, after-life, apparitions or phenomena not verifiable by every 
person from their own experience, or making their own experiments. We permaculture teachers seek to empower any person by practical model-making and applied work, or data based on verifiable investigations. This scepticism of mine extends to religious and political party ideologies.

Mollison (1996: 623)

A smattering of people wandered into the tent, then a few more, until almost all the fold-up seats were taken. Feeling relieved at the numbers, I made a start. A few more people turned up, filing in around the edges, then more and I encouraged them to fill the spaces at the front where they sat around my feet till I was confined to one spot. Then more formed an outer ring, and still more who couldn't squash into the tent and so grouped around the open entrance or peered in through the gaps between the flimsy tent walls and the canopy. Engulfed in a sea of expectant, bright-eyed faces, my presentation started with a question, inspired by developments over the last century in quantum science and the underlying wave-based nature of reality. What else could be at play outside of the small percentage of the electromagnetic spectrum that is visible to the human eye? Indigenous, Majority World cultures are characterised by their holistic worldviews about the nature of reality, and these are reflected in their farming practices. Their interactive relationships with invisible dimensions recognise the existence of spirit, /consciousness and the other-than-human. Yet even though the founding fathers of quantum science were openly influenced and inspired by such worldviews and especially those of the Vedic tradition, modern science is ill-equipped to properly explore these dimensions in agriculture, limited as it is by its own adherence to a particular belief system, one which is underpinned by reductionism and physicalism.

With audience attention still strong, and sensitive to the customary reticence to share on this subject in public, each person was invited to turn to her or his neighbour and share a story or personal experience concerning the hidden half of nature. With just a few exceptions, a multitude of conversations erupted, so animated that the speaker in the neighbouring tent's (rather empty) workshop came to inspect. And then, once people realised that they were in a safe space and wouldn't be laughed at or ridiculed, and that they weren't alone in their experiences, stories began to be shared with the group. The atmosphere was one of vibrant relief; something important had happened on that previously worn-out afternoon in the hot tent in Telangana.

\section{INTRODUCTION: THE STRANGLEHOLD OF THE INDUSTRIAL WORLDVIEW}

Contemporary, ecologically based farming approaches (i.e. agroecology and what may be considered as subcategories - organic and biodynamic farming, and permaculture) have met with strong opposition since they arose over the last century as a conscious effort to divert from the path mapped by the industrial and Green Revolution models (Conford, 2002). Why should something as simple as the desire to caringly produce nutritious foods touch upon such a raw nerve? Exploring this question as part of her doctoral studies in Cuba in the late 1990s, the author asked over 400 of the country's farmers, researchers and government officials why they had not shifted wholescale to more ecological farming. After all, during this period of tough US sanctions and economic instability, several conducive factors were in place: the scant access to agrochemicals and fuel to drive heavy machinery, a plentiful labour supply, relatively widespread knowledge of ecologically based agriculture, and a pro-social politics in favour of human health. Curiously though, the majority of responses to this question fell into either of two categories: those who had not shifted to more ecological farming because they were fearful of losing control - be it over smallholder farmers, specific pests and diseases or nature in general; and those who had not shifted because they were fearful of not having enough, whether it be of chemical inputs, crop yields, fuel or food (Wright, 2009). Such fears were unsurprising given Cuba's economic 
vulnerability after the collapse of the Soviet Union, yet they revealed themselves to be unfounded when evaluated against the scientific and practitioner evidence available, and rather were based on myths or misperceptions around the performance of ecologically based farming (2009: 209, 237). For example, for every farmer who was adamant that the only way to control the maize corn stalk borer was through the application of a chemical control, another farmer down the road would be successfully using a biological control method for the same problem, and this backed up by research data. Fear rather than evidence, the study concluded, was a major driver of Cuba's agricultural strategy, and this in a country with no private sector or corporate interests to champion the industrialised farming approach that prevailed. What the country did have, enduring from its pre-Revolutionary, colonial period and later imported from its Soviet comrades in the 1960 s to 1980 s, was a heavily industrialised conceptualisation or worldview of agriculture, based on a belief in technological expertise which manifested through the design of large-scale monocultures, high levels of specialisation and mechanisation, and reliance on chemical inputs (Mesa-Lago, 1998; Sinclair and Thompson, 2001; Wright, 2009).

In non-socialist regimes, similar fear-based insecurities around a perceived lack of control or of survival necessities are identified as contributing to the relentless drive of agribusiness (Clunies-Ross and Hildyard, 2013). Whether restocking food reserves in post-Second World War Europe (Conford, 2001) or averting food insecurity in the Global South by rolling out Green Revolution technological packages (Sonnenfeld, 1992), this form of agriculture, with its top-down approach, obsessive focus on narrow goals, quick results and lack of consideration of broader impacts, could at best be seen as a short-term, emergency strategy. ${ }^{1}$ So, 70 years on, why are we still farming as if in an emergency? Vorley (2003) and others (e.g. Elder and Dauvergne, 2015; IPES-Food, 2016; Lang, 2004) attribute this stagnation or stranglehold to the persisting political power of agribusiness to maintain industrialised production systems in order to continue expanding sales, lowering production costs and increasing profits. Yet the previously described experience of Cuba indicates that we need to look beyond or behind agribusiness and to the industrialised worldview from whence these behaviours manifest. For it is out of this worldview that we are frequently reminded of the overriding material urgency of 'feeding the world' at the expense of mainstreaming more sustainable, ecologically based farming approaches (e.g., by AGRA (2016), Goulding et al. (2011) and Rickard (2019)). This perspective continues to be propounded in the face of clear and growing evidence that agroecological farming systems can better achieve the more egalitarian objective of 'enabling the peoples of the world to feed themselves', as well as ensuring the health of our life support systems (Ponisio and Erlich, 2016). As the pioneering environmental philosopher Callicott (1990: 270) succinctly explains with regard to the industrial-scientific worldview:

Notoriously it is not working, at least not sustainably and it is based on a bankrupt metaphysics, a worldview that has not sustained critical scrutiny and that is in fact, dead in pure science even though it lives on in applied science...soil compaction, erosion and the loss of fertility, the unforeseen exhaustion of fossil fuels and fossil waters, agrochemical pollution of air, surface and ground waters; and food itself; cyclic outbreaks of pests and the ensuing dialectic of ever more toxic and intensively applied pesticides; the loss of genetic diversity and the loss of wild ancestors and relatives of our cultivars; rural depopulation and disruption of rural patterns of life; the corollary loss of centuries of transmitted agricultural experience and knowledge, the dessication, in short, of the culture of agriculture; concentration of land ownership and the proletarisation of farm labor... all bode ill for the sustainability of modern agriculture.

\footnotetext{
${ }^{1}$ Underlying these altruistic motives were political and economic drivers. In Europe, ammonium nitrate was lucratively repurposed as a fertiliser after WW2 (Conford, 2020), and the rolling out of Green Revolution technologies was seen as a means to quell political unrest during the Cold War period as well as being another lucrative venture for the pharmaceutical industry (Cotter, 2003).
} 


\section{TOWARDS UNDERSTANDING THE COGNITIVE FACTORS BEHIND THE INDUSTRIAL WORLDVIEW}

Which other living creatures soil their own living spaces, food supplies and life support systems? Environmentalist David Orr, who proposed the term 'ecological literacy' as the ability to understand the natural systems that make life on earth possible, explains the need to recognise the relationship between the disorder of ecosystems and a prior disorder of mind (Orr, 1991). Similarly, Roszak (1992) believes that the environmental crisis is rooted in the extreme disturbance of a part of human consciousness. Yet the views of Orr, Roszak and other ecopsychologists who connect the way we treat nature as a reflection of our own mental states have been more widely accepted by environmental scholars (e.g. see Joanna Macy's 'Work That Reconnects' (Macy and Brown, 2014)) than by those in agricultural disciplines. (One early exception was social ecologist Stuart Hill who, with reference to agriculture in the Canadian Prairies, linked ecological with psychological prerequisites and identified 'distressed human states' as resulting in unsustainable farming (1991: 34)). The very act of separating farming from the environment is arguably a manifestation of such a disorder.

This disorder had been spotted long before by people from non-Western cultures. Indigenous American peoples used the term 'wetiko' (from the Cree First Nation) to describe the mentality of the arriving colonisers, defined as a type of cannibal sickness or mind-virus infecting people with symptoms such as greed, ambition, materialism, arrogance or a split personality (Forbes, 2011). In his book on the same subject, journalist Paul Levy (2013) draws on works from Jungian psychology as well as spiritual wisdom traditions to explain how this mind-virus operates at a covert level through our unconscious blind spots, rendering us oblivious to our own madness and compelling us to act against our own best interests.

A more in-depth understanding of this condition has been provided by acclaimed scholar and psychiatrist Iain McGilchrist. McGilchrist's treatise (The Master and his Emissary: the Divided Brain and the Making of the Western World, 2019) concerns the bihemispheric structure of the brain, with the right hemisphere's insightful and holistic approach moderating the left hemisphere's reductionism. In a healthy individual, he explains, the left and right hemispheres of the brain work together, with the right ('the Master') taking the major decisions that the left ('the emissary') then carries out. The problem has arisen that, rather than cooperating, these hemispheres have become involved in a power struggle and this, McGilchrist asserts, has given rise to many aspects of contemporary Western culture.

The Master realises the need for an emissary to do certain work on his behalf (which he, the Master, must not involve himself with) and report back to him. The emissary, however, knowing less than the Master, thinks he knows everything and considers himself the real Master, thus failing to carry out his duty to report back. The right hemisphere's view is inclusive, 'both/and', synthetic, integrative, it realises the need for both. The left hemisphere's view is exclusive, 'either/or', analytic and fragmentary - but, crucially, unaware of what is missing. It therefore thinks it can go it alone.

McGilchrist (2019: xxiv)

With the domination of the left hemisphere and the impact of its vision and priorities on human action, the right is unable to function in its role of counterbalancing with the real world, because the real world is now a manifestation of the left. The left meanwhile is incapable of making a paradigm shift to resolve a problem: 'There is a self reflective hall of mirrors at work, where logic seems to lead back to a solution within the system itself, rather than a need to break out of it' (2019: xxiv). Crucially, although the left hemisphere likes to believe it is more rational and thus more highly evolved, it is in fact the right hemisphere that is in contact with both body and emotion and also has more representation in the pre-frontal cortex which is the most highly evolved part of the brain.

Since it was first published, McGilchrist's treatise has received slight criticism, only for extrapolating on the implications for society which fall outside McGilchrist's own area of expertise. From the food and farming system perspective at least, he may be spot on. His explanation 'The left hemisphere is not impressed by empathy; its concern is with maximising gain for itself, and its driving 
value is utility' (2019: 145) could well be describing a driver for industrial agriculture, where the right hemisphere's priorities, such as nature, culture, the body, the arts, spirituality and soul, have been deconstructed and devitalised. McGilchrist concludes 'I believe that reductionism has become a disease, a viewpoint lacking both intellectual sophistication and emotional depth, which is blighting our ability to understand what is happening and what we need to do about it' (2019: xxv).

Whilst this theory may help us to understand the nature of the underlying disorder or mind-virus that manifests through the industrial worldview, McGilchrist's otherwise comprehensive work omits discussion of gender and the feminine. This absence stands out not only because the worldviews of many of the non-contemporary cultures that McGilchrist refers to were rooted in the feminine, but also because of the clear parallels of his work with those of feminist scholars. One such is psychologist Anne Baring and her classic work The Dream of the Cosmos: a Quest for the Soul (2020). In this, Baring attempts to address the roots of Western culture's multifaceted crisis by exploring its historical and psychological causes. Echoing McGilchrist's perspective of the dominant left hemisphere's inability to hold awareness beyond itself, she asks:

What happens to us if we exist without a relationship to anything beyond our own consciousness? We are left bereft of relationship with the Cosmos. Psychic energy that has nowhere to go implodes on itself... Recognising nothing beyond ourselves, we become both inflated and diminished.

\section{Baring (2020: xvii)}

Baring similarly talks of a malignant pathology and the need for release from our current defective worldview. Whereas McGilchrist identifies the historical decline of key civilisations (the Greeks, Romans and post-Enlightenment West) as triggers for the increasing entrenchment of the left hemisphere, Baring points the finger at two erroneously held beliefs of the three Abrahamic religious cultures (Judaism, Christianity and Islam): the myth that a woman caused the expulsion of humans from Eden, and the belief that humans are separate from both God and nature. Baring notes that, prior to this, cultures dating to 40,000 BC emphasised the feminine (e.g., see Marshack, 1972), and she explains that 'the idea of the whole Cosmos as an entity with consciousness or soul in which all life participates derives directly from the image of the Great Mother' (2020: 30).

A shift from lunar to solar imagery, and from feminine to masculine deities, happened around $2000 \mathrm{BC}$, from which time imagery of the divine feminine was largely repressed or excluded, or became 'almost exclusively associated with nature as a chaotic force to be mastered, whereas the God assumed the role of creating or ordering nature from a "place" that was outside or beyond it' (Baring, 2020: 31). Arguably the most misogynistic manifestations of this belief, Baring points out, were the witch trials, instigated in 1485 by Pope Innocent VIII and spanning the 15th to 18th centuries. Many thousands of women, often herbalists, were tortured and killed (and in the UK, it was only in 1944 that the last woman was convicted under the Witchcraft Act of 1735 (Morton, 2014)). Ultimately, according to Baring, the loss of respect for nature and for woman, and the current ecological crisis, can all be traced to this denigration of the feminine over the last four millennia.

McGilchrist and Baring agree on the problematic manifestation of a certain type of science, a critical rationalism that focuses on the physical dimension and not simply ignores - but proactively ridicules - anything outside of this perceived reality. ${ }^{2}$ Baring states:

We no longer have access to other levels or modes of consciousness because our 'rational' mind has, over the last four centuries, increasingly ridiculed, disparaged and repressed what it has been unable, so far, to accept, prove or comprehend.

Baring (2020: 491)

\footnotetext{
${ }^{2}$ In his essay on the work of Francis Bacon (1561-1626) who was the so-called founding father of the scientific method, Scalercio explains Bacon's perspective, 'The purpose of studying nature was to recover man's original dominion over the earth, bestowed upon Adam in Eden but lost in the Fall' (2018: 1080). Other authors describe how Bacon used the way women suspected of witchcraft were tortured by mechanical devices to extract confessions, as a metaphor to indicate the methods of inquisition by which he thought nature's secrets should be extracted (Conner, 2005; Merchant, 1990).
} 
For the left hemisphere, according to McGilchrist, belief, or the absence of certainty, is seen as a 'feeble form of knowing', whereas for the right, belief is a matter of care or of relationship. In other words, the right believes that one cannot know, whilst the left knows that one cannot believe. He concurs with Baring that 'The sheer vehemence with which the right hemisphere has been dismissed by the representatives of the articulate left hemisphere, despite its overwhelming significance, suggests a possible rivalry' (2019: 129).

To move through this impasse, both authors prescribe new conceptual paradigms. Baring weaves recent developments in consciousness studies with quantum physics and the Vedic philosophies, resulting in a new cosmology that unifies life, consciousness and the cosmos (2020: 340, 350). Similarly, McGilchrist suggests seeing life not as a linear process with piecemeal strategies (the left view) but as holistic, circular systems (the right), and draws from other cultures' cyclical perspectives of history and the universe. Pointing towards East Asian cultures that continue to be grounded in the right hemisphere, he concludes, 'We might have to revise the superior assumption that we understand the world better than our ancestors, and adopt a more realistic view that we just see it differently - and may indeed be seeing less than they did' (2019: 461).

This bihemispheric imbalance of the Western mind, and its correspondent secular-materialist worldview, is of course a generalised stereotype. Baring is careful to note that patriarchy and its associated disconnect from nature were present in some regions of the world prior to their being colonised, and the West itself contains a plurality of worldviews. However, there is certainly a case for the secular-materialist worldview and its science having shaped the West's approach to agriculture. Seeing the industrial worldview as a form of mind-virus or disorder is helpful in that, if the diagnosis is even half true, we are more consciously enabled to take effective, restorative action at a systemic level, a kind of self-medication. For once, the mind may bring awareness to itself rather than continue along the well-trodden path of identifying the problem as being outside of itself, whether externalised as corporate control or climate change.

\section{THE BLIND SPOT OF CONTEMPORARY, ECOLOGICALLY BASED FARMING SYSTEMS}

This chapter commenced by calling to attention the strong opposition to sustainable, ecologically based agriculture by the mainstream, industrialised farming sector. In one sense, there is a clear parallel between the reductionist, nature-disconnected left hemisphere and the industrial worldview, and the holistic, right hemisphere with the systems-thinking, ecological worldview. Various authors contrast the industrial farming approach of yield maximisation, use of chemical inputs, and ecosystem suppression and control, with the ecological approach of yield optimisation, crop diversification and the synergistic integration of natural processes (e.g. IPES-Food, 2016; van der Ploeg et al., 2019; Röling and Jiggins, 1998).

An analysis of fundamental texts of the organic, permaculture, biodynamic and agroecology movements reveals the kind of cyclical approach (to production systems) suggested by McGilchrist as a means to regain balance. For the organic farming movement, one of its most important principles is the 'Law of Return' or the recycling of all organic wastes, advocated by pioneer Albert Howard (1943); permaculture's focus on mimicking the cyclical events and patterns in nature runs throughout its curriculum (Mollison and Slay, 2013); and similarly for biodynamic farming, cycles and rhythms are ever present, from growing cycles to cosmic cycles (Steiner, 1993). Yet as well as considering the cycles of life, the fundamental shift urged by both McGilchrist and Baring should also involve a revival of indigenous cosmologies and ontologies including around the nature of consciousness and spirit. To understand what this means in relation to farming, a closer look is taken at such indigenous perspectives.

\section{Harmony and Balance: The Indigenous Relationship of People, Land and Nature}

Indigenous worldviews from whichever continent place a higher value on spiritual and nonmaterial factors than do contemporary Western cultures (Kohler et al., 2019; Pierotti, 2011), 
and this distinctive spiritual relationship is enshrined in the United Nations Declaration on the Rights of Indigenous Peoples (Article 15, UNDRIP, 2007). In a critique of the impacts of colonialism on African Indigenous Knowledge Systems, Mashingaidze (2016: 25) writes, 'For indigenous peoples, the land is the core of all spirituality and this relationship to the spirit of the earth is central to all the issues that are important to indigenous peoples today'. Similarly, in a comparative study of traditional ecological knowledge systems of the Māori and Quechua peoples, Huambachano explains that 'For Indigenous peoples, land is both an agricultural and sacred space where both human and nonhuman relations work together as stewards' (2019: 1). Marsden (1988) describes the body of knowledge that Māori peoples refer to as 'mātauranga', as being 'the knowledge, comprehension or understanding of everything visible or invisible that exists across the universe; this includes all Māori knowledge systems or ways of knowing and doing'.

The work of Huambachano and others (e.g. Haverkort et al., 2002; Tchombe and Lukong, 2018) provides a generic picture of the dynamic and mutually reinforcing relationships between the human, spirit and natural worlds. These animistic or panpsychic traditions share three pertinent ontological characteristics: (1) that life has an invisible, spirit or energetic dimension; (2) that everything in nature has sentience or consciousness; and (3) that there is every-day communicative interaction between humans and the other-than-human. They also share axiological issues around the need to maintain harmony and equilibrium, to right relationship, to sacredness and to collaboration with the other-than-human. These provide the context for, and influence, their farming and food gathering activities. In his essay on indigenous knowledge, Posey (1998) explains that knowledge of the environment depends on the relationship not only between humans and nature, but also between the visible world and the spirit world. Within this, agriculture provides balance through relationships amongst not only people, but also nature and deities, so that, for example, the blessing of a new field is not a mere spectacle but rather an inseparable part of life where the highest value is harmony with the earth. Following this, Table 1.1 compares key characteristics of a modernist worldview of farming and of nature, with a generic indigenous worldview.

Unsurprising, this invisible dimension of indigenous agriculture has been little explored in academia, yet science has evidenced the highly sophisticated knowledge of indigenous cultures in relevant fields such as applied ecology and genetics, psycho-geography, geomancy, astronomy, transpersonal psychology, geometry and, chronobiology (Critchlow, 1979; Peat, 2005).

TABLE 1.1

\section{Comparison of Modernist with Indigenous Worldviews of Nature and Farming}

\section{Key characteristic}

Main goal

Perspective of life processes (time,

nutrient flows etc)

Relationship with nature

Understanding of the functioning

of nature

Management approach

Understanding of the nature of

nature Modernist (Western) Worldview

Striving for increased productivity

Repetitive and linear

Domination over nature

Nature functions as a set of parts,

a machine

Illness/disease focus

Secular-materialistic

\section{Indigenous Worldview}

Striving for balance and harmony Rhythmic and cyclical

Oneness with nature, communication with nature Nature is complex and holistic

Health and wellness focus

Panpsychism - animism - holds consciousness - spirit

Sources: Duran (2006), Whitewashed Hope (2020). 


\section{Do Ecologicaliy Based Farming Systems Fully Embrace Indigenous Praxis?}

The agroecology, organic farming and permaculture movements pride themselves on being based on a fusion of local and indigenous knowledge with appropriate, modern science. Albert Howard and others in the organic movement had been heavily influenced by exposure to sustainable farming practices in other parts of the world (e.g. see King, 2004). Miguel Altieri describes agroecology as a 'culturally acceptable approach as it builds upon traditional knowledge and promotes a dialogue of wisdoms with more Western scientific approaches' (Altieri and Toledo, 2011: 599). Permaculture's co-founder, Bill Mollison, attributed much of its content to what he learned from the indigenous people of Tasmania and others around the world (Fox, 2009). For biodynamic farming, however, and rather than claiming to draw from indigenous cultures, its knowledge base primarily one set of lectures - was transmitted by one person, Rudolf Steiner, a German-Austrian polymath philosopher, scientist and mystic who lived from 1861 to 1925. Steiner was heavily influenced by German mysticism, theosophy, Gnostic Christianity, the Cathars, alchemists, Buddhism and Hinduism, amongst other traditions (McKanan, 2018), and in particular the works of Johann Wolfgang von Goethe. Primarily though, Steiner explored the spiritual worlds, which he did meticulously (Courtney, 2005), and his lectures were based on his insights and inner visions from these spiritual exercises. 'I bore a content of spiritual impressions within me. I gave form to these in lectures, articles, and books. What I did was done out of spiritual impulses' (Steiner, 1928: 316).

With regard to embracing indigenous concepts, some of the organic farming pioneers did publicly recognise energetic and spiritual dimensions, as evidenced in Eve Balfour's classic address to an IFOAM ${ }^{3}$ conference in Switzerland in 1977 and partly influenced, she acknowledges, by the Steiner-inspired Anthroposophical Society (paras 41, 62):
A food-chain is not only a material circuit, but also an energy circuit. Soil fertility has been defined as the capacity of soil to receive, store and transmit energy. A substance may be the same chemically but very different as a conductor of living energy... We cannot escape from the ethical and spiritual values of life for they are part of wholeness. To ignore them and their implications would be to pursue another form of fragmentation.

Nevertheless, and whatever members' personal beliefs, the organic movement as a whole seemingly made a conscious decision early on to avoid bringing the spiritual into farming, most certainly influenced in the UK by the leading organic protagonist at the time, Albert Howard. This is rather curious in that Howard had spent three decades in India and acknowledges to have learned more from Indian farmers than he could teach them (Howard, 1953). He must therefore have encountered the Vedic worldview and the associated widespread, spiritually oriented, ritualistic farming practices. We may speculate that Howard, who was known to be sceptical of Steiner's teachings (Barton, 2018; Clunies-Ross, 1990), remained unconvinced or that he may have been protecting his own reputation as a credible figure within the scientific establishment, engaging as he did in national scientific debates (Conford, 2001).

With regard to permaculture, Mollison strategically distanced the movement from what he felt were unqualified, personal belief systems (as described in the prelude to this chapter). He may yet have held nonconformist beliefs himself, in one of his recorded lectures letting slip that:

The great preoccupation of Aboriginal Australians is dimension... and they can manipulate time, they can go else-when... There are 5 people alive who... can handle 7 dimensions easily... and they are saying that isn't it funny that as we are being decimated, some few of us are really getting a grip on things. ${ }^{4}$

With regard to the agroecology movement, it has on the one hand positioned itself as the most overtly political of its ecological stablemates and the one that most explicitly defends small-scale,

\footnotetext{
${ }^{3}$ International Federation of Organic Agriculture Movements (IFOAM).

${ }^{4}$ https://www.youtube.com/watch?v=rV6IjtEXyks, This video clip was accessed on 29 June 2020 but has since then (as of September 2020) been taken down by Tagari Publications.
} 
indigenous farmers - and their knowledge systems - worldwide (Gonzalez-De Molina, 2013; van der Ploeg et al., 2019; Rosset and Altieri, 2017; Sevilla-Guzman and Woodgate, 2013). Yet although the movement includes many such farmers' organisations whose members live according to their cultural worldviews (see, e.g., the membership of La Via Campesina: https://viacampesina.org/en), its research and taught practice, like the permaculture and organic farming movements, are more characteristic of secular-material frameworks (see, e.g., Altieri, 1995; Gliessman, 1998). In arguing for the democratisation of knowledge and ways of knowing for agroecology, Pimbert (2018) calls for deep social change in order for new knowledge systems to emerge and identifies participatory democracy as providing the means to do so. Yet according to McGilchrist's treatise, as long as the left hemisphere, the emissary, is facilitating such change and doing so from within the worldview and structures it has itself created, impact at a systemic level may not be guaranteed without a conscious commitment to developing new cosmological and ontological frameworks.

This analysis of the aforementioned farming movements' key texts suggests that only biodynamic farming embraces the invisible dimension as a fundamental component of its cosmological and ontological frameworks and therefore also its research and taught practice. Steiner called his agricultural course, Spiritual Foundations for a Renewal of Agriculture: A Series of Lectures (Steiner, 1993). These lectures were not aimed at those new to farming; they were given as hints or 'indications' to already-practising farmers, veterinarians and others connected with the land and/or interested in spiritual matters. Many in the audience were also anthroposophists - that is, they were practising spiritual science - and they had invited Steiner to provide spiritual-scientific insights into the problems they were facing in agriculture and especially around plant and livestock health. Steiner had earlier developed spiritual science as both a spiritual path and a scientific method, emphasising that there is an objective and comprehensible spiritual basis for a reality that can be directly experienced through the development of human imagination and intuition, and verified by rational thought (McKanan, 2018). Courtney (2005) explains that this spiritual dimension enables biodynamic agriculture to provide a healing of the earth through developing a human understanding of the living forces of growth and life that originate from the sun, moon and zodiacal star system (which in biodynamics is termed 'the formative forces of the cosmos' (2005: 15)). Biodynamic production standards reflect this understanding, stating, for example, that 'In life processes many diverse forces, which do not originate solely from material interactions, work together. All agricultural measures rely on activating processes which enhance and enliven these natural connections' (BDCert, 2012: 7).

Contrary to Mollison's (mis)understanding of biodynamics, Steiner stressed that each farmer should experiment before making any claims about the practices. He explained, 'The aim of these lectures was to arrive at such practical ideas concerning agriculture as should combine with what has already been gained through practical insight and modern scientific experiment with the spiritually scientific considerations of the subject' (Steiner, 1924: 9). So, paradoxically, whilst biodynamic farming does not claim, like the other movements, to draw directly from indigenous knowledge, its worldview is in fact more compatible, and there is evidence that, for this reason, its practices may be synergistic with those of indigenous farming communities (Klocek, 2013; Ramprasad, 2012; Wright, 2019). Sprunt, a sustainable development worker, describes his successful collaboration with farming communities in Northeast India: '...prior to Christian missionaries arriving, they had also used the moon as a guide for various farming practices, they could readily access cow dung and horns - it excited the groups to realise that Biodynamics was appropriate in this context' (Sprunt, 2006: 86).

This blind spot of the agroecological, organic and permaculture movements to the invisible dimension of farming may be depicted through the differing frameworks in Figure 1.1. This chapter has discussed that industrial farming focuses on the visible-material dimension, and on reducing the whole to its component parts (also known as reductionism), as depicted in Figure 1a. Agroecology (in its broad sense) takes into account not only the parts but also the whole system, yet still from a visible-material perspective, as depicted in Figure 1b. This chapter introduces the concept of 'Subtle Agroecologies', that is the invisible counterpart to the physical, which may take a reductionist and/or a systems focus. So if we take both agroecology and Subtle Agroecologies together, we arrive at a 


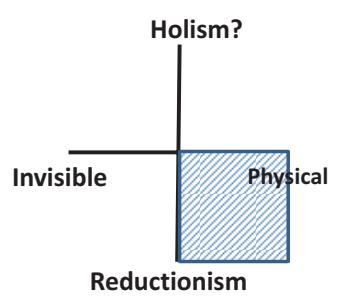

(a)

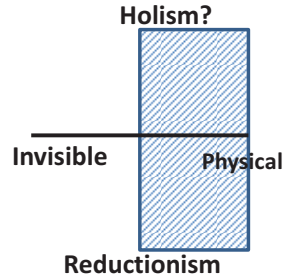

(b)

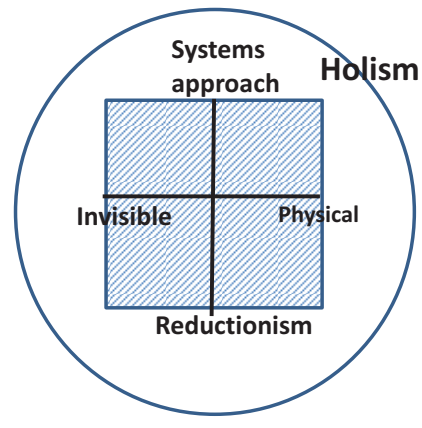

(c)

FIGURE 1.1 The conceptual frameworks of (a) industrial, (b) agroecological and (c) holistic farming.

more holistic framework as shown in Figure 1c. From this figure we can see that, by not recognising the invisible, the left hemisphere defines holism as being the opposite of reductionism, whereas this chapter posits holism as necessarily embracing the entirety of the visible and the invisible dimensions.

Based on the above, this chapter argues that as long as the research and taught practice of the ecologically based farming movements remain immersed in the secular-material dimension, they may only be paying lip service to indigenous worldviews as well as to the concept of holism (as depicted in Figure 1.1). Although those researchers and practitioners who take invisible phenomena seriously have been, at worst, subject to ridicule, and at best, in McGilchrist's words, 'discounted and seen as unimportant' when there appear to be more pressing, material issues to deal with (such as the dominant narrative of 'feeding the world'), this may be a trap of the left hemisphere's inability to reference the whole, and we may only truly solve the physical challenges facing humanity and the global environment when we do involve ourselves with invisible, subtle dimensions. Could embracing the hidden half of nature through farming enable us to experience a more authentic reality and thus to better understand and interact with nature in a more meaningful way? As Einstein and Infeld (1938: 262-263) famously wrote in relation to the nature of wave-particle duality:

But what is light really? Is it a wave or a shower of photons? There seems no likelihood for forming a consistent description of the phenomena of light by a choice of only one of the two languages. It seems as though we must use sometimes the one theory and sometimes the other, while at times we may use either. We are faced with a new kind of difficulty. We have two contradictory pictures of reality; separately neither of them fully explains the phenomena of light, but together they do.

\section{INTRODUCING SUBTLE AGROECOLOGIES: FARMING WITH THE HIDDEN HALF OF NATURE}

In their book on the new science of consciousness, Pfeiffer et al. (2007: xxviii) pose the question: 'What would a world be like, based on a mindset that understood that all is One and interconnected?' Following this, what would farming be like? This chapter has been building up to introduce the concept of Subtle Agroecologies. The term is adapted from David Spangler's reference to the subtle world of spirit which he calls our 'second ecology' (Spangler, 2010). For biodynamic farmers, subtle forces are those that may be perceived by well-trained sense organs (Courtney, 2005). In contrast to the industrial approach, we farm with nature instead of 'doing-to' nature. As corroborated by McGilchrist and Baring, the exploration of indigenous worldviews forms a solid starting point for conceptualising the invisible or hidden half of nature, so as to develop an expanded cosmology that embraces the dimensions of vibrational energy, consciousness and spirit. For modernist societies, one could also take Steiner's teachings as an 'off the peg' cosmological framework, as described by Edmunds (2005). In congruence with indigenous beliefs around animism or panpsychism, Steiner 
refers to an etheric dimension, a body of subtle forces, energy field of light or 'breath' of life, that is present throughout life forms including the plant kingdom (Marti, 2017).

\section{The State-Of-the Art of Subtle Agroecologies}

The scant amount of literature on subtle farming practices may be attributed to several factors. Within contemporary, indigenous cultures, intergenerational knowledge about such practices tends to be passed through oral communication rather than written, and thus is often intangible or tacit (Smith, 2008). Moreover in these contexts, such practices have multiple functions and may not necessarily be identified as solely relating to agriculture, as exemplified in Box 1.1 which provides two examples of farming practices based on such ontologies. Moreover, food acquisition in indigenous cultures is not solely dependent on settled agriculture and its associated practices (Barucha and Pretty, 2010). Thus, whilst works by indigenous authors explore their cosmologies and epistemologies in relation to nature and the environment, (including Katerere et al. (2020), Kimmerer (2013), Liljeblad and Verschuuren (2019), Tuhiwai Smith (2012) and Yunkaporta (2020)), there is less written work that specifically describes subtle food production practices.

\section{BOX 1.1 TWO EXAMPLES OF FARMING PRACTICE BASED ON INDIGENOUS ONTOLOGIES}

From the Indian subcontinent, Ramprasad (2012) analyses the use of manure in traditional Indian agriculture and its relation to Vedic literature, explaining that spiritual and agricultural approaches converge in farming practices, where the objective is to maintain the equilibrium between the very existential elements of life which includes the use of physical products (of the cow) synchronised with planetary positions and the interaction of the five elements (earth, water, air, fire and ether). Underlying this is the Hindu worldview of a spiritual force that connects everything. Ramprasad explains how the ancient practice of applying Panchakavya, a concoction of five products of the (sacred) cow, not only has proven benefits as a biofertiliser, as a biopesticide and for restoring soil fertility, but also has medicinal applications and is used in ceremonies and rituals, for example to provide a link between 'the living and the dead, the seen and the unseen, the physical and the paraphysical, and earthly and heavenly forces' (2012: 179).

Based on a global study, Burke and Halberg (2005) theorised on the nature of the ancient megaliths across South and North America, Europe and Egypt. They identified that these structures were built not when times were good, but during periods of famine, and that archaeological remains consistently uncovered seed offerings at these sites. Interested in the abnormal surges of electrical ground current and airborne electric charge that these precisely engineered and precisely located structures seemed to magnify at specific times of the day, they undertook trials on seed germination and growth on these structures and also in ancient rock chambers, as well as in the laboratory under similar conditions. They found that stronger electrical activity enabled greater seed germination and growth, and conclude that these structures were designed to enhance crop fertility. They explain,

Traditionally the ancients would not separate the physical from the non-physical, the soul from the land... ... tremendous effort was repeatedly taken to create an edifice that seems to us today to be imbued with an aura of ritual, and yet our experiments show that it is tapping natural energy in a way that can increase food production. 
Some re-imagined farming approaches of today do include subtle techniques, such as Shumei Natural Farming from Japan, which aims to help individuals understand the natural laws and principles of the universe (Jerkins, 2012), and Sustainable Yogic Agriculture that derives from the Brahma Kumaris spiritual community in India and intends to harness the power of the human mind (Pandey et al., 2015).

In terms of research, and even accounting for that from the biodynamic movement, the scientific knowledge base on Subtle Agroecologies is also relatively small. Almost completely disregarded within agricultural research, other disciplines are circling more closely to shed light on the underlying concepts and mechanics of Subtle Agroecologies. Each of these contributes a small piece of a jigsaw puzzle whose whole picture is yet to be revealed. The science of sonochemistry, for example, explores the use of sound energy as a driving force for chemical transformations, and has been applied to enhance seed germination (Pour et al., 2016). Similarly, in the field of structural and molecular biology, research has investigated the effects of magnetic fields on germination, growth, development, and yield of plants (Teixeira da Silva and Dobránszki, 2016). From theoretical physics, David Peat examines the interface between quantum science and indigenous cosmologies and epistemologies (2012). Transpersonal psychologist Travis Cox explores the ideological and metaphysical underpinnings of alternative agricultural philosophies and coins the term 'transpersonal agroecologies' to include the processes and experiences of interaction with other-than-human beings on the farm (Cox, 2014). Similarly, Jack Hunter's curated compilation Greening the Paranormal (2019) deals directly with the fundamental issues of belief systems, ecology, consciousness, inter-species communication and reconnection to place. In particular, Hunter draws attention to the concept of re-enchantment in relation to academia as an antidote to the materialistic worldview, quoting Voss and Wilson (2017: 13),

To feel enchanted is to step through a hidden portal into another way of seeing, into a new reality, where the reasonable, the certain, the measurable, and the predictable give way to the awesome, the wonderful, the delightful, the paradoxical, and the uncertain - and perhaps even the longing of the soul for some other kind of life beyond the exigencies of the everyday.

Hunter (2019: 39)

Outside of the formal research academy, individuals and groups of practitioner-researchers have long been exploring this field. Some are based in intentional communities which have, for several decades, been exploring the deep connection between humans and nature in relation to food production (e.g. Caddy, 1978; Small-Wright, 1993). Others have formed farmer learning groups on the cutting edge of agroecology and regenerative agriculture. For example, an Australian farm education provider offers training 'where you learn how to effectively manage subtle energy to improve your profitability' (RCS, 2020). In another example, a selection of farm advisors from the USA and Australia have been interviewed about the energetic dimensions of nutrition farming (Sait, 2003). One of those interviewed, Prof. Philip Callahan (1923-2017), built up a substantial body of knowledge on the use of nonlinear far-infrared radiation for insect control, as well as on the application of paramagnetism in agriculture (2003: 142). Another interviewee, Hugh Lovel (1947-2020), discusses his seminal work 'Quantum Agriculture' how this new and evolving method of agriculture applies the discoveries in quantum physics and quantum biology to scientifically growing food of the highest quality. In his own book, Lovel (2014) explores specific techniques including the astronomical planting calendar, agricultural homeopathy, dowsing and radionics, weather moderation, energy balancing and alchemy.

Similarly inspired by quantum concepts is Henk Kieft (2019), an agricultural engineer whose curiosity was piqued when he met a group of Dutch farmers who had been experimenting with 'unconventional' farming techniques, such as playing music to dairy cows, yet were unable to find more information, support or interest from either agricultural extensionists or researchers. Mindful 
of appealing to the secular-materialist worldview, Kieft has synthesised a range of techniques into three sequential categories:

1. Techniques based on energy and waves - which consider wave-particle duality, the applications of electromagnetism in health care and farming and their influence on physiological processes in the soil, plants, animals and people;

2. Techniques based on information fields, patterns and light language - which consider the energetic and informative aspects of nature, and measurements of vitality;

3. Techniques based on intention, intuition and consciousness - which consider subtle energies and how to sense and work with them.

For Kieft, the underlying concept is the relationship between mass, energy and information, and he throws down the gauntlet for researchers in the quantum sciences to step up to the challenge of exploring this applied field.

\section{Towards a Definition of Subtle Agroecologies}

Rather than a farming system in itself, this chapter proposes Subtle Agroecologies as superimposing a non-material dimension upon existing, materially based agroecological farming systems. Crucially, it is grounded in the lived experiences of humans working on, and with, the land over several thousand years to the present. It is helpful here to return to the concept of re-enchantment, which was originally used by Max Weber to critique modernist, secularised Western society (Jenkins, 2000). Historian Morris Berman advances the idea of re-enchanting the world by proposing that, rather than a return to the animistic traditions that existed prior the Cartesian era, Western society now needs a more appropriate consciousness which he suggests as being ecological, one that is grounded in the real and intimate connection between human and nature (Berman, 1981). In this sense we may conceive of the re-enchanting of agriculture as a way for people in modernist societies to reclaim their indigenous relationship with the living landscape they are in, a real-time, place-based relationship which may, therefore, be accessed and rekindled by anyone, anywhere.

Based on the predominant literature (Kieft, 2019; Lovel, 2014; Moore, 2011), the following is a collection of techniques, methods, arts and sciences associated with Subtle Agroecologies, presented simply in alphabetical order. This collection is not exhaustive, and many of the terms share similarities and may be used simultaneously.

Agro-homeopathy, astronomy, biodynamic preparations, bio-electromagnetism, dowsing, ecoalchemy, feng shui/geomancy, interspecies communication, intuition/direct knowing, love, mantras/ chanting, paramagnetism, planting calendars, prayer/intention, radionics, ritual, sacred geometry, Schumann resonances, sound/ultrasound, teacher plants/psychoactives, water dynamisation.

Kieft (2019) suggests that the secular-materialist mind may be more attracted to those techniques that are based on energies and waves and that use 'technology' as an interface between the perceived subject and object, over those techniques that depend solely upon the human individual or group faculties of consciousness which are as yet both undeveloped and more difficult to scientifically validate. It could of course be counter-argued that every technique undertaken by a human being has an inherent influence of intention or consciousness, whether or not involving a piece of 'kit'.

Additionally, although the focus of Subtle Agroecologies is on farming practices, through an indigenous lens this focus may itself be considered a form of separation from the inextricable human-nature relationship complex, and Huambachano (2019) refers to the inclusion of additional activities that celebrate, revere, give thanks for, seek permission or ask a question of, in the form of dance or other movement, ritual or prayer.

Based on this definition of the practice of Subtle Agroecologies, its science or research then follows as the systematic study of the nature of the invisible world as it relates to the practice of 
agriculture. Depending on the situation, this may take a goal-oriented, reductionist focus on, for example, increasing crop and livestock yields or reducing the incidence of pests and diseases, or a wide-angled vision of simultaneously working with multiple factors and concerns, all based on an ethics of care and with the overall purpose of bringing and maintaining balance and harmony to the farm (and the farmer), the community, and the world.

\section{CONCLUSION}

This chapter has discussed the application of Subtle Agroecological farming practices as a means not only to enhance the sustainability of agriculture but also to fundamentally shift the way we treat nature as a whole. If ecologically based farming is to be truly holistic in its practice and live up to its claims of embracing indigenous knowledge and worldviews, then a serious consideration of Subtle Agroecologies is long overdue. By working on the vibrational-energetic dimension, by becoming more adept at embodied practices that enable more conscious interaction with nature, and by re-evaluating our understanding of our place in the world, we might move towards the healing of the hemispheric rift or imbalance that McGilchrist, Baring and others have spelled out. Through the re-enchantment of agriculture, we may go a long way towards achieving the balance and harmony that contemporary, ecologically based farming movements are ultimately aiming for.

\section{ACKNOWLEDGEMENTS}

Thank you to George McAllister, Miche Fabre Lewin and Flora Gathorne-Hardy for helpfully commenting on earlier drafts of this chapter.

\section{REFERENCES}

Alliance for a Green Revolution in Africa. (2016) Going beyond Demos to Transform African Agriculture: The Journey of AGRA's Soil Health Program. Nairobi: AGRA.

Altieri, M.A. (1995) Agroecology: The Science of Sustainable Agriculture, 2nd Edition. Boulder, CO: Westview Press.

Altieri, M. and Toledo, V. (2011) The agroecological revolution in Latin America: Rescuing nature, ensuring food sovereignty and empowering peasants. The Journal of Peasant Studies, 38(3): 587-612.

Balfour, E.B. (1977) Towards a Sustainable Agriculture - The Living Soil. Address to an IFOAM Conference in Switzerland in 1977. Reproduced with permission from the Organic Gardening and Farming Society of Tasmania Inc@ 1995, Canberra Organic Growers Society Inc. https://www.cogs.asn.au/, Available online: https://soilandhealth.org/wp-content/uploads/01aglibrary/010116Balfourspeech.html (accessed October 10th 2020, paras 41, 62).

Baring, A. (2020) The Dream of the Cosmos: a Quest for the Soul, 3rd edition. Dorset: Archive Publishing.

Barton, G.A. (2018) The Global History of Organic Farming. Oxford: Oxford University Press.

Barucha, Z. and Pretty, J. (2010) The roles and values of wild foods in agricultural systems. Philosophical Transactions of the Royal Society B, 365: 2913-2926.

BDCert (2012) Demeter and Organic Production Standards, for the Use of Demeter and Related Trademarks. Stroud: Biodynamic Association Certification. December 2012 edition. http://bdcertification.org.uk/wp/ wp-content/uploads/2016/10/Organic-and-Demeter_Production-Standards.pdf (accessed September 10th 2020).

Berman, M. (1981) The Re-Enchantment of the World. Ithaca/London: Cornell University Press.

Burke, J. and Halberg, L. (2005) Seed of Knowledge, Stone of Plenty: Understanding the Lost Technology of the Ancient Megalith-Builders. San Francisco/Tulsa: Council Oak Books.

Caddy, E. (1978) Foundations of Findhorn. Moray: Findhorn Press.

Callicott, J.B. (1990) The metaphysical transition in farming: From the Newtonian-mechanical to the Eltonian ecological. Journal of Agricultural Ethics 3: 36-49.

Chief Dan George (2004) The Best of Chief Dan George. British Colombia: Hancock House Publishers.

Clunies-Ross, T. (1990) Organic food: Swimming against the tide. In Marsden, T. and Little, J. (eds.), Political, Social and Economic Perspectives on the International Food System. Aldershot: Avebury, pp. 200-214. 
Clunies-Ross, T. and Hildyard, N. (2013) The Politics of Industrial Agriculture. London: Earthscan.

Conford, P. (2001) The Origins of the Organic Movement. Edinburgh: Floris Books.

Conford, P. (2002) The myth of neglect: Responses to the early organic movement, 1930-1950. The Agricultural History Review, 50(1): 89-106.

Conford, P. (2020) Realising Health, the Peckham Experiment, its Descendents, and the Spirit of Hygiea. Newcastle-upon-Tyne: Cambridge Scholars Publishing.

Conner, C.D. (2005) A People's History of Science: Miners, Midwives and Low Mechanicks. New York: Bold Type Books.

Cotter, J. (2003) Troubled harvest: Agronomy and revolution in Mexico, 1880-2002. Contributions in Latin American Studies. Westport, CT: Praeger.

Courtney, H.J. (2005) What Is Biodynamics? A Way to Heal and Revitalise the Earth: Seven Lectures by Rudolf Steiner. Great Barrington, MA: Steiner Books.

Cox, T. E. B. (2014) Transpersonal agroecology: The metaphysics of alternative agricultural theory. Journal of Transpersonal Psychology, 46: 35.

Critchlow, K. (1979) Time Stands Still, New Light on Megalithic Science. Edinburgh: Floris Books.

Duran, E. (2006) Healing the soul wound: Counseling with American Indians and other native peoples. New York: Teachers College Press. 208pp.

Edmunds, F. (2005) An Introduction to Anthroposophy: Rudolf Steiner's World View. Forest Row: Rudolf Steiner Press.

Einstein, A. and Infeld, L. (1938) The Evolution of Physics: The Growth of Ideas from Early Concepts to Relativity and Quanta. Cambridge: Cambridge University Press.

Elder, S. and Dauvergne, P. (2015) Farming for Walmart: The politics of corporate control and responsibility in the global South. The Journal of Peasant Studies, 42(5): 1029-1046.

Forbes, J.D. (2011) Columbus and other Cannibals: The Wetiko Disease of Exploitation, Imperialism, and Terrorism. New York: Seven Stories Press.

Fox, J.B. (2009) Indigenous science. A celebration of Pacific culture. Cultural Survival Quarterly, 33: 1.

Gliessman, S.R. (1998) Agroecology, Ecological Processes in Sustainable Agriculture. Boca Raton, FL: Lewis Publisher.

Gonzalez-de Molina, M. (2013) Agroecology and politics. How to get sustainability? About the necessity for a political agroecology. Agroecology and the Transformation of Agri-Food Systems: Transdisciplinary and Participatory Perspectives, 37(1): 45-59.

Goulding, K.W.T., Trewavas, A., and Giller, K.E. (2011) Feeding the world: A contribution to the debate. World Agriculture, 2(1): 32-38.

Haverkort, B., van 't Hooft, K., and Hiemstra, W. (eds). (2002) Ancient Roots, New Shoots: Endogenous Development in Practice. London: Zed Books Ltd.

Hill, S.B. (1991) Ecological and psychological prerequisites for the establishment of sustainable agriculture prairie communities. In Martin, J. (ed.), Alternative Futures for Prairie Agriculture Communities. Calgary: University of Calgary, $33 \mathrm{pp}$.

Howard, A. (1943) An Agricultural Testament. New York: Oxford University Press.

Howard, L. (1953) Sir Albert Howard in India. London: Faber and Faber Ltd.

Huambachano, M.A. (2019) Indigenous food sovereignty: Reclaiming food as sacred medicine in Aotearoa New Zealand and Peru. New Zealand Journal of Ecology, 43(3): 3383.

Hunter, J. (2019) Greening the Paranormal, Exploring the Ecology of Extraordinary Experience. Derby: August Night Press.

IPES-Food (2016) From uniformity to diversity: A paradigm shift from industrial agriculture to diversified agroecological systems. International Panel of Experts on Sustainable Food systems. Available online: http://www.ipes-food.org/_img/upload/files/UniformityToDiversity_FULL.pdf (accessed August 14th, 2020).

Jenkins, R. (2000) Disenchantment, enchantment and re-enchantment. Max Weber Studies, 1(1): 11-32.

Jerkins, D. (2012) Spirit of the Land: Shumei Natural Agriculture Philosophy and Practice. Koka: Shumei International Press.

Katerere, D.R., Applequist, W., Aboyade, O.M., and Togo, C. (2020) Traditional and Indigenous Knowledge for the Modern Era. A Natural and Applied Science Perspective. Boca Raton, FL/London/New York: CRC Press, Taylor \& Francis Group.

Kieft, H. (2019) Quantum Leaps in Agriculture: Exploring Quantum Principles in Farming, Gardening and Nature. Mauritius: Lambert Academic Publishing.

Kimmerer, R.W. (2013) Braiding Sweetgrass: Indigenous Wisdom, Scientific Knowledge and the Teachings of Plants. Minneapolis, MN: Milkweed Editions. 
King, F.H. (2004) Farmers of Forty Centuries, Permanent Agriculture in China, Korea, and Japan. New York: Dover Publications Inc.

Klocek, D. (2013) Sacred Agriculture, the Alchemy of Biodynamics. Great Barrington, MA: Lindisfarne Books.

Kohler, F., Holland, T.G., Kotiaho, J.S., Desrousseaux, M., and Potts, M.D. (2019) Embracing diverse worldviews to share planet Earth. Conservation Biology, 33(5): 1014-1022.

Lang, T. (2004) Food Wars: The Global Battle for Mouths, Minds and Markets. Abingdon: Routledge.

Levy, P. (2013) Dispelling Wetiko, Breaking the Curse of Evil. California: North Atlantic Books.

Liljeblad, J. and Verschuuren, B. (eds) (2019) Indigenous Perspectives on Sacred Natural Sites: Culture, Governance and Conservation. London/ New York: Earthscan/Routledge.

Lovel, H. (2014) Quantum Agriculture: Biodynamics and Beyond. Blairsville, Georgia: Quantum Agriculture Publishers.

Macy, J. and Brown, M.Y. (2014) Coming Back to Life: The Updated Guide to the Work That Reconnects. Gabriola: New Society Publishers.

Marsden, M. (1988) The natural world and natural resources. Māori value systems and perspectives. Resource Management Law Reform Working paper 29, Part A. Wellington: Ministry for the Environment.

Marshack, A. (1972) The Roots of Civilisation. London: Weidenfeld \& Nicolson Ltd.

Marti, E. (2017) The Etheric, Broadening Science through Anthroposophy. Volume 1: The World of the Ethers. Forest Row: Temple Lodge Publishing.

Mashingaidze, S. (2016) Cosmovision and African conservation philosophy: Indigenous knowledge system perspective. Environmental Economics, 7(4): 25-33.

McGilchrist, I. (2019) The Master and His Emissary, the Divided Brain and the Making of the Western World, New Expanded Edition. New Haven, CT/London: Yale University Press.

McKanan, D. (2018) Eco-Alchemy, Anthroposophy and the History and Future of Environmentalism. Berkeley: University of California Press.

Merchant, C. (1990) The Death of Nature: Women, Ecology, and the Scientific Revolution. San Francisco, CA: Harper One.

Mesa-Lago, C. (1998) Assessing economic and social performance in the Cuban transition of the 1990s. World Development, 26(5): 857-876.

Mollison, B. (1996) Travel in Dreams: 'One Fat Foot after Another': The Autobiography of Bill Mollison by Bill Mollison. Stanley: Tagari Press.

Mollison, B. and Slay, M.R. (2013) Introduction to Permaculture. Stanley: Tagari Publications.

Moore, A. (2011) Stone Age Farming: Tapping Nature's Subtle Energies for Your Farm or Garden. Victoria: Python Press.

Morton, J. (2014) Britain's Last Witch Trial. News. The Law Society Gazette. 29th September 2014. Available online: https://www.lawgazette.co.uk/obiter/britains-last-witch-trial/5043624.article\#: :text=It\%20will $\% 20$ be $\% 2070 \% 20 y e a r s$, nine\%20months\%20in\%20May\%201944 (accessed June 28th 2020).

Orr, D.W. (1991) Ecological Literacy: Education and the Transition to a Postmodern World. New York: State University of New York Press.

Pandey, S.T., Verma, O., Kewalanand, Pandey, D.S., Gill, S., Patel, J.C., Patel, G.N., Patel, D.M., Patel, B.T., Patel, B.B., Patel, D.S., Patel, I.S., Patel, R.N., Singh. N.K., and Thakur, D.M. (2015) Yogic farming through Brahma Kumaris Raja yoga meditation: An ancient technique for enhancing crop performance. Asian Agri-History 19(2): 105-122.

Peat, F.D. (2005) Blackfoot Physics: A Journey into the Native American Universe. Boston, MA: Weiser Books.

Pfeiffer, T., Mack, J.E., and Devereux, P. (eds.) (2007) Mind before Matter: Visions of a New Science of Consciousness. Hampshire: O Books.

Pierotti, R. (2011) The world according to Is'a: Combining empiricism and spiritual understanding in indigenous ways of knowing. In Anderson, E.N., Pearsall, D., Hunn, E. and Turner, N. (eds.), Ethnobiology. Hoboken, NJ: Wiley-Blackwell, pp. 65-89.

Pimbert, M. (2018) Democratising knowledge and ways of knowing for food sovereignty, agroecology and biocultural diversity. In Pimbert, M. (ed.), Food Sovereignty, Agroecology and Biocultural Diversity, Constructing and Contesting Knowledge. London/New York: Routledge.

Ponisio, L.C. and Erlich, P.R. (2016) Diversification, yield and a new agricultural revolution: Problems and prospects. Sustainability, 8: 1118.

Posey D.A. (1998) The 'balance sheet' and the 'sacred balance': Valuing the knowledge of indigenous and traditional peoples. Worldviews, 2(2): 91-106. 
Pour, M. E., Hobbi, M., Ghasemi, H., and Nazari, M. (2016). Plausible mechanisms by which ultrasonic waves affect seeds. Plant Breeding and Seed Science, 74(1): 85-92.

Ramprasad, V. (2012) Manure, soil and the Vedic literature: Agricultural knowledge and practice on the Indian Subcontinent over the last two millennia, Chapter 12. In Jones, R. (ed.), Manure Matters: Historical, Archaeological and Ethnographic Perspectives. Abingdon: Taylor \& Francis Group.

RCS. (2020) Quantum leap workshop series. RCS Australia. https://www.rcsaustralia.com.au/products/ family-business/graduate-services/quantum-physics/ (accessed September 10th, 2020).

Rickard, S. (2019) Plant Protection Products: The Value of Their Contribution to Lowering UK Household Expenditure on Food and Drink. Peterborough: Crop Protection Association. https://cropprotection.org. uk/media/1153/sean-rickard-food-prices-report-final.pdf.

Röling, N.G. and Jiggins, J. (1998) The ecological knowledge system. In Röling, N.G. and Wagemakers, M.A.E. (eds.), Facilitating Sustainable Agriculture. Cambridge: Cambridge University Press.

Rosset, P. and Altieri, M. (2017) Agroecology: Science and Politics. Agrarian Change \& Peasant Studies Book 7. Rugby: Practical Action Publishing.

Roszak, T. (1992) The Voice of the Earth. New York: Simon and Schuster.

Sait, G. (2003) Nutrition Rules: Guidelines from the Master Consultants. Yandina: Soil Therapy Pty Ltd.

Sevilla Guzmán, E. and Woodgate, G. (2013) Agroecology: Foundations in agrarian social thought and sociological theory. Agroecology and Sustainable Food Systems, 37(1): 32-44.

Sinclair, M. and Thompson, M. (2001) Cuba Going Against the Grain: Agricultural Crisis and Transformation. Washington, DC: Oxfam America.

Small-Wright, M. (1993) Perelandra Garden Workbook: A Complete Guide to Gardening with Nature Intelligences. Virginia: Perelandra.

Smith, J. (2008) Intangible Heritage (Key Issues in Cultural Heritage). Abingdon: Routledge.

Sonnenfeld, D.A. (1992) Mexico's "Green Revolution," 1940-1980: Towards an environmental history. Environmental History Review, 16(4): 28-52.

Spangler, D. (2010) Subtle Worlds: An Explorer's Field Notes. Traverse City, MI: Lorian Press.

Sprunt, J. (2006) Biodynamic agriculture: Adaptability and sustainability for farmers around the world: Case studies from Northeast India. In Kristiansen, P. and Kemp, C. (eds.), Third OFA National Organic Conference "Organics - Solutions to Climate Change", Sydney, Australia 2006. Queensland: Organic Federation of Australia, pp. 86-94.

Steiner, R. (1924) To all members: The meetings at Koberwitz and Breslau. Anthroposophical Movement, 1: 9-11.

Steiner, R. (1928) The Story of My Life. London: Anthroposophical Publishing Co.

Steiner, R. (1993) Agriculture: Spiritual Foundations for the Renewal of Agriculture. East Troy, WI: BioDynamic Farming \& Gardening.

Tchombe, T.M.S. and Lukong, T.E. (2018) Dynamics of indigenous socialization strategies and emotion regulation adjustment among NSO early adolescents, North West region of Cameroon. International Journal of Humanities Social Sciences and Education (IJHSSE), 3(8): 86-124.

Teixeira Da Silva, J.A. and Dobránszki, J. (2016) Magnetic fields: how is plant growth and development impacted? Protoplasma, 253(2): 231-248.

Tuhiwai Smith, L. (2012) Decolonising Methodologies, Research and Indigenous Peoples. London/ New York: Zed Books.

UNDRIP (2007) United Nations declaration on the rights of indigenous peoples. G.A. Res. 61/295. September 13th, 2007. https://www.un.org/development/desa/indigenouspeoples/wp-content/uploads/sites/19/ 2018/11/UNDRIP_E_web.pdf (accessed June 30th 2020).

van der Ploeg, J.D., Barjolle, D., Bruil, J., Brunori G., Costa Madureira, L.M., Dessein, J., Draggg, Z., FinkKessler, A., Gasselini, P., Gonzalez de Molina, M., Gorlach, K., Jürgens K., Kinsella, J., Kirwan, J., Knickel, K., Lucaso, V., Marsden, T., Maye, D., Migliorini, P., Milone, P., Noe, E., Nowak, P., Parrott, N., Peeters, A., Rossid, A., Schermer, M., Ventura, F., Visser, M., and Wezel, A. (2019) The economic potential of agroecology: Empirical evidence from Europe. Journal of Rural Studies, 71: 46-61.

Vorley, B. (2003) Food Inc. Corporate Concentration from Farmer to Consumer. London: UK Food Group/IIED.

Voss, A. and Wilson, S. (2017) Re-Enchanting the Academy. Auckland: Rubedo Press.

Whitewashed Hope: a message from 10+ indigenous leaders and organisations. (2020) Open source document bit.ly/IndigenousWorldViews (accessed November 24th 2020).

Wright, J. (2009) Sustainable Agriculture and Food Security in an Era of Oil Scarcity, Lessons from Cuba. London: Earthscan. 
Wright, J. (2019) A call for the biodynamic movement to come out about spiritual, non-material farming philosophy and practice. In Wahl, V., Hach, A., Sommer, S., Derkzen, P., Brock, C., Fritz, J., SpenglerNeff, A., Hurter, U., and Florin, J.-M. (eds.), Evolving Agriculture and Food: Opening up Biodynamic Research. Contributions to the 1st International Conference on Biodynamic Research, September 5th to 8th 2018, Dornach, Switzerland. Dornach: Section for Agriculture, p. 105.

Yunkaporta, T. (2020) Sand Talk: How Indigenous Thinking Can Save the World. San Francisco, CA: HarperOne. 


\title{
2 From the Mainstreaming of Western Science to the Co-Evolution of Different Sciences Addressing Cognitive Injustice
}

\author{
Bertus Haverkort \\ Retired agricultural development specialist and author
}

\section{CONTENTS}

Introduction: Cultures, Worldviews and Sciences .................................................................... 21

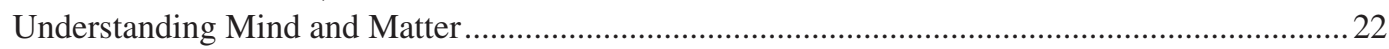

Agricultural Practices from Different Worldviews .............................................................. 23

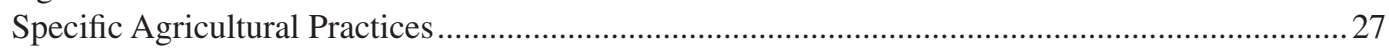

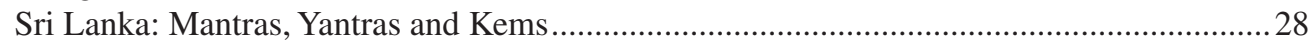

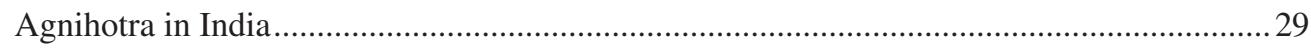

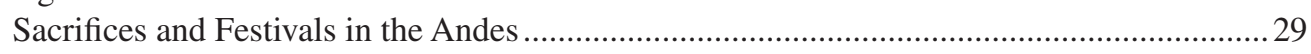

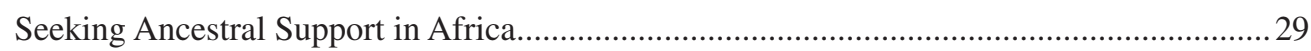

Harmonising the Earth and Cosmic Forces in Europe.......................................................29

The Trans-Cultural Notion of Science and Its Co-Evolution....................................................... 31

Scenarios for Inter-Science Relations: From Domination to Complementarity ........................... 33

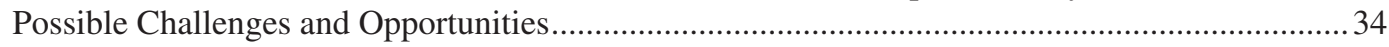

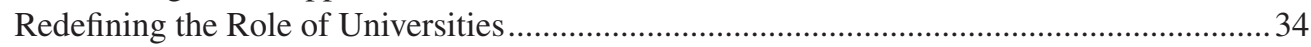

Dealing with the Strong and Weak Points within the Dominant Forms of Knowledge ..........36

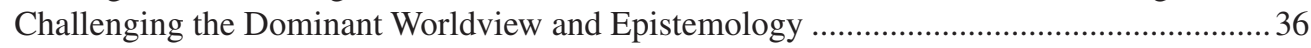

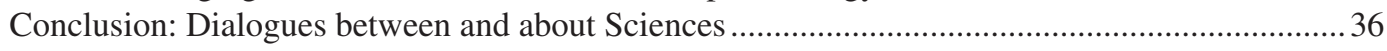

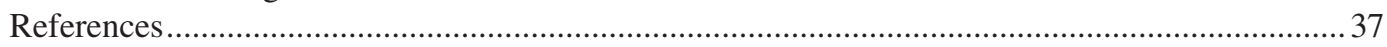

\section{INTRODUCTION: CULTURES, WORLDVIEWS AND SCIENCES}

Presently, the mainstream, Western-based (or modern) sciences are taught, developed and applied in all corners of the globe and have a very strong position because of the attribution of their effectiveness, reliability, applicability and their funding and recognition by the main private and public actors. Yet, till today there is still a great diversity of ways in which different people in different cultures acquire and process knowledge and formulate their own sciences. How people actually know and handle knowledge depends on the worldviews of particular knowledge communities, and the methods they use for learning, their logic and values. Even though mainstream sciences often displace local (or native or indigenous) sciences, a considerable number of local sciences are still being applied, and reproduce themselves despite their marginal position. Over the last two decades, there are a number of initiatives that aim at 
revitalising local knowledge systems - and local sciences - and these search for complementarity and synergy between different sciences.

These initiatives assert not only that global diversity has a physical and biological component, but also that cultural and scientific diversity is also important. In different parts of the globe, indigenous and local experts publish about the scientific basis of their knowledge systems: in New Zealand (Bishop, 1998; Tuhiwai Smith, 1999), Canada (Battiste, 2005), the USA (Barnhardt and Kawagley, 2005; Cajete, 2000; Mihesuah and Wilson, 2004), South America (Rist and Delgado, 2009), Africa (Millar et al., 2006) and India (Balasubramanian and Nirmala Devi, 2006). A great number of research and educational programmes are emerging that aim at revitalising local knowledge traditions, and these seek a complementary relationship with other sciences. These range from the United Nations University Institute of Advanced Studies - Indigenous Knowledge Initiative, and the Inter-institutional Centre for Indigenous Knowledge located in the College of Education at Pennsylvania State University, which comprises more than 20 indigenous knowledge resources centres in North and South America, Europe, Asia, Africa and Oceania, to the Indigenous Women's Network that was founded in 1985 and has a journal of the same name. These indigenous scholars, researchers and institutions address questions such as the following:

- What are the worldviews, basic principles, values and methods according to which learning takes place in different cultural environments?

- What are the strengths and weaknesses of different sciences and what can be done to increase the effectiveness and innovative character of these ways of learning?

- How can the marginalisation and suppression of local sciences be addressed? And

- How can complementarity and co-evolution of sciences be achieved?

Proponents of this approach take the position that neither experiences and methods from minority cultures nor those of the mainstream approach are inherently the most appropriate to explain reality and/or to develop technologies that improve quality of life. The latter may be used to complement local learning processes, but they should not replace them, as is often the case. Exchange between different sciences, and co-evolution rather than domination and substitution are seen as important.

\section{UNDERSTANDING MIND AND MATTER}

Amongst the different worldviews and sciences that exist today, reality is considered and understood in different ways. Globally, a divide can be observed between those who believe that reality is made up of only one basic substance (monists) and those who believe that reality is made up of two different substances (dualists).

Monists focus either on matter or on mind. Materialism asserts that mind is basically a result of biochemical processes. This position is dominant in modern Western paradigms. Within monism, positions that consider reality to be based on spiritual or mental principles are labelled as idealism. These positions are often held in non-Western cultures, and specifically so in the Vedic tradition. Modern science has been struggling with the relation between monism and dualism. It mostly accepted that both realities exist (dualism), but in their research practice, modern scientists address only the quantifiable, which is the material reality.

During the Enlightenment period, the foundations of scientific reasoning were laid by various traditions, including Empiricism by Charles Bacon (1561-1626), Rationalism by Descartes (1596-1650) and Mechanism by Newton (1642-1727). The development of Evolutionism by Darwin (1809-1882) and Classical Economics by Adam Smith (1723-1790) emerged from this scientific revolution with major implications for the worldviews and the way social systems were considered and organised.

Rene Descartes believed in the possibility to reach absolute truth through scientific knowledge. His approach was based on the belief that all aspects of a complex phenomenon can be 
understood by reducing them to their constituent parts, a process called atomisation. He made a clear distinction between mind and matter and replaced the notion of the divine plan of the Creator with a mathematical order of nature. Descartes understood humanity as composed of two independent substances: body and mind. But, he thought that it was only the ratio and quantification of objective phenomena that could lead to good knowledge. During the Enlightenment, the dominant worldview became materialistic: in order to make reality researchable, it became necessary to separate mind from matter, humankind from nature and subject from object. The only thing that could objectively be observed and experienced was matter, and so mind became considered as terra incognita by scientists, a tradition that continues to this day. This Cartesian science has a linear view of time, a mechanistic notion of cause and effect. It values quantity more than quality and is organised into highly specialised and atomised disciplines. The theory of evolution, based on the notion of 'survival of the fittest', has been translated over to economics as the mechanism of competition between commercial entities where the 'winner takes all'. Human traits such as altruism, friendship, cooperation, love and affection have been attributed less importance than competition, individuality, aggression and conquest. This has led to a justification of political and economic domination and acceptance of cultural and biological extinction as part of the price for progress.

Since the colonial period, this version of Western-based science, in combination with Western religions, was disseminated in the South and, to a certain extent, it substituted the various - often animistic - indigenous knowledges, sciences and belief systems. The latter were declared inferior, backward and superstitious and were regarded as a bottleneck to modernisation and development, as were the pre-Enlightenment belief systems in the North.

Western science has led to impressive technologies and highly productive systems of agriculture and industry, impressive medical achievements and communication systems. But it has not fulfilled its promises to serve human needs and allow progress for all. The widespread application of modern technologies has definitely improved food production, health systems and labour conditions in parts of the globe, but not the entire globe. Where it has worked well has often been at the expense of some categories of people. In southern countries, the overlapping categories of women, rural people and peasant farmers have suffered most. ${ }^{1}$ Advancements in modern technology have not led to global peace, ecological stability and social or psychological well-being. Nor have they led to the eradication of widespread hunger or poverty, not even in northern countries, where in spite of affluence, pockets of poverty exist amongst certain communities, and where food systems also cause a serious problem through affluence: obesity and environmental and climatic impacts. This situation justifies a search for new worldviews and scientific methods that challenge Western knowledge's claim to exclusive universality, and a great number of organisations and movements are engaged in this effort. An illustration of the diversity of worldviews and ways of learning is presented in Box 2.1, with some insights from India, Ghana and Bolivia.

\section{AGRICULTURAL PRACTICES FROM DIFFERENT WORLDVIEWS}

From the year 2000 to 2012, two different international programmes have carried out action research to strengthen indigenous knowledge and practices and to enhance endogenous development (development from within). These programmes covered 16 different countries worldwide: Bolivia, Mexico, Guatemala, Chile and Colombia, Ghana, Kenya, Zimbabwe, Uganda and South Africa, Norway, the Netherlands, India, Sri Lanka, Nepal and Indonesia. The first programme was COMPAS, a programme in which several NGOs and a number of universities carried out fieldwork.

\footnotetext{
${ }^{1}$ For a comprehensive overview and critical analysis of the role of peasantry in Peru, Italy and the Netherlands, see van der Ploeg (2008).
} 


\section{BOX 2.1 DIFFERENT WORLDVIEWS, WAYS OF LEARNING AND WAYS OF KNOWING}

India: In the Vedic tradition, the real world and the fundamental principles upon which life systems are organised are different from those in the West (Balasubramanian and Devi, 2006). Reality is a continuum of matter, mind and consciousness. Vedic knowledge has a notion of 9 existential principles, 41 qualities and 5 types of action, upon which, for example, the Ayurvedic health system is based. The term Akasha refers to the unifying energy inherent in all four elements (earth, air, water and fire) in nature and thus also in every living creature. Essentially, it is the all-encompassing spirit energy. In this worldview, all entities can learn, and learning is not limited to the use of the five senses. It takes place through a combination of sensory perception, intuition, inference and teachings of seers or gurus. If the mind is free from prejudices (lust, anger, greed, intoxication, delusion and jealousy), it can learn from within. Meditative techniques and yoga are used in addition to ancient written texts in the pursuit of knowledge for liberation and Enlightenment. Lessons from previous lives can also play a role. In India, traditional knowledge and practices coexist parallel with mainstream knowledge. Ayurvedic hospitals coexist with hospitals based on Western medicine.

Latin America: The Andes: Studies by AGRUCO (AGRUCO 2001; COMPAS-AGRUCO 1998) revealed that in the Andean worldview, the natural, social and spiritual worlds are united. Sacred time-space (Pacha Mama) goes beyond the physical or socio-economic domains. There is a spiral notion of time that is not separated from space (territory); the first ordering principle is relation; everything is related and this leads to a reciprocal relationship between humans, animals, plants, rocks, water, wind, sun, moon and stars. These relations are embodied in astronomy, rituals and fiestas. In these cultures, learning takes place by experiencing the relationship between the human, the natural and the spiritual worlds. 'It is through our connection with Pacha Mama that we learn' (Millar et al., 2006). Learning from within is based on intuition and lessons from nature. More than being interested in mechanical explanations of 'how things are', there is an emphasis on the question 'why things are'. In asking 'why', the interaction between the human, the material and the spiritual world is taken as a given; questions of moral and ethics play an important role, as human behaviour can have a direct influence on the natural and spiritual worlds. In the Andes, traditional and mainstream knowledge have a so-called syncretic relationship. Some traditional concepts have been redefined by mainstream to fit their frame of reference, but continue to be used in the traditional communities. The notion of Pacha Mama has been replaced by Gaia, sometime in combination with the Virgin Mary.

Africa: In the worldview of the Dagaba people in Northern Ghana, the world is made up of ancestors, the living and the not-yet-born, and nature is sacred (Millar et al., 2006). Within this worldview, there is a hierarchy between divine beings, spiritual beings, ancestors, living human beings and natural forces. Nature provides habitats for human and spiritual entities. Time is cyclic and goes from the present to the past. Ancestral spirits have powers that can be used in both negative and positive terms. In the present-day African reality, one can observe two coexisting systems of beliefs and knowledge: traditional and modern. The modern system is formally accepted, but the traditional system persists often in an underground way. The traditional systems are labelled as satanic by imported religions and as superstitious by mainstream scientists. Both traditional and mainstream sciences are based on specific values, logic and interpretation of cause-effect; this often leads to different choices about lifestyle, spirituality and practices of farming and health. In addition, the ways of learning are different. In the traditional African view, learning implies being receptive 
to the teachings of those who have lived before us, the elders, and reading the signals of the spiritual world expressed in nature. Also here, the emphasis of learning is more on 'why things are than on how things are'.

The West: In the 'Enlightenment' view, knowing is based on measuring and the use of the five senses. Rational logic, materialism, mechanism and self-interest of the individual or group are strong ordering principles through which Western people comprehend reality. There is also a perceived duality, expressed in dichotomies such as mind-matter, creator-created, man-nature and object-subject. Science is organised and developed in separate disciplines. In this materialist and mechanistic view, learning is done by subjects that are separate from objects, and quantifiability is important. The emphasis of research and of learning is on 'how things are': how a certain effect is caused within the laws of physics or other sciences. In the 'Postmodern' view, the world is regarded more from a holistic perspective, where uncertainty, diversity, chaos and self-regulation, and synergy are seen as ordering principles. It takes distance from or relativises generic principles and universal science. Sources of knowing include Pre-Enlightenment views, new scientific insights from quantum mechanics and transdisciplinarity, systems thinking, chaos theory, social learning and a diversity of ways of knowing and ways of learning from non-Western cultures.

It set up cooperation between indigenous organisations and development organisations. The most important point was to understand and articulate the worldviews and values of the indigenous people and then to design and test practical ways to strengthen local knowledge. The second programme, CAPTURED, aimed to develop educational material and research methods for universities in their role of enhancing endogenous development.

The results of these programmes (COMPAS, 2007; Haverkort et al., 2003; Haverkort and Reijntjes, 2006) revealed the following:

- In all countries, major changes in political autonomy, demography, economic and cultural integration, technological innovations, exposure to mass media and degradation of environmental resources have taken place and are leading to an erosion of indigenous cultures, knowledge and cosmovisions.

- At the same time, despite the South's apparent acceptance of the dominant technologies, beliefs and values, below the surface a persistent core of indigenous culture survives and a wealth of indigenous knowledge on natural resource use still exists. This determines the values and decision-making of rural populations.

- Many cosmovisions of indigenous farming communities are based on a holistic concept: the reality in which farming takes place generally encompasses the natural world, the human world and the spiritual world (see Figure 2.1). Mankind, the spiritual world and nature are often seen as having a reciprocal relationship. If nature is not treated well, it may react by treating the people badly, through, for example, a plague, a drought or a bad harvest. If the spirits are respected, they will ensure a good life for living creatures. People, therefore, look upon farming not only as an activity in the natural world, but also as an activity in the spiritual world.

- Peoples' understanding and description of the spiritual world is frequently rich, diverse and structured. It is experiential and can be based on the teachings of persons with visions, such as spirit mediums or shamans. It can be expressed in classical texts such as the Vedas, or in linguistic or artistic symbols. The spiritual world is seen as containing both a creative force and a destructive force. There may be a polarity of good and bad forces, and there are 

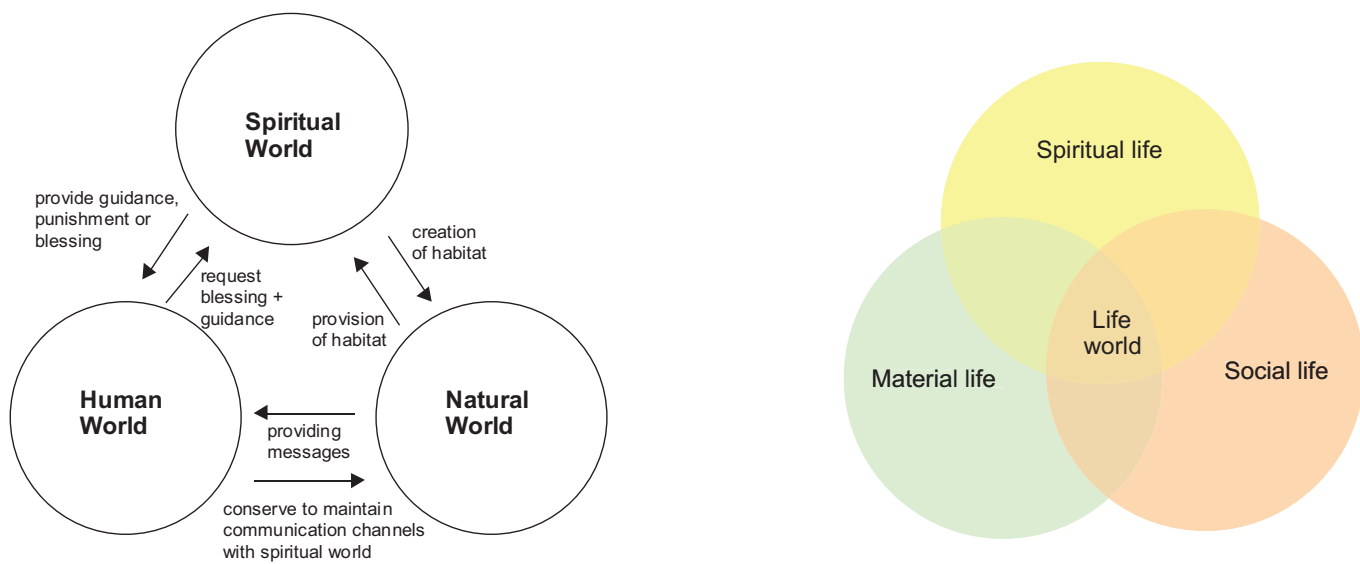

FIGURE 2.1 The three worlds in indigenous sciences and their interactions.

often different spiritual beings such as gods, spirits and ancestors. These spiritual beings may express themselves in nature and through living creatures.

- In many cosmovisions, nature is considered sacred. This finds its expression in concepts like Mother Earth, sacred mountains, rivers, trees and animals. Animals, plants and especially trees are often considered to be linked with the spiritual world and should be treated with respect. The sacred character of nature and the spirituality of the people often lead to the need to conduct rituals during agricultural activities. Some of these relate to spiritual beings or ancestors.

- Cosmic influences are frequently dealt with by using astrological information that determines the moments when different agricultural activities can take place. Thus, in many cases, the agricultural calendar and the ritual calendar are linked and they guide social, natural and spiritual activities.

- Indigenous communities organise themselves on the basis of their cosmovision. Many indigenous institutions regulate the use of land, water and biological resources as well as the way farmers learn, teach and experiment. Traditional leaders often combine their political powers with spiritual skills and functions.

- The way farmers learn and experiment is based on their own concepts, values and criteria.

- Many development activities and conventional systems of education and technology development neglect or reject the importance of cosmovision, culture and indigenous knowledge and suggest the superiority of dominant Western science. This Western scientific system tends to be less holistic and more materialistic than indigenous knowledge systems.

- There is no reason to romanticise cosmovisions. It cannot be concluded that indigenous cosmovisions and traditional practices have always been effective in preventing the overexploitation of soils, overgrazing, deforestation, pollution of water, erosion or environmental disaster. Nor have they always led to maintaining social stability or equity. Indigenous knowledge is not always equally spread in the communities, and some persons may monopolise and misuse certain knowledge.

- For development organisations to be effective, there is a need for them to support endogenous development. This is development that is based on locally available biological and physical resources and the values and knowledge of the local population. This implies a good understanding of the diversity of cultures and the characteristics and dynamics of indigenous knowledge systems and cosmovisions; cooperation with traditional leaders; an appreciation of the potentials and limitations of locally available resources 
for agriculture, health and nature management, and of their possible role in the local economy; and finally, a diversity of approaches to endogenous development that can be applied by local NGOs and governmental organisations for research and development. The partners of the COMPAS and CAPTURED programmes agreed that 'development' should be understood from the perspective of native cosmovision that implies the integration of spiritual life in social and material life. Yet there was a clear difference in the way that the different partners, acting as development agencies, could work with them. In the traditional communities in Bolivia and Ghana and the tribal areas in India, traditional cosmovisions are still quite intact.

- Agricultural production involves biophysical as well as spiritual activities. The agricultural calendar and the ritual calendar coincide. Here, the only way to have a good relationship with the rural population is to understand and appreciate their cosmovision and collaborate with indigenous institutions. In the rural areas in India, in Sri Lanka and in Peru, the traditional cosmovisions have been subjected to considerable erosion and it is difficult to get a good picture of rural people's cosmovision. There is a mixture of traditional and modern ideas that may differ from village to village and from year to year. In these areas, it was noticed that in initial discussions with farmers, traditional concepts were frequently not expressed. However, after further probing beyond the surface, many elements of the traditional cosmovisions gradually began to emerge. Farmers are used to the fact that outside agencies do not understand, respect or tolerate traditional practices or cosmovisions. Therefore, they talk with the outsider with empathy, in the language or concepts they think the outsider appreciates. They have learned that outsiders do not appreciate their cosmovision, and thus, they do not openly express their own concepts and views. There is reason to assume that in traditional societies, but also in countries where traditional cosmovisions are subject to erosion, traditional cosmovision and spirituality are more widespread and prevalent than assumed by outsiders in general. This means that working with traditional institutions is relevant and requires tact and social skills. In the Netherlands and Norway, and to a certain extent also in central Mexico, it seems that traditional cosmovisions and spirituality have almost completely disappeared. In these countries, there is a widespread discontent about the materialistic way of modern farming and a small number of farmers want to restore agriculture's spiritual vision. In such cases, indigenous institutions may no longer exist and, therefore, new institutional allies may have to be sought.

- In essence, the partners concluded that a focus on rural people's cosmovisions can make it possible to reconnect their work with indigenous knowledge in its full significance. Farmers interpret (agricultural) development and define their relationships with outside agencies from within the context of their cosmovision. Development workers are thus challenged to go beyond validating indigenous technical knowledge. Farmers' concepts of life - and the practices based on them - are a reality to which they must relate. This relationship can only be genuine when respect is given to the unknown concepts and traditional institutions. It also provides an opportunity for mutual learning.

The above lessons have been used to build a model for activities to enhance endogenous development (Figure 2.2).

\section{SPECIFIC AGRICULTURAL PRACTICES}

More in-depth studies in Sri Lanka, India, Ghana, Zimbabwe and Bolivia shine a light on specific agricultural practices where the spiritual dimension of the worldviews is being addressed.

Some practical examples are provided in Figures 2.3-2.9 below. 


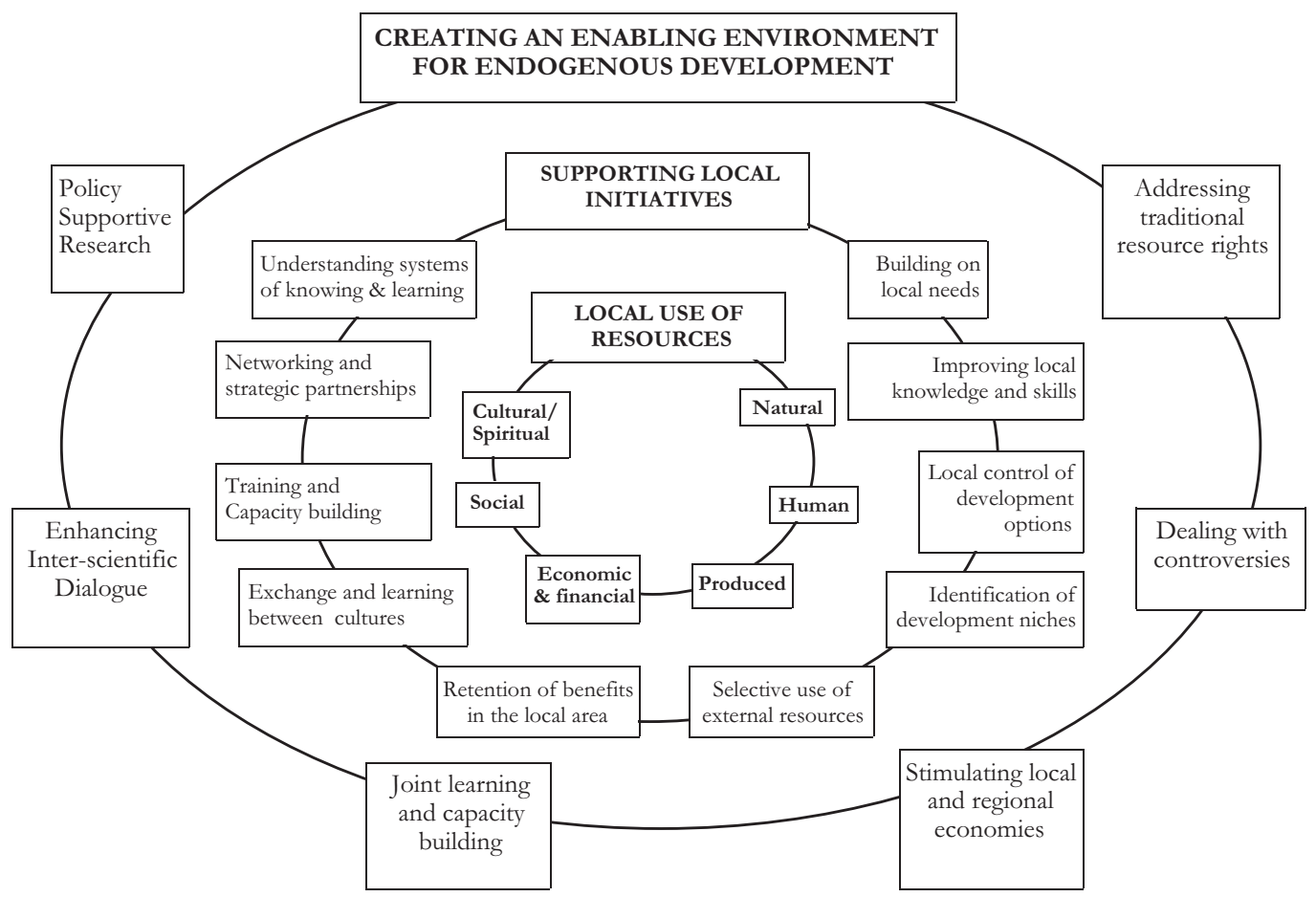

FIGURE 2.2 Creating an enabling environment for endogenous development. (Source: Haverkort et al., 2003: 250.)

\section{Sri Lanka: Mantras, Yantras and Kems}

A ritual in a rice field in Sri Lanka: a combination of mantras, meditation and sacrifices performed by a shaman. He has to live a pious life. The ritual is a commitment of people to the rice field and its natural environment, and a pledge for each being to play its role in the mutual process of coexistence and to avoid taking more than a fair share.
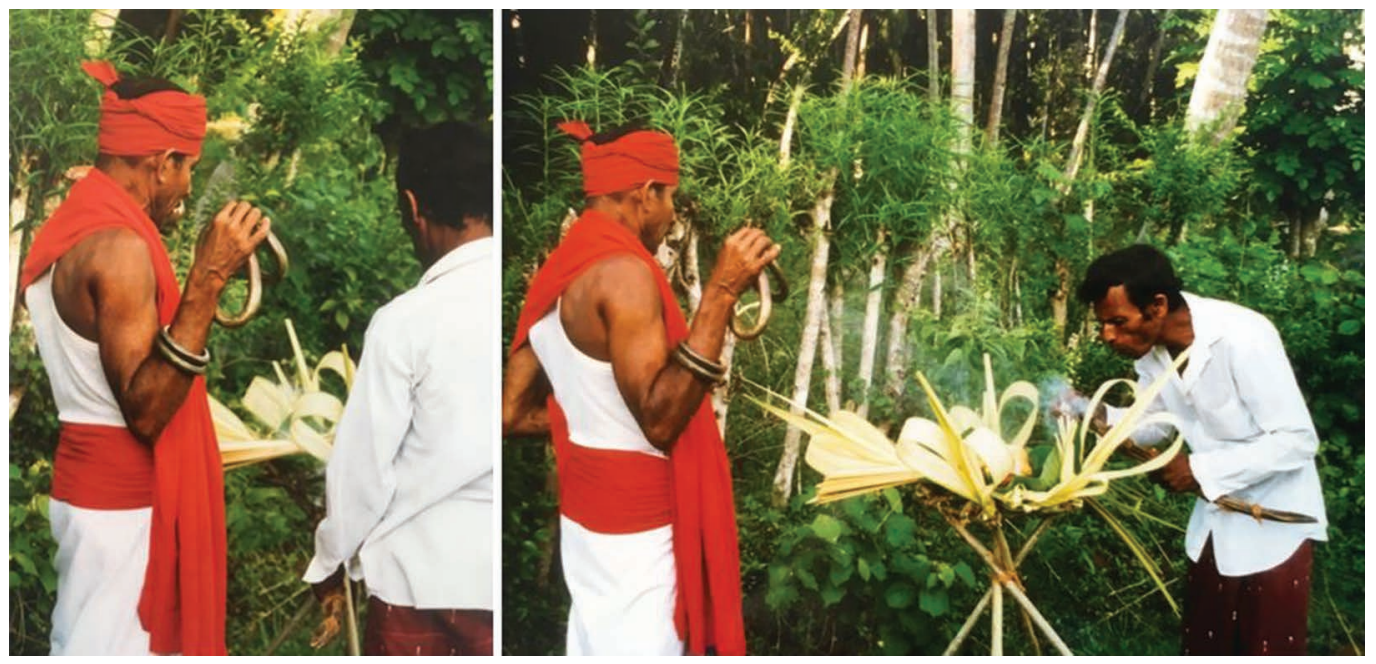

FIGURE 2.3 Ritual in a rice field in Sri Lanka. (Photo credit: author's own.) 


\section{AGNiHOtRA IN INDIA}

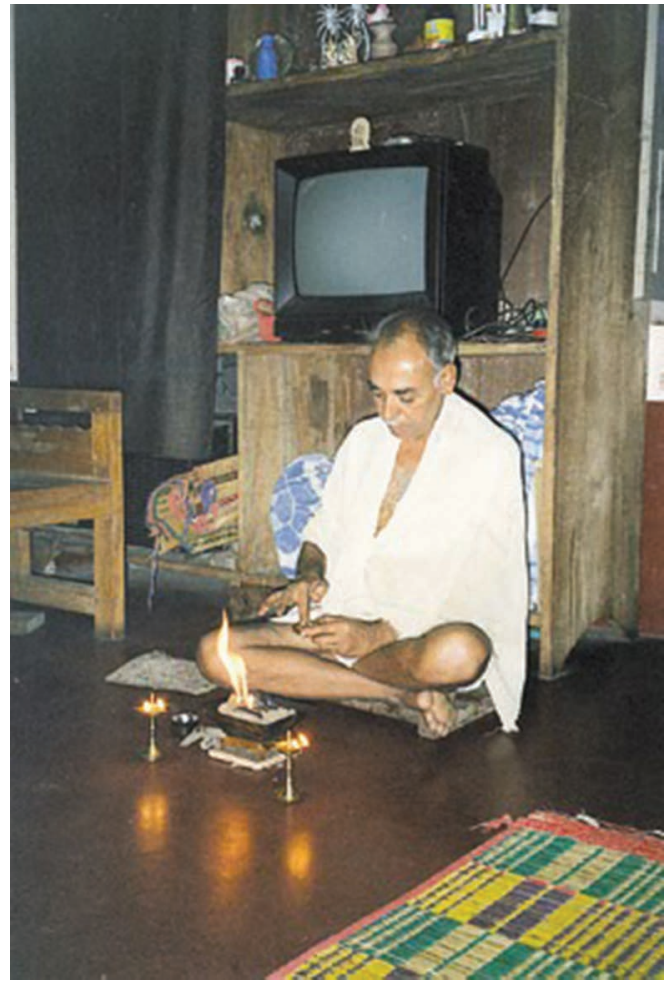

FIGURE 2.4 Agnihotra ceremony, India. (Photo credit: author's own.)

The leader of a farmer's group, Mr Perushotama Rao, performs a fire ritual, Agnihotra. Fire will purify the environment and allow for harmonious relations between plants, animals and human beings. Twice a day a mixture of ghee and rice will be put on the fire. Mr Rao chants a number of mantras, meditates and creates a vibration that causes a healthy environment.

\section{Sacrifices and Festivals in the Andes}

In the Andes, it is common to have rituals in the field to honour Pacha Mama and to establish and reinforce linkages between the land, the vegetation, the animals and people. There are specific rituals for strengthening the links with llamas, with potatoes or with other traditional crops. These are the moments when people celebrate community life amongst themselves.

\section{Seeking Ancestral Support in Africa}

In Zimbabwe, a spirit medium asks the blessing of the ancestors for a tree planting programme and mediates between the living and the dead to consult the ancestors and to build on their knowledge and wisdom.

In Northern Ghana, a soothsayer is consulted to ask the ancestors advice and permission for adopting a new technology. Animal and vegetative sacrifices are performed to mobilise magical powers.

\section{Harmonising the Earth and Cosmic Forces in Europe}

Biodynamic farmers in Europe use preparations in the form of cow horns filled with silica to mobilise cosmic forces. 

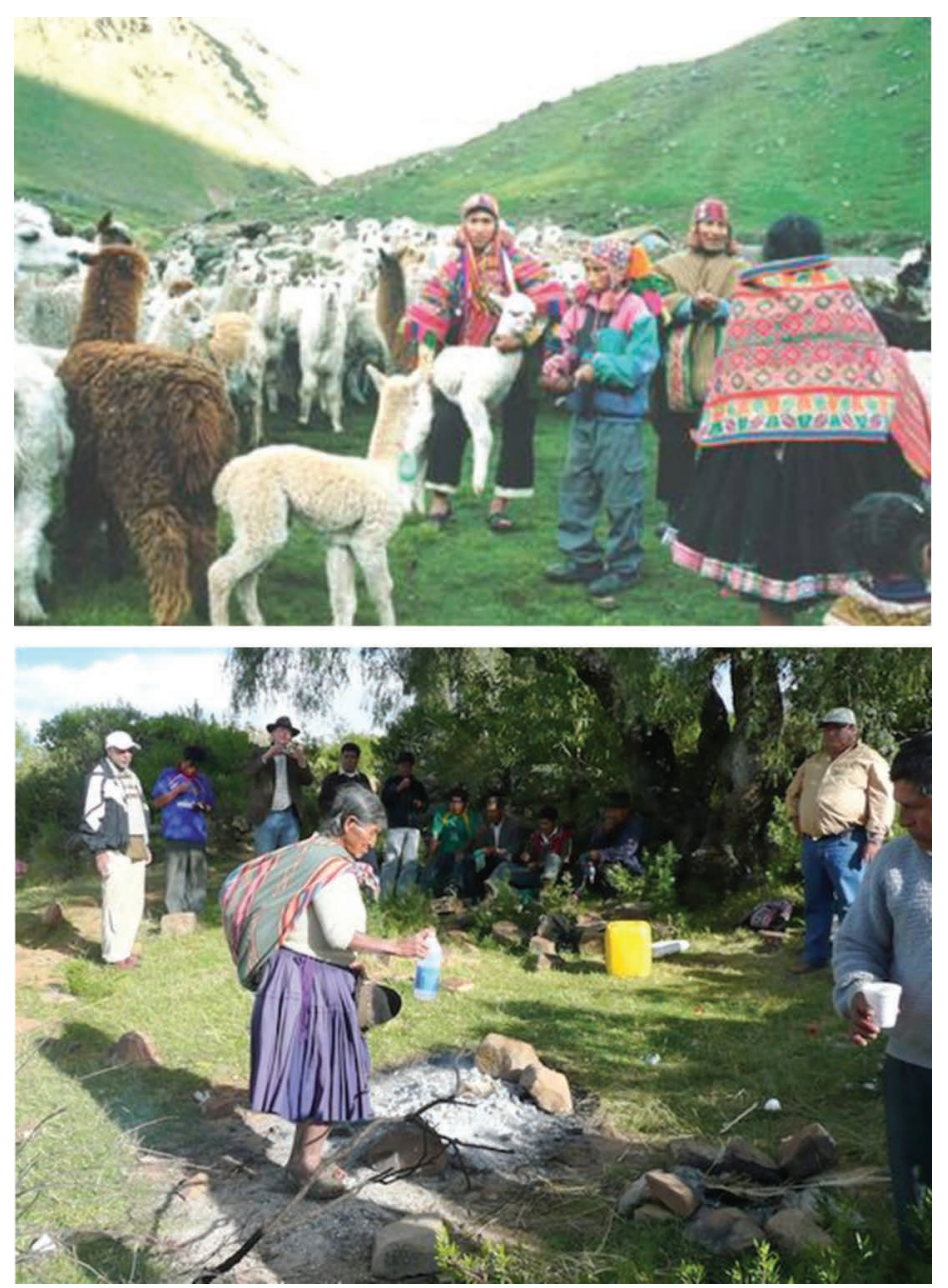

FIGURE 2.5 Pacha Mama ritual in the Andes. (Photo credit: author's own.)

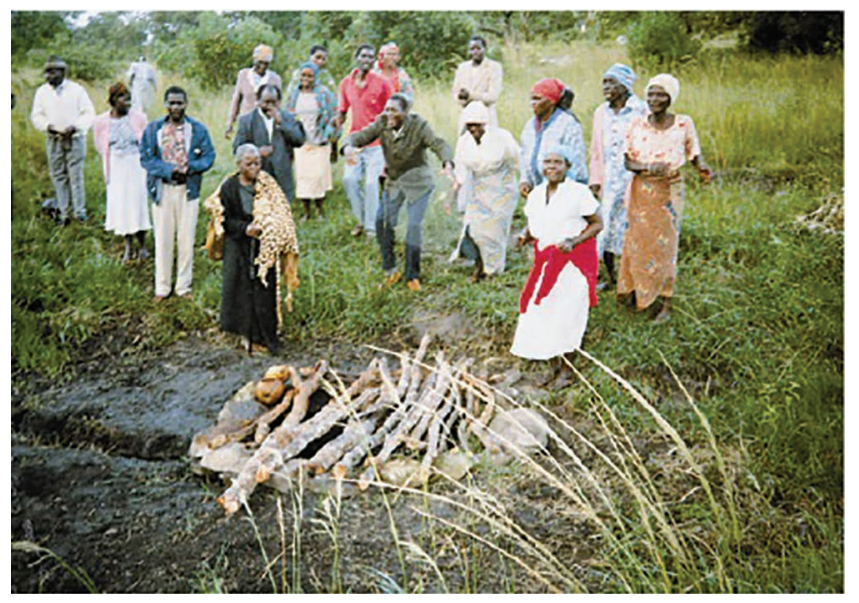

FIGURE 2.6 Ceremony to seek ancestral support in Zimbabwe. (Photo credit: author's own.) 


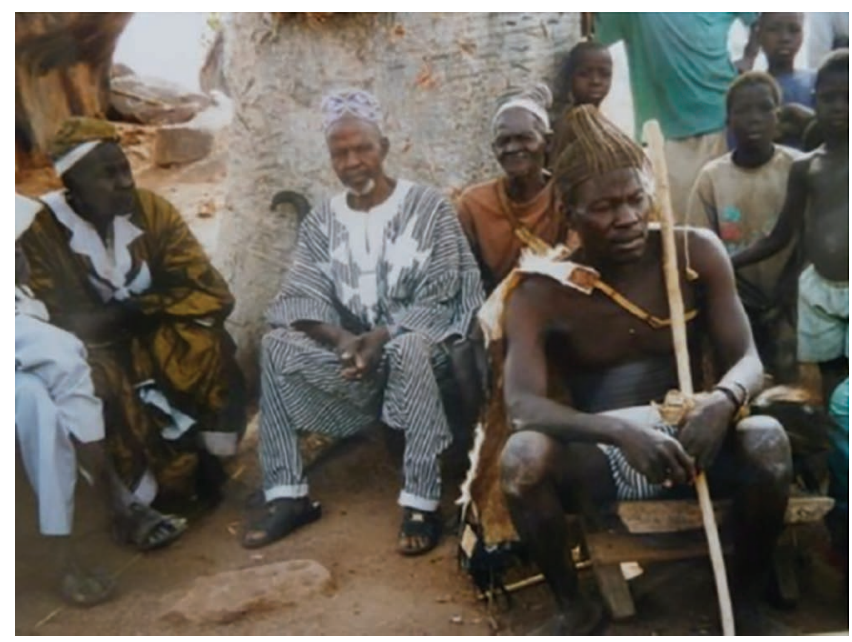

FIGURE 2.7 Consultation with the ancestors prior to adopting a new technology, Ghana. (Photo credit: author's own.)

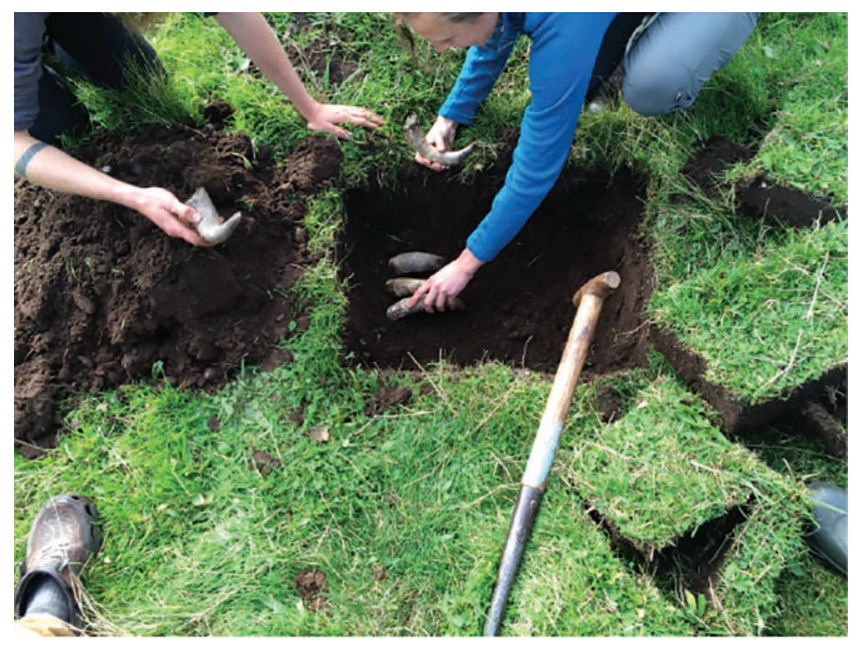

FIGURE 2.8 Group of farmers burying cow horns, Staffordshire, UK. (Photo credit: Alysoun Barrett Bolger.)

\section{THE TRANS-CULTURAL NOTION OF SCIENCE AND ITS CO-EVOLUTION}

Modern philosophers of science such as Popper, Kuhn, Latour and Feyerabend have each on their own, but especially in their combination, challenged the foundations of mainstream science and dismantled the idea of exclusive claims to universality. It goes beyond the scope of this chapter to delve deep into these (postmodern) notions of science. But in a very brief way, one can reflect on the following generalisations:

- Scientific knowledge is only an approximation to the truth. This approximation can be pursued by trial and error only (Popper, 1980, 1965).

- Scientific development should be as a social process in which the worldviews held by scientists and the social process of developing scientific activities should be understood. 
Real new knowledge emerges if the validity of the dominant paradigms is broadly being challenged and is replaced by new paradigms (Kuhn, 1962).

- Scientific facts are not in the first place objectively true; they are rather the result of agreement within the scientific community. This means that negotiation, networking and lobbying to get social recognition for the results of the research in the form of its publications are all important aspects of scientists' work (Latour and Woogar, 1979).

- Objective science is an illusion, as all observation, perception and interpretation are based on more or less deficient instruments and theories. What is considered to be a 'fact' is basically an agreement within a school of scientists. There is not one universally valid method of research, and the monopolistic claims to truth of conventional science are not justified. The history of sciences shows that there are different roads towards truth. Western science is one and only one of the possible sciences, and it is time to correct scientific arrogance and scientific imperialism. Exporting Western sciences and technologies has not exclusively brought well-being to indigenous peoples. We should stop the one-way traffic and rather go for a mutual learning process (Feyerabend, 1975).

Based on the reflections and positions of these philosophers of science, and building on the insights of indigenous scholars, CAPTURED has chosen the following definition of science: ${ }^{2}$

Science is a body of knowledge formulated within a specific worldview. It emerges from specific methods of learning and producing knowledge and uses a consistent theoretical framework that includes assumptions, general principles and theories. It involves an active role of a specific knowledge community that has reached consensus on validity of knowledge. The knowledge acquired and the resulting science are products of a social process and are always limited and subject to modification in the light of new data, information and insights.

The plurality of worldviews and ways of learning can lead to a plurality of sciences. The degree to which ontological positions and sources of knowing differ from each other determines the degree of compatibility and/or complementarity of different sciences. A joint learning process or dialogue between different forms of knowing would be impossible or meaningless if the sciences involved exclude each other. Even if the basic assumptions and methods may seem incommensurable, complementarity may be sought. The CAPTURED programme does not aim at integrating the different ways of knowing into one universal system of research and education. Rather, its focus is to understand the diversity, the differences, possible contradictions and controversies. It looks for revitalisation of the different ways of knowing and co-evolution and possible communalities, complementarities and synergy.

On the basis of this definition, the CAPTURED programme suggested that we look at a science as having a certain expression in each of the following basic elements:

- The Ontology (or Worldview): The way the people see themselves and their relation with the rest of the cosmos: the worldview

- The Gnoseology (or Methodology): Methods for learning, experimenting and teaching. It is obvious that the way of learning is a directly related to the worldview.

- The Epistemology (or the Theoretical Framework): The way knowledge is organised: its logic, theoretical frameworks and paradigms.

- The Axiology (or Values): The moral and aesthetic values of the people.

- The Knowledge Community: The experts, leaders, healers, guides and the way they carry out peer reviews, have debates and discourses on worldviews, methods, theories and values and agree on accepting or rejecting them.

In every culture, people have explicitly or implicitly formulated these notions and are engaged in these knowledge-related processes, and therefore, we assume that in different cultures and different

2 This definition and a discussion on the co-evolution of sciences have been elaborated in Haverkort et al. (2012). 
professional communities, different sciences exist. Some of these sciences are considered as rigorous in certain ways, and others may be considered as being weak in one or more aspects. The aim of the dialogue is to support each other in overcoming the weaknesses.

The plurality of worldviews, through methods of learning, in values, in conceptual frameworks and in ways to assess and review knowledge gained, can lead to a plurality of sciences. The degree in which ontological positions and sources and methods of knowing differ from each other determines the degree of compatibility and/or complementarity of different sciences. A joint learning process or dialogue between different forms of knowing would be very difficult if the basic elements of the sciences involved contradict each other.

The appreciation of the diversity of cultures and worldviews offers a wide range of opportunities for exchange and dialogue. Intercultural contacts can lead to domination and control, and thence to the disappearance of cultures and ways of knowing. But, if the intercultural contacts take place with respect, it can also lead to mutual learning and synergy. Respect does not imply the unconditional acceptance of all differences. It implies the willingness to listen, openness to learn and to be responsive, and the capacity to criticise when necessary (Fay, 1999).

COMPAS and CAPTURED provide a platform for intra- and intercultural and intra-/and inter-/scientific dialogues. Intra-cultural/scientific dialogues take place between persons that are from a particular culture and share a similar knowledge base, whereas intercultural/scientific dialogues take place between persons with a different cultural and scientific background. These exchanges can contribute to a co-evolution of cultures and sciences. In this process, no science is considered a priori superior of inferior. Traditional knowledge is not romanticised and Western knowledge not rejected because of its dominant position. Each science involved is stimulated to develop and improve its methods and theories based on its own dynamics as well as on interaction with other systems of knowing.

The Objectives of Inter-Scientific Dialogues Are as Follows:

- to strengthen and revitalise the marginalised sciences;

- to look for synergy and opportunities for mutual learning as well as for contradictions and exclusions;

- to question, challenge and criticise each other in order to determine those aspects of the science and value systems that need modification and improvement; and

- to balance the power and financial resource base of the different sciences.

The epistemological interpretation of the different Asian, African and Latin American and European knowledge systems, their ways of learning and experimenting and their mutual relationships needs further attention. Therefore, it is important to continue to systematise and make more explicit the concepts and theories behind indigenous forms of knowledge in order to share and improve on them as part of a possible co-evolution of the diversity of sciences.

\section{SCENARIOS FOR INTER-SCIENCE RELATIONS: FROM DOMINATION TO COMPLEMENTARITY}

Complementarity and co-evolution of sciences can only be obtained if the research methods and parameters used are not solely based on those of the dominant or on those of traditional science. The research needs to enhance the ownership, effectiveness and innovativeness of the different sciences involved and to include attention to worldviews, methods, theories, values and knowledge communities. All the research being carried out in the CAPTURED programme focused on these aspects, with the main research tools being transdisciplinary research (Nicolescou, 2004, 1998), action research and indigenous methodologies (Denzin et al., 2008). In all cases, methods and parameters of different scientific traditions are combined, and the knowledge communities of both mainstream and local sciences are involved in the design, implementation and follow-up of the research. 


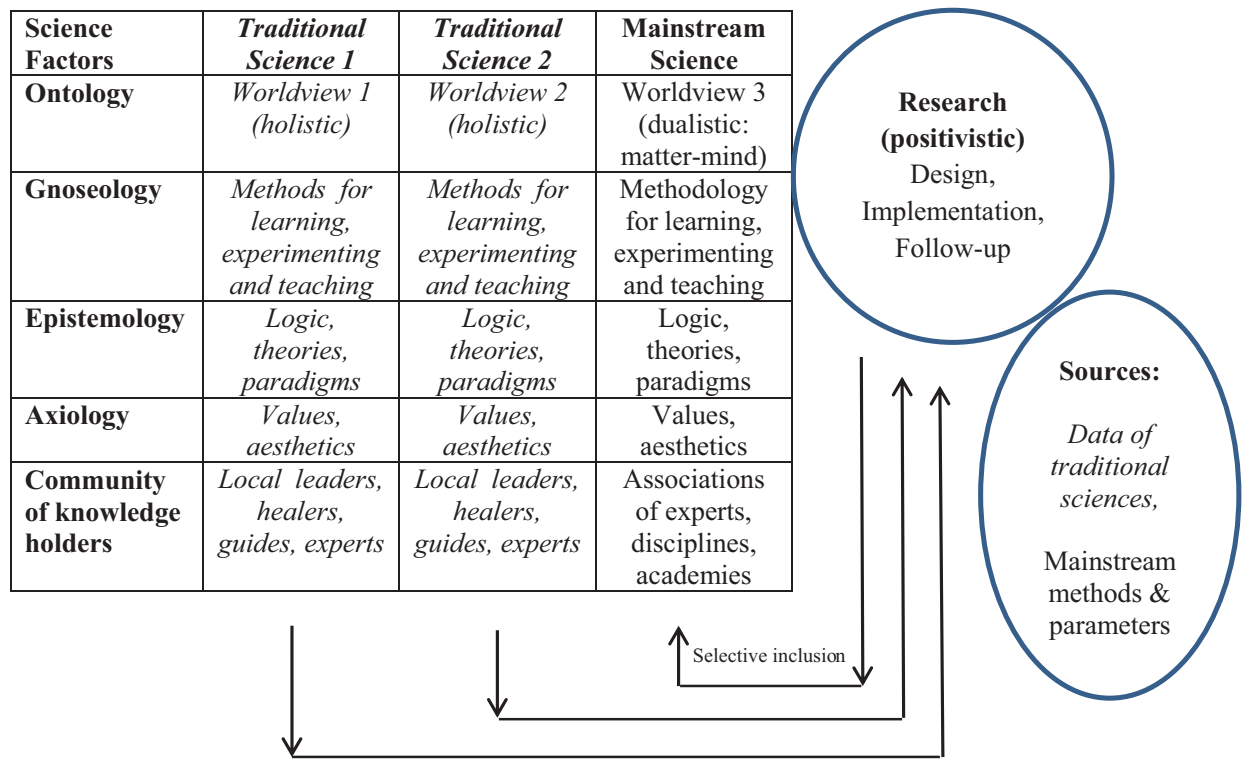

FIGURE 2.9 Scenario 1: marginalisation: suppression, substitution and selective inclusion.

Below, two different scenarios for relating sciences are presented:

Scenario 1: This leads to marginalisation and suppression of local sciences, to substitution by mainstream knowledge and selective inclusion of traditional knowledge in the mainstream, shown in Figure 2.9. This may lead to underground or parallel knowledge systems, to syncretism and/or rebellion or resistance.

Scenario 2: This leads to complementarity, synergy and co-evolution of different sciences, as shown in Figure 2.10.

Assessment of traditional sciences by the mainstream in a one-way process (as shown by the arrows in Figure 2.9). Mainstream research uses positivistic models with mainstream parameters to assess traditional technologies. It may include those elements of local knowledge in its system which are considered positive according to the researchers' parameters, with no feedback to traditional sciences. This often leads to marginalisation, suppression and substitution, 'going underground', syncretism and resistance.

Flows of data and research results to and from all sciences are shown by the arrows in Figure 2.10.

The involvement of actors in the design, implementation and follow-up is defined by protocols and codes of conduct. Inter-science dialogue leads to complementarity, synergy and co-evolution. Research methods can be both quantitative and qualitative and should also involve information exchange and dialogues between social actors such as artists, religious leaders, syndicates, political, emancipatory and environmental movements, business and minorities.

\section{POSSIBLE CHALLENGES AND OPPORTUNITIES}

CAPTURED concluded that there are a number of approaches that together could contribute furthering inter-scientific dialogue that involves local communities, NGOs, universities and regional and international organisations.

\section{Redefining the Role Of Universities}

A prime condition for successful cooperation of these actors will be a relationship between actors that is horizontal as far as possible and is characterised by mutual interest and confidence. Hence, 


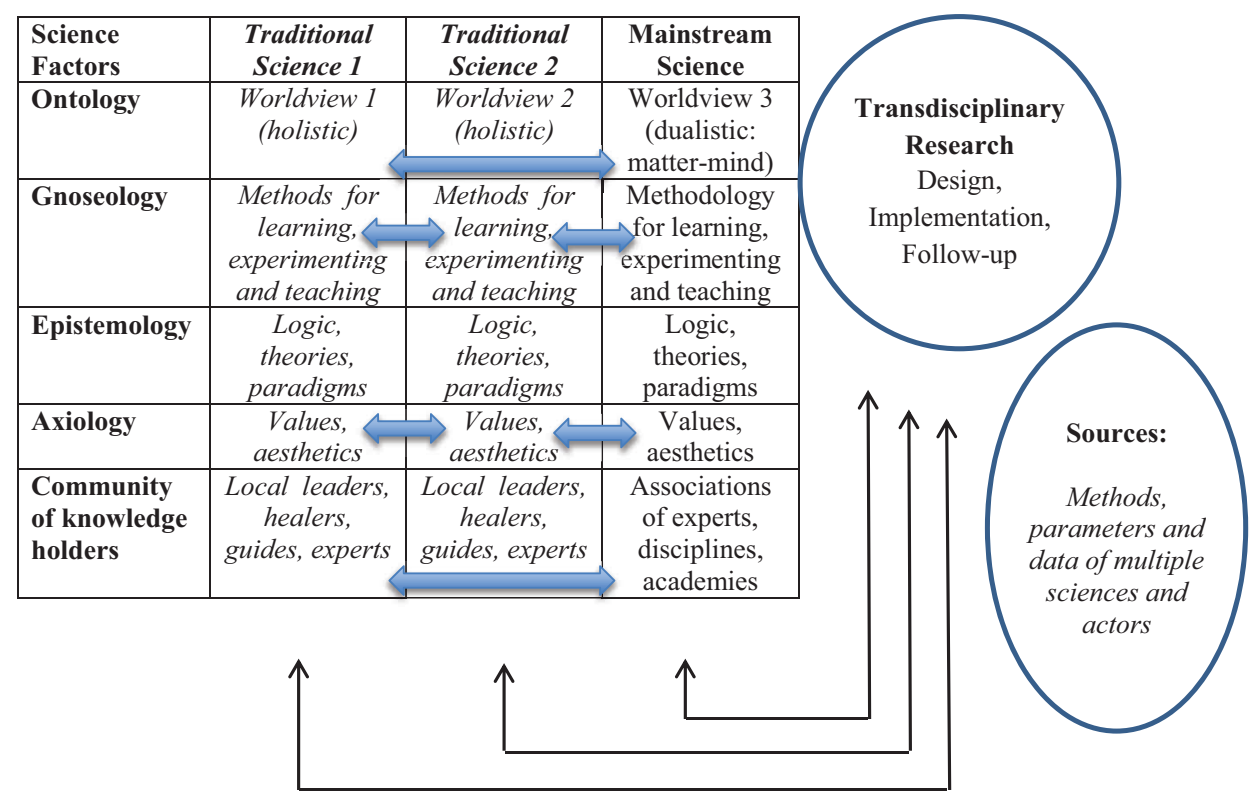

FIGURE 2.10 Scenario 2: complementarity and co-evolution of different sciences.

the first step to take is to critically analyse and reconstruct the different relationships as they currently exist. Field staff and researchers working with rural people have to make clear that their role is not that of an external agent who comes with a certain message or technology to be transferred. Learning with and from local people, and working on the basis of their cosmovision, implies that the outsiders accept the rules of the game as expressed by the communities. The traditional codes for hospitality, confidence building, respect and communication have to be accepted and obeyed. This may mean procedures of selection and processes of initiation, and participation in rituals that have a different cultural background and meaning for local people than for outsiders.

Universities have to accept the fact that their conventional knowledge has its limitations, and also have to accept that their role in this process is predominantly one of learning. Their funding agencies have to get used to downward accountability. The communication and interaction will not only be about conventional professional subjects, but will also involve spiritual and cultural aspects, and a lot will depend on good social relations and skills. This means that the role of supporting people and organisations changes radically: instead of teaching local people how to resolve their manifold problems, they concentrate on learning from local people as the basis for exploring possible synergies between different forms of knowledge. External actors become companions and animators of communications within and between different groups related to endogenous development. This requires a process of personal preparation, where the conventional professional standards, attitudes and skills are scrutinised and modified where necessary.

It is important to find out to what extent local communities are already engaged with the dominant system. Is it possible to describe the relationship of the local culture and way of knowing with the formal/dominant system in the area? Can we learn from the community how they have managed to survive/change and co-evolve with the dominant/formal system? How do they do it? And, how shall NGOs, universities or other supporting organisations relate to that, and deal with this when certain value differences between 'us' and 'them' become clear? What are the possibilities and limitations for intercultural dialogue? 


\section{Dealing with the Strong and Weak Points within the Dominant Forms of Knowledge}

The basic hypothesis of this chapter is that Western knowledge is just one of the possible forms of knowledge. It is not universally applicable. It has its own strengths and weaknesses. An intercultural dialogue based on mutual confidence and horizontal relationships can only take place if all partners involved are prepared to have a self-critical attitude. There are considerable theories and reflections on the character of Western science. In the battlefield of knowledge, debates are held on issues such as objectivity versus subjectivity; universalism versus relativism; specialisation and disciplinarity versus holism or transdisciplinarity; quantitative methods and qualitative methods; and neo-positivism and actor perspectives. Hence, it is clear that also within the dominant 'scientific tower', there are different perspectives and positions. Western knowledge applied to agriculture or health practices has great impact across the globe. It has led to impressive results, but it has not been able to solve all problems related to food security, health, poverty, environmental sustainability and peace. Therefore, there is a perspective for intercultural and inter-scientific dialogue, on condition that Western science also accepts its limitations and is interested in finding ways to deal with them. The balance between sources of knowing-rationality, quantification and the material world, on the one hand, and empathy, intuition, sense and meaning, on the other - needs to be explored and, where necessary, corrected. Non-Western scientific traditions can offer a lot to Western science, and the other way around.

\section{Challenging the Dominant Worldview and Epistemology}

The dominant/mainstream/Western worldview is biased in its dualistic and materialist orientation, and this bias contributes to the existing global ecological, social and spiritual problems. Human behaviour leading to these crises has its roots in the dominant values and the way knowledge and technologies are produced. There is a clear link between the dominant scientific knowledge and the way economic development is governed by the laws of capital (Molenaar, 2006).

As the dominant worldview is at least partly responsible for the poly-crisis in the world, it is being challenged from several angles. More and more the conventional, materialistic and science-based approaches to development are being questioned, and innovative individuals, citizen groups, scientists and policy makers are presenting new ideas on how things can be done.

\section{CONCLUSION: DIALOGUES BETWEEN AND ABOUT SCIENCES}

The insight is emerging that we should look at worldviews, sciences and values, not as universal, where in the end one of the options will turn out to be the best, but as expressions of a pluralist reality. In this view, intercultural dialogues, mutual learning and co-evolution of the diversity of sciences are important. But then, how can we form rules for understanding and exchange between individual knowledge systems? To what extent can we expect contradiction, synergy or complementarity between different forms of knowledge? How can we make an exchange between, for example, Maya knowledge, Shona knowledge, Hindu and Buddhist knowledge, European and global knowledge beneficial for the participants?

Two conditions have been suggested (Klein, 2005) for a fruitful dialogue:

- Acceptance of pluralism, and

- Symmetry in power and resources.

The different partners in the dialogue need to accept that, even though they believe that (considering possible limitations) their own view is probably the best option for their own context, other views may be relevant for other contexts. In other words, there may be more than one way to interpret, study and understand reality.

Symmetry in power, in prestige and in access to human and financial resources will avoid a situation where a dominant system determines the rules of the game. Local knowledge may be weaker 
than mainstream knowledge as the result of historic processes that have led to the discrimination of local knowledge or asymmetric funding of research. But local knowledge should not be assessed by applying the criteria and methods used by mainstream science.

In the current international scientific arena, the rhetoric around the acceptance of pluralism and symmetry is far from the reality. The West has a dominant position in the globe: economically, militarily, ideologically and scientifically; and this makes acceptance of pluralism and symmetric relationships with non-Western systems very difficult.

For inter-scientific cooperation, it is important to have a formulation of the characteristics of different ways of knowing (in terms of the ontology, gnoseology and epistemology) and a self-assessment of the relative strengths and weaknesses of each knowledge system. This could coincide with an assessment of the power relations between the systems involved. During a conference on intra- and inter-scientific dialogue, AGRUCO and Latin American COMPAS partners concluded that intra-cultural dialogue and a revitalisation of indigenous knowledge are preconditions for inter-scientific dialogues (Delgado and Escobar, 2006).

This means that for each scientific tradition that takes part in inter-scientific cooperation, its own worldview should be formulated by the holders of that view themselves. The way of learning should be made explicit and should be the basis on which an epistemology can be formulated. This is not a simple process; it involves different actors, may require time and resources and may lead to confusion or frustration or reveal internal differences.

The objectives of the intra- and inter-scientific dialogues are as follows:

- To understand, describe and exchange the epistemologies and paradigms of the sciences involved.

- To strengthen and revitalise marginalised sciences by providing them sufficient space to flourish in knowledge institutions.

- To determine the strengths, limitations and comparative advantage of each science.

- To look for synergy and opportunities for mutual learning as well as for contradictions and exclusions.

- To question, challenge and criticise each science in order to determine those aspects of the science and value systems that need modification and improvement.

- To promote policies that facilitate balancing the power and financial resource base of the different sciences.

Today, the mainstream 'knowledge space' in institutions for education, research and development is largely dominated by Western science, its values and its epistemic frame. This impoverishes not only the knowledge sector but also development programmes that are based on one dominant knowledge system. The epistemological interpretation of the different Asian, African and Latin American and European knowledge systems, their ways of learning and experimenting and their mutual relationships needs urgent attention, if we are to diversify and enrich both the world's knowledge space and development action. Therefore, it is important to systematise and make more explicit the concepts and theories behind indigenous forms of knowledge in order to share them as part of a possible co-evolution of the diversity of sciences.

\section{REFERENCES}

AGRUCO (2001) Cosmovision Indigena y Biodiversidad en America Latina - Seminario Latinoamericano en Cochabamba. Bolivia: Biodiversidad - Sustento y Culturas, 28 Abril de 2001.

Balasubramanian, A.V. and Nirmala Devi, T.D. (eds.) (2006) Traditional knowledge systems of India and Sri Lanka. Papers Presented at the COMPAS Asian Regional Workshop on Traditional Knowledge Systems and Their Current Relevance and Applications, 3-5 July 2006, Bangalore. COMPAS series on Worldviews and Sciences 5. COMPAS/CIKS September 2006. 
Barnhardt, R. and Kawagley, A.O. (2005) Indigenous knowledge systems and Alaska Native ways of knowing. Anthropology and Education Quarterly, 36(1): 8-23.

Battiste, M. (2005) State of Aboriginal Learning. Ottawa, ON: Canadian Council on Learning, 75 pp.

Bishop, R. (1998) Freeing ourselves from neo-colonial domination in research: A Maori approach in creating knowledge. International Journal of Qualitative Studies in Education, 11: 199-219.

Cajete, G. (2000) Native Science: Natural Laws of Interdependence. Santa Fe, NM: Clear Light Publishers.

COMPAS (2007) Learning Endogenous Development, Building on Bio-Cultural Development. London: Practical Action Publishers/ETC Foundation.

COMPAS-AGRUCO (1998) Plataforma para el Dialogo Intercultural Sobre Cosmovision y Agricultura. Cochabamba: Plural-CID.

Delgado, F. and Escobar, C. (eds.) (2006) Dialogo Intercultura e Intercientifico, Para el Fortalecimiento de las Ciencias de los Pueblos Indigenas Originario. COMPAS and AGRUCO. La Paz: Edicion Plural.

Denzin, N.K., Lincoln, Y.S., and Smith, L.T. (2008) Handbook of Critical and Indigenous Methodologies. London: Sage Publications.

Fay, B. (1999) Contemporary Philosophy of Social Sciences; a Multicultural Approach. Malden, MA: Blackwell Publishers.

Feyerabend, P.K., (1975) Against Method; Outline for an Anarchistic Theory of Knowledge. London: New Left Books, 375 p.

Haverkort, B. and Reijntjes, C. (eds.) (2006) Moving Worldview: Reshaping Sciences, Policies and Practices for Endogenous Sustainable Development. Leusden: COMPAS, Maastricht: ECDPM, and Bern: CDE.

Haverkort, B., van t Hooft, K., and Hiemstra, W. (2003) Ancient Roots, New Shoots: Endogenous Development in Practice. Leusden: COMPAS and London: Zed Books.

Haverkort, B., Delgado Burgoa, F., Shankar, D., and Millar, D. (eds.) (2012) Towards Cocreation of Sciences: Building on the Plurality of Worldviews, Values and Methods in Different Knowledge Communities. Bangalore: Nimby Books, $291 \mathrm{p}$.

Klein, G.K. (2005) Three centuries of global population growth: A spatial referenced population (density) database for 1700-2000. Population and Environment, 26(4): 243-367.

Kuhn, T. (1962) The Structure of Scientific Revolutions. Chicago, IL: University of Chicago Press.

Latour, B. and Woogar, S. (1979) Laboratory Life: The Construction of Scientific Facts. Beverly Hills, CA: Sage Publications.

Mihesuah, D.A. and Wilson, A.C. (2004) Indigenizing the Academy; Transforming Scholarship and Empowering Communities. Contemporary Indigenous Issues Series. Lincoln: University of Nebraska Press, $246 \mathrm{p}$.

Millar, D., Kendie, S.B., Atia Apusigah, A., and Haverkort, B. (eds.) (2006) African Knowledges and Sciences: Understanding and supporting the ways of knowing in Sub-Saharan Africa. COMPAS Series on Worldviews and Sciences 3. Leusden, The Netherlands, Navrongo and Cape Coast, Ghana: Comparing and Supporting Endogenous Development (COMPAS), University of Development Studies (UDS), University of Cape Coast (UCC).

Molenaar, P.C. (2006) Psychophysical dualism from the point of view of a working psychologist. Erkenntnis, 65(1): 47-69.

Nicolescou, B. (1998) The transdisciplinary evolution of the university, condition for sustainable development. International Congress 'Universities Responsibilities to Society', International Association of Universities, Chulalongkorn University, Bangkok, Thailand, November 12-14 1997. Paris: CIRET, Rencontres.

Nicolescou, B. (2004) Toward a methodology foundation of the dialogue between technoscientific and spiritual cultures. In Morena, L.M. (ed.), Differentiation and Integration of Worldviews: Philosophical and Religious Experience. Saint Petersburg: Eidos.

Popper, K. (1965) Conjectures and Refutation: The Growth of Scientific Knowledge. London: Routledge.

Popper, K. (1980) The Logic of Scientific Discovery. London: Hutchinson and Co.

Rist, S. and Delgado, F. (2009) Strengthening endogenous knowledge production through intercultural dialogue. In: Hoffmann, V., Christinck, A., and Lemma, M. (eds.), Handbook: Rural Extension: Examples and Background Material. Weikersheim: Margraf Publishers, vol. 2: 346-353.

Tuhiwai Smith, L. (1999) Decolonizing Methodologies: Research and Indigenous Peoples. London/New York: Zed Books.

van der Ploeg, J.D. (2008) The New Peasantries; Struggles for Autonomy and Sustainability in an Era of Empire and Globalisation. London and Sterling, VA: Earthscan. 


\title{
3 Conversations with Nature Spirits \\ The Political Ecology of Power and Progress in Rural Zimbabwe
}

\author{
Georgina McAllister \\ Coventry University \\ Mike Zeddy Chikukwa \\ Chikukwa Ecological Land Use Community Trust (CELUCT)
}

\section{CONTENTS}

Introduction 39

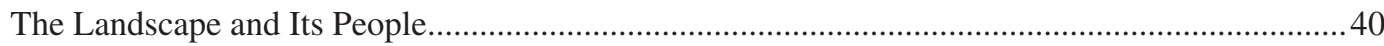

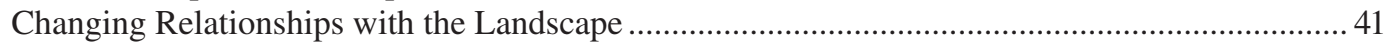

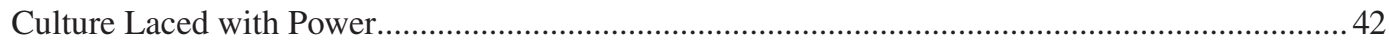

The Role of More-Than-Human Interactions in Generating Change ........................................... 43

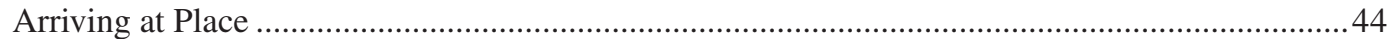

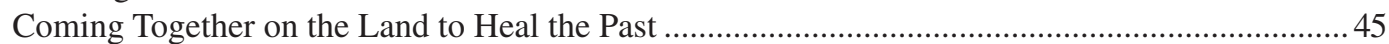

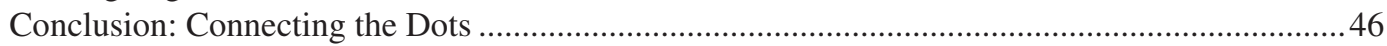

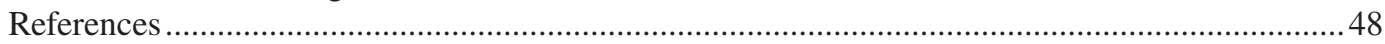

\section{INTRODUCTION}

In this chapter, we present a discussion between a community activist and a political ecologist who reconnected high in Zimbabwe's remote Eastern Highlands, drawn together by Cyclone Idai, the most devastating to ever have hit Zimbabwe. The breath-taking backdrop to our discussion belies the hidden, but no-less dramatic, erosion of bio-cultural diversity, knowledge and social connection shaped by the colonial project since the end of the nineteenth century. This effectively paved the way for the persistence of coercive power relations into independence, and their tangible effects - land grabbing and livelihood loss, structured poverty and dependence, leaving people chronically exposed to disasters, political opportunism and conflicts. In this context, farming approaches that reconnect people to one another and their landscape are seeking to make meaning, restore collective agency, and heal the scars left by societies' most destructive tendencies. Yet the coercive, and sometimes violent environments where these approaches are being re-imagined are rarely conducive to connectivity and healing. Our discussion explores the spirits that inhabit the natural world, the mixed blessings of a crisis, and its capacity to create moments of reflection within which to re-imagine our world afresh.

In picking our way through the complexities of this remote place, this first disembodied voice comes from a so-called 'rational' political ecology perspective to both narrate the context and explore how power shapes our relationship with the environment and each other, while the second 
embodied voice - italicised - comes from a 'more-than-human' perspective that is embedded, and wholly invested, in a traditionalism that holds the tripartite relationships between people, ecology and spirit world as sacred. While our 'voices see through different eyes', they often converge, as if reflecting an interior conversation, with all its inherent concurrence and discordance. As the conversation unfolds, we explore how both are understood in relation to layered and complex relationships and what this means for people farming across landscapes in Zimbabwe today.

Our starting point is a shared recognition of these interconnections, and that the rational technocratic approaches that have come to dominate through a dogmatic belief in the primacy of science often devoid of people, and the relentless developmentalism it perpetuates, have not historically served people, nor the ecology upon which they depend. Through this conversation that interweaves the inherent contradictions between traditionally wielded power, patriarchy and patronage, we attempt to arrive at a better understanding of traditional belief and its practices, and the powerful dissonances, synergies and energies they generate.

\section{THE LANDSCAPE AND ITS PEOPLE}

We first met when George started her doctoral research in Chikukwa in 2016. I was her impromptu cultural guide, advising on how to dress and address others, according to our customs. As we walked across the landscape, visiting the sacred ruins of our ancestors' first settlement, a dawn 'Jickenisheni' drumming convergence as the sun rose over the mountains, and a rain making ceremony at the top of the watershed, we shared stories. We talked about how the Chikukwa clan came to be - how our forefather, Nzvinzvi, arrived from afar on the wing, in the form of ishwa, a flying ant. The ishwa is our clan's totem which, in our African tradition, we are forbidden to harm. Long before we heard of Aladdin and his flying carpet, our tradition was rich with stories of how Nzvinzvi took to the sky, riding on a winnowing basket carrying out heroic deeds to protect the community from wrongdoings.

The remote enclave of Chikukwa sits at the end of the winding ungraded road before the mountains rise towards the Mozambique border. Chikukwa's ten villages sit between a transboundary conservation area and Zimbabwe's once-thriving forestry belt, the creation of each having shaped a history of evictions, land struggles and waves of cross-border migration that has defined local politics and ongoing land tensions. Despite the imposition of the border that formally divided the lands of the Gaza Nguni people under the Anglo-Portuguese Treaty of 1891, this now transnational community regularly crosses the porous border for ceremonial gatherings and rituals that reconnect its five villages in Mozambique. As such, Chikukwans remain one clan, sharing the same dialect and a royal family with a deep lineage, headed by Chief Chikukwa.

Together, our clan elders and the spirit medium visit a shrine in Mozambique called Maate to communicate with the ancestors, to ask the High God Mwari for protection against threats, such as drought, crop pests and diseases. Only after successive droughts are monetary donations collected for messengers to take sacred seed to the most important shrines as an offering.

Fanning across the steep hillsides, Chikukwa's villages are fed by natural springs that have traditionally supported food production in home gardens. Chikukwa's altitude, soils and rainfall conditions, where temperatures rarely fall below $3^{\circ} \mathrm{C}$, are ideal for a range of crops, from coffee and tree crops (fruit and nuts) to vegetables and cereals. Until 2019, seasonal rain-fed agriculture was centred largely on maize production on the wetlands alongside the Musapa River, which flows through the Chimanimani Gap and on into Mozambique. One night, in March 2019, the alluvial soils that made this riverine environment so productive were washed away when the arrival of Cyclone Idai devastated the landscape for 3 days, depositing half the expected annual rainfall in only 12 hours, replacing soils with rivers of boulders from the surrounding mountains. Over these few days, $40 \%$ of cultivable land and 52\% of seed were lost (Chatiza, 2019), placing further strain on resources and relationships in this populous mountain region. 
While understanding that the destructive energy of the cyclone was generated by the warming currents jostling over the Indian Ocean, it is said by some that these currents were spawned by a jostling for control between two mermaids, producing immense pressure. When one mermaid lost, she fled up the Mozambique Channel, drawing the power of the cyclone with her to Zimbabwe.

In cultures globally, often depicted holding a mirror, mermaids are portentous in holding up a mirror to humankind. They can be displeased or antagonised at being disturbed, for instance, by pollutants or people of ill will. A water spirit that is considered neither good nor bad, s/he perhaps represents the antagonistic duality that exists within humanity, through which we may better understand ourselves and our relationship with nature.

A mermaid could pull you down and hold you in her deep pool, from where, if fortunate enough to be released after days, or even years, you would emerge enlightened. So despite her reputation for destruction, mermaids are spirits of good fortune. The force of the cyclone, while doing damage to landscapes, lives and livelihoods, created more pools and eddies to play host to new mermaids. Like the returning biodiversity, she provides a vision of hope for the future.

\section{CHANGING RELATIONSHIPS WITH THE LANDSCAPE}

The heart of our Mwari spiritual landscape lies in the Matopos Hills of south-western Zimbabwe where the vast granite rocks, piled seemingly precariously one on top of the other, attract impressive lightening and rainstorms. These rocks are said to be stitched onto the land-the needles having created the seams through which the water flows, and from which rivers below are formed. We believe that the pools inside the rocks of the Matopos contain the rain clouds and are identified as the source of all water.

Home to the High God Mwari, there are a number of important shrines within the Matopos Hills, the most senior of which is Njelele (or Matonjeni). The interior landscape of the shrines, still visited by emissaries from across Zimbabwe, Zambia and South Africa, is thought to represent the source of all social and biological life - with perennial pools, streams, trees, ancient San rock art and the rocks themselves from which the Voices emanate. In this way, shrines are 'the nucleus of a living and active landscape' (Zvaba, 1988 in Ranger, 1997: 22). Mwari adepts (or oracles) wear traditional leopard skins, sweep the shrines by hand, use stone tools to cut the grass and are forbidden to farm or trade. As messengers of Mwari, their instructions involve obligations to, and relationship with, the landscape.

This way of life has long been under attack from the 'civilising' forces of Christianity ${ }^{1}$ and the not-unconnected technocratic implementation of conservation and pursuance of economic development. Michael Drinkwater referred to this as the 'colonisation of the lifeworld of the Africa people in Zimbabwe' that has led to the marginalisation of traditional religion and its adherents (1991: 107). With the march of settler colonialism and the growth of actively confrontational missions, many believed that God had left Njelele, and so the Voice could no longer be heard. What took place has been described as a form of 'ideological warfare ... about the definition of community, patterns of production and hence about landscape' (Ranger, 1999: 53). At the heart of this lay the early role of Christian missions to liberate people from the superstitions and coercive tendencies of customary authorities, headed by Chiefs, and promote agricultural modernisation for the creation of an entrepreneurial class. This was to lead to progressive nationalist thought and, inexorably, to national liberation. By the time of the liberation war, between 1964 and 1979, rain ceremonies (makoto) were still performed, but fewer people consulted the adepts. After 1980, intricate farming traditions fell into further

\footnotetext{
${ }^{1}$ Native Commissioners of the settler Rhodesian state in the nineteenth century allocated a religion to their area - having been influenced or lobbied by whichever was the dominant mission. Many Africans therefore became, by default, followers of a particular denomination, while they and/or others were directly influenced by mission teachings.
} 
decline as identities were politicised beneath the layered struggles taking place between genders and generations, the new state and its curtailment of traditional authority (Alexander, 2014; Kriger, 1988), and the competing nationalisms that continue to define Zimbabwe's socio-political landscape today.

Despite these historico-political pressures on traditional belief systems, and the dissonance they created, particularly for Christians, many rural livelihoods today remain largely grounded in the indivisibility of the tripartite relationship between people, nature and the spirit world inhabited by the ancestors (Gonese et al., 2003).

For traditionalists like myself, and some Christians, traditional practice and belief continue to moderate resource-use through rules, relationships and norms, within which peoples' identity, cosmology and knowledge are deeply embedded. ${ }^{2}$ Today, we may still collect and mix together open pollinated, drought-tolerant small grains before taking them to the shrine to soak in the waters to ask the ancestors for protection.

However, many of those dispossessed of their land and landscapes have suffered lost connections to knowledge and tradition, reinvented them around new lineage structures or renounced them in favour of monotheism and/or capitalism. And, just as agrarian change shaped reciprocal labour-sharing practices out of necessity, those practices embedded in social relations and place that enable responsiveness to change or stress (Richards, 1989) have, over time, been further eroded by social division, corruption and mistrust.

You see, to damage our ecology is to undermine human existence. In this way of knowing, being and meaning-making for knowledge production, our African religion enhances and generates selfconfidence, provides meaning and direction and is a source of dynamism and creativity.

According to one African proverb, "'Our world is like a drum; strike any part and the vibration is felt all over" ... ringing in the ears of the ancestors, the owners of the land' (Tarusarira, 2017: 408). Despite the association of traditionalism, for many, with the customary forces of domination, for Tarusarira it also has the capacity to increase one's ability to resist exploitation and domination. And so, in rural communities across Zimbabwe, Chikukwa included, where these rituals and relationships persist - having been recovered or reinvented to varying degrees - they do so syncretically with Christianity.

Many people, sometimes reluctantly, still observe chisi or the Chief's day, our traditional day of rest for the soil, as a mark of respect for the ancestors that reside there. They are reluctant because they are sanctioned and may be fined by traditional leaders, many of whom are also Christian converts.

\section{CULTURE LACED WITH POWER}

These contestations and the idiomatic expressions of suffering can be seen in the more recent adoption of climate narratives. For Wilson (1995), this demonstrates the use of discourses to serve different interests, from which one can draw a direct line between coercive state control, conservation and farming. When laid over Zimbabwe's agrarian question, these interrelated discourses are just as likely to be employed for the benefit of one group over another within any given community. Yet, the complex and artful negotiations that incorporate many competing local interests and narratives can also be seen in the blending of indigenous knowledge, contemporary permaculture and spiritual resource governance. This is echoed in Moore's (1996) exposition of material deprivations and symbolic ancestral claims which, when creatively fused and adapted in defence of livelihood, culture and environment, produce cultural meaning that can be employed effectively as a form of resistance to external (state) interference. In this way, 'the micro-politics of resource struggles are animated by local history, mediated by cultural idioms, and gendered through the different practices [that] men and women have pursued in defence of local livelihoods' (Moore, 1996: 140). And it is the relationship with these livelihood resources that has, over time, become politicised and marred by endemic corruption, with customary leaders and elected politicians leveraging their position to consolidate patronage networks in return for loyalty, at others' expense.

\footnotetext{
${ }^{2}$ See also Bernard (2003).
} 


\section{THE ROLE OF MORE-THAN-HUMAN INTERACTIONS IN GENERATING CHANGE}

This conversation hosted at the Chikukwa Ecological Land Use Community Trust, a small community-generated organisation that emerged in 1991, when some residents noticed that their village spring was drying up, seems prescient.

This group would meet to discuss and plan their actions, working side by side to replant the steep water catchment with indigenous trees, and to create awareness of the need to protect these areas. The springs and pools below hold special significance as sacred places in which water spirits and mermaids reside and, if disturbed, will abandon the spring so that the water will stop flowing. According to our custom, it is forbidden to clean black pots (used for cooking) or to use soap when washing in the springs.

From a Western rationalist perspective, this links deeply held spiritual beliefs with practical water quality considerations for downstream users.

As may be the case, nonetheless, this re-linking of the cultural, spiritual and ecological from the outset ensured that the group had the support of the Chief, who later gifted 1 hectare (ha) of land for the development of our permaculture centre.

The drought and cyclone that followed in 1992 also had a devastating effect in Chikukwa. This dramatic event, while far less destructive than the more recent cyclone, served as a catalyst for change.

With more people joining the voluntary workforce to rehabilitate our landscape, much of the knowledge travelled from household to household, farmer to farmer, with many developing their home plots with orchards depending on rainwater catchment patterns, and sharing and adapting skills.

In this way, traditional knowledge and wisdom was blended with exogenous strategies and ideas through extended networks. ${ }^{3}$

As our reputation grew, we generated funds by training others, and our community was able to support its own projects. Indigenous trees and woodlots were planted, with seed collected from different areas. Erosion gullies were filled with stones and planted with wattle. Chikukwa's terraces took shape from contoured swales with raised bunds planted with vetiver grass, and bananas, previously thought impossible to grow, are now a major crop for consumption and trade. As terracing reduced soil loss, yield improvements were quickly apparent; and the introduction of trees led to increased availability of diverse foods.

These patterns, mapped from previous crises, are important for the recollection of our historical memory - thought to have been washed away by the 2019 cyclone, again leaving people exposed and vulnerable to manipulation. Yet, nothing ever stands still.

Successive events since Zimbabwe's independence in 1980 have seen the population of Chikukwa expand exponentially, with people bringing with them different faiths and cultural norms. Some were workers stranded after the collapse of the logging industry and de-industrialisation in 2003, while others were Chikukwans from Mozambique who arrived after the 2001 designation of the Transfrontier Conservation Area. Further migratory flows resulted from the politically motivated urban clearances of 2005. ${ }^{4}$ Those arriving with few farming skills placed significant pressure on fuel wood resources. This period is viewed as one of significant social-ecological disruption in Chikukwa.

In 1991, before the other pressures, they had already started misbehaving ... they cut down trees in sacred spaces and even around springs. There was an old mbuya [grandmother] looking after

\footnotetext{
${ }^{3}$ Zimbabwe was also an early adopter of agroecology, since Australian permaculturalist Bill Mollison was invited to host the first workshop in Harare by a pioneering group of concerned teachers with links to Chikukwa in 1988.

${ }^{4}$ Referred to colloquially as the 'tsunami' due to its wide social impacts, Operation Murambatsvina ('to clean out the filth') is thought to have directly evicted 700,000 people, with 2.4 million people nationally affected by the resulting rural migration (Potts, 2006).
} 
the springs [as the keeper]. But it was because of the clearing in water catchment areas, and due to lack of knowledge. People were just cutting trees for farming - it was bare. There was much less water. The history and links were lost as people died - and the new owners didn't have that understanding. It was not just new people coming in. Some were not respecting the elders. Then [in the 2000s] they took advantage when the Chief passed away - some took other peoples' fields, and cut down trees, and even destroyed the contour ridges...They didn't value what we had built.

What is described here began in the post-independence period characterised by the rapacious liquidation of natural assets, when freedom farming became commonplace as an expression of popular resistance to customary coercion and state control (Mukamuri, 1995a) and the interrelated struggles for rural authority. Migration undoubtedly led to changing cultural norms governing social-ecological relationships and associated practices. But so too has the loss of farming knowledge as a result of earlier (semi-)proleitarianisation, beginning with colonial interventions and evictions into the present day. With a continuation of these colonial productivist logics that aimed to project the modernity of a newly independent Zimbabwe, the 'liberation initiatives have found it very difficult to 'unthink' the epistemologies created by others' (in Murisa and Chikweche, 2015: XX). These factors have combined to fundamentally alter social-ecological relationships and, with it, the land-use practices that continue to shape change in Chikukwa. ${ }^{5}$

Where Chikukwa's permaculture-inspired projects and programmes sought a somewhat pragmatic and purposive approach, we both wonder whether something fundamental was missed with regard to the human-nature spirit connections. Or maybe the community was resistant and unwilling to hear anything of traditional ways, that is until they were visited by the cyclone over those three destructive days of March 2019.

Yes, this is possible. So, in an attempt to reconnect people through our peace and sustainable farming programmes, I began an Indigenous Knowledge Systems (IKS) initiative, as a response to the erosion of knowledge, landscape and trust, including declining trust in our traditional leadership. This initiative aims to re-engage the community in the preservation of bio-cultural diversity, through an ongoing exploration that accepts the dynamic nature of traditions and practices, and the power inequities that can be engendered, to begin a conversation about the changes people want.

Based at an open-sided thatched meeting house, the initiative aspires to map sacred places alongside keystone species, and to revalue knowledge about indigenous plant lore, ritual and healing practices. This includes the introduction of elements of mindfulness artfully blended with cultural thought and practice. These seemingly innocuous processes nonetheless meet some resistance.

In times of change and uncertainty, it also aspires to bridge our religious, political and generational divides to improve understanding, to repair community cohesion in the face of more recent threats and to restore the community's deep connection with our spirit ecology.

As the community seeks to make meaning from the devastation, we turn to deep-rooted questions of what has been lost and how to rehabilitate not only the landscape, but the community's connections with the nature spirits.

\section{ARRIVING AT PLACE}

So it was, in March 2019 and within days of the passing of Cyclone Idai that isolated the community from the outside world for 2 weeks, that two strangers appeared on foot with a message.

Each through their dreams had been guided, like wise men from afar, to visit with Chief Chikukwa and instruct him to prepare a ceremony, involving the surrounding Chiefs, to appease the nature

\footnotetext{
${ }_{5}$ As a result of these population and resource-use pressures, the steeply deforested slopes were increasingly unable to retain their soils and nutrients. The lack of infiltration resulted in poor groundwater storage and erosion, with large gullies beginning to open up and channelling fast-flowing water and landslides down towards homesteads and villages, resulting in consistently poor harvests.
} 
spirits with rapoko [finger millet], a culturally important small grain collected and offered during makoto. To the astonishment of many, some of the chiefs came empty-handed, breaking with tradition. Soon after the ceremony, involving over 150 people, the strangers left. No one ever saw them again or knew their names.

After the meeting, when our traditional leaders consulted the most important spirit medium in the Southern Africa region, Sekuro Matota, it was revealed that the nature sprits were angry and needed to be cooled down. He pointed to areas of Chimanimani that had been particularly hardhit, and whose Chiefs had turned their backs on traditional practices and on their chiefly function, as many see it, to unite their communities - instead reverting to the punitive strategies they have become some accustomed to. This ran alongside accusations that those same Chiefs were diverting the grains traditionally collected from community members who worked collectively at the Zunde raMambo (the Chief's or 'king's' field) to feed the most vulnerable, and were instead feeding their own families or supporters, or selling them for personal gain. Each chieftaincy was therefore instructed to visit sites with strong energy centres, many of which had been long neglected, and to hold a ceremony involving their entire communities. In appeasing the nature spirits of our damaged landscapes, these events were also called to rebuild the unity and trust that has been eroded in our community over decades. Some chiefs acted on this, while others did not.

Patterns of cultural introspection and spiritual renewal, seen through an historical lens, as with the ebb and flow of sociocultural, socio-political and natural crises, have most often followed intense periods of drought (Maxwell, 1995, 2005). The search for answers can result in moral panics aligned with the loss of cultural traditions - responsibilities for which are commonly laid at the door of, and felt most keenly by, women (McAllister, 2018). With every wave to re-establish fading traditions come new attempts to reinvent the past to remake tradition, or reinforce existing power relations. As with Christian-Traditionalist relationships and practices, the by-now well-worn practice of syncretic blending for broad-based appeal and legitimacy is well established. Herein, the re-establishment of a tripartite relationship plays out on a political tightrope. If critical of government, growing political opposition can result in rumours that delegitimise a movement's authenticity and, if too skewed towards traditionalism, can meet with opposition from power-holders in established churches. As recounted by Mawere and Wilson (1995) of the expansion of the Mbuya Juliana cult ${ }^{6}$ after the devastating 1992 drought, such attempts also run the risk of co-option by the narrow interests and agendas of traditional leaders to recover eroded political authority through the reclaiming of ritual practice and tradition.

There is no clear line between traditionalists and Christians. In fact, many of our traditional leaders, and indeed Chiefs, are also observant Christians, leading to accusations by traditionalists that they have 'lost their way'.

What perhaps links both is that they are regularly courted by, and part of, entrenched political patronage networks that hold these ecologies of violence very much in place. The complex alliances of convenience formed to variously resist, comply and/or transgress this equilibrium, while vital for everyday survival, can at once undermine popular support and spiritual authority for the core messages of social-ecological unity.

\section{COMING TOGETHER ON THE LAND TO HEAL THE PAST}

In an era of increasing climate disruption, the cyclone is just the latest in a long line of destructive events - seen through the microcosm of this one community.

We are living with the effects of our past-colonisation was intended to disempower - to disconnect people from their world, and to sow not seeds of harvest, but division. Before, you could be

\footnotetext{
${ }^{6}$ Mbuya Juliana became a cult figure across Zimbabwe, preaching to vast gatherings about a return to traditional culture, and environmental values and farming practices. She claimed to have emerged, with her newfound wisdom, from the grips of a mermaid.
} 
under a tree and ask for food. It wasn't magic; it was a strong connection between the creator and the people.

Within historical memory, trees on cropland were forbidden, seen as hampering productivity. The punishment for such agricultural transgressions was imprisonment. People were even ordered to remove sacred fig trees that were not only indicators of water, but providers of abundance during drought years, and under which communities would gather (Mukamuri, 1995b). The loss of these sacred places, the ritual of sharing, spending time talking about what happened in the past, and learning from and connecting through each other's innate spirituality are still keenly felt.

Folk stories can be written down and documented, but these are our stories, to be repeatedly communicated across generations. The loss of spaces for communication is the same as losing the power of communication. As these stories that guide people through times of change and upheaval are lost, memory is wiped, and the ground for division is sown.

Concerns about the loss of sacred woodland and the pollution of sacred springs connect to concerns about destructive farming practices and the loss of intricate land-use systems associated with riverine gardens, dryland farming and livestock rotations. They relate also to how farmers use intentionality to celebrate or to give thanks, in the field or at home.

When planting seeds, we are not simply planting in the ground, but placing them in different parts of the field as an offering. In the same way, before eating, we remove our shoes and place the grain around different corners of the home. The food is cooked without salt, as a mark of purity and respect. We believe that these rituals protect the home and fields from damage.

In 2017, an infestation of the moth larvae of the fall armyworm, Spodoptera frugiperda, damaged some 150,000 ha of maize and millet in Zimbabwe (FAO, 2017) and led to a state of national emergency. Many farmers were advised to use a pesticide or experiment with integrated pest management, while others deposited sharp lacerating sand in the central core of the emerging leaves that harbours the larvae, to great effect.

In Chikukwa, on the first reports of fall armyworm in 2018, a ceremony was arranged. The larvae were collected by hand and placed in a calabash before being taken to a sacred pool where ceremonial songs were sung, and the calabash was left overnight. The following morning, no larvae were found in anyone's field across the community, which remained free of fall armyworm for the rest of the season. The effectiveness of this traditional response seemed as surprising to the community as the process may seem to outsiders. Nonetheless, the response to why it was effective rests with a belief in the power of actions that benefit the collective. This is because, when the rain falls, it doesn't fall on one man's field. When a disaster attacks, it doesn't just attack one man or one woman.

On returning to the question about authentic spirituality in context, one of us is reminded of the challenges closer to home. Our conversation has highlighted the disconnect between leaders failing to honour their commitments, protect important spaces, undertake their duties fairly and transparently and support the needs of all in a non-partisan way. Life in this beautiful yet troubled microcosm may not be as different as we, elsewhere, may like to believe.

\section{CONCLUSION: CONNECTING THE DOTS}

The moment that you use your intention to work the land-you are aware of the life in the soil. And at that moment, you give value to where you are standing. Self-awareness needs time and honesty to oneself, and trust between people to explore these things openly. It calls on us to learn to listen to the landscape - to the suffering of the earth, to the rivers and trees and to the anger of the nature spirits - now only ever heard above the avarice and poverty during a gasping drought or raging cyclone. Finding ways of listening to, and within, our ecosystem is more important than ever. 
These connections are celebrated through the embodied performance of rituals that have dynamically responded to changes over time and generation. Just perhaps, we ponder, in the search for engaged social relationships in these fragile environments, a new syncretism with agroecology is emerging: one that blends the spiritual importance of small grains with their drought tolerance and nutritional benefits; sees climate change narratives as one with the disruption of complex ecosystems, complete with sacred pools and coppices; and seeks to rebuilt trust and failing community structures by respecting and upholding principles of equity and social justice. While perhaps naïve to suggest that anywhere will be free of power reproduction and the structures it perpetuates, it does hold the potential to reinvigorate a sense of efficacy and optimism to effect, albeit cautious, change.

Here, we ponder the value of social farming in re-forging relationships through which socialecological change may be negotiated and alternative sources of agency and identity may be cultivated to transcend these deeply entrenched patterns of division and (self-)destruction. Moments of renewal are an important articulation of a deeply held dissatisfaction with an equilibrium that holds poverty and marginalisation in place. Yet this comes with a recognition that these same calls to tradition risk co-option by the very forces that benefit from that equilibrium.

I see spirituality as one - it's the source. You talked about re-imagining and revaluing - it's like connecting the dots. We're lucky that we still have dots to connect. But only just, they are disappearing before our eyes. Just look where we are George - we could be the richest people!

Somewhere between the destructive power of cyclones and the popular anger that resulted in the destruction of 'freedom farming' as a popular reflex against coercive power is the collective will to help the landscape and its hosts to regenerate - building bridges, figuratively and literally, that reconnect peoples across landscapes to mobilise knowledge and build new alliances.

Perhaps what joins our conversation is a drive for a socially engaged and authentic, yet quiet and non-confrontational, form of activism. The boundaries here are not always clear and, we agree, have yet to unfold. Where activists tend to rush in, action generated through connections to spirit requires room to breathe and accumulate. Our motivations converge under the increasingly urgent need to recover lost knowledge, to open up and explore different pathways.

Where historical memory is thought to have been washed away by the cyclone, people are more exposed than ever to coercion, be it political or religious, in pursuit of power and influence. Reconstructing our world in new ways requires the recovery of memory. Ritual practice can play an important role in this critical reconnection. Critical, because this is surely not about tightly reconstructing the past, but finding new ways in which the past can better explain the present and inform the future. Critical, because this requires open dialogues about what is retained, what is left behind, what is dynamically co-constructed and by whom.

Ultimately, we are creative creatures, and we have been recreating and redesigning our traditions for millennia.

As ever-more extreme weather events are projected globally and predictions of the worst drought on record since 1992 for Zimbabwe's coming 2020 farming season (Manatsa, 2020), we both wonder whether this small community will find the energy to artfully challenge patterns of degradation, and to collectively re-imagine the long-broken social contract to turn the tide.

Crises are nothing if not traumatic yet magical moments that inspire human reflection, in concert with our rich knowledge ecologies, and call on our creative powers to re-imagine our world afresh.

One of us is reminded of the words of an esteemed agricultural extension specialist that "nothing worthwhile has ever been achieved without an element of coercion'? Yet one could equally argue that nothing at all effective or durable has ever been achieved with coercion. Historically, the uptake

\footnotetext{
${ }^{7}$ Informal conversation with national university professor, 28 November 2019.
} 
of farming techniques and technologies has been utterly rejected unless deeply imbedded in existing knowledge. Hence, if history has taught us anything at all, it is perhaps that the art of syncretism has sustained, whomever marshals it, to mobilise and drive change. So it continues, in Zimbabwe and beyond, that we are left swimming against a powerful tide. And just perhaps, out of these crises, we may all emerge from the depths of that pool more enlightened.

\section{REFERENCES}

Alexander, J. (2014) Things fall apart, the centre can hold: Processes of post-war political change in Zimbabwe's rural areas. Occasional Paper, 8: 131-162. Oxford: University of Oxford.

Bernard, P.S. (2003) Ecological implications of water spirit beliefs in Southern Africa: The need to protect knowledge, nature, and resource rights. USDA Forest Service Proceedings RMS, 27: 148-153.

Chatiza, K. (2019) Cyclone Idai in Zimbabwe: An analysis of policy implications for post-disaster institutional development to strengthen disaster risk management. Oxfam Briefing Paper, November 2019. Oxford: Oxfam GB.

Drinkwater, M. (1991) The State and Agrarian Change in Zimbabwe's Communal Areas. New York: Springer.

FAO (2017) Fall army worm outbreak, a blow to prospects of recovery for Southern Africa. FAO Regional Office for Africa. Briefing, February 2017. http://www.fao.org/africa/news/detail-news/en/c/469532/ (accessed November 30th, 2019).

Kriger, N.J. (1988) The Zimbabwean war of liberation: Struggles within the struggle. Journal of Southern African Studies, 14(2): 304-322.

Manatsa, D. (2020) Drought looms over Zimbabwe. The Herald. https://www.herald.co.zw/drought-loomsover-southern-africa/ (accessed January 4th, 2020).

Mawere, A. and Wilson, K. (1995) Socio-religious movements, the state and community change: Some reflections on the Ambuya Juliana cult of southern Zimbabwe. Journal of Religion in Africa/Religion en Afrique, 25: 252.

Maxwell, D. (1995) The Church and Democratisation in Africa: The case of Zimbabwe. In: Gifford, P. (ed.), The Christian Churches and the Democratisation of Africa. Leiden: EJ Brill, pp. 108-129.

McAllister, G. (2018) Cultivating social-ecological relationships at the margins: Agroecology as a tool for everyday peace formation in fragile environments. Unpublished PhD thesis. Coventry: CAWR, Coventry University.

Moore, D. (1996) Marxism, culture, and political ecology: Environmental struggles in Zimbabwe's Eastern Highlands. In: Peet, R. and Watts, M. (eds.), Liberation Ecologies: Environment, Development, Social Movements. London: Routledge, pp. 125-147.

Mukamuri, B.B. (1995a) Local environmental conservation strategies: Karanga religion, politics and environmental control. Environment and History, 1(3): 297-311.

Mukamuri, B.B. (1995b) Making sense of social forestry. PhD thesis, Tampere: University of Tampere.

Murisa, T. and Chikweche, T. (2015) Beyond the Crisis: Zimbabwe's Prospects for Transformation. Harare: Weaver Press.

Potts, D. (2006) 'Restoring order'? Operation Murambatsvina and the urban crisis in Zimbabwe. Journal of Southern African Studies, 32(2): 273-291.

Ranger, T.O. (1997) Making Zimbabwean landscapes: Painters, projectors and priests. Paideuma: Mitteilungen zur Kulturkunde, Bd 43: 59-73. Frankfurt: Frobenius Institute.

Ranger, T.O. (1999) Voices from the Rocks: Nature, Culture and History in the Matopos Hills of Zimbabwe. Oxford: James Currey.

Richards, P. (1989). Agriculture as a Performance. In: Chambers, R., A. Pacey, A. and Thrupp, L. (eds), Farmer First: Farmer Innovation and Agricultural Research. London: Intermediate Technology, pp. 39-43.

Tarusarira, J. (2017) African religion, climate change, and knowledge systems. The Ecumenical Review, 69(3): $398-410$.

Wilson, K.B. (1995) 'Water used to be scattered in the landscape': Local understandings of soil erosion and land use planning in southern Zimbabwe. Environment and History, 1(3): 281-296. 


\title{
4 The Forgotten Ground Recollecting the Primordial Harmony
}

\author{
Joseph Milne \\ University of Kent
}

\section{CONTENTS}

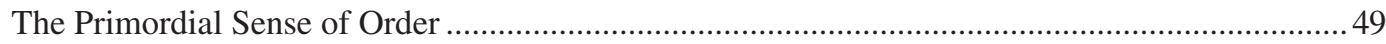

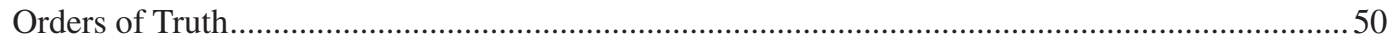

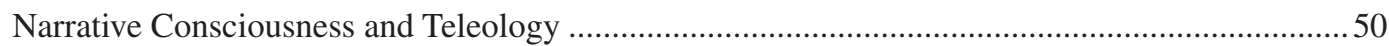

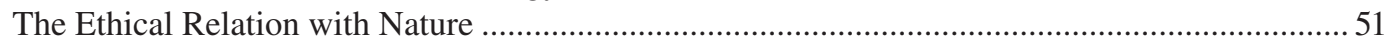

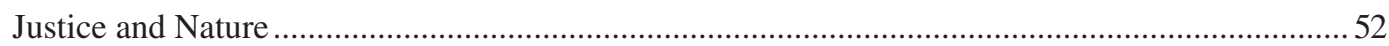

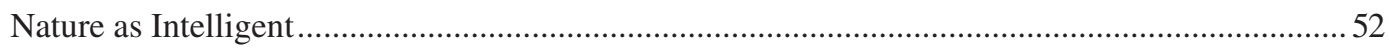

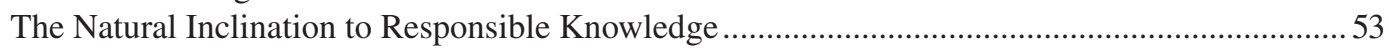

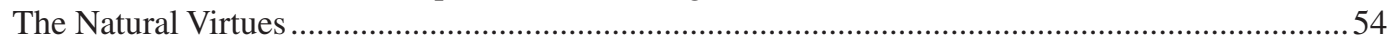

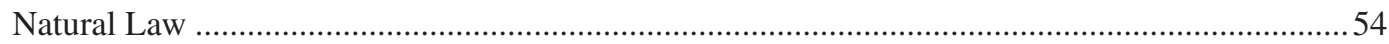

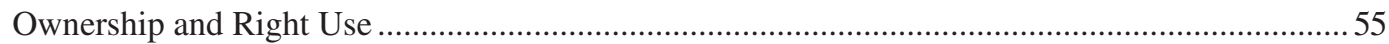

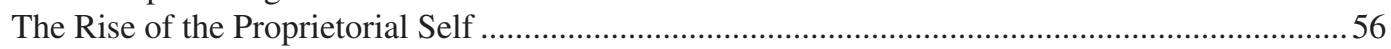

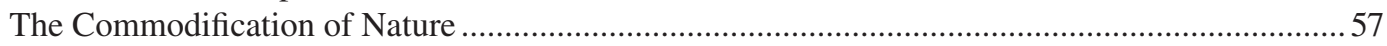

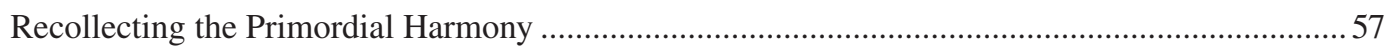

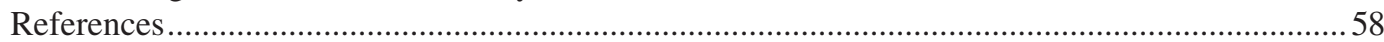

In the old days, all living creatures, from the biggest animal to the tiniest bug, lived side by side with the People in total peace and friendship (Cherokee) (Kerven, 2018: 140).

\section{THE PRIMORDIAL SENSE OF ORDER}

Since most ancient times, the human race has pondered its place in the great order of things. The earliest written records are myths. These ancient myths tell of how at the beginning all the different creatures lived together in harmony. In one form or another, a great order ruled everywhere, either through a natural wisdom of all creatures or through divine beings who presided over the world. Other myths tell of how the world came into existence from a primordial being, such as the Purusha in the Hindu Vedas. In some myths, there was darkness and nothing before anything came into being; in some, there was perpetual ice; in some, there were gods in the heavens but no living creatures on earth till they made them; and in some, there was a great void or chasm out of which arose the world and all beings. The beginning time in some was a Golden Age, a time in which gods and the people lived in harmony and there was no vice and all the earth was shared in common.

Whether these ancient myths conceived the world as always existent in a primordial time, or whether the world arose or was made by divine beings, or from the breaking of the cosmic egg, or from the great ocean, or from the original void, or the progeny of the marriage of heaven and earth, they each give the cosmos a story, a narrative. As the philosopher Paul Ricoeur has shown, narrative understanding is foundational to human consciousness. We initially grasp the world as 
an unfolding event, and through this, we situate ourselves and derive our own sense of being and meaning (Ricoeur, 1991: 99). At its simplest, narrative has two aspects, an empirical and a mythical. History seeks the 'true' relation of events, while story embodies 'imaginative' events. Yet 'story' can equally tell what is true, as Aristotle says of tragedy: 'Poetry, therefore, is a more philosophical and a higher thing than history: for poetry tends to express the universal, history the particular' (Aristotle, 1932).

\section{ORDERS OF TRUTH}

'True' has many dimensions of meaning, though there has been a tendency since the Enlightenment to grant 'truth' only to a single so-called 'objective' dimension. But this objective dimension is itself founded on a presupposed narrative comportment towards reality. Nevertheless, any approach to the world seeks to 'tell it as it is' and to be truth-bearing. And such 'telling', of putting into speech or representation, is rooted in narrative consciousness, and this cannot be circumvented. Every such speaking or representing is in some sense an act of bearing witness to the world. Human consciousness spontaneously seeks to give account of the world and reality, to bring what is seen before itself and to reflect on what is so and what is not so. This is the case whether it is the exchange of mere gossip or the elaboration of a scientific theory. In recounting these things, we express a fundamental characteristic of human nature - as the being who tells of things and who becomes a community through such telling of things. Human accounting and bearing witness situate us in society, and society in the cosmos. Thus, Aristotle distinguishes the human being from all other species as having language (logos), and it is this that makes the political being (Aristotle, 2012: 1253A: 10).

It is from this 'mythic consciousness', the fundamental intuition of the order of things, that Greek philosophy emerged. Plato's famous quarrel with the poets was not because he held the accounts of Homer and Hesiod to be untrue, but because they spoke true things without a real understanding of them. They spoke 'out of their minds', possessed by a divine madness. This divine madness is perfectly legitimate, and the poet cannot make true poetry without it:

If anyone comes to the gates of poetry and expects to become an adequate poet by acquiring expert knowledge of the subject without the Muses' madness, he will fail, and his self-controlled verses will be eclipsed by the poetry of men who have been driven out of their minds.

Plato (1997)

Granting that, it is part of the work of the philosopher to bring into reflection and articulation an order of truth that lies in the deepest memory of the soul, or which belongs to the nature of consciousness itself.

\section{NARRATIVE CONSCIOUSNESS AND TELEOLOGY}

The narrative consciousness is also grounded in a sense of the 'whole', or what we may call the 'cosmic sense'. What unfolds in narrative, or in becoming, unfolds within a totality, embracing reality as a whole, so it is natural to seek the lawful order of things. Here, we may say that the scientist, the philosopher and the poet all work on the same ground, acknowledging universal laws and a coherence to the order of things - even if that coherence always remains beyond full grasp. What is important is that, for the ancient philosophers, the sense of a 'whole' and an order to things belongs to the nature of consciousness itself and this is presupposed by all enquiry into the nature of the order of things. ${ }^{1}$

Two further factors arise from the sense of the whole which are held by the ancient philosophers: the intuition of a teleological order of nature and an ethical sense of our relation with the world

\footnotetext{
${ }^{1}$ For a detailed philosophical discussion of the human sense of cosmos, see Rémi Brague, The Wisdom of the World: The Human Experience of the Universe in Western Thought (2003).
} 
(Blanchette, 1992). These two cannot be entirely separated. This is because it is assumed in ancient thought that the coming into existence of reality is both purposeful and essentially good. For Plato, the good precedes being and illuminates the truth of things. It is also what all things naturally seek in coming into being in the fullness of their potential. There is a teleological order to the universe as a totality, while each particular thing seeks its completeness within the total order and according to its own nature. As Collingwood observes in The Idea of Nature:

The world of nature is thus for Aristotle a world of self-moving things, as it is for the Ionians and for Plato. It is a living world: a world not characterised by inertia, like the world of the seventeenth-century matter, but by spontaneous movement. Nature as such is process, growth, change. This process is a development, i.e. the changing takes successive forms $\alpha, \beta, \gamma, \ldots$ in which each is the potentiality of its successor.

Collingwood (1960: 82)

Understanding nature in this manner, as self-moving, means that its efficient and final causes lie within itself:

And Aristotle arrives at this conception of an immaterial efficient cause by reflection on the fact of development: for development implies nisus, that is, a movement or process not merely oriented towards the realization in bodily form of something not yet realized, but actually motivated by the tendency towards such realization. The seed only grows at all because it is working at becoming a plant; hence the form of the plant is the cause not only of its growing in that way but of its growing at all, and is therefore the efficient cause as well as the final cause of its growth.

(ibid: 84 )

This nisus or inclination of living things towards their natural ends is often assumed in practical experience, even if not theoretically. For example, we may see from experience that every living thing strives towards perfect health and maturity. Medicine remains founded on this principle, even if it is not theoretically acknowledged. It is unfortunate that this teleological understanding of nature was discarded in the seventeenth century in the attempts of the new sciences to escape scholastic Aristotelianism, owing to the rejection of the authority of the Church and the ancient philosophers and the rise of nominalism, ${ }^{2}$ as, for example, we see in Bacon's The New Atlantis. This also meant the overthrow of any hierarchical or sacred conception of the order of nature. Human mastery over 'nature's secrets' became the new aim of knowledge. Later, as a more mechanistic view of nature took hold, any notion of 'purpose' or 'final causality' was entirely eliminated from scientific theory (Lear, 2011). The motion or activity of things was explained by the mechanical effects of one thing upon another, or through outside forces moving them, so that nothing possessed its own cause or moved from its own nature. ${ }^{3}$ The notion of 'purpose' or 'natural ends' was relegated to human subjectivity. And with the elimination of teleology, any ethical conception of the natural order of things becomes impossible. The so-called 'impartial' study of nature rendered nature itself impartial. The mechanistic theory projects itself upon the observed on the assumption it is disclosing the order of things.

\section{THE ETHICAL RELATION WITH NATURE}

However, even if nature is conceived as neither teleological nor tending to some good, the ethical relation of the human species with nature cannot so easily be set aside, least of all with climate change demanding both a rational and an ethical response. Just as human consciousness grasps

\footnotetext{
${ }^{2}$ For a detailed study of this shift in thinking, see Michael Gillespie, The Theological Origins of Modernity (2009).

${ }^{3}$ For a detailed discussion of how the ancient notion of teleology was discarded in the Enlightenment, see Stephen G. Salkever, Finding the Mean (1990: 21-36).
} 
reality narratively and is grounded in an intuition of wholeness, so also it has an ethical sense, a sense that a natural good belongs to everything and that human action is responsible to this. In the Middle Ages, this awareness was termed synderesis (Aquinas, 1920: 1a:79). This informed the practical reason, the reasoning that informs action, as distinct from the intellectual reason. All human action was understood to have an ethical aspect. When Aristotle defined human nature through language (logos), mentioned earlier, he also remarks that:

...speech is for disclosing what is advantageous and what is harmful, and so too what is just and what is unjust. For this is distinctive of human beings in relation to the other animals, to be alone in having a perception of good and bad, just and unjust, and the rest, and it is an association involving these things that makes a household and a city.

Aristotle (2012: 1253A: 10-19)

For Aristotle, as for Plato, human society arises through the sense of justice and injustice. It is this that makes the human animal both social and political. Hence, politics is concerned with law and jurisprudence. But also, and most important, for Aristotle human society is natural (Trott, 2014), as much a part of nature as any other part. One might almost say that society comes into being so that justice can be seen and said. ${ }^{4}$ It was Thomas Hobbes who first conceived of society as an 'artificial' creation and outside nature, although Hobbes derives his view from the ancient sophists who also held that 'justice' was a purely human construct with no foundation in nature. But for Plato and Aristotle, human beings are naturally just, in the sense that they are only truly human when just.

\section{JUSTICE AND NATURE}

For Plato and Aristotle, the question of the nature of justice is a foundational question, inseparable from the ontological question, not simply for philosophy, but for human existence as such. The question of justice goes beyond the social and political domains and extends to nature as a whole, more so if society is itself part of nature. The right way of human life is to live justly in relation to all things. This comes as a responsibility of the capacity to reflect upon all things. Human consciousness not only has a sense of the whole, but this sense of the whole situates human beings within the whole as their natural dwelling place. Seen in this way, it is clear that justice for the ancient Greeks was not merely a matter of individual opinion but rather something belonging to the entire order of the cosmos. ${ }^{5}$

\section{NATURE AS INTELLIGENT}

Plato views the cosmos as intelligent, rational and therefore intelligible. One way Plato demonstrates this is by showing a correspondence between human reason and the order of the heavens and how, by perceiving the rational order of the heavens, the human soul is brought into harmony with itself:

God invented and gave us sight to the end that we might behold the courses of intelligence in the heaven, and apply them to the courses of our own intelligence which are akin to them, the unperturbed to the perturbed; and that we, learning them and partaking of the natural truth of reason, might imitate the absolutely unerring courses of God and regulate our own vagaries. The same may be affirmed of speech and hearing: they have been given by the gods to the same end and for a like reason. For this is the principal end of speech, whereto it most contributes.

Plato, Timaeus (1937: 47c-d)

\footnotetext{
${ }^{4}$ For a detailed discussion of the Greek conception of law founded in the unity of society, see Otto Gierke, Association and Law: The Classical and Early Christian Stages (1997).

${ }^{5}$ For Plato's refutation of the various false opinions of justice, see Republic Book 1.
} 
That the human senses should be related to the nature of things is itself not so strange. But that there should be a purpose to perception that is related to the proper work of intelligence runs counter to the modern notion of the autonomy of human intelligence and the belief that it can stand, as it were, outside the world looking in. ${ }^{6}$ But as soon as it is acknowledged that the cosmos itself is rational and intelligent, then it is clear that human intelligence cannot dissociate itself from the cosmos any more than the body can dissociate itself from the biosphere. On the contrary, it has to be understood as in some sense participating in it, or as 'partaking of the natural truth of reason', as Plato puts it.?

The notion of applying the 'courses of intelligence in the heaven' to 'the courses of our own intelligence' is not simply a poetic manner of speaking. It indicates that human intelligence can align itself with the truth of things with which it has a direct kinship. That alignment goes beyond the capacity simply to give accurate descriptions of things. To align with the truth of things belongs as much to practical reason as to intellectual reason. It 'regulates' the intelligence by conforming it to the cosmic intelligence or reason. When ordered in this manner, the soul is brought into harmony with itself. According to Plato's anthropology, that means that the rational, the spirited and the appetitive parts of the soul are brought into concord with one another and can therefore act truthfully and virtuously. ${ }^{8}$ Otherwise, disorder exists between the parts of the soul, what Plato calls 'vagaries'.

\section{THE NATURAL INCLINATION TO RESPONSIBLE KNOWLEDGE}

Seen in this way, our natural inclination to the truth of things, our desire to enquire, arises from the rational relation of the soul with the rational order of reality itself. There is a continuum between nature and thought. Thus, Aristotle opens his Metaphysics with the observation that:

All human beings by nature stretch themselves out toward knowing. A sign of this is our love of the senses; for even apart from their use, they are loved on their own account, and above all the rest, the one through the eyes.

Aristotle (2002: 980a: 21)

And what the mind seeks through the senses is wisdom. Yet the mind must reach out of itself in order to be itself. When the order of things is apprehended, there is a correlation between outward perception and inward reflection. We might even say that, through being present and perceptible, nature confers the gift of self-reflection upon human intelligence. The Greek word for truth is aletheia, meaning 'unconcealing'. Nature at once conceals and reveals itself. Truth cannot be taken by force, but offers itself to rightly oriented intelligence and reverential intention. ${ }^{9}$

This way of seeing the relation between human intelligence and the rational order of things raises the question of human responsibility towards nature as a whole. Aristotle poses the question: 'One must also consider in which of the two ways the nature of the whole contains what is good and what is best, whether as something separate, itself by itself, or as the order of the whole of things' (Aristotle, 2002: 1075a). That is to say, does the 'good' lie simply in the whole as such, or in some principle ordering the whole? Or are the 'whole' and its principle the same? For what can lie beyond the whole? In asking these questions, we are brought to consider how the 'being' and the 'good' of things are related, or if, ultimately, they are separate. Such metaphysical questions are more easily approached when the responsibilities of the human person are considered in relation to the whole.

\footnotetext{
${ }^{6}$ For a philosophical discussion of why nature cannot be properly accounted for if consciousness is omitted, see Thomas Nagel, Mind \& Cosmos (2012).

${ }^{7}$ For a comprehensive study of Plato's ethics and cosmology, see Gabriela Roxana Carone, Plato's Cosmology and Its Ethical Dimensions (2005).

${ }^{8}$ For Plato's elaboration of the tripartite soul, see Republic IV: 435-442.

9 The consequences of seeking to take truth by force are famously captured in the story of building the tower of Babel in Genesis 11:1-9, and how this destroys the power of speech, the essential human characteristic.
} 
Cicero, taking up this question from a Stoic perspective, conceives of this responsibility in a number of steps:

In order to have value, a thing must either be itself in harmony with nature or else be the means of procuring something which is so. All objects, then, that are in accordance with nature are relatively choiceworthy on their own account, while their opposites have negative value and call for rejection. The primary duty is that the creature should maintain itself in its natural constitution; next, that it should cleave to all that is in harmony with nature and spurn all that is not; and when once this principle of choice and rejection has been arrived at, the next stage is choice, conditioned by inchoate duty; next such a choice is exercised continuously; finally, it is rendered unwavering and in thorough agreement with nature; and at that stage the conception of what good really is begins to dawn within us and be understood.

Cicero, De Finibus, III, 20-21, in Hicks (2018: 80)

Contrary to the Enlightenment notion that 'fact' and 'value' cannot be related, Cicero here shows how the value of anything is to be judged by its integrity or coherence within itself or its harmony with nature as a whole. Every creature has a duty to maintain its integrity, and while the other creatures do this spontaneously through natural inclination, human nature must take up that obligation consciously and deliberately. To elect to 'cleave to all that is in harmony with nature' (Cicero, ibid) is a rational act of aligning thought and action to the greater whole. It is at once a moral and a rational act. Cicero considers holding to action of this kind to be the human duty, and only then can a true understanding of the good begin to be realised.

\section{THE NATURAL VIRTUES}

To live with this kind of resolution is to live virtuously. The virtues are the ancient ground of ethics, as distinct from modern deontological ethics. The virtue ${ }^{10}$ bring order to the inner being and enable right action. According to Zeno, they establish at once individual autonomy and the capacity to act in harmony with nature:

The goal of all these virtues is to live consistently with nature. Each one enables a human being to achieve this [goal] in his own way; for [a human] has from nature inclinations to discover what is appropriate and to stabilize his impulses and to stand firm and to distribute [fairly]. And each of the virtues does what is consonant [with these inclinations] and does its own job, thus enabling a human being to live consistently with nature.

Inwood and Gerson (2008: 26)

Just as the mind has an inclination to reach out to knowledge and understanding, as Aristotle says in the opening of his Metaphysics, so likewise it inclines to the good and to knowledge of the good. These are the 'inclinations to discover what is appropriate', as Zeno puts it. And again, as Aristotle says, the human being desires not only to live, but to live well (Aristotle, 2002. 1095a: 15-22).

\section{NATURAL LAW}

Gathering together our observations on the primordial sense of the whole, the narrative sense, the teleological order of nature, and the ethical sense and intuition of the good, we can trace how this integrated way of considering reality gave birth to the great tradition of Natural Law. This tradition shaped the thought and way of life in the Middle Ages until it finally succumbed to the mechanistic vision of the world in the seventeenth century. The break with the Natural Law tradition severed the relationship of the true and the good, the rational and the ethical, in both the sciences and politics.

\footnotetext{
${ }^{10}$ Primarily, the four cardinal virtues of prudence, courage, justice and temperance.
} 
The seminal text of Natural Law transmitted through the Middle Ages was from Cicero's De Republica:

There is indeed a law, right reason, which is in accordance with nature; existing in all, unchangeable, eternal. Commanding us to do what is right, forbidding us to do what is wrong. It has dominion over good men, but possesses no influence over bad ones. No other law can be substituted for it, no part of it can be taken away, nor can it be abrogated altogether. Neither the people nor the senate can absolve us from it. It wants no commentator or interpreter. It is not one thing at Rome, and another thing at Athens: one thing to-day, and another thing to-morrow; but it is a law eternal and immutable for all nations and for all time.

Cicero (2017: 33)

According to this tradition, all people have an innate knowledge of this immutable law. It is expressed in the universal desire for justice - justice in the sense of things being in harmony with truth and their proper ends. This conception of justice belongs to nature itself, ruling even the animals in their instinctual inclinations, and perceived by the human mind as the 'reason' inherent in nature. It is the 'unwritten law' behind any formulation of civil laws or codified legal system. Any manmade law is recognised as law only so far as it is in harmony with the Natural Law.

It is this law that informs human nature of its proper relation with society and with nature. And this in turn gave birth to the ancient understanding of 'right use' or appropriate ends of things. For Aristotle, the appropriate end of the polis is not simply living together, but living together well or beautifully. This is possible only when citizens are virtuous (Aristotle, 2012, 1278b: 20-30; 2002; 115b:12-13, 1122b: 6-7). Indeed, only the virtuous life may be regarded as forming citizenship since a citizen is one who has forethought for the common good. 'For that which has the power to foresee by thinking is naturally ruling and naturally mastering' (Aristotle, 2012: 1252a: 31). Such foresight is based on the perception that the whole has primacy over the parts: 'And a city is more primary by nature than the household, and more primary than each of us, for the whole is necessarily more primary than its parts' (Aristotle, 2012: 1253a: 12-21).

\section{OWNERSHIP AND RIGHT USE}

To live well or beautifully therefore means regarding all action and use of things in terms of the good of the whole. The question of right use therefore precedes the question of ownership. This applies to the proper use of wealth and directly to our human relationship with the land, the earth, and with the provisions of nature. Properly speaking, no part of nature may be 'owned' by anyone. The land is the free gift to all creatures just as the air, water and sunshine. The Roman poet Ovid laments how this wisdom was lost with the passing of the Golden Age:

The earth itself, which before had been, like air and sunshine,

A treasure for all to share, was now crisscrossed with lines

Men measured and marked with boundary posts and fences.

Ovid (2004: I/134-36)

The Stoic philosopher Seneca also wrote of the Golden Age before this was lost:

The social virtues had remained pure and inviolate before covetousness distracted society and introduced poverty, for men ceased to possess all things when they began to call anything their own ... How happy was the primitive age when the bounties of nature lay in common and were used freely; nor had avarice and luxury disunited mortals and made them prey upon one another. They enjoyed all nature in common, which thus gave them secure possession of public wealth. Why should I not think them the richest of all people, among whom was not to be found one poor man? 
In the Middle Ages, property in land was understood to exist 'legally' but not according to Natural Law.

Community of goods is ascribed to the natural law, not that the natural law dictates that all things should be possessed in common and that nothing should be possessed as one's own: but because the division of possessions is not according to the natural law, but rather arose from human agreement which belongs to positive law.

Aquinas (1920: IIa-IIae, q. lxvi, art. 2)

According to Natural Law, there can be no ownership of what nature provides freely for all. The legal arrangement was simply pragmatic. It assured that property would be cared for as an owner would wish to use it to advantage. But this was qualified by the concept of right use, which meant that all property, not only land, should be employed in such ways as contributed to the common good.

The second thing that is competent to man with regard to external things is their use. On this respect man ought to possess external things, not as his own, but as common, so that, to wit, he is ready to communicate them to others in their need.

(ibid)

This meant that, should anyone be destitute, they were free to take whatever they needed from those with sufficient. The law of theft was suspended and Natural Law re-established (ibid). The modern conception of 'absolute ownership', which allows an owner to dispose of private property however they please, even to destroy it, did not exist. There is a clue in the word 'private' which means to be separated from the whole, to be alienated, from which 'privation' is derived. Thus, private ownership implied separation of both property and person from society and from nature. In other words, law in the Middle Ages implied duties to the community and to nature, as distinct from rights which make claims open community and nature. Natural Law understands the human person as already a participant in the community, while modern rights law understands the human person as contracting into community. ${ }^{11}$

\section{THE RISE OF THE PROPRIETORIAL SELF}

This ancient understanding seems to be natural to indigenous societies, such as the Kalahari Bushmen, the North American Indians or the Australian Aboriginals, for whom landownership has no meaning. The modern West has lost this natural relation to the world. With the rise of individualism, the sense of community has been eroded, and this has given rise to the "proprietorial self' - the self conceived in terms of extended ownership. ${ }^{12}$ Almost the whole of modern economic theory is built upon the notion of ownership, of acquiring and consuming, rather than responsible use..$^{13}$ Modern westerners define themselves in terms of self-ownership and the notion that ownership confers absolute right of disposal (Locke, 1969). The ancient prohibition against suicide, for example, was based on Natural Law which regarded the biosphere as outside ownership. Ownership can only ever be a legal arrangement, a part of positive law, but not of Natural Law. ${ }^{14}$

\footnotetext{
${ }^{11}$ For a discussion of the rise of 'subjective rights' to property in the late Middle Ages, see Annabel S. Brett Liberty, Right and Nature (1997).

${ }^{12}$ For a full discussion of this, see C. B. Macpherson, The Political Theory of Possessive Individualism: Hobbes to Locke (2011).

${ }^{13}$ For an illuminating discussion of medieval economic teaching, see Christopher Franks, He Became Poor (2009).

${ }^{14}$ A powerful critique of Locke's theory of private ownership of land is given in 1832 by Thomas Rutherforth in his Institutes of Natural Law: Being the Substance of a Course of Lectures on Grotius de Jure Belli et Pacis (2016: Chapter 3, X).
} 
The modern proprietorial relationship with the land distorts our relationship with nature, reducing it to a mere 'economic resource', rather than our habitat shared with all other creatures (Leopold, 1949). This raises the question of extending ownership to minerals, plants or genetic material. It also raises the question of the proper relation of research to the community and the 'privatisation' of knowledge. Plato condemns the sophists for demanding payment for their teaching since learning or wisdom cannot be a private possession nor a means of exploitation. By its very nature, knowledge is infinitely distributable.

\section{THE COMMODIFICATION OF NATURE}

With the rise of economics as a discrete discipline in the seventeenth century, despite its early merits, there has been an ever-increasing tendency to view the world and society commercially. This has been reinforced by the reductive mechanistic worldview of the Enlightenment. In his seminal work, The Great Transformation, Karl Polanyi traces how the market economy gradually divided itself off from the medieval community and its traditions, where exchange of goods had been part of the social structure. This led to the commodification of land, labour and money (Polanyi, 2001). Thus, exchange became driven by profit-making and commerce became parasitic on community, rather than enhancing the social structure and serving the common good. The medieval understanding of right use of property vanished from economic theory, preserved now only in Catholic social teachings. ${ }^{15}$ The commodification of land, labour and money is a clear example of the separation of the ethical aspect of the community's relation with the natural order. Merchandising became the new narrative, while dwelling on the land became merely instrumental. ${ }^{16}$

Plato and Aristotle regard the reduction of life to 'money making' as corrosive of human character and destructive of community. 'The life of money making is a type of compulsory activity, and it is clear that wealth is not the good being sought, since it is instrumental for the sake of something else', says Aristotle (2002: 1096a: 1-10). And even more strongly Plato says 'thus, for the sake of money, they try utterly to destroy private individuals and whole households and cities' (Plato, 1980: 909b). What matters for the good of the polis is that its citizens value 'justice in the soul' above all other possessions:

...nor, again, should I take counsel about it with the so-called diviners, who in one way or another will advise me to take what was deposited in the earth. Because I would never benefit as much in money by taking the property as I would increase in substance as regards virtue of the soul and what is just by not taking it, I would thereby have acquired a better possession than that possession, and in a better part of me, by honoring the acquisition of justice in the soul before that of wealth in property.

Plato (1980: 913b)

\section{RECOLLECTING THE PRIMORDIAL HARMONY}

The order of the soul and the proper human relation to the earth are, as we have seen, bound together. Justice - the great measure which all societies in all ages recognise - has the peculiar character of being at once an inward virtue and an external virtue, relating human nature to itself and to the world. It follows from this that if a society adopts an unjust relation with the natural world, then citizens will suffer internal turmoil and discontent. Human fulfilment and living in harmony with nature are inextricably bound together. While the prevailing narrative fails to recognise this, most ordinary people do recognise that we are part of a 'great whole' and ought to live in harmony

\footnotetext{
${ }^{15}$ See Pope Leo xiii Rerum Novarum (1891), the first encyclical to address the exploitation of labour, yet flawed with a contradictory mixture of Natural Law and Lockean economic theory. Nevertheless, later social encyclicals have preserved the concept of right use.

${ }^{16}$ See Melissa Lane, Eco-Republic: Ancient Thinking for a Green Age (2011), for a discussion of how adopting a Platonic model of society can respond to the modern environmental crisis.
} 
together and with nature. There is a kind of primordial memory awakened of the cosmic order and our place within it as expressed in the ancient myths. As Ricoeur says:

For it is only when it is threatened with destruction from without or from within that a society is compelled to return to the very roots of its identity; to that mythical nucleus which ultimately grounds and determines it.

Ricoeur (1991: 584)

\section{REFERENCES}

Aquinas, T. (translator: Fathers of the English Dominican Province) (1920) Summa Theologiae. Cincinnati, $\mathrm{OH}$ : Benziger Brothers.

Aristotle (translator: Butcher, S.H.) (1932) Poetics IX, 1451b. Aristotle's Theory of Poetry and Fine Art. London: Macmillan.

Aristotle (translator: Sachs, J.) (2002a) Nicomachean Ethics. Newburyport, MA: Newburyport Focus Publishing.

Aristotle, (translator: Sachs, J.) (2002b) Metaphysics. Santa Fe, NM: Green Lion Press.

Aristotle (translator: Sachs, J.) (2012) Politics 1253A. Newburyport, MA: Focus Publishing.

Blanchette, O. (1992) The Perfection of the Universe According to Aquinas: A Teleological Cosmology. University Park, PA: Penn State Press.

Brague, R. (2003) The Wisdom of the World: The Human Experience of the Universe in Western Thought. Chicago, IL: The University of Chicago Press.

Brett, A.S. (1997) Liberty, Right and Nature. Cambridge: Cambridge University Press.

Carone, G.R. (2005) Plato's Cosmology and Its Ethical Dimensions. Cambridge: Cambridge University Press.

Cicero, (translator: Featherstonhaugh, G.W.) (2017) De Republica III.XXII. New Delhi: Alpha Edition.

Collingwood, R.G. (1960) The Idea of Nature. Oxford: Oxford University Press.

Franks, C. (2009) He Became Poor. Grand Rapids, Michigan/Cambridge: William B Eerdmans Publishing Company.

Gierke, O. (1997) Association and Law: The Classical and Early Christian Stages. Toronto: University of Toronto Press.

Gillespie, M.A. (2009) The Theological Origins of Modernity. Chicago, IL: The University of Chicago Press.

Hicks, R. (2018) Stoic and Epicurean. New Jersey: Franklin Classics.

Inwood, B. and Gerson, L.P. (2008) The Stoics Reader. Indianapolis, IN: Hackett Publishing Company.

Kerven, R. (2018) The origin of sickness and medicine. In Native American Myths. Northumberland: Talking Stone. pp. $140-152$

Lane, M. (2011) Eco-Republic: Ancient Thinking for a Green Age. Oxford: Peter Lang.

Lear, J. (2011) Aristotle: The Desire to Understand. Cambridge: Cambridge University Press.

Leopold, A. (1949) The Land Ethic. In A Sand County Almanac. Oxford: Oxford University Press. pp. 201-226.

Locke, J. (1969) Second Treatise on Civil Government. London: Awnsham Churchill.

Macpherson, C. B. (2011) The Political Theory of Possessive Individualism: Hobbes to Locke. Oxford: Oxford University Press.

Nagel, T. (2012) Mind and Cosmos. Oxford: Oxford University Press.

Ovid, (translator: Raeburn, D.) (2004) Metamorphosis. Harmondsworth: Penguin Classics.

Plato, (translator: Jowett, B.) (1937) The Dialogues of Plato, Volume I. New York: Random House.

Plato, (translator: Pangle, T.) (1980) The Laws of Plato. New York: Basic Books.

Plato, (translator: Nehamas, A. and Woodruff, P.) (1997) Phaedrus 245a. In Cooper, J.M. (ed.), Plato: Complete Works. Indianapolis, IN: Hackett Publishing Company. pp. 506-556.

Polanyi, K. (2001) The Great Transformation. Boston, MA: Beacon Press.

Ricoeur, P. (1991) The human experience of time and narrative. In Valdés, M.J. (ed.), A Ricoeur Reader: Reflection and Imagination. London: Harvester Wheatsheaf. pp. 99-116

Rutherforth, T. (2016) Institutes of Natural Law; Being the Substance of a Course of Lectures on Grotius de Jure Belli et Pacis, 2nd edition. Clark, NJ: The Lawbook Exchange.

Salkever, S.G. (1990) Finding the Mean. Princeton, NJ: Princeton University Press.

Seneca, (translator: Inwood, B.) (2007) Selected Philosophical Letters. Oxford: Oxford University Press.

Trott, A.M. (2014) Aristotle on the Nature of Community. Cambridge: Cambridge University Press. 


\title{
5 Humans Are Humus Using Eco-Psychology to Highlight the Language of Dualism and the Promise of the Non-Dual
}

\author{
Travis Cox \\ Naropa University
}

\section{CONTENTS}

Eco-Psychology 60

Modern, Western Concerns for Soil: Good Intentions, Problematic Language.................................60

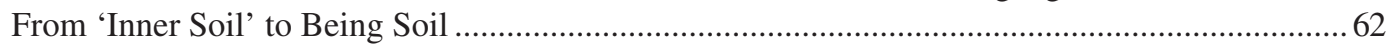

Humans as Humus: An Eco-Psychological Look at Human/Soil Relationships ..........................6 63

Other Non-Dual Perspectives: Buddhist, Eco-Feminist and Indigenous .......................................66

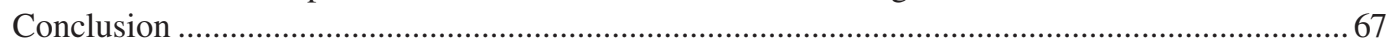

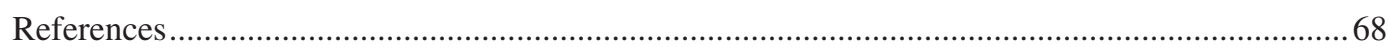

In 2010, As a PhD student in Sustainable Agriculture at Iowa State University, USA, I had the opportunity to take the institution's first organic agriculture class. During the course of the semester, a soil scientist from the National Soil Tilth Lab gave a guest lecture. In that lecture, she revealed that she was pioneering some of the first comprehensive research on soil biology, after 30 years of working at the Lab. Up until that point, the Lab's research was based on the assumption that soil was strictly a medium in which to grow plants using chemical amendments.

Fortunately for the biosphere, this assumption is increasingly coming under scrutiny as science is finding an inconceivable amount of invaluable life present in the soil. Soil scientist Elaine Ingham, formerly Lead Scientist for the Rodale Institute, uses the term soil food web as a way of expressing the biotic nature of soil. Even individuals concerned primarily with economics, such as the Slow Money group from Boulder, Colorado, are becoming aware of the necessities of the living soil. This is typified by the soil themed issue of their annual journal for Winter 2017/2018 (Tasch, 2018).

Rising to the challenge, the environmental humanities research field has also taken up the gauntlet. Environmental philosophy has been attempting to elevate 'dirt' from its lowly status by making philosophical arguments for its consideration as soil. However, when these arguments have their basis in the unquestioned assumptions of modernity, do they go far enough in encouraging the kinds of relationships with soil that will be necessary for the regeneration thereof, and concomitantly for the survival of civilisation through the twenty-first century?

It is the premise of this chapter that an eco-psychological look at soil, especially in eco-psychology's non-dual form, would benefit individuals who are looking to begin a healthy, holistic relationship with soil. A simplistic, yet valuable characterisation of this non-dual relationship between humans and the natural world has its genesis in the origins of the word human, which shares the same root as humus. Indeed, Adam in Hebrew shares a root with the words for ground, earth and soil.

This chapter will expand on the work of Patzel (2009), from an edited volume by Landa and Feller, Soil and Culture, in which he utilises the application of archetypal images from Jungian 
psychology to explore scientists' relationship to the 'outer soil' as a way to understand scientists' 'inner soil'. This chapter will use eco-psychology, in its transpersonal, non-dual form, as a way to examine human relationships with soil, going beyond the various dualistic ways of relating in order to explore the furthest reaches of the holistic view - the non-dual - while simultaneously acknowledging other pathways to non-dualism, including eco-feminism, Buddhism and indigenous perspectives.

\section{ECO-PSYCHOLOGY}

There is a distinct possibility that many people reading this chapter will not have a working understanding, much less a relationship, with the discipline of eco-psychology. This is undoubtedly largely owing to the fact that eco-psychology is still currently in its infancy, with the term itself not being introduced until 1992 and the 'official' discipline being established years later. But it is also, in part, owing to the amorphous nature of what the discipline actually is and does. The easiest way to define eco-psychology may be the intersection of ecology with psychology: with ecology informing psychology (because the discipline of ecology came after the founding of psychology) and psychology assisting ecology. It can do so by using psychology to encourage practices and approaches that are effective in changing behaviour in people who are already 'sympathetic to the cause', as well as helping to 'diagnose' and 'analyse' the reasons why so much of humanity is ecocidal, and also to offer options for 'therapy' for those who are unable to see the necessity for change.

Eco-psychology can, however, be much more than that; so much so that it has been criticised as bordering on a handicap, since the field itself is so broad that it defies definition. The author of this essay does not subscribe to this criticism but rather embraces the potential ambiguity as the very thing that allows for eco-psychology and its potentiality to enter into the realm of the non-dual. There are many aspects to eco-psychology. The implications of embodying ecological interconnectivity can be disorienting. Yet at the same time, it provides a lens through which we can examine the ecocidal disconnection of many modern cultures and institutions, and also offers tools to change individual attitudes, thereby changing these cultures and institutions from ecocidal to life-affirming and life-enhancing ones and helping to heal the biosphere in numerous ways.

Eco-psychology does all of these things by functioning at the level of a worldview. Operationally, eco-psychology is simultaneously grounded within ontology, epistemology, axiology, sociology, anthropology and ecology (Hedlund-de Witt, 2013). This same maddening pluralism, if properly understood, can lead individuals to a non-dual experience, which may prove to be one of eco-psychology's greatest assets: a lived experience of the unity of humans and humus.

\section{MODERN, WESTERN CONCERNS FOR SOIL: GOOD INTENTIONS, PROBLEMATIC LANGUAGE}

Within modern academia, initial attempts to rescue soil from being 'treated like dirt' unfortunately, but expectedly, were undertaken while operating under false conceptions of nature, and in the particular case of soil: a mechanistic, anthropocentric, dualistic perspective. While I acknowledge the value of all attempts to reconnect with soil, I argue for a non-dual, eco-psychological worldview in order to accomplish the aim of a holistic reconnection, in ways similar to other non-dual worldviews (e.g. eco-feminism, Buddhism, systems thinking and First Peoples' perspectives). For a broader analysis of industrial and alternative agricultural worldviews, see Cox (2014).

Fouke (2011) argues that moral concern should be extended to soil, based on an argument from nearness, in which the microbial ecology of the human gut is directly informed by, and in some way mirrors, soil microbial ecology. Thus, since human existence is dependent on both of these communities - and has even been partially defined by them in an evolutionary sense - it behoves modern humans to eschew thinking about soils instrumentally, because in some ways we are soil. 
However, Fouke (2011) uses morality in much the same way that other agricultural philosophers have done in the past, which is a very anthropocentric way of relating to soil (through human-conceived morals) in order to justify its demand on our attention (see also Paden, 1990). While admirable in their intentions, many of these efforts succumb to problematic assumptions, so rooted in Western culture, as to be inherent in the language used to try and talk about these problems. Even though it is true that 'soils provide services worth trillions of dollars annually', to frame it in such a way is problematically anthropocentric because it portrays soil not as a collection of innumerable beings, but as an object in service to humans, to say nothing of the issue of its commodification (Fouke, 2011: 149). While we might risk 'getting into the weeds' over the debate around genetic engineering, it should be noted that there is a tension between the ideas of 'healthy soil [as] a self-organizing system' and the soil ecosystem as 'one of the richest sources of compounds for biotechnology' (ibid), even though biotechnology is intrinsically against self-organisation. If we view soil as a vessel for possible biotechnological pursuits, through which humans reorient organisms towards particular aims that are of interest to themselves, isn't it by definition no longer self-organising?

Another example of academia's struggle to accurately articulate human/soil relationships can be found in inherited language. Kirschenmann (2009) writes about the necessity of having a conversation with the soil, thereby granting the soil some agency through its ability to enter into a conversation with humans. However, elsewhere in the same article, Kirschenmann (ibid) uses the term soil management, even though it is obvious that this term betrays the very intent of his theory. It should be noted, however, that Kirschenmann has a long record of working with numerous stakeholders around issues of soil, and so concessions should be given, knowing that the use of language like soil management would be the norm for most players in the modern agricultural system. These concessions are especially warranted when the position that Kirschenmann is ultimately asking farmers to take is a revolutionary one: "we can only engage farmers in a process that involves them in conversation with their own soils' (ibid: 237).

Nonetheless, this invokes a quintessential dilemma for environmental ethics, best typified in the last page of Bateson's (1972) book of essays, Steps to an Ecology of Mind: 'Is it important that the right things be done for the right reasons?' (ibid: 512). There is a distinct possibility that using the term 'management' reinforces a particular understanding of and relationship to soil. For example, if a conversation is taking place and one party is attempting to 'manage' the other, then what is the quality of that conversation? Even advocates of true agriculture reform still find themselves caught within this ethical dilemma and way of thinking, in which they partially rely on, and give power to, the worldview of industrial agriculture through their language. This dissonance is also an indication of society's current transitional period, where culture is trying to break free of dualism. A good example of this conscious attempt to liberate society from a one-dimensional framework can be found in Robin Wall Kimmerer's work. As Professor of Environmental and Forest Biology at the State University of New York College of Environmental Science and Forestry, Kimmerer advocates for using the term $K i$ when referring to an individual of another species (especially where the gender is unknown) with Kin being the plural, as a way of avoiding the word 'it', which has a connotation of a dead object as opposed to living subjects (Storrs, 2018). With this language, the life in the soil becomes our Kin.

Part of the reliance on dualistic language comes from the use of modern science as the sole legitimate epistemology. The nature of this problem, and eco-psychology's usefulness as an antidote, will be addressed later in this chapter. It will suffice here to mention a very succinct, yet inclusive, characterisation of the problem as a way of highlighting the issue before moving beyond it. The philosopher David Ray Griffin (1988) put it this way:

Recognition that the scientific community seeks truth is fully compatible with the recognition that the truths it seeks are selected according to various interests and prejudices. Recognition that science has discovered a wide range of truths is compatible with the conviction that a wide range of truths it has not discovered exists, and that its formulations of the truths it has discovered are one-sided, presenting only abstractions from the full truth. Recognition that there must be some truth to the "modern scientific 
worldview', which supports and is supported by the select truths of modern science, is fully compatible with the view that other worldviews exist that, all things considered, correspond equally well or even better to the full nature of reality.

Griffin (1988: 9-10, emphasis in the original)

\section{FROM 'INNER SOIL' TO BEING SOIL}

In another attempt to shift away from the dualistic, one-dimensional paradigm of academia, Patzel (2009) unearthed some of the subtler relationships between soil scientists, farmers and soil itself. His discoveries went a long way towards making the conversations between these entities less one-sided by highlighting the various ways that different individuals conceived of their connection to soil, using terms such as 'Mother Earth' or as working with 'the vital forces or spirits' to describe the relationship (ibid). In these exchanges, people were tending to their 'inner soil', meaning they were working with a fuller conception of their humanity and their relationships to the deeper aspects of soil, just as much as they were relating to the 'outer soil', the physical soil itself. For instance, the early European organic farmer, Hans-Peter Rusch (1906-1977), understood that reductionism provided an insufficient understanding of soil, or in his words, 'holy Mother Earth' (Patzel, 2009: 207). Another early European organic farmer, Mina Hofstetter (1883-1967), in Patzel's (2009) characterisation, 'claimed the importance of a spiritually receptive attitude towards Mother Earth' (ibid: 208), seemingly in an effort to create the kind of conversation that Kirschenmann (2009) advocated (see the previous section). When an individual adopts this co-creative outlook while in conversation with soil, Hofstetter notes, 'then suddenly, she [soil, or mother nature] starts talking and becomes understandable' (Patzel, 2009: 208).

From a farmer's perspective, British progenitor of organic agriculture, Lady Eve Balfour (18981990), composed the wholeness approach, which argued that every part of a whole had a right to exist, stating that 'the biota is a whole, of which we are a part' and 'if I am right, this means that we cannot escape from the ethical and spiritual values of life for they are a part of the wholeness' (Patzel, 2009: 217). This mindset wasn't exclusive to farmers; many scientists embraced it as well. Russian soil scientist Vasily Vasilyevich Dokuchaev advocated the study of holistic soil science and stated that 'all its principal elements must be revered and studied alike' (Patzel, 2009: 215, emphasis added). Acknowledging that soil has its own right to exist creates the theoretical foundation necessary to initiate and establish an eco-psychological relationship to soil.

However, even Patzel (2009) recognised possible discrepancies when it comes to relating to the 'inner soil'. He gave the example of two preeminent soil scientists, Fallou (the German founder of modern soil science working in the first half of the nineteenth century) and Jenny (former President of the Soil Science Society of America working throughout the twentieth century), who exhibited an 'inner soil' understanding, but with 'the polarity between the emotional and feeling approach on the one hand, and the fascination with rational order on the other hand', the 'inner soil' experience was discounted or ignored: 'In fact, this had been widely the case, and one might argue that this contributes to the accelerated and ongoing soil deterioration and destruction in large parts of the world' (Patzel, 2009: 216). Jenny (Patzel, 2009) continued to advocate that:

[The soil] speaks to us through the colours and sculptures of its profile, thereby revealing its personality; we acknowledge it by giving soil a name, albeit in a foreign tongue, but we don't mention our emotional involvements. In fact, our soil language is lifeless.

Patzel (2011: 216)

One could further argue that the division of the emotional and the rational is just another manifestation of dualism at work. Patzel (2009) ended his essay by returning to the question posited earlier: 
How could we personally and scientifically relate in an appropriate, fruitful, and sustainable way to our 'inner soil', so that it does not lead us to ideological one-sidedness and dogmatism, but may bestow on us the right idea at the right moment, the energy and guiding symbols to follow our path to what our culture needs next?

Patzel (2009: 223)

The current author believes that looking at soil from an eco-psychological perspective is the right idea, for this moment.

\section{HUMANS AS HUMUS: AN ECO-PSYCHOLOGICAL LOOK AT HUMAN/SOIL RELATIONSHIPS}

As discussed previously, identifying a full and clear definition of eco-psychology can be a difficult task and one that is not necessary here. For the purposes of this chapter, the focus will be on three concepts that help constitute eco-psychology: non-dualism, non-anthropocentrism and alternative epistemologies that support these two former concepts. This definitional framework will help avoid some of the issues encountered by previous attempts of relating to soil. These three concepts seek to address the 'core issues' of psychology in general: "Where is the "me"? Where does the "me" begin?, Where does the "me" stop?, and Where does the "other" begin?' (Hillman, 1995: 17). Furthermore, and specifically for the project of eco-psychology, 'defining the self-world connection' (Conn, 1995: 157) should be obvious: dualism is transcended by the non-dual; human selfishness is muted by non-anthropocentrism; and scientific materialism is negated by a recognition of multiple ways of knowing.

If, at this moment, paradoxical questions are forming in readers' minds, then this chapter is so far meeting with some success. Non-duality, when experienced from within the perspective of duality, is often paradoxical. For instance, Hillman (1995) discussed previous ecologically destructive attempts at cutting the boundary of 'self' and 'other' and highlighted the 'uncertainty about making the cut at all', only to end up saying 'we do need to see, however, that the cut between me and world, arbitrary as it is, nonetheless has to be made' (p. xix). From a dualistic perspective, of course the division has to be made: it is the very nature of human existence - we are not the trees (which is why it is so easy to cut them down). However, from Westernised eco-psychological perspective,

we have, in short, cut ourselves off from our connection to the Earth so thoroughly in our epistemology and our psychology that even though we are 'bleeding at the roots', we neither understand the problem nor know what we can do about it.

Hillman (1995: 161)

In a non-dualistic reality, individuals continually revise the boundaries of 'self' as necessary given their particular worldview and as the context demands. Not only is there an individual 'self', but that 'self' is also holonic, a part of many 'selves' that exist within a whole system: 'family, a community, a bioregion, or the living planetary ecosystem' (ibid: 164). Or, to take non-dualism to its further reaches, 'We are nature with a concept of nature. Nature weeping. Nature speaking of nature to nature' (Griffin, 1978: 226).

Thus, from a non-dual, eco-psychological perspective, one could simultaneously talk about knowing soil on its own terms, that humans are soil, and about humans having a healthy relationship with soil. Greenway (1995) discussed the wilderness effect and how extended wilderness experience programmes can facilitate transpersonal experiences of a non-dual 'self', but also points out that some programmes 'are not experiencing wilderness on its own terms' (p. 133). This is not an epistemologically problematic assertion in eco-psychology. Indeed, it is believed possible to experience an 'other' on its own terms. Like Hillman (1995), Greenway (1995) is acutely aware of the fact that the human ability to: 
Make distinctions, and 'self-reflect', now appears as a beautiful capacity run amok, proceeding from distinction to disjunction, from reflection to alienation, and from alienation to the kind of full blown split between subjects and objects (or between the poles of any disjunction) termed 'dualism'.

Greenway (1995: 131)

Greenway (1995) recognised that yet another way to relate, in the case of this chapter, to soil would be to 'shift from culturally reinforced, dualism-producing reality processing to a more non-dualistic mode' (p. 131), whereby humans honour the Earth by their self-awareness as humus. Even the middle ground between these two 'poles of disjunction' is celebrated in eco-psychology, where 'healthy relationships (between distinct beings) are not an esoteric goal. It is a matter of our very survival and the survival of most of the life upon this Earth' (O'Connor, 1995: 151). In fact, from an eco-psychological lens, it is possible to see all three of these perspectives in enterprises of the soil, such as gardening and farming, 'activities in which people and wild nature intermesh and begin to co-evolve', like 'the physical embodiment of symbiosis and co-evolution' (Harper, 1995: 198).

The non-dual aspects of eco-psychology overlap significantly with its non-anthropocentric aspects. To talk about relating to soil on its own terms is to attempt to remove the human projections onto soil and the projections onto the beings which comprise it and allow soil to present itself as it is. To talk about holistic human relationships with soil is to invoke the symbiotic nature of those relationships which facilitate the well-being of both humans and soil. Furthermore, to talk about humans as soil is to invoke a level of relationship that transcends the boundaries of human and soil and to see the unity at the core of their separate existences, both ontologically and through time and space.

In case this all seems too esoteric, Roszak (1995), who coined the term eco-psychology, explicitly counters that mischaracterisation:

Some are quick to see elements of sentimentality or romanticism in our growing appreciation of the sacred ecologies that guide traditional societies [which are significant contributors to the discipline of ecopsychology]. This is mistaken. There is nothing "mystical" or "transcendent" about the matter as we might understand those words. It is homely common sense that human beings must live in a state of respectful give and take with the flora and fauna, the rivers and hills, the sky and soil on which we depend for physical sustenance and practical instruction.

Roszak (1995: 6)

Or, as Liberty Hyde Bailey (as cited in Cox, 2014: 50), Dean of Agriculture at Cornell University from 1903 to 1913 and pioneer of the US National Extension Service, put it: 'The good spiritual reaction to nature is not a form of dogmatism or impressionism. It results normally from objective experience, when the person is ready for it' (p. 52).

These sentiments, as stated by both Roszak (1995) and Bailey (as cited in Cox, 2014: 50), that non-dual, non-anthropocentric ways of relating to soil are 'common sense' and 'result normally from objective experience' obviously invoke a discussion around alternative epistemologies, where one moves from 'standard resource management models' which 'are almost entirely anthropocentric and utilitarian' towards multiple understandings, including animistic, relating to 'the world no longer as a conglomerate of dead material objects but as ensouled, alive and animate' (Perluss, 2014: 8; Rees, 2010: 28), as well as non-dual, which 'allows eco-psychology to recognize that an individual person is always a part of a greater ecological whole' (Soule, 2014: 29). Indeed, these relationships, and ways of knowing, are so ecologically and psychologically complex as to begin to call into question even the concept of the individual, egoic 'self'.

As an example of our visceral interconnectedness, Professor John Cryan (cited in Wheeler, 2012), Chair of the Department of Anatomy and Neuroscience at the University College Cork in Ireland, believes that his research findings suggest that our thoughts could be directly influenced by 
the microbiome in our intestines. He undertook experiments with rats ${ }^{1}$ and probiotics, with results showing that rats fed probiotics survive longer in standard stress tests (almost double in some cases). This increase in stamina was isolated to the probiotics by cutting the vagus nerve (which runs from the intestines to the brain) in a subsequent experiment, whereby those rats fed probiotics but whose vagus nerve was cut reverted back to a regular stress test endurance. One philosophical extrapolation of these findings is that even the human sense of 'will' may not be entirely human! When rats fed probiotics tried to endure the stress test for longer periods of time, those who have had their vagus nerve cut returned to normal levels. This suggested to Dr. Cryan that the biotic community in the rats used the vagus nerve to stimulate a longer sense of self-preservation. So, shouldn't an understanding of what a rat 'self' is, and by extension a human 'self', include those very same beings who contributed to the rats' and to human preservation?

However, with the one-sided epistemology of a rational, empiricist scientism, there is little chance of understanding the complexity of this non-dual relationship. Eco-psychology, on the other hand, emphasises the necessity of multiple epistemologies. Metzner (1999) incorporated alternative epistemologies as an integral part of his 'green psychology' (p. 175). Sewall (1995) goes so far as to delineate the ways in which alternative perceptions can assist in the task of reconnection: 'We begin to care for that which we see, and ideally, we find ourselves loving the material world, our Earth. Because love alters behaviour, honouring sensory and sensual experience may be fundamental to the preservation of the Earth' (p. 203).

One often-overlooked implication of the singular emphasis on empiricism is the subtle materialism that results, which only continues the dualistic paradigm. Cox (2014) articulated the concept of subtle materialism, building on the concept of Esbjörn-Hargens and Zimmerman's subtle reductionism, 'whereby ecological relationships are principally conceived as relationships between material objects that lack a subjective, interior mode of existence' (p. 96). This subtle materialism, which even Aldo Leopold occasionally recapitulates, has two negative results. One is anthropocentric in that interiority is only ascribed to humans. The other is that relationships between beings are only depicted in materialistic terms.

The roots of this reductionism in ecology theory can be traced back, in part, to Arthur Tansley (as cited in Cox, 2014: 113) who, in 1935, made an explicit effort to move ecology away from 'communities' and instead coined the term ecosystem. Worster (1985) expressed:

The often-repeated notion that the plant assemblage is more than the sum of its parts, that it forms a whole which resists reductive analysis, he took to be a fiction worked up by an overexcited imagination... In short, Tansley hoped to purge from ecology all that was not subject to quantification and analysis, all those obscurities that had been a part of its baggage at least since the Romantic period.

Worster (1985: 301)

However, when it comes to the history of alternative agricultures, alternative epistemologies are almost always invoked alongside alternative practices (Cox, 2014: 56). Two quotations will suffice here for the purposes of illustration. The first is Wes Jackson (cited in Cox, 2014), who discussed inherited worldviews in ways similar to the discussion above: 'Here lies my worry. Most proposals for bringing about a sustainable agriculture and culture carry the fingerprints or markings of the Baconian-Cartesian worldview. At best, it amounts to Smart Resource Management' (p. 51). The second is Wendell Berry (also cited in Cox, 2014), who is overt in his mistrust of reductionism: 'Reduction does not necessarily limit itself to compacting and organizing knowledge; it also has the power to change what is known' (p. 123). Thus, eco-psychology, which is partially constituted by its inclusion of alternative epistemologies, pairs extremely well with alternative agricultures, which also are made up of ways of knowing that go beyond scientistic empiricism and subtle materialism.

\footnotetext{
${ }^{1}$ This author wants to acknowledge that this example is problematic as an example of human interrelationship to the more-than-human world, given that it involves rats being used in very instrumental ways.
} 


\section{OTHER NON-DUAL PERSPECTIVES: BUDDHIST, ECO-FEMINIST AND INDIGENOUS}

Because non-duality is inherently difficult to comprehend, especially from within many Western cultures which are impeded by dualistic concepts, the enterprise of encouraging a non-dual relationship to soil would benefit by highlighting other non-dual frameworks, such as Buddhism, eco-feminism and indigenous perspectives.

Buddhism is fundamentally interested in non-duality because 'non-duality is a concept central to the notion of enlightenment' (Sadakata, 1997: 79). As such, various sectors of Buddhism have created numerous ways of understanding this concept. Perhaps one of the easiest, if not one of the most poetic, interpretations comes from Zen master Thich Nhat Hanh, as expressed by Kornfield (1993):

If you are a poet, you will see clearly that there is a cloud floating in this sheet of paper. Without a cloud there will be no water, without water, the trees cannot grow; and without trees, you cannot make paper. So the cloud is in here. The existence of this page is dependent on the existence of a cloud. Paper and cloud are so close. Let us think of other things, like sunshine. Sunshine is very important because the forest cannot grow without sunshine, and we as humans cannot grow without sunshine. So the logger needs sunshine in order to cut the tree, and the tree needs sunshine in order to be a tree. Therefore, you can see sunshine in this sheet of paper. And if you look more deeply, with the eyes of a bodhisattva, with the eyes of those who are awake, you see not only the cloud and the sunshine in it, but that everything is here, the wheat that became the bread for the logger to eat, the logger's father - everything is in this sheet of paper... The presence of this tiny sheet of paper proves the presence of the whole cosmos.

Kornfield (1993: 202)

Buddhism, like eco-psychology, is not consumed by the perspective of unity; it can also 'honor our individual or personal destiny, our self for this life' (Kornfield, 1993: 207). Here again, there is a framework that encompasses the ideas of non-duality (i.e. humans are humus), subjectivity (i.e. a respect for all beings) and relationship (i.e. the interaction between my personal destiny and that of other beings).

Eco-feminism is another such framework. One of the mothers of eco-feminism, Charlene Spretnak, does a fantastic job of delineating the seemingly ineffable in her article 'Radical Non-duality in Eco-feminist Philosophy'. In it, she highlights the difference between minimal and radical non-duality, discusses non-duality's relationship to oppression and explores non-dual conceptions of 'self'. Her definition of non-duality is 'a dynamic system of relations wherein any particular manifestation functions simultaneously as a distinct part and the unbroken whole' (Spretnak, 1997: 427). With that understanding, she notes a difference between minimal non-dualism, which posits autonomous subjects in interdependent relationships, where this idea still partakes of scientific materialism, and radical non-duality, which posits 'the existence of unitive dimensions of being, a gestalt of a subtle, unitary field of form, motion, space, and time' (Spretnak, 1997: 425). This perspective takes the human/humus relationship even deeper, beyond an understanding of connection based on constituent elements across space and time. It asserts a unity that also exists on an ontological level, thus giving even more credence to the enterprise of recognising human's essential relations with soil.

As important as this understanding is, Spretnak (1997) acknowledges that there can be a danger in how it is applied. Historically, unity (or non-duality) could be used to erase difference, for the benefit of those in power. But that is not the case here, because eco-feminism is an inherently liberationist undertaking, which understands the 'self' as relational and therefore constituted by interactions with 'other' beings and celebrates these aspects of 'self': 'genetic inheritance', 'cognitive functions', 'bodily experience...[and] the self-regulating dynamics of the body-mind', 'exposures to strong and weak electromagnetic fields', 'other relational dynamics that lace the universe' and 'the influences of landscape, weather, and "other dynamics of one's bioregion on imagination and 
mood"' (Spretnak, 1997: 433). In future, when non-dual understandings become more common place, as necessitated by our current social and ecological crises, the non-dual relationship of humans and humus will need to be an explicit component in any list of aspects of 'self', such as the list above. Indeed, as these 'ontolog[ies] based on dynamic and admittedly partial knowledge[s] as well as awe toward the complexity of embodied and embedded existence... contribute substantially to the profound social transformation that is needed' (Spretnak, 1997: 435, emphasis in original), soil will need to be ever present as the very foundation of this work.

Finally, many indigenous belief systems are also non-dualistic in their orientation, though 'non-dual' might not be the preferred term. Nancy J. Turner (2005), author of The Earth's Blanket: Traditional Teachings for Sustainable Living and researcher who has worked with indigenous communities for over 40 years, cited a term from the Nuu-Chah-Nulth Nation, Hishuk ish Ts'awalk, which translates approximately to 'everything is one' (p. 179) when generalising about indigenous understandings of human/nature relationships. In her exploration of Navajo sand painting, Griffin-Pierce (1992) used 'interrelated totality' (p. 66), while Cajete (1999) encapsulated these complexities in the phrase the 'theology of place' (p. 66), which, 'while focused specifically on [a] place, extended to include all of nature' (p. 5).

While the language used to express these indigenous, non-dual understandings may differ significantly, the commonality is a stance against Western dualism. In example after example, Turner (2005) juxtaposed the 'compartmentalize[d]' approach of 'western society', which separates forestry and fisheries into different administrative and academic units, against 'First Nations' which 'lived this interconnectedness between their landscapes and resources, relying fully on all of the components and their associations simultaneously' (p. 180, 183). She ended her exploration by invoking the Haudenosaunee Thanksgiving Address, which is a litany of all the beings that humans are in relationship with, offering gratitude and thanks for the ways these 'other' beings help to constitute human beings. Turner (2005) stated, 'this prayer...epitomizes a world view in which everything is one, and it emphasizes our need to recognize and express our appreciation to all the elements of our universe' (p. 206).

Griffin-Pierce (1992) offered a contrite summary of the issue of dualism: 'What Anglos call the pairing of opposites Navajos conceptualize as the halves of a whole, with each half necessary for completeness' (p. 66). She went on to quote a participant in her research as saying, 'When you say "opposites" it sounds like each part is whole by itself. It misses the point because you need to include them both' (p. 66). In other words, when humans conceive of themselves as something separate from soil, what gets lost is the larger and equally valid perspective where humans are humus.

Cajete (1999) articulated the lived experience of native people living under this dualism, which shows up as alcoholism, depression and many other forms, in very stark terms, 'Tewa people call this state of schizophrenic-like existence pingeh heh (split thought or thinking, or doing things with only half of one's mind)' (p. 17). But, Cajete (1999) doesn't believe that healing this split is the exclusive task of indigenous peoples; rather, 'it is also the task of others who consider themselves people of place' (p. 17), or perhaps people of the soil. According to Cajete (1999), even the word indigenous

is derived from the Latin root indu or endo, which in turn is related to the Greek word endina, which means 'entrails'. 'Indigenous' means being so completely identified with a place that you reflect its very entrails, its insides, its soul.

Cajete (1999: 6)

\section{CONCLUSION}

All human beings, even those living in modern, dualistic cultures, are indigenous to soil, with its microbiotic community finding expression in our entrails. Many recent Western understandings of soil belie that connection and, unfortunately, many attempts to reconnect humans and soil have 
inadvertently recapitulated to the dualism that separate the two. Eco-psychology has the power to synergise the human and the soil, through its non-dualistic, non-anthropocentric and alternative epistemologies. This allows humans to connect to soil on its own terms, to have a holistic relationship with soil and to see humans as soil. But eco-psychology isn't the only system of thought that has the ability to do this. Buddhism, eco-feminism and multiple indigenous belief systems can also reorient human beings towards the non-dual, which is ultimately what I am advocating here: the ability to see humans as humus.

\section{REFERENCES}

Bateson, G. (1972) Steps to an Ecology of Mind. Chicago, IL and London, England: University of Chicago Press.

Cajete, G. (1999) "Look to the mountain" reflections on indigenous ecology. In G. Cajete (ed.), A People's Ecology: Explorations in Sustainable Living (pp. 1-20). Santa Fe, NM: Clear Light Publishers.

Conn, S. (1995) When the earth hurts, who responds? In T. Roszak, M. E. Gomes, and A. D. Kanner (eds.), Ecopsychology: Restoring the Earth, Healing the Mind (pp 156-171). San Francisco, CA: Sierra Club Books.

Cox, T. E. B. (2014) Integral agriculture: Taking seriously the mindset of the farmer, the interiority of the beings on the farm, and a metaphysics that connects them (Doctoral dissertation). Retrieved from https://lib.dr.iastate.edu/etd/14091/.

Fouke, D. (2011) Humans and the soil. Environmental Ethics, 33(2): 147-161.

Greenway, R. (1995) The wilderness effect and ecopsychology. In T. Roszak, M. E. Gomes, and A. D. Kanner (eds.), Ecopsychology: Restoring the Earth, Healing the Mind (pp. 122-135). San Francisco, CA: Sierra Club Books.

Griffin, S. (1978) Woman and Nature: The Roaring Inside Her. New York: Harper Collins.

Griffin, D. R. (1988) Introduction: The re-enchantment of science. In D. R. Griffin (ed.), The Re-Enchantment of Science: Postmodern Proposals (pp. 1-46). Albany, NY: State University of New York Press.

Griffin-Pierce, T. (1992) Earth Is My Mother, Sky Is My Father: Space, Time, and Astronomy in Navajo Sand Paintings. Albuquerque, NM: University of New Mexico Press.

Harper, S. (1995) The way of wilderness. In T. Roszak, M. E. Gomes, and A. D. Kanner (eds.), Ecopsychology: Restoring the Earth, Healing the Mind (pp. 183-200). San Francisco, CA: Sierra Club Books.

Hedlund-de Witt, A. (2013) Worldviews and their significance for the global sustainable development debate: A philosophical exploration of the evolution of a concept. Environmental Ethics, 35(2): 133-162.

Hillman, J. (1995) A psyche the size of the earth: A psychological foreword. In T. Roszak, M. E. Gomes, and A. D. Kanner (eds.), Ecopsychology: Restoring the Earth, Healing the Mind (pp. xvii-xxiii). San Francisco, CA: Sierra Club Books.

Kirschenmann, F. (2009) Comprehending soil within the context of the land community. In E. R. Landa and C. Feller (eds.), Soil and Culture (pp. 227-238). London, UK: Dordrecht Heidelberg and New York: Springer.

Kornfield, J. (1993) A Path with Heart: A Guide through the Perils and Promises of Spiritual Life. New York: Bantam Books.

Metzner, R. (1999) Green Psychology: Transforming Our Relationship to the Earth. Rochester, VT: Park St. Press.

O'Connor, T. (1995) Therapy for a dying planet. In T. Roszak, M. E. Gomes, and A. D. Kanner (eds.), Ecopsychology: Restoring the Earth, Healing the Mind (pp. 149-155). San Francisco, CA: Sierra Club Books.

Paden, R. (1990) Moral metaphysics, moral revolutions, and environmental ethics. Agriculture and Human Values, 7(3-4): 70-79.

Patzel, N. (2009) The soil scientist's hidden beloved: Archetypal images and emotions in the scientist's relationship with soil. In E. R. Landa and C. Feller (eds.), Soil and Culture (pp. 205-226). London, UK: Dordrecht Heidelberg and New York: Springer.

Perluss, B. (2014) For the love of the soul of the world. Ecopsychology, 6(1): 8-9.

Rees, W. E. (2010) Thinking resilience. In R. Heinberg and D. Lerch (eds.), The Post Carbon Reader: Managing the 21st Century's Sustainability Crises (pp. 25-42). Healdsburg, CA: Watershed Media.

Roszak, T. (1995) Where psyche meets Gaia. In T. Roszak, M. E. Gomes, and A. D. Kanner (eds.), Ecopsychology: Restoring the Earth, Healing the Mind (pp. 1-20). San Francisco, CA: Sierra Club Books. 
Sadakata, A. (1997) Transmigration, karma, and enlightenment. In J. S. Sobeck (ed.), Buddhist Cosmology (p. 79). Tokyo, Japan: Kosei Publishing Co.

Sewall, L. (1995) The skill of ecological perception. In T. Roszak, M. E. Gomes, and A. D. Kanner (eds.), Ecopsychology: Restoring the Earth, Healing the Mind (pp. 201-215). San Francisco, CA: Sierra Club Books.

Soule, R. G. (2014) The shared imperative of becoming ecopsychology. Ecopsychology, 6(1): 29-30.

Spretnak, C. (1997) Radical nonduality in ecofeminist philosophy. In K. Warren (ed.), Ecofeminism: Women, Culture, Nature (pp. 425-436). Bloomington, IN: Indiana University Press.

Storrs, A. (Producer) (2018) Robin Wall Kimmerer on indigenous knowledge for earth healing [Audio podcast]. August 2, 2018. Retrieved from https://itunes.apple.com/us/podcast/robin-wall-kimmerer-onindigenous-knowledge-for-earth/id942809988?i=1000417102827andmt=2.

Tasch, W. (ed.), (2018) Slow Money Journal, Winter 2017/2018. Boulder, CO: Slow Money Institute.

Turner, N. J. (2005) Everything is one. In L. Kenward (ed.), The Earth's Blanket: Traditional Teachings for Sustainable Living (pp. 179-210). Seattle, WA: University of Washington Press.

Wheeler, S. (Producer). (2012) Gut feelings [Audio podcast]. April 2, 2012. Retrieved from https://www.wnycstudios.org/story/197242-gut-feelings.

Worster, D. (1985) Nature's Economy: A History of Ecological Ideas. New York: Cambridge University Press. 


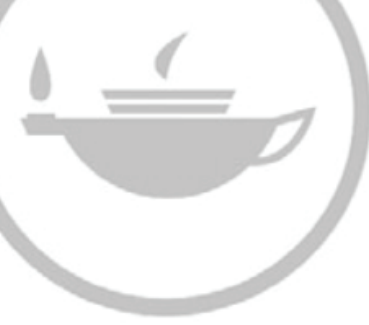

Taylor \& Francis Taylor \& Francis Group http://taylorandfrancis.com 


\title{
6 A New Science from a Historical Figure Goethe as Holistic Scientist
}

\author{
Isis Brook \\ Crossfields Institute
}

\section{CONTENTS}

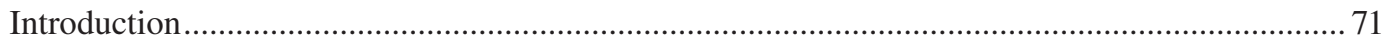

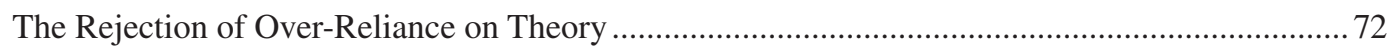

All in Flux: Time and a Sense of Mobility ………………….............................................

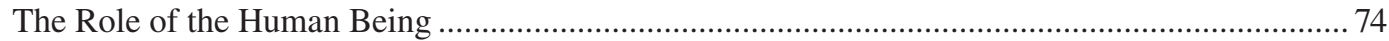

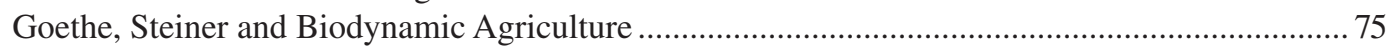

Barbara McClintock's Understanding of Organisms ..................................................................76

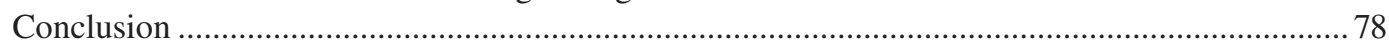

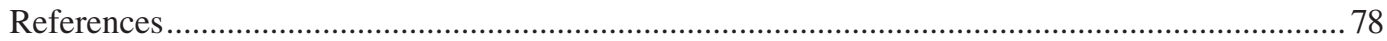

\section{INTRODUCTION}

It might seem odd, in a book about the cutting edge of agroecology, to look back to a historical figure. However, it is worth indulging this narrative because Goethe's scientific work sowed the seeds that may now be brought to fruition. In radically rethinking agriculture, we are rethinking our relationship with nature and with the world, and there are early indications of a holistic approach in Goethe's work that could guide us here. As an early objector to the mechanistic and dualistic direction that science was taking, he lived through a fulcrum period in Western history and created a different path, one that we could have followed and may still yet. To build a historical bridge between Goethe and the current discussion, I will also discuss Rudolf Steiner's research into Goethe and the example of Barbara McClintock's scientific work with maize.

Johann Wolfgang von Goethe's dates are 1749-1832, which place him chronologically at the watershed between the study of what was then called natural history and the new science of biology. His scientific approach countered both vitalism ${ }^{1}$ and mechanistic ways of seeing the world which dominated the science of his time (Steiner, 1985: 92). Although most famous for his literary work, he believed his scientific endeavours were the most important (Seamon and Zajonc, 1998: 1), and there are many complete historical accounts of these contributions (e.g. Nisbet, 1972). The purpose here is not to repeat them but to contextualise key elements of his approach so that we can see why he might be relevant today.

Goethe's scientific work covers the areas of geology, meteorology, osteology and botany and the study of colour. He was also an early exponent of the history of science as a discipline in itself (Fink, 1991: 70). Working across a wide range of subjects seems strange to our ever-more specialised contemporary approach to science. Why would someone hop from one realm to another and risk being labelled a dilettante? Even in the late eighteenth century, this would have seemed to be spreading

\footnotetext{
1 Vitalism has different versions, both ancient and modern, but in Goethe's time, it was characterised by belief that organic entities were infused by a mystical/imperceptible life force or spirit. It gained popularity and adherents as a bulwark against purely mechanistic views.
} 
oneself too thinly to make any progress in any field of science. To understand this and to make sense of Goethe's scientific writings and discoveries, we have to understand him as embracing a form of holism, of seeing nature as one, and investigating sides of that whole in order to see it in its fullness.

In order to present a picture of his approach, I will focus on three aspects of Goethe's science: the rejection of an over-reliance on theory; the grasping of nature as being in flux; and the role of human faculties in understanding nature. In all of these aspects, he was neither representative of his own time nor foreshadowing the direction that science was to follow. Furthermore, although he did have an early fascination with alchemy, and draws on it in his literary work (Gray, 1952), what he was doing here was something new.

\section{THE REJECTION OF OVER-RELIANCE ON THEORY}

At the time that Goethe was writing, mechanistic, reductionist ways of thinking were becoming prevalent in society and science, and these were leading to impressive discoveries and inventions. However, for Goethe, these discoveries were often misunderstandings and science itself was being driven up a blind alley. One aspect of the practice of science on which Goethe writes extensively is the movement towards an over-reliance on theory. What happens is that we no longer see the phenomenon we seek to understand; we see only our own construct. As Goethe argued:

Someday someone will write a pathology of experimental physics and bring to light all those swindles which subvert our reason, beguile our judgement and, what is worse, stand in the way of any practical progress. The phenomena must be freed once and for all from their grim torture chamber of empiricism, mechanism, and dogmatism; they must be brought before the jury of man's common sense.

von Goethe (1995: 309)

Goethe is not saying that theory or hypothesis has no role in scientific investigation; he does, however, want to rein it in and sees it as a tool that needs very careful handling. Goethe rejects both the over-reliance on theory to determine what to look for and the habits of mind that construct phenomena in the way suggested by the preconceived theory. A strong example of this criticism can be seen in the following quotation:

To rid the human mind of an hypothesis that has unduly restricted it, forcing it to observe erroneously and to combine falsely, to muse instead of seeing, to sophisticate instead of judging, is already to render it an inestimable service. Henceforth it sees the phenomena with greater openness of mind, in other relations and interconnections, orders them after its own manner, and once more gets the chance to err after its own manner, a chance that is invaluable if it soon succeeds in perceiving its error.

Goethe, Naturwissenschaftliche Schriften Vol 4, Part 2, cited in Heinemann, (1934: 68)

The method by which one is to 'rid the mind' of constricting hypotheses is to approach the phenomenon from all directions. One of these directions will be prior hypotheses, but that is only one direction amongst many diverse approaches. Apart from the importance of a full investigation of the phenomenon as experienced by the scientist, there is also, as the latter part of the quotation reveals, the conscious attention to the action of theory, hypotheses and opinion on perception itself. Thus, the scientist has to investigate his/her own mind as well as nature to ensure that the necessary openness is maintained and to let the mental faculties be guided by nature.

Out of the many scientific works by Goethe across a range of fields, he finds certain principles that are evident in nature and these, for him, help to explain its endless creativity (Tantillo, 2002). Rather than having strict laws circumscribing what is possible, these four principles are better seen as ways of capturing the way nature does what it does. They are as follows:

Polarity: Goethe's term for the way nature is creative through the juxtaposing of opposites; it remains in flux by breaking apart and rejoining. 
Intensification (Steigerung): Goethe's term for the way all of nature seems to be striving or overcoming itself through increasing complexity.

Compensation: This recognises that nature creates within limits; forms can develop and change, but they are always sacrificing something to develop something else; for example, adaptability is sacrificed for specialisation.

Generativity: This is the principle Goethe recognises to explain the way an organism's parts can work together or even compete, in some sense, to grow. For example, a plant can produce more of itself vegetatively or sexually and these two impulses are both working generatively and express an inner vitality in the plant. Goethe considers that an abundance of generativity suggests a radical freedom at work, as opposed to a hierarchy where certain parts direct development.

These principles operate for Goethe in the way that a theory or hypothesis operates, although they are, he maintains, found in nature, not created by scientists for their convenience nor to constrain or shape what we are seeing. If we approach nature as a machine, we will find machine-like aspects, not because nature is like a machine but because that is the lens we look through. These principles are for Goethe a means to capture something of nature for the human mind to grasp, but they are, like nature itself, ever malleable and undergoing change. One way to understand these principles is as guides for reasonable ways of adding the non-physical meaning aspects of a phenomenon, through contemplation of the phenomenon in the light of these principles.

\section{ALL IN FLUX: TIME AND A SENSE OF MOBILITY}

An aspect of Goethe's science that seems unusual for the time he was writing was his appreciation of nature as continuously in flux. The project of biology in the eighteenth and early nineteenth centuries was to catalogue and order nature. Nature was understood as created by God, and the human task was to know what was there and to order its objects into static tables. Taxonomy: Putting things in the right boxes was the order of the day. Goethe, as we see from the principles above, is more interested in nature as a whole and how it generates itself. Indeed, his first published scientific discovery in 1786 of the intermaxillary bone in humans upsets one of the most fundamental divisions: that between humans and other animals. This bone in humans is fused with the maxillary bone, whereas in other animals (even apes) it is freer. Goethe can see this fusing, as opposed to seeing one discrete bone, because his scientific question is not 'which box does it fit into?' but rather, how does dynamic nature shape bones? He was seeing the hard material of bones more fluidly without preconceptions driven by a theory that must separate humans. This fluidity was so new as a concept that Goethe needs to introduce a new term for it, and in 1796, he used the term 'morphology' for the study of the transformation of organisms (Jensen, 2019).

Morphology also suggests the need for a kind of lively apprehending, not only to see the whole form, but to understand it as a whole. The organic, for Goethe, has no fixed form (von Goethe, 1995: 64). Thus, the organism seen in everyday consciousness is not the organism as a living thing; to see this, we need to bring to it the sense of flux that it is engaging in.

With plants, the picture is even clearer. Unlike his contemporaries, Goethe does not stick to studying plants as dry preserved specimens in herbarium samples. As he discovers, particularly on his extensive and life-transforming trip to Italy (von Goethe, 1989), the way a plant grows reflects aspects of its environment such that there can be no stable sample of a plant - its size and development are shaped by where it grows. In The Metamorphosis of Plants, Goethe sets out his insight that the plant develops by transforming its material through time by shaping and reshaping itself. It does not unfold to a strictly determined plan, but it does express a vitality and a drive to develop and reach a point of fruition, when circumstances allow. His cryptic statement 'all is leaf' means that the plant substance, which might now be expressed as leaf, undergoes a transformation (akin to reproduction) to become the other plant parts: sepal, petal, carpal, stamen, etc. Nature's creative 
process is visible to us once we shift our attention from static form to fluid process. This insight he attributes to encountering the discontinuous metamorphosis in the shape of leaves, which he first noticed with the dwarf palm (Chamaerops humilis L.) in the botanical gardens in Padua in 1786 (Arber, 1950: 42).

\section{THE ROLE OF THE HUMAN BEING}

The third aspect of Goethe's approach to science that needs some explication is the role the human being plays in scientific investigation. As Goethe says, to understand the whole as a metamorphosing possibility we need to 'remain as quick and flexible as nature and follow the example she gives' (von Goethe, 1995: 64). What does he mean by this exactly? The bridge that Goethe uses to make the sequential connection from one instance to another, from one leaf to another, from one plant to another, etc., is that of the human imagination. Rather than seeing human faculties such as imagination, or indeed intuition, as impairing scientific objectivity, Goethe sees these human faculties as the means to really understand nature. By allowing nature to work with the human faculties, he thought we can begin to see with the mind's eye and thus make connections and reveal the workings of nature that are not initially or easily apparent. For Goethe, the supersensible dimension would be that which we can see once we know how to look and bring that looking into our thinking, to contemplate and use the mind's eye (Stephenson, 1995: 13). He is resistant to the notion of a free-floating idea or concept that is not tied to, or indeed given by, the sense perceptible to the human mind through what seems like a shared contemplation (Stephenson, 1995). The observation and identification of key aspects of nature and an open contemplation of them helps to reveal nature as a whole, and this activity, in Goethe's view, is crucial for the progress of science. His use of the term Anschauung captures this well although it is not directly translatable. Agnes Arber, ${ }^{2}$ commenting on Goethe's work, renders it as 'intuitive knowledge gained directly through contemplation of the visible aspect' (Arber, 1954: 122).

Goethe's lively discussion of philosophical problems with the activity of scientific investigation helps to fill out the picture of how he worked and what he thought was possible. Accounts of Goethe's own perceptual abilities abound (Amrine et al., 1987: 379), and he acknowledges that he was naturally very perceptive, but also believes in the development of one's faculties. It is clear that he thought the human sensorium was capable of improvement when he discusses the idea of scientific work opening 'new organs of perception'. 'The human being knows himself only insofar as he knows the world; he perceives the world only in himself, and himself only in the world. Every new object clearly seen, opens up a new organ of perception in us' (von Goethe, 1995: 39). The means to improvement was the exercise of looking at nature. He seems to invoke a cycle of looking at nature, examining oneself, looking at nature again and so on. The procedure then becomes a spiral of enhancing capabilities through experience and closer and closer relationship with the aspect of nature studied. For Goethe, this is the activity of science, he says: 'Insofar as he makes use of his healthy senses, man himself is the most exact scientific instrument possible' (von Goethe, 1995: 331). That sense of having to live into, to merge with, the thing studied comes through in his writing.

Thus, we have a scientist very alive to the problem of presuppositions and human tendencies to shape the world to themselves and yet endorsing faculties such as imagination and intuition to arrive at insights about the workings (or rather the being) of nature. To highlight that seeming conundrum, he talks of the kind of approach that is needed as a 'delicate empiricism'. He says, 'There is a delicate empiricism which makes itself utterly identical with the object, thereby becoming true theory. But this enhancement of our mental powers belongs to a highly evolved age' (von Goethe, 1995: 307). This delicate empiricism is Anschauung: where contemplation leads to intuitive insights by

\footnotetext{
${ }^{2}$ Agnes Arber was a twentieth-century botanist and philosopher/historian of biology who was an insightful interpreter of Goethe's scientific work.
} 
allowing nature to speak because we have placed our faculties at her disposal. Such an enhancement would perhaps allow us to become, for a moment, that which we study, for example, to experience vegetative growth or even photosynthesis. Moreover, it allows us to bring the wider picture of relationships and forces in nature to bear on our perception.

To build a bridge between Goethe's time and our own, I will look at two separate developments. One is the connection between Goethe and Rudolf Steiner (whose work was the impulse behind biodynamic agriculture). The other is a twentieth-century scientist, Barbara McClintock, whose work highlights both attending to nature as in flux and the feeling capacities that the human being can bring to the scientific endeavour.

\section{GOETHE, STEINER AND BIODYNAMIC AGRICULTURE}

Biodynamics, as a cosmologically informed farming method, is discussed elsewhere in this book; the purpose of this section is to look at how Goethe informed Steiner's work. Rudolf Steiner claimed to have been, from childhood, able to perceive the supersensible world. As he grew up, he was able to discriminate between those perceptions that he could share with others and those that would draw blank looks. As a student in Vienna, the problems of equating the scientific theories he was being taught, such as the wave theory of light, with his own way of perceiving, became a problem; what he was expected to learn was in direct contradiction to his own perception. Starting from a firm belief that an unprejudiced examination of phenomena would yield the truth and thus solve these contradictions, Steiner began a detailed study of light and colour. Professor Karl Julius Schröer, who had already shared his enthusiasm for Goethe's poetry with Steiner, was able to see that the ideas this student was developing were close to those in Goethe's Theory of Colours, so he drew Steiner's attention to this text.

Thus began Steiner's lifelong interest and interpretation of Goethe's scientific work, which led to him being asked to edit Goethe's scientific writings for the Deutsche National-Literatur (Steiner, 1978). At that time, Steiner was also reading Schiller and drawing from him the idea of different stages of consciousness. Together, these ideas suggested to Steiner that the 'impassable limits' of science were only impassable in an ordinary state of consciousness. If other states could be actively schooled and used with the same rigour, as he believed to be foundational to science, then a science of nature that included the supersensible could be developed. For Steiner, Goethe was someone who showed how it would be possible to perceive something of this supersensible realm, not from natural clairvoyance, but by developing one's own faculties to understand the nature of physical phenomena. This would mean that the way was open for others to share in his way of seeing, and indeed by working through Goethe's method, Steiner was able to ground his own supersensible perceptions as part of his development.

It is, of course, valid to ask if Goethe saw glimpses of the same world. Some historians, such as Karl Fink, see in Steiner's work on Goethe a one-sided or overemphasised view which does not equate with the bulk of Goethe's scientific work (Fink, 1991). Steiner's work certainly developed Goethe's scientific insights, yet there were already features such as a living richness and a clear divergence from the mechanistic/reductionistic orthodoxy, plus a new working method. Steiner's interpretative work of the scientific works of Goethe is a key inspiration for contemporary Goethean scientists, such as Craig Holdrege (2013), Jochen Bockemühl (1985) and Arthur Zajonc (1998). Goethe's science, in particular his way of approaching phenomena with the human faculties operating in a disciplined 'objective' way - a form of schooled subjectivity - is emphasised repeatedly in the various fields developed out of Steiner's spiritual science, which he called anthroposophy, including Waldorf education, anthroposophical medicine and, of course, most relevant here, biodynamic agriculture.

Thus, there is a clear lineage between Goethe and biodynamics through the work of Steiner, but a lineage should not be necessary. If Goethe is right that the best method of working is drawn from the phenomena themselves, it should be possible to stumble upon this way of working simply by trying to work with whole plants and one's full human faculties. In this last section, I want to examine just such an example. 


\section{BARBARA MCCLINTOCK'S UNDERSTANDING OF ORGANISMS}

Barbara McClintock's work on maize in the 1940s-1950s, as presented in Evelyn Fox Keller's 1983 biography A Feeling for the Organism, shares many features of a Goethean approach. Both the way she went about her work and her concept of the task of science could be described as Goethean. The key similarity, which she so clearly exemplified, was her aim and her ability to 'get to know' the organism with which she worked. It is this aspect of her approach that I will primarily focus on.

Barbara McClintock's career spans many changes in the field of genetics. When she began her life in science, the maize plant was the preferred plant for looking into the action of genes. The colours of the kernels on a cob of maize display genetic traits very clearly. Thus, a yearly crop of this higher plant was seen as the obvious choice for study in an older style of biological research that still focused on the whole organism. Although the study of genetics then moved on to the examination of simpler organisms, with more rigid theoretical models about the behaviour of genes, McClintock continued to study maize. Her determination to stick to a complex organism and older styles of research (1983: 101) was finally vindicated when her work became widely acknowledged as a 20-year precursor of where genetics had reached by the late 1970s. In 1983, she was awarded the Nobel Prize for her work on gene transposition.

As an examination of the pressures at play in the world of science, McClintock's story is an interesting one. However, here her story is used as an example of someone working with a plant for decades and coming to know it. Fox Keller asks the question 'What enabled McClintock to see further and deeper into the mysteries of genetics than her colleagues?' She answers that question with the following:

Her answer is simple. Over and over again, she tells us one must have the time to look, the patience to "hear what the material has to say to you", the openness to "let it come to you". Above all one must have "a feeling for the organism".

Fox Keller (1983: 198)

McClintock's work involved the microscopic examination of chromosomes, but her trips to the field to gather the cobs to be tested allowed her the opportunity to 'guess' what their later examination would show. She became adept at 'seeing' in the plant what a microscopic examination would later reveal. The kind of seeing she recounts was not fully conscious:

It is done with complete confidence, complete understanding. I understood every plant. Without being able to know what it was I was integrating, I understood the phenotype.

Fox Keller (1983: 103)

It could be suggested that she was, through her engagement with the plant, 'developing new organs of perception'. McClintock's experiences with maize demonstrate the ideal of really engaging with the phenomenon: engaging not just with the end product on the bench, but with the living organism in its context through its whole cycle, many, many times.

Her ability with this one plant could also be seen as a training of her observation powers in general. Once she knew she could trust the intuitive flashes of insight, she could apply her abilities to a new problem. In 1944, she helped a colleague by working for a time on a mould (Neurospora) with chromosomes so small that they had not been individually identifiable. Once in her stride with this new organism, McClintock was able to work with it, and her account, reported by Fox Keller is revealing in terms of living into the organism. She said:

I found the more I worked with them the bigger and bigger [they] got, and when I was really working with them I wasn't outside I was down there. I was part of the system. I was right down there with them, and everything got big. I even was able to see the internal parts of the chromosomes-actually everything was there. It surprised me because I actually felt as if I were right down there and these were my friends. 
Once connected to the new organism in this way, she could recognise and follow the development of chromosomes through the meiotic cycle.

However, McClintock's credentials as a scientist, whilst eventually vindicated by her results being corroborated by others, were sometimes doubted. She was working against the flow of developments in genetics and was seen as personally eccentric. If we examine her outlook on science in general, it is possible to find other resonances with Goethe's approach. I shall briefly outline five points that demonstrate a concurrence in their approaches to science which could explain why McClintock's 'feeling for the organism' sounds 'Goethean'. These are as follows:

1. The Recognition of Models as Models: McClintock was resistant to what she saw as the dogmas in genetics. Examples of these would be the following: the integrity of genes; the usefulness of bacteriophage because it is simple and one can apply the laws revealed to complex organisms; and the inability of the environment to affect the genome. She had a deep mistrust of theoretical models when they are used as more than, as Goethe would say, the temporary scaffolding. As Fox Keller explains:

For McClintock it was what she calls "tacit assumptions"-an explicit adherence to models that prevents people from looking at data with a fresh mind. These tacit assumptions impose unconscious boundaries between what is thinkable and what is not. Even glaring lapses in logic become invisible: “They didn't know they were bound to a model and you couldn't show them".

Fox Keller (1983: 178)

2. An Openness of Approach: Not only was McClintock open to the organism as a part of her practice, but she also advocated a more open approach to other ideas as necessary for science. This is particularly clear from her criticism of her colleagues' dismissal of a presentation on extrasensory perception. She said, 'If they were as ignorant of the subject as I was, they had no reason to complain' (1983: 202).

3. Dealing with Whole Organisms: The holism of her approach can be seen in the way she professed to a strong sense of the oneness of all nature. On a practical level in her work with the whole cycle of the plant, the sense of engagement with a continuous process comes through. She felt that it was an important aspect of science that one had the wider picture. 'Basically everything is one. There is no way in which you draw a line between things. What we [normally] do is to make these subdivisions, but they're not real' (1983: 204).

4. Using an Emotional Engagement with Phenomena: Part of the openness to the organism which she cultivated was dependent on an emotional engagement with the object of study, but also a distancing of self. The exacting rigour of her work seems to come from a respect for the organism studied rather than an idealised distancing of the 'less objective' aspects of the scientist. Of the creative points in her life, the intuitive flashes, she says that they come about with an emotional intensity and a losing of one's self. It is as if, as she says, 'I am not there'. An account of the experience which Fox Keller cites is as follows:

Beneath these trees she found a bench where she could sit and think. She sat for half an hour. "Suddenly I jumped up, I couldn't wait to get back to the laboratory. I knew I was going to solve it"... She doesn't quite know what she did as she sat under those trees. She remembers she "let the tears roll a little", but mainly, "I must have done this very intense subconscious thinking. And suddenly I knew everything was going to be just fine".

Fox Keller (1983: 115)

5. Putting Process into Observations of a Static System: Her understanding of the maize plant was aided by her approach to it as a whole, developing, growing organism. Seeing 
things in process rather than as static results perhaps contributed to her ability to see genetic processes as dynamic, as life in the process of living, rather than as mechanism. Fox Keller provides an account of her watching the meiotic cycle of the Neurospora.

\section{Her description of what she had seen 35 years earlier still today holds a vivid narrative quality. It is easy to forget that she had to reconstruct the process from separate slides, that she did not see it unfolding in 'live action' (1983: 115).}

These five interlocking points demonstrate the extent to which McClintock's approach to science and the way she explores phenomena share something of the Goethean approach without, as far as is known, any direct lineage. She was simply trying to understand the organism and not following trends in science that, to her, seemed to be getting in the way.

\section{CONCLUSION}

We have seen from the preceding sections that Goethe was able to bring together careful observation of the sense-perceptible aspects of a phenomenon with the supersensible aspects as revealed by a schooled use of the imaginative and intuitive faculties that are themselves informed by the sense-perceptible phenomenon. Historically speaking, this is important as it avoided the errors of two conflicting approaches that were informing the science of his time: vitalism and the mechanistic approach. For Goethe, vitalism gives away the self-generative power of organisms and of nature herself to a vague mystical idea of some free-floating force and is thus a kind of obfuscating mystery mongering, whereas the mechanistic approach ignores the complexity of the intertwined relationships in nature and denies the generative power of organisms in their full majesty. Science, as it developed from the eighteenth and into the nineteenth centuries, rejected vitalism and embraced mechanism with gusto. This ignored the possibility that other options were available.

To address the problems we face in the twenty-first century, we need a way of working with nature, one that does not destroy it or replace it with some limited imaginings. The approach of Goethe and of those who continued developing his insights and carrying out his suggested method of working could have much to offer. In a later chapter, I set out what that method is and how one might examine a phenomenon to develop 'new organs of perception' such that we could have 'delicate empiricism' as a practical approach to researching a more holistic variant of agroecology.

\section{REFERENCES}

Amrine, F., Zucker, F., and Wheeler, H. (eds) (1987) Goethe and the Sciences: A Reappraisal. Dordrecht: D. Reidel Publishing Co.

Arber, A. (1950) The Natural Philosophy of Plant Form. Cambridge: Cambridge University Press.

Arber, A. (1954) The Eye and the Mind. Cambridge: Cambridge University Press.

Bockemühl, J. (ed) (1985) Towards a Phenomenology of the Etheric World. New York: Anthroposophic Press Inc.

Fink, K. (1991) Goethe's History of Science. Cambridge: Cambridge University Press.

Fox Keller, E. (1983) A Feeling for the Organism. New York: Freeman and Company.

Gray, R. (1952) Goethe the Alchemist: A Study of Alchemical Symbolism in Goethe's Literary and Scientific Works. Cambridge: Cambridge University Press.

Heinemann, F. (1934). Goethe's phenomenological method. Philosophy, 9(33): 67-81.

Holdrege, C. (2013) Thinking Like a Plant: A Living Science for Life. Great Barrington, MA: Lindisfarne Books.

Jensen, A. (2019) Johann Wolfgang von Goethe. Internet Encyclopaedia of Philosophy, https://www.iep.utm. edu/goethe/\#H4 (accessed August 19th 2019).

Nisbet, H.B. (1972) Goethe and the Scientific Tradition. London: Institute of Germanic Studies.

Seamon, D. and Zajonc, A. (1998) Goethe's Way of Science: A Phenomenology of Nature. New York: SUNY Press. 
Steiner, R. (1978) A Theory of Knowledge: Implicit in Goethe's World Conception. Trans. Wannamaker, O. New York: The Anthroposophic Press.

Steiner, R. (1985) Goethe's World View. Trans. Linderman, W. New York: Mercury Press.

Stephenson, R.H. (1995) Goethe's Conception of Knowledge and Science. Edinburgh: Edinburgh University Press.

Tantillo, A. (2002) The Will to Create: Goethe's Philosophy of Nature. Pittsburgh, PA: University of Pittsburgh Press.

von Goethe, J.W. (1989) Goethe: Italian Journey. Eds Saine, T. and Sammons, J. trans. Heitner, R.R. New York: Suhrkamp Publishers.

von Goethe, J.W. (1995) Goethe: Scientific Studies. Ed. and trans. Miller, D. New York: Suhrkamp Publishers. 


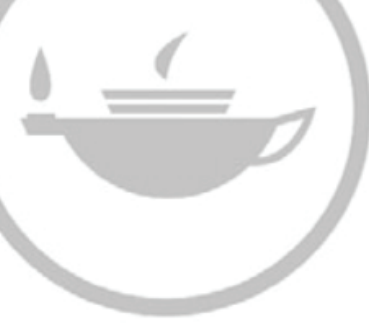

Taylor \& Francis Taylor \& Francis Group http://taylorandfrancis.com 


\title{
7 From Quantum Biology Towards Quantum Consciousness
}

\author{
Jack Tuszyński \\ University of Alberta \\ Politecnico di Torino
}

\section{CONTENTS}

Introduction

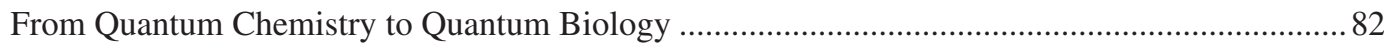

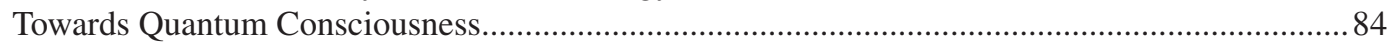

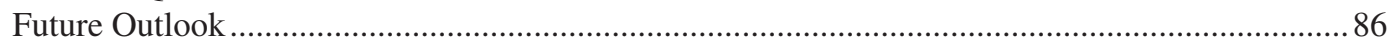

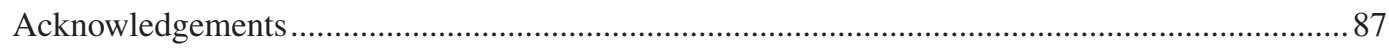

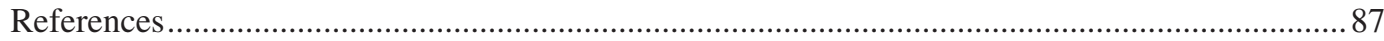

\section{INTRODUCTION}

Today, perhaps the most dynamically expanding branches of science are genetics and molecular and cellular biology, which are amassing impressive reams of data well ahead of scientists' capacity to fully analyse it all. Computational biology is emerging gradually as a response to the challenge of big data analytics. Quantum biology, on the other hand, is positioning itself to explain not so much the huge amounts of data but, like physics a century ago, a limited number of important, yet poorly understood phenomena such as photosynthesis, bioenergetics, vision, olfaction and bird navigation. Yet, the grandest challenge of all is to explain how the human brain works and, in particular, how conscious behaviour emerges from the structure and function of the human brain and its cellular and sub-cellular components. In this chapter, I revisit some historical issues in the development of quantum physics and then look at the emergence of quantum biology and finally quantum consciousness, aiming to provide new insights into these topics from both a physical and a historical perspective.

The birth of modern physics can be traced back to the reluctant introduction of what turned out to be a fundamental constant of nature, the so-called Planck constant, i.e. $h=6.6 \times 10^{-34} \mathrm{Js}$. Its introduction in an energy quantisation formula was the only solution to the problem of the heat emission spectra experimentally determined for physical objects at various temperatures. Max Planck postulated that these spectra originate from a discrete nature of energy levels in physical systems that can be quantised by the general relation:

$$
E_{n}=(n+1 / 2) h f
$$

where $n$ enumerates the energy levels and $f$ is the characteristic frequency of internal oscillations. This led to a revolutionary transformation of physical principles departing from the mechanistic laws of Newtonian physics to provide wave function descriptions of quantum physics that were developed in the decades that followed. In quantum physics, objects possess both a wave aspect and a particle aspect, a view of the physical world known as the principle of wave-particle duality, or 
complementarity. According to the Copenhagen interpretation of quantum mechanics, all the information about a particle or a system of particles can thus be described in a wave-like manner that is denoted mathematically by a wave function, $\phi(x, t)$. However, wave functions behave like waves and can diffract, and interfere together forming superpositions, implying that quantum particles simultaneously exist in multiple spatial locations and states. When a measurement is made, one of the multiple states is chosen and the quantum superposition of states ends being reduced to a classical state in a process known as the collapse of the wave function.

While quantum mechanics was developed with elementary particles in mind, its subsequent applications extended its validity to systems of many particles such as those encountered in condensed matter physics, e.g. in the description of the conduction electron 'sea', excitons, magnons, polarons, polaritons, etc. These types of quantum properties of macroscopic physical systems are called collective excitations. A system of many particles under specific conditions cannot be separated into individual wave functions for each particle; rather, the system is described by a single wave function describing its collective behaviour. This physical property is called quantum coherence, and it is characterised by individual particles losing their separate identities so that the entire system acts as a whole. Particles that were once unified in a common quantum state remain physically connected even at a distance. As a consequence of the collective behaviour of many-body systems, hallmarks of quantum mechanics can be seen in the properties of macroscopic objects such as crystals or ferromagnets, even above room temperature. There are also more exotic direct manifestations of quantum behaviour in macroscopic systems such as superconductors (with no measurable resistance to electrical current and ideal diamagnetism) or superfluids (with no viscosity and infinite vorticity). However, these latter two examples have so far been limited to very low temperatures. The precise location of the boundary (in terms of both the object's size and ambient temperature) between quantum and classical regimes is still under debate.

\section{FROM QUANTUM CHEMISTRY TO QUANTUM BIOLOGY}

Extensions of quantum mechanics to chemical compounds and chemical reactions proved to be exceedingly successful, and an entire field of quantum chemistry was developed as a consequence. In order to understand the creation of chemical bonds, especially covalent bonds in which electrons are shared between atoms of a molecule, a quantum mechanical wave function was introduced into the formalism as one of the postulates of quantum mechanics. All chemistry, including biochemistry, is based on the creation and destruction of bonds between atoms and hence on quantum interactions. Hence, by extension the structural stability of all living systems, like non-living systems, depends on quantum states at the level of chemical bonds. However, the quantum effects are commonly claimed to be washed out due to decoherence taking place at scales larger than individual atoms or sub-atomic particles, at higher temperatures and in aqueous media, which provide a noisy environment for particle interactions. Thus, the likelihood of quantum states playing functional roles at macroscopic scales in 'warm, wet and noisy' biological systems seems problematic due to environmental decoherence effects. On the other hand, it is reasonable to expect that evolution, through the process of natural selection over billions of years of experimentation and countless parallel attempts of trial and error, may have solved the decoherence problem so that quantum states may be essential features of biological systems (Rosa and Faber, 2004).

Erwin Schrödinger, Niels Bohr, Werner Heisenberg, Eugene Wigner and their contemporaries all offered speculations about quantum effects in living systems, while Schrödinger's famous book What Is Life? (Schrödinger, 1944) actually paved the way for the birth of molecular biology in the 1950 s. What is still very much a mystery, however, is the perfect synchronisation of biological processes across spatial and temporal dimensions that connect the hierarchical organisational scales of a living system. Here, quantum mechanics may indeed come to the rescue, if only we could explain the required absence of decoherence. 
Unfortunately, biological systems are so large and complex compared to standard physical systems that it is hard to separate 'pure' quantum effects from a large number of essentially classical processes that are also present. Thus, there is plenty of scope for disagreement about the extent to which life utilises non-trivial quantum processes. Given that the basic processes of biology take place at a molecular level, employing quantum effects for greater efficiency does not seem a priori implausible. Quantum coherence, collective modes of excitation and condensation phenomena, also offers attractive features that could shed light on the mechanisms of robustness and integrity of biological organisms. However, it is reasonable to expect that some of life's processes have evolved to the 'quantum edge', where a compromise may be struck between speed and accuracy. Since both physics and chemistry crucially depend on the power of quantum mechanics to provide fundamental insights into the world around us, it is natural to inquire whether biology offers examples of phenomena where quantum mechanics is the only viable explanation. This is indeed becoming increasingly clear, although examples of quantum effects in biology can so far be considered only a minor part of life processes as we know them.

G. Albrecht-Buehler (1992) found by clever experimentation that living cells perceive infrared electromagnetic waves with the peak of their sensitivity close to the wavelength of $1,000 \mathrm{~nm}$. He hypothesised that mitochondria, by proton transfer involved in energy production, release photons. Conversely, centrioles, dubbed by him the eye of the cell, are intricately structured to absorb these photons and trigger a signalling cascade. G. Albrecht-Buehler has been advocating a theory of cell functioning based on his conviction that the centriole plays the key role in orchestrating cellular activities by being both an eye and a brain of the cell. Cell movement is not random but directed and intentional. This is a crucial characteristic that distinguishes living from non-living matter. Cells control the movement of every part of their body. Furthermore, various parts of the cell can be likened to parts of the human body in their functional roles. Plasma membrane and cortex correspond to the skin and the musculature of a cell, which consists of small autonomously moving 'microplasts'. Their autonomy implies that cells contain a control system preventing the autonomous units from moving independently and randomly. The bulk cytoplasm including the mitochondria, organelles and intermediate filaments comprises the actual cell body excluding the nucleus, and corresponding to the 'guts' and 'innards' of the cell body. Its main cytoskeletal components are the intermediate filaments although microtubules (MTs) traverse this compartment everywhere. MTs mediate between the control centre (the centriole) and the autonomous domains. The control centre detects objects and other cells by pulsating near-infrared signals. Cells have structures functioning essentially as their 'eyes' in the form of centrioles. They are able to detect infrared signals and steer the cell movements towards their source. Evidence has been put forward that the signal detection is strongly localised in a narrow band of the near-infrared spectrum. If cells can detect light sources and measure space and time variables such as angles, distances, curvatures or durations, they must be able to derive these abstract quantities from the physical objects or signals of their environment. In response to exogenous signals, the centrosome may send destabilising signals along its radial array of MTs. The observed destabilisation is the signal that is propagated along the MTs like along nerves.

Engel et al.'s 2007 study of photosynthesis was a game-changer in the emerging field of quantum biology. Photosynthesis is a highly complicated and sophisticated mechanism that harvests light energy to split water by using individual photons to create a cascade of reactions. The process is extraordinarily efficient and represents a classic example of how evolution has fine-tuned the design of a physical system to attain near-optimal performance. The primary receptor of the light energy is a complex of pigment molecules known as chromophores that can become excited, and pass on the energy of excitation in a multi-stage process to the final reaction centre where charge separation occurs. Because the wavelength of the photon is much larger than the molecular assemblage, a superposition state of many excited pigment molecules is initially created and proceeds to evolve over a timescale of some hundreds of femtoseconds. Fleming and his group (Engel et al., 2007) used laser excitation and probe pulses to study the relaxation pathways of these light-harvesting 
complexes and observed a 'quantum beating' effect in which the maximum amplitude of the excitation visits and revisits different molecules in the system coherently. Fleming claims that, with appropriate timing, the system can 'grab' the coherent excitation (which persists for a few $100 \mathrm{fs}$ ) with greater probability than if it was merely distributed according to classical statistical mechanics. He believes this could lead to a multiplying of the speed of the energy transfer. An important feature of photosynthesis is that the molecular architecture involved is structured in a highly unusual and compact manner, suggesting it has been 'customised' to exploit long-range quantum effects (Blankenship and Engel, 2010). It could be that the particular configuration is efficient at preserving coherence for surprisingly long durations, enabling the system to 'explore' many pathways simultaneously and thus speed up a 'solution' (i.e. delivering energy to the reaction centre). In the light-sensitive complexes, reaction centres capture individual photons and transfer exciton energy by tunnelling avoiding decoherence even at room temperatures, which has been invoked on numerous occasions as a serious impediment to quantum biology (Tegmark, 2000) but also defended on various grounds (Hagan et al., 2002).

Beck and Eccles (1992) argued that the process of neurotransmitter release in the functioning of synapses is governed by the quantum uncertainty principle and involves quantum tunnelling. They further suggest that the introduction of quantum indeterminacy into neurotransmitter release mechanisms would allow for human free will of action. Their notion is that a quantum process, such as an electron tunnelling through an energy barrier, triggers exocytosis. The sheer size of the vesicle and the large number of neurotransmitter molecules contained in it make it next to impossible to lend itself to quantum tunnelling processes. Although the Beck-Eccles model contains very attractive ideas, the crux of the theory is incompatible with the present-day molecular biology of vesicular neurotransmitter release (Smith, 2009). Lowenstein (2000) made a powerful argument for the usefulness of quantum processes in receptor functions involving molecular recognition. All sensory inputs depend on this type of activity (olfaction, vision, sound, touch), and they all involve single molecules being triggers for amplification of these signals up to the neuron level and eventual brain activation. This amplification mechanism of the quantum signalling connects the microscopic and macroscopic levels which is critical to our understanding of the binding problem.

At the level of organs and tissues, it has been demonstrated that the human eye is capable of detecting light at an extremely low threshold, perhaps as few as two to three photons at a time (Hecht et al., 1942). Similarly, recent work by L. Turin, M. Stoneham and collaborators (Brookes et al., 2007) has provided strong support to the claim that the sense of smell (olfaction) is based on a quantum resonant energy transfer mechanism involving vibrational degrees of freedom of aromatic molecules and receptors in the membranes of olfactory nerves.

Special attention must be paid to the structural hierarchical organisation of biological systems, which in turn translates into an interlocking hierarchy of timescales. Faster timescales may inform processes at slower timescales about rapid processes taking place at a small spatial level. Amazingly, neural rhythms operate on timescales that vary from milliseconds to seconds, synchronise the forebrain and are mediated by neurotransmitter systems such as acetylcholine, norepinephrine and serotonin (Woolf et al., 2010). The neurotransmitter systems further fluctuate according to endogenous, circadian rhythms that also fluctuate according to the season of the year, which ultimately leads to an enormous range of timescales spanning between eight and ten orders of magnitude. Since neural events at the millisecond timescale can affect neural states at the circadian level, by extension it is entirely possible that quantum states at the picosecond scale could affect neural activity at the millisecond scale and above. Coupling between scales and amplification effects may offer a solution to some of these issues.

\section{TOWARDS QUANTUM CONSCIOUSNESS}

Does study of consciousness belong in the realm of natural sciences or is it a philosophical or even metaphysical area of inquiry? These questions have been pondered by many scientists, philosophers and spiritual leaders whose opinions diverge largely due to the subjective nature of consciousness. 
Obviously, the existence of this phenomenon cannot be denied as we all experience it as sentient humans. The author of this chapter firmly subscribes to the point of view that not only is consciousness a valid topic for scientific research but, in fact, it is also one of the most important unsolved scientific problems of our time. The problem of consciousness has defied conventional approaches, which view the brain as a classical computer, with neurons and synapses playing the roles of bit states. Specifically, the following enigmatic features remain unexplained: (1) the 'hard problem' of the nature of conscious experience, for example addressing the experience of 'qualia', our inner life; (2) the binding of disparate brain processes into unified concepts, objects and sense of self; (3) transition from preconscious processes to consciousness itself; (4) free will, or non-algorithmic (e.g. intuitive) processes; (5) the subjective flow of time; and (6) non-locality, i.e. paranormal connections between humans and also between humans and non-human species across large spatial and temporal domains (e.g. precognition, telepathy). Conventional neuronal-level computational approaches suggest conscious experience 'emerges' at a critical level of computational complexity. Binding is proposed to be accounted for by temporal synchrony (e.g. coherent 40-Hz oscillations) but, with no sense of the nature of conscious experience, temporal synchrony is merely correlative rather than explanatory. Perhaps the most potentially tractable problem is the transition from preconscious processes to consciousness itself. It is generally agreed upon that the vast majority of brain processes are non-conscious and that consciousness is the tip of an iceberg of brain activity. However, no specific brain area houses consciousness; neural activity in a given area may be non-conscious at one moment and correspond with consciousness at another. The classical approach suggests a critical level of computational complexity results in the transition via the emergence of consciousness, but again no threshold, biological correlate nor testable prediction has been put forth. Free will, subjective time flow and non-locality have not been seriously addressed by conventional approaches. Another shortcoming of conventional approaches is that neurons and synapses are considered as simple switches, whereas real biological cells are far more complex. For example, single-cell organisms such as paramecium swim, avoid obstacles and predators, learn, and find food and mates, all without possessing a single synapse. These cognitive functions can potentially be accomplished by the cell's cytoskeletal structures, primarily MTs.

Perhaps the first attempt to describe the brain using the terminology of quantum physics was made by Ricciardi and Umezawa (1967). Based on experimental observations of brain activity, they proposed that the brain could be conceived of as a spatially distributed system placed into particular quantum states by stimuli from the external environment. Thus, information can be thought of as being coded into the brain in the form of metastable excited states representative of short-term memory. This code would then be later on transferred to the ground state of the system by in the manner of Bose-Einstein condensation, which would account for learning and long-term memory. This model proposes that brain functions are manifestations of spontaneous symmetry breaking in the dynamics of the brain and regulated by long-range correlations. The model put forth by Ricciardi and Umezawa (1967) relating macroscopic quantum states to brain function, specifically memory, was later extended by these authors who proposed that the brain is a mixed physical system. In this model, the brain is considered to consist of two distinct interacting parts, the first part where the classical electrochemical interactions of the neurons of the brain occur, and the second being the macroscopic quantum state responsible for the creation and maintenance of memory.

R. Penrose $(1989,1994)$ hypothesised that quantum effects play a fundamental role in human consciousness by enabling the brain to perform non-computable computations. In his explanation of how the new physics can explain the mind and consciousness, he examined the division between classical and quantum physics, specifically the measurement problem, and related the collapse of the wave function to conscious events using the notion of objective reduction. This led to the suggestion that MTs within neurons provide the brain with structures capable of orchestrating the collapse of the wave function via quantum computations. This combination has become known as the Penrose-Hameroff orchestrated objective reduction (Orch OR) theory (Hameroff, 1998; Hameroff and Penrose, 2014). The basic idea on which Orch OR rests is that MTs within the brain's neurons 
function as quantum computers, with MT protein subunits (tubulins) existing transiently in quantum superposition of two or more conformational states (i.e. as quantum bits, or 'qubits'). The quantum state reductions yield conscious perceptions and volitional choices, which then govern neuronal actions. This is essentially the same idea on which technological quantum computing is based, except that in Orch OR the proposed qubits are tubulin protein conformations, and the reduction/ collapse occurs due to a specific objective threshold (objective reduction) rather than environmental interaction. The theory considers a conscious event as a quantum computation, which concludes via objective state reduction. The biological conditions in the brain, including synaptic activity, are considered to influence the quantum computations, thus orchestrating the collapse of the qubits and giving rise to a conscious event. 'Orch OR' is an attempt to place consciousness within the empirical sciences as a fundamental concept in science. The central postulate of the Orch OR theory is that the site of action of consciousness is located within the brain's MTs which operate at the interface between classical neurophysiology and quantum gravitational forces. These are very bold claims that have found both ardent supporters (Stapp, 1995) and vocal critics (Seife, 2000) in the scientific community.

There have been many debates concerning whether the quantum description of consciousness is valid, realistic or needed. However, only recently have advances in nanotechnology been made, allowing for serious empirical investigation into the biophysical workings of sub-cellular structures. As such, the lack of evidence in support of quantum brain theories should not be taken as proof against these theories, but rather as an area in need of careful and vigorous scientific investigation. The several enigmatic features of consciousness are still, for the most part, left unexplained by classical theories. The apparent ability of quantum theories to answer these questions may provide new avenues of investigation into consciousness. Macroscopic quantum phenomena such as superconductivity, and superfluidity need to be highly isolated from their environment in order to avoid the effects of decoherence. In order for such phenomena to exist in the brain, nature would need to provide mechanisms to isolate against decoherence. Clearly, these issues are not completely resolved. Thus, investigations into the quantum nature of MTs are still badly needed.

Empirically, a host of studies indicate that the MT matrix in dendrites is structurally reorganised with learning and memory. Using an associative learning paradigm combined with immunohistochemistry, fear conditioning either to tone or to the training context induced significant changes in MT-associated protein (MAP2) in circumscribed regions of the cerebral cortex or hippocampus, with alterations correlating with the type of training (Woolf et al., 1994, 1999). In terms of molecular biophysics, based on their ability to propagate signals through the neuron, MTs and actin filaments can be viewed as computationally relevant nanowire networks that operate within neurons (Woolf et al., 2010). Rather than inputs to neurons being limited to causing discrete responses, this viewpoint offers the possibility of local and global neuroplasticity, based on the cytoskeleton computing and storing templates that translate patterns of inputs across widespread synapses into the 'behavioural' output of the neuron. This behavioural output of the neuron is not limited to axonal firing and dendritic integration of electrochemically mediated inputs. Instead, it includes connecting the cell nucleus with the postsynaptic density, initiating transport of receptor molecules, membrane proteins, organelles and mRNA, regulating neurite motility, restructuring of spines and complex dendrite architecture, the lateral movement of receptor and membrane proteins of neurons, and governing the availability of ion channels in the membrane.

\section{FUTURE OUTLOOK}

I foresee major progress in bridging the gap between nanoscience and consciousness in the area of nano-neuroscience where MTs, actin filaments and motor proteins connect between neurophysiology and molecular biology. Studying neural phenomena at a nanoscale could lead to monumental breakthroughs in science and medicine and aid in consciousness studies. Further possibilities involving physically based quantum mechanisms of consciousness should also be considered. The 
basic idea is to investigate if there are other quantum network architectures that could be operating in the brain. First of all, quantum entanglement in such a network could provide at least a partial answer to the binding problem of consciousness allowing for a delocalised quantum state involving many neurons. This requires a thorough understanding of quantum networks. It is worth emphasising that quantum networks may lead to quantum memories, whereby entangled states store information such as visual inputs. Moreover, quantum networks could generate communication channels that would transport information and process it performing complex operations. Quantum computation in the brain (Litt et al., 2006) would surely be beneficial from an evolutionary standpoint, and biology has had 4 billion years to solve the decoherence problem.

Recently, an interesting proposal was put forward suggesting direct involvement of nuclear spin in long-lived quantum states attributed to consciousness in the human brain (Fisher, 2017). However, several challenging issues remain to be addressed. First of all, due to thermal fluctuations, a magnetic field of sufficient strength would be required to prepare the spin system in a pure enough state. On the other hand, there are no naturally occurring large magnetic fields and we also know that strong magnetic fields such as in magnetic resonance imaging (MRI) machines do not have a significant effect on the state of consciousness of the person subjected to MRI scans. Regarding quantum communication channels, photon emission and absorption is the best candidate mechanism for such phenomena. Biophotonics is an emerging field in spite of its long history of false starts and intermittent periods of dormancy. A recent review (Cifra and Pospíšil, 2014) summarises the landscape in this field, emphasising a relatively narrow range of wavelengths playing a role in biophotonics, namely between 350 and $1,300 \mathrm{~nm}$. The generation of photons inside living cells is mainly related to recombination of reactive oxygen species. It is also interesting to consider signal amplification and transmission over macroscopic distances along axons and dendrites of neurons. The tenuous connection between quantum biology, consciousness and electromagnetic fields, if properly supported by precise experimental investigations, could become a nexus for rigorous explorations of how our brain operates beyond the confines of conventional neuroscience.

Understanding the biological basis for sustained quantum coherent superposition and entanglement would not only help solve the enigmatic features of consciousness, but also enable future quantum information technologies.

\section{ACKNOWLEDGEMENTS}

The author acknowledges funding support for his research from NSERC (Canada).

\section{REFERENCES}

Albrecht-Buehler, G. (1992) Rudimentary form of cellular "vision". Proc. Natl. Acad. Sci. U. S. A. 89: 8288-8292.

Beck, F. and Eccles, J.C. (1992) Quantum aspects of brain activity and the role of consciousness. Proc. Natl. Acad. Sci. U. S. A. 89: 11357-11361.

Blankenship, G.R. and Engel, G.S. (2010) Long-lived quantum coherence in photosynthetic complexes at physiological temperature. Proc. Natl. Acad. Sci. U. S. A. 107(29): 12766-12770.

Brookes, J.C., Hartoutsiou, F., Horsfield, A.P., Turin, L., and Stoneham, A.M. (2007) Could humans recognize odor by phonon assisted tunneling? Phys. Rev. Lett. 98(3): 038101.

Cifra, M. and Pospíšil, P. (2014) Ultra-weak photon emission from biological samples: Definition, mechanisms, properties, detection and applications. J. Photochem. Photobiol. B Biol. 139: 2-10.

Engel, G.S., Calhoun, T.R., Read, E.L., Ahn, T.K., Mancal, T., Cheng, Y.C., Blankenship, R.E. and Fleming, G.R. (2007) Evidence for wavelike energy transfer through quantum coherence in photosynthetic systems. Nature 446(7137): 782-786.

Fisher, M.P. (2017) Are we quantum computers, or merely clever robots. Int. J. Mod. Phys. B 31(07): 1743001. Hagan, S., Hameroff, S.R., and Tuszynski, J.A. (2002) Quantum computation in brain microtubules: Decoherence and biological feasibility. Phys. Rev. E 65(61901): 1-10. 
Hameroff, S. (1998) Quantum computation in brain microtubules? The Penrose-Hameroff 'Orch OR' model of consciousness [and discussion]. Phil. Trans. R. Soc. London A 356(1743): 1869-1896.

Hameroff, S. and Penrose, R. (2014) Consciousness in the Universe: A review of the "Orch OR" theory. Phys. Life Rev. 11(1): 39-78.

Hecht, S., Shlaer, S., and Pirenne, M.H. (1942) Energy, quanta, and vision. J. Gen. Physiol. 25: 819-840.

Litt, A., Eliasmith, C., Kroon, F.W., Weinstein, S., and Thagard, P. (2006) Is the brain a quantum computer? Cognit. Sci. 30: 593-603.

Lowenstein, W. (2000) Touchstone of Life. Oxford: Oxford University Press.

Penrose, R. (1989) The Emperor's New Mind. Oxford, New York and Melbourne: Oxford University Press.

Penrose, R. (1994) Shadows of the Mind. Oxford, New York and Melbourne: Oxford University Press.

Ricciardi, L.M. and Umezawa, H. (1967) Brain and physics of many-body problems. Kybernetik 4(2): 44-48.

Rosa, L.P. and Faber, J. (2004) Quantum models of the mind: Are they compatible with environment decoherence? Phys. Rev. E. 70: 031902.

Schrödinger, E. (1944) What Is Life? Cambridge: Cambridge University Press.

Seife, C. (2000) Cold numbers unmake the quantum mind. Science 287(5454): 791.

Smith, C.U. (2009) The 'hard problem' and the quantum physicists. Part 2: Modern times. Brain Cogn. 71: 54-63.

Stapp, H. (1995) Why classical mechanics cannot naturally accommodate consciousness but quantum mechanics can. Psyche 2(5): 1-23.

Tegmark, M. (2000) Importance of quantum coherence in brain processes. Phys. Rev. E 61, 4194-4206.

Woolf, N.J., Young, S.L., Johnson, G.V., and Fanselow, M.S. (1994) Pavlovian conditioning alters cortical microtubule-associated protein-2. Neuroreport 9: 1045-1048.

Woolf, N.J., Zinnerman, M.D., and Johnson, G.V. (1999) Hippocampal microtubule-associated protein-2 alterations with contextual memory. Brain Res. 6: 241-249.

Woolf, N.J., Priel, A., and Tuszynski, J.A. (2010) Nanoneuroscience: Structural and Functional Roles of the Neuronal Cytoskeleton in Health and Disease. Heidelberg: Springer Verlag. 


\title{
8 Healing Our Relationship with Gaia through a New Thrivability Paradigm
}

\author{
Anneloes Smitsman \\ EARTHwise Centre \\ Jude Currivan \\ WholeWorld-View
}

\section{CONTENTS}

Introduction.

The Cost of Conventional Progress.

Comparing Indigenous and Mechanistic Worldviews ................................................................ 91

What We Can Learn from the Infodynamics of Healthy Living Systems ...................................92

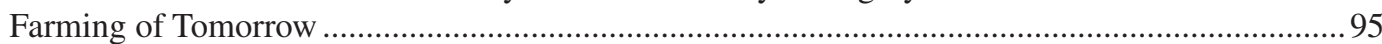

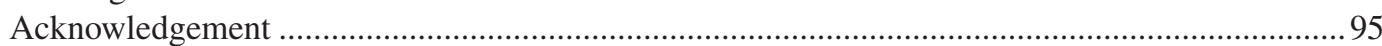

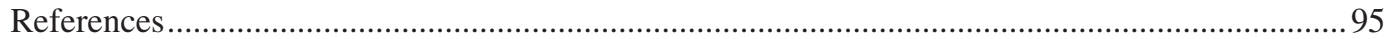

\section{INTRODUCTION}

Our worsening climate crisis, biodiversity loss and increasing societal challenges are all clear indicators that it is time for us to wise up and grow up. It is essential that we become conscious that the growth models that we have adopted for, and which shape, our developmental trajectories are not only unsustainable, but also imminently catastrophic. The resounding calls for a new paradigm with new norms are accelerating in strength around the world, even more so in the light of our current at the time of writing - coronavirus crisis. However, underlying each paradigm is a growth model, and unless this model is also transformed, the shift in paradigms will be limited and not generate new patterns for our collective thrivability.

The pursuit of growth in the economic domains has typically taken place via policies that only measure the quantitative aspects of growth, leading to extractive and unsustainable practices. In response, calls for degrowth are becoming more widely heard from sustainability movements. What is often missing in the discussion, however, is a deeper evaluation of what we mean by growth. Our usage of the word growth goes beyond the narrow conventional meaning that indicates an increase in size or quantity. We propose to emphasise the qualitative aspects of growth that are also developmental, as can be seen in the growth dynamics of living systems. Such growth often results in asymmetry, owing to structural changes between the variables that result from the new growth, which can temporarily perturb the balance of the system. Living systems are responsive, and it is precisely this shift in systemic balance due to growth changes that activates its learning and development. Living systems respond to emerging asymmetries through the formation of new organisational dynamics that enable the system to regulate and adjust to the changes. The formation of new balancing loops and informational flows is a process of systemic learning and development. 
Development over larger scales and longer time horizons can thus become an evolutionary growth process (Smitsman and Smitsman, 2020).

Our mainstream growth models have a tendency to focus only on the quantitative dimensions of growth, based on a mechanistic and dualistic worldview of the reality of life and the process of evolution. Instead of seeing life as a unified, interdependent and interconnected reality, life is perceived in a dualistic manner in which the external and internal are regarded as separate realities, and where the world is seen in terms of random events of separate particles. This mechanistic worldview also has a tendency to create extractive degenerative growth dynamics and constantly polarised, winlose divisions, which have brought not only us but also millions of other species, and even possibly the entire biosphere of Gaia, to the brink of extinction.

Over the last 50years, we have reduced biodiversity by half (IPCC, 2018; WWF, 2018). The anthropogenic damage to our planetary ecosystems, biodiversity resilience and climate systems extensively evidences that we are triggering the sixth mass extinction event in our planet's history (Meyer, 2019). The recent renaming of our age from the Holocene to the Anthropocene (Zalasiewicz et al., 2016), due to the irreversible human impacts on the geosphere and biosphere of our planet, indicates the urgency for seriously examining how to change our societal models (Bauer and Ellis, 2018).

In order to transform our growth and development models, and our mechanistic, separatist systems, we first need to become aware of and address our dualistic relationship with food and the ecology of life (Haukeland, 2013; Smitsman et al., 2019). The concept of sustainable development was initially adopted to address the impacts of these mechanistic systems, with the Brundtland Commission of 1987 coining the term and defining sustainable development as development that meets the needs of the present without compromising the ability of future generations to meet their own needs (Brundtland et al., 1987: 1). Through the years that followed, the concept of sustainable development expanded to include the safeguarding of the Earth's life-support systems on which the welfare of current and future generations depends (Griggs et al., 2013). Whilst this focus on safeguarding is important, it does not invite people to participate in a transformational change process that invokes their own evolutionary development.

We therefore offer the concept of thrivability, or our ability to thrive, as the transformational change process that invites people into a generative and evolutionary model that is both life-centred and future-oriented. To better understand what we mean by thrivability, we offer the following definition by Anneloes Smitsman, based on her $\mathrm{PhD}$ research on this topic:

Thrivability is the Life-intrinsic developmental potential for our self actualizing evolutionary growth. Thrivability as a developmental potential unfolds through an ecosystemic evolutionary learning process. Through this process we develop the future creative capabilities, awareness, and love to enact and embody the actualization of the thrivability potentials within the worlds and systems of which we form part. Embodied, these potentialities become possibilities for further growth and development in a way that is Life generative and creates conditions for each of us, and Life as a whole, to thrive.

Anneloes Smitsman (2019: 37)

A thrivability growth model, as will be explained further in greater detail, seeks to safeguard and strengthen the vital conditions of life that should never be sacrificed in the pursuit of food and resource development. With a broader focus, thrivability also invites us to explore the conditions and qualities of food cultivation systems and consumption patterns that honour and support our reciprocity, mutuality and inter-being with Gaia and the larger ecology of life.

\section{THE COST OF CONVENTIONAL PROGRESS}

When considered from an ecological whole-system perspective, the question 'what are progress and success?' provides a very different focus and narrative compared to how it continues to be defined by our mainstream economic, political and educational systems (Brewer and Smitsman, 
2018; Smitsman, 2019; Wahl, 2016). When we look at living systems, the feedback and feedforward informational loops support the overall thrivability of the whole system in a way that is both collaborative and actualising of consciousness; i.e., it is evolutionary coherent and developmental (Capra and Luisi, 2014; Laszlo and Laszlo, 2016). This is in stark contrast to many of our current societal systems where their progress, development and success come at a huge cost to its members and the environments from which it draws its resources (Scharmer and Kaufer, 2013; Korten, 2015). This cost is still not accounted for, even though international frameworks such as the Global Reporting Initiative (GRI) and Integrated Reporting (IR) are making it possible to broaden the capitalist model and report not only on the financial impacts of businesses but also their impacts on the environment and society (Hutchins, 2019).

Underlying these mechanistic systems that create more deficiencies than prosperity is a growth model that is completely out of sync with life. Unfortunately, many of our modern food cultivation methods are part of this vicious cycle (Haukeland, 2013). Research on modern farming practices is increasingly being linked to the progressive incidence and prevalence of systemic and autoimmune diseases of people and animals, as well as to contamination and degradation of the land (Sandifer et al., 2015). The current coronavirus crisis emphasises this even further, calling for a drastic review of food cultivation approaches as well as our livestock practices (see Van der Poel, 2020). To better understand why this growth model has turned so destructive, we will first explore its underlying worldviews and developmental processes.

\section{COMPARING INDIGENOUS AND MECHANISTIC WORLDVIEWS}

To better understand the development of mechanistic worldviews and practices, we offer some key reflections from other worldviews that are founded on a unity view of life and our relationship within the natural world. Such worldviews can still be found in the cosmologies and practices of many indigenous communities (Jacobs, 2016; Lane, 2019a; Randall, 2007; Smitsman et al., 2019), where reciprocity and co-dependency are regarded as guiding principles and which take great care to safeguard and honour these reciprocal relationships with the natural systems from which food resources are extracted (Lane, 2019b; Sanchez, 2017).

What we can learn from such indigenous worldviews is the evolutionary perspective of life (Lane et al., 2019). The health and thrivability of our ecosystems depend on the fine-tuning and intricate regulation of complex interdependencies that are nested holarchically - as holons within larger holons (Sahtouris, 2000). The term holarchy was coined by philosopher Arthur Koestler to describe how each whole thing within nature is a holon, a whole made of its own parts, yet itself part of a larger whole (Koestler, 1967). Holarchy also describes behaviour that is partly a function of individual nature and partly a function of the nature of the embedding system (Smitsman, 2019), and contrasts with growth models that developed from mechanistic dualistic worldviews which have hierarchical modes of organisation.

Such mechanistic growth models originate from societal changes that started about 5,000 years ago, when warlike kingdoms or empires started to develop (see Sahtouris, 2000). This period is characterised by aggressive policies for domination and control, driven by zero-sum game, winlose, competitive dynamics. Empire dynamics still dominate today through geopolitical shifts to the empire of corporations (see Sahtouris and Smitsman, 2019).

The modern dominant conception of progress and development originates from the empire dynamics and its mechanistic worldviews (Smitsman et al., 2019). Restoring a wholeworld-view ${ }^{1}$ is crucial to see the full picture and take responsibility for the impacts of the growth and prosperity models that we employ today for our societal development. No form of progress can be justified if this entails the

\footnotetext{
${ }^{1}$ The term wholeworld-view is used to differentiate its wholistic understanding of the wholeworld from otherwise fragmented worldviews.
} 
widespread destruction of our planet and the future conditions of our collective thrivability. Cosmologist Jude Currivan describes this emerging wholeworld-view in the following way:

While retaining the uniqueness of our personal, microcosmic expressions of consciousness, this wholeworld-view embraces the meso-cosm of our collective human experience and the macrocosm of our entire Universe, existing as a finite expression of the infinity and eternity of cosmic mind. When fully realized, such a view of the world does away with the conflictual interactions of duality perception, empowers mitigation of selfishness, and enhances cooperation and altruism, not only with each other but with all life as well.

Jude Currivan (2017: 229)

Another fundamental quality of many indigenous worldviews is the emphasis on gratitude for life itself. In all environments, whether abundant or scarce of resources, the expression of gratitude for honouring our reciprocity with nature is a cornerstone in many indigenous communities. For example, in the Quechua language of Peru, the word ayni embodies this, offering back to Mother Earth, Pacha Mama, in appreciation of what she offers us with such benevolence. The Q'ero shamans in Peru, whose small communities eluded the Spanish invaders over five centuries ago by escaping to the highest and most challenging reaches of the mountains, continue to live by principles of gratitude and honouring reciprocity.

This focus on gratitude and reciprocity can also be found in the indigenous landscapes of the United Kingdom. For example, excavations at Avebury in England, which has been standing as a monument for over 6,000 years, revealed an ancient offering. This offering, $2 \mathrm{ft}$ deep into the chalk bedrock from which flints were extracted, consisted of carefully placed, knapped flint implements and animal bones over 5,000 years old. This suggested to the archaeologists who found it that whoever had extracted the flint had made the offering in gratitude for its valued provision (Currivan, 2004).

Many indigenous traditions, both ancient and contemporary, have a wholistic worldview which accepts and honours the existence of multidimensional realms. From the beings known as huldufolk to Icelanders, to the kami of Japan, the apukuna mountain spirits of South America and the other and many names of elemental, devic and angelic entities around the world, such encounters are as old as humanity itself. Contemporary conscious communities such as the Findhorn Foundation in Scotland, founded in 1962, also commune with such realms as natural, everyday, realities. In many indigenous traditions, the honouring of these spirits and deities is regarded as an integral responsibility of growing and consuming food resources. Such realms appear invisible for those who have not developed their full or extra sensory capacities (Baring, 2015; Laszlo and Currivan, 2008).

The impact of our mechanistic worldviews is also apparent in the loss of a sense of the sacred. Land has become a commodity, rather than a living entity with intrinsic rights. Sacred sites are now tourist attractions, and mechanistic industrial farming practices have replaced indigenous ones around the world, which in the Amazon have damaged the rich black Terra Preta soils (Cornell University, 2019; Gibbons, 2019).

One of the first actions of adopting a thrivability paradigm would be a transformation of our current food industry and industrial farming practices. Such a transformation requires a deep understanding of the informational dynamics of healthy living systems, and how to implement this knowledge into design practices for a thrivability-based developmental trajectory. We will unpack those infodynamics in the following section.

\section{WHAT WE CAN LEARN FROM THE INFODYNAMICS OF HEALTHY LIVING SYSTEMS}

Thrivability sciences emerge as part of a new twenty-first-century paradigm whereby 'things' are in reality interdependent informational dynamics (infodynamics) within an integral living whole (Bateson, 2016; Laszlo and Laszlo, 2016; Smitsman, 2019). In this new paradigm, scientific laws are 
no longer viewed as mechanistic rules regarding the interaction patterns of particles, but rather are redefined and expanded in terms of informational content, coding and processes (Currivan, 2017: 6). This is being revealed at all scales of existence and across many fields of scientific research (Currivan, 2017; Smitsman and Currivan, 2019).

The science of infodynamics has previously been described as the study of the accumulation of informational constraints during system development (see Salthe, 2001). Jude Currivan has taken this study further to reinterpret the first two laws of thermodynamics as laws of infodynamics, for a better understanding how our universe evolves as a holographically informed wholeness, where its three-dimensional appearance is actually a holographic projection from the two-dimensional boundary of space (Currivan, 2017; Smitsman and Currivan, 2019). The science of infodynamics focuses on changes and impacts of meaningful in-formational ${ }^{2}$ patterns and content in living systems. Based on a universal 'alphabet' of the 1s and 0s of digitised information, it reveals how implicit cosmological dimensions underlie our manifest physical world and meaningfully combine these to in-form the forms of complex and living systems. It reveals that our physical world is a semiotically informational world and dissolves the dualistic notion that matter and energy are different. The concept of information is more fundamental than energy-matter and space-time and expresses in complementary ways as emergent phenomena of our universe. The science of infodynamics reveals, therefore, how from non-physical causative realms - the infinity and eternity of cosmic mind in Einstein's terminology - a finite universe is created that exists and evolves as a fundamentally interconnected coherent and unified entity (Currivan, 2019: 3).

The study of infodynamics also helps us to deepen our understanding of life as a generative field of possibilities (Sahtouris, 2000, 2013). By studying the infodynamics of life, we can learn how to apply this to the design of generative human systems that are evolutionary coherent and cosmologically informed. For example, this is currently applied to the world design of new economic and educational systems based on the cosmological principles of living systems (see Smitsman and Thurm, 2020; Smitsman and Houston, 2021). Accordingly, we can develop a generative wholeworld-view for guiding the evolutionary development of our world and future (Smitsman, 2019). When we shift our focus to generativity, and not mere sustainability, we start to design our worlds with the cosmological intelligence of life. Hence, our proposed focus on thrivability, as earlier explained in this chapter, as a generative future-creating process.

The study of infodynamics further opens a new, non-dualistic way of looking at causality. Life is a complex system of various interdependent, holarchically nested feedback and feedforward informational dynamics and flows. These flows reveal how we each are an infodynamic pattern within an evolutionary coherent and informing universe that affords possibilities for self-reflection and self-awareness and so allows us to become conscious of our evolution as the infodynamics for evolution (Smitsman et al., 2018). The study of infodynamics shows us how consciousness can emerge as an intrinsic quality of life and our universe, where consciousness is not something we have, but is what we and the wholeworld are (Currivan, 2017).

This dynamic informational flowing also forms the very conditions for evolutionary learning and development. Evolutionary learning cannot take place without, on the one hand, infodynamic flows that are generated by our activities that are interplaying within the larger whole called life and, on the other hand, the capacity to attune, adjust and respond to these flows (Fogel, 1993, Smitsman, 1997; Smitsman and Smitsman, 2020).

When we now apply this understanding to food cultivation and consumption within the growing field of agroecology, it enables us to deepen our understanding of what is implied by terms such as integrated farming. Words such as integrated and integral imply a multi- and inter-dimensional approach that requires knowledge and understanding of infodynamics. When we grow and consume

\footnotetext{
2 'Inform' and 'information' are sometimes written in this chapter as 'in-form' and 'in-formation' to emphasize how this type of cosmological information plays a key role in the formation and manifestation of our physical world.
} 
food, we also create specific informational patterns, and not all of those patterns are conducive for our thrivability and planetary health.

Owing to their lack of reciprocity with the healthy patterns of planetary ecosystems, food produced through systems that inhabit diseased information patterns also produces informational disease patterns that we in turn consume and propagate (Sahtouris, 2013). This gives a whole new meaning to the saying that you are what you eat. This understanding of health and disease as specific informational patterns is starting to emerge in the field of holistic medicine (Laszlo, 2017).

In order to better understand which infodynamics to apply for healthy and ecological food cultivation, we first need to understand the infodynamics of thrivable living systems. Living systems, compared to mechanistically created human systems, emerge from and generate healthy and regenerative infodynamic patterns due to the direct resonance and in-tunement with the cosmological intelligence of life.

Currivan's book and research demonstrate that when we reinterpret the first two laws of thermodynamics as laws of infodynamics, we start to see how the universe's informational content increases and diversifies as it spatially expands over time. This gives rise to growing complexity and evolutionary coherence (Currivan, 2017). Understanding evolutionary complexity is essential if we are to address complex issues such as runaway climate change, as indicative of systemic barriers that emerge from harmful complexity and degenerative growth patterns (see Smitsman, 2019).

The cosmological insights about the infodynamics of living systems through this chapter transform our understanding of reality itself - and turn the perception of a material, separate and essentially meaningless world on its head. Our beliefs drive our behaviours, and a wholeworld-view has the potential to empower transformational social change, including our behaviour towards our planetary home.

We will now apply some of these key points to evolutionary systems' design, which can also be applied to the design of evolutionary farming systems and practices. Anneloes Smitsman's PhD dissertation summarises the infodynamics of thrivable living systems as falling into five categories (adopted from Smitsman, 2019: 436):

1. Embodied Informational Wholeness That Is Holographically Distributed: Wholeness is a fundamental organisational principle of living systems, which cannot be understood by merely studying the parts of systems (Capra and Luisi, 2014). Thrivable living systems embody the systemic informational wholeness of life in their in-formation, organisation and behaviour. Informational wholeness in living systems gives rise to diversification (variability) that remains evolutionary coherent and unified (integrated) at deeper levels of the system (Smitsman and Currivan, 2019). When living systems grow more complex, their consciousness-actualising capacity also increases (Sahtouris, 2013). This embodying capacity is incredibly important from a developmental perspective of how consciousness as potentiality becomes aware through actualisation, from undifferentiated to differentiated awareness and back (Smitsman and Smitsman, 2020).

2. Future Creative Attractors: The future creative capacity of a living system is based on its capacity for renewal through its evolutionary development. The term 'future creative' also refers to a creative process that generates new patterns and new possibilities, i.e. new futures. In living systems, such a future creative process emerges from its evolutionary learning and development capacity. Evolutionary learning and development requires specific systemic attractors, affordances and sensory organs that combined make it possible to explore the infodynamics of the system's activities for new goals and purposes. Accordingly, living systems develop the sensory and attuning capabilities for adjusting their patterns and structures in a way that enables their further evolutionary development. The possibility space of a living system, its future potential, is precisely what acts as the attractor towards this developmental learning process (see Smitsman and Smitsman, 2020). 
3. Consciousness-Actualising Affordances: The evolutionary coherent complexity of living systems acts as affordance for consciousness to actualise, through developing self-awareness at various scales of being and inter-being. If a system does not afford the emergence and development of awareness, and does not afford the actualisation of consciousness, it is not a thrivability system.

4. Holarchic Complex Developmental Patterns: All living systems are complex developmental systems that generate holarchic patterns. A holarchic pattern is an organisational pattern whereby holons (wholes) are nested within larger holons (wholes) (Koestler, 1967). Holarchic patterns of complexity are generative, dynamic and evolutionary coherent. This is in contrast to hierarchic patterns that are degenerative, rigid and divisive. Information distribution in holarchic systems can be accessed at any level of the system due to its holographic nature and is attracted to the realisation of greater wholeness (Smitsman and Smitsman, 2020).

5. Evolutionary Coherent Behaviours: This is one of the most important qualities of thrivability systems; behaviour is sourced from the embedded informational wholeness and holographically distributed in a non-localised manner through the entire system. Accordingly, at any level of the system, the parts of the system can remain sourced from wholeness and informed by unity whilst diversification and growing complexity remains in dynamic place. This is the key to evolutionary coherence. This has also been referred to as the unity in diversity principle. Humanity is yet to master this evolutionary coherence in its behavioural patterns.

By learning from the behaviours of living systems and embedding those fractal potentialities in the design of our societal systems and interactions, we might start to understand how to systemically design for thrivability.

\section{FARMING OF TOMORROW}

The study of the infodynamics of healthy living systems, in this chapter also referred to as thrivability systems, provides guidelines for developing the agroecological farming systems of tomorrow. Indigenous science and practice has shown us the importance of including the infodynamics of living systems. If agroecological farming is to become truly wholistic in its practice, then it also requires inclusion of the non-local and multiple dimensions that inform growth in the finite, space-time-bound, local dimensions of our world.

Our current multifaceted global crisis offers an opportunity to enter into a conscious, healing and evolutionary relationship with Gaia. When we start to grow and cultivate our food from a sense of unity with all of life, and honour the integrity of our planetary ecosystems, a new thrivability model can emerge based on a fundamentally different relationship with food, resource cultivation, the land, each other and the larger ecology of life. Through this chapter, we hope to have inspired a deeper envisioning and regeneration of a healed and whole relationship with Gaia, the larger ecology of life and the wholeworld.

\section{ACKNOWLEDGEMENT}

We thank Dr Meredith Lowry for her valuable contribution.

\section{REFERENCES}

Baring, A. (2015) The Dream of the Cosmos: A Quest for the Soul. West Melbury: Archive Publishing. Bateson, N. (2016) Small Arcs of Larger Circles: Framing through Other Patterns. Axminster: Triarchy Press. Bauer, M. and Ellis, E.C. (2018) The Anthropocene divide: Obscuring understanding of social-environmental change. Current Anthropology 59(2). DOI: 10.1086/697198. 
Brewer, J. and Smitsman, A. (2018) Into the heart of systems change with Nora Bateson. EARTHwise Centre. https://youtu.be/QuA42Q_Ztto (accessed June 14th 2019).

Brundtland, G. et al. (1987) Our Common Future: Report of the 1987 World Commission on Environment and Development. Oxford: Oxford University Press.

Capra, F. and Luisi, P.L. (2014) The Systems View of Life: A Unifying Vision. New York: Cambridge University Press.

Cornell University (2019) Terra Preta de Indio. https://bit.ly/1SURQ9I (accessed September 12th 2019).

Currivan, J. (2004) Walking between worlds: Cosmology embodied in the landscape of Neolithic and Early Bronze Age Britain. PhD Dissertation. Reading: University of Reading.

Currivan, J. (2017) The Cosmic Hologram: In-formation at the Center of Creation. Rochester, Vermont: Inner Traditions/Bear and Company.

Currivan, J. (2019) A New INSCIght of INformational SCIence. www.judecurrivan.com (accessed August 23rd 2019)

Fogel, A. (1993) Developing through Relationships: Origins of Communication, Self and Culture. Chicago, IL: University of Chicago Press.

Gibbens, S. (2019) The Amazon is burning at record rates_-and deforestation is to blame. National Geographic, August 21, 2019. https://on.natgeo.com/2MsH1Pv (accessed September 15th 2019).

Griggs, D., Stafford-Smith, M., Gaffney, O., Rockström, J., Öhman, M.C., Shyamsundar, P., Steffen, W., Glaser, G., Kanie, N., and Noble, I. (2013) Sustainable development goals for people and planet. Nature, 495, 305-307.

Haukeland, P.I. (2013) Homo consumens, needless consumption and sources of transformation. Proceedings of Transformation in a Changing Climate, 19-21 June 2013, Oslo, Norway. University of Oslo. Interactive, pp. 89-96.

Hutchins, G. (2019) Natural business for a world that's waking up. The Nature of Business. https://bit.ly/ 2xhdBtZ (accessed June 30th 2019).

IPCC. (2018) Summary for policymakers. In Masson-Delmotte, V. et al., (eds), Global Warming of $1.5^{\circ} \mathrm{C}$ : An IPCC Special Report on the Impacts of Global Warming of $1.5^{\circ} \mathrm{C}$ above Pre-Industrial Levels and Related Global Greenhouse Gas Emission Pathways (32 pp.). Geneva: World Meteorological Organization.

Jacobs, D.T. (Four Arrows) (2016) Point of Departure: Returning to Our More Authentic Worldview for Education and Survival. Charlotte, NC: Information Age Publishing, Inc.

Koestler, A. (1967) The Ghost in the Machine (1990 reprint ed.). London: Hutchinson (Penguin Group).

Korten, D. (2015) From serving money to serving life: A sacred story for our time. Online lecture. https:// youtu.be/Aad6E9TgqS0.

Lane, P. (2019a) International treaty to protect and restore mother earth. The Four Worlds International Institute. https://bit.ly/2ZiGC6T (accessed September 1st 2020).

Lane, P. (2019b) Sixteen indigenous guiding principles for co-creating a sustainable, harmonious, prosperous world. https://bit.ly/32b5IV5 (accessed June 4th 2019).

Lane, P., Ramer, J., Longboat, K.D., and Moldow, D. (2019) Prophecies, dynamic change, and a new global civilization: 2020-2030-2050. https://goo.gl/Lomwav (accessed March 3rd 2019).

Laszlo, E. (ed.) (2017) Beyond Fear and Rage: New Light from the Frontiers of Science and Spirituality. Cardiff, CA: Waterfront Digital Press.

Laszlo, E. and Currivan, J. (2008) CosMos. Carlsbad, CA: Hay House.

Laszlo, E. with Laszlo, A. (2016) What Is Reality? The New Map of Cosmos and Consciousness. New York: SelectBooks, Inc.

Meyer, R. (2019) The cataclysmic break that (maybe) occurred in 1950 sixty-nine years ago, a new geological era may have begun on Earth. The Atlantic, April 2019. https://bit.ly/2UY3oA4 (accessed August 8th 2019).

Randall, B. (2007) Kanyini. Resurgence and Ecologist 2(1): 243.

Sahtouris, E. (2000) EARTHDANCE: Living Systems in Evolution. Bloomington, IN: iUniverse.

Sahtouris, E. (2013) Gaia's Dance: The Story of Earth and Us: A Children's Book for Grownups. Kindle Edition.

Sahtouris, E. and Smitsman, A. (2019) Into the heart of systems change with Dr Elisabet Sahtouris. EARTHwise Centre YouTube Channel. https://youtu.be/jhSPsJQZe8E.

Salthe, S.N. (2001) What is infodynamics? In Ragsdell, G. and Wilby, J. (eds), Understanding Complexity (pp. 31-38). Boston, MA: Springer.

Sanchez, A. (2017) The Four Sacred Gifts: Indigenous Wisdom for Modern Times. New York: Atria/Enliven Books, Simon and Schuster. 
Sandifer, P.A., Sutton-Grier, A.E., and Ward, B.P. (2015) Exploring connections among nature, biodiversity, ecosystem services, and human health and well-being: Opportunities to enhance health and biodiversity conservation. Elsevier Ecosystem Services 12: 1-15.

Scharmer, O. and Kaufer, K. (2013) Leading from the Emerging Future: From Ego-System to Eco-System Economies. San Francisco, CA: Berrett-Koehler Publishers, Inc.

Smitsman, A.W. (1997) The development of tool use: Changing boundaries between organism and environment. In Dent-Read, C. and Zukow-Goldring, P. (eds), Evolving Explanations of Development: Ecological Approaches to Organism-Environment Systems (pp. 301-329). Washington, DC: American Psychological Association.

Smitsman, A. (2019) Into the heart of systems change. Doctoral dissertation. Maastricht: University of Maastricht, Maastricht Sustainability Institute.

Smitsman, A. and Currivan, J. (2019) Systemic transformation: Into the birth canal. Systems Research and Behavioral Science 36(4), 604-613. DOI: 10.1002/sres.2573.

Smitsman, A and Houston, J. (2021) Future humans: A spiritual science novel for our greatest transformation [forthcoming].

Smitsman, A. and Smitsman, A.W. (2020) The future-creative human: Exploring evolutionary learning. World Futures: The Journal of New Paradigm Research 76(4): 214-239.

Smitsman, A. and Thurm, R. (2020) The future normals webinar series. EARTHwise Centre and r3.0, https:// bit.ly/316lphJ.

Smitsman, A., Laszlo, A., and Barnes, K. (2018) Attracting our future into being: The syntony quest. World Futures: The Journal of New Paradigm Research 75(1): 1-22.

Smitsman, A., Martens, P., and Laszlo, A. (2019) The polarization effect: Healing our worldviews. Systema 7(1): 1-23.

Van der Poel, W. (2020). Staying ahead of viruses. Online article, Wageningen University. https://weblog.wur. eu/spotlight/staying-ahead-of-viruses/.

Wahl, D.C. (2016) Designing Regenerative Cultures. Axminster: Triarchy Press.

WWF (2018) The Living Planet Report 2018: Aiming Higher. Gland: WWF International.

Zalasiewicz, J., Summerhayes, C., Barnosky, A.D., Poirier, C., Gałuszka, A., Cearreta, A., Edgeworth, M., Ellis, E.C., Ellis, M., Jeandel, C., Leinfelder, R., McNeill, J.R., de Richter, D.B., Steffen, W., Syvitski, J., Vidas, D., Wagreich. M., Williams, M., Zhisheng, A., Grinevald, J., Odada, E., Oreskes, N. and Wolfe, A.P. (2016) The Anthropocene is functionally and stratigraphically distinct from the Holocene. Science 351(6269): $\operatorname{aad} 2622$. 


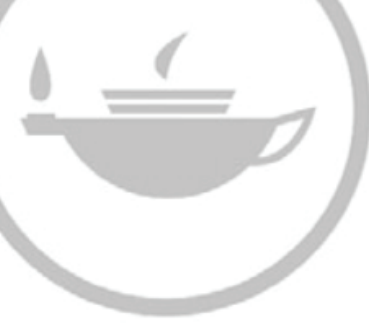

Taylor \& Francis Taylor \& Francis Group http://taylorandfrancis.com 


\section{Section 2}

The Intersection of Wave-Based

Science and Agriculture 


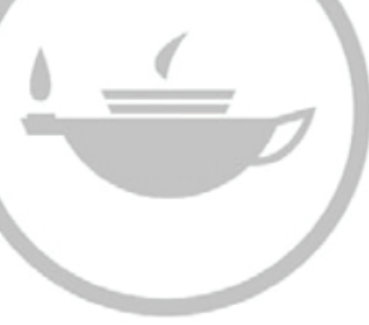

Taylor \& Francis Taylor \& Francis Group http://taylorandfrancis.com 


\title{
9 Electromagnetic Fields Mitigate Adverse Effects of Environmental Stresses in Plants
}

\author{
Angel De Souza-Torres \\ Granma University
}

\section{CONTENTS}

Introduction. 101

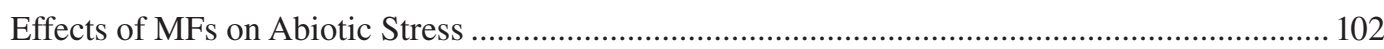

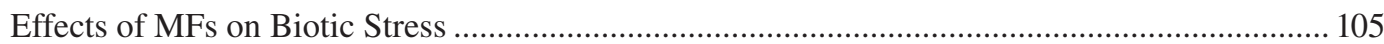

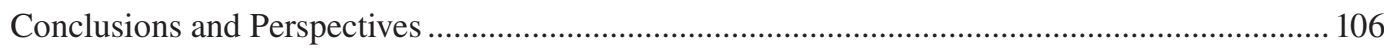

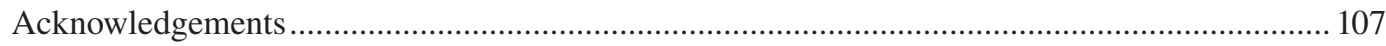

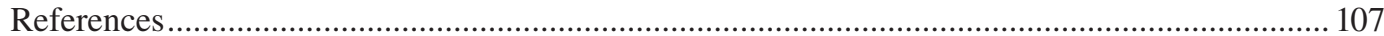

\section{INTRODUCTION}

This chapter provides a state-of-the-art overview of the mitigating effects of electromagnetic fields (EMFs) on plants sown under abiotic and biotic stresses and thus their implications for agroecology. It considers static and alternating magnetic fields (MFs) and pulsed fields (PEMFs) ranging from $1.5 \mu \mathrm{T}$ up to $800 \mathrm{mT}$ in the range of extremely low frequencies $(0-300 \mathrm{~Hz})$.

Environmental stress may be defined as an adverse external condition for plant growth and development or productivity of plants, caused by either environmental or biological factors, or both (Verma et al., 2013). Plant stress can be divided into two main categories: abiotic stress and biotic stress. Abiotic stress imposed on plants by the environment may be either physical or chemical (drought, salinity, high temperatures, ultraviolet light, heavy metal toxicity), while biotic stress imposed on plants is a biological factor such as insects, bacteria, viruses, pathogens and weeds (Gull et al., 2019; Verma et al., 2013). Exposure of plants to biotic and abiotic stress induces a disruption in plant metabolism, implying physiological costs (Bolton, 2009; Heil and Bostock, 2002; Massad, et al., 2012; Swarbrick et al., 2006), and thus leading to a reduction in fitness and ultimately in productivity (Shao et al., 2008). Abiotic stress has a great impact on plant growth by causing growth reductions of up to $50 \%$ in most plant species and, consequently, is responsible for severe losses in the field (Wang et al., 2003). Still, biotic stress is an additional challenge, inducing a strong pressure on the plant and adding to this damage through pathogen, pest, insect or herbivore attack (Brown and Hovmoller, 2002; Maron and Crone, 2006; Mordecai, 2011; Strauss and Zangerl, 2002). Under natural conditions, concurrent occurrence of two or more different types of stresses, such as drought and salinity, is more detrimental to global crop production (Pandey et al., 2015; Prasch and Sonnewald, 2013; Suzuki et al., 2014). The nature of the interactions between the abiotic and biotic stresses and the duration of stress exposure can lead to a series of effects on plant growth, development and overall yield and also determine the extent of the influence on crop productivity. 
It is predicted that, with climate change and especially global warming, environmental stresses will become more intense and frequent in the future. Therefore, maintaining crop yields under adverse environmental stresses is one of the major challenges facing modern agriculture, and plants might react to environmental stress on several levels: on the biochemical, cellular or morphological scale, and at species or population level. However, different studies suggest that static and alternating MFs and PEMFs prevent the huge injuries of abiotic and biotic stresses on agricultural crops and other economically important plants and play a role in triggering plant defence responses and antioxidant defence systems by reducing the oxidative damage in plants caused by stress situations (Anand et al., 2012; Baby et al., 2011; Baghel et al., 2018; Chen et al., 2017; Javed et al., 2011; Karimi et al., 2017; Ruzic and Jerman, 2002; Radhakrishnan et al., 2012; Sen and Alikamanoglu, 2016; Trebbi et al., 2007; Shine and Guruprasad, 2012; Shine et al., 2012).

\section{EFFECTS OF MFS ON ABIOTIC STRESS}

Abiotic stress exerts a negative impact on the growth rate and reproduction of a plant (Gull et al., 2019). Drought, salinity, heavy metal toxicity, ultraviolet light and low and high temperatures are examples of abiotic stress factors. It has been claimed that abiotic stress causes the most crop loss of any other factor, causing most major crops to have over 50\% lower yields than their potential (Fahad et al., 2017).

Several studies have shown that a magnetic treatment at pre-sowing alleviated the adverse effects of drought, salinity, heavy metal toxicity, ultraviolet light and high temperatures or heat stress in some plant species (Table 9.1).

The results of several investigations indicate that MF can provide protection against the adverse effects of drought stress. For example, when common fig (Ficus carica L., cv. Sabz) nodal explants were subjected to static MF of $170 \mathrm{mT}$ for 15, 30 and $60 \mathrm{~min}$ every day under drought stress (three concentrations of polyethylene glycol 6000 (PEG): 0,3 and 6\%w/v) in vitro conditions, a protective

TABLE 9.1

\section{Examples of Effects of Electromagnetic Fields of Plants Sown under Abiotic Stress} Conditions

\begin{tabular}{|c|c|c|c|c|}
\hline \multirow[b]{2}{*}{ Plant Species } & \multicolumn{2}{|l|}{ Abiotic Stress } & \multirow[b]{2}{*}{ Effects Described } & \multirow[b]{2}{*}{ References } \\
\hline & Type & MFs Applied & & \\
\hline Glycine $\max \mathrm{L}$. & Drought & $\begin{array}{l}\text { Static MF, } 200 \mathrm{mT} \\
\text { for } 1 \text { hour }\end{array}$ & $\begin{array}{l}\text { Enhanced plant growth, biomass } \\
\text { accumulation, photosynthetic } \\
\text { performance, photosynthetic pigment } \\
\text { content, efficiency of photosystem II, } \\
\text { photosynthesis rate, nitrate reductase } \\
\text { activity and yield }\end{array}$ & $\begin{array}{l}\text { Baghel et al. } \\
\text { (2018) }\end{array}$ \\
\hline Glycine $\max \mathrm{L}$. & Salinity & $\begin{array}{l}\text { Static MF, } 200 \mathrm{mT} \\
\text { for } 1 \text { hour }\end{array}$ & $\begin{array}{l}\text { Increased plant growth, biomass } \\
\text { accumulation and photosynthetic } \\
\text { performance. Improved the activity of } \\
\text { nitrogen fixation and leghaemoglobin } \\
\text { content and hemichrome content in the } \\
\text { root nodule }\end{array}$ & $\begin{array}{l}\text { Baghel et al. } \\
\text { (2016) }\end{array}$ \\
\hline Glycine $\max \mathrm{L}$. & $\begin{array}{r}10,20,30 \text { and } \\
40 \mathrm{mM} \mathrm{NaCl}\end{array}$ & $\begin{array}{c}\text { Pulsed MFs, } 0.1,1 \text {, } \\
10 \text { and } 100 \mathrm{~Hz}\end{array}$ & $\begin{array}{l}\text { Increased frequency of shoot and root } \\
\text { regeneration and number and length of } \\
\text { shoots and roots. Induced greater } \\
\text { number of roots and enhancement of } \\
\text { root length at } 40 \mathrm{mM} \mathrm{NaCl}\end{array}$ & $\begin{array}{l}\text { Radhakrishnan } \\
\text { and Kumari } \\
\text { (2013) }\end{array}$ \\
\hline
\end{tabular}


TABLE 9.1 (Continued)

Examples of Effects of Electromagnetic Fields of Plants Sown under Abiotic Stress

Conditions

$\begin{array}{cc}\text { Plant Species } & \begin{array}{c}\text { Abiotic Stress } \\ \text { Type }\end{array} \\ \text { Glycine max L. } & \begin{array}{c}\text { Salt stress } \\ (10 \mathrm{mM} \mathrm{NaCl})\end{array} \\ & \\ & \\ & \\ \text { Triticum aestivum } & \text { 60 g/L } \\ \text { (cv. Nina and } & \text { polyethylene } \\ \text { Flamura-85) } & \text { glycol (as a } \\ & \text { drought stress } \\ & \text { inducer) or } \\ & 100 \mathrm{mM} \text { NaCl } \\ & \text { (as a salinity } \\ & \text { stress inducer) }\end{array}$

\begin{tabular}{|c|c|c|}
\hline $\begin{array}{c}\text { Eucalyptus } \\
\text { globulus }\end{array}$ & $\begin{array}{l}\text { Heavy metal } \\
\text { toxicity (soil } \\
\text { containing } \mathrm{Cd} \text {, } \\
\mathrm{Hg}, \mathrm{Pb}, \mathrm{Zn}, \mathrm{Cr} \\
\text { and } \mathrm{Cu} \text { ) }\end{array}$ & $\begin{array}{l}\text { Static MFs, 30, 60, } \\
120,150 \text { and } 400 \\
\mathrm{mT}\end{array}$ \\
\hline
\end{tabular}

Triticum aestivum Heavy metal toxicity (lead and cadmium)

Cucumis sativus Ultraviolet B $\left(3.5 \mathrm{~kJ} / \mathrm{m}^{2}\right.$ ultraviolet $\mathrm{B}$, $315 \mathrm{~nm}$ ) stress

\section{MFs Applied}

1.0-Hz uniform for 5 hours a day for 20 days

Static MF, 2.9-4.7 $\mathrm{mT}$ for 2.2 and $19.8 \mathrm{~s}$

Static MFs, 200, 400, 600 and 800 $\mathrm{mT}$ for $1 \mathrm{~ms}$

Static MFs, 0, 0.2 and $0.45 \mathrm{~T}$ pulsed MF, $1.5 \mu \mathrm{T}$

\section{Effects Described}

Increased calli fresh weight, total soluble sugar, total protein and total phenol contents.

Decreased ascorbic acid, lipid peroxidation and catalase activity. Enhanced calli tolerance to salt stress in terms of increase of flavonoids, flavones or flavonoles, alkaloids, saponin, total polyphenol, genistein and daidzein contents. Reduced overproduction of proline.

Improved plant growth. Increased the amount of superoxide radical and hydrogen peroxide in roots under drought stress or salt stress in total chlorophyll, chlorophyll a and chlorophyll b in leaves.

Enhanced antioxidant enzyme activities (superoxide dismutase, guaiacol peroxidase, catalase, ascorbate peroxidase and glutathione reductase) and total glutathione and oxidised glutathione contents.

Increased biomass yield. 150-mT MF improved the phytoremediation and alleviated the environmental risk, which shortened the time to purify $\mathrm{Cd}, \mathrm{Pb}$ and $\mathrm{Cu}$. Higher transpiration rate of plants along with exposure to static MFs induced lower soil moisture content and was beneficial to environmental control Increased germination by $600 \mathrm{mT}$ for 1 ms. Decreased catalase, superoxide dismutase, glutathione reductase activity, glutathione concentration and shoot biomass for 200, 400, 600 and $800 \mathrm{mT}$ for $1 \mathrm{~ms}$

Increased germination rate, seedling growth and development, lipid oxidation and ascorbic acid contents. Seed MF treatment increased the sensitivity of cucumber seedlings to ultraviolet-B radiation. Decreased seedling growth and development and actual quantum yield of photosystem II and increased oxidative pressure under combination of ultraviolet-B irradiation and MF

\section{References}

Radhakrishnan

et al. (2012)

Sen and Alikamanoglu (2016)

Luo et al. (2019)

Chen et al.

Yinan et al. 
effect was found in treated plants by absorbing more water (23.1\%), accumulating more proline (44.1\%) in their leaves and increasing the thickness (17.9\%) of their leaves. The treatment 170-mT MF for 15 min showed the best results (Karimi et al., 2012). Maize (Zea mays L.) plants from magnetically treated seeds with static MF of 100 and $200 \mathrm{mT}$ for 2 and 1 hour and sown under greenhouse conditions significantly enhanced seedling growth $(34.3 \%)$ and leaf water status (leaf water potential $(20.6 \%)$, turgor potential $(46.9 \%)$, relative water content $(3.5 \%)$ and photosynthesis rate $(71.4 \%)$ ) and lowered the antioxidant defence system (peroxidases $(50 \%)$ and catalase $(66.7 \%)$ ) of seedlings under soil drought stress (Anand et al., 2012).

Magnetic treatment has been found to provide protection of some plant species against salt stress without adversely affecting the environment. Pre-treated maize seeds with $200 \mathrm{mT}$ of static MF for 1 hour enhanced germination percentage (16\%), germination stress tolerance index $(23.2 \%)$, seedling vigour (70\%), growth parameters (plant height (41\%), leaf area (18\%) and biomass accumulation (137\%)), photosynthetic pigments content (46\%), the rate of photosynthesis (28\%) and stomatal conductance $(40 \%)$, which resulted in improved yield (29\%) of maize plants and decreased hydrogen peroxide $\left(\mathrm{H}_{2} \mathrm{O}_{2} ; 32 \%\right)$ under saline conditions (Baghel et al., 2019). A static MF of $35 \mathrm{mT}$ for $0.5 \mathrm{~min}$ caused an increase in all tested germination indexes (36.4\%), seedling growth (seedling shoot and root length (43.6\% and 46.8\%), seedling dry weight (23\%) and seedling vigour (18\%)), relative water content (19.6\%), salt tolerance index (10.2\%), antioxidant enzyme activity (peroxidase (15.6\%), polyphenol oxidase (24\%) and chitinase $(21.5 \%)$ ) and field performance characteristics of barley plants $(40.6 \%)$ in combination with water, proline or arginine under different salinity stress levels (324, 2,000, 4,000, 6,000 and 8,000 ppm; Hozayn et al., 2018).

Enhanced germination percentage (10\%-19\%) and early seedling growth (root and shoot length $(15 \%-40 \%$ and $18 \%)$ and vigour indexes $(40 \%)$ ), increased $\alpha$-amylase and protease activities $(15.4 \%-56.3 \%$ and $4 \%-10.5 \%)$ and increased levels of superoxide radical and hydrogen peroxide (13.8\%-31\% and 9.65-13.2\%) under different salinity levels $(0-100 \mathrm{mM} \mathrm{NaCl})$ were observed in maize and soybean plants grown from pre-treated seeds with static MF of $200 \mathrm{mT}$ for 1 hour as compared to control plants (Kataria et al., 2017a).

Sweet corn (maize) plants emerging from magnetically treated seeds using weak (15 mT) or strong (150 mT) MFs for 6, 12 and 24 hours showed an increase in germination rate and percentage $(5 \%-25.3 \%)$ and plant growth $(11.5 \%-13.4 \%)$ and a reduction in proline accumulation $(25.8 \%)$ by improving water absorption $(25.9 \%)$ under $\mathrm{NaCl}$ stress $(0,50$ and $100 \mathrm{mM})$. The highest germination rate was obtained by the stronger MF; however, the seedlings were more vigorous after treatment with 15-mT MF (Karimi et al., 2017).

Different experimental results have shown that MF treatment can ameliorate heavy metal toxicity stress in some crops. For example, mung bean seedlings treated with 600-mT MF under cadmium stress reduced the concentration of malondialdehyde (23.4\%-72.2\%), hydrogen peroxide $(25 \%-27.8 \%)$ and superoxide radical $(3.6 \%-22.1 \%)$ and the conductivity of electrolyte leakage (16.1\%-24.6\%), while the nitric oxide (NO) concentration $(33.3 \%-39.8 \%)$ and nitric oxide synthase (NOS) activity (13.3\%-22.2\%), photosynthesis rate (13.4\%) and growth parameters $(13.3 \%-22.6 \%)$ increased compared to cadmium stress alone, indicating that MF compensates for the toxicological effects of cadmium exposure and is related to NO signalling (Chen et al., 2011). A stimulating effect on the growth of spruce (Picea abies) seedlings (69\%) was observed for 50-Hz MF of $103 \mu \mathrm{T}$ and aluminium solution (in the form of $\mathrm{AlCl}_{3}$ ) of $100 \mu \mathrm{M}$, while slight positive responses were also found within the range of concentrations between 40 and $160 \mu \mathrm{M} \mathrm{Al}^{3+}$. These results suggest the importance of the synergistic action of the MF with metal aluminium stressor as well as the existence of physiological windows in addition to the frequency and power ones (Ruzic et al., 2000).

Some results demonstrated an alleviating effect of MF on ultraviolet light stress in plants. Exposure of sorghum seeds to a static MF of strength $125 \mathrm{mT}$ for 6 hours revealed a significant effect on the percentage of germinated seeds (34.8\%), speed of germination (40.5\%), seedling length (45\%) and number of leaves (14.4\%), while the MF application followed by immediate irradiation with ultraviolet- $C$ radiation at $254 \mathrm{~nm}$ for 30 and $60 \mathrm{~min}$ showed no significant effect on germination 
and seedling growth, indicating the magnetically untreated seeds with the exposure time $60 \mathrm{~min}$ of ultraviolet-C gave the highest seedling growth (Lazim and Nasur, 2017). A static MF of $200 \mathrm{mT}$ for 1 hour reduced the amount of hydrogen peroxide (36\%) and activities of antioxidant enzymes such as superoxide dismutase (38\%), glutathione reductase $(60 \%)$ and guaiacol peroxidase $(66 \%)$ of soybean (var. JS-335) plants that emerged from MF-treated seeds under ambient ultraviolet (280$400 \mathrm{~nm}$ ) stress compared to the control. The reduction in the hydrogen peroxide content (30\%) and antioxidant enzyme activities (40\%) after MF treatment and ambient ultraviolet exclusion indicated that solar ultraviolet components exert a significant stress on soybean plants. Similarly, the levels of ultraviolet-absorbing compounds $(14.6 \%-15 \%)$ were also decreased by exclusion of both ultraviolet and MF treatment. The results indicate that the exclusion of solar ultraviolet components and MF pre-treatment eliminates the need for defence against the ambient ultraviolet stress (Kataria et al., 2017b).

Some experimental results have exhibited a protective response of the MF against high temperatures or heat stress. The effects of pre-sowing magnetic treatments (MF of $120 \mathrm{mT}$ for $10 \mathrm{~min}$ and $80 \mathrm{mT}$ for $5 \mathrm{~min}$ ) on the growth and yield of tomatoes (cv. Vyta) increased notably root length (18\%), fresh and dry root weight (48.2\% and $80.7 \%)$, stem length (35.9\%), fresh and dry stem weight (39.6\% and $75.4 \%$ ), leaf area and foliole dry weight (39.3\% and 26.7\%), fruit number (21.3\%), mean fruit weight $(25.5 \%)$ and fruit yield per plant $(51.7 \%)$ and per area $(50.8 \%)$ under high temperature stress $\left(34^{\circ} \mathrm{C}\right.$ ) and under field conditions (De Souza et al., 2005). A weak sinusoidal and 50-Hz MF of $100 \mu \mathrm{T}$ alleviated the inhibitory effect of heat stress $\left(40,42\right.$ and $45^{\circ} \mathrm{C}$ for $\left.40 \mathrm{~min}\right)$ on the growth of cress seedlings (Lepidium sativum; 15\%) only when applied previously, whereas the application of MF alone and after heat stress did not produce any significant growth effects. It was also evident that with a stronger stress $\left(42^{\circ} \mathrm{C}\right.$ and $\left.45^{\circ} \mathrm{C}\right)$, the MF produced a more potent protective effect than at $40^{\circ} \mathrm{C}$, indicating the protective effect of MF against high temperatures (Ruzic and Jerman, 2002). These studies suggest that MF treatment ameliorates the adverse effects of drought, salinity, heavy metal toxicity, ultraviolet light and high temperatures.

\section{EFFECTS OF MFS ON BIOTIC STRESS}

Biotic stress in plants is caused by living organisms, especially viruses, bacteria, fungi, nematodes, insects, arachnids and weeds (Gull et al., 2019). These biotic stress agents cause various types of diseases, infections and damage to crop plants and ultimately affect the crop productivity. They depend on the environment and thus vary from region to region, from one agroecology to another, from one country to another country (Suzuki et al., 2014). Biotic stress plays a central role in regulating outbreaks of pests, pathogens, insects and weeds (McDonald et al., 2009; Peters et al., 2014; Ziska et al., 2010). Plants respond to biotic stress through a defence system, and this mechanism is classified as an innate and systemic response. After infection, reactive oxygen species (ROS) are generated and oxidative bursts limit pathogen spread (Atkinson et al., 2012). Several adaptive responses of plants have shown the role of MF on plant defence response under biotic stress conditions (Table 9.2).

Magnetic treatment has been found to protect some plant species against fungi, bacteria, phytoplasma and virus. For example, exposure to $0.2-\mathrm{mT}$ MF for $7 \mathrm{~min} 48 \mathrm{~s}, 11 \mathrm{~min} 42 \mathrm{~s}$ and $15 \mathrm{~min}$ $36 \mathrm{~s}$ on tomato seed infected by Fusarium sp. increased the rate of flowering (4.4\%), flower number (3.4\%), the rate of fruiting (2.8\%) and fruit number (11.\%), while the combination of MF exposure and seed soaking treatment enhanced flower number, the rate of fruiting and fruit numbers. 0.2-mT MF for $7 \mathrm{~min} 48 \mathrm{~s}$ showed the highest rate of flowering and the largest number of tomatoes, while 0.2-mT MF for $11 \mathrm{~min} 36 \mathrm{~s}$ exhibited the most number of flowers (13.4\%) and the highest rate of fruiting (5.1\%). However, soaking tomato seeds for $15 \mathrm{~min}$ before the $0.2-\mathrm{mT}$ MF treatment gave a better effect by increasing the rate of the plants to form flowers and fruits and increase the number of fruits (Agustrina et al., 2018).

A static MF of $0.1,0.5$ and $1 \mathrm{mT}$ decreased the growth of phytopathogenic microscopic fungal colonies by $10 \%$. At the same time, the number of developed conidia of Alternaria alternata and 


\section{TABLE 9.2}

\section{Examples of Effects of Electromagnetic Fields of Plants Sown under Biotic Stress Conditions}

\begin{tabular}{|c|c|c|c|c|}
\hline Plant Species & $\begin{array}{c}\text { Biotic Stress } \\
\text { Type }\end{array}$ & MFs Applied & Effects Described & References \\
\hline $\begin{array}{l}\text { Capsicum, } \\
\text { Zea mays }\end{array}$ & $\begin{array}{l}\text { Phytopathogenic } \\
\text { fungi } \\
\text { (Fusarium } \\
\text { oxysporum } \\
\text { conidia, } \\
\text { Alternaria } \\
\text { alternata and } \\
\text { Curvularia } \\
\text { inaequalis) }\end{array}$ & $\begin{array}{c}\text { Static MFs, } 0.1 \\
0.5 \text { and } 1 \mathrm{mT}\end{array}$ & $\begin{array}{l}\text { Decreased the growth of phytopathogenic } \\
\text { microscopic fungi colonies and the number of } \\
\text { Fusarium oxysporum conidia. } \\
\text { Increased the number of developed conidia of } \\
\text { Alternaria alternata and Curvularia inaequalis. } \\
\text { MF influenced the formation of conidia }\end{array}$ & Pál (2005) \\
\hline $\begin{array}{l}\text { Nicotina } \\
\text { tobaccum }\end{array}$ & $\begin{array}{l}\text { Tobacco mosaic } \\
\text { virus }\end{array}$ & $\begin{array}{l}\text { Pulsed MFs (static } \\
\text { MFs of } 17 \text { and } 13 \\
\mu \mathrm{T} \text { combined } \\
\text { with a } 10-\mathrm{Hz} \\
\text { sinusoidal MF of } \\
25.6 \text { or } 28.9 \mu \mathrm{T} \text { ) }\end{array}$ & $\begin{array}{l}\text { Increased resistance in plants by a decrease in } \\
\text { lesion area and number, particularly after } \\
\text { magnetic treatment for } 8 \text { hours. } \\
\text { Increased ornithine decarboxylase and } \\
\text { phenylalanine ammonia-lyase activities involved } \\
\text { in resistance mechanisms, in particular for } 13-\mathrm{mT} \\
\text { static MF plus } 28.9-\mathrm{mT}, 10-\mathrm{Hz} \text { sinusoidal MF for } \\
24 \text { hours. } \\
\text { Enhanced hypersensitive response of tobacco to } \\
\text { tobacco mosaic virus }\end{array}$ & $\begin{array}{l}\text { Trebbi et al } \\
(2007)\end{array}$ \\
\hline
\end{tabular}

Curvularia inaequalis increased by 68\%-133\%, but the number of Fusarium oxysporum conidia decreased by $79 \%-83 \%$ (Nagy and Fischl, 2004).

The effect of MFs of modulated amplitude square waves in the frequency range $0.5-20 \mathrm{~Hz}$ for 24 hours reduced significantly the linear growth $(24.7 \%-56.5 \%)$ and biomass gain $(30.3 \%)$ of Sclerotium rolfsii in vivo and in vitro, the number of sclerotia (58.4\%), percentage of germination $(55 \%)$ and germ tubule length $(83.3 \%)$ of sugar beet plants. The sensitivity of the fungus for 24 hours counteracted the potency of fungus exposed to MFs of $0.5,5$ and $15 \mathrm{~Hz}$ which stimulated seedling emergency (7.8\%-77.1\%) in comparison with non-infested plants (Rizk, 2003).

Application of $10-\mathrm{Hz} \mathrm{MF}$ of $25 \mathrm{mT}$ for 1 hour affected the amylase activity of bacteria Rhodospirillum rubrum, which was verified by the increase in standard deviations $(250 \%)$ in distribution of the residual starch concentration. The use of 10-Hz MFs can regulate bacterial activity, and thus, 10-Hz MFs could be used for biotechnological application (Khokhlova and Vainshtein, 2017).

A significant delay in the appearance of first symptoms of geminivirus (7-9 days) and early blight (7-10 days) and a reduced infection rate (43\%-55.3\%) of early blight were found in the tomato plants grown from seeds exposed to increased MFs of $100 \mathrm{mT}$ for $10 \mathrm{~min}$ and $170 \mathrm{mT}$ for $3 \mathrm{~min}$ (De Souza et al., 2006). These findings indicate that MF triggers the plant defence response and protects plants against biotic stress. However, the mechanisms by which magnetic treatment protects the plants against the adverse effects of the abiotic and biotic stresses are still not fully understood.

\section{CONCLUSIONS AND PERSPECTIVES}

The seeds and plants treated with static and alternating MFs and PEMFs, from $1.5 \mu \mathrm{T}$ up to $800 \mathrm{mT}$ in the range of extremely low frequencies, showed an increase in seed vigour, plant growth and development, water relations, photosynthesis, accumulation of biomass and concentration of secondary 
metabolites and a decrease in free radicals as well as triggering the plant defence responses and antioxidant defence system under abiotic and biotic stress as well as non-stress conditions. This indicates that MF treatment improves tolerance or resistance to abiotic and biotic stresses. Therefore, an approach is revealed for ways to face the environmental stresses being generated by global warming and other causes that disturb agricultural efficiency. The MF treatment of seeds and plants may allow us to design more complex experiments to study the interaction between two or three different types of stress in order to better understand the net impact of stress combinations on plants.

The technology required to treat seeds and plants with MFs is a type of magnetic treatment in the range from 80 to $200 \mathrm{mT}$ for several exposure times (1-10 min; De Souza et al., 2006, 2010, 2014, 2020). This technology is appropriate and inexpensive for the small farmer with diverse crops; however, its application is limited at a larger scale and more research is therefore required to find ways to scale up the procedure.

\section{ACKNOWLEDGEMENTS}

The author wishes to thank Prof. Ben Greenebaum, University of Wisconsin-Parkside, for his valuable comments and suggestions on this chapter.

\section{REFERENCES}

Agustrina, R., Nurcahyani, E. and Irawan, B. (2018) Tomato generative growth from the seeds exposed to 0.2 mT of magnetic field and infected by Fusarium sp. J Phys Conf Ser 1116:052002.

Anand, A., Nagarajan, S., Verma, A., Joshi, D., Pathak, P. and Bhardwaj, J. (2012) Pre-treatment of seeds with static magnetic field ameliorates soil water stress in seedlings of maize (Zea mays L.). Indian J Biochem Biophys 49:63-70.

Atkinson, N.J., Lilley, V.J. and Urwin, P.E. (2013) Identification of genes involved in the response to simultaneous biotic and abiotic stress. Plant Physiol 162:2028-2041.

Baby, S.M., Narayanaswamy, G.K. and Anand, A. (2011) Superoxide radical production and performance index of Photosystem II in leaves from magnetoprimed soybean seeds. Plant Sign Behav 6:1635-1637.

Baghel, L., Kataria, S. and Guruprasad, K.N. (2016) Static magnetic field treatment of seeds improves carbon and nitrogen metabolism under salinity stress in soybean. Bioelectromagnetics 37:455-470.

Baghel, L., Kataria, S. and Guruprasad, K.N. (2018) Effect of static magnetic field pretreatment on growth, photosynthetic performance and yield of soybean under water stress. Photosynthetica 56:718-730.

Baghel, L., Kataria, S. and Jain, M. (2019) Mitigation of adverse effects of salt stress on germination, growth, photosynthetic efficiency and yield in maize (Zea mays L.) through magnetopriming. Acta Agrobot 72(1):1757.

Bolton, M.V. (2009) Primary metabolism and plant defense-fuel for the fire. Mol Plant Microbe Interact 22:487-497.

Brown, J.K.M. and Hovmoller, M.S. (2002) Aerial dispersal of pathogens on the global and continental scales and its impact on plant disease. Science 297:537-541.

Chen, Y., Li, R. and He, J.M. (2011) Magnetic field can alleviate toxicological effect induced by cadmium in mungbean seedlings. Ecotoxicology 20:760-769.

Chen, Y., Chen, D. and Liu, Q. (2017) Exposure to a magnetic field or laser radiation ameliorates effects of $\mathrm{Pb}$ and $\mathrm{Cd}$ on physiology and growth of young wheat seedlings. J Photochem Photobiol, B Biol 169:171-177.

De Souza, A., García, D., Sueiro, L., Licea, L. and Porras, E. (2005) Pre-sowing magnetic treatment of tomato seeds: Effects on the growth and yield of plants cultivated late in the season. Spanish J Agric Res 3(1):113-122.

De Souza, A., Garcia, D., Sueiro, L., Gilart, F., Porras, E. and Licea, L. (2006) Pre-sowing magnetic treatments of tomato seeds increase the growth and yield of plants. Bioelectromagnetics 27:247-257.

De Souza, A., Sueiro, L., García, D. and Porras, E. (2010) Extremely low frequency non-uniform magnetic fields improve tomato seed germination and early seedling growth. Seed Sci Technol 38:61-72.

De Souza, A., García, D., Sueiro, L. and Gilart, F. (2014) Improvement of the seed germination, growth and yield of onion plants by extremely low frequency non-uniform magnetic fields. Sci Hortic 176:63-69. 
De Souza, A., Sueiro-Pelegrin, L., Zambrano-Reyes, M., Macias-Socarras, I., Gonzales-Posada, M. and Garcia-Fernandez, D. (2020) Extremely low frequency non-uniform magnetic fields induce changes in water relations, photosynthesis and tomato plant growth. Int J Radiat Biol 96(7):951-957.

Fahad, S., Bajwa, A.A., Nazir, U., Anjum, S.A., Farooq, A., Zohaib, A., Sadia, S., Nasim, W., Adkins, S., Saud, S., Ihsan, M.Z., Alharby, H., Wu, C., Wang, C.D. and Huang, J. (2017) Crop production under drought and heat stress: Plant responses and management options. Front Plant Sci 8:1147.

Gull, A., Lone, A.A. and Wani, N.U.I. (2019) Biotic and Abiotic Stresses in Plants. In Alexandre Bosco de Oliveira (ed), Biotic and abiotic stresses in plants (pp. 1-6), IntechOpen, London. DOI: 10.5772/ intechopen.85832.

Heil, M. and Bostock, R.M. (2002) Induced systemic resistance (ISR) against pathogens in the context of induced plant defenses. Ann Bot 89:503-512.

Hozayn, M., EL-Mahdy, A.A. and Zalama, M.T. (2018) Magneto-priming for improving germination, seedling attributes and field performance of barley (Hordeum vulgare L.) under salinity stress. Middle East J Agric Res 7(3):1006-1022.

Javed, N., Ashraf, M., Akram, N.A. and Al-Qurainy, F. (2011) Alleviation of adverse effects of drought stress on growth and some potential physiological attributes in maize (Zea mays L.) by seed electromagnetic treatment. Photochem Photobiol 87(6):1354-1362.

Karimi, S., Hojati, S., Eshghi, S., Moghaddam, R.N. and Jandoust, S. (2012) Magnetic exposure improves tolerance of fig 'Sabz' explants to drought stress induced in vitro. Scientia Horticul 137:95-99.

Karimi, S., Eshghi, S., Karimi, S. and Hasan-Nezhadian, S. (2017) Inducing salt tolerance in sweet corn by magnetic priming. Acta Agric Slovenica 109(1):89-102.

Kataria, S., Baghel, L. and Guruprasad, K.N. (2017a) Pre-treatment of seeds with static magnetic field improves germination and early growth characteristics under salt stress in maize and soybean. Biocatal Agric Biotechnol 10:83-90.

Kataria, S., Baghel, L. and Guruprasad, K.N. (2017b) Alleviation of adverse effects of ambient UV stress on growth and some potential physiological attributes in soybean (Glycine max) by seed pre-treatment with static magnetic field. J Plant Growth Regul 36(3):550-565.

Khokhlova, G. and Vainshtein, M. (2017) Application of static and impulse magnetic fields to bacteria Rhodospirillum rubrum VKM B-1621. Khokhlova Vainshtein AMBExpr 7:60.

Lazim, S.K. and Nasur, A.F. (2017) The effect of magnetic field and ultraviolet-C radiation on germination and growth seedling of sorghum (Sorghum bicolor L. Moench). J Agric Vet Sci (IOSR-JAVS) 10(10):30-36.

Luo, J., He, W., Xing, X., Wu, J. and Gu, X.W.S. (2019) The phytoremediation efficiency of Eucalyptus globulus treated by static magnetic fields before sowing. Chemosphere 226:891-897.

Maron, J.L. and Crone, E. (2006) Herbivory: Effects on plant abundance, distribution and population growth. Proc R Soc B 273:2575-2584.

Massad, T.J., Dyer, L.A. and Vega, C.G. (2012) Cost of defense and a test of the carbon-nutrient balance and growth-differentiation balance hypotheses for two co-occurring classes of plant defense. PLoS One 7:e7554.

McDonald, A., Riha, S., DiTommaso, A. and DeGaetano, E. (2009) Climate change and the geography of weed damage: Analysis of US maize systems suggests the potential for significant range transformations. Agric Ecosyst Environ 130:131-140.

Mordecai, E.A. (2011) Pathogen impacts on plant communities: Unifying theory, concepts, and empirical work. Ecol Monogr 81:429-441.

Nagy, P. and Fischl, G. (2004) Effect of static magnetic field on growth and sporulation of some plant pathogenic fungi. Bioelectromagnetics 25:316-318.

Pál, N. (2005) The effect of low inductivity static magnetic field on some plant pathogen fungi. J Central Eur Agric 6(2):167-171.

Pandey, P., Ramegowda, V. and Senthil-Kumar, M. (2015) Shared and unique responses of plants to multiple individual stresses and stress combinations: Physiological and molecular mechanisms. Front Plant Sci $6: 723$.

Peters, K., Breitsameter, L. and Gerowitt, B. (2014) Impact of climate change on weeds in agriculture: A review. Agric Sustain Dev 34:707-721.

Prasch, C.M. and Sonnewald, U. (2013) Simultaneous application of heat, drought, and virus to Arabidopsis plants reveals significant shifts in signaling networks. Plant Physiol 162(4):1849-1866.

Radhakrishnan, R. and Kumari, B.D.R. (2013) Protective role of pulsed magnetic field against salt stress effects in soybean organ culture. Plant Biosyst 147(1):135-140. 
Radhakrishnan, R., Leelapriya, T., Ranjitha, B.D. and Kumari, D. (2012) Effects of pulsed magnetic field treatment of soybean seeds on calli growth, cell damage and biochemical changes under salt stress. Bioelectromagnetics 33:670-681.

Rizk, M.A. (2003) Possible control of sugarbeet pathogen Sclerotium rolfsii Sacc. by ELF amplitude modulated waves. Pakistan J Biol Sci 6(1):80-85.

Ruzic, R. and Jerman, I. (2002) Weak magnetic field decreases heat stress in cress seedlings. Electromagn Biol Med 21:69-80.

Ruzic, R., Vodnik, D. and Jerman, I. (2000) Influence of aluminum in biology effects of ELF magnetic field stimulation. Electro Magnetobiol 19(1):57-68.

Sen, A. and Alikamanoglu, S. (2016) Interactive effect of static magnetic field and abiotic stressors on growth and biochemical parameters of germinating wheat cultivars. IUFS J Biol 75(1):19-38.

Shao, H.B., Chu, L.Y., Jaleel, C.A. and Zhao, C.X. (2008) Water-deficit stress-induced anatomical changes in higher plants. C. R. Biol. 331:215-225.

Shine, M. and Guruprasad, K. (2012) Impact of pre-sowing magnetic field exposure of seeds to stationary magnetic field on growth, reactive oxygen species and photosynthesis of maize under field conditions. Acta Physiol Plant 34:255-265.

Shine, M., Guruprasad, K. and Anand, A. (2012). Effect of stationary magnetic field strengths of 150 and 200 $\mathrm{mT}$ on reactive oxygen species production in soybean. Bioelectromagnetics 33:428-437.

Strauss, S.Y. and Zangerl, A.R. (2002) Plant-insect interactions in terrestrial ecosystems. In Herrera, C.M. and Pellmyr, O. (eds), Plant-Animal Interactions: An Evolutionary Approach (pp. 77-106), Oxford: Blackwell Science.

Suzuki, N., Rivero, R.M., Shulaev, V., Blumwald, E. and Mittler, R. (2014) Abiotic and biotic stress combinations. New Phytol 203:32-43.

Swarbrick, P.J., Schulze-Lefert, P. and Scholes, J.D. (2006) Metabolic consequences of susceptibility and resistance in barley leaves challenged with powdery mildew. Plant Cell Environ 29:1061-1076.

Trebbi, G., Borghini, F., Lazzarato, L., Torrigiani, P., Calzoni, G.L. and Betti, L. (2007) Extremely low frequency weak magnetic fields enhance resistance of $\mathrm{NN}$ tobacco plants to tobacco mosaic virus and elicit stress-related biochemical activities. Bioelectromagnetics 28:214-223.

Verma, S., Nizam, S. and Verma, P.K. (2013) Biotic and abiotic stress signalling in plants. Stress Signaling Plants Genomics Proteomics Perspect 1:25-49.

Wang, W., Vinocur, B. and Altman, A. (2003) Plant responses to drought; salinity and extreme temperatures: Towards genetic engineering for stress tolerance. Planta 218:1-14.

Yinan, Y., Yuanm, L., Yongqing, Y. and Chunyang, L. (2005) Effect of seed pretreatment by magnetic field on the sensitivity of cucumber (Cucumis sativus) seedlings to ultraviolet-B radiation. Environ Exper Botany 54:286-294.

Ziska, L.H., Tomecek, M.B. and Gealy, D.R. (2010) Evaluation of competitive ability between cultivated and red weedy rice as a function of recent and projected increases in atmospheric $\mathrm{CO}_{2}$. Agron J 102:118-123. 


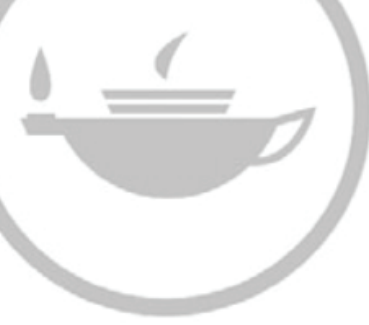

Taylor \& Francis Taylor \& Francis Group http://taylorandfrancis.com 


\title{
10 Practical Uses of the Method of Epigenetic Regulation of Protein Synthesis in the Agricultural Field
}

\author{
Victor Prévost, Michel Duhamel and Pedro Ferrandiz \\ Genodics SAS \\ Joël Sternheimer \\ Université Européenne de la Recherche
}

\section{CONTENTS}

Introduction: The Genodic Method. 111

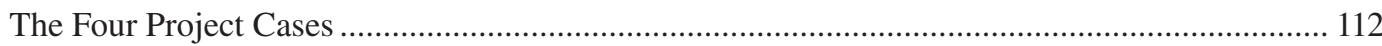

Materials and Methods for the Four Cases ….......................................................................... 112

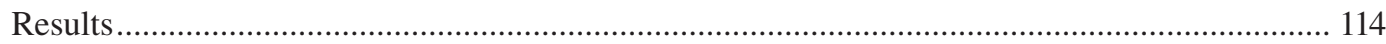

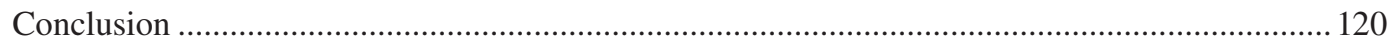

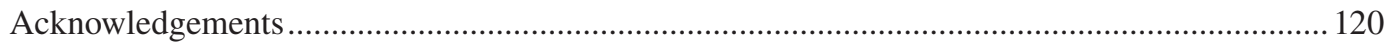

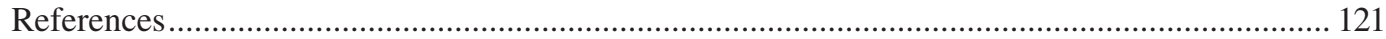

\section{INTRODUCTION: THE GENODIC METHOD}

Genodics is a discipline introduced by the physicist Joël Sternheimer that aims to describe interactions of an undulatory, wave-like nature (de Broglie waves; de Broglie, 1924) that are involved in the regulation of the biosynthesis of macromolecules associated with gene expression. The application of this discipline has resulted in a method for the epigenetic regulation of the biosynthesis of specific proteins in living organisms, by means of sound diffusions called proteodies, which reproduce certain characteristics of the targeted proteins through a succession of audible frequencies forming a structured melody. The process was discovered and patented by Sternheimer based on his work in theoretical physics that subsequently found applications in biology (Sternheimer, 1992).

All proteins are chains of molecules called amino acids, in a specific order. To transpose them into modulated sound waves or protein melodies (proteodies), each amino acid is allocated a sound wave frequency calculated with the matter-wave equation of de Broglie and transposed into the audible range according to the rules of harmonics. The resulting series of sound are interpreted by choosing a type of voice and a tempo and modulating the duration of each note, in order to get an actual musical score. On small samples, such as in a laboratory, the broadcast equipment can be a simple mp3 reader, combined with a time programmer. In greenhouses or outside, bigger broadcast devices are used that are autonomous (with solar panel and battery), water-resistant and programmable via Global System for Mobile Communications (GSM). More powerful than small mp3 readers, with 4 loudspeakers and 2 amplifiers, each proteody box or P-Box can cover up to 15 ha. Broadcasted programmes are short, from 5 to 10 minutes, but can be repeated from 1 to 5 times daily, according to the needs of plants. Each broadcast programme includes several relevant 
proteodies and corresponds to a specific metabolism to regulate or to a plant disease to reduce. On polycultures, the broadcast programmes are modified more often than on monocultures, in order to respond day after day to the needs of each type of plant, as observed by the farmer.

Genodics is also the name of a biotechnology company, created to develop applications for this process and to provide market proof of the concept. To date, the company has established 280 treatment installations, spread over 2,500 ha of crops (vines, market gardening and arboriculture) and 180 farms. The company's activities address many different agricultural issues.

\section{THE FOUR PROJECT CASES}

In this chapter, we present four projects conducted by Genodics, the results of which show a significant number of effects that hold potential for the expansion of the process and the development of new applications. The projects are outlined below.

Case $1 a, b$ and $c$ : The prevention and reduction of the effects of Esca on vines between 2008 and 2019. Esca is a cryptogamic (spore-based), vascular wilt disease involving a large number of anaerobic fungi, which develop inside the woody parts of the vine and can lead to the sudden death of the vine stock by blocking the rise of sap (apoplexy). This project was carried out throughout France following the ban on the use of sodium arsenite in 2002 (Ferrandiz et al., 2018; Bargoin et al., 2004).

Case 2: The prevention and reduction of the impact of Grape Powdery Mildew on a 7-ha vineyard. This mildew is caused by the fungus Plasmopara viticola. It affects the leaves and berries and can substantially weaken the vigour of the vines, as well as the volume of the harvest and the quality of the wine.

Case 3: The prevention and reduction of the impact of Erwinia on endives. Erwinia is a bacterial disease causing brown rot in endive, which has a strong impact on their quality and the marketable quantity.

Case 4: The reduction of the impact of mosaic viruses on courgettes. Zucchini Yellow Mosaic Virus (ZYMV) and Watermelon Mosaic Virus (WMV2) affect cucurbit crops. These viruses can cause extremely severe damage, resulting in significant crop losses.

The data used in this study come directly from the farms using the genodic process. The data were collected either by the farmer and his/her teams or by the Genodics team with verification and validation by the farmer. All measurements were based on the actual production of the farms under normal conditions, and therefore reflect the actual impact, in real terms, of the use of the process.

In general, the acoustic sequences produced from the protein structures of the plants concerned aim to stimulate their defence metabolisms, and those corresponding to pathogens aim to reduce their activities. The process thus tends to inhibit the pathogen and limit its impact on the host (Sternheimer, 2006).

\section{MATERIALS AND METHODS FOR THE FOUR CASES}

In the cases presented, the following evaluation methods were used, as shown in Table 10.1.

These cases are representative of the spectrum of action of the process on different kingdoms of living organisms, whether vegetal (vine, endive, courgette), bacterial (Erwinia), fungal (Esca and Mildew) or viral (Mosaics).

The installation of the acoustic diffusion system required is adapted to the agricultural context and the evaluation method chosen. In general, a stand-alone sequence diffusion box is installed to cover a maximum surface area, with additional diffusion boxes on larger surfaces. In order to highlight a diffusion gradient (in the cases of Grape Powdery Mildew and courgette Mosaic), part of the production is deliberately left out of reach of the diffuser in order to be able to compare the 
TABLE 10.1

\section{Evaluation Methods Used for Each of the Four Cases}

$\begin{aligned} & \text { Case } \\ & \text { All cases (general) }\end{aligned}$
$\begin{aligned} & \text { Counting (exhaustive or statistically significant sampling) of symptoms and mortality related to the } \\ & \text { presence of a pathogen in the study population } \\ & \text { Comparison with historical data from the same plots } \\ & \text { control }\end{aligned}$
$\begin{aligned} & \text { Esca with control } \\ & \text { Mildew and Mosaic } \\ & \text { viruses }\end{aligned}$
$\begin{aligned} & \text { Comparison with data from a control group with the same characteristics and growing conditions } \\ & \text { the power of the sound (the acoustic scattering mode) }\end{aligned}$

development of the crop as well as the presence of the fungus or viruses at different distances from the diffusion device.

Case $1 a$ and $b$ : Prevention and reduction of the effects of Esca on vines.

A count of vines showing symptoms of Esca was carried out each year over 1-6years around the harvest period on 91 plots of productive vineyards in France, covering a total of 260 ha, and compared with counts undertaken on the same plots during 1-3 years before the broadcast of sequences, in order to accurately estimate the pressure linked to the presence of the pathogen on the plots as well as the mortality associated with it. Mortality by vine apoplexy was the most reliable indicator for assessing the impact of Esca on both production and the condition of the plot. This parameter was therefore used as a reference for the comparison of the impact of Esca with and without the use of the genodic process. Case study la groups the plots for which historical data on Esca-related mortality could be retrieved from vine growers (chefs de culture des vignes) who are in the habit of counting and replacing dead strains every year. With these data, a chronology of the mortality rate before and after the implementation of the genodic process was carried out, in order to report on the comparative evolution of each plot exposed to the acoustic sequences. The reference value of the mortality rate used in Case $1 \mathrm{~b}$ corresponds to the average of the mortality rates of the previous years, before the genodic process was set up, as evaluated by the vine growers when replacing the dead strains, a task that they carry out every 2 or 3 years. In both cases, an evaluation of Esca-related mortality was carried out at the end of the first year of application of the process, by the Genodics team accompanied by the vine grower, and was repeated in subsequent years.

Case 1c: Prevention and reduction of the impact of Esca on the vine, with a control plot.

Study carried out at the Château Gaudrelle in Vouvray, from 2014 to 2019, on two plots about $500 \mathrm{~m}$ apart, planted in the same year (1986) with the same grape variety and in the same terroir. The counting of vines showing symptoms of Esca has been carried out every year since the genodic process was implemented, and systematically validated with the vine grower, on the same day for both plots $(3,972$ individual plant locations for the control plot and 6,050 locations for the tested plot).

Case 2: Prevention and reduction of the impact of Mildew on a 7-ha vineyard.

At the Château Fayau in Cadillac, in 2016, a 7-ha vineyard received the usual anti-mildew fungicidal treatment applied by the vine grower. The diffuser was placed at one end of the vineyard, and diffusions were perceptible up to $150 \mathrm{~m}$ from this spot. Eighty-five plots comprising five vines each were selected, regularly spaced to cover the entire vineyard. At the beginning of July 2016, the number of mildew blotches on grapes (visible mark of the disease) on each plot was recorded.

Case 3: Prevention and reduction of the impact of Erwinia on endives.

Study carried out at the market garden Delahaye in Touraine, during the growing season 2011-2012 from mid-October 2011 to the end of March 2012. This experiment was carried out 
during the endives' forcing phase, inside a thermo-regulated room with ambient humidity saturation. For each batch of endives, placed in containers, the cultivation period (forcing) lasted about 20 days, during which time the roots were permanently bathed in a nutrient solution. On maturity, the containers were removed from the forcing room and the endives harvested. New containers were immediately put in place for the next crop. During the 25 weeks of the season, acoustic diffusions were made for periods of 21 days, followed by 21 days without diffusion, alternating. Thus, depending on their date of entry into the forcing room, the endives in each container received between 1 and 20 days of these sound broadcasts, during which the sequences were broadcast daily for 24 minutes at the beginning of season and 34 minutes at the end of season.

In this way, a diffusion gradient over time was realised in order to compare the batches, with some receiving 500+ minutes at the beginning of the season and others $700+$ minutes at the end. The loudspeakers of the diffusion system were installed inside the thermo-regulated room, while the amplifier and programmer were placed outside the room. For each batch, in addition to its exit date from the forcing room (i.e. the date of harvest), the following characteristics were recorded:

- Quantity of endive produced, in kilograms;

- Duration of the broadcast on the batch, from 0 to the total number of days spent in the room (up to 21 days);

- Percentage of 'second-grade' endive (based on the exterior appearance such as shape, size and quality) in relation to the total produced;

- Production yield, in number of endives and in kilograms per container (based on kg per container $\times$ no. containers per batch).

A total of 541 tonnes of endives produced under these conditions, grouped by batch, were analysed.

Case 4: Reduction of the impact of Mosaic Virus on courgettes.

This experiment was carried out on the market garden of l'Oustalet, Bouches-du-Rhône, in 2009, in 7 polytunnels on a sample of 100 courgette plants per tunnel (over $400 \mathrm{ft}$ of plants in total, of the Satellite variety). The tunnels were $7 \mathrm{~m}$ wide, $80 \mathrm{~m}$ long and $3 \mathrm{~m}$ apart. The tunnel closest to the diffusion device was $20 \mathrm{~m}$ from the device, and the furthest tunnel was between 87 and $94 \mathrm{~m}$ from the device. The tunnels were installed perpendicular to the direction of the Mistral wind, and the sound was emitted in the opposite direction to the Mistral. The sequences, aimed at reducing the proliferation of viruses and stimulating the resistance of the courgettes, were broadcast once a day for 6 minutes throughout the production phase from 30 July (planted on 6 July, first harvest on 6 August). For each selected courgette plant in each tunnel, the following criteria were recorded:

- healthy plants;

- plants showing virus-related symptoms (filiform or mottled leaves);

- dead plants.

In this way, the degree of impact of the virus could be assessed in a gradient from the loudspeaker to the furthest tunnels.

\section{RESULTS}

Case 1a: Prevention and reduction of the effects of Esca on the vine, with historical data.

The historical values of the Esca mortality rate are plotted in Figure 10.1a and b, together with mortality rates collected year by year from the start of the genodic process (year 1). Prior to year 1, the mortality rate averaged between $1.8 \%$ and $5.5 \%$. From year 1 onwards, there is a progressive decrease in the mortality rate, around $1.5 \%$ in year 1 (start of the diffusion process) and then between $1 \%$ and $2 \%$ mortality in the following years. The difference between before and after 


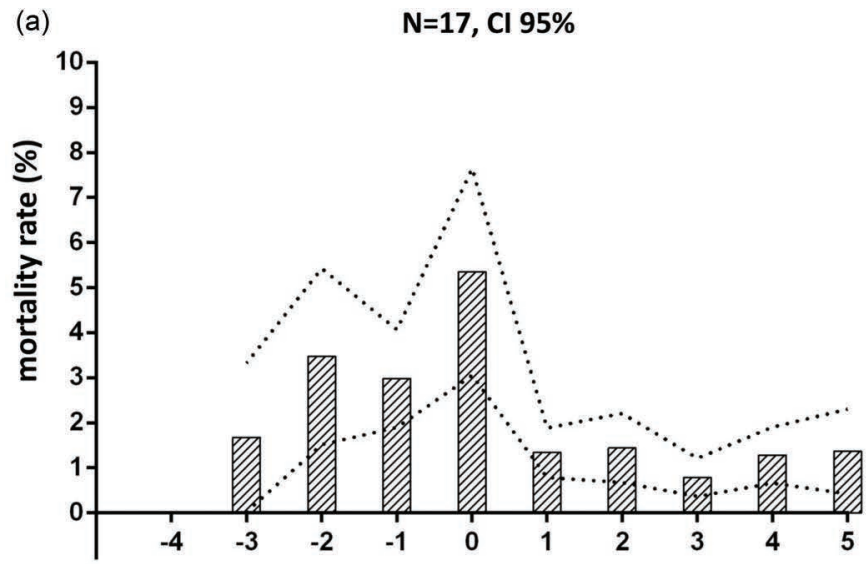

(b)

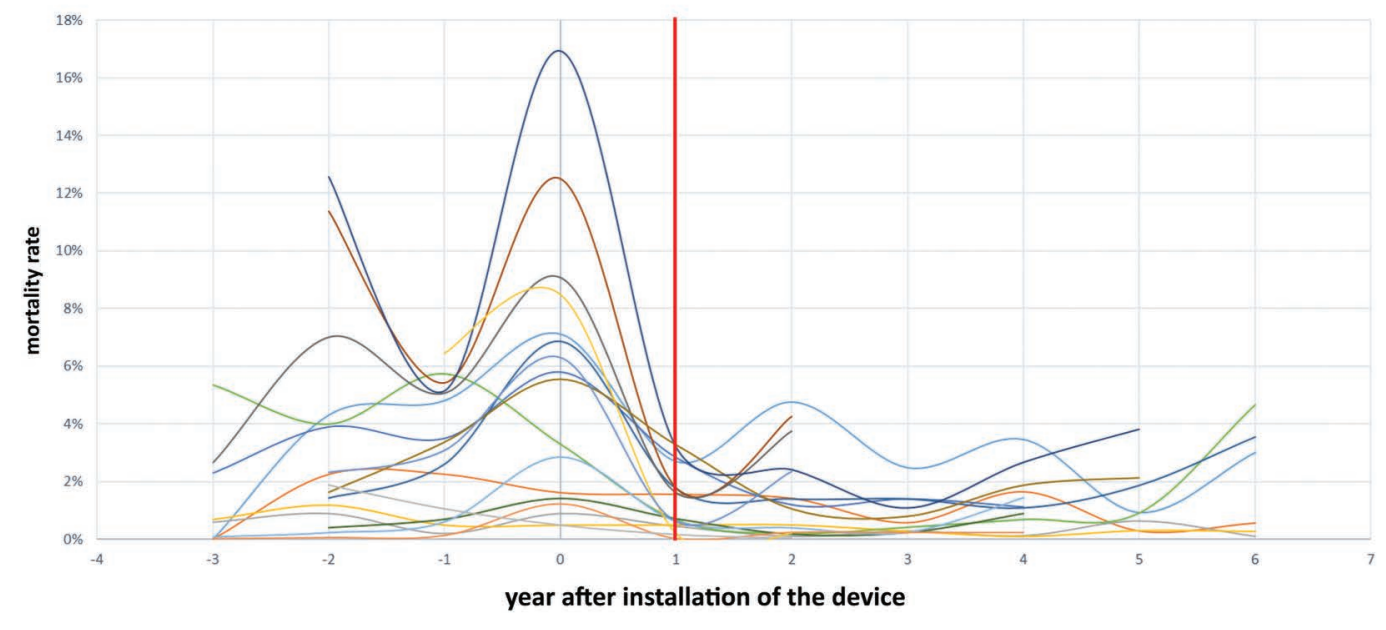

FIGURE 10.1 (a) Evolution of Esca-related mortality rate before and after genodic use. (b) Esca-related mortality rate before and after genodic use.

implementation of the process is significant with a $95 \%$ confidence interval. These results cover data from 17 plots, for a total area of 43 ha (about 200,000 vine stocks).

Case 1b: Prevention and reduction of the impact of Esca on vines, with historical averages.

Mortality data related to Esca collected year after year were used to calculate the evolution of this mortality based on the historical average of each plot. The historical average was the percentage loss per year before the beginning of the experiment, based on 3-5 years of available data. The colour curves in Figure 10.2 show the evolution of mortality rates on the 91 plots, each compared with the local average mortality rate; the black line shows the annual means; and the vertical bars show the confidence intervals for each year's data, with a chosen confidence index (CI) of 99\%. There is an average decrease in the mortality rate of $57 \%$ from the first year of use, then a stabilisation in the following years to between $50 \%$ and $65 \%$ of the initial mortality rate. The yearly variations are mainly related to differences of climatic conditions in the areas of these plots.

Figure 10.2 also shows the raw data used to calculate the average data, represented by the curve described above. It is interesting to note that the variations in the mortality rate have a large amplitude depending on the plots. The dispersion of these results reflects a statistical effect of the process, spread over all the treated plots, with a central value of between $50 \%$ and $70 \%$ reduction in Esca-related mortality. 


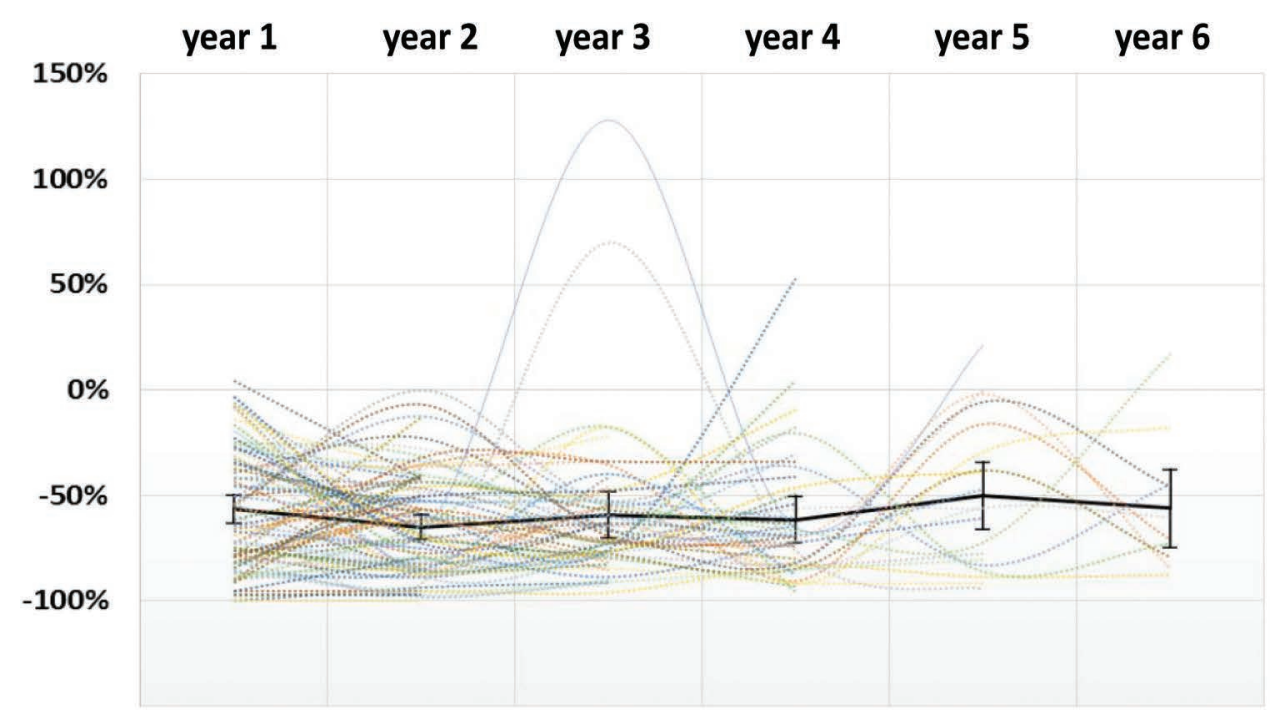

FIGURE 10.2 Evolution of the Esca mortality rate compared to the average historical mortality rate ( $N=91$ plots), 1,209,020 vine stocks on 260 ha total, CI 99\%.

Case 1c: Prevention and treatment of Esca on vine, with control plot.

By comparing the results obtained for the control plot and the genodic plot, it can be noted that for both symptoms and mortality rate, Esca expression varies in the same way depending on the year on both plots. This corroborates the similarity of the plots and the context in which they evolve (climate, pathogens, exposure, etc.). Concerning symptoms such as mortality, a systematically lower rate is observed on the genodic plot that received the acoustic sequences (Figure 10.3a and b). These differences are between $38 \%$ and $80 \%$ less for total Esca expression (symptom + mortality) in the plot that received the sequences (Figure 10.3e). When observing the distribution of results in graphs in Figure 10.3c and d, it appears that the dispersion of values is greater for the control plot, which is more marked for the symptoms (value between $0 \%$ and $4 \%$ for the 'genodic' plot and between $0.5 \%$ and $11 \%$ for the 'control' plot). All these results indicate a difference in the development of Esca on these two plots with otherwise identical characteristics. The annual seasonal patterns that condition the natural development of the Esca are well distributed from plot to plot each year, but appear to be markedly reduced, between $38 \%$ and $80 \%$, in the plot that was exposed to the genodic sequences.

Case 2: Prevention and reduction of the impact of Mildew on a 7-ha vineyard.

The number of blotches on bunches of grapes relating to the presence of mildew was counted by plots of five vines ( $n=83$ plots). These values were represented according to the distance of each group from the scattering device. Figure 10.4 shows an increase in the number of mildew blotches as a function of distance, particularly at distances of $150-200 \mathrm{~m}$. The linear regression of the data on the graph (curving upwards) shows a strong decrease at this distance, which corresponds to the acoustic diffusion range limit of the installed equipment. Between 0 and $150 \mathrm{~m}$, the number of blotches by plot ranges from 0 to 1 , and then, it varies from 1 to 7 blotches by plot between 150 and $250 \mathrm{~m}$. The correlation between proximity to the device and the number of blotches is represented by the linear regression curve, within the $99 \%$ confidence interval shown as a dotted line on the graph. These results show an increase in the impact of mildew on grape clusters as one moves away from the genodic sequence diffuser, with a noticeable increase more than $150 \mathrm{~m}$ from the diffuser.

Case 3: Prevention and reduction of the impact of Erwinia on endives.

Batches of endives were grouped according to the duration of their stay in the forcing chamber. Figure 10.5a shows the change in the percentage of second-grade endives as a function of the duration of exposure, showing a clear decrease in the rate of second-grade endives with increasing exposure 
(a) Esca symptoms evolution 2014-2019

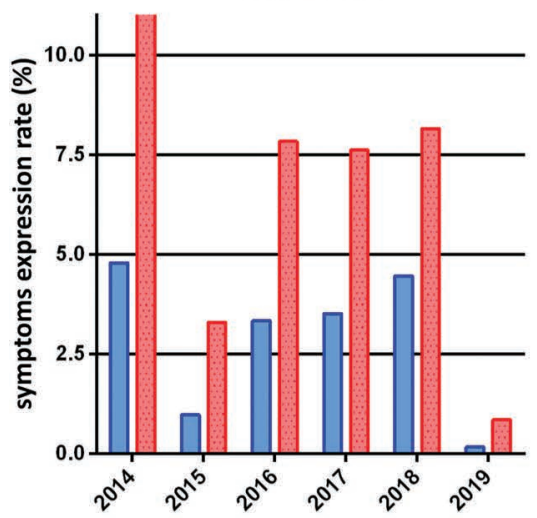

(c) Synthesis of symptoms expression

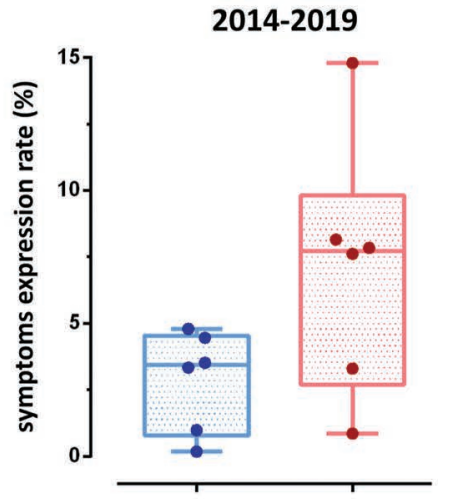

(b) Esca-related mortality evolution

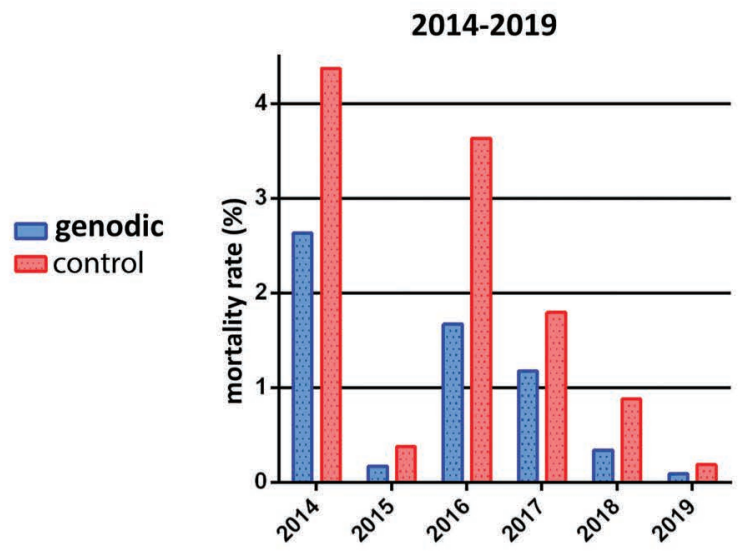

(e)

Esca symptoms comparison

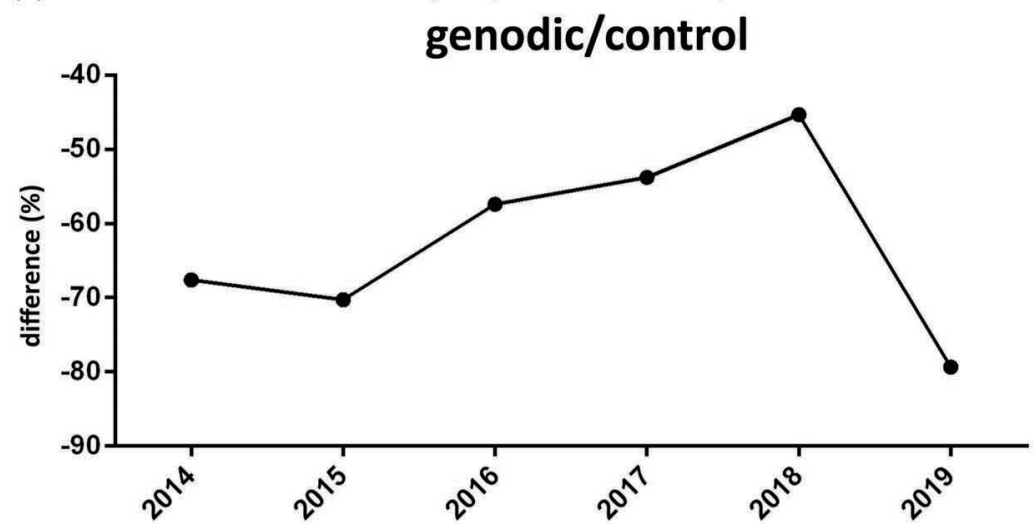

FIGURE 10.3 (a-e) Comparison of the evolution of Esca with and without genodic treatment. 


\section{Number of mildew blotches by plots of 5 vines as a function of the distance from the device $\mathrm{Cl} 99 \%-\mathrm{N}=83$ plots/415 vines}

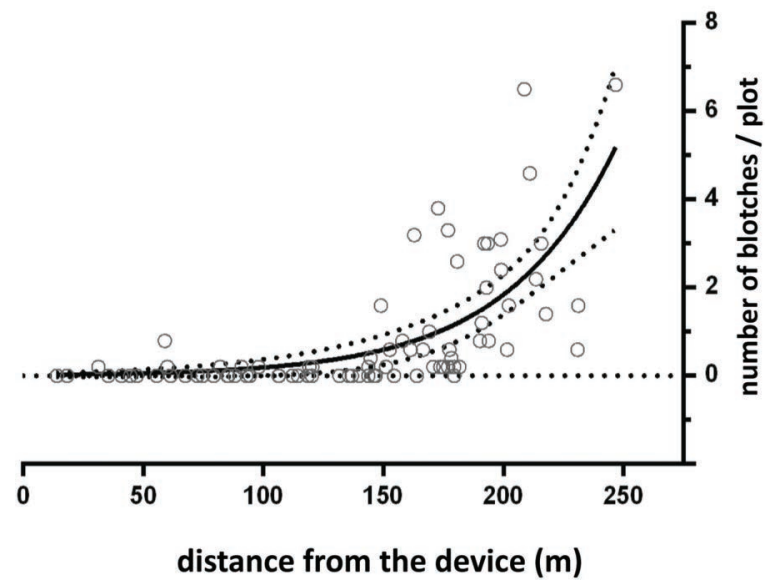

FIGURE 10.4 Number of mildew blotches on grapes, on each plot of five vines, as a function of the distance from the broadcasting device.

(a) $\mathrm{Cl} 95 \%-\mathrm{N}=\mathbf{2 1 1}$ series/541 $\mathrm{t}$ of endives

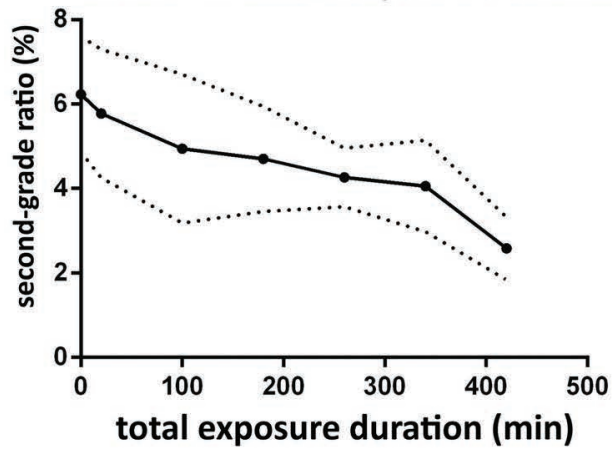

Linear regression of the curve

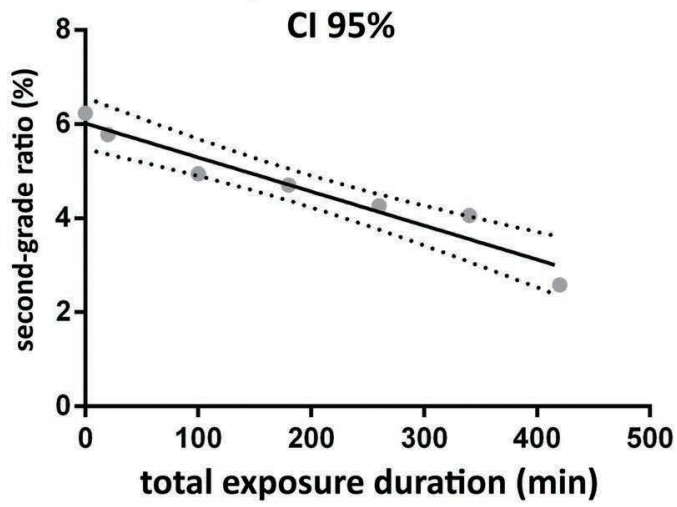

(b) $\mathrm{Cl} 95 \%-\mathrm{N}=\mathbf{2 1 1}$ series/541 $\mathrm{t}$ of endives

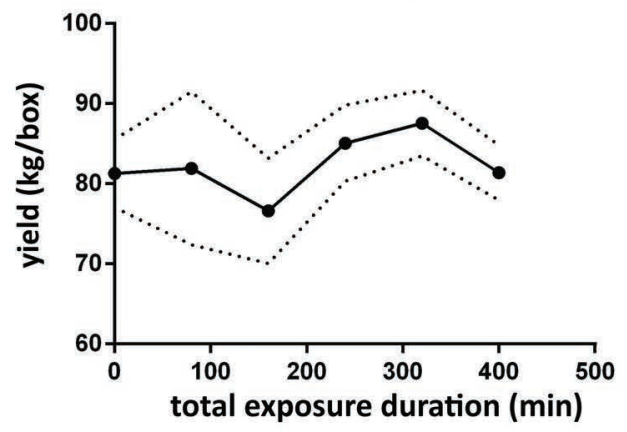

total exposure duration ( $\mathrm{min})$

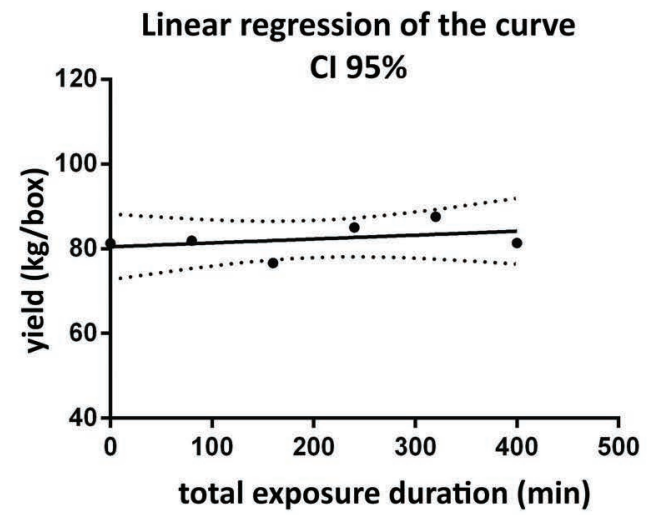

FIGURE 10.5 (a) Change in percentage of second-grade endives as a function of duration of exposure. (b) Evolution of endive yield as a function of exposure time. 
to the genodic sequences. Batches that received no diffusion had a rate of second grade of around $6 \%( \pm 1.5 \%)$; then, this rate decreases with diffusion time until it reaches the minimum value around of $2.5 \%( \pm 0.5 \%)$ for a maximum diffusion time of 400 minutes spread over the duration of the forcing (20 minutes each day). The linear regression of these points shows a reduction by a factor of 2 , between no diffusion (6\%) and 400 minutes of diffusion (3\%). In Figure 10.5b, there is an insignificant increase in performance as a function of the duration of exposure to the sequences. The high variability for the production of each batch results in a large confidence interval (between \pm 5 and $\pm 10 \mathrm{~kg} /$ container, although a (insignificant) trend towards increased yield can be observed by linear regression of the data.

Case 4: Reduction of the impact of Mosaic Virus on courgettes.

(Actual distances from the tunnels on the device are as follows: 20, 30, .., $80 \mathrm{~m}$.)

In each tunnel, the values for the number of healthy, diseased or dead plants (as a result of Mosaic Virus) were plotted as a function of the distance from the tunnel to the sequence delivery device. The number of diseased plants increased sharply $30 \mathrm{~m}$ away from the diffusion apparatus (tunnel number 3), and then increased more gradually up to plants between 80 and $100 \mathrm{~m}$. The number of symptomatic plants at $30 \mathrm{~m}$ appears to be an exception in the linear progression of the number of unhealthy plants, as observed in the linear regression of values (Figure 10.6). The number of healthy
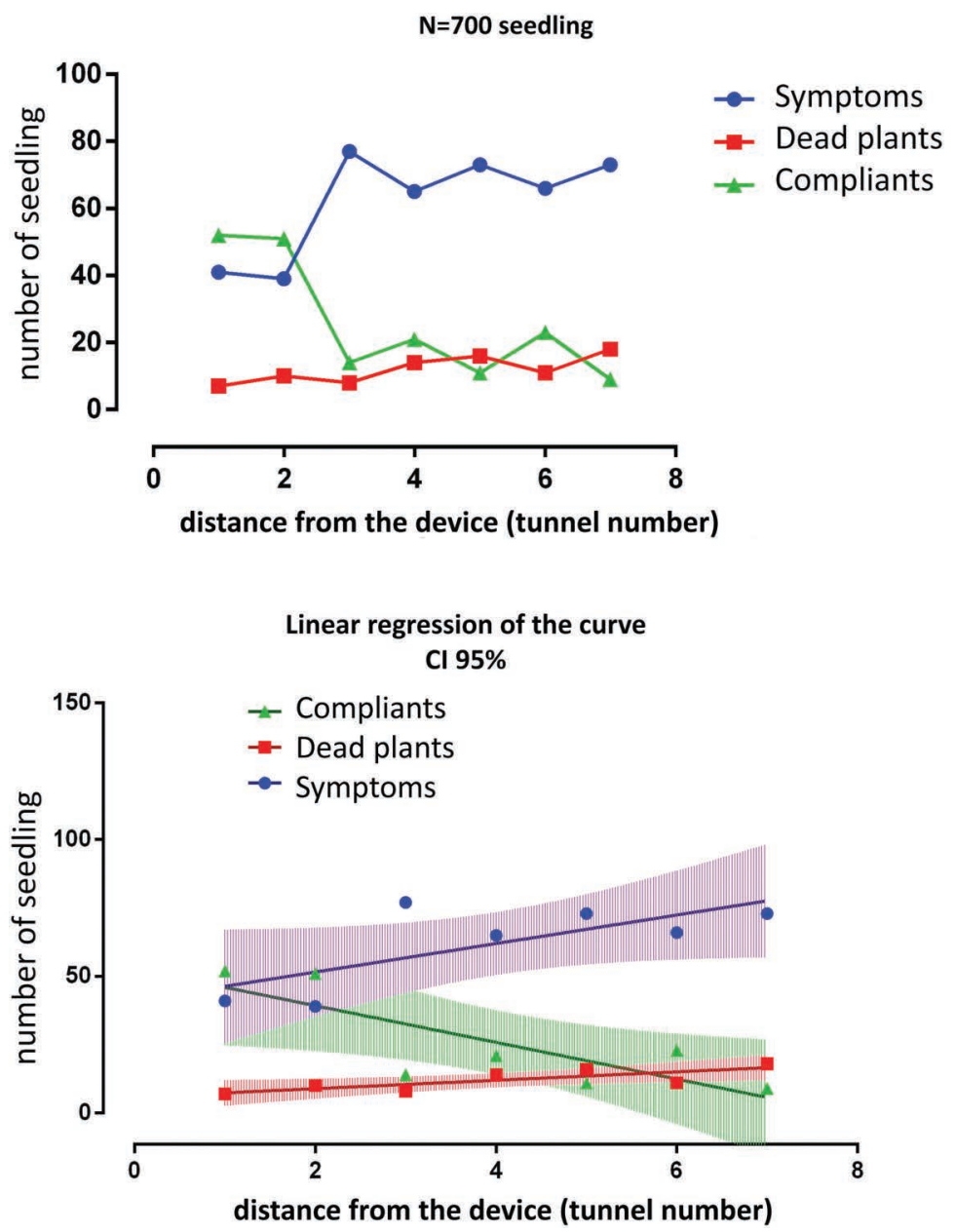

FIGURE 10.6 Virus expression as a function of distance from the delivery device (where compliant signifies healthy). 
plants follows the same progression in reverse, decreasing with the distance from the scattering device, from $50 \%$ at $20 \mathrm{~m}$ to $0 \%$ at $80 \mathrm{~m}$. Mortality increased linearly with distance, from $5 \%$ at $20 \mathrm{~m}$ to $20 \%$ at $80 \mathrm{~m}$. The most reliable parameter here is the evolution of mortality, which had a narrower confidence interval and showed a more significant trend. However, the tendency for symptoms to decrease with distance from the device is clearly identifiable, particularly through linear regression of the data.

\section{CONCLUSION}

Through these case studies, we have observed the effects of the diffusion of the sound sequences designed by Genodics on plant production results as the following:

- a significant decrease in mortality linked to the vine fungus Esca (between 50\% and 70\%);

- a reduction in the proliferation of Mildew on grapes by a factor of 6 ;

- a reduction in virulence in the case of Mosaics on courgettes;

- a significant reduction in the number of second-grade endives, by a factor of 2 , through the prevention of Erwinia.

Our experiments demonstrated that within a certain range, the effect of proteodies on plants is proportional to the duration of the broadcast and the power of the sound. This second factor diminishes with the distance from the loudspeaker, resulting in an effect gradient which can be measured.

In the case of Mildew on grapes and Mosaic on courgettes, a spatial gradient of the effect of genodic sequences was noted, while in the case of endives, there was a temporal gradient. This corroborates observations made elsewhere in the field with regard to distance from the diffusion apparatus and diffusion duration. The results are consistent with the characterisation of the effects obtained with this process, over a large number of repeated measurements and several models. These results, in addition to those obtained during the validation of Sternheimer's patent, ${ }^{1}$ provide elements that validate the concept developed by Sternheimer and the applications that have followed on since.

This observation is further supported by recent experiments conducted on human cancer cell cultures, published in 2018, during which the assay of the protein specifically targeted by the acoustic sequences was carried out (Orhan \& Gulbahar, 2016). Further, plant culture and target protein assays under the conditions of application of the genodic process have recently been implemented in the ERRMECe laboratory at the University of Cergy-Pontoise, Paris (CERGY, 2017). These results, which largely concur with those of this study, were published in September 2020 (Prevost et al., 2020).

The cases presented here represent only a portion of the applications developed by Genodics. The other applications have not benefited from as exhaustive and precise monitoring as the studies cited here, and some applications did not succeed, either because their results were inadequate to be economically interesting or for reasons independent of Genodics' activity. This study demonstrates the effectiveness of chemical-input-free methods for crop protection and support.

Disclaimer: The information contained in this chapter is the property of Genodics SAS. The implementation of the proteodies is protected by copyright.

\section{ACKNOWLEDGEMENTS}

We would like to thank all those who participated in the development of this work in biology, in particular Marie-Claude Lang, Vincent Bargouin and Michel Cressy, as well as Jacques-Joël Houziel,

\footnotetext{
${ }^{1}$ METHOD FOR THE EPIGENETIC REGULATION OF PROTEIN BIOSYNTHESIS BY SCALE RESONANCE, https://worldwide.espacenet.com/publicationDetails/originalDocument?FT=D\&date=20070829\&DB=EPODOC\&local e=fr_EP\&CC=EP\&NR=0648275B1\&KC=B1 (accessed 23 September 2020).
} 
Jean-Marie Pelt and Christian Loizeau. We would also like to thank the vine growers, market gardeners and arboriculturists who have placed their trust in us and who have contributed to these and other research projects. We would also like to thank all Genodics shareholders and all those who have supported and accompanied the company since its inception.

\section{REFERENCES}

Bargoin, V., Ferrandiz, P. Sternheimer, J. et al., (2004) Application Expérimentale d'un Procédé de Régulation Epigénétique de la Biosynthèse des Protéines au Traitement de 1‘ESCA. Réseau Associatif de Chercheurs Indépendants (RACHI), Paris, France.

CERGY (2017) La Musique Soigne les Plantes: ERRMECe à la recherche de preuves scientifiques. Research News, 30.11.2017. CERGY Paris Université. https://www.u-cergy.fr/fr/recherche-et-valorisation/ actualites-recherche/musique-et-plantes.html.

de Broglie, L. (1924) Recherches sur la théorie des Quanta. Physique [physics]. Migration - université en cours d'affectation, Français. https://tel.archives-ouvertes.fr/tel-00006807/document.

Ferrandiz, P., Duhamel, M., and Sternheimer, J. (2018) Epigenetic Regulation of Protein Biosynthesis by Scale Resonance: Study of the reduction of ESCA effects on vines in field applications - summary 2016. In Life Sciences, Information Sciences (pp. 305-315). https://www.researchgate.net/publication/324266455_ Epigenetic_Regulation_of_Protein_Biosynthesis_by_Scale_Resonance_Study_of_the_Reduction_of_ ESCA_Effects_on_Vines_in_Field_Applications_-_Summary_2016.

Orhan, I. and Gulbahar, B. (2016) Stimulation of protein expression through the harmonic resonance of frequency-specific music. Clinical and Investigative Medicine 39(6): S34-S38.

Prevost, V., David, K., Ferrandiz, P., Gallet, O., and Hindié, M. (2020) Diffusions of sound frequencies designed to target dehydrins induce hydric stress tolerance in Pisum sativum seedings. Heliyon 6(9): e04991

Sternheimer, J. (1992) Procede de Regulation Epigenetique de la Biosynthese des Proteines par Resonance d'Echelle. Patent: EP 0648275 B1. https://www.researchgate.net/publication/279181729_PROCEDE_ DE_REGULATION_EPIGENETIQUE_DE_LA_BIOSYNTHESE_DES_PROTEINES_PAR_ RESONANCE_D'ECHELLE.

Sternheimer, J. (2006) Genodics applied to ecosystem healing. Colloque Serge Winogradsky aujourd'huiAt: SIAAP; Colombes (France). https://www.researchgate.net/publication/269402342_Genodique_appliquee_ a_la_guerison_des_ecosystemes. 


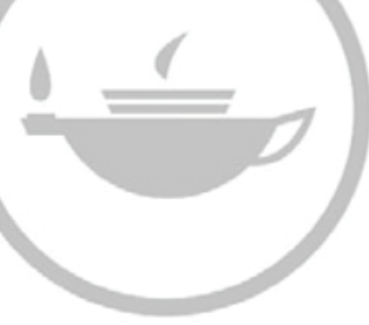

Taylor \& Francis Taylor \& Francis Group http://taylorandfrancis.com 


\title{
11 Astronomical Rhythms in Biodynamic Agriculture A Brazilian Case Study on the Yield and Quality of Daucus carota $L$. under Biodynamic Management
}

\author{
Pedro Jovchelevich \\ Brazilian Association of Biodynamic Agriculture
}

\section{CONTENTS}

Introduction. 123

The Importance of Ethno-Astronomy, Past and Present ......................................................... 123

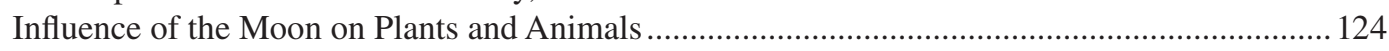

The Use of Astronomical Rhythms in Biodynamic Agriculture ............................................ 126

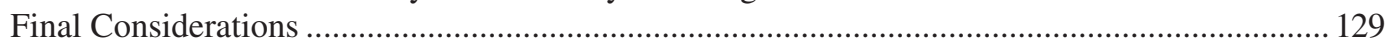

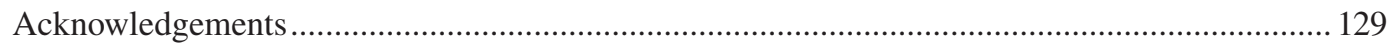

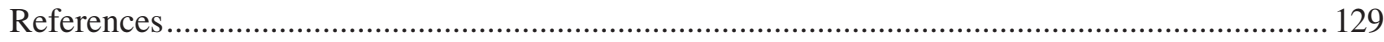

\section{INTRODUCTION}

The history of the great civilisations of the past (such as the Egyptians, Babylonians, Greeks, Incas and Aztecs) shows the importance they gave to astronomical rhythms, not only for agriculture, but for all daily activities (ethno-astronomy). Today in Brazil and elsewhere, indigenous populations still apply this knowledge in agriculture. In the 1920s, Rudolf Steiner reconsidered this popular knowledge and extended it, incorporating other rhythms of the Moon and the movement of the planets and the Sun into the planning of agricultural activities. In the international biodynamic movement, the best known astronomical/agricultural calendar is the one created by the farmer Maria Thun (Thun, 1986), which is translated into several languages for worldwide use, and updated every year. Some biodynamic researchers, such as Spiess (1994) and Goldstein (2000), have studied this theme of chronobiology or biological rhythms in cultivated plants. This chapter aims, first of all, to provide some examples of the use of ethno-astronomy in the South, mainly in Brazil, and then reviews selected scientific research on the influence of the Moon on plants and animals, and in biodynamic agriculture. It concludes by reporting the results of some of the author's own field trials on chronobiology.

\section{THE IMPORTANCE OF ETHNO-ASTRONOMY, PAST AND PRESENT}

Various ethnological studies document the relationship between the farming practices of indigenous peoples and their knowledge of astronomical phenomena. This knowledge is disappearing, but it can still be observed in traditional populations and especially the use of Moon phases in agriculture and forestry management (Restrepo-Rivera, 2004). Miller (2004) reports the discovery in 1993 
of the oldest known celestial disc. It dates from $1600 \mathrm{BC}$ and was found on Mittelberg Hill in Germany. This copper disc, with gold astronomical indications, has been studied by astronomers. It was found to indicate the movement of the Sun between the summer and winter solstices, showing the time when the frosts ended in the region by the position of the sunrise on a certain hill, as seen on the horizon. This information indicated the time when sowing should begin.

Jovchelevich and Vilela (2006), studying the common knowledge of the elderly population in the rural area of Roseira District in Botucatu, SP, Brazil, found that consideration of the lunar phases was a tradition that still persisted, with people having acquired this knowledge from their parents. The use of the waning Moon predominated in their diverse agricultural activities, in particular for chopping wood, but also in the planting and harvesting of grains. The knowledge of the traditional population at the Juréia-Itatins Ecological Station in São Paulo, Brazil, was investigated by Sanches (1997) who observed that the cutting of wood and vines depended on the phases of the Moon, the ideal time for this activity being 3 days before the waning Moon and up until 3 days afterwards.

The astronomical knowledge of the Bororo indigenous people in the state of Mato Grosso (Brazil) was studied by Fabian (2006) who observed their use of the synodic rhythm (the period of time that it takes for the Moon to compete a full cycle), or 'Ari' in their language, for the collection of palm shoots for handicrafts and the planting of specific types of seeds. They also considered the position of the Pleiades star cluster in the Taurus constellation as a seasonal indicator for agricultural activities. Interestingly, Afonso (2006a), who studied ethno-astronomy in sub-Saharan Africa, also cites the use of the star cluster of Pleiades by the Bantu indigenous people. They saw these stars as the shape of a plough, and when this cluster appeared on the horizon after sunset, they knew that the time had come to cultivate the land for planting. He found that the Tupi-Guarani indigenous people in Brazil also knew about and used the Moon phases for hunting, planting and cutting wood (Afonso, 2006b).

Recognition of Moon phases and their use in farming practice plays an important role in 'Quilombola' agricultural management. Quilombos are the descendants of enslaved peoples brought to Brazil, who live in rural communities characterised by subsistence agriculture and by cultural repertoires that have a strong link with their African heritage. They place special emphasis on the waning Moon phase which is when they sow and plant rice, beans, cassava and corn (although for cassava, some farmers prefer the new moon). The waning Moon phase begins 3 days after the full Moon and lasts up to 3 days before the new moon (Jovchelevich et al., 2016).

\section{INFLUENCE OF THE MOON ON PLANTS AND ANIMALS}

There is now a growing body of evidence worldwide indicating a relationship between lunar cycles and plant development and growth. Yet when dealing with complex systems, the direct and consistent causal relationship that science seeks is not always detectable. As early as 1953, Simão (1953) undertook doctoral research on the influence of Moon phases on vegetable productivity, using only the Moon phase change day. He concluded that there was no Moon influence, and attributed the changes he found to probable temperature variations and photoperiodism.

Palmer (1974), citing the work of Brown and Chow from 1973, discusses an experiment with beans (Phaseolus vulgaris), in which the dried seeds were stored in a cold chamber and then immersed in water for 4 hours every day, from noon, for 8 months over 1 year. A total of 158,000 seeds were used, and their daily weight gain was evaluated. A relationship between the proportions of water in the seeds with the synodic ${ }^{1}$ rhythm of the Moon was identified, the weight gain being greatest 1 day before the full Moon.

Endres and Schad (2002:161) describe the work of Maw who in 1967 studied the influence of ionised air on the growth of Lepidium sativum L. (garden cress), and noted that growth around the

\footnotetext{
${ }^{1}$ In the case of the moon's orbit around the Earth, this synodic period corresponds to observations of the moon's phases. The moon has a synodic period of 29.5 days.
} 
full Moon was poor, while growth around the new moon was vigorous. The same authors discuss the research of Rounds (1982) who explored the influence on the activity of leaf extracts from the following plants: Coleus blumei, Phaseolus vulgaris, Philodendron sagittifolium, Forsythia sp., Lilium tigrinum, Ulmus americana and Geranium sp. Rounds found that the stimulating effect was less in extracts made from leaves harvested just before the full and new moons.

In Germany, Spiess (1994) studied the influence of the Moon on several plants (radish, rye, carrot, beans and potatoes) for 6 years and noted the influence of various rhythms on the yields of these species. Potato planted before the full Moon had lower yields, and higher yields were achieved by planting near the lunar perigee (the point of the Moon's orbit closest to Earth). Radish productivity depended on the anomalistic ${ }^{2}$ and tropical ${ }^{3}$ rhythms of the Moon. In rye, the major Moon phases influenced the germination of the seeds, while the tropical rhythm of the Moon influenced the beans. Carrots sown approximately 3 days before the full Moon and in the Virgo constellation had a higher productivity than when sown in any other zodiac ${ }^{4}$ constellation, reaching up to $22 \%$ higher productivity, adjusted by a seasonal index. The Moon in Sagittarius gave the lowest productivity for carrots, and carrot cultures were influenced by synodic, sidereal ${ }^{5}$ and tropical rhythms.

In the USA, Goldstein (2000) experimented with the influence of the Moon phases on carrot yield. He observed the most positive effect when planting took place the day before the full Moon, causing a $15 \%$ increase in productivity (to $11.5 \mathrm{t} / \mathrm{ha}$ ). This percentage increase was statistically significant at $p=1 \%$. Planting during the new moon appeared to reduce productivity by $12 \%$ (10.9 t/ha), with a significance level of $p=11 \%$. Planting during the waning Moon reduced productivity even further, by $17 \%(9.7 \mathrm{t} / \mathrm{ha})$, and this contrast was significant at $p=2 \%$.

Zürcher et al. (2012) studied the variability of several properties of wood, by analysing measurable parameters. The material stemmed from four different sites in Switzerland, representative of central European conditions. The study involved 576 trees - Norway spruce (Picea abies Karst.) and sweet chestnut (Castanea sativa Mill.) - felled on 48 dates throughout the autumn and spring of 2003-2004. The wood properties analysed were water loss, shrinkage under controlled drying, and air- and oven-drying density. The statistical analysis of the complete data series revealed (in addition to a seasonal trend) a generally weak but significant role of the synodic and sidereal Moon cycles and, to a lesser extent, the tropical cycle. The lunar-related differences were more marked for the middle months of the trial. The most obvious variation in spruce occurred between samples of trees felled immediately before and after the full Moon.

Deep and Mittal (2014) in India studied the effects of the lunar activity on the sprouting of mung beans and observed a rhythmic character to their potassium content and sprout length that coincided with lunar phases. Statistical analysis of these variations ruled out randomness, with potassium content being highest when they are sown near the new moon, in its first quarter and just after the full Moon (supermoon).

Turning to animals, Elliott (2004) enumerated several scientific studies, showing the relation of the phases of the Moon with the behaviour of mainly aquatic animals. He found that North American crabs mated in the new and full Moons in May and June, grunion fish (Leuresthes tenuis) in California migrated to the beach to reproduce a few nights after the full or new moons between February and September, and coral polyps on the Great Barrier Reef reproduced after the full Moon in October and November.

Lobreiro (2002) analysed the relation between date of artificial insemination and the sex of dairy cattle with the anomalistic rhythm. Drawing from 7 years of recorded information from a dairy farm in Mato Grosso do Sul State, Brazil, and data on the occurrence of the lunar perigees

\footnotetext{
${ }^{2}$ In one anomalistic month, the moon describes its orbit from perigee to perigee, the point at which it is nearest to Earth.

${ }^{3}$ The ascending and descending moon periods, whereby the moon passes through six constellations approximately every 14 days, completing one cycle in about a month.

4 The set of constellations traversed by path of the Sun across the celestial sphere over the course of the year. The moon and all the planets also traverse these constellations, but at different times.

5 Timekeeping of the moon's movement through the 12 regions of the zodiac. The moon has a sidereal period of 27.3 days.
} 
and apogees (the point of the Moon's orbit furthest from to Earth), he noticed a greater tendency for male births close to the apogee and females close to the perigee, and more so when insemination occurred within a day of either.

\section{THE USE OF ASTRONOMICAL RHYTHMS IN BIODYNAMIC AGRICULTURE}

In modern biology, chronobiology is the sub-discipline that studies the rhythms of life. It includes not only lunar rhythms, but also the rhythms of the day and the Sun (Endres and Schad, 2002). The conceptual basis of biodynamic agriculture embraces the concept of such unseen forces. The farm property is seen as an individuality, an organism with its different components (including soil, plants, animals and humans). Within this, the biodynamic method considers three basic factors: (1) the cycles of substances and forces (forms of activity), (2) the interrelations between the components and the locality and (3) the organisation of the agricultural enterprise. The main goal is the fertilisation of soils in a lasting way through the activation of biological activity to modify the physical and chemical properties of the soil. To this biological aspect is added the dynamic aspect, which consists of the use of biodynamic preparations, using organic and mineral substances in a very diluted (homeopathic) form, and of research-based calendars on the influence of astronomical cycles on land and plants. Thus, biodynamic agriculture has its foundation not only in the practices that it shares with organic agriculture, but also in the recognition that the health of the soil, plants, animals and human beings depends on a broader relationship with forces that stimulate natural processes (Koepf et al., 1983).

Biodynamic agriculture revalues the common knowledge on using the phases of the Moon in agriculture and amplifies it, incorporating other rhythms of the Moon and the movement of planets related to agricultural activities in general. Rudolf Steiner, in the lectures of his agricultural course, addressed this cosmic influence on life here on Earth: the influence of the Moon, the Sun and the various planets and their relationships with soil, plants and animals. According to the first conference of Rudolf Steiner's agricultural course (2001: 34),

Hence we shall never understand plant life unless we bear in mind that everything which happens on the Earth is but a reflection of what is taking place in the Cosmos.

One of the basic principles of the Maria Thun calendar is related to the movement of the Moon around the Earth in its cycle of 27.3 days, and its passage through the 12 regions of the zodiac (i.e. the sidereal rhythm of the Moon). On each of these days within the cycle, plants receive stimuli that act on the development of their different constituent organs (root, stem, leaf, flower and fruit) (Thun, 2000).

This calendar is also based on the tropical rhythm of ascending and descending Moon periods. These periods should not be confused with the phases of the Moon at different times of the year. Another principle of Thun's calendar is to avoid agricultural activities in so-called unfavourable times. These are periods of eclipses, positions of lunar nodes of the Moon (the draconic rhythm), and perigee (anomalist rhythms) and the negative influence of planets' nodes. (Thun, 2000).

\section{Case Study: Yield and Quality of Daucus carota L. under Biodynamic Management, Related to Moon Rhythms}

Jovchelevich and Camara (2008) evaluated the influence of Moon rhythms (synodic, sidereal, anomalistic, tropical and draconic) on the yield and quality of carrot (Daucus carota L.) roots under biodynamic management sown on different dates. This participatory research was carried out over 2 years on a biodynamic farm in Botucatu, São Paulo State, Brazil. The farmer already held traditional knowledge about sowing carrot on the waning Moon. The influence of rhythms was tested by observing the effects of seeding at different planting dates in spring. In 2005, carrot was sown 
every day for 31 days, and in 2006, carrot was sown every other day during the same period as for 2005. The experiment was performed with 4 randomised blocks and 31 treatments (different dates) in 2005 and 14 treatments in 2006. The harvest was undertaken 82 days after the sowing, when carrot roots hold the most desirable qualities for organic and biodynamic consumers. The data for average yields on different days of planting were used to calculate a polynomial equation (as shown in Figure 11.1). This equation produced a line that described the general trend of effects that were due to planting at different times in the spring. The magnitudes of effects associated with planting at a specific lunar position were measured by the deviations from the trend curve (as shown in Figures 11.2 and 11.3). The more deviation up the curve, the better the result. The following characteristics were evaluated: fresh mass of roots and leaves, dry mass, root diameter, root length, the nitrogen, phosphorus and boron contents of the roots, and the perishability of the roots at 30 , 60 and 90 days post-harvest. These values were then analysed using a statistical analysis package. Statistical contrasts were used to compare the yields obtained (see Table 11.1).

Dry root mass was the only characteristic in the contrast between averages that showed significant results in both years of the experiment. Dry root mass is a very important characteristic because the roots are where all the nutrients of the plant are stored. Results showed that seeds sown in the new moon phase grew better than those sown in the waxing and waning Moon phases,

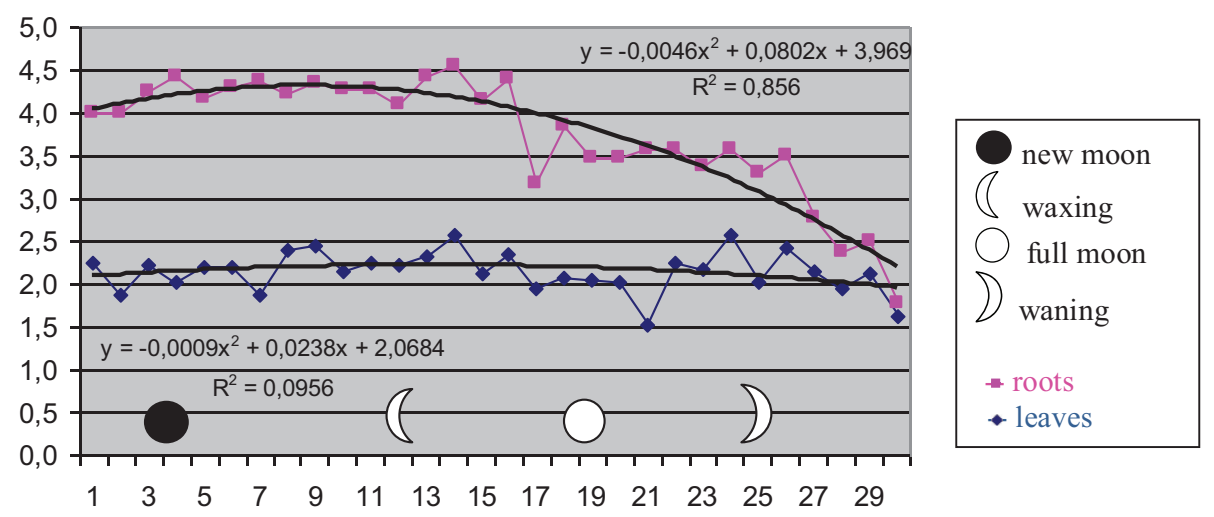

FIGURE 11.1 Fresh mass of roots and leaves (kg, Y-axis) for the different dates of sowing (X-axis) in 2005.
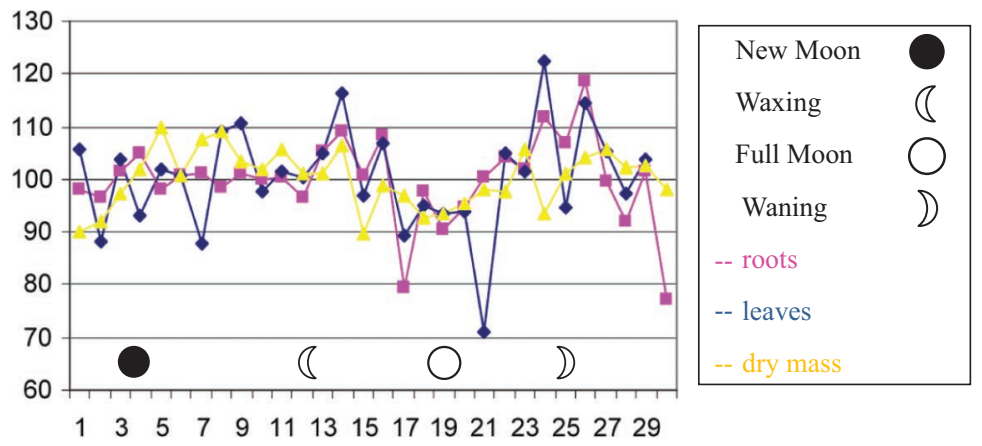

FIGURE 11.2 The per cent deviation from the trend line of the fresh root and leaf mass and dry mass of roots (Y-axis) for the different sowing dates (X-axis) in 2005. 


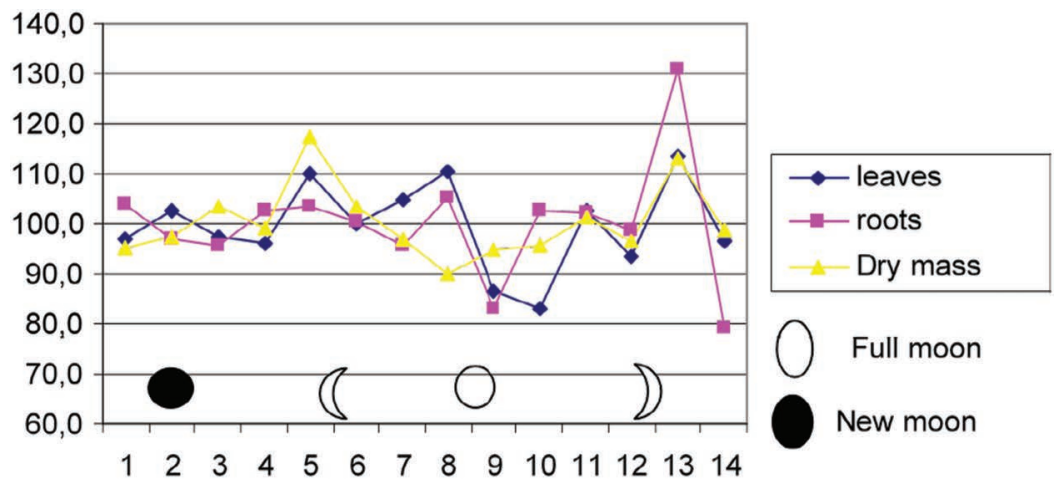

FIGURE 11.3 The per cent deviation from the trend line of the fresh mass of roots and leaves and dry mass of roots (Y-axis) for the different sowing dates (X-axis) in 2006.

TABLE 11.1

Deviations from the Trend Curve (\%) of Fresh Mass of Roots (FMR) and Leaves (FML) and Dry Mass of Roots (DMR) of Carrots, According to the Different Lunar Rhythms, in 2005 and 2006

\begin{tabular}{|c|c|c|c|c|c|c|}
\hline & FMR & FMR & FML & FML & DMR & DMR \\
\hline Lunar rhythms & 2005 & 2006 & 2005 & 2006 & 2005 & 2006 \\
\hline \multicolumn{7}{|l|}{ Synodic } \\
\hline Before full Moon & 95.84 & 105.37 & 97.05 & 110.55 & 96.06 & 89.85 \\
\hline Before new moon & 98.89 & 103.81 & 99.19 & 96.97 & 93.15 & 95.04 \\
\hline \multicolumn{7}{|l|}{ Sidereal } \\
\hline Root days & 101.43 & 97.95 & 102.56 & 101.58 & 100.77 & 100.57 \\
\hline Fruit days & 95.41 & 94.69 & 91.91 & 95.55 & 99.20 & 98.76 \\
\hline Flower days & 103.15 & 102.16 & 103.25 & 100.00 & 101.20 & 95.20 \\
\hline Leaf days & 99.89 & 105.28 & 100.42 & 101.79 & 99.39 & 105.01 \\
\hline \multicolumn{7}{|l|}{ Tropical } \\
\hline Descending & 101.31 & 101.22 & 101.00 & 98.25 & 100.18 & 100.15 \\
\hline Ascending & 98.61 & 98.41 & 98.28 & 101.36 & 100.06 & 100.21 \\
\hline \multicolumn{7}{|l|}{ Anomalistic } \\
\hline Apogee & 99.18 & 100.40 & 97.62 & 99.99 & 101.78 & 103.46 \\
\hline Perigee & 89.18 & 117.36 & 70.91 & 105.23 & 98.11 & 104.10 \\
\hline \multicolumn{7}{|l|}{ Draconian } \\
\hline Ascending node & 93.36 & 117.36 & 92.72 & 105.23 & 97.13 & 104.10 \\
\hline Descending node & 107.72 & 95.80 & 106.79 & 104.82 & 98.78 & 96.77 \\
\hline
\end{tabular}

Source: Botucatu - UNESP (2007).

and grew worse of all in the full Moon phase. In the 2 years of research, the dry mass production of seeds sown at the new moon phase was higher than that of those sown at the full Moon phase $(p<5 \%)$. Goldstein (2000) observed better results when carrot seed was sown 1 day before the full Moon, while Spiess (1994) observed better results when the carrot was sown 2 days before the full Moon. While there is little research on this topic, these different results may be because of the 
influences of the northern and southern hemispheres, indicating that attempts to compare between different geographic regions may be problematic.

According to Thun's astronomical calendar, carrots should be sown on a 'root day' (when the Moon is passing through Virgo, Taurus or Capricorn), yet I found no evidence that seeds sown on such days were more productive, so further research with longer periods of observation is required here. The evaluation of the sidereal rhythm in 2006 showed that seeds sown on leaf days were more productive than those sown on root days, and both showed better results than those sown on the fruit and flower days (Table 11.1). Spiess (1994) observed that carrots sown when the Moon was in Virgo (a root day) had a higher productivity than those sown when the Moon was in any other constellation.

The negative effect of the nodes and perigees on yields of fresh root matter was statistically significant in 2005, but was not observed in 2006 (Table 11.1). According to Thun's astronomical calendar, both the nodes and perigees are unfavourable for sowing.

On the other hand, the tropical rhythm of the Moon did not present statistically significant results at all: the reason for this could be that Botucatu City is located very close to the tropic of Capricorn and is not strongly influenced by tropical rhythms, whereas Thun's studies occurred at higher latitudes.

Comparing the results of the research with traditional knowledge about the influence of the Moon on crop growth, the empirical results support the traditional practice of sowing carrots between the waning Moon and the new Moon phases.

\section{FINAL CONSIDERATIONS}

Various ethnological studies document the relationship between the farming practices of indigenous peoples and their knowledge of astronomical phenomena. Some biodynamic researchers have studied this theme of chronobiology or biological rhythms in cultivated plants. In Brazil, the effect of the Moon's synodic rhythm is highly valued by family farmers and indigenous people and it was precisely this aspect that provided the most consistent statistical results. The results of our field trials support the common wisdom of sowing carrot from the waning Moon to the new moon phase. Our experiment showed that dry mass was the only measured aspect that showed significant positive results in the two periods of the experiment, with the results indicating that the synodic new phase was a superior time to sow compared to the other phases.

Modern agriculture uses costly artificial technologies with little consideration of their environmental or human health impacts. Such technologies are far removed from the ancestral knowledge of past civilisations and current indigenous communities. Biodynamic farming recovers the importance of lunar rhythms to enhance sustainable agricultural management. This research shows the complexity of life and the need to search for a new scientific paradigm, with a more holistic approach for understanding complex systems, and highlights the need for further research on the influence of astronomical rhythms in agriculture.

\section{ACKNOWLEDGEMENTS}

I am grateful to farmer Didi Baldini (in memory) for his willingness to share his knowledge and experimental results, and for the support of the Brazilian Association of Biodynamic Agriculture.

\section{REFERENCES}

Afonso, G. (2006a) Mitos e estações no céu tupi-guarani. Scientific American Brasil, 4(45): 38-47, São Paulo. Afonso, G. (2006b) Relações Afro-indígenas. Scientific American Brasil, Edição especial Etnoastronomia, 14: 2-79.

Deep, K. and Mittal, R. (2014) Macronutrient K variation in mung bean sprouts with lunar phases. European Scientific Journal, 10(9): 1857-7881. 
Elliott, J. (2004) À luz do luar. National Geographic - Brasil, Ano 4, nº 47.

Endres, K.P. and Schad, W. (2002) Moon Rhythms in Nature: How Lunar Cycles Affect Living Organisms. Edinburgh: Floris Books, 308 p.

Fabian, S.M. (2006) Astrônomos do Cerrado. Scientific American Brasil, Edição especial Etnoastronomia, 14: $56-61$.

Goldstein, W. (2000) The effects of planting dates and lunar positions on the yield of carrots. Biodynamics, 230: $13-17$.

Jovchelevich, P. and Camara, F.L.A. (2008) Influência dos ritmos lunares sobre o rendimento de cenoura (Daucus carota), em cultivo biodinâmico. Revista Brasileira de Agroecologia, 3(1): 49-57.

Jovchelevich, P. and Vilela, G.F. (2006) Levantamento do uso da lua e utilização de plantas alternativas na alimentação pelos moradores mais idosos do bairro roseira no município de Botucatu-SP. In Congresso da Sociedade Botânica de São Paulo, 16. Piracicaba, CD-ROM.

Jovchelevich, P., Kishimoto, A., and Pasinato, R. (2016) Calendário 2016 - Sistema agrícola quilombola. Programa Vale do Ribeira: Instituto Socioambiental.

Koepf, H., Pettersson, B.D., and Schumann, W. (1983) Agricultura biodinâmica. São Paulo: Nobel, 316 p.

Lobreiro, J.C.T. (2002) Efeito do apogeu e perigeu lunar sobre a determinação do sexo de bezerros. Boletim Agricultura Biodinâmica, n. 87, Botucatu.

Miller, H. (2004) Sinais do Céu. National Geographic - Brasil, Ano 4, no 45, São Paulo.

Palmer, J.D. (1974) Biological Clocks in Marine Organisms. New York: John Wiley.

Restrepo-Rivera, J. (2004) La Luna: El sol nocturno em los trópicos y sua influencia em la agricultura. Manágua: Fundação Juquira Candiru.

Sanches, R.A. (1997) Caiçaras e a Estação Ecológica Juréia-Itatins (Litoral Sul de São Paulo): Uma abordagem etnográfica e ecológica da relação homem e meio ambiente, Tese de mestrado, IB- USP.

Simão, S. (1953) Contribuições ao estudo da suposta ação lunar sobre plantas hortícolas. Tese de doutorado. Piracicaba: ESALQ, USP.

Spiess, H. (1994) Chronobiologische Untersuchungen mit besonderer Berücksichtigung lunarer Rhythmen im biologisch-dynamischen Pflanzenbau. Darmstadt: Institut für Biologisch-Dynamische Forschung.

Steiner, R. (2001) Fundamentos da Agricultura Biodinâmica, $3^{\circ}$ edição. São Paulo: Editora Antroposófica.

Thun, M. (1986) O Trabalho na Terra e as Constelações. Botucatu: Associação Brasileira de Agricultura Biodinâmica.

Thun, M. (2000) Sembrar, plantar y recolectar em armonía com el Cosmos. Madrid: Editorial Rudolf Steiner. 


\title{
12 Electromagnetic Parameters Related to Plants and Their Microbiomes
}

\author{
Ed Moerman \\ Koppert Biological Systems
}

\section{CONTENTS}

Introduction....

Explanation of Some Electrical Terms

Electric Phenomena Inside the Plant.

Using These Electrical Parameters to Better Understand and Monitor Plants' Status,

Development and Processes.

Effects of Applied, External, Electrical (Electromagnetic) Factors on Plants and

Their Microbiomes

Don't Forget the Root Microbiome.

Discussion and Conclusions

References.

\section{INTRODUCTION}

Few people relate electricity or electromagnetism to plants and plant growth, perhaps because the electrotechnical and plant physiological disciplines seem so different. But there are many electrical and electromagnetic parameters that can be measured in plants and in their environment. This chapter describes a number of these parameters and how they can help us to better understand the plant and may even be used to enhance plant growth. Electrophysiology is the discipline that deals broadly with the flow of ions/electrons in biological tissues and, in particular, to the electrical recording techniques that enable the measurement of this flow. Prof. Volkov has edited various books on this subject, collecting work from scientists from all over the world. The latest work is titled Plant Electrophysiology, Signaling and Responses (Volkov, 2012: v). Its preface gives a comprehensive description of electrophysiology:

Plant electrophysiology is the study of the electrochemical phenomena associated with biological cells and tissues in plants. It involves measurements of electrical potentials and currents on a wide variety of scales from single ion channels to tissues to entire plants or trees. Electrical properties of plant cells mostly derive from the electrochemical properties of their membranes. Electrophysiological study of plants includes measurements of the electrical activity of the phloem, xylem, plasmodesmata, stomata and particularly the electrical signal's propagation along the plasma membrane. Action potentials are characteristic responses of excitation that can be induced by stimuli such as applied pressure, chemical substances, thermal stimuli, electrical or magnetic and mechanical stimuli, and biotic stressors.

Around 2010, the company I work for started to sell biostimulants to professional growers to improve the resilience of their crops to biotic and abiotic stresses. One of my tasks as knowledge manager was to search for indicators of plants' resilience by asking the following questions: Is there 
any method to quantify the condition of the plant and the risk for those stressors causing economic damage? and How can you measure improved resilience after the application of biostimulants? During one of many field visits to greenhouse growers, I experienced a kind of life-changing incident. A top-level Dutch gerbera grower I was visiting had been facing serious problems with his crop from the moment he had installed a combined heat and power (CHP) system in a room next to his new greenhouse. Yearly production figures gradually dropped from 300 to 200 flowers $/ \mathrm{m}^{2}$, and in addition to that, chemical pesticides showed sub-optimal performance. This had already been going on for more than a year, and no one was able to discover the reason for these problems. While brainstorming during a stroll through the greenhouse, a seemingly simple remark of the grower drew my attention. He said that the irrigation water pipe from the borehole to the greenhouse was installed very close to the CHP's power output cable. This did not feel right, although I could not find any hard evidence against it. Despite this, and desperate to solve the problem, the grower changed the irrigation water supply from borehole to tap water and started using a water vitaliser (a device that improves the molecular structure of water by exposing it to certain vibrations). The result was beyond all expectations: within a week, the grower observed visible change in the plants' appearance, and after some weeks, production returned to the previous high level of 300 flowers $/ \mathrm{m}^{2}$ on a yearly basis. This broadened my perspective, and I started collecting publications about plants, stressors and electric phenomena and undertook some basic measurements myself in ongoing experiments and with practical growers to become more familiar with the topic.

This chapter is a compilation of what I have learned from publications, participating in experiments and talking to people who are already more familiar with this topic. It has been an interesting journey, one which has perhaps only just begun. To begin with, the following section explains the main electrical terms used.

\section{EXPLANATION OF SOME ELECTRICAL TERMS}

For a good understanding of the rest of the chapter, here are some short definitions of terms related to electricity. Electricity is the set of physical phenomena associated with the presence and motion of matter that has a property of an electric charge: electrons, as well as protons $(\mathrm{H}+)$ and other ions. At the beginning of the nineteenth century, electricity was considered as being unrelated to magnetism. Later on, many experimental results and the development of Maxwell's equations ${ }^{1}$ indicated that both electricity and magnetism are from a single phenomenon: electromagnetism.

The movement of any moving charged particles through a conductor is known as an electric current, measured in (milli)amperes. A simple voltmeter can be used to measure the voltage (or potential difference) between two points in a system; often a common reference potential, such as the ground of the system, is used as one of the points. A voltage may represent either a source of energy (an electromotive force which can create a current) or lost, used or stored energy (potential drop). Current can flow through electrical conductors meeting a certain resistance (measured in ohms). The resistance is a consequence of the motion of charged particles through a conductor. In metals, for example, resistance is primarily due to collisions between electrons and ions.

Conductivity is expressed in $\mathrm{mS} / \mathrm{cm}$ and is the inverse parameter of resistance. Liquids show a lower resistance (or higher conductivity) when more ions/electrolytes are dissolved.

Current can be direct current (DC) or alternating current (AC). DC is a one-directional flow of charge; AC reverses direction repeatedly at a certain frequency (expressed in $\mathrm{Hz}$, fluctuations per second). This is often sinus shaped, but other shapes such as blocks also exist.

The electrical properties of inductance and capacitance are only observed under AC. Inductance describes the tendency of an electrical conductor, such as a coil, to oppose a fluctuation in the electric current going through it. A capacitor is a device which allows electricity to pile up by

\footnotetext{
${ }^{1}$ Maxwell's equations describe how electric and magnetic fields are generated by charges, currents and changes in the fields.
} 
providing space for it to spread out. A capacitor has a capacitance, measured in farads (F), or more often microfarads.

An electric field is created by a charged body in the space that surrounds it, and results in a force exerted on any other charges placed within the field. The electric power produced by an electric current (I) passing through an electric potential $(\mathrm{V})$ difference is expressed in watts $((P=I \times V$; work done per unit time).

Many important biological processes involve redox reactions. Oxidation is the loss of electrons or an increase in oxidation state; reduction is the gain of electrons or a decrease in oxidation state by a molecule, atom or ion. The reduction potential (mostly expressed in millivolts $-\mathrm{mV}$ ) is a measure of the tendency of the oxidising agent to be reduced.

The phase angle is the phase difference between an alternating voltage applied to a conductor or capacitor and the alternating current driven through it. It is expressed in degrees, as shown in Figure 12.1.

Electrical impedance is the measure of the opposition or resistance that a circuit presents to a current when a voltage is applied.

\section{ELECTRIC PHENOMENA INSIDE THE PLANT}

What drives life is just a little electric current, kept up by the sunshine. All the complexities of intermediary metabolism are but the lacework around this basic fact (Szent-Gyorgyi, 1960).

Photosynthesis is the process that increases the potential energy of electrons as they move from water to sugar. Photosynthesis relies on flows of energy and electrons initiated by light energy, which causes the excitation of electrons in chlorophyll that pushes them out of their orbit. The electrons instantly fall back into place, releasing resonance energy. This energy passes rapidly to the chlorophyll molecules, like the transfer of energy from one billiard ball to another. Photosynthesis thus converts light energy into chemical energy, stored in organic molecules. In terms of redox, reduction takes place (see Table 12.1). Reduction implies an increase of electrons in the plant tissue, enabling the plant to mitigate free radicals and better cope with oxidative stress.

A living plant (or tree) transports electrons from the earth to its top. Electrical engineer Arthur Ramthun (2015) used a digital voltmeter and oscilloscope to measure and record the electric potential between the ground, trunk and branch tips of many different trees. Billions of electrons appear to flow up the trees and outwards to branch tips (e.g. $2.8 \times 10 \mathrm{E}+11$ electrons per second to each Aspen branch tip). His model calculations show that this amount of electrons creates enough repulsive force at the branch tips to direct growth direction and influence plant geometry. This phenomenon he named 'electrotropism'. From measurements on a specially prepared young corn plant, he learned that electrons came from the water, through the roots and to the stem of the plantlet.

Clark et al. (2013) demonstrated that plants create an electric field with negative potential around flowers. Pollinators (such as the bumblebee Bombus terrestris) are able to detect and distinguish these electric fields. Pollinators usually possess a positive electric potential, acquired during their

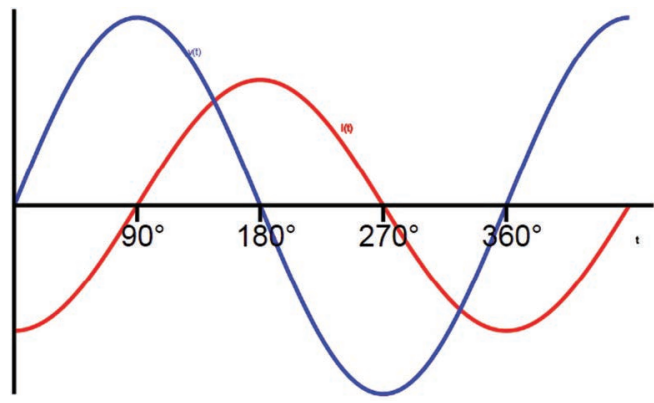

FIGURE 12.1 Phase angle: alternating current (red line) lags $90^{\circ}$ behind alternating voltage (blue line). 
TABLE 12.1

\section{Reduction and Oxidation in Relation to Plant Growth}

\begin{tabular}{lll} 
& \multicolumn{1}{c}{ Reduction } & Oxidation \\
Electrons & Gained & Lost \\
Eh value & Decreases & Increases \\
Takes place in plant & Photosynthesis & Dissimilation: oxidation (of reduced compounds) \\
processes & Proteosynthesis & avails energy, used for metabolic processes in plants \\
& Liposynthesis & \\
Energy & Synthesis of antioxidants, phenols, etc. & \\
Meaning & Increases chemical potential of molecules & Uses energy stored in molecules \\
& Antioxidants important for plant defence & Plant stresses have oxidising effect
\end{tabular}

flight. The potential difference between pollinator and flower is one of the cues that helps pollinators to find flowers that are ready to be pollinated. It is also a driving force for the transfer and adhesion of pollen during the flower visit. The deposition of pollen and the resulting pollination change the flower's electric potential, so the electric field differs according to the pollination status of the flower. This helps pollinators to focus on the flowers that still need pollination, and not to revisit the pollinated ones.

In 2015, Koppert Biological Systems performed greenhouse trials with tomatoes grown in rockwool substrate with different additions of biostimulants and biochar to stimulate the development of the root microbiome (Moerman, unpublished research, 2015). Orienting measurements of potential differences between the rockwool slabs and the stem base of tomato plants in these greenhouse trials showed a potential difference between 0.5 and $0.6 \mathrm{~V}$, the stems having the lower value. These values, and the polarisation, correspond with what other researchers, Ramthun (2015) and Rajda (2004), found in trees and herbaceous plants.

\section{USING THESE ELECTRICAL PARAMETERS TO BETTER UNDERSTAND AND MONITOR PLANTS' STATUS, DEVELOPMENT AND PROCESSES}

In this section, I discuss a range of examples of how various electrical parameters can help to better understand and monitor the plant. The examples given are just a snapshot of the huge amount of work done in this field. They are selected on the basis of their simplicity and potential to provide answers to my search for a method to quantify the condition of the plant and its resilience. The equipment needed to undertake the measurements should be affordable to growers/advisors and simple to operate.

Rajda (2004) measured the electric current flowing between the ground (measured in the soil at some distance from the stem base) and the stem base of hundreds of individual trees. Stems always showed a negative potential compared to the earth. Measurements showed different values for different tree species, positively correlated with stem diameter (and showing a typical seasonal pattern), and lower values for unhealthy trees. With this information, he was able to predict health problems by frequently checking the seasonal current and benchmark this value against the same values of similar trees. Table 12.2 shows the range of values measured in different groups of plants. Frequent measurements of these parameters helped to predict which trees were going to have health problems, before the symptoms were visible.

Vivent, ${ }^{2}$ a Swiss-based bio-signal company, is developing an innovative device for exploring and monitoring electrical signals in plants. These devices capture the bio-signals that plants themselves 
TABLE 12.2

\title{
Range of Currents and Potential between Ground and Stem Base in Different Types of Trees or Plants
}

\author{
Type of Plant/Tree \\ Deciduous trees \\ Conifers \\ Vegetables and ornamental plants \\ Source: Rajda (2004).
}

Maximum Current $(\mu \mathrm{A})$ Related to

Stem Diameter $(\mathrm{cm})(\mu \mathrm{A} / \mathrm{cm})$

200-500

100

Potential (V)

8-117

1.2

1.0

$0.4-0.7$

are transmitting. The device (PhytlSigns) measures potential differences between the root zone, stem base and leaves. Measured values (voltage) are recorded at very short time intervals. Deep analysis (with the help of artificial intelligence) of the voltage line patterns comparing plants with and without known biotic and abiotic stressors reveals that different types of plant/stressor combinations show a typical pattern. At present, the device is already used by a Swiss research station and had demonstrated that a pesticide spray can put plants 'on hold' for hours to days, depending on the type of pesticide (Personal communication with N. Wallbridge, 2019). The company claims that this device 'can be used to investigate plant responses to diseases, pests, crop protection treatments and environmental conditions'. ${ }^{3}$ In time, this device could provide an intelligent monitoring system to detect stressors early on in order to help the grower anticipate potential problems.

The investigation of plant roots is inherently difficult and therefore often neglected. Being out of sight, roots are often out of mind. Nevertheless, roots play a key role in the exchange of mass and energy between soil and the atmosphere, and therefore, it is useful to be able to better monitor root growth and root activity.

The size and activity of the plants' root system are good predictors for plant condition, but difficult to assess. Cseresnyés et al. (2013) did a lot of work on how to use electrical impedance spectroscopy $^{4}$ to measure root systems and stressed the usefulness of measuring the phase angle between alternating potential (voltage) between the stem and root zone and resulting $\mathrm{AC}$, for the rapid in situ investigation of the root system size and root activity without any intrusion into plant life functions.

Dietrich et al. (2013) report that electrical capacitance, measured (with an LCR meter ${ }^{5}$ ) between an electrode inserted at the base of a plant and an electrode in the rooting substrate, is often linearly correlated with root mass. Electrical capacitance has often been used as a proxy for root mass and is conventionally interpreted using an electrical model in which roots behave as cylindrical capacitors wired in parallel. However, recent experiments in hydroponics show that this interpretation may not be correct and a newer model has been proposed by Dietrich in his doctoral thesis (2013), in which he revised the existing model of resistance-capacitance circuits in plants and which is tested in solid substrates. The results were consistent with the new physical interpretation of plant capacitance. Substrate capacitance and plant capacitance combine according to standard physical laws. For plants growing in wet substrate, the capacitance measured is largely determined by the tissue between the surface of the substrate and the electrode attached to the plant. While the measured

\footnotetext{
${ }^{3}$ From the company website https://www.phytlsigns.com/product-solutions (accessed 1 July 2020).

${ }^{4}$ Electrical impedance (EI) and electrical capacitance (EC) measurements in a plant-soil system offer good opportunities of rapid in situ investigation of the root system size and root activity. By fixing an electrode at the plant stem and embedding the other one in the soil and connecting them by an LCR instrument, the measured root EI and EC are directly correlated with root mass, root length or root surface area (Chloupek, 1972; Ozier-Lafontaine and Bajazet, 2005; Rajkai et al., 2002).

5 An LCR meter is an electronic test equipment used to measure the inductance, capacitance and resistance of an electronic component.
} 
capacitance can, in some circumstances, be correlated with root mass, it is not a direct assay of root mass (Figure 12.2).

In 2015, Koppert Biological Systems performed a dedicated propagation trial with cucumbers grown in perlite to validate the findings of Dietrich (2013) and Cseresnyés et al. (2013) in a greenhouse situation (Moerman and Weber, unpublished research, 2015). Measurements of the phase angle and dry root weight of 2 groups of 25 plants taken on 4 and 9 March 2015 confirmed the

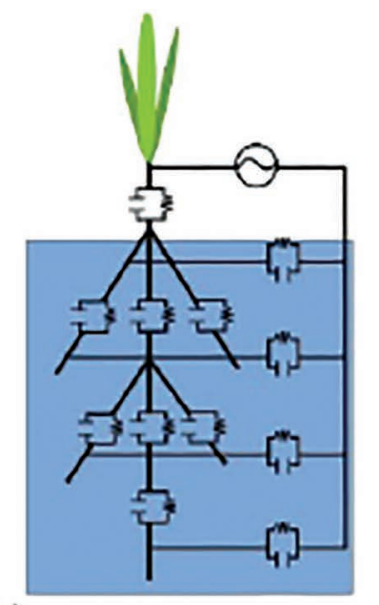

(a)

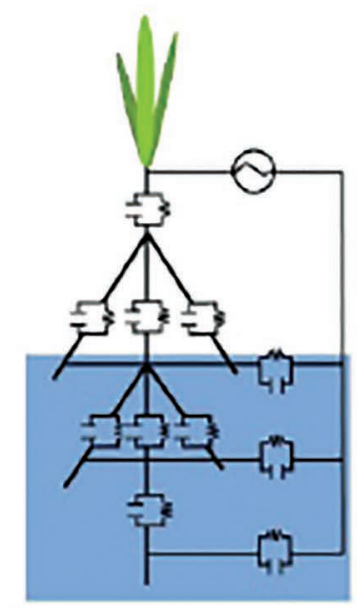

(c)
- pathway of the electrical current
conducting nutrient solution
- root tissuc
$\vartheta$ capacitance bridge
Q. resistance-capacitance unit of the solution
\% resistance-capacitance unit of plant material

(d)
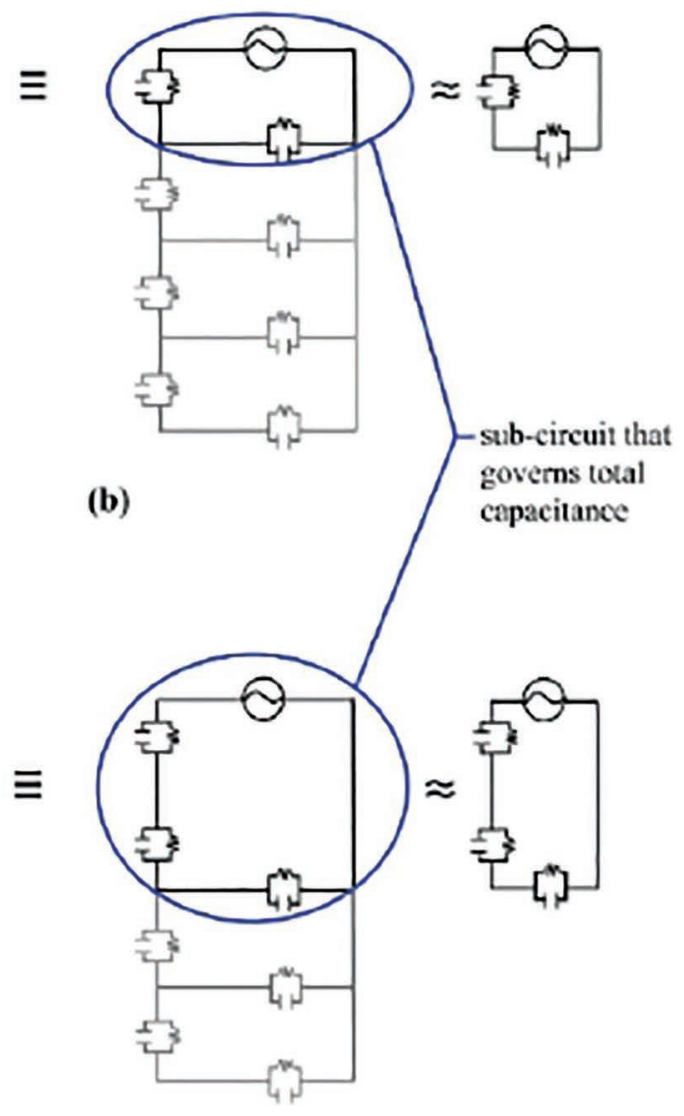
correlation between phase angle and dry weight of the root system and showed that a non-destructive measurement of phase angle has the potential to replace the destructive and time-consuming measurement of root dry weight (Figures 12.3 and 12.4).

Postic and Doussan (2016) compared various electrical methods to estimate root mass. The parallel measurement using a clamp as a stem electrode of capacitance and a hand-held LCR meter at an alternating current gave the most reliable results. They found that the frequency of the AC current used plays a role in the accuracy of the outcome.

Benada (2017) described his investigations on variable resistance in wheat plants as a starting point for considering the nature of variable disease resistance of cereals against obligate

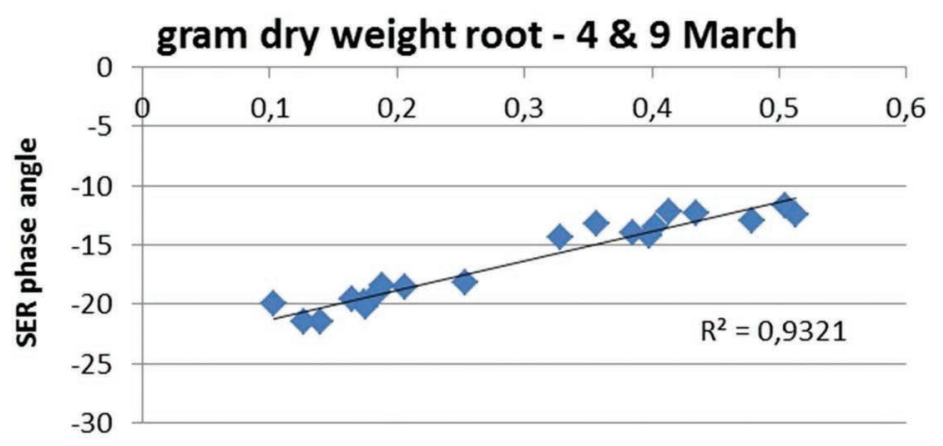

FIGURE 12.3 Correlation between gram dry root weight per plant (X-axis) and phase angle (Y-axis).

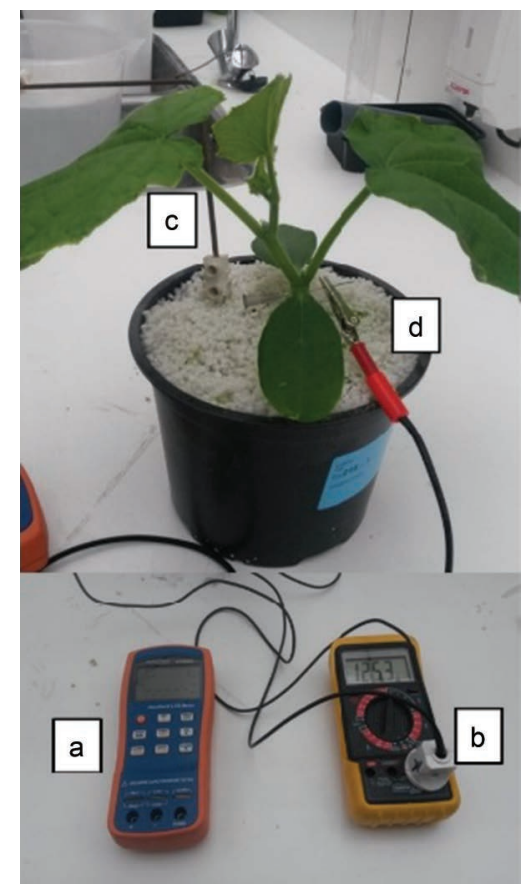

FIGURE 12.4 Simple LCR meter (a) and voltmeter (b) used for measurements of cucumber plants in pots. (c) The grounding probe and (d) a crocodile clamp on a needle inserted into the stem at the plant base. 
parasites ${ }^{6}$ such as powdery mildew and rust, in which redox potential and $\mathrm{pH}$ measurements in leaf sap were the main observations. He developed a simple and quick method for redox measurements in the tissue of detached leaves and formulated a hypothesis for why the biophysical status of a plant plays such an important role in resistance, and plant physiology in general. He found that the principle of resistance lies in the ability of the parasite to gain the energy from the host cell. The parasite uses the terminal oxidase of the host plasmalemma (the plasma membrane of the cell wall) as its energy source.

Plant roots generate electric currents and associated electric fields as a consequence of electrogenic ion transport at the root surface. van West et al. (2002) demonstrated that swimming zoospores of oomycete plant pathogens ${ }^{7}$ to plant roots are partly attracted by electrotaxis (the movement of an organism in an electric field) in natural root-generated electric fields. The zones of accumulation of anode- or cathode-seeking zoospores adjacent to intact and wounded root surfaces correlated with their in vitro electrotactic behaviour (either attracted to the anode or the cathode). Manipulation of the root electric field was reflected in changes in the pattern of zoospore accumulation, and imposed focal electric fields were capable of overriding endogenous signals at the root surface. Data suggested that electrical signals from a potential difference (voltage) between root and rhizosphere/ rhizoplane can augment or override chemical cues in mediating short-range tactic responses of oomycete zoospores at root surfaces. These findings may help in the future to better assess risks for infection of root-borne diseases.

Akay and Kara (2006) investigated quality parameters that can be measured by different methods. One of them is Vincent's bioelectronic method (BEV). The $P$-value is measured in sap pressed from fruits or vegetables. It is based on three factors: $\mathrm{pH}$ (acidity), $\mathrm{rH}$ (redox potential) and $R$ (resistivity). The $P$-value integrates the three parameters to a parameter of quality and is calculated as $[30 \times(\mathrm{rH}-2 \mathrm{pH})] 2 / R$ (Hoffmann, 1991), which is expressed in microwatts $(\mu \mathrm{W})$.

These electrochemical parameters can tell us something about the production conditions and the effects on humans after consumption. Products with low $P$-value are supposed to be health promoting. Good foods give us more power than bad ones and are good for our health. Life processes in plants and animals can be described as chains of electrochemical or redox reactions. The $P$-value is used in the areas of environment, human medicine and food research. Food with low redox values provides many electrons that counteract free radicals (in other words have an anti-oxidising effect) and hence contribute to health. Good examples of these 'curing foods' are beetroot, (organic) carrots and fermented cabbage.

Hoffmann et al. (2007) worked on electrochemical quality assessment, using the redox potential ( $\mathrm{rH}$ in $\mathrm{mV}$ ), resistivity (ohm) and $\mathrm{pH}$ of a liquified, homogenised sample. In his book, Hoffmann explained the relationship between redox value and entropy: a lower redox potential coincides with lower entropy, which means less chaos or more organised tissue.

Northolt et al. (2004) investigated the usefulness of electrical parameters to assess carrot quality and the development of the inner quality concept and concluded that these measurements can be valuable. Their report presents a comprehensive explanation of the meaning of the different parameters, as provided in Box 12.1.

\section{EFFECTS OF APPLIED, EXTERNAL, ELECTRICAL (ELECTROMAGNETIC) FACTORS ON PLANTS AND THEIR MICROBIOMES}

This section explores a number of experiments aiming to influence plant growth to the benefit of the grower/farmer. Although this work started in the beginning of the twentieth century, to the author's

\footnotetext{
${ }^{6}$ An obligate parasite is a parasitic organism that cannot complete its life cycle without exploiting a suitable host. If an obligate parasite cannot exploit a host, it will fail to reproduce.

7 Oomycetes, also known as 'water moulds', are a group of several 100 organisms that include some of the most devastating plant pathogens. The diseases they cause include seedling blight, damping-off, root rot, foliar blight and downy mildew.
} 


\section{BOX 12.1 EXPLANATION OF THE USEFULNESS OF DIFFERENT ELECTRICAL PARAMETERS (NORTHOLT ET AL., 2004: 56)}

Life processes in plants and animals can be described as chains of electrochemical or redox reactions. Hoffmann (1991) explains how Haas developed a bioelectric theory to derive an electrical energy value for food from measurements of $\mathrm{pH}$, redox potential and electrical resistance. He suggested that food with high reducing power, later expressed as low $P$-value, promotes health. The $P$-value is calculated from the three stated parameters which are affected by the growth conditions of the product. The $\mathrm{pH}$ value is the best known electrochemical parameter to measure proton concentration or acidity. The $\mathrm{pH}$ is measured by potentiometry using suitable electrodes. The measured $\mathrm{mV}$ value is logarithmically transformed to the $\mathrm{pH}$ value. The potentiometric equilibrium is at $\mathrm{pH} 7$ and $0 \mathrm{mV}$. A difference in $\mathrm{pH}$ of 1 (at $25^{\circ} \mathrm{C}$ ) equals $59 \mathrm{mV}$. In plants, proton activity has energy aspects. The redox potential Eh $(\mathrm{mV})$ reflects the gradient of electrons which life processes utilise for their cellular work (Kollath, 1978). The redox potential represents the equilibrium between oxidising and reducing substances. When redox potential is low, plant cells have more energy for their activity. Traditionally, the flow of electrons is considered to be the main form of respiratory energy transport in an organism with oxygen as the terminal electron acceptor. Electrical resistance $R$ $(\mathrm{ohm})$ gives an indication of the dissipation of electrolytes in plant cells. High values of electrical resistance indicate that electrolytes are more integrated in membranes and cell organelles. Low values indicate free-moving electrolytes, which might be a sign of deterioration in plant cells and tissues.

knowledge only a few patents have been filed and none of them are as yet applied on a commercial scale. Undoubtedly, there may be many more examples.

Blackman et al. (1923) performed detailed research on the effect of a positively loaded discharge point just above the top of grounded cereal plants, showing it had a lasting effect on the growth rate of barley sheaths. Similar trials in which the direction of the current was reversed did not give the same positive effects, and in some cases results were even negative. So the direction of the current appeared to be important.

Rajda (2004) managed to enhance plant growth by putting a DC voltage on positive and negative electrodes on opposite sides of the substrate in a growing table. However, the mode of action was not explained and could be caused directly by the potential difference or by electrolytic effects on the dissolved nutrients. Wawrecki and Zagorska-Marek (2007) demonstrated that even a weak (1 $\mathrm{V} / \mathrm{cm}$ ) DC electric field with a horizontal direction disturbed the pattern of cell divisions in plant root meristems of maize. This in turn changed the global organisation of the root apical meristem: it influenced the direction of apical root growth. A field of slightly higher strength also damaged root cap initials, terminating their division. This implies that care should be taken when applying this technique and not to apply too high an intensity of treatment. It is not clear if and how this phenomenon could be used to the benefit of growers/farmers. But one could image that stray current ${ }^{8}$ could not only affect farm animals but also crops in a way that is not yet understood.

Gasner (2013) demonstrated a positive effect of grounding the root medium of pepper plants grown in pots. Devices were inserted into the plants' growing medium at an angle towards the centre of the pot and connected to earth. Grounded plants grew better and produced more fruits than ungrounded plants. The measure of grounding provided the plants with a continuous stream of electrons from the earth, which could also be measured. The voltage between grounded plants and

\footnotetext{
${ }^{8}$ Stray current refers to the electricity flow via buildings, ground or equipment due to electrical supply system imbalances or wiring flaws. It refers to an existence of electrical potential that can be found between objects that should not be subjected to voltage.
} 
earth varied between 200 and $300 \mathrm{mV}$, which is in the same range as in herbaceous plants (Rajda 2004) and also concurs with the author's own (unpublished) trials in 2015 of tomatoes grown in rockwool. Unfortunately, while there are many publications about the positive effects of grounding on human health, this is the only publication showing the positive effects of grounding on plant growth, and the grounding devices for plants that the author has developed may have a commercial potential. There is a patent filed for grounding rods for plants, ${ }^{9}$ but it is unclear if this has yet been commercialised.

Olyslaegers (2012) states that electroculture has been investigated for a long time, but with inconsistent results. He defines electroculture as any electrical stimulation of plants. His research focused on the question of whether young tomato plants (Solanum lycopersicum) could be electrically stimulated in a manner that would be practically feasible in commercial greenhouses. As well as the attempt to demonstrate the 'proof of principle' and investigate possible mechanisms, attention was paid to the possibilities of this technique with regard to a decrease in the costs and quantities of nutrient usage in intensive greenhouse cultivation. He worked with a low DC voltage (0.1-0.2 $\mathrm{V} / \mathrm{cm}$ ) and two polarities, applied via a piece of felt underneath rockwool blocks. The results were inconsistent.

A recent publication from India (Patil, 2018) describes experiments to study the effect of electricity on germination and growth of radish (Raphanus sativus). Here, plants were only briefly exposed to low DC voltage: 3, 6 and $9 \mathrm{~V}$ for 10 minutes per day. This helped increase germination rates from $85 \%$ in the control sample to $95 \%$ in the treated sample.

A very promising method to stimulate plant growth with electricity is described in PJJ van Zyl's thesis (2012) on radio frequency energy for bioelectric stimulation of plants. This principle uses electromagnetism. The study is about utilising low power radio frequency (RF) energy signals from leaky transmission lines for the benefit of plant growth and production in hydroponic systems. The way it works is that plant cell walls are covered with tightly bonded, positively charged calcium ions that affect the inflow of nutrients into the cell. As calcium ions have a mass twice that of the potassium ion, the fundamental harmonic of calcium is equal to the first harmonic of potassium (32 Hz). Thousands (10k:1) fewer positive potassium ions also exist around the cell wall, and when stimulated at their resonance frequency $(16 \mathrm{~Hz})$, they will bounce against the bonded calcium ions so that these calcium ions become dislodged from the cell wall. When this happens, more nutrients can enter the cell causing an acceleration in plant growth. However, it is important to control the process, because if too many calcium ions are released it would cause plant stress and a breakdown in the plant structure. The amplitude modulated (block, as opposed to sinus) wave allows sufficient time for the calcium ions to return to the cell walls during the period without externally applied energy. One medium to apply radio energy to a plant is to transmit the energy into two leaky transmission lines to cause standing waves, which can then be absorbed by plants placed between these transmission lines. The energy from the radio waves is then used to create window periods during which the calcium ions are dislodged, allowing additional nutrients to enter the plant cell, enhancing plant growth and production. In the thesis, van Zyl also refers to a US patent from Kertz (1995) where principles of electronic stimulation of plants are described extensively and illustrated with trial results. Van Zyl himself performed some trials to validate the principle. In these trials, treated plants were healthier and produced significantly more biomass and tomato yield than the control plants.

\section{DON'T FORGET THE ROOT MICROBIOME}

From what has been described above, plants need electrons to aid all kinds of metabolic processes. This is also the case for microorganisms (which make up the plant microbiome, part of the soil food web). These microbes also need and give electrons for and through everything they do. They need

\footnotetext{
9 https://patents.google.com/patent/US20140020294A1/en.
} 
electrons to consume nutrients or spew out methane or expel carbon dioxide, or any other biological process. It is often observed that the microorganisms that make up the root microbiome thrive in the presence of biochar. There had been no clear explanation for this, but scientists from Cornell University (Sun et al., 2017) have now discovered that biochar provides high-definition electron pathways in the soil that allow electrons to travel through the soil farther and more efficiently.

Field trials undertaken by Koppert Biological Systems demonstrated that the addition of a liquified stable carbon source to rockwool enhances Trichoderma (fungal) growth, resulting in at least a 10 -fold colonisation of the fungus on the roots in the rockwool slabs that had been treated with liquid carbon. Trichoderma harzianum T22 acts as a biological fungicide against Pythium, Fusarium and Rhizoctonia in many crops. It also has plant growth-promoting features. Growers often struggle to get this beneficial fungus established on the plant roots in rockwool substrate. But the addition of a liquid biochar-like carbon gave remarkable improvements. The mode of action has not been investigated. It is unlikely that the Trichoderma fungus uses the carbon as a food source, since it is a very stable form that cannot further be digested. This is confirmed by Sun et al. (2017) who note that the use of biochar as a food source can be discarded because microorganisms cannot consume much of it. So the effect may be explained either in that it provides a more friendly place for Trichoderma to grow than the 'hostile' rockwool substrate or in that high-definition pathways for electrons are created by the carbon.

\section{DISCUSSION AND CONCLUSIONS}

The above is a snapshot of the research undertaken to better understand the role of electromagnetic phenomena in plants. The matter has many facets and is quite complicated, and the results are not always consistent. Many methods have been tried. Some look promising, and certainly, the rapid developments in the domain of sensors, artificial intelligence and the Internet of things will help to develop systems that enable growers to better monitor plant growth and have more comprehensive information to support their decision-making. Bioelectric methods could also help with simple and cheap comparisons of fruit and vegetable products and their internal quality.

The same holds true for the methods investigated that promote various types of electromagnetic effects on plant growth. Many approaches have been tried, yet none have really shown a breakthrough so far. The notion that plant growth concerns more than particles at least has started to be accepted in some quarters. There is a need for more in-depth and systematic analysis as to whetherand to what extent - the elements of energy and information connected to electricity can be applied and managed to benefit plant growth.

As a common thread running through all that has been presented above, I am beginning to see a lot of similarities between water and electrons. Both must be able to flow freely from the root zone, upwards through the plant, partly leaving the plant through the leaves and partly stored in the plant tissue. They need electrons to be present in a free and available form, to help flowers to be more visible for pollinators, to facilitate metabolic processes throughout the rhizosphere and the rest of the plant, to store energy in an excited form to help plants cope with oxidative stress and to contribute to the health of those who eat the parts of the plant harvested for food or feed. Similarly, water has to be available in the root zone, be taken up and transported via the root system, carry water-soluble components up and down and be part of many metabolic processes. Water must also be amply available in the leaves for evaporation to regulate leaf temperature, but sufficiently kept in the plant tissue to maintain turgor.

The question arises that if these concepts have been worked on for almost a century, why have there not been more major commercial breakthroughs and uptake? Several factors are at play here. It is curiosity that has driven many researchers and others (including myself) to dive into this topic. For farmers and growers, the combination between the disciplines of electro(magnetism) and (plant) physiology may not be sufficiently attractive. In the area of monitoring, practical people may prefer direct or visible (e.g. morphological or symptomatic) observations above indirect or invisible 
(electromagnetic) ones. My own search only started when I wanted to measure plant resilience against stresses, something you cannot see on the outside of a plant. Further, in terms of influencing plants and their microbiomes, the results of experimental electromagnetic interventions are not always as obvious and consistent as chemical and biological interventions, which are also more trusted because they fit with current practices.

At the company where I work ${ }^{10}$, we encounter this in terms of growers' and advisors' acceptance of new bioprotection systems: new systems based on beneficial arthropods are more easily accepted than those based on beneficial microbes. Visibility plays a role here: what you see and can manage helps learning and builds trust quicker than something invisible, what you believe or hope to happen.

I hope that this chapter contributes to an improved understanding of plant growth beyond the plant physiological principles that are commonly known and accepted and encourages further research and experimentation in this field.

\section{REFERENCES}

Akay, A. and Kara, Z. (2006) P-value and some other quality characters of tomato cultivars grown in greenhouse. Pakistan Journal of Biological Sciences, 9: 1991-1994.

Benada, J. (2017) Measurement of redox potential and $\mathrm{pH}$ in plants and their function in the mechanism of plant resistance and in plant physiology. International Journal of Advanced Research in Electrical, Electronics and Instrumentation Engineering, 6(1): 1-9.

Blackman, V.H., Legg, A.T. and Gregory, F.G. (1923) The effect of a direct electric current of very low intensity on the rate of growth of the coleoptile of barley. Proceedings of the Royal Society of London. Series B, Containing Papers of a Biological Character, 95(667): 214-228. https://royalsocietypublishing. org/doi/pdf/10.1098/rspb.1923.0034.

Chloupek, O. (1972) The relationship between electric capacitance and some other parameters of plant roots. Biologia Plantarum, 14(3): 227-230.

Clark, D., Whitney, H., Sutton, G. and Robert, D. (2013) Detection and learning of floral electric fields by bumblebees. Science, 340(6128): 66-69.

Cseresnyés, I., Rajkai1, K. and Vozáry, E. (2013) Role of phase angle measurement in electrical impedance spectroscopy. International Agrophysics, 27: 377-383.

Dietrich, R.C. (2013) A novel hypothesis for plant capacitance. Doctoral Thesis, Plant Science Division, College of Life Science, University of Dundee at The James Hutton Institute. https://discovery.dundee. ac.uk/ws/portalfiles/portal/1857194/Dietrich_phd_2013.pdf.

Dietrich, R.C., Bengough, A.G., Jones, H.G. and White, P.J. (2013) Can root electrical capacitance be used to predict root mass in soil? Annals of Botany, 112(2): 457-464.

Gasner, W.G. (2013) The theories and effects of imposing natural electrical fields and currents on potted plants. Poster. Department of Business, Entrepreneurship and Organizations, Brown University, USA. https://browntia.files.wordpress.com/2013/10/theories-in-action-poster-william-gasner.pdf.

Hoffmann, M. (1991) Elektrochemische merkmale zur differenzierung von lebensmitteln. In: Meier Ploeger, A. and Vogtmann, H. (eds), Lebensmittelqualitat-Ganzheitliche Methoden und Konzepte-Alternative Konzepte Nr.66. Germany: Deukalion Verlag, pp. S67-S86.

Hoffmann, M., Staller, B. and Wolf, G. (2007) Lebensmittelqualität und Gesundheit - Bio-testmethoden und Produkte auf dem Prüfstand. Schwerin: Baerens and Fuss, 164 p.

Kertz, M.G. (1995) Electronic stimulation of plants, patent no. USOO.546445.6A. US States Patent. https:// patentimages.storage.googleapis.com/87/2b/fc/941fa7fc4824bd/US5464456.pdf.

Kollath, W. (1978) Regulatoren des Lebens - Vom Wesen der Redox-Systeme, 2. Heidelberg: Auflage.

Northolt, M., van der Burgt, G.-J., Buisman, T. and Vanden Bogaerdeet, A. (2004) Parameters for Carrot Quality and the Development of the Inner Quality Concept. Driebergen: Louis Bolk Institute, 90 p. https://core.ac.uk/download/pdf/10921505.pdf.

Olyslaegers, S. (2012) Het effect van elektrische stimulatie op de groei van jonge tomaatplanten bij verschillende nutriëntenconcentraties van de voedingsoplossing. (Effect of electrical stimulation on growth of young tomato seedlings at different nutrient concentrations). MSc. Thesis. Ghent: University of Ghent. https://lib.ugent.be/fulltxt/RUG01/001/894/489/RUG01-001894489_2012_0001_AC.pdf.

\footnotetext{
${ }^{10}$ Koppert Biological Systems
} 
Ozier-Lafontaine, H. and Bajazet, T. (2005) Analysis of root growth by impedance spectroscopy (EIS). Plant and Soil, 277: 299-313.

Patil, M.B. (2018) Effect of electroculture on seed germination and growth of Raphanus sativus (L). African Journal of Plant Science, 12(12): 350-353.

Postic, F. and Doussan, C. (2016) Benchmarking electrical methods for rapid estimation of root biomass. Plant Methods, 12: 33.

Rajda, V. (2004) Metabolische Energie und Elektrodiagnostic der Pflanzenvitalität. Short message in 10th International Meeting Electrochemical Quality Test, Boden Technik Qualität (BTQ). Friesenheim, Germany, May 6-7 2004.

Rajkai, K., Végh, K. and Nacsa, T. (2002) Electrical capacitance as the indicator of root size and activity. Agrokémia és Talajtan, 51: 89-98.

Ramthun, A. (2015) Plant electrotropism. https://www.thunderbolts.info/wp/2016/03/09/arthur-ramthunplant-electrotropism-eu2015/.

Sun, T., Levin, B.D.A., Guzman, J.J.L., Enders, A., Muller, D.A., Angenent, L.T. and Lehmann, J. (2017) Rapid electron transfer by the carbon matrix in natural pyrogenic carbon. Nature Communications 8 : 14873.

Szent-Gyorgyi, A. (1960) Introduction to a Submolecular Biology, Chapter 3. New York: Academic Press Inc. van West, P., Morris, B.M., Reid, B., Appiah, A.A., Osborne, M.C., Campbell, T.A., Shepherd, S.J. and Gow, N.A.R. (2002) Oomycete plant pathogens use electric fields to target roots. Molecular Plant-Microbe Interactions, 15(8): 790-798.

van Zyl, P.J.J. (2012) Radio frequency energy for bioelectric stimulation of plants. M-Tech Dissertation, Johannesburg: Technology University of Johannesburg. https://ujcontent.uj.ac.za/vital/access/services/ Download/uj:7535/CONTENT1?view=true.

Volkov, A.G. (ed) (2012) Plant Electrophysiology, Signaling and Responses. Berlin: Springer Verlag, 377 p. http://diyhpl.us/ nmz787/pdf/Plant_Electrophysiology___Signaling_and_Responses.pdf.

Wawrecki, W. and Zagorska-Marek, B. (2007) Influence of a weak dc electric field on root meristem architecture. Annals of Botany, 100: 791-796. 


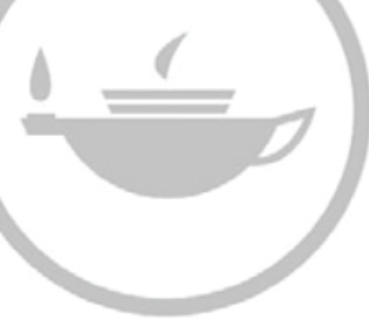

Taylor \& Francis Taylor \& Francis Group http://taylorandfrancis.com 


\title{
13 Homeopathy Applied to Agriculture Theoretical and Practical Considerations with Examples from Brazil
}

\author{
Pedro Boff \\ Santa Catarina State University \\ University of Planalto Catarinense \\ Rovier Verdi \\ Santa Catarina State University \\ Coventry University \\ Leonardo Felipe Faedo \\ Santa Catarina State University \\ Coventry University
}

Agricultural Research and Rural Extension Agency of

\section{CONTENTS}

Introduction: Historical Overview

Towards Understanding the Mechanisms behind the Concept of Homeopathy ............................. 147

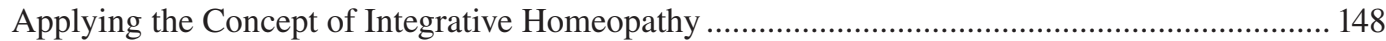

Examples of the Use of Homeopathy in Agriculture ................................................................ 149

The Appropriateness of Homeopathy for Agroecology ………………………………………... 151

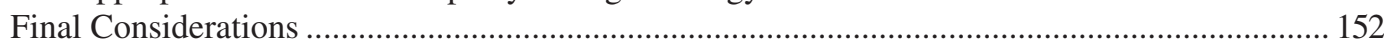

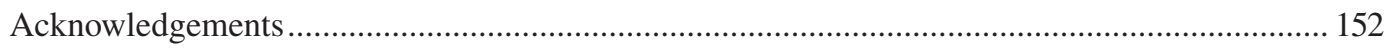

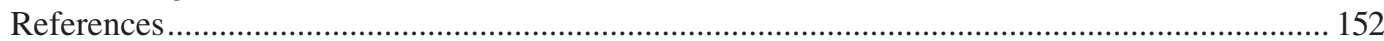

\section{INTRODUCTION: HISTORICAL OVERVIEW}

Homeopathy, as a science and art of healing, has been used worldwide for more than two centuries. It was proposed by the physician C.F. Samuel Hahnemann (1755-1843) through the publication of his pioneering treatise in 1796 which outlined the axioms for this new area of science, 'Essay on a new principle for ascertaining the curative powers of drugs, with a few glances at those hitherto employed' (Dougeon, 1989). Nowadays and as well as treating humans, the use of homeopathy is successfully applied in agriculture to treat animals, plants and water, as well as the environment as a whole. In order to understand its role in agriculture, we need to consider its historical development.

Early in his career, Hahnemann began to realise that the health care employed at that time was neither safe nor effective. The main therapeutic methods used were blood-letting, leeches, 
blistering, intestinal purging, induced vomiting and profuse sweating, and the administering of toxic drugs such as mercury. These techniques were frequently more harmful than the diseases they were intended to cure (Dean, 2001). Disappointed with this practice of medicine, Hahnemann, also a linguist, decided to give up his profession and instead he kept time only to translate medical texts to earn a living (Aversa et al., 2016).

Hahnemann's crucial observation was made whilst translating, from English to German, 'A Treatise of Materia Medica' by William Cullen (1710-1790). Cullen stated that the bark of Cinchona (a flowering plant from South America), that was an accepted medicinal plant to cure for malaria, was effective because it was bitter and worked like a tonic. Disagreeing with Cullen, Hahnemann started taking himself doses of the bark powder from Cinchona and carefully observing its effects upon his own healthy body or organism. Based on his experience, he hypothesised that Cinchona bark cures malaria because, in healthy people, it can provoke similar symptoms to those caused by malaria (e.g. intermittent fever) (Fisher, 2012). Hahnemann subsequently began giving repeated doses of many common substances to healthy volunteers and recorded the symptoms they induced. This technique is known as 'proving' or undertaking a human pathogenic trial, and the descriptions of symptoms, which include physical, emotional and mental, are recorded in compendiums called Homeopathic Materia Medica (Dougeon, 1989).

After his important discovery, Hahnemann began clinical practice again, but now testing the veracity of his new principles of homeopathy, and 6 years later, he came up with the basic premise: similia similibus curentur or the like-cures-like principle. In the words of Hahnemann,

We should imitate nature, which sometimes cures a chronic disease by super-adding another, and employ in the (especially chronic) disease we wish to cure, that medicine which is able to produce another very similar artificial disease, and the former will be cured; similia similibus.

Dougeon (1989: 265)

This principle itself was not new; it had already been point it out by others such as Hippocrates and Paracelsus. Hippocrates (460-367 B.C.) observed empirically that through the similar, the disease develops, and through the use of the similar, the disease is healed (Viganò et al., 2015). Theophrastus Bombastus von Hohenheim (1493-1542), better known as Paracelsus, proposed the theory of natural signatures or 'signa naturae', according to which the therapeutic properties of plants or minerals can be deduced from some similarity between their forms or colours and the various parts of the human body (Viganò et al., 2015). Hahnemann may have taken some ideas from Paracelsus, but he did not follow its method. Instead, he emphasised that remedies must reveal their curative properties through proving in healthy human bodies and that a similar set of symptoms in an ill body would then be extinguished. In doing so, Hahnemann was the first to build a medical approach based on a principle that could be confirmed by experience. He was also the first to undertake this systematically, making it a central tenet of his method which is implicit in the name 'Homeopathy' - from Greek homoios, meaning similar, and pathos, meaning suffering (Walach et al., 2005).

Another important principle of homeopathy concerns the totality of symptoms, a kind of holism, which considers the sick organism as a whole rather than a focus only on the diseased part itself. Hahnemann advocated that remedies should be selected based on the 'total' set of symptoms, from which those more representative of the ill-individual state could be found (Hahnemann, 1810). This meant that two patients with the same clinical diagnoses, for example upper respiratory tract infection, could be treated with different remedies based on their individual characteristic symptoms. Hahnemann also insisted that only one remedy should be used for a given patient at any time considering the totality of symptoms (Hahnemann, 1842).

Throughout his life, Hahnemann continued improving his theory and adding new concepts. One such was the concept of potentisation or dynamisation, which consists of a series of successive dilutions combined with 'succussions' (vigorous shaking) of the homeopathic preparation (Brasil, 2011). At first, Hahnemann only diluted the remedies in order to minimise the side effect of any toxic 
ingredients. However, after numerous observations, he noted that the dilutions should be intimately and uniformly mixed (by vigorous shaking) in order to better extract the healing power of the substance (mineral, vegetable, animal or other) (Aversa et al., 2016). Hahnemann became convinced that the healing power could be maintained, by shaking, from the less to the more diluted preparation and did not depend on the physical presence of the original active ingredients but rather on their action, which he called 'spirit-like' (Hahnemann, 1842). Homeopathic remedies are used at a wide range of dilutions (Brazil, 2011). If we take the homeopathic centesimal dilution beyond $12 \mathrm{CH},{ }^{1}$ it is statistically unlikely to contain a single molecule of the original active ingredient because this surpasses Avogadro's constant (i.e. the proportionality factor that relates the number of constituent particles in a sample with the amount of substance in that sample).

The fundamental homeopathic textbook is the 'Organon of Rational Art of Healing' (Hahnemann, 1842). Hahnemann published two other important works: 'Materia Medica Pura', a compilation of homeopathic 'proving' reports, and 'Chronic Diseases', where Hahnemann revised and elaborated on his therapeutic approach (Hahnemann, 1846a,b, 1996). His original ideas have been preserved and some adaptations made since, in order to improve its practicality. This has led to the emergence of different schools of homeopathy (Madsen, 2019).

In relation to this, anthroposophical medicine and the biodynamic preparations - as developed by Rudolf Steiner and Ita Wegman in the early part of the last century - are sometimes erroneously classified as being based on homeopathy. Whilst some substances used may be potentised, they do not follow the principle of similarity, nor the same method of diagnosis (Steiner, 2001).

\section{TOWARDS UNDERSTANDING THE MECHANISMS BEHIND THE CONCEPT OF HOMEOPATHY}

Hahnemann himself hated speculation. His approach was purely empirical to start with, he would theorise only after numerous observations and he constantly corrected his works, resulting in six editions of the 'Organon'. He believed that the healing process was a secondary effect of a reaction by a 'life force' or dynamism of the sick organism towards health (Hahnemann, 1810).

Through consecutive dilutions and succussions, the remedies tend to the infinitesimal, exceeding Avogadro's constant, as pointed above, at which point the particles cannot be detected. According to dose dependent response, this ought to limit the action of the homeopathic preparation (Silva et al., 2005), and this fuels the argument that a placebo effect is involved. However, scientific evidence shows otherwise. Various fields of study have discussed the nature of high dilutions, ranging from attempts to extrapolate mechanistic rationality through to drawing on complexity theory using nonlinear systems models (Bell et al., 2002; Bonamin et al., 2008). Despite the alleged lack of molecules of the original active ingredients remaining, their biological effect has been systematically and regularly proven in the treatment of plants, animals and humans (Bonfin and Casali, 2012). Double-blind homeopathic trials have also eliminated any subjective (placebo) effect between the patient and the researcher (Betti et al., 2009). Silva et al. (2005) has demonstrated the mode of action of homeopathic remedies through the Quantum theory. The persistence of a biological effect allows us to hypothesise that the curative property of homeopathy may be conserved as an image impregnated in the water/alcohol solvent of the high dilutions (Silva et al., 2005). If this is the case, then the active property of the remedies may be preserved even after consecutive dynamisations, reliably identifiable with the characteristics of the original raw material.

Another approach was reported by Chikramane et al. (2010). They used electron microscopy and emission spectroscopy techniques to confirm the presence of physical entities in the form of nanoparticles, in these extreme dilutions. They suggest that the succussion process causes acoustic cavitation - a mechanism that generates vapour bubbles - and confirm corresponding patterns between the nanoparticles and the starting material. They were also able to measure differences in patterns between different dilutions of remedies when various levels of radiation were applied.

${ }^{1} \mathrm{CH}$ dilutions are centesimal (C) dilutions, using Hahnemann's (H) dilution method. 
Another way of understanding high dilutions is to consider the concept of vitality or life force, which can have several compositions. Zanco (2016) has shown that biophotonic techniques (the study of light photons) are suitable for detecting subtle effects in the use of high dynamised dilutions by identifying different bioelectric signals among different treatments. Also, Kokornaczyka et al. (2014) using the crystallisation method with droplet evaporation could detect structural differences amongst high dynamic dilutions.

As well as the above, homeopathy has had its theoretical-methodological framework legitimised by scientific peers in several internationally recognised journals working in biological, agrarian and/ or agrarian and/or related sciences (Betti et al., 2009; Bonfim and Casali, 2012). Several compendia in the form of homeopathic prescriptions have been made available for the treatment of plants and animals and include the practical effects of their application (Bonato, 2007; Kaviraj, 2012; Maute, 2011).

In the following section, we will discuss homeopathy as an integrative therapy, proposed and developed by the group of Homeopathic Studies and Agroecology anchored at the Laboratory of Homeopathy and Plant Health of EPAGRI-Lages, ${ }^{2}$ in collaboration with Santa Catarina State University and the University of Planalto Catarinense, in southern Brazil.

\section{APPLYING THE CONCEPT OF INTEGRATIVE HOMEOPATHY}

Practices such as homeopathy are embedded in a world view that considers humans as part of ecosystems. Therefore, there is a case for their application to improve not only the health of agricultural ecosystems, but also that of farmers and other humans within the system (Boff, 2009; Casali et al., 2009). Similarly, the interconnectedness of the components within an agricultural system leads us to presuppose that what makes the soil, water, plants or animals sick does the same for humans (Khatounian, 2001).

According to Boff (2009), the most effective way of ensuring the long-term health of the agroecosystem is to redesign it to maximise homeostasis or dynamic equilibrium through its own self-organising life force. This gives rise to resilience (Soule and Piper, 1992). Effective homeopathic preparations need to act on this force in order to treat the agroecosystem, as a whole or in its parts.

Systems theory explains how living organisms are dependent for their life processes on the constant exchange of energy, matter and information with their external environment, at all levels from the quantum to the macro-dimensional (Bertalanffy, 1967). The wave function in the sense of quantum theory was already used by Silva et al. (2005) to understand the mode of action by which homeopathic preparation does resonate in biological systems. A recent paper by Manzalini and Galeazzi (2019) attempts to explain homeopathy through quantum electrodynamics. In it, the authors show how each component has its own macro-wave function with its specific oscillatory pattern that resonates with other specific oscillatory patterns. In order to minimise uncertainty, this process tends towards increasing resonance with other systems around it at multiple levels, which explains how 'organelles, cells, tissues, organs, organ systems, up to a whole organism, are characterized by their own specific wave functions, whose phases are perfectly orchestrated in a multi-level coherence oneness' (Manzalini and Galeazzi, 2019: 4). This may explain how it is possible to use homeopathic remedies not only for humans but also for animals, plants and even the environment. It could be a single apple tree or the whole orchard, a single sheep or the entire herd, the farm or the farmer him/herself (see Figure 13.1). If the apple needs healing, then the orchard needs healing too; if the farmer is ill, then we can assume that the farm is ill too. Treatment may be based on an analogy of symptoms of interest or on the observation of exacerbated effects predominant in the diseased or healthy state of the plant/animal compared to the symptoms as described in the Materia Medica for humans (Casali et al., 2009; de Rezende, 2009).

The effectiveness of homeopathic therapy in agriculture is dependent on its local contextualisation which rests on the practitioner's experience of perceiving the whole sick organism, the relationships

${ }^{2}$ EPAGRI is the Institute of Agricultural Research and Rural Extension of Publica Service of Santa Catarina State, Brazil. 


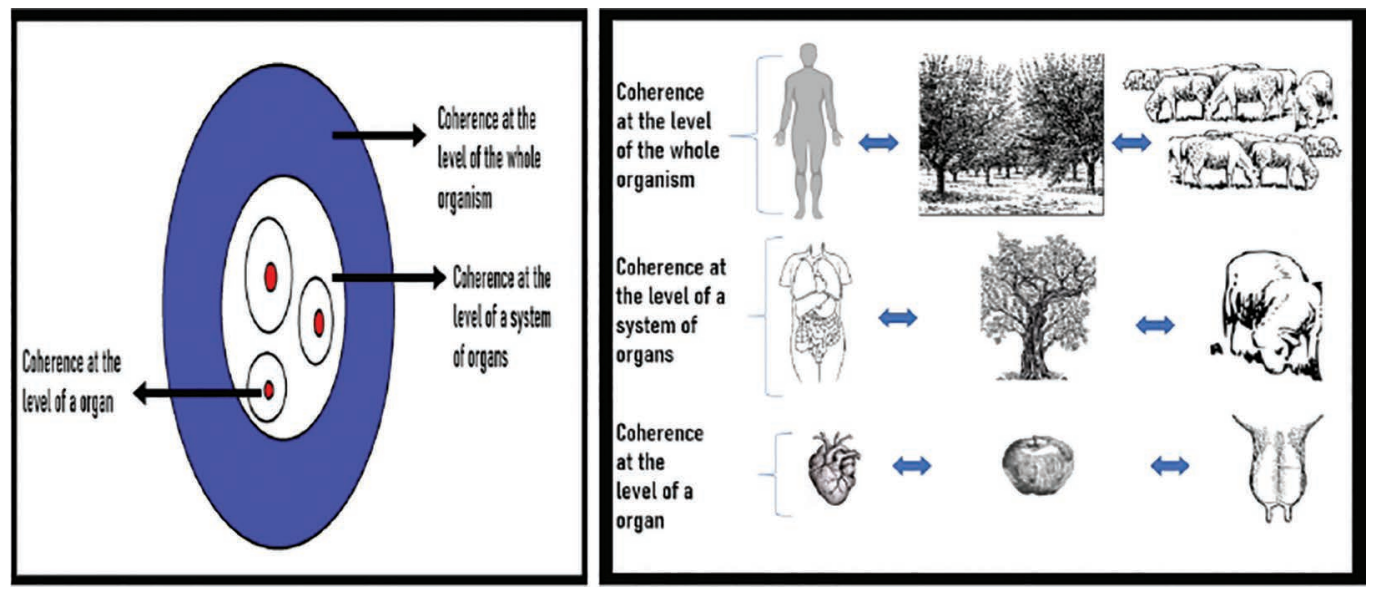

FIGURE 13.1 Levels of coherence/similarities to help select what needs to be healed. (Adapted from Manzalini and Galeazzi, 2019)

between the parts, and the emergent properties rising at different levels of the system (Boff, 2009). Further, before the healing process starts, any obstacles to healing - such as any practices misaligned with agroecological principles - should be identified and removed so that the homeopathic revitalisation of the system as a whole can be fast, smooth and lasting (Hahnemann, 1842).

However, the greatest challenge to the use of homeopathic remedies in plants and animals is applying the homeopathic principle of similarity (Carneiro, 2011). This is due to having to correlate the symptoms described in the Homeopathic Materia Medica - which were developed for and on humans - with those of diseased plants and animals, and has led to the emergence of various alternative approaches. Some practitioners use electronic instruments, electro-acupuncture devices, pendulums or their own intuition to select remedies (Jonas, 2003). Intuition, for example, is appropriate because as well as being a rapid and unconscious process, it does not follow simple, cause-and-effect logic and is able to address, integrate and make sense of multiple, complex pieces of data (Greenhalgh, 2002). Specifically with regard to biodynamic agriculture, the deep knowledge of the farm system and its components has been used to understand the influence of high dynamised dilutions on plants (Kolisko and Kolisko, 1978). Tichavský (2009) has proposed using morphological or physiological symptoms as a guide to search for the best homeopathic remedy for plant treatment. Such a biotype could be understood as the result of the morphic resonance process proposed by Sheldrake (2013) in which the starting point is a memory present in the morphic fields where homeopathy could have some action.

\section{EXAMPLES OF THE USE OF HOMEOPATHY IN AGRICULTURE}

Homeopathy has been scientifically recognised for its application in agroecosystems (Betti et al., 2009; Bonfim and Casali, 2012). Whilst researchers, practitioners and companies use different methods to select the homeopathic remedies with crops and livestock, a commonality is its success whether in conventional or in ecological based farming systems. It is important to note that homeopathy remedies can be easily deactivated whenever necessary, which makes it far safer than the use of pharmaceuticals or agrochemicals (Boff, 2009; Moreno, 2017; Savian et al., 2018).

In Brazil, companies producing homeopathic remedies have made inroads into the agricultural sector. Interestingly, the majority of clients are large scale, conventional farms producing commodities such as coffee, soybean, citrus, livestock and dairy. The contribution of homeopathic remedies in re-establishing the vitality of these systems is particularly effective owing to their poor state of health prior to treatment. In terms of diagnosis and treatment, some homeopathic companies undertake their 
TABLE 13.1

\section{Materia Medica for Some Farm Crops}

Homeopathic Remedy

Arnica Montana

Belladonna

Carbo vegetabilis

Staphisagria

Nux vomica

Sulphur

Calcarea carbonica

\section{Symptoms}

In cases of stress such as when transplanting, thinning, pruning, water deficiency and sudden damage by insects/frosts/harvests

Too many ants (spray remedy on leaves, plants and pathways)

When there is general weakness, e.g. after insect attack, defoliation, water deficiency, close spacing, flower loss, death of buds, plants in compacted soils

Attack of aphids, nematodes or mites, plants in excess shade, grafted plants and artificial insemination in animals, flea infestations

Plants and soils polluted by pesticides

Excess transpiration, plants with high fertility needs, itches and scabies in animals (the remedy induces detoxification in plants, soils and animals)

Plants unresponsive to good fertility, chlorosis, seedlings sensitive to cold, delay in new root growth, slow plant development and leaf yellowing, where slow composting is required, e.g. where there is a high $\mathrm{C} / \mathrm{N}$ ratio

Source: de Rezende (2009).

own diagnoses and prepare remedies using local materials, whilst others use preformulated remedies but focus on advising and training the farmers to be actively engaged in the healing process and to understand the medicines as part of this process. For example, the University of Viçosa, Minas Gerais State, has produced technical guidelines for farmers on the use of homeopathy with plants, as shown in Table 13.1 (de Rezende, 2009).

Much research has explored the use of homeopathy in promoting crop growth. Arnica montana $30 \mathrm{CH}$ and Calendula officinalis $30 \mathrm{CH}$ have been shown to promote stronger regrowth and higher fresh mass weight in yerba mate (Ilex paraguariensis) forests after drastic pruning, thus contributing to the sustainable management of native forest resources (Domingues et al., 2019). The substitution of pesticides with homeopathic treatments has also been shown to improve the performance of rice plants and to increase grain yield ( $\geq 2,000 \mathrm{~kg} / \mathrm{ha}$ ) (Verdi et al., 2020). Faedo et al. (2009) verified higher germination amongst lettuce seeds treated with Arsenicum album 7CH: lettuce is one of the most important commercial crops and thus of income for small farmers in Brazil. Verdi et al. (2020) obtained longer branches and higher multiplication success (79\%) on the root cuttings of the flowering plant popularly known in Brazil as erva-de-touro (Poiretia latifolia) with Calcarea phosphorica $20 \mathrm{CH}$. The clean (toxin-free) production of this medicinal plant is commercially very important. Nunes et al. (2019), also working with medicinal plants, used Kali carbonicum $12 \mathrm{CH}$ to assist in the breakage of dormancy and average germination time of Hypericum perforatum (St John's Wort) seeds.

Research has also explored the use of homeopathy in pest management of tomato under field conditions (Mododon et al., 2012). For example, the control of bean weevil has been demonstrated by Deboni et al. (2017). In orchards, insect traps to which Ac. tannicum $30 \mathrm{CH}$ was added attracted 20\% more Anastrepha fraterculus (South American fruit fly) than the control. This assisted in the reduction in the numbers of fruit flies, and it is a method that can be used in organic orchards (Brilinger et al., 2018). Giesel et al. (2012), using a high dynamised dilution (nosode) of Acromyrmex species (leafcutter ants) and Belladonna $30 \mathrm{CH}$, reduced the foraging activity of two species A. laticeps and A. heyeri - without causing colony collapse or re-colonisation elsewhere. Portales (2020) observed that when comparing homeopathy with the conventional treatments in dairy farms, homeopathy was more effective at keeping the SCC (somatic cell count per millilitre) below the 250 threshold. Prior to homeopathy treatment, only $22 \%, 25 \%$ and $27 \%$ of the samples from each farm had an SCC below 250. Once homeopathy treatment was started, these farms reached $66 \%, 56 \%$ and $46 \%$ (respectively) of days with SCC below 250 . 
Overall, homeopathic remedies appear to be able to harmlessly restore the dynamic equilibrium in agroecosystems. In recent studies, Bonamin (2020) verified the protective role of isotherapy (the treatment of viral and bacterial illnesses by administering dilute dosages of those microorganisms to infected patients) in Artemia salina (brine shrimp) exposed to pesticides and heavy metals. The treatment of Artemia cysts exposed to glyphosate and lead with the respective isotherapy induced better adaptation of these animals to the harmful medium, reducing problems with egg hatching and the incidence of malformations in the newborn larvae. Bonamin also observed that the treatment of a natural water source with Phosphorus $30 \mathrm{CH}$ produced significant changes in dipole moment in water samples harvested from different and distant locales of the same environment.

\section{THE APPROPRIATENESS OF HOMEOPATHY FOR AGROECOLOGY}

The ethical and social potential of homeopathy lends itself well to the toolkit of alternative agricultural movements (Kohler and Negrão, 2018), and homeopathy in agriculture is recognised as an effective social technology (Andrade and Casali, 2011). Social technologies need to be simple, cheap, effective and accessible to all farmers without causing dependency on costly inputs. In Brazil, integrative and complementary practices - including homeopathic preparations - have been legislated for public use in the national health system, as well as in organic food production systems (Brasil, 2007).

Homeopathy has been adopted by farmers from the 'Movimento dos Trabalhadores Sem Terra' (the landless workers' movement) in Santa Catarina State. In 2018, in the city of Ponte Alta, 44 families, who cultivate around 200 ha, completed a 6-month training course, organised by the Laboratory of Homeopathy and Plant Health, on the theory and practice of homeopathy, which took place in their own communities. These farmers received homeopathic kits for general use on their farms, with the remedies in these kits being in liquid form which allowed them to make up different potencies for the treatment of livestock, plants and the environment. Through sharing this knowledge in their communities, the farmers were able to empower others and build community resilience, something which the use of purchased agrochemicals is unable to engender.

Because of its holistic nature, homeopathy also holds potential to encourage multidisciplinary collaboration. Over the last decade, the integrative homeopathy course held at the EPAGRI station in Lages and UDESC, Santa Catarina, has trained not only farmers, but also agronomists, veterinarians, holistic therapists, medical doctors, dentists, physiotherapists, psychologists, teachers, undergraduate and postgraduate students, all of whom attend the 150 hour-long course during which they discuss the philosophy of science, vitality, homeopathic science, quantum methodologies and more. Through workshops, case studies and delivering training themselves, they develop a sense of collectiveness as they experience how homeopathy can be applied in different disciplinary situations.

Other research groups, in Brazil and abroad, have also been generating knowledge and delivering extension on homeopathy. Examples are given as following. Within Brazil, there is the work of the Research Group on Biological and Alternative Phytosanitary Controls (COBALFI) and the Popular Homeopathy Group of Western Paraná (CAPA), both based at the State University of Western Paraná (UNIOESTE). Paraná state also has Carlos Bonato's team at the University of Maringa and the Paranaense Agroecology Reference Centre which has been delivering specialised courses in homeopathy for almost 15 years. At Viçosa Federal University, Minas Gerais State, Vicente Casali and his team have, since 1995, been developing participatory research aimed at popularising homeopathy amongst farmers and local communities. Further afield, in France, there is La Groupe International de Recherche sur l'Infinitésimal (International Research Group on Very Low Dose and High Dilution Effects, G.I.R.I.), which was founded in 1986 and consists of more than 100 researchers ranging from physicians, chemists, biologists, pharmacologists, physicists to agronomists, from 22 different countries. In Italy, at Bologna University, Lucietta Betti and her colleagues in the Department of Agricultural and Food Sciences are building evidence on the use of homeopathy in crop production. 


\section{FINAL CONSIDERATIONS}

Over the last 30 years or so, the theoretical and methodological framework of homeopathy has expanded from the treatment of humans to that of animals, crops and agroecosystems (Bonamin, 2014). The biggest challenge of the homeopathic therapist working in agriculture is to identify the remedies that restore the dynamic equilibrium in such agroecosystems. This exercise of understanding the sick system as a unique and individualised organism, and seeking the medicine that can best remedy it whilst prioritising the most important symptoms, requires the homeopathic therapist to be an integrative healing artist.

Clearly, homeopathy in agriculture is based on a very different scientific rationality from that of Cartesian materialism, which seeks to maximise the factors of production for the continuous increase in productivity. Thus, the medic prescribing pharmaceuticals, the veterinarian prescribing drugs, or the agronomist prescribing agrochemicals is not usually receptive of homeopathy for family farmers, a concept which takes into account the entire interactive environment. Therefore, there is a need in the agricultural arena for both new concepts and new training that embrace such complexity.

Hahnemann believed that homeopathy should help people to reach the highest purpose of their existence which is living in harmony with themselves, and their (social and natural) environments. In particular, homeopathy as a social tool may assist more vulnerable communities to free themselves from the dependencies imposed by the conventional agriculture system. Agroecology is concerned with biomimicry and social issues that relate to, for example, diversity, inclusion, cooperation, complementarity and self-determination. If farmers are provided with knowledge of a theoretical and methodological framework that can deal with such complexities on their farms, and are able to apply low-cost homeopathic solutions, this provides them with a unique opportunity to enhance and work with the connectivity and integrity in the animal, plant, soil, water and human components of the agricultural organism in search of harmony of the dynamic, whole, agroecosystem.

\section{ACKNOWLEDGEMENTS}

Many thanks to the Study Group on Homeopathy and Agroecology brought together by the Laboratory of Homeopathy and Plant Health of EPAGRI-Lages that works with postgraduate students and docents and professors from UDESC and UNIPLAC, Santa Catarina State, Brazil. We should also like to thank our colleagues Leyza P. de Oliveira, Marcelo S. Pedroso, Mari I. Carissimi Boff and Amarilys Cesar for their valuable contributions to the manuscript. This study was partially supported by Conselho Nacional de Desenvolvimento Científico e Tecnológico (CNPq), who granted the first author a PQ scholarship as a researcher, and by the Fundação de Amparo a Pesquisa e Inovação do Estado de Santa Catarina (FAPESC) for additional research funding. The second and the third authors were partially funded by the Coordenação de Aperfeiçoamento de Pessoal de Nível Superior (CAPES).

\section{REFERENCES}

Andrade, F. and Casali, V.W.D. (2011) Homeopatia, Agroecologia e Sustentabilidade. Revista Brasileira de Agroecologia, 6(1): 49-56.

Aversa, R., Petrescu, R.V.V., Apicella, A. and Petrescu, F.I.T. (2016) About homeopathy or "similia similibus curentur". American Journal of Engineering and Applied Sciences, 9(4): 1164-1172.

Bell, I.R., Baldwin, C.M. and Schwartz, G.E. (2002) Translating a nonlinear systems theory model for homeopathy into empirical tests. Alternative Therapies in Health and Medicine, 8(3): 58-66.

Bertalanffy, L.V. (1967) General theory of systems: Application to psychology. Information (International Social Science Council), 6(6): 125-136.

Bertalanffy, L.V. (1973) Teoria geral dos sistemas. [General System Theory, 1968]. Petropolis: Ed. Vozes Ltda, $351 \mathrm{p}$. 
Betti, L., Trebbi, G., Majewsky, V., Scherr, C., Shah-Rossi, D., Jäger, T. and Baumgartner, S. (2009) Use of homeopathic preparations in phytopathological models and in field trials: A critical review. Homeopathy, 98(4): 244-266.

Boff, P. (2009) Agropecuária Saudável: Da prevenção de doenças, pragas e parasitas a terapêutica não residual [Healthy agriculture; from prevention of diseases, pests, and parasites to nonresidual therapy]. Lages: EPAGRI/UDESC.

Bonamin, L.V. (2014) Homeopathy, ethics and environment: A systemic approach. International Journal of High Dilution Research, 13(47): 91-92.

Bonamin, L.V. (2020) Homeopathy and environmental challenges. Homeopathy, 109(1): A002.

Bonamin, L.V., Lagache, A. and Bastide, M. (2008) Research on ultra-dilutions and the theory of corporeal signifiers: The follow up. In: Bonamin, L.V. (ed.), Signals and Images. Dordrecht: Springer Science, $3-25$.

Bonato, C.M. (2007) Homeopatia Simples: Alternativa Para Agricultura Familiar. Candido Rondo, PR: Gr. Lider, $36 \mathrm{p}$.

Bonfim, F.P.G and Casali, V.W.D. (2012) Homeopathy: Plant, Water and Soil, Scientific Evidence of the High Dilution. Viçosa, MG: UFV, 89 p.

Brasil (2007) Decreto n. 6323 de 27 dezembro 2007; Regulamento da Lei dos Orgânicos [Law no. 6323 of 27 December 2007; Organic regulation of Brazil]. http://www.agricultura.gov. br/desenvolvimento-sustentavel/organicos/legislacao.

Brazil (2011) Farmacopeia homeopatica Brasileira. Brasilia: ANVISA, 364 p.

Brilinger, D., Pereira, B.A., da Rosa, J.M., Franco, C.R. and Boff, M.I.C. (2018) Efeito de preparados homeopáticos sobre a viabilidade de pupas da mosca-das-frutas Ceratitis capitata. Anais do Congresso de Homeopatia nas Ciências Agrárias e do Ambiente. Ribeirão Preto: Instituto Homeopático e de Praticas Integrativas, $81 \mathrm{p}$.

Carneiro, S.M. de T.P.G. (ed.) (2011) Homeopatia: Princípios e aplicações na agroecologia. Londrina: IAPAR, $234 \mathrm{p}$.

Casali, V.W.D., Andrade, F.M.C. and Duarte, E.S.M. (2009) Acologia de Altas Diluições. Viçosa: UFV, 238 p.

Chikramane, P.S., Akkinhekkibbal, K.S., Jayesh, R.B. and Shantaram, G.K. (2010) Extreme Homeopathic dilutions retain starting materials: A nanoparticulate perspective. Homeopathy, 99(4): 231-242. doi: 10.1016/j.homp.2010.05.006.

das Kaviraj, V. (2012) Homeopathy for Farm and Garden: The Homeopathic Treatment of Plants. Kandern: Narayana Pub, $332 \mathrm{p}$.

de Rezende, J.M. (2009) Caderno de Homeopatia: Instruções práticas geradas por agricultores sobre o uso da homeopatia no meio rural. Viçosa: Universidade Federal de Viçosa, Departamento de Fitotecnia.

Dean, M.E. (2001) Homeopathy and "the progress of science." History of Science, 39(3): 255-283.

Deboni, T.C., Boff, P., Boff, M.I.C. and Marcon, M.C. (2017) Bioatividade de preparados homeopáticos e extratos vegetais sobre Acanthoscelides obtectus (Coleoptera: Bruchidae) em grãos de feijão armazenados. Revista Brasileira de Agroecologia, 12(2): 152-158.

Domingues, S., Werner, S.S, Bof, M.I.C. and Boff, P. (2019) Regrowth of yerba mate plants (Ilex paraguariensis A. St. - hill.) submitted to dynamized high-dilution preparations. Journal of Experimental Agriculture International, 36(6): 1-11.

Dougeon, M.D.R.E. (1989) The Lesser Writings of Samuel Hahnemann. New Delhi: B. Jain Publishers Pvt. Ltda, $784 \mathrm{p}$.

Faedo, L.F., Faxina, T.C., Silva, K.M., Atanasio, W.M., Damasceno, M.S. and Boff, P. (2009). Germination of Lactuca sativa under different dynamization levels of Arsenicum album. In Simpósio Internacional de Ciência, Saúde e Território, 5, 2019, Lages, SC: Uniplac.

Fisher, P. (2012) What is homeopathy? An introduction. Frontiers in Bioscience (Elite Edition), 4: 1669-1682.

Giesel, A., Boff, M.I.C. and Boff, P. (2012) The effect of homeopathic preparations on the activity level of Acromyrmex leaf cutting ants. Acta Scientiarum Agronomy, 34(4): 445-451.

Greenhalgh, T. (2002) Intuition and evidence-uneasy bedfellows? British Journal of General Practice, 52(478): 395-400.

Hahnemann, S. (1810) Organon of Rational Art of Healing, 1st edition, Reprint (1913). Kandern: Narayana Pub, 592 p.

Hahnemann, S. (1842) Organon da Arte de Curar [Organon der Heilkunst, $6^{a}$. ed. 2001]. São Paulo: Robe Editora, 248 p.

Hahnemann, S. (1846a) Materia Medica Pura, 1996. New Delhi: B. Jain Publishers Ltd, 709 p.

Hahnemann, S. (1846b) The Chronic Diseases: Their Specific Nature and Homeopathic Treatment. New York: Radde, 396 p. 
Jonas, W. (2003) A critical overview of homeopathy. Annals of Internal Medicine, 139(8): W-76.

Khatounian, C.A. (2001) A Reconstrução Ecológica da Agricultura. Botucatu: Agroecologica, SP, 348 p.

Kohler, F. and Negrão, M. (2018) The homeopathy/agroecology nexus: A discourse-centered analysis in a Brazilian agrarian settlement. Dialectical Anthropology, 42(3): 241-255.

Kokornaczyka, M.O., Trebbi, G.D.G., Marotti, I.B., Nani, D., Borghini, F. and Betti, L. (2014) Droplet evaporation method as a new potential approach for highlighting the effectiveness of ultra-high dilutions. Complementary Therapies in Medicine, 22(2): 333-340.

Kolisko, E. and Kolisko, L. (1978) Agriculture of Tomorrow, 2nd edition. Bournemouth: Kolisko Archive Publications.

Madsen, R. (2019) Characteristics of contemporary methodologies of classic homeopathy. Homcopathic Links, 32(1): 18-22.

Manzalini, A. and Galeazzi, B. (2019) Explaining homeopathy with quantum electrodynamics. Homeopathy, 108(3): 169-176.

Maute, C. (2011) Homeopathy for Plants: A Practical Guide for House, Balcony and Garden Plants with Tips on Dosage, Application and Choice of Potency. Kandern: Narayana Pub, 158 p.

Modolon, T.A., Boff, P., Boff, M.I.C. and Miquelluti, D.J. (2012) Homeopathic and high dilution preparations for pest management to tomato crop under organic production system. Horticultura Brasileira, 30(1): 51-57.

Moreno, N.M. (2017) Agrohomeopatía como alternativa a los agroquímicos. Revista Medica de Homeopatia, 10(1): 9-13.

Nunes, A., Werner, S.S., Boff, M.I.C. and Boff, P. (2019) Feasibility in seed germination of Hypericum perforatum $L$. submitted at different temperatures and treatments with high dilutions. International Journal of High Dilution Research, 18(3-4):2-12.

Portales, M.F. (2020) Efficacy of homeopathic herd health management in antibiotic resistant dairy cattle in Northern Spain. Homeopathy, 109(1): P012.

Savian, M., Faedo, L., Boff, P. and Boff, M.I.C. (2018) Agricultura urbana e o uso da homeopatia na pecuária em Lages, Santa Catarina. In Congresso de Homeopatia nas Ciências Agrarias e do Ambiente, 2018, Ribeirão Preto. Anais do Congresso de Homeopatia nas Ciências Agrárias e do Ambiente. Ribeirão Preto, IHPI, 2018, pp. 50-51.

Sheldrake, R. (2013) Uma nova ciência da vida. São Paulo: Cultrix, 326 p.

Silva, W.R.G., Pinto, S. and Carvalho, C.T. (2005) The ultra-high dilutions and its virtual structures. Arztezeitschrift fur Naturheiverfaren, 46(10):614-618.

Soule, J.D. and Piper, J.K. (1992) Farming in Nature's Image: An Ecological Approach to Agriculture. Washington, DC: Island Press, 286 p.

Steiner, R. (2001) Fundamentos da agricultura biodinâmica: vida nova para a terra. Antroposófica, 2. ed. Tradução de Gerard Bannwart. São Paulo: Editora Antroposófica.

Tichavský, R. (2009) Homeopatía para las Plantas. Monterrey: Ed. Fujimoto, 236 p.

Verdi, R., Bettoni, J.C., Werner, S.S., Boff, P. and Boff, M.I.C. (2020) Effects of the phenological stage, type of cutting and plant growth regulators on the propagation by stem cutting of Poiretia latifolia Vogel, a Brazilian native medicinal plant. Revista Colombiana de Ciencias Hortícolas, 14(2): 1-16.

Verdi, R., Nunes, A., Faedo, L.F. and Boff, P. (2020). Manejo homeopático no cultivo de arroz irrigado. Brazilian Journal of Development, 6(9): 65540-65549.

Viganò, G., Nannei, P. and Bellavite, P. (2015) Homeopathy: From tradition to science? Journal of Medicine and the Person, 13(1): 7-17.

Walach, H., Jonas, W.B., Ives, J., Wijk, R.V. and Weingärtner, O. (2005) Research on homeopathy: State of the art. Journal of Alternative and Complementary Medicine, 11(5): 813-829.

Zanco, J.J. (2016) Biofotonica na Caracterização de Sementes Submetidas à Altas Diluições Dinamizadas. PhD Thesis, Lages SC: UDESC, 238 p. 


\section{Effect of Low-Power Laser Biotechnology Pretreatment on Shooting and Initial Growth of White Mulberry and Sugarcane under Flood Stress}

Sergio Rodríguez Rodríguez

University of Granma

Eduardo Ortega Delgado

University of Havana

Juan José Silva Pupo

University of Granma

Alexander Álvarez Fonseca

Research Agricultural Institute "Jorge Dimitrov"

Medardo Ángel Ulloa Enríquez

Technical University of Cotopaxi

Luis Enrique Arias Basulto

University of Granma

\section{CONTENTS}

Introduction.

Effects of Low-Power Laser Biotechnology Pretreatment on the Shooting and

Initial Growth of Mulberry and Sugarcane

Materials and Methods

Results and Discussion

Effects of Low-Power Laser Biotechnology Pretreatment under Flooding Stress in

Mulberry and Sugarcane

Materials and Methods

Results and Discussion

References. 


\section{INTRODUCTION}

The problem of soil flooding is global and affects crop yields on all the continents of our planet (Peratae et al., 2011), and it is estimated that 6\% of terrestrial land is waterlogged or prone to temporary flooding, due to heavy rainfall and poor soil drainage (De la Cruz et al., 2012; Maltby, 1991). In Latin America, waterlogging affects $11.3 \%$ of the cultivated land, while in Cuba, poor drainage affects up to $40.3 \%$ of the cultivated agricultural area (CIGEA, 2001).

The term flooding encompasses both excess water accumulation in the soil and submersion. The accumulation of water can involve soil flooding, where only the roots are exposed to these conditions, and immersion, when the plant is partially or fully submerged (Sasidharan and Voesenek, 2015). Flood events have become more frequent, severe and unpredictable and are strongly associated with climate change.

The gas exchanges in the organs of flooded plants lead to the restriction of two vital plant processes, photosynthesis and respiration, which can be attributed to water being an extremely poor medium for the diffusion of gases, mainly oxygen. Most terrestrial plants, including major crops, are extremely sensitive to wet conditions. The adaptation of a plant to flooding includes molecular, physiological, morphological and anatomical changes. Initiating these changes requires an accurate and timely perception by the plant of excess water in order to invoke adaptive responses in the early stages of vegetative growth (Sasidharan and Voesenek, 2015).

In industrial farming, different chemical additives are used to raise the productivity of plants and livestock. Their application can cause the contamination of raw materials for food production with toxins that are dangerous for consumers' health as well the environment. On-farm safety for fresh produce requires the development and implementation of new methods for quality assurance. Through the substitution of chemical ameliorations by physical methods, one can reduce the toxins in the raw materials and thus raise the food safety levels and mitigate environmental concerns (Aladjadjiyan, 2007; Aladjadjiyan and Kakanakova, 2008; Jacubiak and Gdowska, 2013).

Thus, the treatment of seeds from agricultural crops by non-polluting substances and techniques could bring both qualitative and quantitative increases in agricultural production: a possibility that has led to increased interest in applying biophysical techniques in agriculture (Hernández et al., 2010; Mosneaga et al., 2018; Vasilevski, 2003).

Among the biophysical methods used for seed priming are treatments involving magnetic fields (De Souza and Garci, 1999; De Souza et al., 2006), temperature or thermo-priming (Paparella et al., 2015); light amplification by stimulated emissions of radiation or laser (Álvarez et al., 2011); X-rays (Ramírezet al., 2006); ultrasound (Yaldagard et al., 2008); gamma and beta radiation (Mirshekari, 2015); the use of plasma (Volin et al., 2000); and microwave radiation (Banik et al., 2003). All are potential alternatives to reducing the synthetic additives and fertilisers applied to the soil and plants.

Laser treatment involves emitting monochromatic coherent light waves in a controlled fashion (Aladjadjiyan, 2007). The literature concludes that it can be considered a safe technique, as it does not alter the molecular bonds, has no mutagenic effect and does not cause marked morphological changes in the structure of the tissue (Mosneaga et al., 2018). Laser biotechnology has a wide range of applications; it can be used in sustainable environmental engineering and preventive biotechnology to eliminate heavy metal contamination on degraded land, as well as in wastewater treatment bioremediation (Dobrowolski, 2010; Dobrowolski et al., 2012a,b; Mosneaga et al., 2018).

There are many studies about low-power laser biostimulation treatment, applied to plants to stimulate germination, shooting, rooting and plant growth. These include the following:

- improved growth and yield by stimulating morphological change (Hernández et al., 2016; Ivanova, 1998; Perveen et al., 2011; Podlesny and Podlesna, 2004; Podlesny et al., 2012; Ying and Chen, 2010);

- stimulating germination (Abu-Elsaoud, 2013; Hoseini et al., 2013; Jamil et al., 2013; Muthusamy et al., 2012; Podlesna et al., 2015); 
- seedling growth (Mosneaga et al., 2018);

- stimulation of cell proliferation through photostimulatory effects in mitochondria $(\mathrm{Hu}$ et al., 2007);

- protection against UV-B radiation damage (Abu-Elsaoud and Shahda, 2017; Al-Zhen et al., 2012; Chen and Han, 2014, 2015; Jia and Duan, 2013; Yang et al., 2012);

- stimulated leaf area and parameters of photosynthetic activity (Rybinski and Garczynski, 2004);

- increased nuclease activity of the leaves and roots (Zhang and Han, 2009);

- increased ATP level in cells cultivated under in vitro conditions (Karu et al., 1995); and

- improvements in the chemical composition and structure of lipids in tissue culture (Salyaev et al., 2007).

Laser treatment has been used to increase tolerance to various types of stress, such as the following:

- drought stress (Wu et al., 2007; Metwally et al., 2014; Qiu et al., 2008a,b; Qiu et al., 2017);

- increased drought stress resistance for repairing damage to plants exposed to osmotic stress (Qiu et al., 2008c, 2010) and membrane lipid peroxidation (Wu et al., 2007);

- low temperatures (Chen et al., 2010);

- salinity stress (Ashrafijou et al., 2010; Duan et al., 2010; Gao et al., 2014; Mohammadi et al., 2012; Rasouli et al., 2012; Zare et al., 2014); and

- changes in oxidative stress in response to antioxidant defence (Abu-Elsaoud, 2013; Abu-Elsaoud and Tuleukhanov, 2013; Chen, 2009; Qiu et al., 2013).

In the international scientific literature, most laser treatment research has been conducted with botanical seeds, and less with plant cuttings (Bąbelewski and Szajsner, 2014; Jakubiak and Gdowska, 2013; Rimal et al., 2014; Szajsner and Bąbelewski, 2014).

Plant growth regulators, as well as exogenous plant hormones (bioregulators), are known to be able to increase their tolerance to excess water in the environment. This has been encouraged with the use of paclobutrazol (Lin et al., 2006), putrescine (Yui et al., 2009a), spermine (Yiu et al., 2009b) and ethylene (Wang et al., 2016). Specific attention is drawn to the use of the bioregulator 5-aminolevulinic acid (ALA) in stress pretreatments, as it regulates several key physiological processes; for example, it significantly improves the waterlogging tolerance of fig (Ficus carica) and promotes root breathing, leaf photosynthesis and antioxidant capacity (An et al., 2016).

Mulberry (Morus alba) and sugarcane (Saccharum spp.) are two important species of plants grown commercially in Cuba; the former is increasingly used as a fodder crop and the latter is the main commercial crop for sugar production, but has multiple other uses, such as animal feed and derivatives. Commercially, both crops are propagated by stakes to ensure varietal homogeneity, but varietal characteristics, management factors and environmental conditions may result in low shooting rates and poor early-stage growth that affects crop yields.

The objective of this research was to determine the effect of low-power laser biotechnology pretreatment on the shooting and initial growth of mulberry and sugarcane under normal irrigation conditions and under flood stress.

\section{EFFECTS OF LOW-POWER LASER BIOTECHNOLOGY PRETREATMENT ON THE SHOOTING AND INITIAL GROWTH OF MULBERRY AND SUGARCANE}

\section{Materials and Methods}

Ninety 1-bud sets of the Acorazonada variety were cut from the mulberry seed bank (Morus alba) of the Plant Biotechnology Study Center, University of Granma, Cuba, along with 90 one-bud sets from 10-month-old sugarcane (variety C90-469) and their stalks from the sugarcane seed bank of 
the sugar company 'Archimedes Colina', Mabay, Bayamo, Granma, Cuba (using the methodology of the National Institute of Sugarcane Research) (INICA, 2002).

Sixty stalk segments of one-bud sets of each crop were irradiated with laser beams using medical laser or He-Ne, wavelength $660 \mathrm{~nm}$, red light power density of $360 \mathrm{~mW} . \mathrm{cm}^{-2}$. The laser treatments consisted of two irradiation times to the buds: 10 seconds (30 one-bud sets) and 20 seconds (30 one-bud sets), with a control treatment consisting of 30 one-bud sets that did not receive laser treatment. The buds were placed in nylon containers that are commonly used to market milk or yogurt in Cuba, with a substrate consisting of 50\% soil and 50\% cow manure. The percentage of vegetative bud break in each species was determined after 15 and 30 days.

In both crops, the variable was checked to see whether it met the criteria for a variance analysis, the normal distribution of data through the Shapiro-Wilk test, using InfoStat 2019 (Di Rienzo et al., 2019), and the homogeneity of variances using the Levene test (Minitab, 2013). The data were found to be distributed normally, and their variances were homogeneous. The data were statistically processed through a fixed-effect simple-classification variance analysis, with a two-factor treatment of $2 \times 2$. Factor 1 corresponded to the laser-beam treatment with two exposure times: 10 and $20 \mathrm{sec}-$ onds; and factor 2 corresponded to the two different times when the evaluations were performed: 15 and 30 days. The multiple comparisons of the mean treatments were made using Tukey's test at $5.0 \%$ probability. The mean of each treatment and its standard error were represented in a bar chart (see Figure 14.1).

\section{Results and Discussion}

A significant response to the laser applications was found for vegetative bud breaks in mulberry. The best response was found to the laser applications lasting 10 seconds, with $76.7 \%$ of vegetative bud break, compared to $63.3 \%$ with a laser application lasting 20 seconds, and $60.6 \%$ bud break (Figure 14.1a) in the control treatment (with no laser application). No significant differences were found between the two time intervals evaluated (Figure 14.1b), indicating that during this period there were no morphological qualitative changes in the development of new mulberry shoots through the effect of laser beams (Figure14.1).

When the percentages of vegetative bud breaks for the two laser exposure time periods were combined and compared to the control, significant differences in the interactions between these two treatments were found (Figure 14.1c). The higher percentages of budding occurred in buds that received laser treatments for a space of 10 seconds, percentages that increased as the days passed. The lowest percentages were obtained in the control at 15 days, with an increase at 30 days, while with 20 seconds of laser exposure, intermediate results were achieved in both evaluations (after 15 and 30 days)

The same procedure was repeated on the sugarcane (variety C90-469), and produced similar results to the mulberry (Figure 14.2). The highest percentage of vegetative bud break, at $85.6 \%$, was with the application of the laser for 10 seconds, followed by the control treatment with $64.4 \%$, while the lowest bud break was the application of the laser for 20 seconds, with 58.9\% (although there was no significant difference between the latter two). As with the mulberry experiment, no significant time factor effects were found.

\section{EFFECTS OF LOW-POWER LASER BIOTECHNOLOGY PRETREATMENT UNDER FLOODING STRESS IN MULBERRY AND SUGARCANE}

\section{Materials and Methods}

For this experiment, plants from the laser treatment that resulted in the best bud break - exposure for 10 seconds and after 30 days- were used, together with a control. Forty cuttings were prepared (20 of mulberry cuttings and 20 of sugarcane) from the first experiment that were exposed to 
(a)

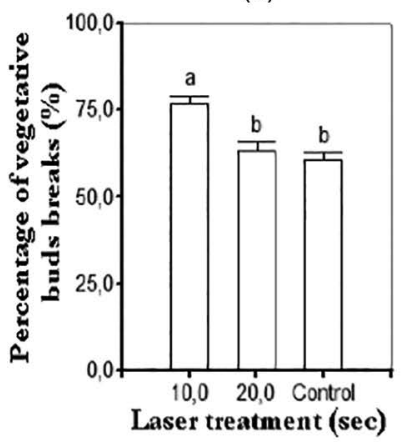

(b)

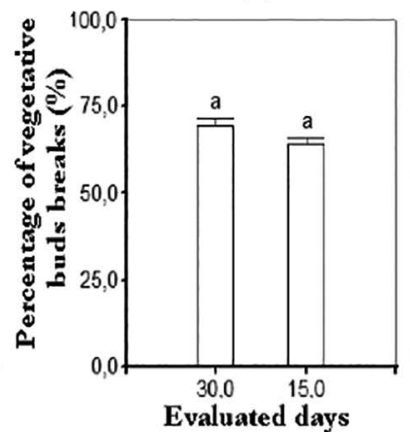

(c)

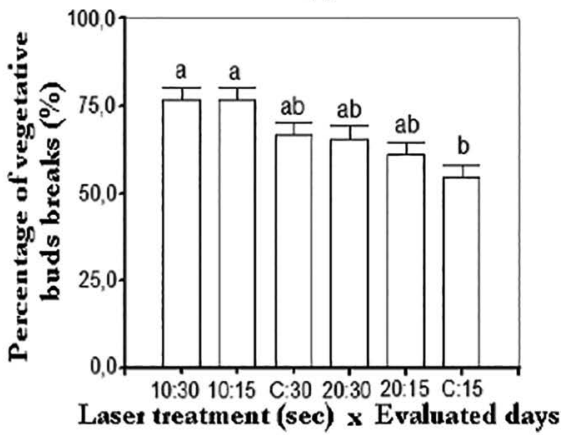

FIGURE 14.1 Percentage of vegetative bud breaks in mulberry, variety Acorazonada, produced by the effect of two laser treatments (10 and 20 seconds) plus the control (graph a), assessed at 15 and 30 days from the initiation of treatments (graph b), and the combination of the two (graph c). Different letters indicate significant differences at $p<0.05$ using Tukey's test.

(a)

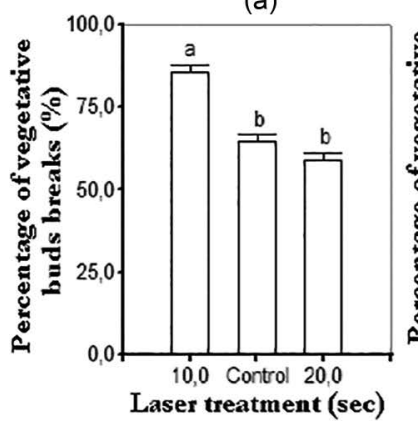

(b)

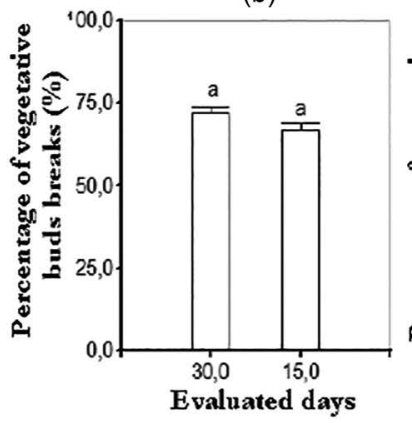

(c)

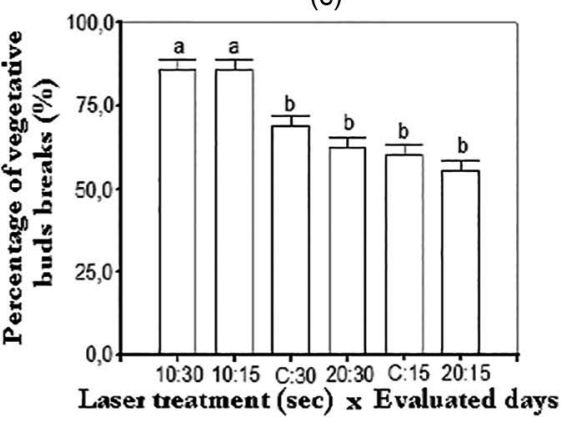

FIGURE 14.2 Percentage of vegetative bud break in sugarcane, variety C90-469, produced by the effect of two laser treatments (10 and 20 seconds) plus the control (graph a), assessed at 15 and 30 days from the initiation of treatments (graph b), and the combination of the two (graph c). Different letters indicate significant differences at $p<0.05$ using Tukey's test.

this most favourable treatment. Thirty-five days after the treatment, the bud bags (20 stakes with their shoots) were immersed in a pond to a water level that did not completely cover the shoots. They were kept there for 3 days and then held for 4 days out of the water. This weekly process was repeated for 4 weeks (replicating flooding conditions).The remaining 20 cuttings of each crop were applied with water every 3 days (without excess, replicating non-flood conditions). A control treatment was established for both crops at the same age, without the application of laser and without stress due to excess water. At the end of 4 weeks or 63 days in total if counting from the start of the first experiment, the length of the shoots (in $\mathrm{cm}$ ) and the area of the aerenchyma ${ }^{1}\left(\right.$ in $\left.\mu \mathrm{m}^{2}\right)$ were assessed.

For the histological study, samples of first-order branched roots of each crop (which were physiologically active, characterised by light coloration, absence of necrosis and suberisation) of an average diameter of $2 \mathrm{~mm}$ and a total length of $5 \mathrm{~cm}$ were collected. Three replicates were selected

\footnotetext{
${ }^{1}$ Aerenchyma is spongy tissue that forms spaces or air channels in the leaves, stems and roots of some plants, which allows exchange of gases between the shoot and the root. There are two types: lysigenous and schizogenous.
} 
from each variety and ten root samples were taken from each replicate. Histological sampling was performed in the area between 1.0 and $1.5 \mathrm{~cm}$ from the apex of the root upwards.

The root samples were kept in liquid nitrogen until they were taken to the lab. From there, crosssections of $0.2 \mathrm{~mm}$ thickness were made and analysed under an optical microscope. Digital photos were taken, and the aerenchyma tissue area was calculated using the Motic Images Plus 2.0 program (Motic Instruments Inc., Richmond, Canada) through morphometric methods that gave a magnification of up to $400 \times$.

Prior to the analysis of variance of variations in vegetative bud break in this experiment, it was checked whether the variable met the premises of the analysis of variance, the normal distribution of the data through the Shapiro-Wilk test (Di Rienzo et al., 2019) and the homogeneity of variances using the multiple comparison test (Minitab, 2013). The data were statistically processed through a fixed-effect simple-classification variance analysis, with three treatments for both crops, cuttings with their shoots that received lasers for 10 seconds and a life cycle of 30 days in non-flooding conditions (10`30d NF) and in flooding conditions (10`30d F) and one treatment control (laser-free and stress-free). As the data collected did not follow a normal distribution, the variance analysis of nonparametric form was by the Kruskal-Wallis test. The comparison of treatments was made through the range means (Conover, 1999). For each treatment, the mean of means and their standard error were determined.

\section{Results and Discussion}

Table 14.1 shows the differences in leaf shoot length in mulberry, which was significant between the three treatments in general. However, the use of the laser in conditions of stress due to over-wetting was not significantly different from the laser treatment in normal conditions of humidity of the substrate, which suggests that regardless of whether there is excess water, the influence of the laser stimulates the growth of the leaf shoots. The length of the shoot in the control treatment (without the application of laser) was significantly lower than that reached in the treatments where the laser was applied.

For aerenchyma tissue, the three treatments showed significantly different results: a greater growth of this tissue was found on samples that were treated with the laser and placed in conditions of excess water in the substrate, significantly more than those subject to the laser treatment but not to excess water. The lowest growth of the aerenchyma was in the control treatment (in which the laser treatment was not applied and the moisture conditions of the substrate were normal).

Similar results were found when evaluating sugarcane shoots, variety C90-469 (Table 14.2). Both results show that the physical effect of laser beams triggers biochemical and physiological

TABLE 14.1

Mean Values of Foliar Bud Length (cm) and Root Aerenchyma Area (in $\mu \mathrm{m}^{2}$ ) in Mulberry Seedlings, Acorazonada Variety, Treated with Laser for 10 Seconds and Evaluated under Flood (F) and Non-Flooded Stress (NF) in the Substrate, and the Control (No Laser Treatment and No Excess Moisture)

Leaf Shoot Length (Mulberry)

\begin{tabular}{lc}
\hline Treatments & Average \pm SD \\
$10 ` 30 \mathrm{~d} \mathrm{NF}$ & $16.09 \pm 0.70$ \\
$10^{\prime} 30 \mathrm{~d} \mathrm{~F}$ & $15.86 \pm 0.45$ \\
Control & $14.03 \pm 0.97$
\end{tabular}

Aerenchyma Area (Mulberry)

\begin{tabular}{ccc}
\hline Ranges & Average \pm SD & Ranges \\
$41.40^{\mathrm{a}}$ & $10739122.9 \pm 3056151$ & $30.5^{\mathrm{b}}$ \\
$37.38^{\mathrm{a}}$ & $30182546.9 \pm 2714263$ & $50.5^{\mathrm{a}}$ \\
$12.73^{\mathrm{b}}$ & $186826.1 \pm 120669,9$ & $10.5^{\mathrm{c}}$
\end{tabular}

Different letters indicate significant differences at $p<0.05$ through the differences between the averages of the ranges. 
TABLE 14.2

Mean Values of Foliar Shoot Length (cm) and Root Aerenchyma Area (in $\mu \mathrm{m}^{2}$ ) in Sugarcane Seedlings, Variety C90-469, Treated with Laser for 10 Seconds and Evaluated under Flood (F) and Non-Flooded Stress (NF) in the Substrate, and the Control (No Laser Treatment and No Excess Moisture)

Leaf Shoot Length (Sugarcane)

\begin{tabular}{lc}
\hline Treatments & Average \pm SD \\
$10^{\prime 30 d ~ N F ~ F ~}$ & $96.08 \pm 5.59$ \\
$10 ` 30 d$ F & $96.23 \pm 5.88$ \\
Control & $91.51 \pm 4.64$
\end{tabular}

\begin{tabular}{ccc}
\multicolumn{3}{c}{ Aerenchyma Area (Sugarcane) } \\
\hline Ranges & Average \pm SD & Ranges \\
$35.15^{\mathrm{a}}$ & $6437131 \pm 2010409$ & $30.5^{\mathrm{b}}$ \\
$35.25^{\mathrm{a}}$ & $18046968.8 \pm 1406608.9$ & $50.5^{\mathrm{a}}$ \\
$21.10^{\mathrm{b}}$ & $108691 \pm 72487.7$ & $10.5^{\mathrm{c}}$
\end{tabular}

Different letters indicate significant differences at $p<0.05$ through the differences between the averages of the ranges.

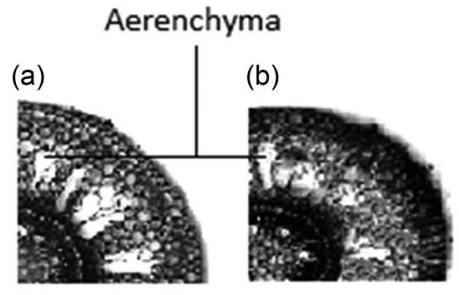

Mulberry

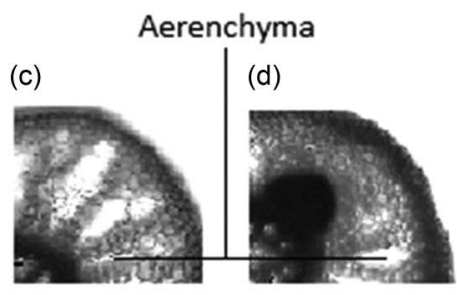

Sugarcane

FIGURE 14.3 Histological cross section. (a) Mulberry root, Acorazonada variety, with laser application for 10 seconds in conditions of excess water; (b) mulberry root, Acorazonada variety, with no application of laser rays in conditions of excess water; (c) sugarcane root, variety C90-469, with laser application for 10 seconds in conditions of excess water; and (d) sugarcane root, variety C90-469, with no application of laser rays in conditions of excess water.

mechanisms that produce greater elongation of the main mulberry and sugarcane shoots in a substrate with oxygen restriction, indicating that pretreating the buds of these crops has a robust effect, which allows them a normal early-stage growth and better subsequent development under stress conditions with an oxygen deficit.

The laser-stimulating effect on the leaf shoot length under the effect of oxygen deficiency in relation to the control may be associated with a greater development of the aerenchyma tissue (Tables 14.1 and 14.2 and Figure 14.3) at the roots of mulberry and the sugarcane shoots, which accentuated the formation of aerenchymatic tissue in the substrate with water excess. This suggests that the laser stimulates the synthesis of the ethylene hormone, which under these conditions is responsible for the formation of this tissue by apoptosis or cell death of the genetically programmed parenchymal cells. This in turn promotes the formation of porous spaces or ducts from the roots to the aerial parts of the plant and facilitates the entry of oxygen from the surrounding atmosphere to the roots. As such, it constitutes an important adaptation of certain plant species to live and develop in soils with excess water.

Although ethylene has an inhibitory effect on stem growth for most plant species, it has been found that certain plant species are tolerant of oxygen deficits in the soil. This plant hormone can act as a stimulator of stalk growth due to an increase in the synthesis of the precursor of ethylene, 1-aminocyclopropane-1-carboxylic acid (ACC), under hypoxia conditions (Jackson, 2007; Voesenek et al., 1992; Voesenek et al., 1993), which causes a decrease in the levels of the phytohormone 
abscisic acid (ABA) and an increase in the phytohormone gibberellic acid (GA; Azcón-Bieto and Talon, 2008; Voesenek and Van Deer Veen, 1994).

It is important to look at other morphological adaptations. The C90-469 sugarcane variety showed inverse correlations between stoma density and stoma length in the stimulated flood conditions (Rodríguez et al., 2017). In the gas exchange between the plant and the environment, there is a connection between stomata and aerenchyma tissue.

\section{CONCLUSIONS}

The growing world population is constantly putting pressure on the need to increase food production, which in turn is affected by the edaphoclimatic phenomena (the influence of soils on plants in relation to climate), such as the frequent extreme events of high and low temperatures, droughts and floods and hurricanes. Flooding is a natural disaster that affects both humans and plants, and man-made driving factors of flooding include deforestation, and intensive agriculture characterised by extensive use of machinery and chemical products, which contaminate water sources, plants, animals and humans as well as being one of the causes of the increase in greenhouse gases that exacerbates climate change due to the increase in the annual average temperature. Agroecological production of food offers a balanced and sustainable alternative, and one more sustainable tool is preconditioning seeds and buds with physical methods. The use of lasers to precondition plant buds such as mulberry and sugarcane in order to increase sprouting and initial growth seems to be a viable method. It has the effect of activation of biochemical, physiological and morphological factors that can increase the tolerance of plants to excess water in the soil, by increasing the aerenchymatic tissue at the root. This apparently stimulates the synthesis of the ethylene hormone within the plant that, under this type of stress, induces shoot growth. This research needs further development although we are confident that the use of low-power biotechnological laser may provide a useful technique for conditioning seeds and vegetative parts in stressful environments at an industrial scale.

\section{ACKNOWLEDGEMENTS}

This research is part of the project 'In vitro plant biotechnology to increase food security in eastern Cuba', TEAM2017PR438-75644, funded by the Vlaamse Interuniversitaire Raad (VLIR),between the Laboratory of Applied In-Vitro Plant Biotechnology, Department of Applied Biosciences Engineering, University of Ghent, Belgium, and Plant Biotechnology Study Center, Faculty of Agricultural Science, University of Granma, Cuba.

\section{REFERENCES}

Abu-Elsaoud, A. M. (2013) Double-pulse laser light treatment stimulate germination and changes the oxidative stress and antioxidant activities of wheat (Triticum aestivum). Journal of Ecology of Health and Environment 1:1-11.

Abu-Elsaoud, A. and Shahda, R. (2017) Role of the He-Ne laser pretreatment in protecting Zea mays against the deleterious effects of ultraviolet radiations. Egyptian Journal of Experimental Biology (Botany) 13:403-422.

Abu-Elsaoud, A. M. and Tuleukhanov, S. T. (2013) Can He-Ne laser induce changes in oxidative stress and antioxidant activities of wheat cultivars from Kazakhstan and Egypt? Science International 1:39-50.

Aladjadjiyan, A. (2007) The use of physical methods for plant growing stimulation in Bulgaria. Journal Central European Agriculture 8:369-380.

Aladjadjiyan, A. and Kakanakova, A. (2008) Physical methods in agro-food chain. Journal Central European Agriculture 9:789-794.

Álvarez, A., Ramírez, R., Chávez, L., Camejo, Y., Licea, L., Porras, E. and García, B. (2011) Efecto del tratamiento de semillas con láser de baja potencia, sobre el crecimiento y rendimiento en plantas de tomate (Solanum lycopersicum L.). ITEA 4:290-299 [In Spanish].

Al-Zhen, M. A., Su-Hua, L. I., Xiao-Li, W. E. I. and Rong, H. A. N. (2012) Effects of He-Ne laser and enhanced ultraviolet-B radiation on MAP65s of wheat seedlings. Journal of Biology 4:015. 
An, Y., Qi, L. and Wang, L. (2016) ALA pretreatment improves waterlogging tolerance of fig plants. PLoS One 11(1): $\mathrm{e} 0147202$.

Ashrafijou, A., Sadat Noori, S. A., Izadi Darbandi, A. and Saghafi, S. (2010) Effect of salinity and radiation on proline accumulation in seeds of canola (Brassica napus L.). Plant Soil Environment 56:312-317.

Azcón-Bieto, J. and Talon, M. (2008) Fundamentos de Fisiología Vegetal, Segunda Edición. Ed. Interamericana, MacGraw-Hill-Interamericana de España: Madrid, 651p, [In Spanish].

Bąbelewski, P. and Szajsner, H. (2014) Attemption of applying laser photostimulation to the rooting of shoot cuttings of juniper species. Acta Scientiarum Polonorum Hortorum Cultus 13:135-144.

Banik, S., Bandyopadhyay, S. and Ganguly, S. (2003) Bioeffects of microwave:A brief review. Bioresource Technology 87:155-159.

Chen, H. and Han, R. (2014). He-Ne laser treatment improves the photosynthetic efficiency of wheat exposed to enhanced UV-B radiation. Laser Physics 24:105602.

Chen, H. and Han, R. (2015) He-Ne laser influenced acting filaments alleviate the damage of UV-B in wheat. Laser Physics 25:5601.

Chen, Y. P. (2009) Response of antioxidant defense system to laser radiation on apical meristem of Isatis indigotica seedlings exposed to UV-B. Plant Signaling and Behavior 4:571-573.

Chen, Y. P., Jia, J. F. and Yue, M. (2010) Effect of $\mathrm{CO}_{2}$ laser radiation on physiological tolerance of wheat seedlings exposed to chilling stress. Photochemistry and Photobiology 86:600-605.

CIGEA (2001) Síntesis del Diagnóstico de la Desertificación y la Sequía en Cuba. Caracterización del archipiélago Cubano. Centro de Información, Gestión y Educación Ambiental: La Habana [In Spanish].

Conover, W. J. (1999) Practical Nonparametric Statistics. John Wiley and Sons, Inc.: New York.

De la Cruz, J., Moreno, P. and Magnitskiy, S. (2012) Respuesta de las plantas a estrés por inundación. Revista Colombiana de Ciencias Hortícolas 6:96-109 [In Spanish].

De Souza, A. and Garci, D. (1999) Efecto del tratamiento magnético de semillas de tomate (Lycopersicon esculentum Mill.) sobre la germinación y el crecimiento de las plántulas. Investigación Agronómica de Protección Vegetal 14:437-444 [In Spanish].

De Souza, A., Garci, D., Sueiro, L., Gilart, F., Porras, E. and Licea, L. (2006) Pre-sowing magnetic treatments of tomato seeds increase the growth and yield of plants. Bioelectromagnetics 27:247-257.

Di Rienzo, J. A., Casanoves, F., Balzarini, M. G., Gonzalez, L., Tablada, M. and Robledo, C. W. (2019) InfoStat versión 2019. Centro de Transferencia InfoStat, FCA, Universidad Nacional de Córdoba, Argentina. http://www.infostat.com.ar.

Dobrowolski, J. W. (2010) Laser biotechnology for more efficient bioremediation and sustainable development. Journal of Chemical Technology and Biotechnology 150:264-265.

Dobrowolski, J. W., Budak, A., Trojanowska, D., Rymarczyk, M. and Macuda, J. (2012a.) Laser stimulation of Trichophyton mentagrophytes for the enhancement biodegradation of hydrocarbons. Environmental Engineering and Management Journal 11:1783-1788.

Dobrowolski, J. W., Śliwka, M. and Mazur, R. (2012b) Laser biotechnology for more efficient bioremediation, protection of aquatic ecosystems and reclamation of contaminated areas. Journal of Chemical Technology and Biotechnology 87:1354-1359.

Duan, Z. Y., Yang, Z. F. and Yang, Z. R. (2010) Effects of He-Ne laser irradiation on salt tolerance of tomato seedlings. Acta Laser Biology Sinica 2:7.

Gao, L. M., Li, Y. F. and Han, R. (2014) He-Ne laser preillumination improves the resistance of tall fescue (Festuca arundinacea Schreb.) seedlings to high saline conditions. Protoplasma 1:1-14.

Hernández, A. C., Domínguez, P. A., Crúz, O. A., Ivanov, R., Carballo, C. A. and Zepeda, B. R. (2010) Laser in agriculture. International Agrophysics 24:407-422.

Hernández, A. C., Domínguez, P. A., Cruz, O. A., Podlesna, A., Ivanov, R., Carballo, C. A., Perez, R. M. C., Sanchez, H. G., Zepeda, B. R. and Lopez, B. J. L. (2016) Bioestimulación láser en semillas y plantas. Gayana Botanica 73:132-149 [In Spanish].

Hoseini, M., Feqenabi, F., Tajbakhsh, M. and Babazadeh-Igdir, H. (2013) Introduction of seed treatment techniques (seed priming). International Journal of Biosciences 3:1-12.

Hu, W. P., Wang, J. J., Yu, C. L., Lan, C. C. E., Chen, G. S. and Yu, H. S. (2007) Helium-neon laser irradiation stimulates cell proliferation through photostimulatory effects in mitochondria. Journal of Investigative Dermatology 127:2048-2057.

INICA (2002) Normas y Procedimientos del Programa de Mejoramiento Genético de la Caña de Azúcar en Cuba. Instituto Nacional de Investigaciones de la Caña de Azúcar. Boletín No. 1 Cuba and Caña INICA: La Habana, Cuba, 315 p [In Spanish].

Ivanova, R. (1998) Influence of pre-sowing laser irradiation of seeds of introduced flax varieties of linseed oil on yield quality. Bulgarian Journal of Agricultural Science 4:49-53. 
Jackson, M. (2007) Ethylene-promoted elongation: An adaptation to submergence stress. Annals of Botany 101:229-248.

Jakubiak, M. and Gdowska, K. (2013) Innovative environmental technology applications of laser light stimulation. Energy and Automation 3:14-21.

Jamil, Y., Perveen, R., Ashraf, M., Ali, Q., Iqbal, M. and Ahmad, M. (2013) He-Ne laser-induced changes in germination, thermodynamic parameters, internal energy, enzyme activities and physiological attributes of wheat during germination and early growth. Laser Physics Letters.doi:10:045606-045614.

Jia, Z. and Duan, J. (2013) Protecting effect of He-Ne laser on winter wheat from UV-B radiation damage by analyzing proteomic changes in leaves. Advances in Bioscience and Biotechnology 4:823-829.

Karu, T., Pyatibrat, L. and Kalendo, G. (1995) Irradiation with He-Ne laser increases ATP level in cells cultivated in vitro. Journal of Photochemistry and Photobiology B 27:219-223.

Lin, K., Tsou, C. Hwang, S. Chen, L. and Lo, H. (2006) Paclobutrazol pre-treatment enhanced flooding tolerance of sweet potato. Journal of Plant Physiology 163:750-760.

Maltby, E. (1991) Wetlands their status and role in the biosphere. In: Jackson, M. B., Davies, D.D. and Lambers, H. (eds) Plant Life under Oxygen Deprivation: Ecology, Physiology and Biochemistry. The Hague: SPB Academic, pp. 3-21.

Metwally, S. A., Mohamed, S. L. M., Abou-Leila, B. H., and Aly, M. S. (2014) Effect of drought stress and helium neon (He-Ne) laser rays on growth, oil yield and fatty acids content in caster bean (Ricinus communis L.). Agriculture, Forestry and Fisheries 3:203-208.

Minitab Inc. (2013) Minitab Statistical Software Release 17 for Windows. State College:Pennsylvania.

Mirshekari, B. (2015) Physical seed treatment techniques may influence stand establishment and yield of wheat in delayed cropping. IDESIA 33:49-54.

Mohammadi, S., Shekari, F., Fotovat, F. and Darudi, A. (2012) Effect of laser priming on canola yield and its components under salt stress. International Agrophysics 26:45-51.

Mosneaga, A., Lozovanu, P. and Nedeff, V. (2018) Investigation of biostimulation effects on germination and seedling growth of some crop species. Cellulose Chemistry and Technology 52:551-558.

Muthusamy, A., Kudwa, P. P., Prabhu, V., Mahato, K.K., Sankar Babu, V., Radhakrishna Rao, M., Mantdyat Gopinath, P. and Satyamoorthy, K. (2012) Influence of Helium-Neon laser irradiation on seed germination in vitro and physico-biochemical characters in seedlings of brinjal (Solanum melongena L.) var. Mattu Gulla. Photochemistry and Photobiology 88:1227-1235.

Paparella, S., Araújo, S. Rossi, G. Wijayasinghe, M. Carbonera, D. and Balestrazzi, A. (2015) Seed priming: state of the art and new perspectives. Plant Cell Report 34:1281-1293.

Perata, W., Armstrong, W. and Voesenek, L. A. C. J. (2011) Plants and flooding stress. New Phytologist 190:269-273.

Perveen, R., Jamil, Y. Ashraf, M. Ali, Q. Iqbal, M. and Ahmad, M. R. (2011) He-Ne laser induced improvement in biochemical, physiological, growth and yield characteristics in sunflower (Helianthus annuus L.). Photochemistry and Photobiology 87:1453-1463.

Podlesna, A., Gladyszewska, B., Podleśny, J. and Zgrajka, W. (2015) Changes in the germination process and growth of pea in effect of laser seed irradiation. International Agrophysics 29:485-492.

Podleśny, J. and Podlesna, A. (2004) Morphological changes and yield of selected species of leguminous plants under the influence of seed treatment with laser light. International Agrophysics 18: $253-260$.

Podleśny, J., Stochmal, A., Podleśna, A. and Misiak L. E. (2012) Effect of laser light treatment on some biochemical and physiological processes in seeds and seedlings of white lupine and faba bean. Plant Growth Regulation 67:227-233.

Qiu, Z. B., Liu, X., Tian, X. J. and Yue, M. (2008a) Effects of $\mathrm{CO}_{2}$ laser pretreatment on drought stress resistance in wheat. Journal of Photochemistry and Photobiology B., Biology 90:17-25.

Qiu, Z. B., Liu, X., Tian, X. J. and Yue, M. (2008b) Influence of He-Ne laser irradiation on protective enzyme activities and lipid peroxidation in wheat seedlings by drought stress damage. Journal of Plant Ecology (Chinese Version) 32:1002-1006.

Qiu, Z. B., Li, F. M., Wang, F. and Yue, M. (2008c) Effects of $\mathrm{CO}_{2}$ laser on glutathione-dependent antioxidative system in wheat seedling under drought stress. Journal of Wuhan Botanical Research 26: 402-406.

Qiu, Z. B., Li, J. T. and Yue, M. (2010) The damage repair role of He-Ne laser on wheat exposed to osmotic stress. Canadian Journal of Plant Science 90:691-698.

Qiu, Z., Li, J., Zhang, M., Bi, Z. and Li, Z. (2013) He-Ne laser pretreatment protects wheat seedlings against cadmium induced oxidative stress. Ecotoxicology and Environmental Safety 88:135-141. 
Qiu, Z, Yuan, M., He, Y., Li, Y. and Zhang, L. (2017) Physiological and transcriptome analysis of He-Ne laser pretreated wheat seedlings in response to drought stress. Scientific Reports 7:6108.

Ramírez, R., Gonzalez, L. M., Camejo, Y., Zaldívar, N. and Fernández, Y. (2006) Estudio de radiosensibilidad y selección de rango de dosis estimulantes de rayos $\mathrm{X}$, en cuatro variedades de tomate (Lycopersicom esculentum Mill). Cultivos Tropicales 27:63-67 [In Spanish].

Rasouli, Z., Mohammadi, S. P., Shekari, F. and Khan Mohammadi, S. (2012) Effect of laser priming and salinity stress on canola characteristics using ANN. American-Eurasian Journal of Agricultural and Environmental Sciences 12:1395-1405.

Rimal, B., Ranaivoson, R. M., Czarnecka, K. P. and Dobrowolski, J. W. (2014) Laser biotechnology for enhanced rooting and shooting of Salix viminalis in hydroponic condition for better adaptation in industrially contaminated land. International Journal of Environmental Bioremediation and Biodegradation 2:228-230.

Rodríguez, S., Ortega, E. and Silva, J. (2017) Effect of flooding on stomatal density and stomatal length in six sugarcane genotypes. International Journal of Advanced Research 5:709-718.

Rybinski, W. and Garczynski, S. (2004) Influence of laser light on leaf area and parameters of photosynthetic activity in DH lines of spring barley (Hordeum vulgare L.). International Agrophysics 18:253-260.

Salyaev, R. K., Dudareva, L. V., Lankevich, S. V., Makarenko, S. P., Sumtsova, V. M. and Rudikovskaya, E. G. (2007) Effect of low intensity laser irradiation on the chemical composition and structure of lipids in wheat tissue culture. Doklady Biological Sciences 412:87-88.

Sasidharan, R. and Voesenek. V. (2015) Ethylene mediated acclimations to flooding stress. Plant Physiology 169:3-12.

Szajsner, H. and Bąbelewski, P. (2014) The Influence of laser beam and auxins on rooting of leather leaf viburnum (Viburnum rhytidophyllum Hems1.) cuttings. Journal of Horticultural Research 22:63-66.

Vasilevski, G. (2003) Perspectives of the application of biophysical methods in sustainable agriculture. Bulgarian Journal of Plant Physiology Special Issue:179-186.

Voesenek, L. A. C. J. and Van Der Veen, R. (1994) The role of phytohormones in plant stress: two much or too little water. Acta Botanica Neerlandica 43:91-127.

Voesenek, L. A. C. J., Van der Sman, A. J. M., Harren, F. J. M. and Blom, C. W. P. M. (1992) An amalgamation between hormone physiology and plant ecology: A review on flooding resistance and ethylene. Journal Plant Growth Regulation 11:171-188.

Voesenek, L. A. C. J., Banga, M., Thier, R. H., Mudde, C., Harren, F., Barendse, G. W. M. and Blom, C. W. P. M. (1993) Submergence induced ethylene synthesis, entrapment and growth in two plant species with contrasting flooding resistances. Plant Physiology 103:783-791.

Volin, J. C., Denes, F. S., Young, R. A. and Park, S. M. (2000) Modification of seed germination performance through cold plasma chemistry technology. Crop Science 40:1706-1718.

Wang, X., Huang, M., Zhou, Q., Cai, J., Dai, T., Cao, W. and Jiang, D. (2016) Physiological and proteomic mechanisms of waterlogging priming improves tolerance to waterlogging stress in wheat (Triticum aestivum L.). Environmental and Experimental Botany 132:175-182.

Wu, J., Gao, X. and Zhang, S. (2007) Effect of laser pretreatment on germination and membrane lipid peroxidation of Chinese pine seeds under drought stress. Frontiers of Biology in China 2:314-317.

Yaldagard, M., Mortazavi, S. A. and Tabatabaie, F. (2008) Application of ultrasonic waves as a priming technique for accelerating and enhancing the germination of barley seed: optimization of method by the Taguchi approach. Journal of the Institute Brewing 22:22-27.

Yang, L., Han, R and Sun, Y. (2012) Damage repair effect of He-Ne laser on wheat exposed to enhanced ultraviolet-B radiation. Plant Physiology and Biochemistry 57:218-221.

Ying, C. and Chen, Y. P. (2010) Research trends on the regulating effect of laser pretreatment on plant growth. Chinese Journal of Eco-Agriculture 18:1125-129.

Yiu, J. C., Juang, L. D., Fang, D. Y. T., Wei, L. C. and Wu, S. J. (2009a) Exogenous putrescine reduces flooding-induced oxidative damage by increasing the antioxidant properties of Welsh onion. Scientia Horticulturae 120(3):306-314.

Yiu, J. C., Wei, L. C., Fang, D. Y. T. and Lai, Y. S. (2009b) Waterlogging tolerance of Welsh onion (Allium fistulosum L.) enhanced by exogenous spermidine and spermine. Plant Physiology and Biochemistry 47(8):710-716.

Zare, N., Sadat Noori, S. A., Mortazavian, M. and Mohammad, S. (2014) Effect of laser priming on accumulation of free proline in spring durum wheat (Triticum turgidum L.) under salinity stress. International Transaction Journal of Engineering, Management, and Applied Sciences and Technologies 5:119-130.

Zhang, J. and Han, R. (2009) Study on the nuclease of wheat seedling under He-Ne laser and ultraviolet-B radiation. Chinese Journal of Laser 36:2619-2624. 


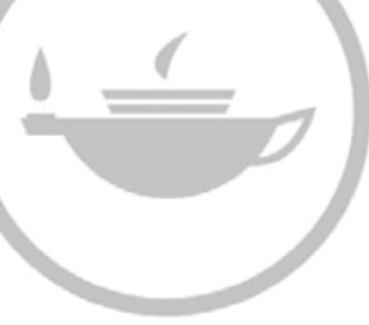

Taylor \& Francis Taylor \& Francis Group http://taylorandfrancis.com 


\title{
15 Fluorescence Excitation Spectroscopy (FES) to Evaluate the Farming System's Impact on Food Quality
}

\author{
Jenifer Wohlers, Peter Stolz and Gudrun Mende \\ Forschungsinstitut KWALIS gGmbH
}

Jürgen Strube (in Memoriam)

\section{CONTENTS}

Introduction 167

The Method of FES Measurements 168

Effects of Farming Systems on Food Quality, Measured by FES............................................... 168

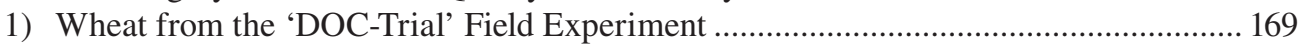

2) Apple Quality: Maturation and Growing Conditions ..................................................... 170

3) Emission Spectrums as Dependent on the Type of Sample and the Sample State......... 172

4) Cocoa Beans Grown in Monocultures or in Agroforestry Systems ............................... 173

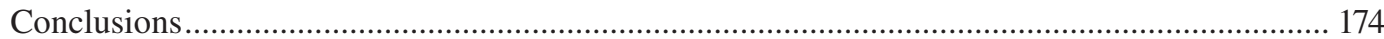

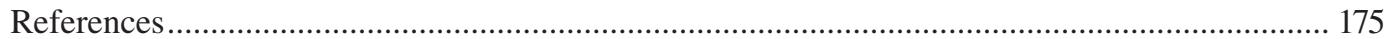

\section{INTRODUCTION}

Fluorescence Excitation Spectroscopy (FES) was developed by J. Strube in the 1980s and 1990s based on the investigations of F.A. Popp $(1984,2013)$. Popp used the term 'biophotons' for photons which were emitted by organisms at a very low intensity (ultra-low) and invisible to the human eye. Photons themselves are countable units of light, physically detectable as particles. Popp evaluated the relation between these ultra-low photon emissions - or biophotons - and human health, especially in relation to carcinogenic diseases and the quality of foodstuffs from organic farming. The inspiration for his research was provided by Gurwitsch (e.g. Gurwitsch and Gurwitsch, 1932) who, as a biologist and medical scientist, was interested in growth-stimulating effects. In his experiments on onion roots and yeast cultures, Gurwitsch found that mitosis (cell division giving rise to genetically identical cells) was encouraged by neighbouring root tips. He concluded that growing or living organisms emit light - which he named 'mitogenetic radiation' - which influences other organisms. Nowadays this is named 'ultra-weak photon emission' (UWPE) or 'ultra-low photon emission' (ULPE) and is used to describe a very weak emission of light, in wavelengths of the visible and ultraviolet light. It is now known that coloured light (special wavelengths) stimulates specific metabolic pathways in plants and humans, resulting (in the case of plants) in flowering, growing or ripening (Eichhorn Bilodeau et al., 2019; Monostori et al., 2018), or (in humans) in higher levels of alertness or fatigue (Askaripoor et al., 2018; Bauer et al., 2018; Rahman et al., 2017). 
Between the 1960s and 1980s, Popp's thesis made a comeback among some scientists in Germany. Popp argued that high-quality food contains measurable amounts of biophotons and that these could have a nutritive value for humans and may help us to stay healthy. At this time, there was growing scepticism in Europe about the supposed benefits of mineral fertilisers and synthetic pesticides. This raised the question of whether organically grown food might be qualitatively different from that which was industrially grown. In this context, FES was developed, with the aim of determining food quality in a holistic way. Differences between crop samples grown under organic and conventional conditions were explored, as well as the effects of the biodynamic preparations, which at that time were known by some farmers to be potent, but whose mechanistic pathways were not yet understood scientifically.

More recently, scientific research has confirmed the real differences in soil parameters, plant health, product quality and more, between industrial and organic/biodynamic farming (e.g. Geier et al., 2016; Mäder et al., 2006; Mie et al., 2017). Research also shows that the use of biodynamic preparations may ${ }^{1}$ result in enhanced product quality, which is measurable through picture-forming methods (Doesburg et al., 2014; Fritz et al., 2017; Bloksma et al., 2001, 2007) as well as by FES (Stolz et al., 2019; Strube and Stolz, 2010). With ongoing developments in analytical capacity, these differences can also be shown by the metabolic pattern (or 'metabolomics'; Shewry et al., 2018; Zörb et al. 2009), by 1H-NMR (nuclear magnetic resonance spectroscopy) (Picone et al., 2016) or by modern gas-chromatographic and mass-spectrometric devices (Bigot et al., 2018).

This chapter describes the general methodology of the FES measurement and provides some relevant results and reflections on the epistemology of the approach. The aim is to encourage the reader not only to think in terms of the dominant mainstream worldview that focuses on material form, but also to consider life processes. Light energy mediates such life processes and is thus also of importance when studying metabolites, and this light- and life-process-related aspect of food quality needs to be taken into consideration when evaluating FES results.

\section{THE METHOD OF FES MEASUREMENTS}

The procedure of FES consists of an illumination (excitation) of the sample and a measurement of the subsequent emission of photons (see Figure 15.1). The measurements are conducted in a climate-controlled dark room (at $15 \pm 1^{\circ} \mathrm{C}$ with $40 \pm 5 \%$ relative humidity). The excitation is done by projecting light in seven different colours (i.e. red, yellow, blue, etc.) one after the other onto the sample, each colour representing a defined range of wavelengths of visible light. Detection after each colour excitation is realised by a photomultiplier which counts the subsequent emitted photons at intervals, and the declining curve over time is documented (Figure 15.2). The data evaluation is performed on the basis of repeated measurements of each sample, and parameters such as the short-time emission (the first data point of the declining curve, Mw1) or the long-term emission (the mean of the last 40 or 80 data points of the declining curve, R40) for each excitation colour are of interest, as well as the relationships between them.

A more detailed description of the method and the devices used is given in Stolz et al. (2019) and Wohlers and Stolz (2019).

\section{EFFECTS OF FARMING SYSTEMS ON FOOD QUALITY, MEASURED BY FES}

To date, thousands of such FES measurements have been performed at the research institute KWALIS in Germany, many of which focusing on the impact of farming systems on food quality. To explain the concept of quality evaluation via FES, four examples are provided which show the following:

\footnotetext{
${ }^{1}$ The term 'may' is used here rather than 'does' because the biodynamic preparations do not work like standard industrial inputs, such as nitrogen fertiliser, and thus should not be compared to or treated as such. The preparations enhance quality in the way that is appropriate for each given situation; they encourage growth and enable other possibilities without forcing the plant.
} 


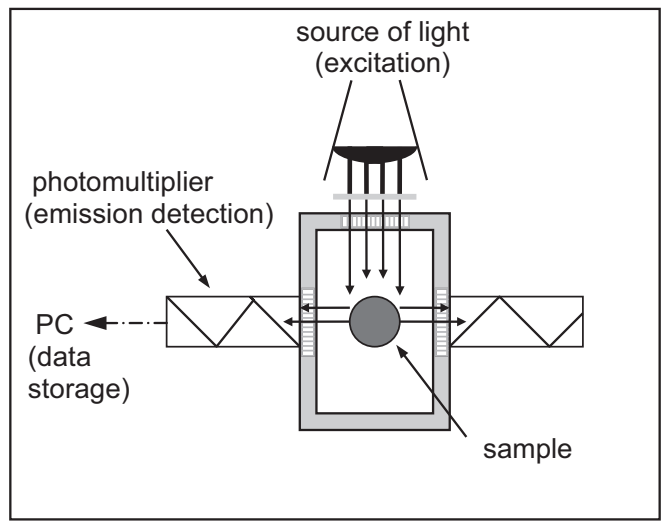

FIGURE 15.1 Schematic overview of the FES measuring apparatus with $90^{\circ}$ position between excitation illumination and emission detection by photomultipliers. The time sequence between excitation and emission is regulated by shutters.

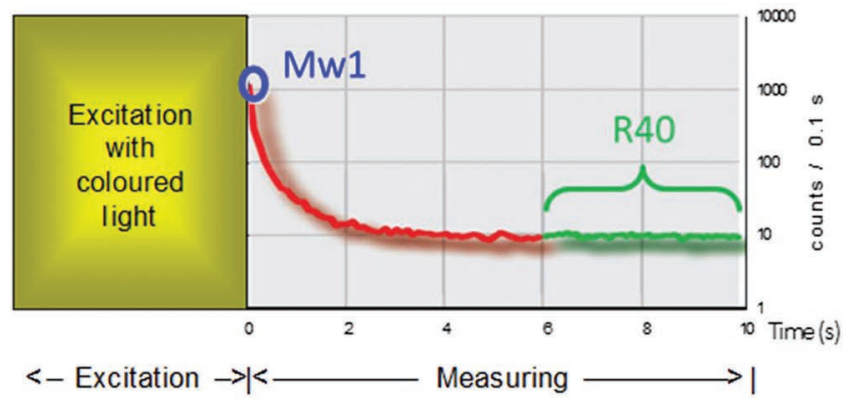

FIGURE 15.2 Schematic illustration of the excitation and measuring interval and a characteristic declining curve of the delayed emission. Mw1 indicates the short-time emission, and R40 indicates the long-term emission.

i) influences of farming systems on the induced emission of food (Nos. 1 and 4),

ii) the variation of induced emission, caused by maturation and growing conditions, and in relation to different parts of the plant (No. 2),

iii) phenomena of induced emission in relation to aspects of holistic quality (No. 3).

\section{1) Wheat from the 'DOC-Trial' Field Experiment}

The DOC-trial was established in Switzerland in 1978 to evaluate differences in yield, plant health, crop quality and soil parameters between the biodynamic farming method (represented by D2 in Figure 15.3), organic farming (without biodynamic preparations, O2) and industrial farming systems that use mineral fertilisers, either with (K2) or without (M) the additional use of manure (Mäder et al., 2002, 2006).

Wheat samples from this experiment were measured over several years by FES, and the results were published in Strube and Stolz (2010) and Hermanowski et al. (2013).

Significant $(p<0.05)$ differences between the samples were observed. The FES parameter R40yellow/blue (Figure 15.3) showed low yellow-by-blue ratios for the organic and biodynamic 


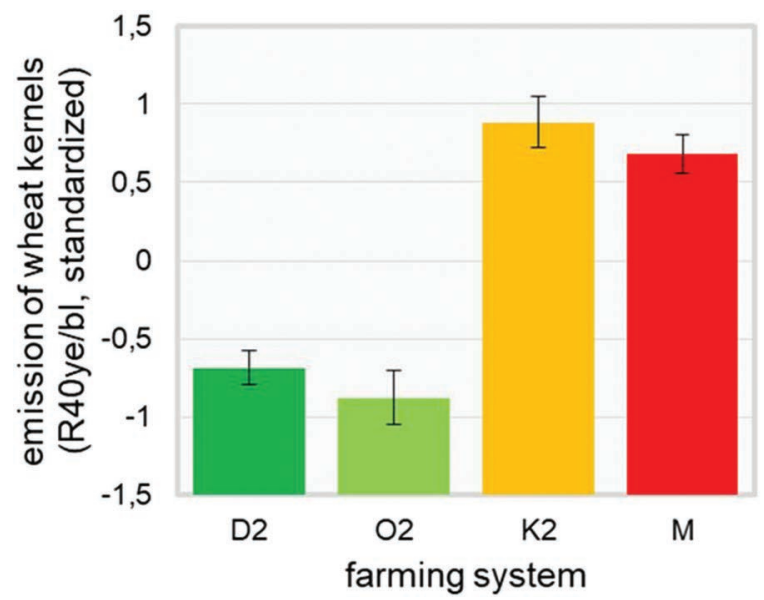

FIGURE 15.3 Differences between the wheat samples collected over 6 (O2 and K2) and 8 years (D2 and $\mathrm{M}$ ), on the basis of mean values per year and farming system (standardised by year of harvest). Whiskers indicate standard error of the mean. D2=biodynamic; O2=organic; K2=conventional (manure+mineral); $\mathrm{M}=$ mineral fertilisation only.

samples in 7 of 8 years. Other parameters, such as Mwlgreen-by-blue or R40yellow, similarly showed a difference between organic/biodynamic (D2, O2) and industrial farming systems (K2, M). Higher R40yellow/blue values (as observed in the industrial samples) can be interpreted as less maturation in seeds (Strube and Stolz, 2010) and are in accordance with other investigations on bean seeds (Strube and Stolz, 2001c) and calendula seeds (Strube and Stolz, 2001b). This yellow-by-blue parameter was determined as relevant for seeds since those in dormancy have higher biophoton emissions after blue than after yellow excitation, whereas the opposite occurs in germinating and unripe seeds (cf. also No. 2 of this chapter). Fertilisation intensity also changes this parameter to high values, which are characteristic for vegetative states where the seed has not completed the differentiating growth phase (cf. also No. 3 of this chapter).

\section{2) Apple Quality: Maturation and Growing Conditions}

An experiment with apple trees was carried out in the year 2000 in the Netherlands by the Louis Bolk Institute, to examine the effects of maturation stages, light intensities and biodynamic preparations on the quality of apples according to the 'Inner Quality Concept'2 (Bloksma et al., 2003, 2004, 2007). The whole apples as well as the kernels of the apples were measured (full results are published in Bloksma et al. (2001) and Strube and Stolz (2002)).

As the apples matured (Figure 15.4), the values in the R40yellow/blue parameter for the whole apples increased, while the seeds of these apples showed lower values. This divergence in values during seed development can be viewed in relation to the morphologically visible increasing inner differentiation of the apples from their seeds. This was also indicated by increasing amounts of secondary metabolites: the kernels became seed-typical, and the fruits became fruit-typical (cf. No. 3 of this chapter). The highest degree of quality (called 'integration' by Bloksma et al. (2003), or 'product-typical' according to our own terminology) was reached with full maturation, including a specific equilibrium between reduced growth processes (mass production, related to primary

\footnotetext{
2 The 'Inner Quality Concept' is a quality concept for food based on the life processes of growth and differentiation. It was developed to show the additional value of carefully grown organic food, to explain properties such as 'vitality' and 'coherence' and to relate to health aspects.
} 


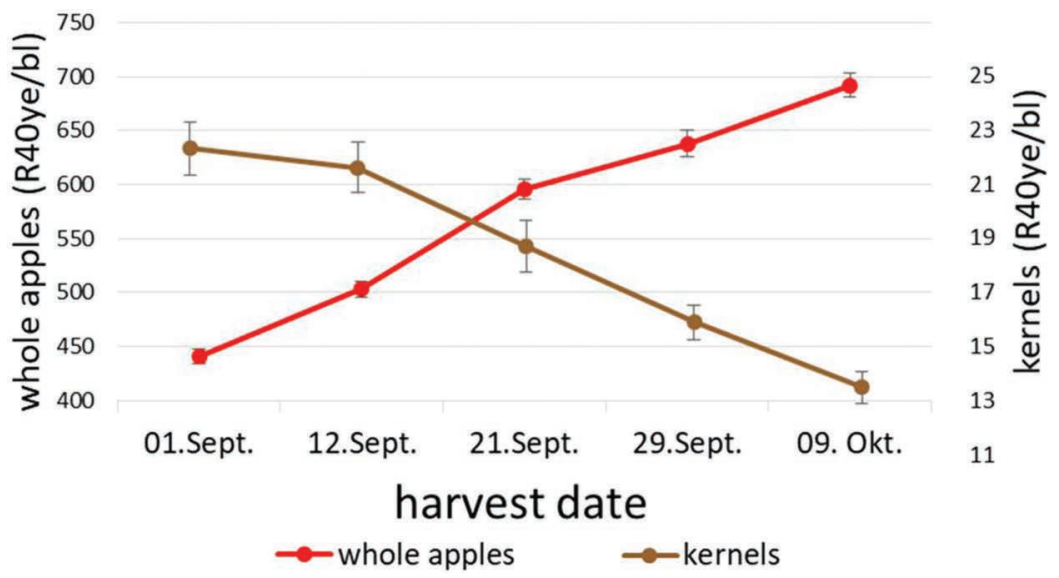

FIGURE 15.4 R40yellow/blue of whole apples and their seeds at different maturation stages. Whiskers indicate standard error of the mean. An increasing divergence of the induced emission of whole apples and their kernels during maturation was observed, these being indicated on the figure by the crossing of the lines.

metabolites) and increased differentiating processes (diversity of tissue structure and integration of small molecules into larger ones relating to secondary metabolites).

Another experiment with factors including light intensity and biodynamic preparations (Figure 15.5) showed that at full light and with biodynamic preparations, an emission with high yellow-by-blue ratios was observed, indicating that under these growing conditions, a fruit developed which was comparable to mature fruits, while shadow resulted in apples which looked as though they were not completely ripened.

Yellow/blue is the most obvious of the colour parameters in terms of excitation and can be found in several other sample sets as relevant to maturation and ripening of seeds. (Single colours are less specific to maturation, and these absolute parameters are more intensively related to, for example, the size of the sample or freshness.) The challenge of this method is that the parameter

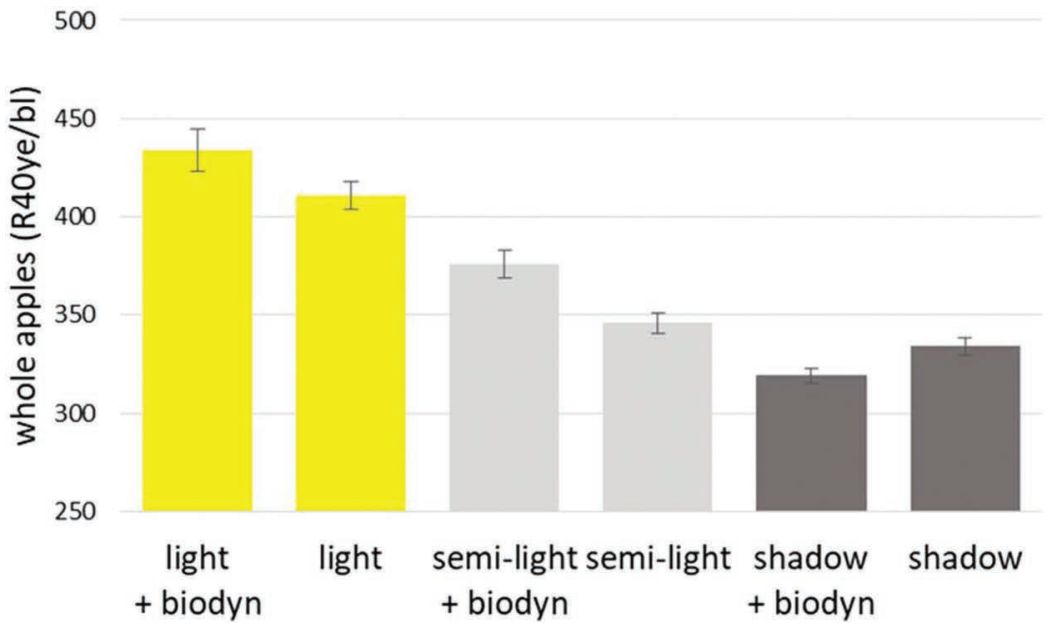

FIGURE 15.5 R40yellow/blue of whole apples from different growing conditions (light intensity and application of biodynamic preparations). 
R40yellow/blue is relative and is not a simple value for maturation, such as of the amount of secondary metabolites. It has to be interpreted depending on the sample: the sample type, the plant's organs such as e.g. seed, fruit, leaf have to be considered, and the evaluation scale has to be obtained from the object itself. As the maturation stages of fruits are the plant's steps on its way to its characteristic well-formed, well-shaped, evolved final stage of development before it decays in several stages to death, it can be seen that the different organs differ with progressing maturation, and the FES results represent this. Strube and Stolz (2002) concluded that this development can be interpreted as an increased differentiating, organisational capacity or performance (in German: Organisationsleistung, cf. also Egerer, 2009) and that it was present in the apples grown under full light or in those with biodynamic preparations (Figure 15.5; Strube and Stolz, 2002). In other situations, such as where the crop is intensively fertilised or grown in in vitro cultivation, growth showed less differentiation.

\section{3) Emission Spectrums as Dependent on the Type of Sample and the Sample State}

To compare the different characteristics of the spectrally excited emissions of different kinds of samples, measurements have to be performed at the same excitation intensity and the same measuring intervals, which normally have to be set specifically due to different emission intensities of different kinds of samples. It was observed that leaves expressed an intense emission after being subjected to all excitation colours (the most after yellow or red excitation) - and this is named a 'broadband spectra' (cf. Figure 15.6) - whereas a pure chemical substance like citric acid only showed considerable emission after blue excitation - which is a narrowband spectra. Seeds (wheat grains) fell in between these characteristics - they had a low emission when excited with yellow or red light and an intermediate emission after excitation with blue light. These spectra are of importance when evaluating quality in the context of the sample's natural state, that is the whole mass of substances of the sample that are present at the moment of detection (including its life processes and specific composition of substances and physiological processes).

Strube and Stolz (2004) have also observed that when seeds are not totally dried, they may emit more like a leaf, with higher emission intensity after yellow or red excitation - as they are not yet in total dormancy and thus their physiology is more active. Further, when wheat was grown with higher amounts of nitrogen fertiliser, resulting in higher amounts of crude protein in the wheat

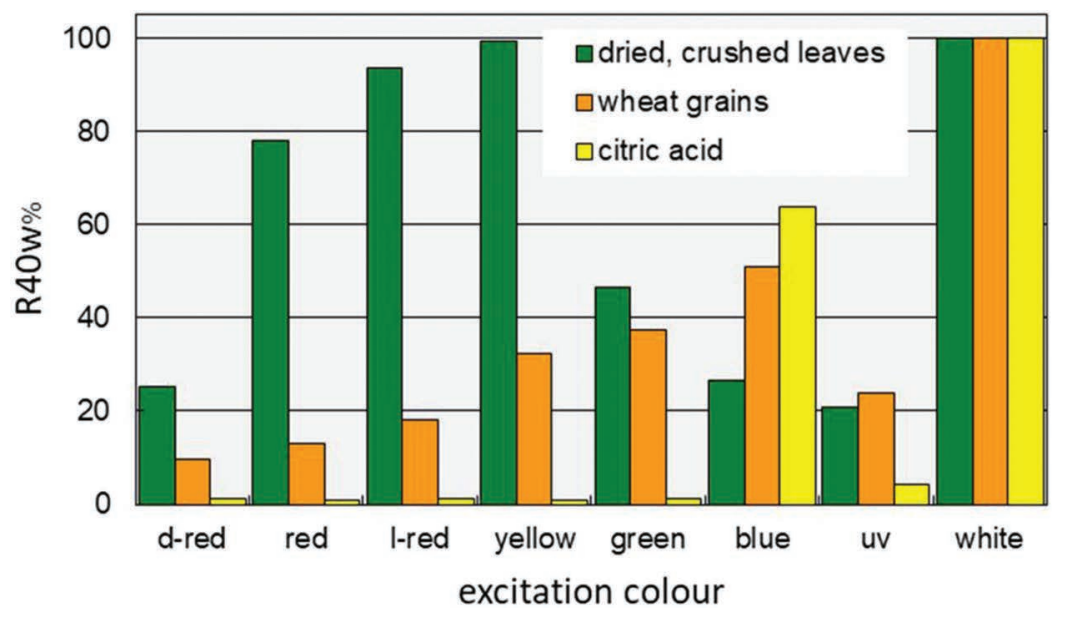

FIGURE 15.6 Fluorescence excitation spectrum of different kinds of samples: emission of leaves (dried crushed nettle leaves), of seeds (whole wheat kernels) and of citric acid. (Derived from Strube and Stolz, 2001a.) 
kernels, its emissions were similar to those of a vegetative in-growth state, while the emissions of other samples were more dormant and seed-like. This indicates that the excitation spectroscopy can detect whether growing and ripening were performed and finished by the plant's own characteristic physiology under natural conditions, or whether it was influenced by fertilisers or other physiology-influencing factors.

On the basis of these results, it can be concluded that the biophoton emission after colour excitation can indicate whether the sample is in a more or less characteristic state,

- being more leaf-like, representing vegetative growth-processes,

- being more seed-like, representing generative, mature, dormant situations, where physiological processes are reduced, resulting in conservation and storage of growth-relevant substances,

- or being more like a pure chemical substance, representing minerals which are not actually integrated in life processes.

\section{4) Cocoa Beans Grown in Monocultures or in Agroforestry Systems}

A scientifically controlled field trial with cocoa plants was installed in 2009 in Bolivia (Sara Ana, near La Paz), to compare the effects of the farming system on ecological aspects (biodiversity), soil parameters, plant health and product quality. The experimental factors were as follows: (1) monoculture (Mono) vs. agroforestry (AF) farming and (2) conventional (Conv) vs. organic (Org) farming; additionally, a successional agroforestry system (SAFS) was investigated. FES measurements were performed on fermented cocoa beans which were harvested in 2012.

The results are provided in Figure 15.7 for the five farming systems in comparison, and in Figure 15.8, the differences between organic and conventional systems are presented.

The emission of the cocoa beans - although fermented - showed a comparable spectral excitation ability to wheat kernels. Organic and agroforestry (AF) farming systems resulted in lower long-term emission intensities after yellow excitation (Figure 15.7), indicating a more seed-typical quality. The ratio between yellow and blue (R40yellow/blue; Figure 15.8) was higher among the conventional samples than among the organic samples and may indicate a seed with a low degree of specific maturity, again comparable to the conventional wheat samples (K2 and M) from the DOC-trial. The low values of the organic samples may indicate that the seeds reached seed-typical qualities.

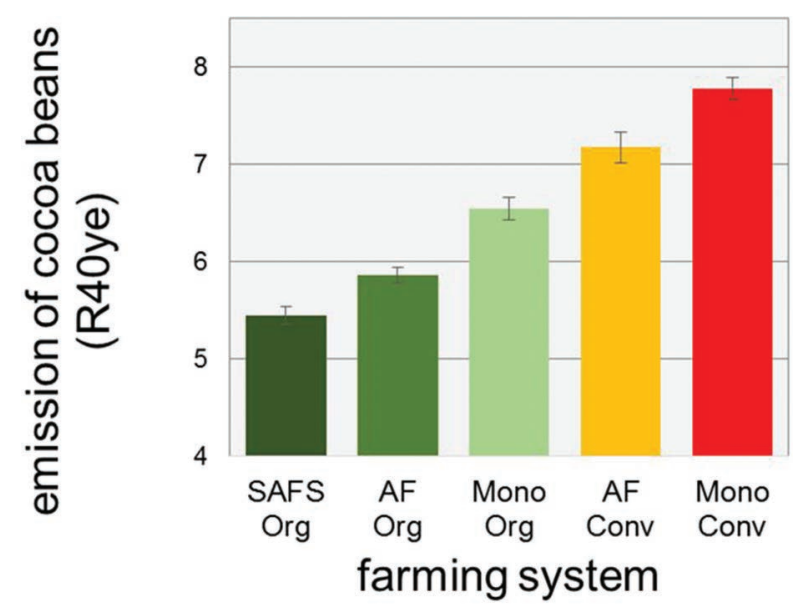

FIGURE 15.7 Emission intensity (R40yellow) of fermented whole cocoa beans from a cultivation trial. Whiskers indicate standard error of the mean. 


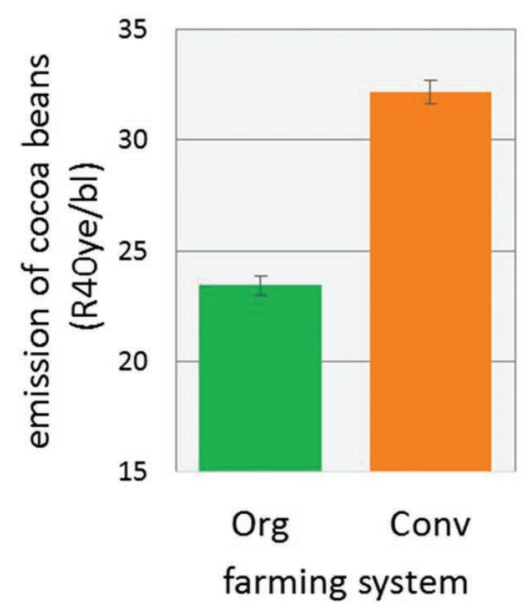

FIGURE 15.8 Differences between conventional and organic farming in cocoa beans in the relative emission intensity of R40yellow/blue.

The SAFS sample had an overall very low emission intensity, characteristic for seeds in dormancy or grown under extensive conditions. Overall, the implications are that more sustainable farming systems are better able to produce or achieve products that are closer to their optimum, naturally predisposed potential.

\section{CONCLUSIONS}

The FES has repeatedly been able to show differences between samples originating from different farming systems, and a classification of samples according to their origin has been possible, which was comparable to the classification on the basis of their analytical parameters (Hermanowski et al., 2013). It will be just a question of time before the underlying principles of the induced emission characteristic are better understood. Still, the existing results of the FES measurements are sufficient to support the rationale that the scientific view should be broadened to look not only at the microscopic and analytical world, but also at the phenomena of life and, holistically, at the farming system as a whole that influences the organisms within it and their development, their metabolism and interactions.

A theory common among biologists is that plants seek a balance between growth and differentiation (Bloksma et al., 2003, 2007; Herms and Mattson, 1992; Stamp, 2003). This is based on the evidence that plants may - dependent on the growing conditions - express a more growth-related metabolism with enhanced nitrogen-related primary metabolism, resulting in enhanced yields, or a metabolism which aims at the differentiation of matter by enhancing carbon-related secondary metabolites. The latter is often observed in plants of organic origin, and such plants are observed to suffer less damage from predators or diseases (de Lange et al., 2019). This balance or equilibrium changes with the ongoing development of the plant, from more growth-related to more differentiation-related processes, and each part of the plant and each species has its own characteristic balance.

So when FES results indicate that crop samples of organic, biodynamic or agroforestry origin are 'more typical' than conventional/industrial samples, including those from monocultures, the measured emission can be seen as an indication of the growing conditions which were more or less in congruence with the species-specific demands. Under such optimum conditions, plants may express their own individual quality and shape more explicitly than in less optimal conditions. For example, in highly fertilised, conventional or monoculture conditions, where the plants are restricted in their resilience to stay healthy (Döring et al., 2012, 2015), or to exhibit all stages of 
development (Bloksma et al., 2007; Lammerts van Bueren and Hospers, 1991), they are forced into a specific growth-related development.

In all investigations with FES, the relative emission after blue excitation and yellow excitation seems to be important in evaluating the sample's quality and metabolic state. Yet it is not just expressing a metabolism which is related either to more differentiation (indicated by secondary metabolites) or to more growth (indicated by primary metabolites). It also has to be interpreted in relation to the type of sample and its biologically predefined physiology. A leaf is most leaf-like when it enhances the carbon metabolism of the plant by photosynthesis, when it expresses life processes. Fruits are most fruit-like when they are ripening and store sugar and polyphenols - also products of life processes. In these cases, high emissions after excitation with red or yellow can be observed, and high ratios of yellow-by-blue are characteristic. The opposite is found for seeds: their emission after red or yellow excitation declines with ripening - so for seeds, a high emission indicates a metabolism which is not seed-like - it is growth-like or life-like, but not dormant, as a seed should be when it is in its typical state. So with FES, the typical expression of a plant's organ may be evaluated in terms of its state of expressing its own, naturally desired condition, its metabolic state, seen as the operating processes of life.

On the basis of this ability of the FES to tell us something about the plant's life processes, it may in the future be used not only to differentiate between farming systems, but also to help farmers or scientists to decide which farming practice is helpful in obtaining the best quality product, or which breeding line offers the most product-typical opportunities.

\section{REFERENCES}

Askaripoor, T., Motamedzadeh, M., Golmohammadi, R., Farhadian, M., Babamiri, M. and Samavati, M. (2018) Non-image forming effects of light on brainwaves, autonomic nervous activity, fatigue, and performance. J Circadian Rhythms 16:1-13.

Bauer, M., Glenn, T., Monteith, S., Gottlieb, J.F., Ritter, P.S., Geddes, J. and Whybrow, P.C. (2018) The potential influence of LED lighting on mental illness. World J Biol Psychiatry 19:59-73.

Bigot, C., Métivier, R., Montet, D. and Meile, J.-Chr. (2018) Traceability and authentication of organic foodstuffs, Chapter 6. In: Montet, D. and Ray, R.C. (eds), Food Traceability and Authenticity: Analytical Techniques, pp. 116-136. Boca Raton, FL: CRC Press/Taylor \& Francis.

Bloksma, J., Northolt, M. and Huber, M. (2001) Parameters for Apple Quality: Part 2-Annexes. Driebergen: Louis Bolk Instituut.

Bloksma, J., Huber, M., Northolt, M., van der Burgt, G.J. and Adriaansen-Tennekens, R. (2003). The Inner Quality Concept for food, Based on Life Processes. Driebergen: Louis Bolk Instituut. http://orgprints. org/4894\%.

Bloksma, J., Northolt, M., Huber, M., Jansonius, P. and Zanen, M. (2004). Parameters for Apple Quality - 2, and the Development of the 'Inner Quality Concept' 2001-2003. Driebergen: Louis Bolk Instituut. http://orgprints.org/4266/.

Bloksma, J., Notholt, M., Huber, M., van der Burgt, G.-J. and van de Vijver, L. (2007) A new food quality concept based on life processes. In Cooper, J., Leifert, C. and Niggli, U. (eds), Handbook of Organic Food Safety and Quality. Cambridge: Woodhead Publishing. http://www.louisbolk.org/downloads/1910.pdf.

De Lange, E.S., Kyryczenko-Roth, V., Johnson-Cicalese, J., Davenport, J., Vorsa, N. and Rodriguez-Saona, C. (2019) Increased nutrient availability decreases insect resistance in cranberry. Agric Forest Entomol 21: $326-335$.

Doesburg, P., Huber, M., Andersen, J.O., et al. (2014) Standardization and performance of a visual Gestalt evaluation of biocrystallization patterns reflecting ripening and decomposition processes in food samples. Biol Agric Hort 31:128-145.

Döring, T.F., Pautasso, M., Finckh, M.R. and Wolfe, M.S. (2012) Concepts of plant health: Reviewing and challenging the foundations of plant protection. Plant Pathol 61:1-15.

Döring, T.F., Vieweger, A., Pautasso, M., Vaarst, M., Finckh, M.R. and Wolfe, M.S. (2015) Resilience as a universal criterion of health. Sci Food Agric 95:455-65.

Egerer, U. (2009) Feldstudie zur Eignung der Biophotonenmessung für die Differenzierung von ökologisch und konventionell erzeugten Hühnereiern [Field Study on the Suitability of the Biophoton Measurement for the Differentiation of Organically and Conventionally Produced Chicken Eggs]. PhD dissertation, University of Hohenheim. http://opus.ub.uni-hohenheim.de/volltexte/2009/404/. 
Eichhorn Bilodeau, S., Wu, B.-S., Rufyikiri, A.-S., MacPherson, S. and Lefsrud, M. (2019) An update on plant photobiology and implications for cannabis production. Front Plant Sci 10:296.

Fritz, J., Athmann, M., Meissner, G., Kauer, R. and Köpke, U. (2017) Quality characterisation via image forming methods differentiates grape juice produced from integrated, organic or biodynamic vineyards in the first year after conversion. Biol Agric Hort 33:195-213.

Geier, U., Fritz, J., Greiner, R. and Olbrich-Majer, M. (2016) Biologisch-dynamische Landwirtschaft [Bio-Dynamic Agriculture] (Chapter 4). In Freyer, B. (ed.), Ökologischer Landbau - Grundlagen, Wissensstand und Herausforderungen, pp. 101-23. Stuttgart: UTB Taschenbuch.

Gurwitsch, A. and Gurwitsch, L. (1932) Die mitogenetische Strahlung. Zugleich zweiter Band der "Probleme der Zellteilung" [The Mitogenetic Radiation. And 2nd Part of the "Problems of Cell Division"]. (Monographien aus dem Gesamtgebiet der Physiologie der Pflanzen und der Tiere. Band 25). Berlin: Justus Springer.

Hermanowski, R., Boner, M., Bonte, A., Bonte, A., Henryson, A.S., Hofem, S., Langkämper, G., Mäder, R., Mende, G., Neuendorff, J., Niehaus, K., Stolz, P. and Strube, J. (2013) Weiterentwicklung und Nutzungsempfehlung ausgewählter Methoden zur Unterscheidung von ökologischen und konventionellen Produkten [Evaluation and recommendation of further use of selected methods for determining organic and conventional products]. Frankfurt: Forschungsinstitut für biologischen Landbau (FiBL). http://orgprints.org/22444/.

Herms, D.A. and Mattson, W.J. (1992) The dilemma of plants: To grow or defend. Q Rev Biol 67:283-335.

Lammerts van Bueren, E. M. and Hospers, M. (1991) Technologisch groen versus biologisch groen -een onderzoek naar de kwaliteit van industrieel en biologisch-dynamisch geteelde pluksla [Technologically Green Versus Organically Green: An Investigation into the Quality of Industrially and Biodynamically Grown Pickled Lettuce]. Driebergen: Louis Bolk Instituut.

Mäder, P., Fliessbach, A., Dubois, D., Gunst, L., Fried, P. and Niggli, U. (2002) Soil fertility and biodiversity in organic farming. Science 296:1694-1697.

Mäder, P., Fliessbach, A., Dubois, D. et al. (2006) The DOK experiment (Switzerland). In Raupp, J., Pekrun, C., Oltmanns, M. and Köpke, U. (eds), Long-term Field Experiments in Organic Farming, pp. 41-58. Berlin: Dr. Köster, Scientific Series; Int. Society of Organic Agriculture Research (ISOFAR).

Mie, A., Andersen H.R., Gunnarsson S., Kahl, J., Kesse-Guyot, E., Rembialkowska, E., Quaglio G. and Grandjean, P. (2017) Human health implications of organic food and organic agriculture: a comprehensive review. Environ Health 16:111.

Monostori, I., Heilmann, M., Kocsy, G., Rakszegil, M., Ahres, M., Altenbach, S.B., Szalai, G., Pál, M., Toldi, D., Simon-Sarkadi, L., Harnos, N., Galiba, G. and Darko, E. (2018) LED lighting: Modification of growth, metabolism, yield and flour composition in wheat by spectral quality and intensity. Front Plant Sci 9:605.

Picone, G., Trimigno, A., Tessarin, P., Donnini, S., Rombola, A.D. and Capozzi, F. (2016). 1H NMR foodomics reveals that the biodynamic and the organic cultivation managements produce different grape berries (Vitis vinifera L. cv. Sangiovese). Food Chem 213:187-195.

Popp, F.-A. (1984) Biologie des Lichts - Grundlagen der ultraschwachen Zellstrahlung [Biology of Light Basics of ultra-weak Cell Radiation]. Berlin: Paul Parey.

Popp, F.-A. 2013. Biophotons: Background, experimental results, theoretical approach and applications. In: Popp, F.-A. and Beloussov, L.V. (eds) Integrative Biophysics: Biophotonics, pp. 386-438. Berlin: Springer Science and Business Media.

Rahman, S.A., Hilaire, M.A. St. and Lockley, S.W. (2017) The effects of spectral tuning of evening ambient light on melatonin suppression, alertness and sleep. Physiol Behav 177:221-229.

Shewry, P., Rakszegi, M., Lovegrove, A., Amos, D., Corol, D. I., Tawfike, A., Miko, P. and Ward, J. L. (2018) Effects of organic and conventional crop nutrition on profiles of polar metabolites in grain of wheat. $J$ Agric Food Chem 66:5346-5351.

Stamp, N. (2003) Out of the quagmire of plant defense hypotheses. Q Rev Biol 78:23-55.

Stolz, P., Wohlers, J. and Mende, G. (2019) Measuring delayed luminescence by FES to evaluate special quality aspects of food samples: An overview. Open Agric 4:410-417.

Strube, J. and Stolz, P. (2001a) Lichtspeicherung und Lebensmittelqualität [Light storage and food quality]. Ökologie Landbau 117:15-19. http://orgprints.org/1960/.

Strube, J. and Stolz, P. (2001b) Untersuchungen zur Qualität von Calendula-Samen mittels zeitaufgelöster Fluoreszenz-Anregungs-Spektroskopie [Investigations to evaluate Quality of Calendula-Seeds by timeresolved Fluorescence-Excitation-Spectroscopy], Speech at: Jena: 36. Vortragstagung der Deutschen Gesellschaft für Qualitätsforschung e.V. http://orgprints.org/2332. 
Strube, J. and Stolz, P. (2001c) Bohne ist nicht gleich Bohne [Not all beans are created equal]. Ökologie Landbau 120:37-39.

Strube, J. and Stolz, P. (2002) Fluoreszenz-Anregungs-Spektroskopie zur Bestimmung der Qualität von Äpfeln aus ökologischem Anbau [Fluorescence-excitation-spectroscopy for determination of quality of apples from organic farming]. Speech at the 37th Conference Vortragstagung der Deutschen Gesellschaft für Qualitätsforschung e.V., Hannover, 04.03.2002-05.03.2002, pp. 209-214. http:// orgprints.org/00002335/.

Strube, J. and Stolz, P. (2004) Lebensmittel vermitteln Leben [Food Mediates Life]. Dipperz: KWALIS Qualitätsforschung Fulda.

Strube, J. and Stolz, P. (2010) The application of fluorescence excitation spectroscopy of whole samples for identification of the culture system of wheat and carrots: Method, validation, results. Biol Agric Hort 27:59-80.

Wohlers, J. and Stolz, P. (2019) Differentiation between milk from low-input biodynamic, intermediate-input organic and high-input conventional farming systems using fluorescence excitation spectroscopy (FES) and fatty acids. Biol Agric Hort 35:172-186.

Zörb, C., Niehaus, K., Barsch, A., Betsche, T. and Langenkämper, G. (2009). Level of compounds and metabolites in wheat ears and grains in organic and conventional agriculture. J Agric Food Chem 57: 9555-9562. 


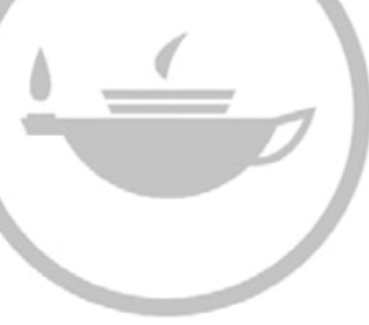

Taylor \& Francis Taylor \& Francis Group http://taylorandfrancis.com 


\title{
16 Picturing Vitality, the Crystallisation Fingerprint Method
}

\author{
Paul Doesburg \\ Crystal Lab
}

\section{CONTENTS}

Introduction.

The Crystallisation Method...

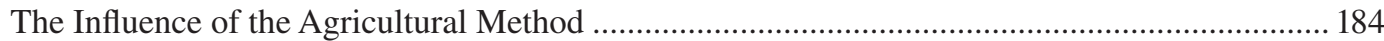

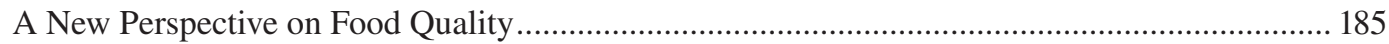

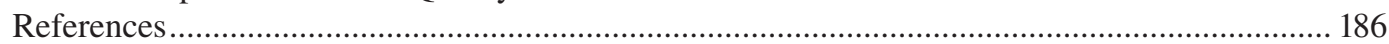

\section{INTRODUCTION}

Nowadays, food is increasingly being divided into 'good' and 'bad'. This perspective focuses on the nutrients, rather than on the products that we actually eat. This nutrient-oriented framing of food regards food quality as good when it contains few potentially harmful constituents - 'the bads' - and higher levels of health-supporting constituents - 'the goods'. Logical reasoning, right? However, when you take a closer look, this issue is somewhat more complicated, because a living organism is much more complex than a simple chain of cause-effect relations between single ingredients. Lycopene, for instance, is a major antioxidant that is widely distributed in the human body, and is thought to act as a preventive agent against prostate cancer. While isolated lycopene does appear to be effective against single prostate cancer cells grown in a Petri dish, the results from animal and human patient studies are ambiguous. A few studies demonstrated a preventive action from tomato powder (which contains lycopene), but not from isolated lycopene itself (Applegate et al., 2019; Boileau et al., 2003). Even more striking, the daily consumption of carrots by smokers appears to reduce the incidence of lung cancer, a variant on the proverb 'An apple a day keeps the doctor away'. However, when you regularly give smokers beta-carotene tablets - the most important antioxidant in carrots - the risk of developing lung cancer actually increases. Why is that? Doctors aren't completely sure about the difference between the absorption of nutrients through food and their intake as a supplement, but they do acknowledge that the relationship between diet and cancer is far more complex than simply supplementing one's daily nutrition with a few micronutrients (Whitworth, 2006).

Clearly, this cause-effect approach has provided us with a wealth of information concerning the structure and functioning of the inorganic world, but remains inadequate to understand organic aspects such as shape, self-regulation and resilience': characteristics of 'the whole plant' or 'the whole animal' from which our food originates. Living organisms permanently protect their integrity

\footnotetext{
${ }^{1}$ Vitality indicates how the 'self-regulation' of an organism is expressed as 'resilience' - resilience in the sense of 'elasticity', the capacity to cope with challenges. This may be related to the product itself or to the effect of the product on the consumer (Kahl et al., 2012). Self-regulation is the ability of organisms to adjust and maintain various physiological and other biological parameters at comparatively constant levels. Individuality is the characteristic (species-specific) nature of living organisms.
} 


\section{BOX 16.1 THE CRYSTALLISATION METHOD}

The crystallisation method was developed in the 1930s by Ehrenfried Pfeiffer (1899-1961), a German scientist, who was strongly connected to the biodynamic agricultural movement. Pfeiffer received an honorary degree of Doctor of Medicine from Hahnemann Medical College in Philadelphia in 1939 for his contribution to the development of the crystallisation method in relation to the detection and localisation of the early onset of cancer via blood samples.

against different environmental influences. Organic agricultural research works from the hypothesis that cultivation measures (fertilisation, tillage, seed variety, etc.) influence the degree to which an organism can maintain its integrity, and this has a strong correlation with the organism's health, whether plant, animal or human (Velimirov et al., 2010). Following this line of thought, a whole food product should not be reduced to a set of chemicals, but should be seen as a dynamic, hierarchically organised unit. Because of this, one could argue that the results of nutritional tests cannot be reduced to the chemical composition of the food. From a systemic biology perspective, it is acknowledged that an organism cannot be regarded as a simple chain of cause-effect relations between its different compounds, but instead as a highly complex coherent whole (Sauer et al., 2007).

\section{THE CRYSTALLISATION METHOD}

I encountered the crystallisation method in 2000 at the Dutch Louis Bolk Institute and was overwhelmed. I realised that this method makes it possible to acquire a 'fingerprint' of this extremely complex 'coherence' of our food. ${ }^{2}$ Box 16.1 describes the crystallisation method.

The method is based on the generation and subsequent evaluation of dendritic crystallisation patterns (i.e. the 'fingerprints'), which emerge when an aqueous dihydrate cupric chloride solution $\left(\mathrm{CuCl}_{2} \cdot 2 \mathrm{H}_{2} \mathrm{O}\right)$ is crystallised on a glass plate in the presence of a water-soluble additive (the sample; Busscher et al., 2010a; Gallinet and Gauthier-Manuel 1992). Additives can be single molecules as well as complex food matrices. The crystallisation patterns are additive specific (Andersen et al., 1998, 2001; Fritz et al., 2017; Kahl et al., 2014, 2016; Seidel et al., 2015; Shibata et al., 2000; Schweizer et al., 2010; Szulc et al., 2010; Vester, 1960) (see Figure 16.1) and emerge through a self-organisation process of the copper chloride $\left(\mathrm{CuCl}_{2}\right)$ which is influenced by the physical, chemical and biological properties of the additive (Busscher et al., 2010b, 2014, 2018). A remark by Rudolf Steiner, that 'spirit is never without matter, and matter is never without spirit', helps me to regard the crystallisation images as a 'manifestation' of the spiritual dimension of the organism that the pictures originate from, and the degree to which they're able to maintain their integrity.

The characteristics of the crystallisation patterns can be evaluated by human visual evaluation using defined criteria, developed according to adapted ISO norms for sensory analysis (Huber et al., 2010a; Doesburg et al., 2015), and/or by computer-based image analysis using texture or structure variables (Andersen et al., 1999; Doesburg and Nierop, 2013; Unluturk et al., 2013). This kind of fingerprint analysis has been applied to a broad range of additives, addressing different research

\footnotetext{
${ }^{2}$ Crystallisation research in the Netherlands took place at the Louis Bolk Institute in Driebergen until 2010. Since 2010, Paul Doesburg maintained an independent laboratory, Crystal Lab (https://www.crystal-lab.nl/), in the former monastery Roepaen in Ottersum (the Netherlands), which is connected to a European consortium of five crystallisation laboratories. Paul is currently rebuilding his crystallisation laboratory at the Hiscia Research Institute in Arlesheim, Switzerland.
} 


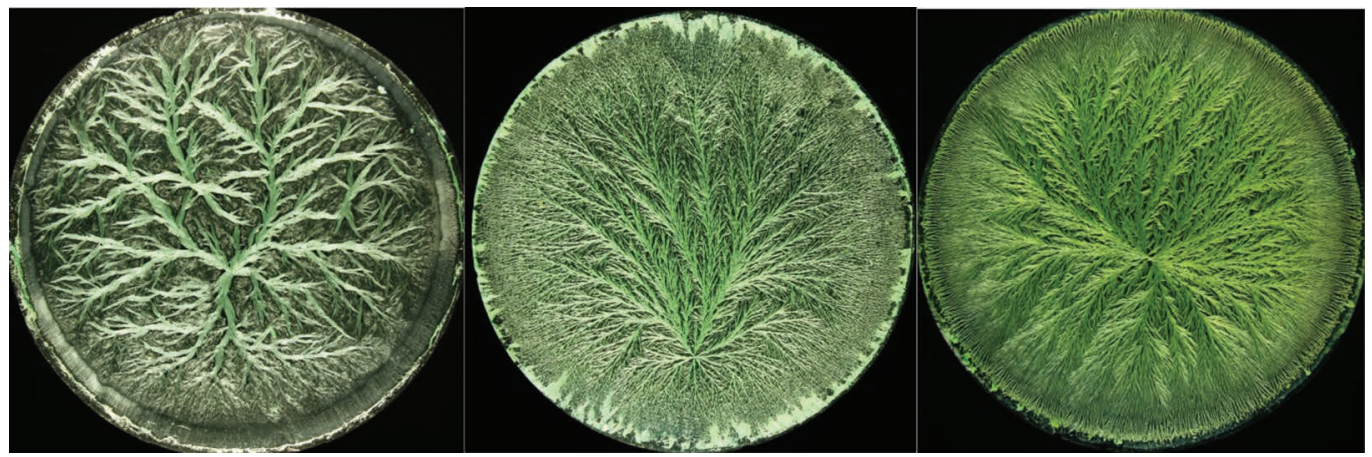

FIGURE 16.1 Product-specific crystallisation patterns of barley (left), tomato (middle) and white cabbage (right).
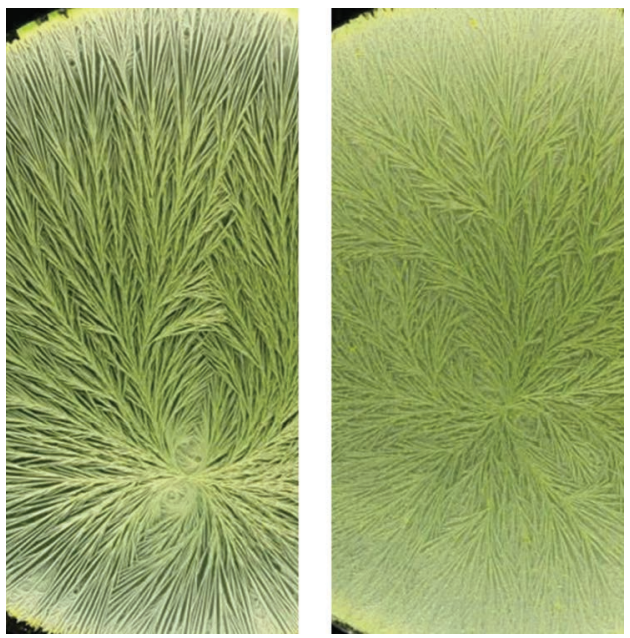

FIGURE 16.2 Crystallisation patterns of the effect of milk processing: raw unprocessed milk (left) and the same sample after homogenisation at 50 bar (right). We can see an enormous conversion of the structure of the crystallisation pattern. During homogenisation (commonly at 200-300 bar, or 200-300 kg pressure/cm2), milk is passed under high pressure through a tiny orifice. The structure and size of the fat globules in the milk are influenced by this. This means that the natural creaming of the milk, which many people find unpleasant, doesn't take place.

questions, such as the effect of innovative processing techniques (Marzaleka et al., 2019), the biological effects of ultramolecular homeopathic preparations (Baumgartner et al., 2012; Doesburg et al., 2019, 2021), the diagnosis of diabetics (Shibata et al., 2000), doping (Shibata et al., 1996), the early onset of cancer (Barth, 1990; Koopmans, 1990) and other pathologies (Piva, 1994) in human blood, but predominantly in food quality analysis. With respect to the latter, the method has been shown to reflect plant physiological processes such as ripening and decomposition (Fritz et al., 2011, 2017, 2018), the effects of processing (see Figure 16.2), feeding regimes and farming systems (Kahl et al., 2009, 2015, 2016; Seidel et al., 2015; Szulc et al., 2010) in a broad range of agricultural products, which demonstrate the method's systemic approach to food quality. The crystallisation method fits seamlessly with the principles of organic farming, in which the focus is on the development of 


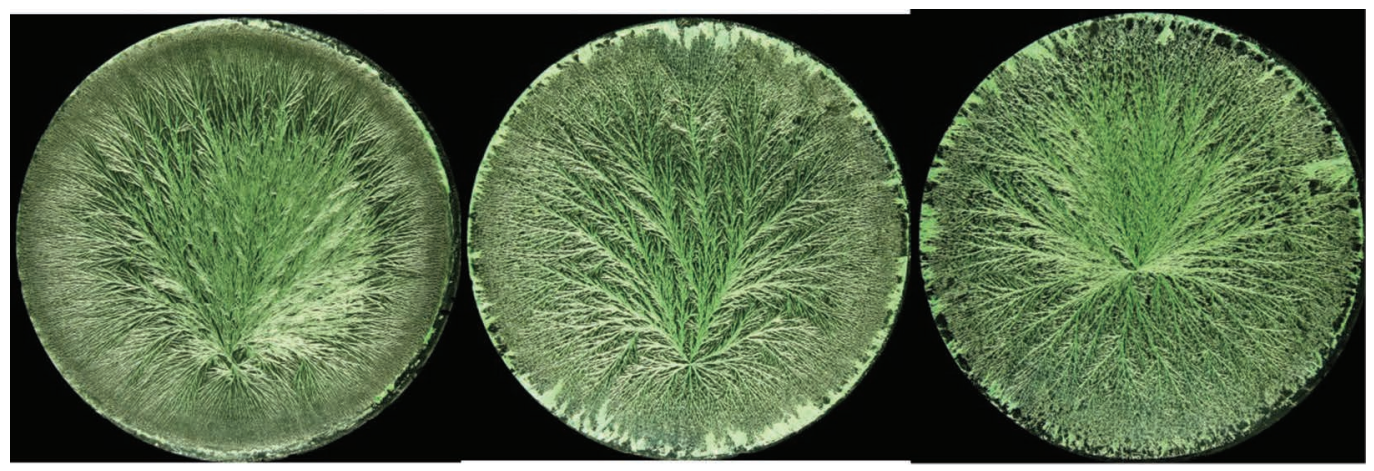

FIGURE 16.3 Crystallisation patterns of different ripening stages of vine tomatoes: unripe, little structure and condensed patterns (left); ripe, structure and cohesion (middle); and overripe, loss of structure and cohesion (right).

robust, resilient soil, crops and animals, hence the use of the crystallisation method for decades in organic and biodynamic food quality analysis.

By means of the crystallisation method, I aim to deduce more about the quality of food than solely the nutrient content. The method allows you to visualise differentiation and ageing statuses in agricultural products (see Figure 16.3). Particularly in ageing experiments (based on sample ageing or processing), it is striking to see how crystallisation patterns fall apart and lose their cohesion. This corresponds perfectly with the image one would generally associate with a loss of structure. Consequently, quality is literally made visible (see Figure 16.4).

The images are evaluated in two different ways: visually and by means of computerised image analysis (Andersen et al., 1999; Doesburg and Nierop, 2013). Depending on the research question, we choose one of the two methods or a combination. Computerised analysis allows us to find significant differences between products or treatments, allows the analysis of large datasets and is regarded as 'objective' which aids communication within the scientific arena. However, this approach misses the nuances of the method which are captured with a visual evaluation. For this, standardised evaluation criteria have been developed and validated within a European collaboration between several crystallisation laboratories according to adapted ISO norms for sensory panels (Huber et al., 2010a). Herewith, the general characteristics - the phenomena of a crystallisation image - can be described. The empirical basis of the visual evaluation of the crystallisation patterns is that the degree of wholeness of a sample is in some way transferred to the microscopic and macroscopic arrangement of the crystal needles. Wholeness in such is the degree to which the sample is capable of forming a hierarchically organised unit.

As reflected in the photos of the ageing carrot juices or the wheat derived from different farming systems (see Figures 16.4 and 16.6), an increasing degree of wholeness generates a better coordinated pattern with a stronger perradiation ${ }^{3}$ and a higher degree of regularity in the branching frequency and in the onset and angle of the side needles. Generally, this is observed as a higher degree of harmony in the image.

Currently, I am involved in establishing a scientifically communicable manner to evaluate this wholeness perceived in the images (Doesburg et al,. 2021). For this, we are evaluating the potential of proprioceptive (kinaesthetic) experience, i.e. the perception of one's own position, posture,

\footnotetext{
${ }^{3}$ Perradiation is the length and perceived tension of the gesture that can be sensed in the main branches that run from the centre towards the peripheral zone, where the movement fades out.
} 

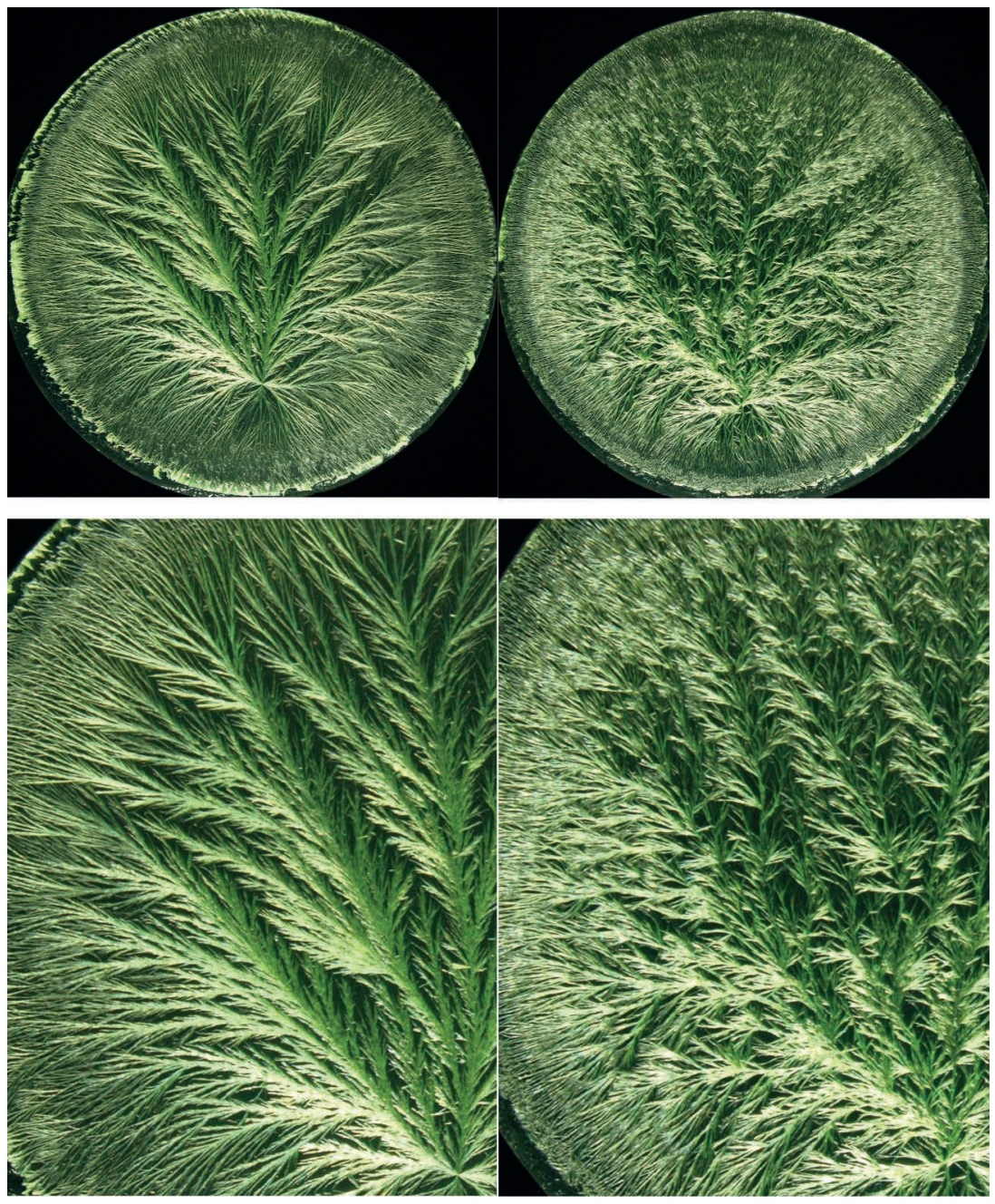

FIGURE 16.4 Crystallisation patterns of fresh (left) and aged carrot juice (right; after 7 days of storage at $\left.4^{\circ} \mathrm{C}\right)$. A loss of structure and organisation is apparent in the aged carrot juice.

equilibrium or internal condition applied to sense perception content instead of body self-awareness. It's comparable to the bodily sensation that we are all familiar with when, for example, affected by a dramatic gesture in an artwork. Proprioceptive experience, coupled with the emotional resonance it triggers, is likely to be a crucial component of our aesthetic experience of artworks (Freedberg and Gallese, 2007).

According to the 'growth-differentiation balance hypothesis', an optimal product quality is the result of a harmonious plant development (Bloksma et al., 2007). In the plant's development, two fundamental life processes can be distinguished: growth (mass formation) and ripening (flower and seed formation, flavour and scent). Within this, harmony refers to a balance between these two life processes by mutual influence. It's possible to learn to perceive the patterns by which these life processes express themselves (Doesburg et al., 2015). A harmonious plant development results in an integrated wholeness leading to resilient, crop-specific, tasteful products with a long shelf life (Bloksma et al., 2007). 


\section{THE INFLUENCE OF THE AGRICULTURAL METHOD}

The method also shows differences between products from conventional, organic and biodynamic origin. Organic/biodynamic agriculture wields a systemic approach which aims towards healthy and resilient plants and animals that have a strong immune system and thus omits the need for pesticides.

One aspect I often see in crystallisation images from products originating from conventional agriculture is that the differentiation phase seems to be missing. This phase, which can be considered the refinement or finishing touch of the crop's development, is irreducibly connected to a harmoniously developed product. These conventional products are often fertilised too heavily, causing a one-sided growth. Instead of quietly maturing, degradation trends already start to dominate in the growth phase. To put it more simply, the plants in which growth predominates act like a teenager with ageing symptoms (Figures 16.5 and 16.6). Such a crop is far more susceptible to disease and often does not reach the differentiation phase. It is in this phase that most health-promoting nutrients and aroma substances are formed, which influence taste considerably (Barański et al., 2017).

A justified question is whether harmonious crystallisation images of food samples have health benefits. In 2010, the Dutch government financed a research project 'Is organic more healthy?' (Huber et al., 2010b), to once and for all address the question of whether organic agricultural food products have an increased health benefit.

A feeding trial was performed with three genetically different groups of chickens over two generations. The chickens were fed with identically composed organic or conventional feeds. Although the animals constituting the two feeding groups were all healthy, differences between the groups were apparent. The conventionally fed chickens showed an overall higher weight gain than the organically fed chickens, even though feed intake of the two feeding groups and the metabolisable energy of the feeds were comparable. The animals of the second generation of both groups underwent an immune challenge, causing a significant reduction in growth rate. Yet the organically fed chickens, of all three genetic varieties, showed a stronger immune reactivity, as well as a significantly stronger 'catch-up growth' after the challenge, indicative of an increased resilience, compared to the conventionally fed chickens. Of the feed ingredients analysed with the crystallisation method, only two ingredients (soy and wheat) originated from a standardised field trial (i.e. the same location, seed variety and
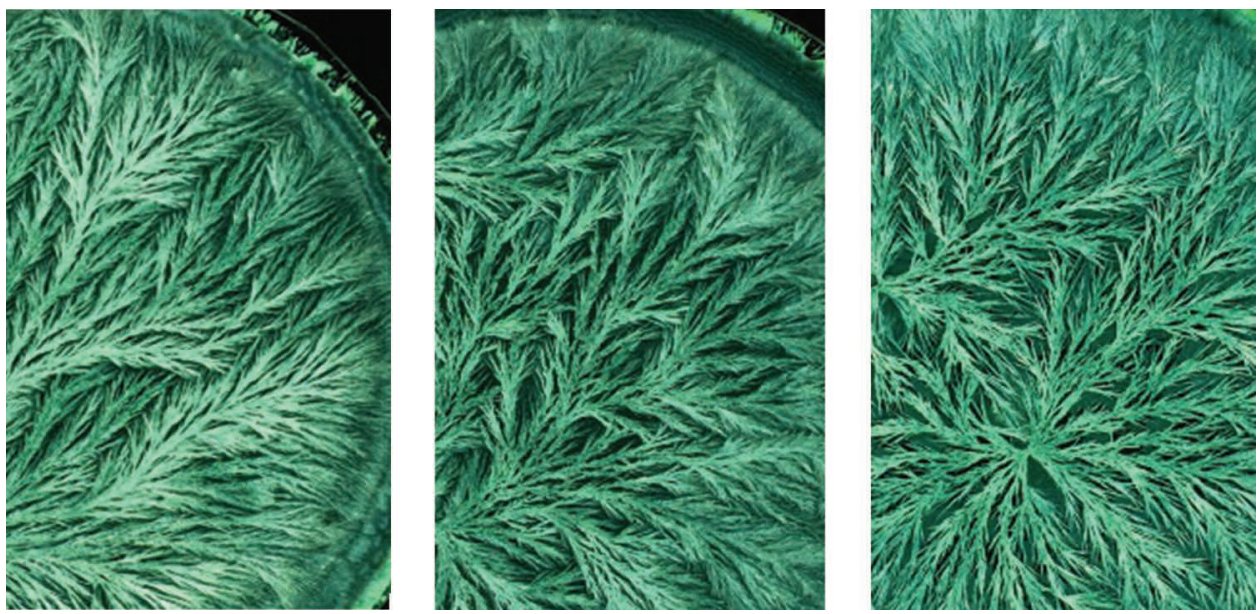

FIGURE 16.5 Enlarged details of crystallisation patterns of a wheat aging series. Left: fresh extract; middle: extract stored for 3 days at $4^{\circ} \mathrm{C}$; and right: extract stored for 12 days at $4^{\circ} \mathrm{C}$. The photos show a loss of structure and organisation as aging of the wheat extract progresses. 

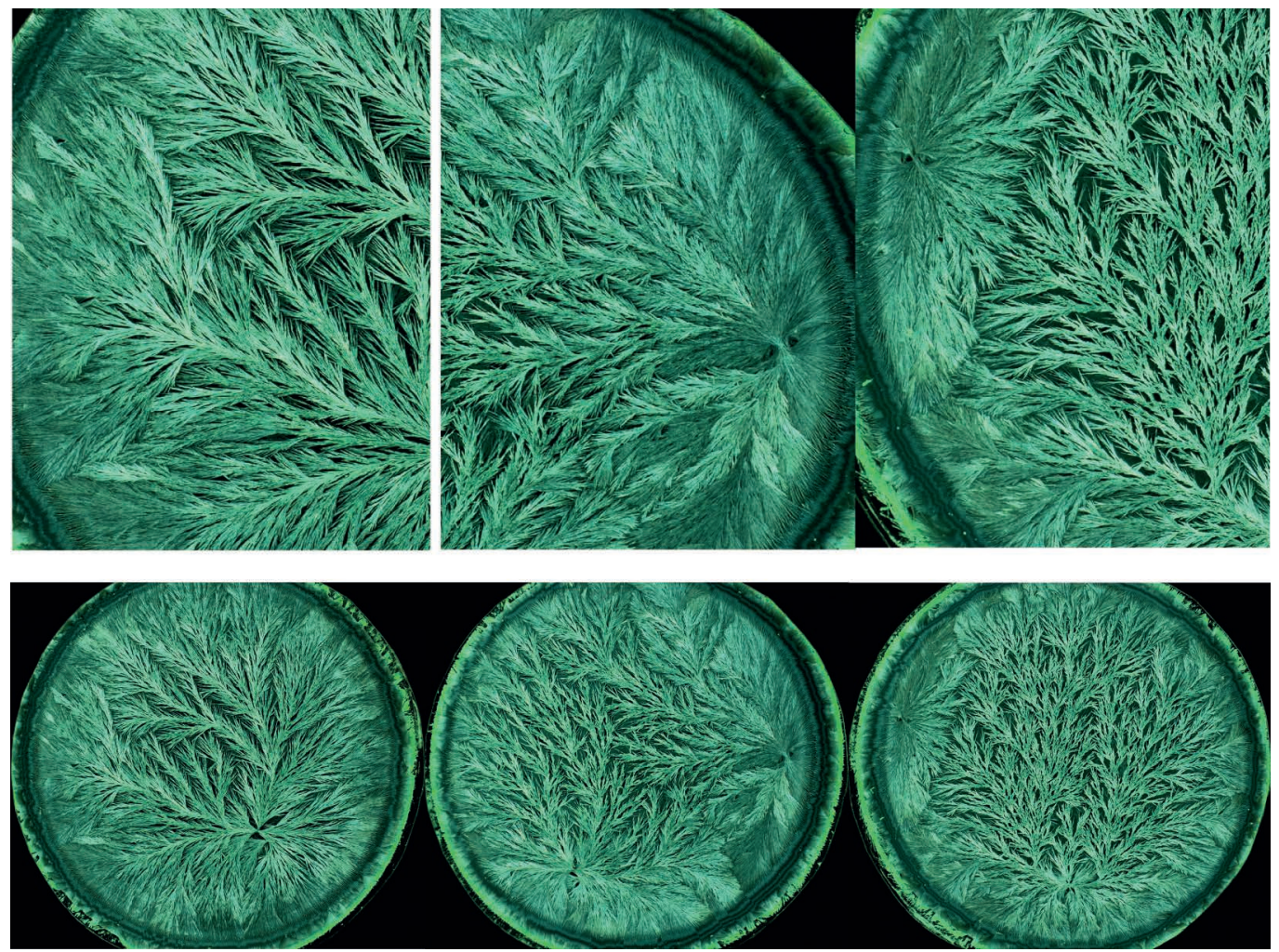

FIGURE 16.6 Crystallisation patterns of 12-day-aged wheat extract originating from a long-term DOC field study (FiBL, CH). Since 1978, wheat has been cultivated according to biodynamic (D), organic (O) and conventional (C) guidelines, in which soil and climate variations are ruled out. Photos bottom: whole images; and top: enlarged details. Biodynamic wheat (left), organic wheat (middle) and conventional wheat (right). The images show an increasing loss of structure and organisation which is minimal in patterns originating from the biodynamic wheat extract and maximal in the patterns from the conventional cultivation (for comparison, also consider the aging series in photo 5). (Images: J. Fritz, Uni Bonn, Germany.)

microclimate), allowing a fair comparison of the effect of the two farming systems on the resulting crystallisation patterns. For both soy and wheat, the visual evaluation clearly pointed to a superior quality of the organic ingredients, which of course is a very interesting find.

\section{A NEW PERSPECTIVE ON FOOD QUALITY}

The crystallisation method generates a physical image of the life processes inside an organism. Evaluating the crystallisation images appeals to one's morality when one sees the effect of the agricultural system and/or processing techniques, similar to the frequently applied Röntgen detection technique for the detection of foreign particles (metal, glass and plastics) in food. This opens up an entire field of research. There is a need for new research methods that can visualise or otherwise detect aspects such as vitality, resilience, individuality and self-regulation and make them broadly communicable. These aspects currently are not part of the remit of nutritional science, but the aim of my work is to contribute to broadening this scope, based on the understanding that life is not an ancillary element of chemical and physical processes, but actually expresses itself through these processes. Food is so much more than just a bag of nutrients! 


\section{REFERENCES}

Andersen, J.-O., Laursen, J. and Koelster, P. (1998) A refined biocrystallization method applied in a pictomorphological investigation of a polymer. Elemente der Naturwissenschaft 68: 1-20.

Andersen, J.-O., Henriksen, C. B., Laursen, J. and Nielsen, A. A. (1999) Computerised image analysis of biocrystallograms originating from agricultural products. Computers and Electronics in Agriculture 22: 51-69.

Andersen, J.-O., Kaack, K. V., Nielsen, M., Thorup-Kristensen, K. and Labouriau, R. L. (2001) Comparative study between biocrystallization and chemical analyses of carrots (Daucus carota L.) grown organically using different levels of green manures. Biological Agriculture and Horticulture 19: 29-48.

Applegate, C., Rowles Joe, I., Miller, R., Wallig, M., Clinton, S., O’Brian, W. and Erdman, J. (2019) Dietary tomato, but not lycopene supplementation, impacts molecular outcomes of castration-resistant prostate cancer in the TRAMP model (P05-015-19). Current Developments in Nutrition 3(Suppl 1): nzz030. P05-015-19.

Barański, M., Rempelos, L., Iversen, P. O. and Leifert, C. (2017) Effects of organic food consumption on human health; the jury is still out! Food and Nutrition Research 61: 1287333.

Barth, J. G. (1990) Empfindliche Kristallisation-Krebs und Prekanzerose. Elemente der Naturwissenschaft 52: $42-51$.

Baumgartner, S., Doesburg, P., Scherr, C. and Andersen, J.-O. (2012) Development of a biocrystallisation assay for examining effects of homeopathic preparations using cress seedlings. Evidence-Based Complementary and Alternative Medicine, 12. DOI: 10.1155/2012/125945.

Bloksma, J., Northolt, M., Huber, M., van der Burgt, G.-J. and van de Vijver, L. (2007) A new quality concept based on life processes. In Cooper, J., Leifert, C. and Niggli, U. (eds), Handbook of Organic Food Safety and Quality, pp. 53-73. Cambridge: Woodhead Publishing.

Boileau, T. W.-M., Liao, Z., Kim, S., Lemeshow, S., Erdman, Jr., J. W. and Clinton, S. K. (2003) Prostate carcinogenesis in N-methyl-N-nitrosourea (NMU)-testosterone-treated rats fed tomato powder, lycopene, or energy-restricted diets. JNCI: Journal of the National Cancer Institute 95: 1578-1586.

Busscher, N., Kahl, J., Andersen, J.-O., Huber, M., Mergardt, G., Doesburg, P., Paulsen, M. and Ploeger, A. (2010a) Standardization of the biocrystallization method for carrot samples. Biological Agriculture and Horticulture 27: 1-23.

Busscher, N., Kahl, J., Doesburg, P., Mergardt, G. and Ploeger, A. (2010b) Evaporation influences on the crystallization of an aqueous dihydrate cupric chloride solution with additives. Journal of Colloid and Interface Science 344: 556-562.

Busscher, N., Kahl, J. and Ploeger, A. (2014) From needles to pattern in food quality determination. Journal of the Science of Food and Agriculture 94: 2578-2581.

Busscher, N., Doesburg, P., Mergardt, G., Sokol, A., Kahl, J. and Ploeger, A. (2018) Influence of dewetting on the crystallization behavior of $\mathrm{CuCl}_{2}$ in the presence of BSA during evaporation in a Petri dish. Heliyon 5: 01102.

Doesburg, P. and Nierop, A. F. (2013) Development of a structure analysis algorithm on structures from $\mathrm{CuCl}_{2} \cdot 2 \mathrm{H}_{2} \mathrm{O}$ crystallization with agricultural products. Computers and Electronics in Agriculture 90 : 63-67.

Doesburg, P., Huber, M., Andersen, J.-O., Athmann, M., van der Bie, G., Fritz, J., Geier, U., Hoekman, J., Kahl, J., Mergardt, G. and Busscher, N. (2015) Standardization and performance of a visual Gestalt evaluation of biocrystallization patterns reflecting ripening and decomposition processes in food samples. Biological Agriculture and Horticulture 31: 128-145.

Doesburg, P., Andersen, J.-O., Scherr, C. and Baumgartner, S. (2019) Empirical investigation of preparations produced according to the European Pharmacopoeia monograph 1038. European Journal of Pharmaceutical Sciences: Official Journal of the European Federation for Pharmaceutical Sciences 137: 104987.

Doesburg, P., Fritz, J., Athmann, M., Bornhütter, R., Busscher, N., Geier, U., Mergardt, G. and Scherr, C. (2021) Kinesthetic engagement in Gestalt evaluation outscores analytical 'atomic feature'evaluation in perceiving aging in crystallization images of agricultural products. Plos one, 16(3): e0248124.

Freedberg, D. and Gallese, V. (2007) Motion, emotion and empathy in esthetic experience. Trends in Cognitive Sciences 11: 197-203.

Fritz, J., Athmann, M., Kautz, T. and Köpke, U. (2011) Grouping and classification of wheat from organic and conventional production systems by combining three image forming methods. Biological Agriculture and Horticulture 27: 320-336. 
Fritz, J., Athmann, M., Meissner, G., Kauer, R. and Köpke, U. (2017) Quality characterisation via image forming methods differentiates grape juice produced from integrated, organic or biodynamic vineyards in the first year after conversion. Biological Agriculture and Horticulture 33: 195-213.

Fritz, J., Athmann, M., Andersen, J.-O., Doesburg, P., Geier, U. and Mergardt, G. (2018) Advanced panel training on visual Gestalt evaluation of biocrystallization images: Ranking wheat samples from different extract decomposition stages and different production systems. Biological Agriculture and Horticulture 35: 21-32.

Gallinet, J. P. and Gauthier-Manuel, B. (1992) Wetting of a glass surface by protein adsorption induces the crystallization of an aqueous cupric chloride solution. Journal of Colloid and Interface Science 148: $155-159$.

Huber, M., Andersen, J.-O., Kahl, J., Busscher, N., Doesburg, P., Mergardt, G., Kretschmer, S., Zalecka, A., Meelursam, A., Ploeger, A., Nierop, D., van de Vijver, L. and Baars, E. (2010a) Standardization and validation of the visual evaluation of biocrystallizations. Biological Agriculture and Horticulture 27: $25-40$.

Huber, M., van de Vijver, L. P., Parmentier, H., Savelkoul, H., Coulier, L., Wopereis, S., Verjeij, E., van der Greef, J., Nierop, D. and Hoogenboom, A.P. (2010b) Effects of organically and conventionally produced feed on biomarkers of health in a chicken model. British Journal of Nutrition 103: 663-676.

Kahl, J., Busscher, N., Doesburg, P., Mergardt, G., Huber, M. and Ploeger, A. (2009) First tests of standardized biocrystallization on milk and milk products. European Food Research and Technology 229: 175-178.

Kahl, J., Baars, T., Bügel, S., Busscher, N., Huber, M., Kusche, D., Rembialkowska, E., Schmid, O., Seidel, K., Taupier-Letage, B., Velimirov, A. and Zalecka, A. (2012). Organic food quality: A framework for concept, definition and evaluation from the European perspective, Journal of the Science of Food and Agriculture 92: 2760-2765.

Kahl, J., Busscher, N., Hoffmann, W., Mergardt, G., Clawin-Raedecker, I., Kiesner, C. and Ploeger, A. (2014) Development and performance of crystallization with additives applied on different milk samples. Food Analytical Methods 7: 1373-1380.

Kahl, J., Busscher, N., Mergardt, G., Mäder, P., Torp, T. and Ploeger, A. (2015) Standardization and performance test of crystallization with additives applied to wheat samples. Food Analytical Methods 8: 2533-2540.

Kahl, J., Busscher, N., Doesburg, P., Mergardt, G., Will, F., Schulzova, V., Hajslova, J and Ploeger, A. (2016) Application of crystallization with additives to cloudy and clear apple juice. Food Analytical Methods 10: 247-255.

Koopmans, A. (1990) Pfeiffersche blutkristallisatien und malignom-bereitschaft. Elemente der Naturwissenschaft 52: 28-35.

Marzaleka, K., Doesburg, P., Starzonek, S., Szczepańska, J., Woźniaka, L., Lorezno, J.M., Skapska, S., Rzoska, S. and Barba, F.J. (2019) Comparative effect of supercritical carbon dioxide and high pressure processing on structural changes and activity loss of oxidoreductive enzymes. Journal of $\mathrm{CO}_{2}$ Utilization 29: 46-56.

Piva, M. T. (1994) Cupric chloride crystallization with human blood-study of pictures obtained in different pathologies. Elemente der Naturwissenschaft 61: 25-39.

Sauer, U., Heinemann, M. and Zamboni, N. (2007) Getting closer to the whole picture. Science 316: 550-551.

Schweizer, F., Andersen, J.-O. and Laursen, J. (2010) Beobachtungen bei der Kupferchloridkristallisation: vom "Eiweiß-Vorbild" zum "Kupferchlorid-Nachbild". Elemente der Naturwissenschaft 92: 62-92.

Seidel, K., Kahl, J., Paoletti, F., Birlouez, I., Busscher, N., Kretzschmar, U., Särkkä-Tirkkonen, M., Seljåsen, R., Sinesio, F., Torp, T. and Baiamonte, I. (2015) Quality assessment of baby food made of different preprocessed organic raw materials under industrial processing conditions. Journal of Food Science and Technology 52: 803-812.

Shibata, T., Takakuwa, Y., Tanaka, A., Iguchi, T., Kogure, M. and Ogawa, T. (1996) Doping effect of human blood on surface microstructure of cupric chloride dendrites grown from aqueous solutions. Journal of Crystal Growth 167: 716-718.

Shibata, T., Matsumoto, S., Kogure, M., Iguchi, T., Tanaka, A., Nagano, T. and Ogawa, T. (2000) Effects of diabetic human blood addition on morphology of cupric chloride dendrites grown from aqueous solutions. Journal of Crystal Growth 219: 423-433.

Szulc, M., Kahl, J., Busscher, N., Mergardt, G., Doesburg, P. and Ploeger, A. (2010) Discrimination between organically and conventionally grown winter wheat farm pair samples using the copper chloride crystallisation method in combination with computerised image analysis. Computers and Electronics in Agriculture 74: 218-222. 
Unluturk, S., Pelvan, M. and Unluturk, M. S. (2013) The discrimination of raw and UHT milk samples contaminated with penicillin $\mathrm{G}$ and ampicillin using image processing neural network and biocrystallization methods. Journal of Food Composition and Analysis 32: 12-19.

Velimirov, A., Huber, M., Lauridsen, C., Rembiałkowska, E., Seidel, K. and Bügel, S. (2010) Feeding trials in organic food quality and health research. Journal of the Science of Food and Agriculture 90: 175-182.

Vester, F. (1960) Zur Indikation biochemischer Vorgänge durch kristallisierendes Kupferchlorid. Experientia 16: $279-281$.

Whitworth, A. (2006) Micronutrients: To supplement, or not to supplement? JNCI: Journal of the National Cancer Institute 98: 230-232. 


\section{Section 3}

In Search of More Embodied Methodologies 


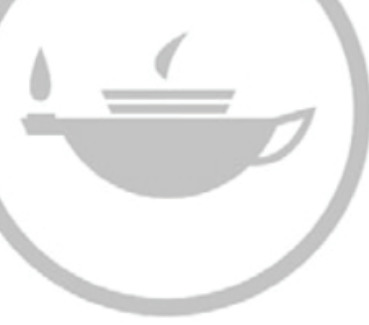

Taylor \& Francis Taylor \& Francis Group http://taylorandfrancis.com 


\title{
17 Calibrating the Body Embodied Research Strategies for Attuning to Subtle Information
}

\author{
Eline Kieft \\ Clover Trail, University of Winchester, \\ Coventry University
}

\section{CONTENTS}

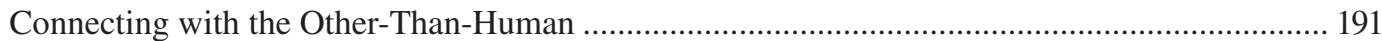

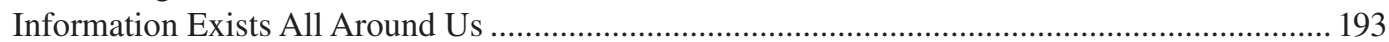

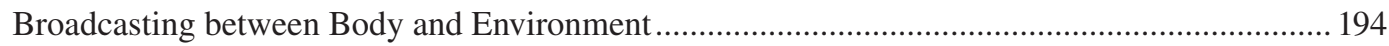

Opening Up to Different Ways of Knowing and Learning ....................................................... 195

Calibrating the Body as Instrument: Towards Multi-Levelled Literacy ........................................ 196

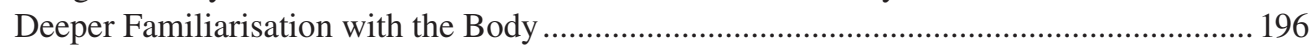

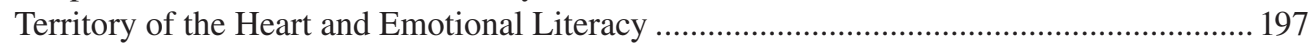

Cultivating Right-Brain Abilities and Expanding Consciousness ......................................... 198

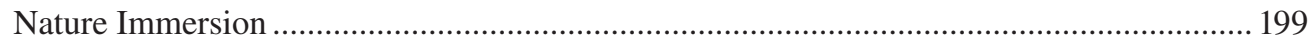

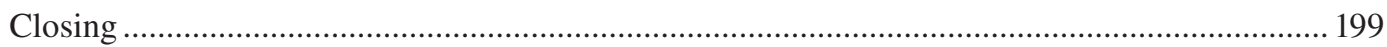

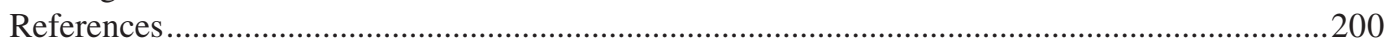

Our hope, says philosopher David Abram, is to reinvigorate the language of the body, learn to let our muscles, sinews, blood, and bones sing again in harmony with the wild chorus of the land, sea, and air-to feel again the pulse of natural kinship. We need to open the vital channels between our words-even our written words-our bodies, and the articulate flesh of the world. We need to feel and respond to the deep intelligence of the matter of the planet and cosmos from which we are born. We need to pay attention to the stirrings of mind in matter, to the symphony of universal meaning-to the deep narrative of matter itself.

(de Quincey, 2002: 104, ital. in original).

\section{CONNECTING WITH THE OTHER-THAN-HUMAN}

This chapter proposes ways to sensitise and educate the body to perceive intangible aspects of the natural world. It shows how we can recognise and interact with the deep intelligence and narratives of matter all around us. My journey of understanding the body as an antenna is informed by four strands of study: the general disciplines of consciousness studies and shamanic techniques, and two more specific approaches of ECOintention and Movement Medicine. Each of these (which are briefly introduced below) have ways of addressing and exploring the intricate connections between matter (particles), energy (waves) and consciousness (information): aspects that feature strongly in the relatively young field of quantum agriculture, or quantum-informed agriculture (Q(I)A), which builds on traditional models of agriculture, including, yet going beyond, matter and particles (soil management, chemical compounds, food production). Waves, in the form of sound and other electromagnetic techniques, for example, are being used for increasing crop production, or managing 
disease in cattle. Q(I)A also recognises the information derived through, for example, farmers' intuition, animal communication and nature constellations (Kieft, 2019; Lovel, 2014).

ECOintention offers an approach to monitor and increase the health of trees, gardens and forests. This method was designed by biologist Hans Andeweg and X-ray lab technician Rijk Bols (Andeweg, 2009). Between 2003 and 2005, I learned about such energetic techniques to assess, balance and optimise natural systems. ${ }^{1}$ The theoretical framework of this approach is that health consists of a combination of matter (the optimal amount of water, sunlight, balanced animal populations and so on), its energetic frequency (resonance or vitality) and the degree of congruency of a system or how well it is adapted to its circumstances and integrated with its surroundings. ECOintention combines working on levels of particles, energy and information. This is done through setting a clear intention, ${ }^{2}$ using pre-defined measurement scales, understanding subtle changes within one's own body and finally communicating them with others. A large part of this method consists of learning to read and interpret one's body's physical responses to the focus of inquiry. The body is the instrument through which information is received. Although personal responses are subjective, i.e. unique to the person, the use of pre-defined measurement scales ensures a calibration of outcomes, so from subjective data the observations become intersubjective.

In May 2005, I attended Soul in Nature, a 3-week residential and immersive course at Schumacher College, Devon, UK, featuring three well-known teachers. Investigating the connection between mind and matter, one of the teachers, Christian de Quincey, posited consciousness as the missing link, present within every bit of matter beyond even the smallest atom. He argues that matter is tangibly located somewhere in space (particles) and that energy spreads out through space (waves), whereas consciousness, the third phenomenon, is 'the process of matter-energy informing itself' (de Quincey, 2002: 59). His work helped me to understand the connection with nature from a more theoretical angle, using the three main elements of Q(I)A: particles, energy and information.

Teaching on the same course, Jonathan Horwitz introduced me to shamanic techniques to interact with other-than-human-beings ${ }^{3}$ in the natural world. I have continued to study with him ever since. In an animist view, everything is imbued with an energetic quality, life force or 'spirit essence'. ${ }^{4}$ This includes stones and minerals; plants, trees and animals; natural features such as mountains or oceans; and the four elements of earth, water, fire and air. Through techniques of rhythmic drumming to expand our consciousness, it becomes possible to contact and interact with those qualities. As in ECOintention, the underlying aim of shamanic practices is to increase balance within systems, individuals and communities, again, guided by a strong intention (Kieft, 2018, 2020).

Finally, Movement Medicine, a contemporary shamanic dance practice, features (mostly) improvised movement as a deeply embodied activity to (re)connect with the world around us. Inspired by spatial practices such as medicine wheels and mandalas as energetic representations of meditative focus, as well as family constellation theory (Cohen, 2006; Whittington, 2016), Movement Medicine facilitates dancing 'with', 'in relation to' and 'as' any type of being imaginable. This can include physical plants and animals, but also natural systems such as rainforests and oceans, as well

\footnotetext{
${ }^{1}$ ECOintention was originally called ECOtherapy. Developed in the early 1990s, this method has since been successfully adapted and applied to other systems such as schools, theatres and businesses. See https://www.ecointention. com/index_e.htm. Ubiquity University now offers an MSc degree in ECOIntention, https://www.ubiquityuniversity.org/ courses/msc-master-of-science-in-ecointention/ accessed: March 3rd 2021.

2 Setting an intention is done by clarifying the focus of a particular inquiry. This can be compared to picking up the phone and dialling a specific number: who are you going to 'talk' to? Are you 'tuning in' to a tree, a plot of land, a food item? This clarity helps to zoom in on and interpret clues cleanly while not being distracted by interference of other information.

${ }^{3}$ For a discussion of the term 'other-than-human-beings', see Harvey $(2003,2014)$. Other disciplines work with related concepts such as archetypes (in psychology), memes as independent and self-replicating units that transmit cultural ideas and behavioural patterns (in cultural studies), and morphic field resonance (in biology). They each address an energetic quality or imprint of concrete and/or intangible phenomena.

${ }^{4}$ Spirit itself is a difficult concept to define. The original Latin connotation of spirit includes 'breath, life, wind, awe, mystery, and invisibility', and early philosophers such as Plato and Augustine referred to it (Morris, 2006: 15). Horwitz uses a description of spirits as "bundles of the energy of the universe, [that] appear to people in forms that they can recognise" (quote from interview in E. Kieft, 2020).
} 
as archetypal and spirit essences. Such practices enable us to learn from and be inspired by 'the other', and also help give them 'expression' and 'agency' through our physicality (Darling Khan, S. and Darling Khan, Y. A., 2009; Kieft, 2013, 2014, 2017a).

My understanding of the potential of dance and shamanic practice as alternative ways of knowing is informed by these four strands, which are both intellectual and experiential. From a positivist research perspective, this intertwinement of personal and professional understanding may raise some methodological questions. In the arts and humanities however, approaches such as ethnography (Madden, 2017; Pink, 2015), Practice as Research (Nelson, 2013; Spatz, 2015) and Embodied Inquiry (Snowber, 2016; Todres, 2007) recognise that any knowledge produced is always a result of entanglements not only within the research itself, but also between the researcher and her practice. Neither of these can be seen as independent, but rather, they are 'ontologically and epistemologically bound' (Naccarato, 2018: 436). Indeed, they emerge and become together, not unlike the aspects of our quantum universe: particles, waves and information. Addressing ways of knowing outside our western models of knowledge creation requires a reassessment of ontology and epistemology, as well as pedagogies for experiential learning and ways to 'validate' such intersubjective learning experiences. $^{5}$

This chapter continues with four parts. The first argues that intangible information exists all around us and is accessible by and through the human body. I specifically introduce panpsychism as a cosmology that recognises degrees of consciousness within matter, mostly guided by the work of Christian de Quincey and Rupert Sheldrake. The second examines the possibilities of connecting with that information and consciousness as part of our innate human abilities. Here, I briefly discuss the work of Gregory Bateson, Tim Ingold and David Bohm on the relationship between body and environment. The third describes some ingredients and prerequisites for ontology and epistemology that are supported by (subjective) experience and immersion. Here, I draw on the writings of Les Todres and Christian de Quincey. The final section offers a practical approach for reawakening a multi-levelled literacy that includes body, heart, mind, consciousness, intuition, movement and nature.

\section{INFORMATION EXISTS ALL AROUND US}

Questions regarding the nature of reality and how we relate to it feature in most cultures, and there are striking parallels between science and indigenous knowledge. Anthropologist Jeremy Narby (1999 [1995]) describes the overlap between ancient (shamanic) cosmologies and recent discoveries in quantum physics. A wide variety of disciplines, including philosophy, psychology, biology, electromagnetics and quantum physics, address phenomena such as information, consciousness and spirit, and many theories seek to explain deeply intertwined connections within and across the universe. Some examples are Bohm's implicate order, Laszlo's Akashic fields, Jung and Pauli's synchronicity and collective unconscious, Capra's tao of physics, Sheldrake's morphic fields, Wilber's integral theory and Lovelock's Gaia hypothesis (Ferrer, 2015; Hardy, 2015; Schäfer, 2008). ${ }^{6}$

For example, Rupert Sheldrake proposed a theory of morphic fields that hold information relevant to a specific species or phenomenon. These morphic fields 'are not confined to the brain, or even to the body, but extend beyond it into the environment, linking the body to the surroundings in which it acts' (Sheldrake, 1988: 198). Information is a pattern of coherence that exists in form. Trees, for example, hold information about their growth and survival needs, but also about seasonal and weather patterns. With the right access or means, and through various forms of intelligence, ${ }^{7}$

\footnotetext{
${ }^{5}$ For further methodological reflections on intersubjectivity, see Kieft (2020).

${ }^{6}$ In The Field: A quest for this apparent secret force of the universe, Lynne McTaggart attempts to unify several of these theories by means of popular science journalism (McTaggart, 2001).

${ }^{7}$ Intelligence is the degree to which individuals (of all manners of species) make coherent sense of, and apply, the information that they have access to. In terms of human intelligence, Howard Gardner proposed a theory of seven different types of intelligence, including logico-mathematical, linguistic, musical, spatial, bodily kinaesthetic, intrapersonal and interpersonal intelligences (Gardner, 1983). Except for the first two, the other forms allude to a concrete interaction between body and surroundings.
} 
information can be deciphered and contribute to knowledge. That deciphering can happen between species and other natural phenomena, for example when animals anticipate specific natural events before they actually happen. Just as learning to read helps us to decipher the meaning of letters on a page, we can learn to read subtle information in other forms.

Yet, how can we derive information from sources with which we cannot communicate in the traditional (verbal or written) sense? Panpsychism ${ }^{8}$ is an ontological theory that considers everything in the universe as having 'an interior, subjective reality' (de Quincey, 2002: 105). Just as animism recognises soul or life force within phenomena, panpsychism speaks of consciousness or mind (Larson, 2014). Such views were described by early western philosophers ${ }^{9}$ but can be traced much further back to pre-philosophical cosmologies. They also still feature in contemporary (animistic and pantheistic) cosmologies that incorporate shamanic techniques (de Quincey, 2002: 105: 110-26).

Referring back to de Quincey's view of consciousness as the missing link between matter and energy, we can consider consciousness as the functional, mental state of access beyond our bodily boundaries (Van Gulick, 2018), and also as being inherent in other beings and phenomena. This implies that techniques of expanded consciousness can be a way to communicate with other-than-human-beings without necessarily sharing the same (or any) capacity for language.

\section{BROADCASTING BETWEEN BODY AND ENVIRONMENT}

Many cultures see body and environment as inseparable, interrelated and continuous. Case studies show that body and self, person and environment and past and present are interconnected (Grau, 2005). Coding and transmitting meaning is a crucial topic within anthropology. This happens both within and outside of the body, and these internal and external pathways are not separate. Indeed, 'the mental world — the mind - the world of information processing — is not limited by the skin' (Bateson, 1972: 460). Quantum physicist David Bohm also explored the interconnection of body and environment (Bohm, 1985). His concept of 'soma significance' describes how meaning arises both through physical responses (adrenalin flow, increased heart rate and blood pressure, pain and other nervous system responses) and through external sound waves, gestures, textual objects and technology. Indeed, this links up 'the whole of society in one vast web of soma-significant and signa-somatic activity' (Bohm, 1985: 78). Our material environment is then a 'somatic result' of the (ever-changing) meaning we attribute to objects. Meaning is not static, fixed or complete, but rather a structure that constantly extends and actualises, accommodating flexibly for the movement of ongoing, unfolding meaning (Bohm, 1985: 79-82).

This structure bears strong resemblance with anthropologist Tim Ingold's 'meshwork', a field of relational involvement in the world in which relation does not 'happen' between two phenomena, but exists as a 'trail of movement or growth... along which life is lived' (Ingold, 2011: 69, ital. in original). While relations in a network imply two, previously 'separate', elements and an existence of some kind prior to integration into the network, in a meshwork 'things are their relations' (Ingold, 2011: 70, ital. in original), through multiple trails, pathways and interwoven lines. Ingold questions whether "what we have been accustomed to calling "the environment" might not be better envisaged as a domain of entanglement. It is within such a tangle of interlaced trails, continually ravelling here and unravelling there, that beings grow or 'issue forth' along the lines of their relationships' (ibid: 71).

Important for this argument, Ingold incorporates animacy into his theory, not as 'projected onto objects' by human persons, nor as 'the result of an infusion of spirit into substance, or of agency into materiality, but (...) ontologically prior to their differentiation’ (2011: 68, ital. in original).

\footnotetext{
${ }^{8}$ From Greek: 'pan means all, and psyche means soul or mind' (Sheldrake, 2017: 84-85, ital. in original).

9 De Quincey refers to Pythagoras' mathematical-material forms, Plato's substance-Form and Aristotle's hylomorphic matter-form, as attempts to understand underlying 'unlimited', 'immortal' or 'spark' essence that shapes a material manifestation of form (de Quincey, 2002: 112, capitalisation in original). Earlier philosophers include Thales, Anaximander and Anaximenes (ibid: 110-111).
} 
In this view, animacy is a given, innate, quality existing 'as one' with its object or being. This leads to understanding a lifeworld as an 'entire field of relations within which beings of all kinds, more or less person-like or thing-like, continually and reciprocally bring one another into existence' (ibid: 68).

Both Bohm and Ingold underline relationality, fluidity, changeability and the primacy of movement as foundational to our understanding of that which surrounds us. Such understanding challenges the assumptions and procedures of science within the western tradition, which developed on the merits of separation, through distancing researchers and 'objects' and aiming for control, predictability and repeatability (Kieft, 2018, see also Ingold, 2011: 75). We will look at this more closely in the next section.

\section{OPENING UP TO DIFFERENT WAYS OF KNOWING AND LEARNING}

When we recognise that western ontology, which advocates the separation between body and environment, is no longer tenable, our epistemology or ways of knowing need to change accordingly. 'Knowing' is no longer a process that happens separately from the environment, but something that emerges from interconnection. Knowing and being become fused. Our being, or the "essence of the knower', blends 'with "that being known", a process of 'radical knowing' that also transforms the knower (de Quincey, 2002: 124). ${ }^{10}$ Since, like all matter, our whole body is pervaded by consciousness, de Quincey proposes 'somatic feeling' as an alternative epistemology, which can be practised by paying attention to the body 'as it interacts with the world' (de Quincey, 2002: 145).

Les Todres, a philosophically oriented psychologist and researcher, also underlines the role of feelings in the process of understanding. Drawing from the work of Dilthey and Heidegger on emotional atmosphere, Todres describes how our (apparently reflective and abstract) understanding is never neutral, but is always preceded by 'how we are in relation to things in a prereflective and unthematised manner' (Todres, 2007: 10). Hence, our emotional texture and mood form a background quality that always informs our knowing.

Feeling is determinedly not separate from the rest of our experience, including sensorial information, reason, consciousness and intuition. De Quincey describes intuition as 'a gift of grace', coming from 'somewhere else' through 'a different shaft of knowing' (de Quincey, 2002: 145). This means negotiating the channels that connect us to external, more mystical sources of knowing and not knowing, a state of paradox-consciousness that can be reached, among other things, through silence and meditation. Rudolf Steiner (1861-1925; a mystic, philosopher and scientist who also founded biodynamic farming) considered intuition as a result of the meeting between imagination (from within us) and inspiration (from the outer world and spiritual plane).

These are but a few authors who describe the role of feelings and intuition for accessing other shafts of, or paths to, wisdom. Although this sometimes happens spontaneously, during an experience of 'flow' (Czikszentmihalyi, 1975) or peak experience (Maslow, 1994), many spiritual and meditative practices offer structured approaches to increase the possibility of connecting to such shafts of wisdom. Whatever the tradition or background, each practice provides a method or procedure that involves careful preparation, a clearly formulated intention and full focus, a change of time-space perception and often a clear invitation for 'otherness' to come through. ${ }^{11}$ Dance practices worldwide also offer a path to transcend the ordinary and communicate with other dimensions of reality (Hume, 2007: 68, 75).

\footnotetext{
10 'Radical knowing' combines (at least) four different approaches to, or gifts of, knowledge. The philosopher's gift is based in reason and clear thinking; the scientist's gift in the senses, observation and method; the shaman's gift in participatory feeling; and the mystic's gift in direct experience. Simultaneously, they address the levels of mind, body, soul and spirit (de Quincey, 2005: 221-243).

${ }^{11}$ In this respect, de Quincey proposes the POR method (Procedure, Observation, Report), for a radical science that can process any type of inquiry, including more subjective insights gained through experiences of meditation or shamanic journeying (de Quincey, 2005: 138, ital. in original).
} 
Whatever the nature of the practice (including transcendental and out-of-body experiences), the body is always the point of departure as well as return and integration after such experiences (Kieft, 2017b). Creating a literacy of body, heart and consciousness therefore seems essential to fine-tune our 'antennae' to other sources of information around us. Elsewhere (Kieft, 2018) I address the necessity of moving towards a multi-levelled literacy that includes, yet goes beyond, reason and cognition and addresses the following: (1) embodied approaches to increase perception; (2) abilities to skilfully navigate emotions and feelings; and (3) expanded mental capacities to include imagination and intuition and create space for the soul. These suggestions are not intended to undermine or replace, but rather to complement positivist methodologies towards a more inclusive and holistic approach to knowledge. To reach such multi-level literacy requires multi-level learning and pedagogy as well, which I address in the next section.

\section{CALIBRATING THE BODY AS INSTRUMENT: TOWARDS MULTI-LEVELLED LITERACY}

So far we have looked at the deep intertwinement and inseparability of mind and body, and the need to widen our epistemology. We saw that perception and insight can arise through different channels. In addition to mental and cognitive abilities (often referred to as 'intellectual', left-brain abilities), understanding is cultivated through sensorial body awareness, emotional feeling qualities, and intuitive, meditative and expanded states of consciousness. These different channels mutually affect each other.

This final section offers simple and practical ways to nurture and develop multi-levelled literacy, in order to increase awareness and perception and open ourselves up to alternative avenues of knowing. These practical invitations (in italics, below) emerge from my experience and practice as dancer and dance facilitator. Like a Russian doll, calibrating the body as instrument includes all these different levels: the body is home to the heart and the mind, as well as an anchor within a larger stream of consciousness. As previously discussed, many disciplines offer approaches to deepen these suggestions, including, but not limited to, ECOintention, shamanic practice, Movement Medicine and meditation.

\section{Deeper Familiarisation with the Body}

In order to value our body as instrument, we first need to address our relationship with it. This is not always easy. Our body-sense might be compromised through stress, lack of self-confidence, chronic pain, traumatic experience or (mental) illness. However, despite such challenges, our body remains a miracle of intricate connections, balance and perception.

Pause for a moment to consider this. Acknowledge your breathing and the capacity of your lungs to provide you with oxygen. Feel the pulse of your heart, pumping precious lifeblood through all your body. Imagine your organs and digestive system at this very moment being busy extracting nutrients from your food to provide you with energy. Look at your hands, and think of all the amazing tasks your hands can perform. Acknowledge the range of emotions that come with being human. Realise what a unique experience your life is, and what a unique being you are. Keep breathing.

The more familiar we are with the processes and states within the physicality of our body, the more we are able to discern what arises independently. By monitoring subtle states and shifts inside ourselves, we become more adept at noticing changes in the world around us. This will foster interaction with the 'other-than-human'.

Pay attention to the processes and states of your body. Notice your breathing, and whether it is shallow, deep, high or low in the chest. Is your heart beating slowly, or fast? How are your energy levels right now? Are you awake, energetic, tired? Does this vary during the day, or after meals? How is your digestive system? Your body temperature? Are you more aware of your upper or lower 
body? Is something physically uncomfortable distracting you? Do you perceive any tight or sore spots anywhere? Can you describe your current bodily experience with one 'quality adjective' (e.g. relaxed, cold, tingly, taut, soft, foggy and centred - be aware of not yet crossing from physical sensations to emotional qualities, stay with a descriptor rather than an interpretation of it).

It would not be surprising if, during the above exploration, the last invitation was difficult. Concrete physiological feedback of our bodily functions is strongly intertwined with our perception of that feedback. In neuroscience, this phenomenon is called 'interoception' (interior perception). Physical sensations play an important part in our moods, emotions, behaviour and sense of well-being - including gut feelings and heartache (Cameron and Hamilton, 2002; Wiens, 2005). Becoming even more familiar with these interconnections further enables us to discern shifts and fluctuations around us.

Zoom in on one quality from your previous inquiry, and observe any interpretations, judgements, feelings or emotions related to it. You might notice a sense of familiarity and recognition ('I always feel like this after lunch') or a new internal awareness ('wow, I haven't noticed that before'). Observe if it has to do with the state of your body (pleasant or unpleasant), or with what you are doing (engaging or boring). Is it a state you are comfortable with, or want to 'move away from'? Try, however, to accept and receive it as it is, without changing anything. There is no right or wrong. There also does not have to be a concrete outcome. Just try to follow the interrelationships between your physical sensations and your mental and emotional state. You might, for example, perceive coldness in your hands and feet, a slow digestive system and perhaps a lack of concentration or disinterest in what you are doing. ${ }^{12}$

\section{Territory of the Heart and Emotional Literacy}

I use the term 'emotional literacy' for the ability to navigate feelings and emotions without 'drowning' in them, 'acting them out' or projecting them onto others. It requires skill to hold the wildness and tenderness of our heart without numbing, ignoring or unhelpfully amplifying its voice. Usually, this literacy matures with conscious attention to personal growth and/or spiritual practice. However, there are a few specific ingredients to consider that are largely ignored in western education. Four are briefly explored here.

First of all, emotional literacy includes not only the acceptance of uncertainty and not knowing, but also acknowledging such states and experiences as fertile and creative. Although it takes courage to enter the unknown, this is the place where we expand our knowledge (see also Ellis, 2009; Melrose, 2007). Pedagogically, we learn best when we are slightly, but not too far, out of our comfort zone; otherwise, we are either under- or overstimulated, and neither is conducive to growth and learning.

Secondly, emotional literacy includes recognition of, and fluidity around, ambiguity and paradoxes. We are often taught something is either this or that; it cannot be both. Learning from a quantum landscape, we know that the universe contains particles and waves. Can we similarly grow towards and/and inclusivity rather than either/or exclusivity in our emotional landscape?

Thirdly, emotional literacy enhances the ability to deal with apparent failure in case of so-called mistakes. We live in a culture that rewards success and celebrates fast achievers. However, not (yet) knowing something often means that we are learning. Can we accept that making mistakes is a natural part of being human, and treat them with humour and compassion and as part of our learning trajectory?

Finally, emotional literacy acknowledges our inherent vulnerability and ultimate mortality and aims to find our peace with that. How can we integrate inevitable change and death without becoming paralysed with fear? How can this contribute to a positive and conscious use of our life force?

\footnotetext{
12 'Focussing' is a psychotherapeutic process developed by Eugene Gendlin to explore the 'felt sense' of internal knowing, to increase awareness of (often preverbal) responses to life situations (Gendlin, 1978).
} 
At an appropriate time, take a journal and reflect on the themes raised above. For example: How is the balance in your life between change and predictability? Are you comfortable with that, or would you like more of one or the other? How often are you out of your comfort zone? It is important to find out where comfort zone ends and unknown begins for you. Do you feel 'thrown' out of your comfort zone, or do you actively seek to go there by trying new activities?

How is your relationship to the unknown, to not knowing? Do you experience excitement and curiosity, a sense of moving towards it, perhaps a sense of empowerment? Or do you experience antipathy, resistance, fear, a sense of closing down, moving away from? Both are absolutely fine, and this is simply an inquiry into your flexibility to deal with not knowing. This is not intended in any way as a judgement of inflexibility but as a means to find out more about your levels of comfort regarding not knowing, in order to understand more of how you learn and navigate life.

If your feelings regarding the unknown are uncomfortable, reflect on what will help you find courage to go out of your comfort zone in order to learn something new. Set a realistic goal for yourself-for example, try something new once every day/week/month/year (a level that is just out of your comfort zone but not too far that it would be daunting). Ask support from a trusted person to help you accomplish this.

Similarly, reflect on your relationship with the other ingredients of emotional literacy: ambiguity and paradoxes, failure and making mistakes, vulnerability and mortality. Inquire, without judgement, on how it is now, and how you can create more fluidity around this in your own personal circumstances.

\section{Cultivating Right-Brain Abilities and Expanding Consciousness}

Artistic and spiritual techniques stimulate and strengthen our connection to our subliminal mind and our ability to perceive extrasensory information. These include visualisation, creative arts, stories, symbols, archetypes, meditation, yoga and dreamwork (see, e.g., Roney-Dougal, 1991: 25-28). ${ }^{13}$ Movement, as we discussed earlier (Bohm, 1985; Ingold, 2011), is primary to our relational understanding of what surrounds us. It also enhances our capacity to perceive and imagine, enables shifts in consciousness and is accessible to everyone, anywhere. We do not need to be trained professionally or otherwise in order to move. Indeed, we are all made of movement. Movement is an act of creating and becoming 'patterns of sensing and responding to other movements' that happen in, around and through us (Lamothe, 2014: 59). It cultivates our ability to perceive things differently, whether through thoughts, feelings or imagination. At the same time, it influences and perhaps even defines our being, including, again, our sensing, feeling and thinking capacities, but also our ways of meaning-making, our (inter)actions and growth. Perhaps especially because movement does not depend on words or images, it allows us to tune into 'the presence, power and reality of what may be' (Lamothe, 2014: 60), and is therefore such a strong route into the other ways of knowing that we discussed in the previous section. How can we further develop movement as a way of knowing?

For this exploration, take 20 minutes when you can work undisturbed in a space of at least $2 \times 2 m^{2}$ to move freely. Start by searching for lines and angles both in your body and in the space you are in. Gently move your hands, knees, elbows and arms into different positions, into linear and angular shapes. Can you move through the space in lines and angles?

Now explore the shapes of circles and spirals. What circles, curves and spirals can you make with your hands, knees, elbows, arms and whole body? What circles and curves do you observe in the space? Can you move in circles and curves?

In your own timing, switch back and forth between the linear and the circular, between the angular and the spiral. How does it feel to move in these different ways? What associations come up for you while moving? Do you feel more comfortable with one set of movement patterns than with the other?

\footnotetext{
${ }^{13}$ There are many online resources that offer practices, activities and techniques to cultivate right-brain abilities. Please feel free to visit my website www.clover-trail.com for inspiration.
} 
Still moving, distil your experience into three or more keywords for lines and three or more keywords for circles. Let your writing be part of your movement exploration. What have you learned? What has moving with these polarities and shapes taught you? How does it feel to translate your movement experience into written words? $?^{14}$

We can explore any type of question in movement. Ingredients and tools of somatic practices can support our inquiry, for example through concepts such as sensory awareness, touch, textures, weight, speed, density, resistance, posture, how we relate to place, space and atmosphere, and pairs of tension/relaxation, unity/diversity and light/dark. This awakens our body awareness as well as tangible, physical connection with the space around us (which includes both material and immaterial aspects). ${ }^{15}$

\section{NAture IMMersion}

Nature offers a space where we can fully be ourselves, and therefore provides an ideal place to practise all the above, especially with regard to cultivating our right-brain abilities and (re)connecting with what surrounds us. Simply being in nature can give us a different sense of perspective. One option is immersion without an 'agenda', regarding such time as a creative, meditative space that can resource your body and your imagination. You can, for example, find a 'power place' and let the energy of that specific spot nourish and rebalance you so that you return refreshed to your daily life (see, e.g., Lüttichau, 2017: 81-87).

Another option is to prepare a specific question beforehand and regard your time outside as a 'medicine walk' or 'mini vision quest', asking nature to be your teacher. Open yourself to receive specific answers to your question that can come from, for example, the direction of the wind, the shape of a leaf, the behaviour of an animal, a repetitive number you might see in a cluster of flowers, trees, or times that a specific animal shows itself. Observe the interaction between your body-being and the land around you. Do you see fences or hedges? Are you in the dark or in the light? Do you feel connected or separate? Such observations might all contribute to an answer to your question.

If you know that you have a wonderfully critical left-brain mind, and rightfully take pride in that, try to let go of any specific expectations, and do not go into an immediate mental analysis about how to read, or whether to dismiss, a specific sensation or experience. Taking the first steps of calibrating your body is a process of slowly creating a greater familiarity and intimacy with your instrument, which will increase trust of the things you perceive. You can even take your mind 'by the hand' and say 'please let me have this experience to learn and experience something without analysing or dismissing it right away, and we will look at it critically afterward'.

\section{CLOSING}

This chapter addresses ways to attune the body to subtle information around us, which can be applied in the ontological shift from a world view based in matter and particles, to understanding nature also as (electromagnetic) waves and information. As agriculture moves from a 'traditional' to a more quantum-informed perspective, different ways emerge to explore the relationship between various aspects within ourselves as human beings, and between human and other-than-human-beings that we work with and/or are entrusted in our care.

I propose that the body is a multi-layered phenomenon, consisting of physical matter (particles), infused with feelings (waves), intuition and consciousness (information). Similar qualities exist externally, and through techniques of clear focus and expanded consciousness, we can connect

\footnotetext{
${ }^{14}$ This exploration is available as a free online video resource via the National Centre for Research Methods website: https://www.ncrm.ac.uk/resources/online/embodied_methodologies/

${ }^{15}$ The Somatics Toolkit (Kieft et al., 2019) offers another free online resource with audio recordings to explore different ways of moving with questions, emotions and concrete aspects of any research cycle as well: http://somaticstoolkit.coventry.ac.uk.
} 
to subtle sources of information outside of us. The body can be trained to receive such external information through a concrete intention to enhance literacy across all these different layers. In this chapter, I specifically introduce two methods: the use of movement and nature immersion that can help us to realise our embeddedness in, and inseparable connection with, what surrounds us. Such techniques ultimately enable us to have a more intuitive relationship with animals, farms, gardens and food.

\section{REFERENCES}

Andeweg, H. (2009) In Resonance with Nature: Holistic Healing for Plants and Land. Edinburgh: Floris Books.

Bateson, G. (1972) Steps to an Ecology of Mind. Chicago, IL: The University of Chicago Press.

Bohm, D. (1985) Soma-significance: A new notion of the relationship between the physical and the mental. In Unfolding Meaning: A Weekend of Dialogue with David Bohm. London: Routledge, pp. 72-120.

Cameron, O. G. and Hamilton, W. D. (2002) Visceral Sensory Neuroscience: Interoception. New York: Oxford University Press.

Cohen, D. B. (2006) Family constellations: An innovative systemic phenomenological group process from Germany. The Family Journal, 14(3), 226-233.

Czikszentmihalyi, M. (1975) Beyond Boredom and Anxiety: Experiencing Flow in Work and Play. San Francisco, CA: Jossey-Bass.

Darling Khan, S. and Darling Khan, Y. A. (2009) Movement Medicine: How to Awaken, Dance and Live Your Dreams. London: Hay House.

de Quincey, C. (2002) Radical Nature: Rediscovering the Soul of Matter. Montpelier, VT: Invisible Cities Press.

de Quincey, C. (2005) Radical Knowing: Understanding Consciousness through Relationship. Rochester, VT: Park Street Press.

Ellis, S. (2009) Performance-presentation: Hands That Don't Want Anything, discussing recent collaborations with Kirstie Simson. Plymouth: Theatre and Performance Research Association (TaPRA) Performance and the Body working group, meeting 7 September 2009.

Ferrer, A. (2015) From newtonian physics to quantum theory; from new science to spiritual philosophy and wisdom: the crucial question of consciousness, Ars Brevis.

Gardner, H. (1983) Frames of Mind: The Theory of Multiple Intelligences. London: Fontana Press.

Gendlin, E. T. (1978) Focusing. New York: Bantham Books.

Grau, A. (2005) When the Landscape becomes flesh: An investigation into body boundaries with special reference to Tiwi dance and Western classical ballet. Body and Society, 11(4), 141-163.

Hardy, C. H. (2015) Nonlocal Processes \& Entanglement as a Signature of a Cosmic Hyperdimension of Consciousness. Journal of Consciousness Exploration \& Research, 6(12), pp. 1015-1030.

Harvey, G. (2003) General Introduction, In Harvey, G. (ed.) Shamanism: A Reader. London: Routledge, pp. $1-23$.

Harvey, G. (ed.) (2014) The handbook of contemporary animism. Oxon \& New York: Routledge.

Hume, L. (2007) Portals: Opening Doorways to Other Realities through the Senses. Oxford: Berg.

Ingold, T. (2011) Being Alive: Essays on Movement, Knowledge and Description. London and New York: Routledge.

Kieft, E. (2013) Dance, empowerment and spirituality: An ethnography of movement medicine. University of Roehampton, Unpublished $\mathrm{PhD}$ thesis, London.

Kieft, E. (2014) Dance as a moving spirituality: A case study of movement medicine. Journal of Dance, Movement and Spiritualities, 1(1), 21-41.

Kieft, E. (2017a) Dance, empowerment and spirituality in movement medicine. In Delft, M.V., Gündüz, Z., Koolen, H., Voets, J. and Wijers, L. (eds), Danswetenschap in Nederland. Utrecht: Vereniging voor Dansonderzoek, pp. 85-92.

Kieft, E. (2017b) (Re)discovering the enchanted garden through movement and the body. Revue Théologiques, 25(1), 139-154.

Kieft, E. (2018) Clearing the way towards Soulful Scholarship. In Ellis, S., Blades, H. and Waelde, C. (eds), A World of Muscle, Bone and Organs: Research and Scholarship in Dance. Coventry: C-DaRE at Coventry University, pp. 456-479. 
Kieft, E. (2020) Dancing with the Spirits, Act 1: 'Being grounded and being able to fly are not mutually exclusive'. Dance, Movement and Spiritualities, 6(1and2), 27-48.

Kieft, E., Spatz, B. and Weig, D. (2019) A Somatics Toolkit for Ethnographers. Coventry: Coventry University, available online: http://somaticstoolkit.coventry.ac.uk.

Kieft, H. (2019) Quantum Leaps in Agriculture: Exploring Quantum Principles in Farming, Gardening and Nature. Beaubassin: Lambert Academic Publishing.

Lamothe, K. L. (2014) Transformation: An ecokinetic approach to the study of ritual dance. Dance, Movement and Spiritualities, 1(1), 57-72.

Larson, P. (2014) Pantheism. In Leeming, D.A. (ed), Encyclopedia of Psychology and Religion. New York: Springer, pp. 1283-1285.

Lovel, H. (2014) Quantum Agriculture: Biodynamics and Beyond. Forest Row: Rudolf Steiner Press.

Lüttichau, C. (2017) Calling us Home: Find Your Path, Your Balance and Your Inner Strength. London: Head of Zeus.

Madden, R. (2017) Being Ethnographic: A Guide to the Theory and Practice of Ethnography, 2nd Edition. Los Angeles, CA and London: Sage Publications.

Maslow, A. (1994) Religion, Values and Peak Experiences. New York: Viking.

McTaggart, L. (2001) The Field: The Quest for the Secret Force of the Universe. New York: HarperCollins Publishers.

Melrose, S. (2007) The (Written) Confessions of an Uneasy Expert Spectator. Available at: http://www.sfmelrose.org.uk (accessed: November 21st 2017).

Morris, B. (2006) Religion and Anthropology: A Critical Introduction. Cambridge, New York: Cambridge University Press.

Naccarato, T. (2018) Artistic practice-as-research: A genealogical account. In Ellis, S., Blades, H. and Waelde, C. (eds), A World of Muscle, Bone and Organs: Research and Scholarship in Dance. Coventry: C-DaRE at Coventry University, pp. 435-455.

Nelson, R. (2013) Practice as Research in the Arts: Principles, Protocols, Pedagogies, Resistances. Basingstoke: Palgrave Macmillan UK.

Pink, S. (2015) Doing Sensory Ethnography. London: Sage Publications.

Roney-Dougal, S. (1991) Where Science and Magic Meet. Shaftesbury, Dorset: Element Books.

Schäfer, L. (2008) Nonempirical reality: transcending the physical and spiritual in the order of the one, Zygon, 43(2), pp. 329-352.

Sheldrake, R. (1988) The Presence of the Past: Morphic Resonance and the Habits of Nature. Rochester, VT: Park Street Press.

Sheldrake, R. (2017) Science and Spiritual Practices. London: Coronet.

Snowber, C. (2016) Embodied Inquiry: Writing, Living and Being through the Body. Rotterdam: Sense Publishers.

Spatz, B. (2015) What a Body Can Do: Technique as Knowledge, Practice as Research, Abingdon, Oxon and New York: Routledge.

Todres, L. (2007) Embodied Enquiry: Phenomenological Touchstones for Research, Psychotherapy and Spirituality. Basingstoke and New York: Palgrave Macmillan.

van Gulick, R. (2018) Consciousness, In Zalta, E. N. (ed.) The Stanford Encyclopedia of Philosophy, Spring 2018 Edition. California: Stanford.

Whittington, J. (2016) Systemic Coaching and Constellations: The Principles, Practices and Application for Individuals, Teams and Groups, 2nd Edition. London: KoganPage.

Wiens, S. (2005) Interoception in emotional experience. Current Opinion in Neurology, 18(4), 442-447. 


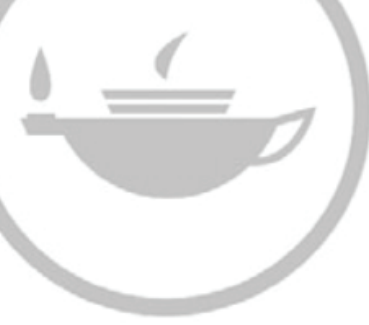

Taylor \& Francis Taylor \& Francis Group http://taylorandfrancis.com 


\title{
18 The Art of Food Rituals as a Practice in Sympoiethics
}

\author{
Miche Fabre Lewin and Flora Gathorne-Hardy \\ Coventry University
}

\section{CONTENTS}

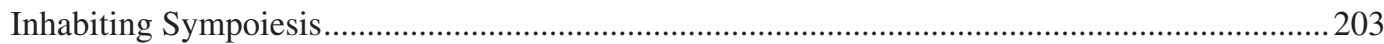

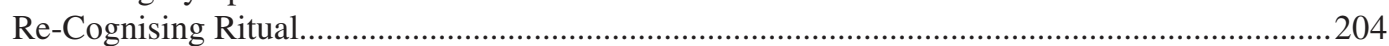

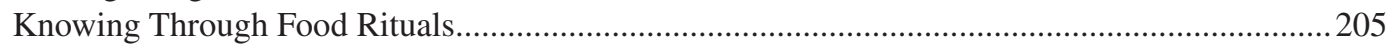

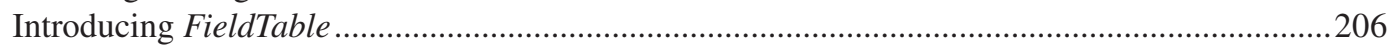

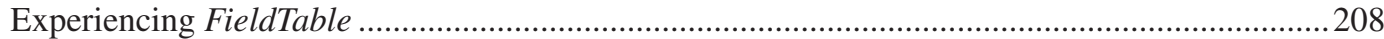

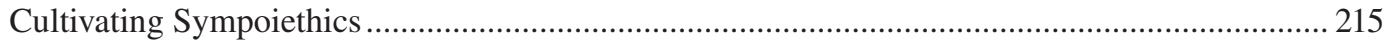

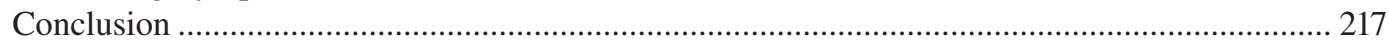

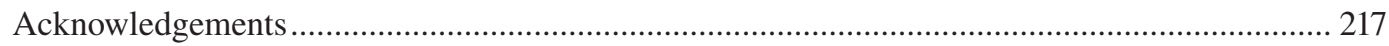

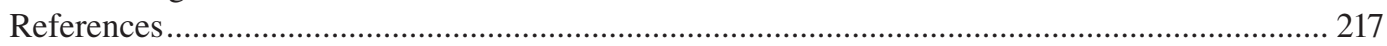

\section{INHABITING SYMPOIESIS}

In a humble gesture of touching the soil with the fingers of his right hand, Buddha shows his allegiance to the Earth as his authority, reminding us that our human bodies are in a vital and everyday relationship with the body of the planet. His gesture is in resistance to Mara's temptations to draw him into the conditioned existence of separation, delusion and desire and an expression of his understanding that the Earth is his witness (Thomas, 2000). This sacred image of the Buddha with his own body in connection with the Earth grounds ethical conduct as part of whole-bodied consciousness. Our humanity flourishes as part of the animate and interconnected systems of the living Earth where we are in an on-going entanglement with each other and the matter of all existence (Abram, 2010; Barad, 2012; Gablik, 1992; Haraway, 2016; Ho, 2008; Laszlo, 1996; Weiwei, 2020). Addressing and engaging in social and environmental justice is an invitation for us to notice and practice our humanhood as an embodied and physical experience in relationship with the other-than-human world (Roszak 1977). Traditional knowledge systems and ancient spiritual wisdoms recognise this embodied, participatory worldview and the unifying consciousness where, in kinship with Gaia, 'we participate in the intimacy of all things with each other' (Berry, 2006: 137). This is a poetic ecology that enables our fragmented selves 'to find our place in the grand whole again' (Weber, 2019: 3) (Figure 18.1).

For, while we as living creatures are bounded as independent, autopoietic organisms with the capacity to self-reproduce and cohere living processes (Maturana and Varela, 1980), we also co-exist within the interdependence of ecosystems with synergistic behaviour of 'linkages, feedback, cooperation' (Dempster, 2000: 4). Complementing the concept of autopoiesis, biologist Beth Dempster conceived the term 'sympoiesis' to describe the inherently interactive and cooperative behaviour of living systems sym meaning with, or together, and poiesis to make, create or produce (ibid). In adopting a sympoietic sensibility, the separation between nature and culture dissolves and we as humans become active, sensing organisms within the dynamic flow of a non-heirarchical and interconnected cosmology.

Sympoiesis diffracts with current feminist, decolonial and environmental narratives of power by re-orienting us towards a worldview based on life-affirming encounters between our personhood, each other and the habitats of the animist world. Donna Haraway speaks of naturecultural 


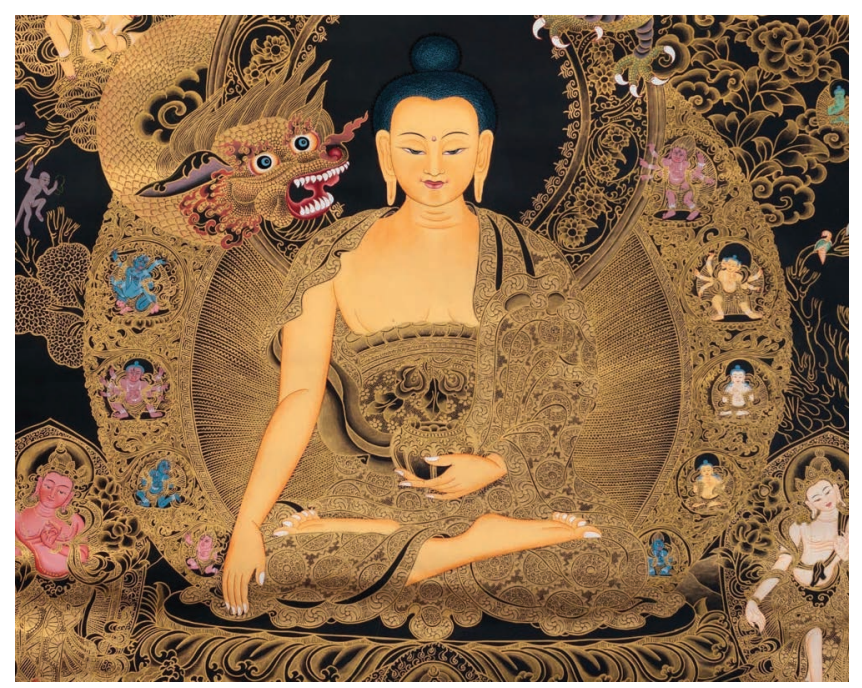

FIGURE 18.1 Buddha resisting the temptation of Mara. (Image credit: Exotic India Art.)

being and becoming-with to describe this interconnectedness as a mode of being where "nothing makes itself', rather, 'we are worlding-with, in company' (Haraway, 2017: M25). Maria Puig de la Bellacasa reflects on such naturecultural thinking as emerging through 'knots of relations involving humans, nonhumans, and physical entanglements of matter and meaning' (Puig de la Bellacasa, 2017: 141). Addressing the feelingful body as one with the thinking mind, Weber calls for a position of 'enlivenment' where thought and practical action are reanimated with 'life' and 'aliveness'(Weber, 2019: 11). Minna Salami presents 'exousiance' as 'the catalytic power of being and becoming together with everything else that is being and becoming' (Salami, 2020: 1-2). This power of aliveness is what we as humans share with every living entity, a power which arises from source and has the capacity for integrating social change with ecological restoration.

Sympoiesis interweaves the concept of the convivial, which also invokes the expression of interrelationship with its Latin roots of con 'with' and vivere 'to live'. The convivial guides us towards an embodied ethics where 'we creatively and autonomously live, work and relate to each other in the everyday life' (Ballantyne-Brodie, 2018: 1034-1035). A convivial praxis attends to the larger whole by animating inclusive cultural spaces where we all, human and other-than-human, can experience, recover and respond within a continuous intra-acting with the matter and life processes of the world. Within forest ecology, refugia are spaces for habitat restoration through the revival of ecological and agricultural biodiversity (Barthel et al., 2013). Inspired by the work of Anna Tsing (Tsing et al., 2017), Haraway reframes bio-cultural refugia as places of naturecultural resurgence for the revival and flourishing of ways of living that have been forgotten, denied or subjugated (Haraway, 2015). For us to become more wholly human, we are called into a radical conviviality of co-existence and responsiveness with each other and the other-than-human world.

\section{RE-COGNISING RITUAL}

Ritual has the potential to manifest bio-cultural refugia as collective gatherings that are inclusive of all inhabitants of a place by creating bounded space and time to explore, open to and cultivate new forms of interrelationship that are non-hierarchical and connecting across differences. Ritual practice has been embedded within the making of naturecultures since the birth of humanity as a cultural form for generative sympoietic interaction (Grimes, 2015; Turner, 1969). Affirming the role of ritual as an ecological and participatory practice of life, Ronald Grimes defines it as 'the basic social act, the fabricator, the device for world-and meaning-making' (Grimes, 2015: 2). As performative acts, 
rituals are spatial and temporal encounters that 'include order, tradition, and prescribed actions but also innovation and creativity, improvisation and randomness' (Grimes, 2015: 3). Rituals enacted for the sacred naturecultural purpose of world-making share an interweaving sequence of three transitions: the separation from ordinary everyday life; the liminal, threshold space of transformative experiences and closure, which embraces the potential reincorporation of the wisdoms and teachings which have occurred during the ritual encounter (Turner, 1969; Van Gennep, 1960).

The innovation of ritual practices as containers to restore deeply experiential ways of knowing within a participatory consciousness is an active recovering of Rta, the Sanskrit roots from which both 'art' and 'ritual' originate. Rta is understood as 'the synergy of materials, forms and processes ... the dynamic movement from which all arises' (Haley, 2016: 46). These ritual practices offer the potential for embodied, emergent and evolutionary forms that are responsiveness to self, other, matter and place. As Victor Turner confirms, the liminal quality inherent in ritual offers the potential to 'generate and store a plurality of alternative models for living ... in the direction of radical change' (Turner, 1985: 33). Echoing Turner, Frederique Appfel-Marglin conveys the essential dynamic role of performing intra-actions or rituals ceremony for 'making a livable common world' (Apffel-Marglin, 2011: 162).

Rituals afford us rigorous and extensive thinking-feeling practices by engaging our bodyminds in the matter, substances and processes of life. As a contemporary ecological arts practice, Touchstones Earth co-evolve and host rituals as refugia for embodied thinking within a sympoietic sensibility that honours the sacred as 'the changing, flowing, thinking/Of the world' (Bateson quoted in Charlton, 2008: xiv). These choreographies in time and space are performative encounters that encourage interaction between feeling and knowing, site and psyche, mind and body, nature and culture and the cycles of past, present and future (Mathews 2003). Within a bounded form, the bodymind experiences being-with oneself, other people, matter and place as a conscious process of regenerative world-making - the 'material engagement in labours to sustain interdependent worlds' (Puig de la Bellacasa, 2017: 198; Ryan et al. 2016). As Clifford Geertz reflects, rituals are spaces where we can come to know how to act because we know how we feel (Geertz, quoted in Grimes 2015: 1). Thus, it is in the making of ritual that we can cultivate and practice a sympoietic and political consciousness that respects our interdependent origins with each other and the Earth (Gablik 1992a). Joanna Macy, in her despair and empowerment sessions, animates healing with ritual work. These rituals become conduits for deepening into our inner emotional life, reaching out to each other and cultivating actions in respect of the other-than-human world of which we are a part (Macy, 1991). In his work with ritual, Malidome Some reflects that participation in a communitas is 'a pre-requisite for true ritual healing, for a sense of belonging that satisfies, and for a rewarding understanding of Spirit' (Some, 1998: 294). As Matthew Fox considers in conversation with Rupert Sheldrake, ritual has its value for a radical cosmology of interconnectedness and forms the basis of morality. Fox writes:

All healthy ritual is an invitation to doing things together, not being spectators watching someone else do something, but inviting people to truly participate with their own bodies, their own images, their own breath and their own visions.

Fox and Sheldrake (1996: 147)

\section{KNOWING THROUGH FOOD RITUALS}

Food decisions impact on all aspects of our lives, every day, every mouthful. Carolyn Steel writes, 'food emerges as something with phenomenal power to transform not just landscapes, but political structures, public spaces, social relationships, cities' (Steel, 2008: 307). Reflecting on the art of Joseph Beuys and his culinary happenings, Lemke writes of 'gastrosophy', a philosophy which reframes the ritual of food-making as an art and aesthetics of everyday life (Lemke, 2007: 53). In the ancient Hindu philosophical scriptures of the Upanishads, the nature of knowledge is explored through the substance and metaphor of food as part of life's interconnected cycles of decay and renewal. The translated extract from Sanskrit is a testimony to how food is a profound medium for 'coming to know': 
First Know Food

From food all things are born.

By food they live,

Toward food the move

And into food they return.

Taittiriya Upanishads

Through the medium of food, naturecultural entwine. Touchstones Earth draw on the power of food as a way of knowing to co-evolve contemporary food rituals within the fields of ecological food cultures, regenerative agroecology and social healing. Central to this ritual practice are embodied encounters with the matter of the living food cycle - the cycle of soil and water care, food growing, food sharing and food composting where food waste is returned back to the soil. Cultivating food rituals as refugia engages the bodymind in enlivening encounters with agricultural methods, culinary traditions and the geographies of food cultures. This extensive and reflexive experience with food provides space and time for participants to sense, imagine and awaken memories, feelings and thoughts (Curtin 1992). They enact threshold containers for remembering forgotten wisdoms, reviving artisanal skills and generating new possibilities in respect of naturecultural living. Such embodied explorations cultivate a politics of participatory consciousness where the bodymind is in a coming to know and a becoming-with the world, in an integrated expression of care as an ethics of the everyday.

Touchstones Earth's rituals as refugia respect, reframe and improvise within an existing lineage of cultural and agricultural food ritual traditions. Within Jewish culture, the ritual table of the Haggadah with its Seder plate recalls the experience of Passover and, through symbolic foods, remembers the significance of the Exodus from Egypt. Agricultural traditions that acknowledge and work through and with the subtle energies of nature include: the Vedic ceremony of the daily fire ritual Agnihotra performed at sunrise and sunset; and Rudolf Steiner's teachings that elaborate the application of biodynamic preparations for soil and plant health in attunement with celestial and diurnal rhythms. Agrarian harvest festivals are celebrated across the world to honour the first fruits of the season with thanksgiving rituals and feasts. These rituals of the table and the field are healing, purifying and restorative as they encourage an awareness and a focus of intention to histories and geographies through spacious, sensuous and sympoietic interactions. They respect the energies of genius loci, the agency of human experience and the regenerative power inherent in plant, animal and mineral - all in a dance with seasonal rhythms, natural elements and the Earth's solar system.

\section{INTRODUCING FIELDTABLE}

The food ritual FieldTable grew from Miche's impulse to create an edible intervention as an embodied agricultural alternative to a Union Carbide advertisement within the 1976 Scientific American journal addressing 'The Future of Agriculture' (Scientific American 1976). The text within the double-page spread reads, 'We are expecting a few extra people for dinner tonight'. The dramatic image is of a long, white-clothed table which curves into the horizon within a ploughed field of barren soil denuded of all plants and biodiversity. At the table, the green velvet chairs are empty. The plates and glasses are empty. Below the image are promises of the power and efficiency of the 'green revolution' to grow more food using artificially synthesised insecticides, gels, crops and plant treatments for the 213,000 'extra people'.

The precursor to FieldTable was conducted in 2006. In collaboration with an organic farmer in Shropshire, UK, Miche hosted an environmental dining experience CloverField Feast in a field of clover grazed by cattle. Here, participants experienced an embodied taste of eating as an agricultural act (Berry, 1993). As part of the ritual, the 12 participants were invited to engage with the question, 'What is food'? A decade later in 2016, the opportunity emerged to manifest FieldTable on a biodynamic farm near Stellenbosch in the Western Cape of South Africa. During Miche's Living Cultures: Kitchen culture meets agriculture Artist Research Residency at the Sustainability Institute she and Flora met a local landowner who gave them a tour of his biodynamic farm in the Lynedoch region. Whilst walking in and with the land, Miche shared her idea of hosting a 
regenerative farm-based food intervention. This notion was greeted with enthusiasm by the farmer and preparations began to curate this edible experience on one of his biodynamic fields.

Addressing and engaging with the personal and political dimensions of oppression through emancipatory practice motivates all of Miche's work in the world. As a woman with Jewish heritage born white into the colonial regime of Rhodesia, Miche recognises and engages with the multiple dynamics of oppression. Aware of how white body supremacy has conferred privilege on her life (Menaken, 2020) she is also tuned into how her human existence entwines within other systemic discriminations which segregate, marginalise and exploit. Her contemporary food rituals arise from a body of work which is committed to intervening in and countering the separation between ourselves, each other and the multisentient communities of our planet. Through creating liberatory conditions for embodied experiences with the living food cycle these convivial encounters prepare a common ground for fostering respectful, inclusive and celebratory relationships.

Given the legacies of apartheid in South Africa and on-going land contestation coupled with food insecurity the invitation to host the food experience FieldTable was politically dynamic. The durational ritual was conceived as a convivial intervention for participants from diverse ethnicities, cultures, ages, classes and genders to gather around a dining table in an unfamiliar context to share different experiences, perspectives, aspirations and vocations. Those at FieldTable included agroecology students and educators, gardeners and farmers, organisational leaders and activists, bakers and chefs, scientists and ecologists, journalists and researchers and artisan food producers. This kinship of people emerged from relationships Miche and Flora had developed during the 3-month artist research residency at the Sustainability Institute. Everyone round the table shared a dedication to agroecological food cultures and regenerative artisanal food production within the region. The event was thus a communitas for the guardianship of soil, water and land as a practice in social, ecological and food justice.

On a September Saturday, the ritual process began with a sensorial travelling experience in a lavender-strewn truck where 22 participants were driven up to a farm track. Continuing on foot, all walked towards a field of grazing cattle where a dining table stood amongst the meadow grasses. As the participants approached FieldTable, they were invited to pause at a shrine, the liminal threshold which signalled the bounded container of a ritual space. The ritual shrine was in honour of the field and its genius loci and was composed of large slice of tree trunk and a selection of matterful objects including a granite touchstone, kalahari salt, a vessel of water, a bowl of soil and a ball of red thread. Miche welcomed people and offered gratitude to the soil and water. Here she invited participants to consider the question 'What are we hungry for'? and to hold this during the food sharing. Once seated, Miche introduced the evolution of FieldTable, and before beginning to eat, participants were asked to pause for a minute of silence in contemplation of their surroundings and with the food on their plate. The mainly plant-based menu of dishes was hand-prepared and cooked using culinary artisanal traditions to enhance the nutritional value. All the produce was sourced and donated from the gardens and farms of local growers who sat around the table. The simplicity of fare included the fresh, the fermented, the raw and the cooked, all composed from the season's local harvests. Sourdough breads from heritage grains were specially baked in woodfire as small baguettes for sharing between two as a gesture of companionship. Seeking to amplify the vitality of the food, to give it voice and allow it to reveal its own nature, the food on the plate displayed a vibrant composition of natural colour, form and texture - food to awaken the senses.

As part of the ritual dining experience, some of the participants stood up to share their passion for their culinary, artisanal and agricultural practices, thereby stimulating the spontaneous reflections and stories of others. Once the food was eaten, leftovers from the plates were collected into bokashi bins to activate a fermentation process that enables foodwaste to become natural fertiliser for the land. The final phase of FieldTable opened a space for self-reflexivity where participants were asked to respond in writing with the question 'How has your hunger been satisfied'? This was followed by closure through exchanges of thanks and farewells (Figure 18.2).

As a durational food ritual, FieldTable was a provocation for the bodymind, enlivening people's capacities to come to know through the senses, the imagination, emotion, intuition and 


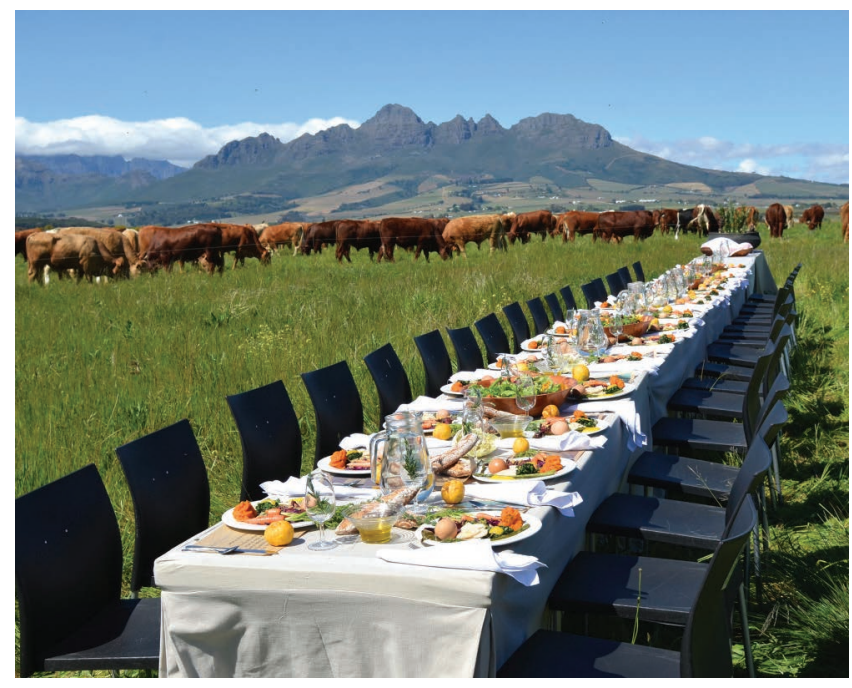

FIGURE 18.2 FieldTable prepared for participant diners. (Image credit: Eva van Niekerk.)

memory in direct contact with the geography and the matter of food. The co-creation of such bio-cultural refugia as a ritual, situated in an agricultural field on biodynamic land, offered the opportunity to know food and to be-with food while experiencing its source and the place of its origin, the living soil. As well as being a thanksgiving ritual in celebration of regenerative and biodynamically grown food of the land, FieldTable sought to be a sympoietic manifestation of convivial life as an 'autonomous and creative intercourse among persons, and the intercourse of the persons with their environment' (Illich, 2001: 86). What follows is a photo-montage of the encounters that unfolded during FieldTable for the reader to pause and feel into, muse on and dwell-with (Figure 18.3-18.16).

\section{EXPERIENCING FIELDTABLE}

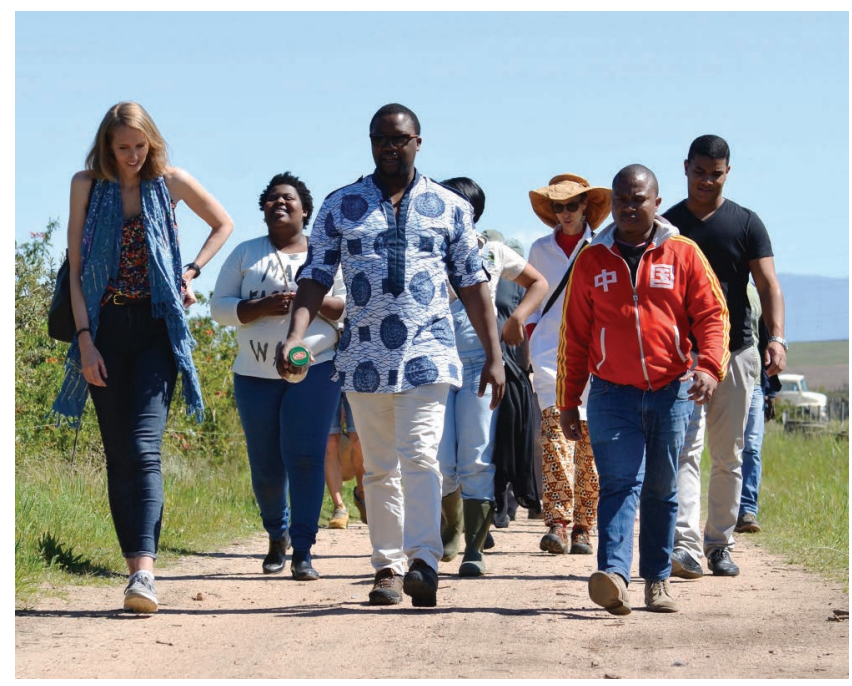

FIGURE 18.3 Participants walking up the farm track to the entrance of the field. (Image credit: Eva van Niekerk.) 


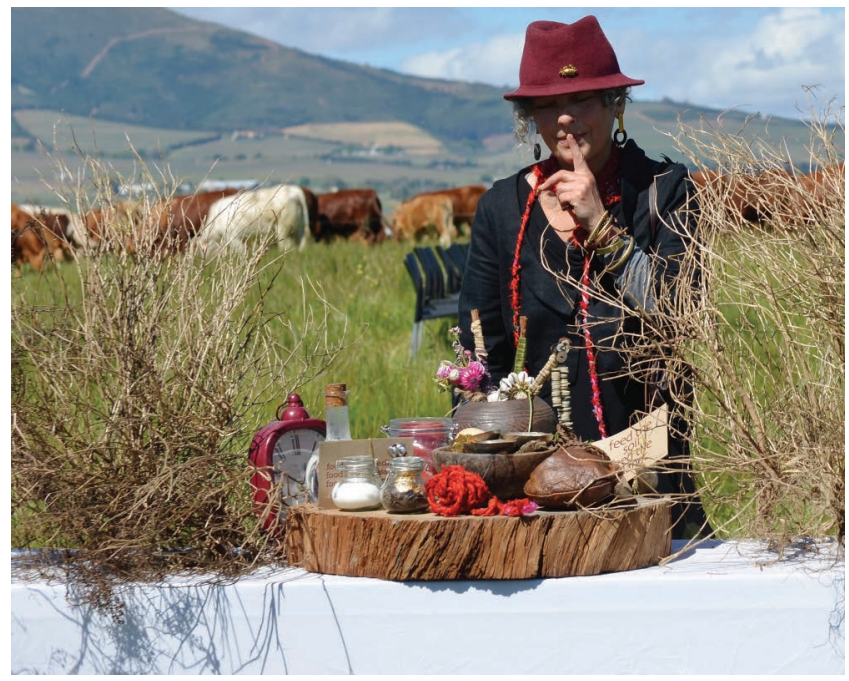

FIGURE 18.4 The field shrine to FieldTable. (Image credit: Eva van Niekerk.)

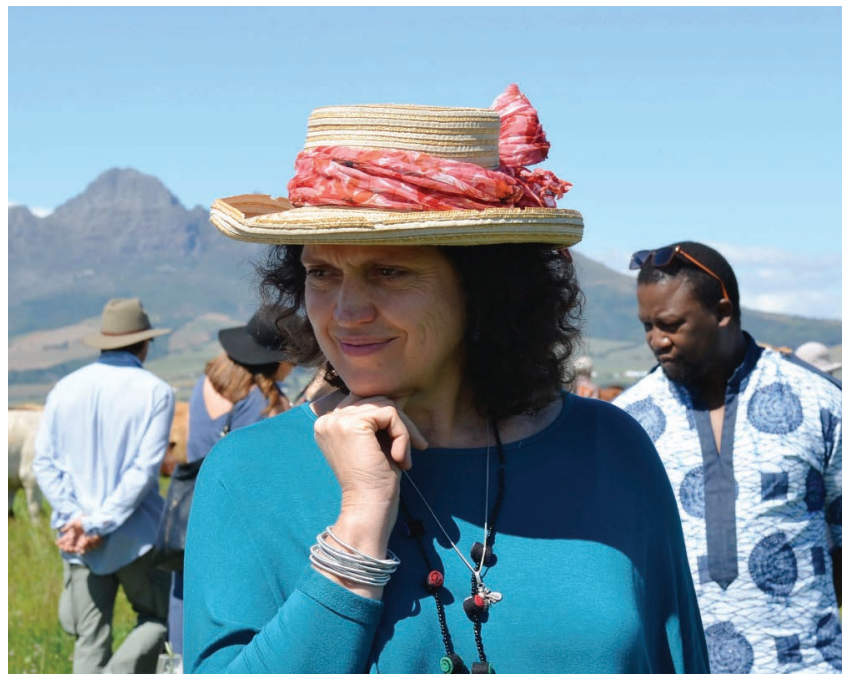

FIGURE 18.5 Being in silence to encounter the genius loci, the grazing cattle and the table of food. (Image credit: Eva van Niekerk.) 


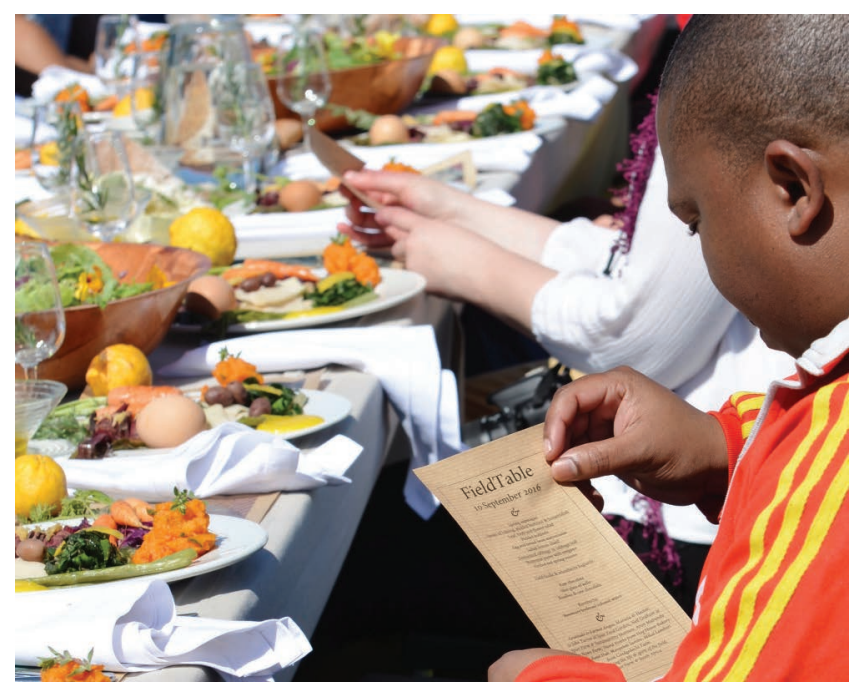

FIGURE 18.6 Reading FieldTable menu of dishes from the season's bounty. (Image credit: Eva van Niekerk.)

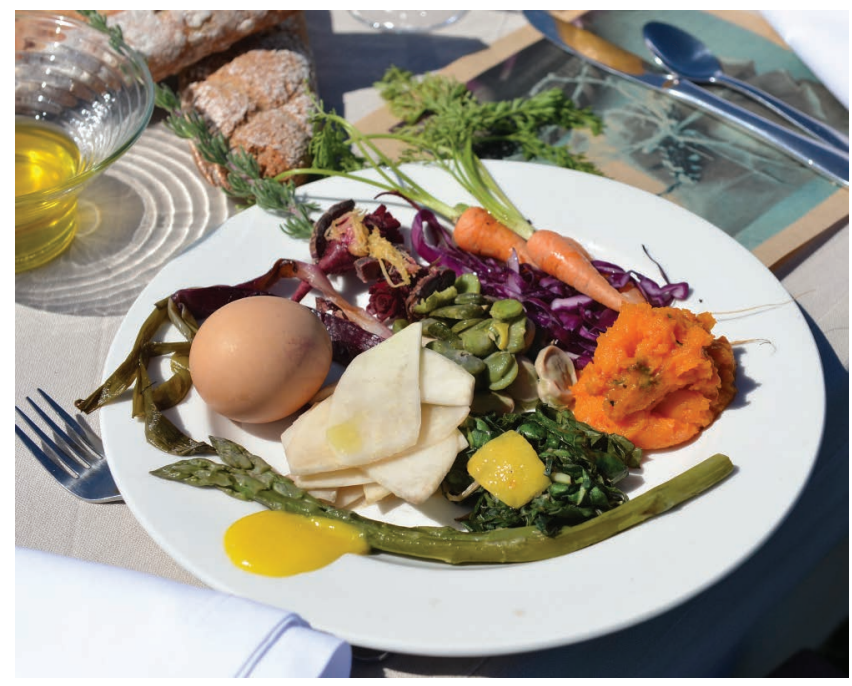

FIGURE 18.7 A plate of locally and naturally grown 'bare awakening food' composed of: poached asparagus; brochettes of biltong, pickled beetroot and horseradish paste; marinated kohlrabi; broad beans with freshly made mayonnaise; salted lemon chard; fermented cabbage; butternut squash puree with oregano; grilled red spring onions; raw whole carrot and boiled egg in shell. (Image credit: Eva van Niekerk.) 


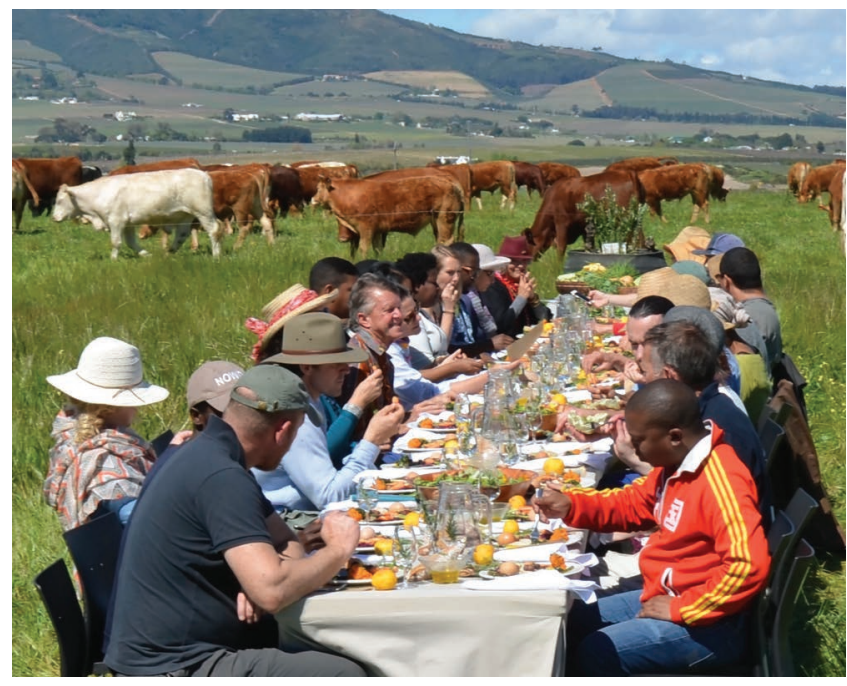

FIGURE 18.8 Participants conversing at FieldTable. (Image credit: Eva van Niekerk.)

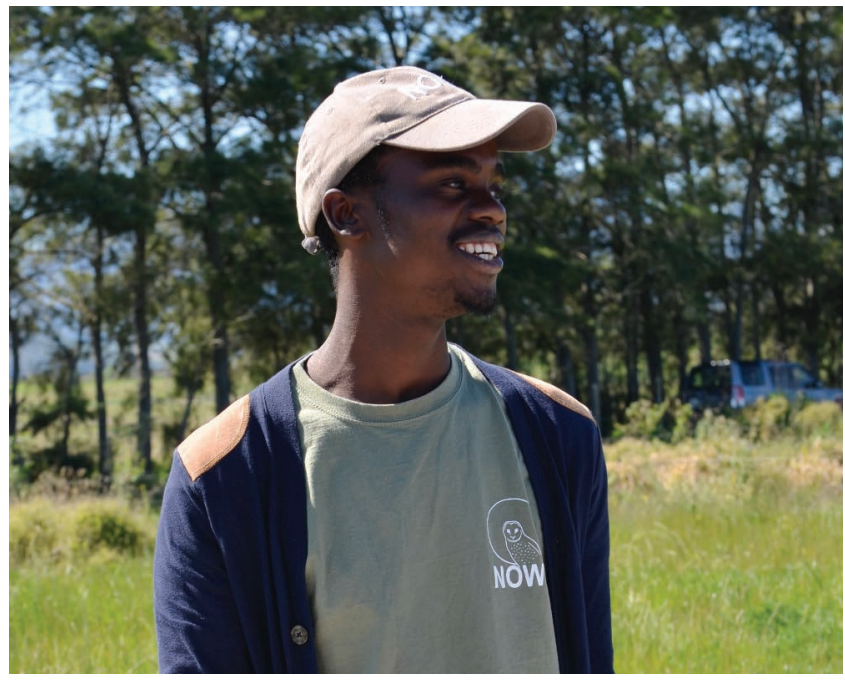

FIGURE 18.9 A young farmer sharing his passions and aspirations for change. (Image credit: Eva van Niekerk.) 


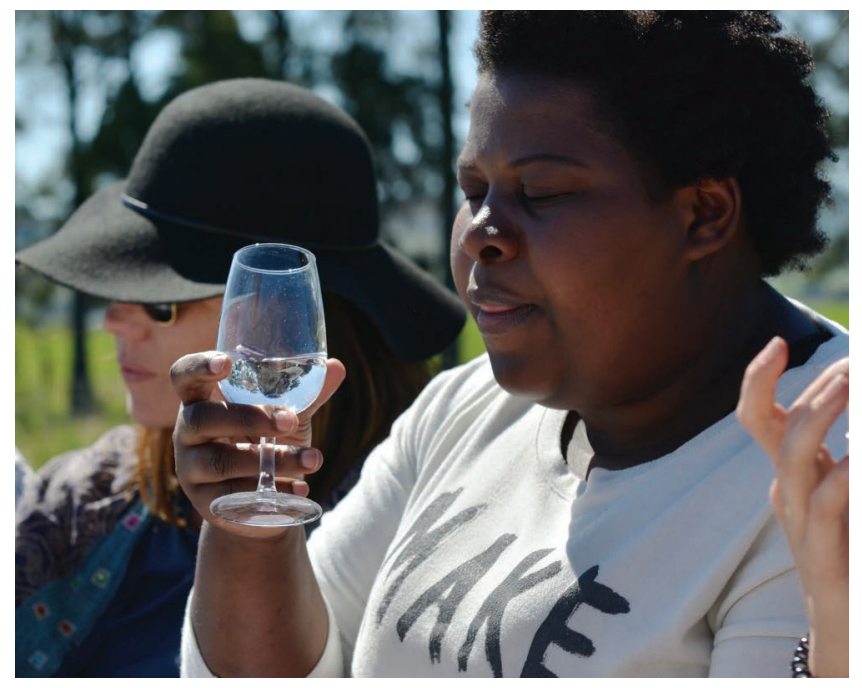

FIGURE 18.10 Tasting rosemary-infused water. (Image credit: Eva van Niekerk.)

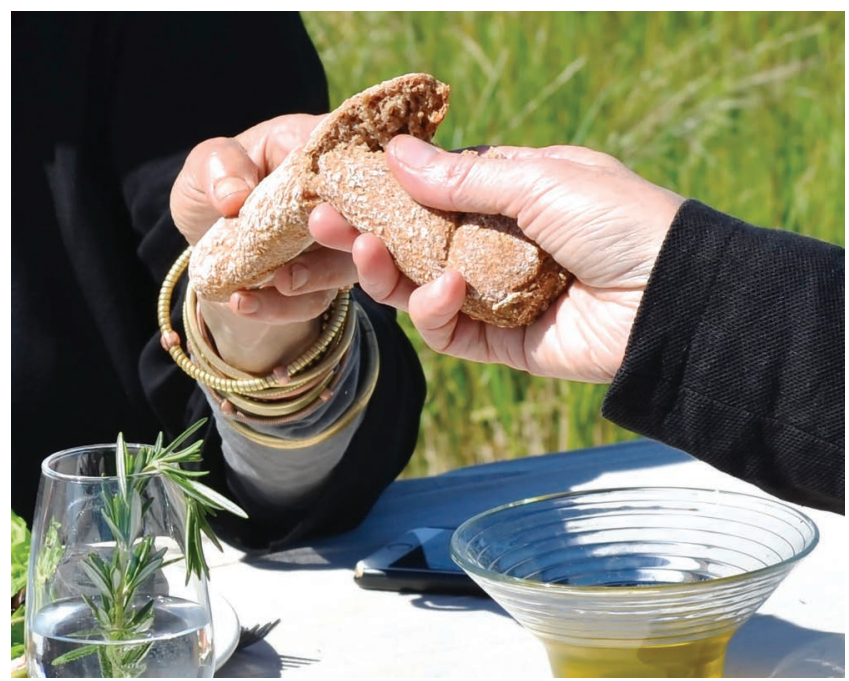

FIGURE 18.11 Breaking bread as a gesture of companionship. (Image credit: Eva van Niekerk.) 


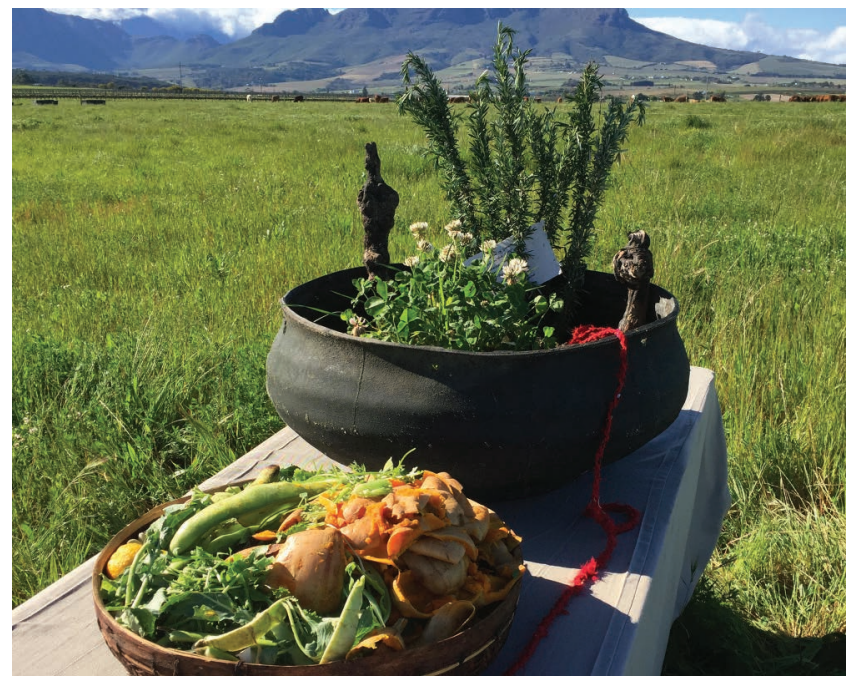

FIGURE 18.12 Soil Shrine making visible examples of natural methods for increasing soil fertility through composting foodwaste and growing clover as a nitrogen-fixing plant. The sprigs of rosemary call us into remembrance. (Image credit: Eva van Niekerk.)

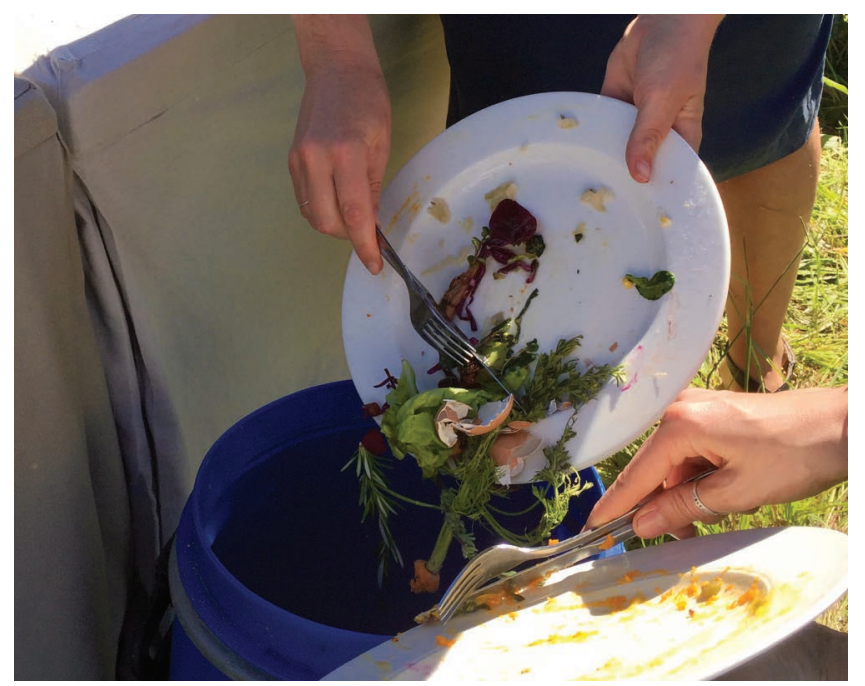

FIGURE 18.13 Leftover food emptied into a bokashi bin. This Japanese fermentation method prepares foodwaste to become a natural fertiliser for soil regeneration. (Image credit: Eva van Niekerk.) 


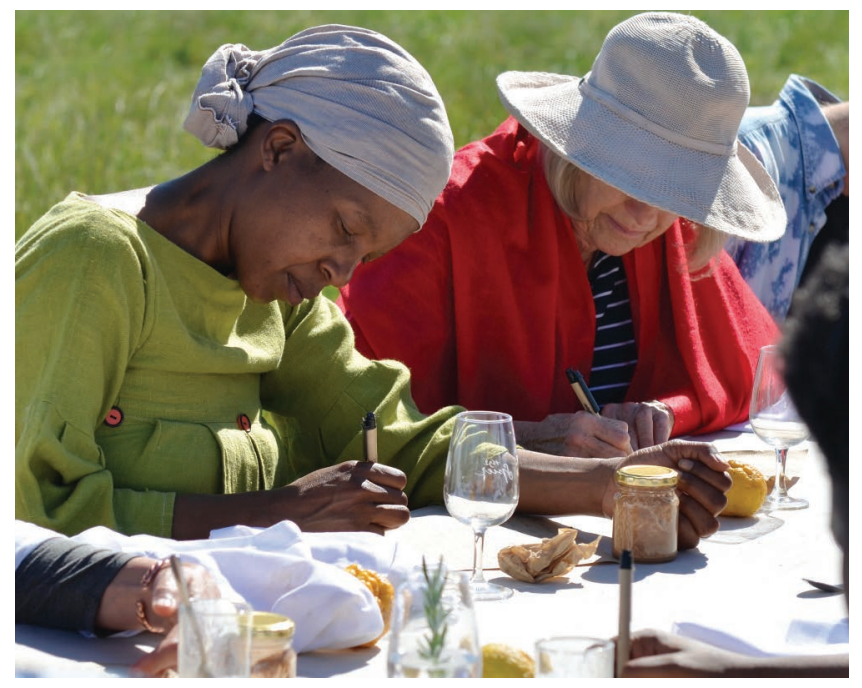

FIGURE 18.14 At the end of the meal, participants write about their experiences of FieldTable and reflect on how their hunger has been satisfied. (Image credit: Eva van Niekerk.)

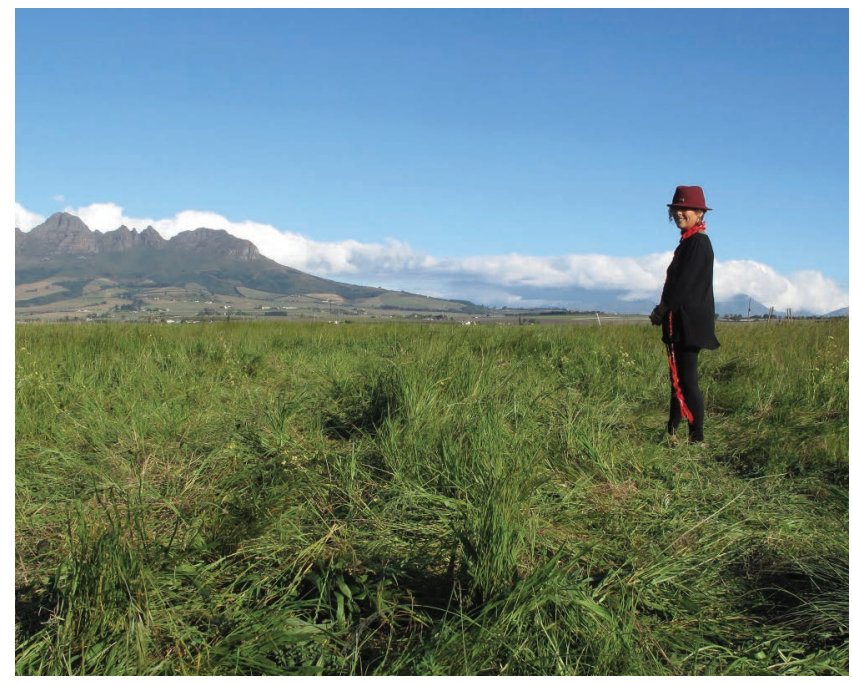

FIGURE 18.15 FieldTable was set up and completed in a day. (Image credit: Touchstones.) 


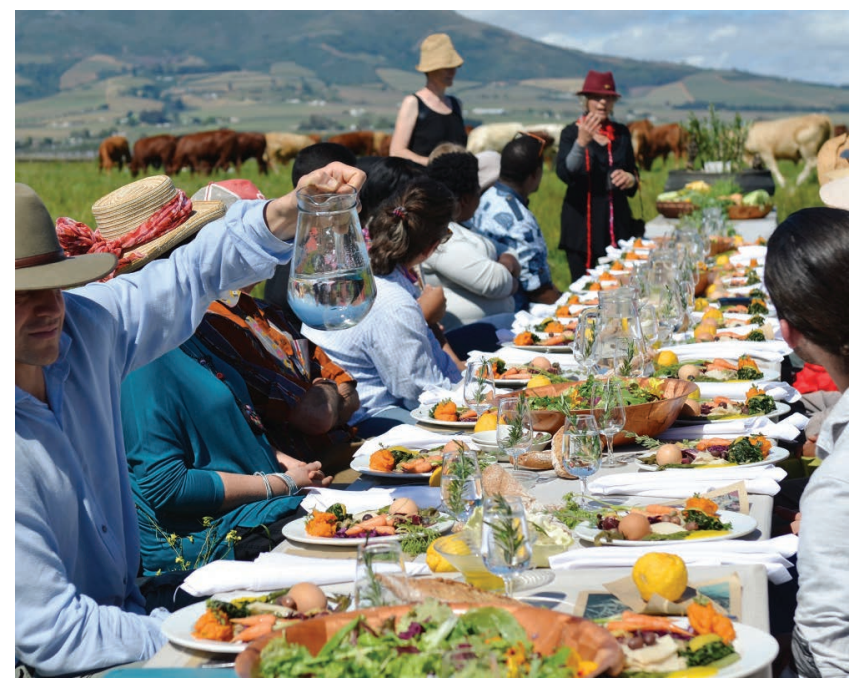

FIGURE 18.16 FieldTable manifests in 2016 as a convivial, local and agroecological narrative to counter the 1976 Union Carbide advert promising synthetic and genetically modified solutions to world hunger. (Image credit: Eva van Niekerk.)

\section{CULTIVATING SYMPOIETHICS}

The food ritual FieldTable responds to Merleau-Ponty's call to artists to 'awaken the experiences which will make the idea take root in the consciousness of others' (Merleau-Ponty, 1945: 8). As a ritual and an edible intervention, FieldTable emerged through relationships between people, matter and the habitats of place. By making visible the abundance and natural fertility of regenerative farming methods through its local harvests of colourful, seasonal produce, and the health of well-reared animals, FieldTable was a space for awakening, inhabiting and re-imagining agroecological futures for the region. As noted above, during the ritual, two questions were asked: at the start of the meal, 'What are you hungry for'? and, at the end, 'How has your hunger been satisfied'? Here follows a selection of participants' responses which shares the diversity of perspectives from women and men of different occupations, ages, cultural heritages and ethnic communities.

The return of the sacred to the table has created time, space

and thinking partners to look at this hunger,

to imagine its voice, its sounds, its texture, its feeling and

find out how to hear it, how to respond to it.

Understanding what my belly inherently needs and wants

to be fully nourished - re-awakening intuition.

I am starving for revolution to our food systems. Starving to see farmers doing away with the systems that harm the mother earth. I want food to be accessible to everyone because food is life.

This is my love for life, my sanctuary, my home.

A sense of freedom, a chance to engage.

A society where diversity is treasured, where food is not wasted;

where Nature becomes and is the most revered

or 'desirable' thing, asset, goal; where food and conversation serve

to respect the farmer, the cook, the soil, and ourselves.

I am searching for beauty ... a new beauty.

A beauty that emerges when time is taken to appreciate and experience

and rediscover what feeds our soul and what we need to do

in order to build resilience to the true challenges of today.

You are re-igniting culture and coming back to what it means to be community ... community along the lines of land and food. 
Under culture you get ritual and agriculture,

it felt literally like what it means to be going back to being human

I hunger to be part of a community that holds at the centre,

so it can hold me, remind me when I get lost in my 'busy-ness',

when I forget about the sacred ... be present

where I can hold this space for other beings, all beings.

Deep changes are, more often than not, slow gradual processes that seem so natural that we hardly notice they are even happening, like the cultural changes taking place beneath the soil, in our guts, and at our tables. I'm hungry for change.

I understand collaboration of life-giving and not life-taking.

The creation of living community in that time and space

helped create a collective mindset to preserve

and create energy that is positive.

Let's go to the townships with this. Because in the townships, we do get to reach people who are practicing organic gardening,

who are using indigenous knowledge to produce.

These reflections from participants document how FieldTable enlivened ways of coming to know through the interrelationship between themselves and the animate matter of life. Within the liminal space of this food ritual as refugia, our human capacity for naturecultural thinking and being-with was enlivened through personal and collective intra-actions with food, artefacts and substances. Their words speak of a longing for more sensuous experiences, for expansive conversations and for regenerative cultural and agricultural practices that foster life-giving interconnectedness between the personal body, the collective body and the body of land. In an exchange with Flora, Miche reflects on the significance of naturecultural rituals within agriculture and explores how FieldTable contributes to such a recovery of the 'cultural evolutionary potential' of ritual (Turner, 1985: 165):

For us humans to be discovering what it means to be truly here is to reconnect with embodied knowing. Being in a continuous relationship with the matter and processes of life is what makes us natureculture creatures: our lifeblood, our life capacity and our consciousness comes from continuous interaction and relationships through our bodies with the dynamic flow of the cosmos. Being in touch with, noticing more, with spaciousness and focus, is what ritual allows, a space and time for attuning and attending through our bodyminds with the living processes of the Earth. It also gives a great sense of joy to be in a ritual that is respecting the self and the collective within the naturalcultural. Ritual connects us to the life force.

Conversation Exchange between Miche and Flora (5 June 2020).

FieldTable offered a taste of the catalytic power of the life force of exousiance which Salami identifies as a stimulus of energy and will for change. FieldTable was a threshold space, a naturecultural refugium for people to experience their bodyminds, within communitas, as an instrument of participatory and political consciousness in a relationship with the biodiversity of the land. Encounters with each other and the matter of food within this contemporary ritual form generated new thoughts, openings and actions. The initiatives emerging from FieldTable were wide-ranging and continue to unfold, and include: the commission of a large-scale FieldTable artwork for the farm office; the impulse to create the infrastructure for food sharing with staff at the farm where FieldTable took place; the Sustainability Institute linking to a local cooperative food hub and creating food citizen lunches from the food garden and a follow up Agroecology Ndaba forum exploring agroecological training with educators, students farmers, food activists and policymakers. Daryl Jacobs, Deputy Director at Elsenburg Agricultural Training College reflected on the role of food and soil rituals as offering transformative experiences of nature-based farming for young trainee farmers:

What I value and treasure is the real deepened transformation ... your healing of soul and soil. It emphasises that we are part of one system, but unless we transform our thoughts processes from deep within, from the soul, it will be superficial. 
Naturecultural food rituals as refugia are a reminder of how our human response-abilities are intimately entangled with interdependence. This relational way of knowing is embraced by the concept of 'sympoiethics' where our artful bodyminds become the divining instrument for enculturing art and ethics as a practice of life. Miche expands on her concept of 'sympoiethics' in a conversation with Flora;

Human existence is lived through and within a dynamic nexus of living processes. Human oppression is intertwined with the degradation of the Earth. Authentic human flourishing emerges through restoring an ethos where the dignity of selfhood is interwoven with a respect for place and care for our sentient, multispecies Earth. A sympoiethics combines sympoieisis with ethics. Ethics, rooted in ethos, defines dwelling places where we come to know together through place-based relationships

Exchange between Miche and Flora (April 2020)

\section{CONCLUSION}

The Buddha's enlightenment under the Bodhi tree symbolises how our human existence flourishes through our care for each other and the Earth. Consciousness and knowing arise through embodied encounters with naturecultures which call for us to notice and value the body's multiple intelligences and the subtle energies which surround us (Fabre Lewin, 2012). A sympoiethics awakens us, with and through our bodyminds, to emancipatory practices and reciprocal responsibilities for living, loving, thinking, being and acting in ways that are equitable and responsive to our co-dependent existence (Fabre Lewin, 2019). Naturecultural food rituals create the conditions to enliven our ecological selfhood through an authentic relationship with food - experiential rituals as refugia which are practices for transitioning towards a participatory world view and a politics of consciousness. It is within this nexus that food is a changemaker with its role in reorienting the matter of our thinking, reshaping our landscapes and reconfiguring our responseabilities as humans within the geography of our planet. In co-creating naturecultural rituals, we are reviving thinking-feeling practices that respect each other's embodied knowing, attend to the voice of nature and cultivate a sympoiethics that draws its life-affirming power from our caring for and becoming-with the living Earth.

\section{ACKNOWLEDGEMENTS}

Gratitude to all beings who have been in generous collaboration with, contribution to and enlivening of the evolution and manifestation of FieldTable.

\section{REFERENCES}

Abram, D. (2010) Becoming Animal: An Earthly Cosmology. New York: Vintage Books.

Apffel-Marglin, F. (2011) Subversive Spiritualities: How Rituals Enact the World. Oxford: Oxford University Press.

Ballantyne-Brodie, E. (2018) 'Designing convivial food systems in everyday life'. Paper presented at ServDes2018 - Service Design Proof of Concept, School of Design, Politecnuio di Milano, Available online https://ep.liu.se/ecp/150/086/ecp18150086.pdf [Accessed 15.3.2021].

Barad, K. (2012) 'Interview with Karen Barad: Matter feels, converses, suffers, desires, yearns and remembers'. In Dolphijn, R. and Van der Tuin, I. (eds), New Materialism: Interviews and Cartographies, pp. 44-70. Michigan: Open Humanities Press.

Barthel, S., Crumley, C., and Svedin, U. (2013) 'Bio-culturalrRefugia: Safeguarding diversity of practices for food security and biodiversity.' Global Environmental Change 23: 1142-1152.

Berry, W. (1993) Standing on Earth. Ipswich: Golgonooza Press.

Berry, T. (2006) Evening Thoughts: Reflecting on Earth as Sacred Community. San Francisco: Sierra.

Charlton, N. (2008) Understanding Gregory Bateson: Mind, beauty, and the sacred Earth. New York: SUNY series in Environmental Philosophy and Ethics.

Curtin, D. (1992) 'Recipes for values'. In Curtin, D. and Heldke, L. Bloomington (eds), Cooking, Eating, Thinking: Transformative Philosophies of Food. Indianapolis, IN: Indiana University Press. 
Dempster, B. (2000) 'Sympoietic and autopoietic systems: A new distinction for self- organizing systems', available online from http://www.isss.org/2000meet/papers/20133.pdf.

Fabre Lewin, M. (2012) 'Liberation and the art of embodiment'. In Hogan, S. (ed.), Revisiting Feminist Approaches to Art Therapy, pp. 15-124. London: Bergahn.

Fabre Lewin, M. (2019) Artful bodymind: Enlivening transformative research methodologies. PhD Manuscript, available online at www.touchstones.earth.

Fox, M. and Sheldrake, R. (1996) Natural Grace: Dialogues on Science and Spirituality. London: Doubleday.

Gablik, S. (1992) Connective aesthetics. American Art 1(2): 2-7.

Grimes, R. (2015) Ritual studies: Practicing the craft. Available online: https://humanitiesfutures.org/papers/ ritual-studies-practicing-the-craft/ [accessed July 18th 2019].

Haley, D. (2016) A question of values: Art, ecology and the natural order of things. In Demos, T. (ed.), Elemental: An Arts and Ecology Reader, pp. 41-62. Manchester: Gaia Project Press.

Haraway, D. (2015) Anthropocene, Capitalocene, Plantationocene, Chthulucene: Making Kin. Environmental Humanities 6: 159-165.

Haraway, D. (2016) Staying with the Trouble. London: Duke University Press.

Haraway, D. (2017) Symbiogenesis, sympoiesis, and art-science activisms for staying with the trouble. In Tsing, A., Swanson, H., Gan, E., and Busbandt, N. (eds) Arts of Living on a Damaged Planet. London: University of Minnesota Press, M35-M50.

Haley, D. (2016) A question of values: Art, ecology and the natural order of things. In: Demos T. J. (ed.) Elemental: An arts and ecology reader. Manchester: Gaia Project Press.

Ho, M. (2008) The Rainbow and the Worm: The Physics of Organisms. London: World Scientific Publishing.

Illich, I. (2001) Tools for Conviviality. London: Marion Boyars.

Laszlo, E. (1996) Manifesto on planetary consciousness. Paper adopted by the Club of Budapest on 26 October 2016. Available online: www.issuu.com/exopolitika/docs/the_manifesto_on_planetary_consciousness [accessed May 12th 2015].

Lemke, H. (2007) The extended art of eating: Joseph Beuys' unknown gastrosophy'. In SANSAI: An Environmental Journal for the Global Community, 2: 53-65.

Macy, J. (1991) World as Lover, World as Self. Berkeley: Parallax Press.

Mathews, F. (2003) For the Love of Matter: A Contemporary Pansychism. Albany: State University of New York Press.

Maturana, H. R. and Varela, F. (1980) Autopoiesis and Cognition: The Realization of the Living. Dordrecht, Holland: D. Reidel Publishing Company.

Menaken, R. (2020) 'Notice the rage; notice the silence' Online interview with Krista Tippett. Available online: https://onbeing.org/programs/resmaa-menakem-notice-the-rage-notice-the-silence/.

Merleau-Ponty, M. (1945) Cezanne's doubt. Available online: www.//faculty.uml.edu/rinnis/cezannedoubt.pdf [10 August 2016].

Puig de la Bellacasa, M. (2017) Matters of Care: Speculative Ethics in More Than Human Worlds. London: University of Minneapolis Press.

Roszak, T. (1977) Person/Planet: The Creative Disintegration of Industrial Society. Lincoln: i- Universe.

Ryan, K., Myers, N., and Jones, R. (eds) (2016) Rethinking Ethos: A Feminist Ecological Approach to Rhetoric. Carbondale: Southern Illinois Press.

Salami, M. Exousiance: A black feminist vision of power and nature. Available online: http://www.whatisemerging.com/opinions/exousiance-a-black-feminist-vision-of-power-and-nature-7c08ddb2-d336-4885add4-be8aca6a376e (accessed August 1st 2020).

Scientific American (1976) 'Future of Agriculture'. Volume 235 Issue 3.

Some, M. P. (1998) The Healing Wisdom of Africa: Finding Life Purpose through Nature, Ritual and Community. New York: Tarcher Putnam.

Steel, C. (2008) Hungry City: How Food Shapes Our Lives. New York: Random House.

Thomas, E. (2000) The Life of Buddha as Legend and History. New York: Dover Publications.

Tsing, A., Swanson, H., Gan, E. and Busbandt, N. (eds) (2017) Arts of Living on a Damaged Planet. London: University of Minnesota Press.

Turner, V. (1969) The Ritual Process: Structure and Anti-Structure. London: Transaction Publishers.

Turner, V. (1985) Liminality, Kabbalah, and the Media. London: Academic Press.

Van Gennep, A. (1960) The Rites of Passage. Chicago, IL: University of Chicago Press.

Weber, A. (2019) Enlivenment: Towards a Poetics for the Anthropocene. London: MIT Press.

Weiwei, I. (2020) Weiweisms. Available online at https://aiweiweihumanity.com/weiweisms/ [accessed May 3rd 2020]. 


\title{
19 The Systemic Constellations Method Applied to Agriculture
}

\author{
Melissa Roussopoulos \\ Forgotten Connections
}

\section{CONTENTS}

Introduction 219

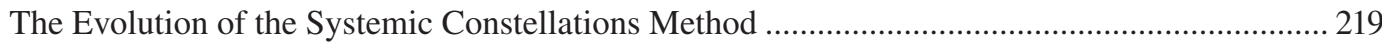

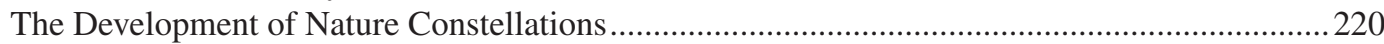

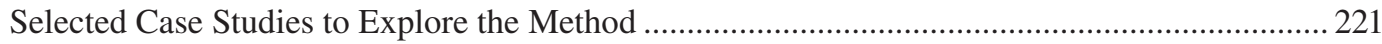

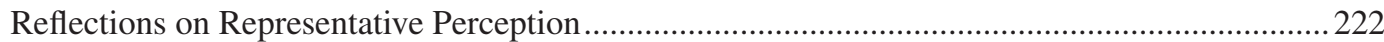

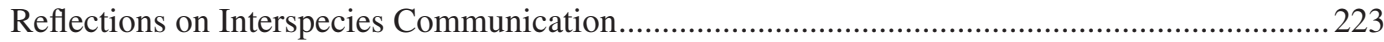

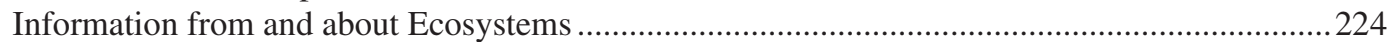

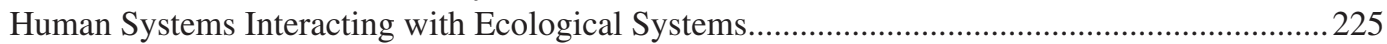

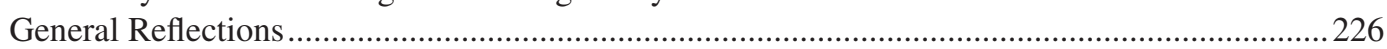

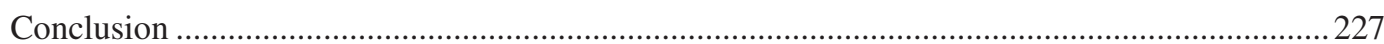

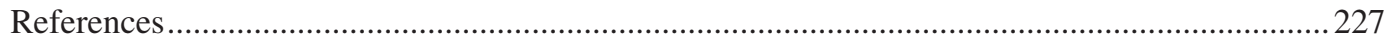

\section{INTRODUCTION}

Systemic Constellations is an experiential group methodology that reveals the usually invisible dynamics of complex systems. This essay charts its evolution into a series of forms that have successfully provided insights and solutions in a range of professional fields. Most recently, it has been applied to systems which include animals, plants and various components of ecosystems.

Research by the author is presented through case studies to illustrate this application and explore the questions it raises, in particular whether the information that emerges is coming from other-than-humans. The evidence strongly suggests that it is, and further case studies demonstrate ways in which the method can be of value within agriculture.

\section{THE EVOLUTION OF THE SYSTEMIC CONSTELLATIONS METHOD}

The method was developed by Bert Hellinger in Germany to help clients resolve their personal issues. He was trained in various Western therapeutic modalities and was also influenced by the indigenous knowledge and understanding of the Zulu people, having spent 16 years among them in South Africa (Franke, 2003).

A trained facilitator (the Constellator) would address a client's issue in a workshop setting with a group of people who were not related to the client. This process was called a 'Constellation' and it began with the Constellator interviewing the client to identify the individuals in the client's family who might be relevant to his/her issue. The client would then choose individuals from the present group to 'represent' these family members. These 'representatives' (reps) were then intuitively positioned by the client to stand in specific places in the room. From wherever they were placed, the reps would describe what they felt in their bodies, their emotional state and their relationships with the other reps.

The author's first experience as a rep was in 2000, when a client invited her to represent her sister. She was positioned among five or six other reps, and then suddenly found herself intensely angry, 
specifically with a male rep standing about $2 \mathrm{~m}$ behind her. She had never met the man being the rep before, nor did she know which family member he was representing. Intensely surprised by the strength of the anger, as well as the fact that she was feeling it, she reported it to the Constellator. He told her that this was the kind of information they were looking for, then the client revealed that the man the author was angry with was representing her father and 'my sister hates my father'.

Hellinger had discovered that reps, who had no previous knowledge of the client or of his/her family, reported information which was accurate for the member of the family they were representing. He could not explain this phenomenon, called 'representative perception', but he observed that it took place consistently.

The initial positioning of the reps was found to reflect the current dynamics between the family members. The Constellator would then facilitate a process during which reps moved or spoke. The other reps reported how these actions impacted them and, over a long period of experimentation, what emerged were repeating patterns in the experiences of the reps. From these, as well as family therapeutic understanding, interventions were developed to support the healthier functioning of family systems. Through these, the clients' issues would be resolved.

This first form of Constellations emerging in the 1990s became known as 'Family Constellations'. It identified two foundational elements on which all subsequent evolutions of Systemic Constellations (the generic term) are based. The first is the use of representative perception as a consistent and valid way to access information. The second is the understanding that individuals are profoundly influenced by the systems of which they are a part. Individuals inevitably belong within their family systems, but they are also part of the organisational systems where they work, the social and cultural systems within which they live and the natural systems which sustain them.

By the mid 1990s, the Constellations methodology was being applied to organisational systems (Organisational Constellations). Workshops took the same format with clients, a Constellator and a group, but the issues were professional and the reps took roles not only as other people, but also as internal teams, the whole organisation, its customers or even abstract concepts such as 'purpose'. As before, reps would experience sensations in their bodies and feelings about the other reps. Crucially, their experiences made sense in the context and led to insights and solutions. Organisational Constellators identified interventions that supported organisational systems to thrive and the method proved successful for companies such as Daimler-Chrysler, IBM and BMW (Horn and Brick, 2009).

In 2004, the International Forum for System Constellations in Organisations (infosyon) was founded in Germany, developing quality standards, training standards and a code of conduct. Along with certifying facilitators and training courses, the Forum supports ongoing interdisciplinary research and development into the method. Some of the many theses written about Organisational Constellations can be found on its website ${ }^{1}$ and it has links to a group of professors and lecturers who are researching and using the method within European universities. The Forum's most recent bi-annual conference in 2018 attracted participants from 18 countries. ${ }^{2}$

Beyond family and organisational systems, Constellators have been developing the method for use in a range of fields including politics, drug rehabilitation, education and prisons. Many academic papers and books now exist on these topics; Constellations conferences have taken place throughout Europe, in North and South America, Australia and South Africa; and there are trainings and professional bodies in a number of countries.

\section{THE DEVELOPMENT OF NATURE CONSTELLATIONS}

In 2003, the author, an environmentalist by background, witnessed an Organisational Constellation which indicated that the methodology might be able to help with environmental questions. She trained in Organisational and Family Constellations and then held a post researching the application

\footnotetext{
${ }^{1}$ www.infosyon.com.

2 Personal communication with Katrina Barry, Chairperson of infosyon, November 2019.
} 
of Constellations in different professional fields. Through facilitating exploratory Constellations on a range of issues involving human and ecological systems, she developed her approach. Over a similar period, an international group of Constellators began to explore using Systemic Constellations with nature. They conducted experiential research in many domains including: domesticated animals, forest management, the healing properties of plants and international environmental issues (Mason Boring, 2007). The first book about what have come to be known as Nature Constellations (NCs) features 14 practitioners working in 5 countries, the common thread being the inclusion of other-than-humans in their Constellations (Mason Boring and Sloan, 2013).

\section{SELECTED CASE STUDIES TO EXPLORE THE METHOD}

Since 2014, and inspired by collaborations with academics in the agricultural sector, the author has been formally researching some of the NCs she facilitates: obtaining informed consent, audio recording NCs and interviewing clients afterwards to track the impacts. Case studies from this work are presented below to illustrate the method, investigate the questions it raises and assess its potential to address agroecological issues. (Unless otherwise stated, all NCs described were run by the author and names have been changed.)

\section{Case Study 1: A Home for a Horse}

Phoebe and her mother owned and cared for a horse, Mascot. When her mother died, Phoebe had to choose where Mascot would live. At the time he was staying with a woman who kept him as a companion for her own horse, but Phoebe felt she would be letting her mother down if she did not look after Mascot herself. She undertook a NC to help her decide.

Phoebe chose a rep to be Mascot and he reported that he felt pain in his right wrist. When she set up a rep for herself (P), P described having a heavy, burdened feeling in their belly area. When $\mathrm{P}$ tested how it would be to have Mascot living with her, as an option within the NC, P burst into tears saying 'I'm in crisis, I can't take on any more'. At some point Mascot's rep said 'I want to be with other horses'.

The best outcome was shown to be for Mascot to be with another horse and not living with Phoebe. Attention was also paid to Phoebe's feelings of letting her mother down and to resolving these.

During the follow-up interview, Phoebe revealed that she had been sceptical about the method to start with. Thus, when Mascot's rep had reported pain in his right wrist, she had been shocked. Mascot had navicular syndrome, a degenerative disease in his right front fetlock - equivalent to where the rep had experienced pain in his body - and Phoebe had not said anything about this to the group. For Phoebe, this was an 'a-ha' moment and helped her to trust what was unfolding. It also transpired that Phoebe had a medical condition in her belly (also unmentioned), the same area her rep had felt heavy and burdened.

At the time of the NC, Phoebe was caring for various members of her family and was not well herself. Had Mascot been moved to live with her, it would have added a considerable burden in terms of time and energy, particularly as she would have had to take on a second horse to keep him company. Phoebe later explained that she has a strong tendency to take on too much responsibility, without realising the negative impacts on herself: 'so it was very powerful to see someone representing me go in and just have a complete melt down and say "I can't cope".

Phoebe reported that the NC had helped her decide to keep Mascot where he was and 'I... stopped beating myself up about the horse being with someone else'. Five years later, she is clear that her life has been easier through not having had to look after him and Mascot is thriving with his caretaker and horse companion. 


\section{REFLECTIONS ON REPRESENTATIVE PERCEPTION}

On learning how reps spontaneously experience body sensations, emotions or just 'know things' relevant to their roles, people often question if it is really happening. The best way to answer this question is to directly experience it. While case studies can describe it, and the entire Constellations field attests to it, any written account of representative perception falls short of the actual experience. A participant at a NC workshop in 2012 described representing for the first time: 'I found it amazing how easy it was to tune into non-human consciousness in a whole-body experience and for it to be so obvious that I was not making up or imagining the experiences I was having'.

The next question is usually to ask how it could be happening. In 2006, the author identified a number of potential scientific explanations (Roussopoulos, 2006) and since then advances in consciousness studies, science and cosmology have led to more integrated and complete explanations (Laszlo et al., 2016). However, representative perception has successfully underpinned Systemic Constellations for decades without practitioners knowing how it works.

The author holds that the most important question for agricultural applications of NCs is to ask where the information is coming from. If the data about the human/ecological system in question originates, consciously or unconsciously, solely from the client or holding group, it is merely someone's belief, or at best second-hand information. Two phenomena have been observed in all forms of Systemic Constellations which indicate that reps may be picking up their data directly from the beings they are representing. The first is when information emerges in a Constellation which no-one present knows about and which is subsequently proven to be accurate. The second is when something spontaneously changes in the system being represented, in line with what happened within the Constellation, but where there has been no contact between the people present at the Constellation and the beings in the actual system. The next two case studies illustrate these phenomena taking place in NCs.

\section{Case Study 2: Struggling Cabbages}

Laura wanted to know what she could add to the soil to support the health of her cabbages. A female rep for the cabbages $(\mathrm{C})$ initially reported that her roots needed to be stronger and that she felt vulnerable to being nibbled. C's body was leaning over, her top half moving in circles around her torso as if her head were very heavy. She would go down, then just about manage to pull herself up. Laura, watching from the sidelines, commented that perhaps the cabbages had not had time to grow good roots and she was concerned that the rep, C, would fall over. Laura could have added manure, lime or biodynamic preparations to the soil, so reps were brought in for each of these options. C experienced a jolt when the biodynamic preparations came in, and then found that the manure felt better to her. However, only the presence of lime stabilised her movement.

Not long after the NC Laura contacted the author, very excited - she had just uncovered her cabbages, which had been under fleece for the previous 4-5 months. They were a type of cabbage that would usually stand upright with their heads on stalks about six inches high. She had been expecting to find small, under developed heads, instead of which: 'to my utter amazement... they had actually grown so enormous that they couldn't hold their own weight on the stalks... they had toppled... I've never seen them fall over before... so it completely reflected what the representative was doing'.

Neither Laura, nor anyone else in the group, had known the state of her cabbages when she did the NC. The behaviour of rep C - leaning over with a heavy head - accurately mirrored the heavy heads of the actual cabbages. Also, as such big heads were unusual, Laura had not anticipated them. The 
information revealed through rep $\mathrm{C}$ could not have come from Laura or the group, consciously or unconsciously.

\section{Case Study 3: A Traumatised Dog}

In October 2016, an incredibly friendly, mainly Fox Terrier mongrel, Tommy, witnessed his owner being killed. Tommy continued to live in the same home as before with his owner's partner, Paul, but his behaviour totally changed. He became extremely clingy and demanding, unable to tolerate being left alone. In March 2017, Paul did a short NC about Tommy. Five days later he wrote: 'When I got home, late evening, Tommy greeted me in a sedate and very peaceful manner. Having been locked up in the house all day, he would normally go ballistic. It was astounding how different he was. What is more, he has been much calmer with me since'.

Perhaps being left alone all day had somehow cured the dog, but when questioned about this during a follow-up interview, Paul felt that this was unlikely because Tommy had never enjoyed being alone. Another possibility was that, on his return, Paul had behaved differently to Tommy, which is why Tommy's response had changed. Paul, however, insisted that his own behaviour had not altered and was convinced that the NC was responsible for the healing in Tommy. Five months later, Paul reported that Tommy had never reverted to his previous extremely anxious behaviour.

There is thus the possibility that the NC itself impacted Tommy as it took place, which suggests a connection between the rep for Tommy, or some other aspect of the NC, and Tommy himself.

\section{REFLECTIONS ON INTERSPECIES COMMUNICATION}

While the two case studies above do not prove that the reps' information comes from the other-than-humans being represented, Nature Constellators' consistent and extensive experiences lead them to believe that it does. In addition, the multiple case studies demonstrating the success of the NCs method make it probable (Mason Boring and Sloan, 2013; Roussopoulos, 2018).

In the author's opinion, a NC involves the human reps in the Constellation connecting directly with the actual humans and other-than-humans who are being represented. This would mean that NCs facilitate distant two-way communication between humans and other-than-humans, a proposition generally considered impossible within mainstream western culture and academia.

M. J. Barratt, Assistant Professor at the University of Saskatchewan, observes that the existence of communications from other-than-humans is 'acknowledged and experienced by many, both Indigenous and non-Indigenous' (Barratt, 2011: 125). In her opinion, these communications are downplayed within academia, which considers rationality and the intellect to be the primary, if not the only, valid ways of knowing. Animistic methods of research, on the other hand, validate the body as capable of receiving information and create spaces "where the "voices" of other-than-human "persons" (in their many forms) can be heard' (Barratt, 2011: 134). Scientific experiments indicate that telepathic interspecies communication is the most likely explanation for certain observed phenomena (Sheldrake and Morgana, 2003) and a few academics are beginning to address how this might work (Erickson, 2011).

The author has listened, formally and informally, to personal accounts of interspecies communications from many people, including farmers, vets, indigenous trackers, a professor of consciousness studies, agricultural researchers, shaman and professional animal communicators. All were certain that they had experienced communication with other-than-humans, be they animals, plants or areas of land. The following case studies describe NCs that are relevant for the agricultural sector and an opportunity to reflect on whether these NCs are indeed a form of interspecies communication. 


\section{INFORMATION FROM AND ABOUT ECOSYSTEMS}

\section{Case Study 4: Bees in the Bush}

Francesca Mason Boring teaches a range of Systemic Constellations forms including NCs. When a $\mathrm{NC}$ reveals information which could have public benefit, she obtains the group's agreement to waive confidentiality so that the learning can be disseminated. Hence, she could report on a NC she facilitated in a coastal community (Mason Boring and Sloan, 2013: 13-14). The NC included a rep for a bee, and Mason Boring became nervous that there was no flower for the bee. The bee's rep told her that he did not need a flower because 'I am very strong when I stand by this bush'. The bush being represented grew in the local area.

Mason Boring shared that she did not understand why the bee did not need a flower, only to discover that someone in the group was a biologist with a specialty in botany. He was astounded by what had happened and was able to explain it. The bush in question had an extremely high protein content. Come spring time, as the bees came to life in that cold region, they could quickly find the most efficient food source through that bush. In Mason Boring's opinion, the NC demonstrated that the bees needed that specific bush. Unfortunately, the bush was considered unattractive and was becoming very rare.

This case study indicates that NCs have the potential to show what other-than-humans need in order to thrive, as well as the inter-relationships between parts of an ecosystem. The botanist's knowledge provided verification that the relationship described was accurate. Since pollinators, such as bees, are crucial to food production, such information could be invaluable for farmers.

\section{Case Study 5: Exploring Beneficial Growing Conditions}

In Greece, a grove of olive trees were getting old and their owner was considering adding animal manure and/or planting leguminous vetches to enrich the soil and hopefully strengthen the trees. She was about to start a NC to check which of these would best support the olives, when one of her employees mentioned that wild asparagus could be another option.

A rep for the olive trees (OT) was positioned and immediately said: 'I feel the roots but something is missing'. A rep for manure (M) was brought in, which made OT feel easier. OT had no response to a rep for the vetches (V), but when a rep for wild asparagus (WA) was brought in, she said: 'I feel better... I feel energy'. Combining WA with M, OT reported 'even better, more energy', however on adding V as well, OT said: 'it's OK but it doesn't make any difference'. She preferred to be without $\mathrm{V}$, while $\mathrm{V}$ reported feeling good but 'I don't feel any attachment to the olive'. OT consistently felt energy when WA was present. The NC indicated that the olive trees' preference was to have wild asparagus planted, as well as livestock manure added.

Afterwards, the employee shared that farmers used to plant olives together with wild asparagus, which she believed was because, in nature, the asparagus was found under olive trees. Neither the owner nor the person representing the olive trees had known this beforehand.

The olive tree rep feeling 'energy' in the presence of wild asparagus could imply a synergistic relationship between the two species, in which each supports the other. At the very least, the NC indicated a compatibility between olive trees and wild asparagus. A few years after this, the author learned of an EU-funded multi-stakeholder project which included development research and promotion of the mixed cropping of wild asparagus in olive orchards. Both species require the same growing conditions and it was found that growing asparagus under the olive trees did not reduce 
the olive yield. Having two crops raised the productivity of the land, requiring few additional inputs other than labour, while helping to protect farmers from extreme crop failure (Rosati, 2017).

On a few other occasions, the author has been able to check generic information about ecosystems learned from NCs against independent research, and each time the data matched, as per the above two case studies.

\section{HUMAN SYSTEMS INTERACTING WITH ECOLOGICAL SYSTEMS}

Farming involves both human and ecological systems and because Constellations always seek the well-being of the whole, both are taken into account. Organisational Constellations (OC) techniques can be brought in to support the organisational aspects of agriculture. OC theory holds that the purpose of any endeavour needs to be clear, appropriate and supported, while OC practices have developed so that activities can be planned over time in alignment with a purpose. These OC approaches were integrated into the series of NCs described below.

\section{Case Study 6: Vineyards Coming into Being}

Fenia had a project to develop 10 ha of mainly fallow land on a Greek island. Fruit, olive trees and aromatic herbs were already growing there, with some processing and selling of the produce. Tourists were staying in restored buildings on the site, however the total income only covered about a third of the maintenance costs. While Fenia was considering a range of income-generating options, she also had a strong desire to listen to the other-than-humans involved in the project.

In 2015, the author worked with Fenia to design a bespoke NCs workshop, both to get clarity about the next steps, and to co-create with nature. A rep for the 10 ha of land (Land) was set up in relation to a rep for Fenia's purpose for the project. Land expressed a strong need to be cultivated, specifically she wanted vineyards 'near the orange groves'. Fenia then revealed that this was exactly the area where vineyards were possible, and where it was likely that vines had been grown in the distant past. When a rep for Fenia's husband came in, it became clear that his priorities were in conflict with Fenia's stated purpose.

Fenia's husband had bought the land, so although Fenia was in charge, both were part of the project. A second NC identified a new purpose that was both welcomed by Land and supported by the reps of both Fenia and her husband. This made it possible to run a third NC to assess which of the proposed activities would best support the fruition of this purpose. To do this, a rep was set up for the whole project (Project), who described feeling big already 'but I feel the potential of a bigger scale'. Reps for various possible next steps were being introduced to identify which of them had a place, when Project spontaneously stated 'I want the vineyard'. When a rep for a vineyard (V) was brought in, Project responded 'I feel very positive excitement for the vineyard here'. V remained close to the Project as other future steps were evaluated in relation to the new purpose.

Immediately after the NCs, Fenia described having learned 'implicit things in this which are something we couldn't have presupposed without this work. [One is that] the vineyard will generate an empowerment that will make other things happen easier'.

Interviewed 2 weeks later, Fenia explained that she had considered a vineyard on the land but 'personally it was an option that was sounding a bit too much for me... a very ambitious project... I did have a prejudice against it'. Because of what she had seen and heard, she was no longer so dismissive of the idea.

Over the next few years, the island unexpectedly developed an extremely good reputation for wine. Fenia's husband, who knew nothing about the NC work, proposed that they plant a vineyard to make wine. It was a long process that involved soil testing and gaining permissions from the Greek state, as well as EU funding to help build the wine making plant. Fenia - who was happy to do what she perceived the land itself wanted - was aligned with her husband throughout the process. 
In April 2019, they planted 11,000 vine roots over an area of $30,000 \mathrm{~m}^{2}-$ in precisely the location that the rep for the $10 \mathrm{ha}$ of land had identified in the first NC. This area was ten times the $3,000 \mathrm{~m}^{2}$ that Fenia had originally considered planting and which, in 2015, had felt too intimidating for her. In July 2019, Fenia described how beautiful the vineyard looked and how their commitment to it had enabled many other aspects of the wider project on the land to gel together. She felt that things were falling into place and confirmed that all their activities were in line with the new purpose identified back in 2015 .

OCs sometimes refer to 'the future that wants to emerge'. Could this be what was identified through the NCs for Fenia? What does it mean for a piece of land to have a desire, for a 'project' to ask for vineyards to be included? NCs challenge many of our assumptions about where consciousness is located and how information flows between different consciousnesses. But NCs are not alone: evidence from a wide range of disciplines indicates that a new paradigm is both required and emerging (Laszlo et al., 2016). NCs provide a method and data that could support the development of such a new paradigm.

\section{GENERAL REFLECTIONS}

Apart from the preceeding case studies, Mason Boring and Sloan (2013) and Roussopoulos (2018) describe how NCs have already demonstrated their value for a range of agricultural and environmentally-related issues. These include: the specific relationship dynamics between particular humans and other-than-humans; the general relationships that hold within ecosystems; planning of land development projects; support for environmental and agricultural organisations; and explorations of global environmental and policy issues. After 15 years facilitating NCs and tracking the results where possible, the author's assessment is that NCs constitute a form of interspecies communication that could support agriculture in countless ways.

The method continues to evolve, and research is ongoing to build understanding of what they are capable of, the reliability of the data, and how and when they can best be implemented. Collaboration between Nature Constellators and researchers within the agricultural field would enhance this process, while also contributing to the theory and practice of sustainable farming.

NCs are themselves an innovative form of research into human/ecological systems. Agricultural systems are coming under increasing pressure through climate change, pollution and other stressors, and deeper insights into these complex and rapidly shifting systems are essential. Systemic Constellations evolved to map and work with the interconnected dynamics of complex systems that more linear or traditional research methods fail to grasp. NCs can do this for agroecosystems. They can provide information about systems' dynamics in real time and track the relationships between the different parts. Proposed actions could be tested within NCs and, through the reps' responses, the likely impacts on the whole system would become visible - impacts that modern reductionist science is unable to predict and which could serve as signposts for further investigation.

Finally, NCs bring benefits beyond simply providing information. Other-than-human reps regularly offer their own suggestions, so the process becomes not just co-operative, but co-creative. There may be spontaneous positive changes in the system represented, not to mention in the client present. A few months after doing a NC about the projects on his farm, the owner wrote: 'the end [of the Constellation]... was so fantastic that I broke down crying when I related it to my wife and even got emotional when sharing it with other people'. Frequently clients and reps experience profound shifts in their relationships with the other-than-human life around them towards more understanding, appreciation and respect. 


\section{CONCLUSION}

Nature Constellations is a relatively new development of the Systemic Constellations methodology and has only recently been applied in the agricultural field. The research presented indicates that NCs can access accurate information about the other-than-human life around us, effectively forming a means of communication with it. While further research into NCs would hone their application, they have already demonstrated their value in addressing agroecological issues, particularly when integrated with the theory and practice of Organisational Constellations.

As well as addressing specific questions brought by clients, NCs offer a unique method of research into human/ecological systems which could supplement traditional agricultural research. By providing insights into the current state of agroecosystems, revealing the relationships between the parts and indicating what would benefit the whole system, NCs could make a valuable contribution to the thriving of all life.

\section{REFERENCES}

Barratt, M. J. (2011) Doing animist research in academia: A methodological framework. Canadian Journal of Environmental Education 16:123-137.

Erickson, D. L. (2011) Intuition, telepathy, and interspecies communication: A multidisciplinary perspective. NeuroQuantology 1:145-152.

Franke, U. (2003) The river never looks back: Historical and practical foundations of Bert Hellinger's family constellations. Heidelberg: Carl-Auer-Systeme Verlag.

Horn, K. P. and Brick, R. (2009) Invisible dynamics: Systemic constellations in organisations and business, Second Edition. Heidelburg: Carl-Auer-Verlag.

Laszlo, E., Dennis, K. L., et al. (2016) What is reality: The new map of cosmos and consciousness. New York: SelectBooks Inc.

Mason Boring, F. (2007) Nature constellations: Mother Earth belongs. The Knowing Field International Constellations Journal 9:14-17.

Mason Boring, F. and Sloan, K. E. (eds) (2013) Returning to membership in Earth community: Systemic constellations with nature. Pagosa Springs, Colorado: Stream of Experience Productions.

Rosati, A. (2017) Wild asparagus in olive orchards: Get more income from your orchard. Agroforestry Innovation Leaflet 19. Available online: www.agforward.eu/index.php/en/intercropping-and-grazingof-olive-orchards-in-italy.html (accessed 23rd June 2020).

Roussopoulos, M. (2006) Anyone know the URL for the truth? Science and constellations. The Knowing Field International Constellations Journal 8:16-21.

Roussopoulos, M. (2018) Nature constellations: Exploring our profound interconnectedness with all life. The Knowing Field International Constellations Journal 31:61-71.

Sheldrake, R. and Morgana, A. (2003) Testing a language-using parrot for telepathy. Journal of Scientific Exploration 17:601-615. 


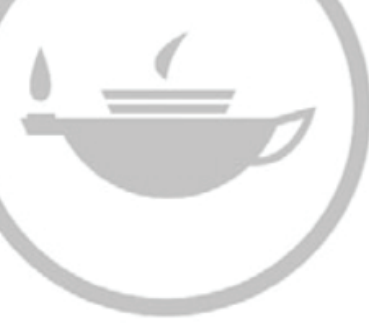

Taylor \& Francis Taylor \& Francis Group http://taylorandfrancis.com 


\title{
20 Engaging in the Goethean Method An Approach for Understanding the Farm?
}

\author{
Isis Brook \\ Crossfields Institute
}

\section{CONTENTS}

Introduction. 229

Goethean Observation as a Careful Process ............................................................................. 229

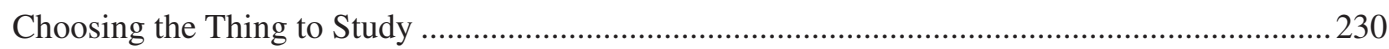

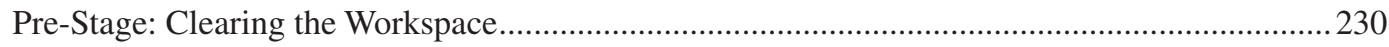

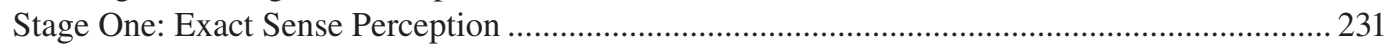

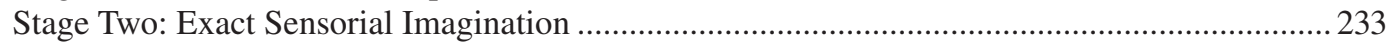

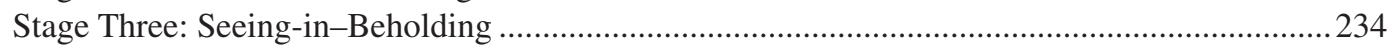

Stage Four: Being One with the Object ......................................................................... 235

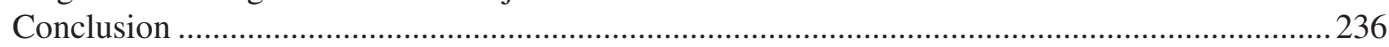

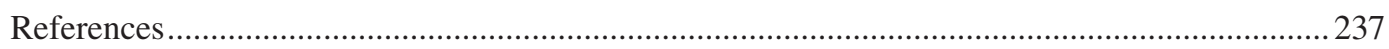

\section{INTRODUCTION}

In my first chapter in this book, I provided some background to Goethe's scientific work and indications of why it might be relevant to us today in developing a holistic approach to farming and to agricultural research. This approach can help with both our understanding of the world and how we might see ourselves as working in harmony with it. This chapter sets out a way of working that follows Goethe's indications on how to develop 'new organs of perception'. The applicability of this to agroecology is as much to do with adjusting our own way of being for a better understanding of the land and our relationship with it, as it is about how or what to plant or harvest.

As we saw in the earlier chapter, key aspects of Goethe's approach are: to hold back on theorising; to open oneself to the phenomenon being studied (be that a plant, an animal, a landscape or a farming community); to use our human faculties such as imagination, inspiration and intuition in the service of the thing being studied and to approach it as part of a whole that is in constant creation.

\section{GOETHEAN OBSERVATION AS A CAREFUL PROCESS}

Goethean observation as a means to come to know a phenomenon is widely recognised as having four stages (Bockemühl, 1985, Hoffmann, 2007, Holdrege, 2005, Seamon and Zajonc, 1998). This chapter draws from the training given by evolutionary biologist Dr Margaret Colquhoun and 
others through the Life Science Trust ${ }^{1}$ and the author's subsequent working with and studying this approach, to inform what is set out here.

The four stages are usually preceded by a preliminary stage of recognising one's habitual responses. In my own practice and my own teaching of this process, I place more emphasis on this pre-stage than others do. Perhaps, this is because I am a philosopher by training and thus am aware of the epistemologically controversial nature of claims such as 'being able to see how the world really is'. Moreover, this pre-stage is useful for highlighting that Goethean observation requires a challenging switch from our culturally habitual dualistic thinking to a more holistic thinking.

A real strength of the Goethean approach is that it lays out a formal staged process. Skilled practitioners will move between and meld these stages, but to begin with, it helps to explore them in a systematic way. This might seem and, at times, feel slow and pedantic, but the point is that we can follow consciously and rigorously what is happening in the world and in ourselves as the practice progresses. Experiencing this process can sometimes be unnerving or strange; for example, we may become aware for the first time of odd physical responses, insights or mystical states. However, we now have a careful record and thus a fuller understanding of this shifting relationship between our external and internal worlds that can then be moved into and out of by retracing our steps.

\section{CHOOSING THE THING TO STUDY}

As with any research question or journey of enquiry, we need to have a focus - what is it that you will be observing? For early practice with Goethean study, it is good to work with something that draws your attention in some way; not necessarily something you already know a lot about or for a practical purpose - that can come later when you are familiar with the method. Being able to find the thing that it would be fruitful to study is as much about waiting for it to call you, to just wander around and let something strike you. This requires patience and a child-like receptivity to hear what it is about the world that you are particularly suited to explore. Being drawn to something could be an attraction or curiosity or it could be a feeling of revulsion or challenge - a troublesome 'weed' plant, for example.

When teaching this approach, or helping people to familiarise themselves with it, I always recommend working with some aspect of the plant realm to start with, even if your later focus will be on an animal or landscape or something from the human realm such as an organisation or farm community. The plant was foundational for Goethe's understanding of his method of investigation. Practice with a plant yields benefits later on with more complex organisms, such as animals, and less responsive entities such as rocks. With a plant you can more easily reach an understanding of what these stages feel like and so be more comfortable about the process.

Before moving on, you need to have selected - or perhaps we can say you need to have been selected by - your plant.

\section{PRE-STAGE: CLEARING THE WORKSPACE}

Our ways of thinking, feeling, moving, responding and simply being in the world are shaped by our physical environment, culture, personal history and a whole web of interactions. Many of these are permeated by the dominant Western tradition of mind-body dualism, scientific reductionism and the practical concerns of survival. It is one thing to know this but quite another to escape it. Mind-body dualism, for example, shapes our language so that even to express how something

\footnotetext{
${ }^{1}$ The Life Science Trust organised a remarkable series of seminars through residential workshops (some 7 or 9 days and some 3 weeks), each focused on a particular realm of nature, for example, rocks or plants or animals. They were held over a number of years between the 1990s to 2000s at various venues in the UK and latterly at The Life Science Centre, Pishwanton in Scotland. Participants generally attended at least four workshops to experience this method with a range of phenomena such as: colour, the plant, the animal, the human skeleton or the landscape.
} 
could be different involves using the language that has developed to embody how it is always assumed to be. For example, even when we talk of the environment, the use of 'the' separates us and places us outside of that in which we are actually environed. The process of Goethean observation is a honing of the human being as a scientific instrument. If this is what we are going to be engaged in, understanding the starting point - that is, our normal way of thinking and being - is going to be essential.

To clear the workspace, we need to take a preliminary look at what is actually there and how it usually works. In the Goethean process, this is done by approaching your chosen phenomenon in a normal, everyday way and then setting down your first impressions in whatever form they may take. Examples of the kinds of impressions that can emerge in this part of the process are: your habitual likes and dislikes, how you might use it, feelings of boredom or anger, snippets of information, inspiring ideas or urges to put something right and so on. What is different, and what makes this the pre-stage of a process, is that instead of acting on these impressions or continuing them with further thoughts or day-dreams, we consciously lay them out for inspection and then set them aside. Keeping a record of these thoughts and feelings is an important part of the process. By naming attitudes and presuppositions that are in the background, you can spot when they might creep in to your work in the later stages of the process. That said, a first impression may be very perceptive and its veracity may re-emerge later on.

What should become apparent is just how much the Goethean method involves self-examination and critical reflection. It is a qualitative approach to the world, but not one that revels in undisciplined subjectivity.

Before moving on, you need to have made some notes about your usual thoughts and feelings about your phenomenon. A small journey into speculation about the origins of those attitudes can be helpful, but without holding up the next stages of the process that need to be worked through far more slowly.

\section{STAGE ONE: EXACT SENSE PERCEPTION}

The first proper stage is characterised by standing away from that very personal first encounter and observing the phenomenon freshly. Try to experience your chosen phenomenon as if you had never seen it before. From that perception, begin to record all that you can about the phenomenon. Recording as you go is important: have a note book and writing/drawing materials to hand. It is important to remember that you have multiple senses, so don't just concentrate on sight. With plants, smell and texture are obviously important as is, for example, response to the wind. Taste can also be explored - with caution (do check that your plant is not known to be poisonous before tasting it). You are in a process of meeting a being and, as the pre-stage emphasised, you need to do that on its own terms without overlaying it with your own preconceptions or normal ways of thinking. Not only personal feelings, but also any known theories about a phenomenon need to be held back in order to let the 'facts' speak for themselves. This practice can be seen in Goethe's extraordinarily detailed observations of colour phenomena. Rather than draw hasty hypotheses or work from an existing theory, such as Newton's, his painstaking investigations followed every conceivable avenue of experimentation (Sepper, 1988). Thus for Goethe, finding out about the nature of colour involved aspects such as: complimentary colour afterimages, how artists use colour, how dyers use reagents and so on, rather than just the latest ideas on colour from physics.

Recording your observations can be done in a number of ways such as writing detailed descriptions. However, drawing the phenomenon is one of the best ways to focus your attention on the hitherto unnoticed detail and the relationships between parts. If your aim is to really see a particular tree that happens to be an oak, drawing can be very helpful to prevent you slipping into your usual 'seeing oak trees' mode of perception. Artists have the additional problem of having to avoid their personal 'drawing style' influenced mode of perception. The categorised artefact that your usual mode of perception creates, must be ignored in order to let you see the oak tree as if you had 
not seen one before. ${ }^{2}$ Such exercises can include drawing the outline of a plant without looking at the paper, using shading for depth with no regard for actual shades or shadows, or creating the form by shading the outside area of the paper as if chipping the form from a block. You could also use watercolour paint, pencils or pastels to mix the exact colour of different parts. One of the most useful drawing exercises, and this one should never be left out or cut short, is to draw from memory. You may think that you know everything about the appearance of a plant, only to have that assumed knowledge disappear the moment the plant is hidden from view. Drawing from memory by closing your eyes and building in your imagination the plant as you have come to understand it, is extremely helpful in trying to build the bridge - so crucial to Goethean science - between the phenomenon and the human being as a scientific instrument. You need to set aside any personal concerns about your ability to draw; the point is not to produce a beautiful picture, but to train your perceptions.

Another tool you can use is to ignore pre-existing knowledge, for example, the names of things, and instead to see and describe them outside of learned classifications. This restriction on nomenclature is helpful when sharing observations in a group. Finding a word that expresses what you are seeing rather than taking the ready-made one prompts more looking and thus more potential to see fresh relationships. Still, it is impossible to continue in exact sense perception indefinitely. To register all the great amount of variety and detail would be, as Goethe said, 'like trying to drink the sea dry'. (1995: 24). Simply amassing facts about the phenomenon as a static object at the moment at which we are observing it will not allow you to really see what the thing is nor come to any firm idea of it. Exact sense perception is only the foundation on which the following stages rest and to which they return, when necessary, to compare conclusions reached by other means.

Jochen Bockemühl's work on phenomenology (1985) uses the four elements (earth, water, air, fire) as a helpful way of characterising each of the stages. This first stage has an 'earth' quality: the solid facts are gathered, and the feel of the process here is one of careful exactitude. Although fascination with detail is appropriate, we should not get carried away. For some, this stage is experienced as being rather tedious, yet for others it is very satisfying, and such differences in themselves show something of our personalities. In the training mentioned earlier, we spent several days on each stage with our chosen phenomenon. With the plant it can be hard to stay in this mode, for example, you will be tempted to describe things as 'growing' or 'wilting' and generally anticipating future states or imagining past ones that you think you have known; it is quite a discipline to hold those imaginings back and stick with the present.

Before leaving the first stage, it is also worth mentioning that, in gathering information, you may also use secondary sources. It can be helpful to know what other people have discovered. For a plant, you could turn to some botanical knowledge, or the relevance of the plant in agriculture, herbalism, myth or even the language of flowers in mediaeval paintings. The important point about using secondary sources is to avoid them to begin with (apart from checking in regard to poison) and then have a sceptical eye and always return to the primary source, the plant itself, for verification. You need to be alive to the fact that with secondary sources you are gathering what other people have said and they could be working from presuppositions and not from the plant itself. Secondary sources might give you new ideas or other forms of access to your phenomenon or questions to pose for further investigation. On the other hand, it also gives you more material that you have to set aside in order to really see the plant.

Do not move on until you have a collection of drawings and descriptions and a solid feeling of getting to know the 'what is' of your plant. This will provide your anchor for the work ahead.

\footnotetext{
2 A number of drawing exercises are helpfully detailed in Margaret Colquhoun and Axel Ewald's 1996 book New Eyes for Plants: a Workbook for Observing and Drawing Plants.
} 


\section{STAGE TWO: EXACT SENSORIAL IMAGINATION}

With the previous stage, you were attempting to capture what the phenomenon is presenting to you right there in the present. The activity was about being exact about what you see, hear, feel or smell etc. but the entity you are studying cannot really be captured in a frozen present. It exists as a process, and so to get to what it really is, you are going to have to live into that process yourself so that you can begin to accompany it in its being. We do this by using the human faculty of imagination, but not imagination as we often think of it in the human realm as distanced from reality. Imaginative activity in Goethe's sense is called by him 'exact sensorial imagination' (Bockemühl, 1985) and it builds on the rigour of the previous stage, but now it is set in motion. The aim of this activity is to perceive the phenomenon as a dynamic entity. Just as the previous stage required a certain policing of one's usual ways of thinking, our imaginations also need some schooling to allow us to stick with the phenomenon, not as we have come to know it as an entity frozen in time, but as a being in process. Working with a plant often draws us into this mode (observing growing, wilting, etc.), so you may have already ventured into it and had to hold back.

There is something dreamlike about this stage. However, because we have already lain aside our theories, our presuppositions and undergone a rigorous working in exact sense perception, our dreams are in the style of the phenomenon and not drawn from our own personal fancies. These experiences need to remain dreamlike, because any fixing of them will put us back into the first stage.

One of the easiest ways into experiencing this type of imagination, and seeing how it could lead to understanding something about a phenomenon, is through Goethe's work on the metamorphosis of plants. It is here that we can see his use of exact sensorial imagination as a kind of shift in consciousness that now connects with the phenomenon in a new, but nevertheless still rigorous, way. The most immediate easy experience of moving a plant imaginatively is through observing with plants at different stages of growth. For example, you could be studying a particular wild carrot (Daucus corota) but around it are others at earlier and later stages of growth or flowering or fading. Thus, you can imaginatively take your wild carrot backwards or forward in time using these others as indications of your plant's process. It is also possible to enter into the plant as a process in a freer way through what Goethe called its discontinuous metamorphosis. Many plants produce a sequence of different leaves, often beginning with a simple shape, becoming more differentiated and then contracting to a more pointed form and eventually there is a transition to the flower parts (Holdridge 2013:76). To school our imagination, we could imaginatively move through this sequence, as if from the inside of our plant. We could even imaginatively produce leaf forms that could appear in between those that are evident in the plant. This helps you to experience the plant as a dynamic process of metamorphosis as opposed to recording only its visual form. (If your chosen plant does not show any obvious aspect of this metamorphosis, you could practice with one that does, such as mustard, buttercup or groundsel, to get a feel for these changes before returning to your plant.) Jochen Bockemühl, whose work makes extensive use of leaf sequences, explains the process and shows just how different this kind of watery perception is from the earthy style exact sense perception of stage one.

With the mode of observation corresponding to the watery element, it becomes possible to go beyond the single elements of form and reach a realm not directly accessible to sense perception; here the sequence of forms appears as formative movement, and the formative forces can be experienced. If something is observed as an object, it is always seen from the outside, it is seen separately and seemingly from all sides at once. There, one's own standpoint is unimportant. The object exists without me. If, however, one begins to become aware of the formative forces in the way described, one's own inner activity (intentionality) and one's own position within the whole becomes significant.

Bockemühl (1985: 21)

With any living entity, it is easy to move into this second stage because the phenomenon simply seems to require it. We cannot capture the livingness of a plant if we stick with exact sense 
perception. Our thinking in that mode is too static to live into the phenomenon and experience it as changing and growing. Something of the phenomenon has to live in us if we are to make a connection between, for example, the sapling and the tree. Our thinking has to be mobilised to grasp the becoming of nature and the way nature is constantly creating. Although we know plants grow and change in ordinary consciousness, here we experience it afresh and understand it in a new way.

It is imagination that makes this mobilisation of our thinking possible. In this mode of perception, we are living in the phenomenon as a process. We are imaginatively engaged in those same processes. We need to enter this not by bringing in human meanings but by living in the phenomenon as the being it is. Although we cannot leave our humanity out of the picture, as this is the source of our imaginative ability, in this and the stages that follow we are placing our faculties in the service of the phenomenon. Exact sensorial imagination leads us to a holistic apprehending where we understand, for example, the plant as a metamorphosing possibility, connected to its place and to the plant realm.

Exact sensorial imagination exercises to help here include imaginatively growing your plant through a whole life cycle or imaginatively taking your plant through the seasons. The richer the pictures you can build, for example, the changing light, the changing insect visitors and so on, the more you will be sensing into the plant. Growing the plant in your imagination before sleep can be very helpful for continuing your study the following day. It seems to connect you with that dreamlike realm that is needed here and it facilitates the later stages.

You could also try, with care, 'imagining it otherwise' (Brook, 1998: 55). This is where you purposely misuse your imaginative faculty to impose something on the plant, for example, imagining an ash tree is evergreen. The purpose here is to feel for a response. By now, you will be in a relationship with the plant and will feel (perhaps viscerally or emotionally) the wrongness of your imaginative fancy. Such a response kick helps to get you listening in to what is really there and tuning into where insightful responses might come from in your own body.

It is the plant realm that gives us a clear picture of the need for this shift in our thinking if we are to understand a plant as a plant and not just as a marker in our system of classification or an entity to be utilised. This is where we can first detect that the empiricism, which in the first stage seemed exacting and pedantic, is now on a path to what Goethe termed a delicate empiricism. Delicate because it does not impose a theory, and neither does it deny the human faculties their role in coming to know the world. Rather, the faculties have to treat the world with delicacy in order to find it, rather than just find humanness reflected in it.

Ensure you have felt the shift in consciousness into this dreamy, watery style of thinking and feeling before moving on. You should now be able to move freely into and out of the phenomenon and carry something of its being in your consciousness.

\section{STAGE THREE: SEEING-IN-BEHOLDING}

Once you can shift your thinking into that fluid mode you can build up the phenomenon imaginatively through its changing forms. However, this still feels somewhat attenuated. It provides the training of the imagination so that you can now move on to tuning in to the phenomenon as it is, as a living whole, rather than as parts you bring together imaginatively. The element here is air. For this, you need to move even further back from your ordinary way of engaging with the world; you must even quiet your imaginative activity in order to make space for the phenomenon to present itself.

You need to be like air, not flowing through the forms like water, but making them visible. Using elemental language to describe these stages does not mean that we are looking for particular characteristics in a thing. You are not looking for airy aspects of the phenomenon; instead what you need to do is to be airy in your own consciousness. Bockemühl describes the way the observer must be:

It is characteristic of air to expand in all directions, offering its own being and activity in order that the being and activity of another can appear. Insofar as we move inwardly in accordance with this image 
of air, we reach the cognitional attitude corresponding to the air element. An inner readiness is thus created for that which manifests in the world to reveal itself in us, as an image which discloses a being.

Bockemühl (1985: 26)

It is the human faculty of inspiration that now offers itself to the phenomenon. Through your stillness, the phenomenon can present its real self, and this is often felt as a particular gesture, a gesture that somehow speaks or presents that phenomenon. The insights that arrive in this third stage can seem strange to your normal ways of thinking. It can be exciting or emotionally moving, and because what arrives seems foreign to yourself, this enhances the sense that it is given to you. It should feel like something received rather than made. These received indications can be captured and explored in some form of artistic representation where gesture and meaning are brought out and the inner mood is expressed.

You might find that this inspirational stage is best expressed in emotional language, which is paradoxical as it is far from the normal, self-absorbed emotional subjectivity. Working artistically with colour can also help to deepen the indications that arrive. What should be expressed is the being of the phenomenon, something of its essential nature. Again, do not be concerned about any lack of familiarity with, for example, writing poetically or painting, it is the process of attempting that is important.

Stage one gave us the solid facts that anchored our imagination to the phenomenon and allowed us, in stage two, to enter into the livingness of the phenomenon, which in turn gave us enough familiarity with it to see through to and express its inner/fundamental gesture. This gesture of the whole can push us into the fourth stage of being-one-with the object (Goethe, 1995: 75).

Make sure you have captured any insights into the gesture of your phenomenon. This can be hard to record in language or image, but try to get something down. The process of writing, painting, moving or singing etc. is not just representation of the insight, it helps you to live into the insight and to feel it more deeply.

\section{STAGE FOUR: BEING ONE WITH THE OBJECT}

The first three stages of the Goethean method involve different activities and ways of thinking, and these could be characterised as first using perception to see the form; second, using imagination to perceive its mutability and, third, inviting inspiration to reveal the gesture. The fourth stage uses intuition to both combine and go beyond the previous stages. Here we experience the 'what it is' of the phenomenon in its full power and potentiality. It is here that the phenomenon can be understood, and it presents itself to the human being as an idea or even a theory. Thus, in the Goethean process, we do not start with theory and overwrite the phenomenon with our own thinking, instead we place our human thinking and theorising capacities at the service of the phenomenon.

In terms of the elements, the shift in consciousness we now need is fire. This fourth stage is also the most physically abstract, having the least connection to the outer appearance of the phenomenon. However, that abstraction from the specific allows the perception of what is essential to the inner nature of the thing. Bockemühl calls this an experience of the 'being's beingness'. He expresses the fire stage thus:

We are here at the limit of what can be called a mode of observation. The warmth enters us - our inner activity itself becomes an organ. We do not experience the outer expression of a being, we become aware of its inner impulse. At these moments of inner identity, all outer manifestations disappear. They are 'burned up'.

Bockemühl (1985: 30)

Fire or warmth is also suggestive of another feature of this stage: the connection to the inner impulse of the thing comes about through our own inner impulse to act. At this point, we are prompted to 
action, not only in the sense of wanting to express something of the being, as in the third stage, but to do something about it. We feel 'fired up'. Because of the journey that precedes it, this is not a subjective expression of your own personal will. The intention is to combine the being of the phenomenon with the human ability to both think and to act in the world.

How you arrive at this is harder to explain, in my experience it just arrives suddenly when working in stage three. It is as if from the acquiescent air process, where our usual thinking is held back, concept or idea or determination suddenly arrives, but with a strange clarity, a kind of shininess, that is unlike one's normal thought processes or perceptions.

In teaching this method with groups, particularly with regard to landscape, it is interesting to note the difference between a pre-stage impulse to do something - make a change, clear an area, develop a path - and an impulse that arrives out of combining one's thinking with the phenomenon. The pre-stage and the four steps are intended to bring us to a point of understanding and collaboration with the phenomenon. Now we are in a position to move forward, to act in unison with the phenomenon.

\section{CONCLUSION}

The stages with their indicative elements and human faculties emphasised can be summarised in Table 20.1 for ease of reference.

Once you are familiar with the shifts in consciousness of these four stages by experiencing them through a journey or two with something from the plant realm, it is possible to branch out to other realms and take a phenomenon such as a rock, or an animal. In terms of agroecology, this approach is particularly helpful when considering actions involving whole landscapes or particular areas of a farm or garden. Within a Goethean process, if you want to make changes inspired by insights from the fourth stage, you need to move forward further into a new set of phases that mirror the previous stages (3,2 and 1). This is about testing out and double-checking a planned action before landing it (earthing it) in the world. ${ }^{3}$

This approach is a means to begin the process of undoing our habitual dualistic patterns of thought, and nourishes new organs of perception that are receptive to, and respectful of, nature so that we might begin to glimpse what nature really is, what place we have within it and how we may collaborate or co-evolve with it.

How might such an approach impact on agriculture or agroecology? To some extent, this can be seen in biodynamic agriculture where, for example, understanding the whole farm as an organism captures something of Goethe's holistic vision. This should be no surprise as we saw in my previous chapter in this book how Rudolf Steiner's work on the Goethe archives influenced his approach to agriculture. However, as the presentation of the stages of the Goethean method above has shown, this should not be viewed as a system to be applied, rather, it is about a personal engagement and the

\section{TABLE 20.1}

\section{The Four Stage Goethean Approach and Related Human Faculties and Elements}

\begin{tabular}{llll}
\multicolumn{1}{c}{ Stage } & Human Faculty & \multicolumn{1}{c}{ Elemental Feel } \\
1 & Exact sense perception & Perception & Earth - solidity \\
2 & Exact sensorial imagination & Imagination & Water - flowing \\
3 & Seeing in beholding & Inspiration & Air - surrounding but ephemeral \\
4 & Being one with the object & Intuition & Fire - fast, concentrated \\
\hline
\end{tabular}

\footnotetext{
${ }^{3}$ A useful discussion of these mirrored steps with practical examples can be seen in Christopher Day's 2003 book Consensus Design: Socially Inclusive Process.
} 
transformation of your thinking and your being for more responsiveness to the climate, land, people, animals and plants that form the basis of the agroecological vocation.

\section{REFERENCES}

Bockemühl, J. (1985) Elements and Ethers: Modes of Observing the World. In Bockemühl, J. (ed) Toward a Phenomenology of the Etheric World. New York: Anthroposophic Press Inc.

Brook, I. (1998) Goethean science as a way to read landscape. Landscape Research 23(1):51-69.

Colquhoun, M. and Ewald, A. (1996) New Eyes for Plants. Edinburgh: Hawthorn Press.

Day, C. (2003) Consensus Design: Socially Inclusive Process. Oxford: Architectural Press.

Goethe, J.W. (1995) Scientific Studies. ed. and trans. Miller, D. New York: Suhrkamp Publishers.

Hoffmann, N. (2007) Goethe's Science of Living Form. New York: Adonis Press.

Holdrege, C. (2005) Doing Goethean science. Janus Head 8(1):27-52.

Holdrege, C. (2013) Thinking Like a Plant: A Living Science for Life. Great Barrington, MA: Lindisfarne Books.

Seamon, D. and Zajonc, A. (1998) Goethe's Way of Science: A Phenomenology of Nature. New York: SUNY Press.

Sepper, D. (1988) Goethe Contra Newton, Cambridge: Cambridge University Press. 


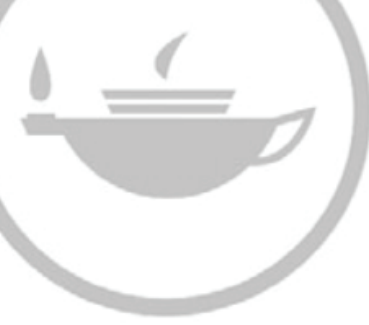

Taylor \& Francis Taylor \& Francis Group http://taylorandfrancis.com 


\title{
21 Intuitive Farming Heart-Based Decisions for Harmony in Agricultural Ecosystems
}

\author{
Saskia G. von Diest \\ Stellenbosch University
}

\section{CONTENTS}

Introduction: Intuitive Communication as an Age-Old Practice................................................2 239

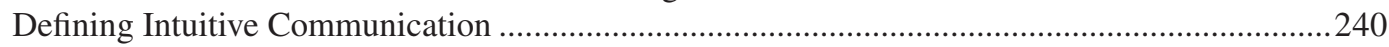

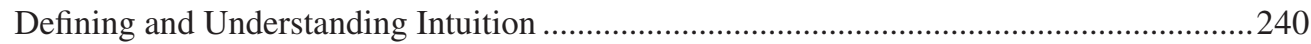

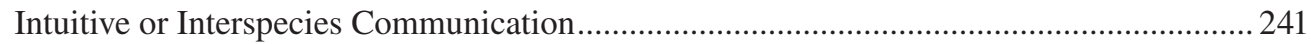

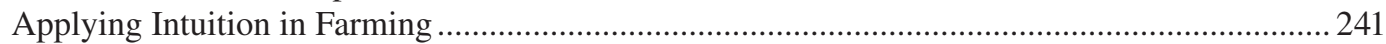

Emerging Research on Intuitive Communication in Farming ........................................... 241

The Transformation of the Intuitive Farmer ..................................................................... 243

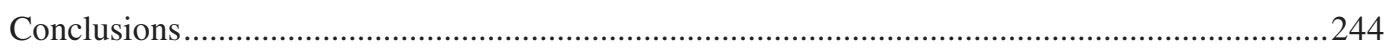

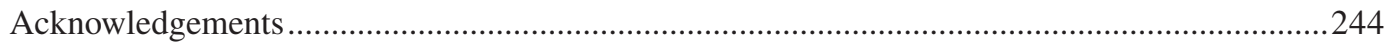

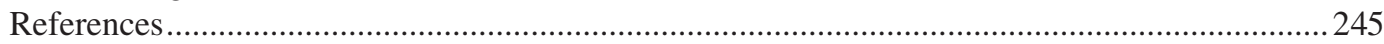

\section{INTRODUCTION: INTUITIVE COMMUNICATION AS AN AGE-OLD PRACTICE}

Intuition is seen as a crucial component of decision-making in various fields, including psychology, business management, neuroscience and medicine. Most judgements and decisions rely on intuition to some degree, often because of time constraints and the virtual impossibility of obtaining 'complete' information (Kahneman, 2003; Nuthall and Old, 2018). Over the last three decades, agricultural science has also started paying attention to intuition, largely due to the growing awareness of different 'ways of knowing' that exist in indigenous and traditional agricultural systems (van Eijk, 1998). Yet the importance of farmer intuition remains peripheral to mainstream agricultural research, even though a review by von Diest et al. (2020) revealed that farmers in dairy, stock cattle, vegetable and mixed farming systems across various countries often prefer an intuitive approach over formal management tools and concluded that enhancing farmer intuition may improve decision-making.

Intuition allows access to tacit (internal, informal) knowledge that is not available through analytical processes, and which can aid holistic decision-making (Hogarth, 2010; Nonaka and van Krogh, 2009). Decisions that are 'holistic', from holos (Greek) meaning 'whole' (Smuts, 1926) consider more information or factors than using only rationale/logic, offering a more complete perspective of the situation in question.

Intuition also informs interspecies communication (two-way dialogue between humans and other-than-humans) (Erickson, 2011; Kieft, 2015; Kulick, 2017), which can bring additional, potentially valuable information to decisions. Sometimes called intuitive communication, this has received even less attention from agricultural science than intuition itself. While considered to be 
'New Age' (Kulick, 2017), this phenomenon is supported by a century of scientific evidence (Dutton and Williams, 2009; Erickson et al., 2016), as well as in grey literature.

Indigenous cultures worldwide share the notion that maintaining a dialogue with other-than-human elements of their food production landscapes is crucial, for practical management reasons, as well as to evolve new strategies to adapt to changing conditions (Gagliano, 2013; Kieft, 2015; Parry, 2005). Even in the West, numerous organisations and intentional communities have been founded and operate with the belief that interspecies communication can be used to inform everyday practical decisions, including in food growing, such as the Findhorn Foundation (Scotland), Tamera (Portugal), the Damanhur Federation of Communities (Italy), Perelandra Garden (USA), Cooperative BioBalance (USA), and Govardhan and Auroville (India).

The existing evidence of the use of intuition and intuitive communication in food growing warrants more attention by both farming research and practice (van Eijk, 1998).

\section{DEFINING INTUITIVE COMMUNICATION}

\section{Defining and Understanding INTUITION}

Academic literature on intuition emanates largely from the fields of psychology and business management, and while these fields provide no unifying definition of intuition, they concur that it is an immediate, pervasive and involuntary part of all decisions and provides highly useful information beyond analysis (Dane and Pratt, 2007; Hogarth, 2010; Khatri and Ng, 2000).

A critical review of intuition from the nursing profession provides further interesting pointers as to its characteristics (King and Appleton, 1997). The authors explain that intuition is often described in terms of 'gut feelings, sixth sense, insight, instinct, presentient, common sense, inner feelings, hunches, pre-monitions, foreboding and presentiment' (ibid: 195). They suggest that, because of this non-rational element, scientists have deliberately sidelined it. Yet the authors stress that nursing would change dramatically if, or when, all forms of knowing are recognised as valid. Here, we may see parallels with the sidelining of intuition in the agricultural sector, as indicated earlier.

The etymology of intuition, stemming from in-tuir (Latin), offers another useful definition as 'knowing from within', in other words 'knowing without knowing how you know' (Hodgkinson, Langan-Fox and Sadler-Smith, 2008). Carl Jung identified intuition as one of four basic functions of the conscious psyche required for holistic orientation, along with thinking (comprising the intellect and logic), sensation perception (using sense organs) and feeling (more subjective valuation). Jung defined intuition as 'perception by way of the unconscious, or perception of unconscious contents', which enables humans to 'divine hidden possibilities in the background' (Jung, 1933 [1921]: 567-568). Jung's definition remains widely accepted in mainstream psychology and management science, characterising intuitive decisions as those where one is not lucidly aware of the process preceding the decision (Dane and Pratt, 2007).

Yet, about two decades before Jung, Rudolf Steiner (whose lectures on agriculture form the basis of biodynamic agriculture) also examined intuition. He believed that intuition operates at a superconscious level, surpassing the intellect, which, when developed together with imagination and inspiration, enables super-sensible perception, i.e. perception beyond the five physical senses (Steiner, 1967). Steiner described intuition as one aspect of spiritual knowledge, and it may be for this reason that his interpretation is far less commonly acknowledged (von Diest, 2019).

In explaining how human cognition deals with information, social and cognitive neuroscience, psychology and related fields select just two of Jung's four basic functions: intuition and thinking, to describe a dual-processing model. Here, the process of intuition is characterised as being fast, automatic, effortless, affectively charged (influenced by mood), associative (through pattern recognition) and not easily verbalised. This intuitive process runs simultaneously with the analytical or 
rational process, which is slower, controlled, conducted with awareness, neutral and can be verbalised (Kahneman, 2003; Hodgkinson, Langan-Fox and Sadler-Smith, 2008; Keller and Sadler-Smith, 2019).

In an attempt to understand the mechanics of intuition, McCraty (2015) breaks it down into three types: implicit intuition - that is knowledge gained through tacit learning, which is the most commonly understood type; energetic sensitivity - when the nervous system detects and responds to signals in the environment, such as from electromagnetic fields; and non-local intuition - which is not limited to time and space, such as precognition or clairvoyance.

While intuition seems to operate with neural correlates across various regions of the brain (Keller and Sadler-Smith, 2019), the heart, which has an electromagnetic field 5,000 times stronger than the brain, seems to be involved in receiving, processing and decoding intuitive information and can respond to an event before it actually happens (McCraty, 2015). These considerations may explain both the immediacy of intuition and the possibility of the information originating from outside the body.

\section{INTUITIVE OR INTERSPECIES COMMUNICATION}

Some researchers have explored the associations between intuition and interspecies communication (Erickson, 2011; Kieft, 2015; McCraty, 2015). Dutton and Williams (2009) reviewed empirical and anecdotal evidence for animal psychic or paranormal phenomena (termed $p s i$, such as is associated with non-local intuition), mostly between humans and domesticated or laboratory animals. The evidence supports the idea that there is psi communication between humans and other species, and the researchers conclude that future research in this area should carefully consider the assumptions around how psi is expressed and interpreted in animals. Erickson (2011) advises against clinging to conventional perceptions of human/animal communication. This accords with the discussion by Tompkins and Bird (1973: 22-24), on the scientific evidence for extrasensory perception (ESP) and communication between humans and plants.

Intuitive interspecies communication is described, not as a one-way flow of information, but as a dialogue, and the information is often conveyed somatically (through the body) in the form of feelings, sensations and emotions. From both epistemological and phenomenological perspectives, this makes it difficult to accurately translate into a linguistic form, and the authors call for an expansion of the theory of language, as well as the vocabulary (Gagliano and Gimonprez, 2015; Kulick, 2017). For example, the terms and concepts of 'noetic ecology' - the different ways of knowing nature (Zylstra et al., 2018) - and 'ecofluency' - the ability to fluidly and accurately communicate with other-than-human nature using an expanded spectrum of human sensory awareness (von Diest, 2019) - may help the exploration of the human-nature relationship through diverse ways of knowing and communicating.

\section{APPLYING INTUITION IN FARMING}

\section{Emerging Research on Intuitive Communication in Farming}

While there is growing evidence of farmers using their intuition, Kieft $(2006,2015)$ provides the earliest published scientific research in English on intuitive communication informing practical management decisions in agriculture. Surveying farming practices in Europe, Sri Lanka and South America, he found that additional practices such as meditation and dowsing assisted in conversing with nature. Importantly, the reliability of intuitive information depends on one's paradigm,

A set of ideas and assumptions on how people perceive life, beings, things, the natural and the super-natural and the processes in the world around them - determines what questions you ask, how you try to know nature, and hence how you farm. 
Building on Kieft's work, a qualitative study was conducted between 2014 and 2020, through Stellenbosch University, South Africa, in collaboration with Coventry University, UK. The study included semi-structured interviews with 17 farmers and food gardeners in South Africa, the Netherlands, the UK, Italy and China. The following two cases are presented here as examples.

\section{Case Study 1: From Conventional Dairy Farming to Dancing with Cows}

In the Gelderland Province in the Netherlands, is a fourth-generation, family-run dairy farm, which by local standards is large, covering 50 ha and with a herd of 90 cows. It converted from a conventional to certified organic system in 1991, and in 2004, it became the first dairy farm in the Netherlands to stop using antibiotics and vaccines.

The farmer explained that the transition to chemical- and pharmaceutical-free farming was a struggle: while they continued to use a logical approach to select which of the more than 300 homeopathic remedies to apply, their success rate was only around 50\%. However, when they started using their intuition, their success rate rose to between $80 \%$ and $90 \%$, and they now rely almost entirely on intuition and interspecies communication to determine whether or not, and how, to apply remedies to the soil and to their animals. By 2014, the incidence of all diseases on their farm was so low that they were only having to apply three homeopathic remedies a year.

Soon after the family decided to stop cutting the horns off their cows, realising that it plays an integral part in their digestive and immune systems, and the 'identity' of the cows, they rebuilt their barn to a design that came from a conversation with the cows, in order to make them more comfortable. This design was oval, more spacious and open on all sides, and other farmers in the region have since copied their design. Over the past 10 years, the farm's dairy products have received local and international awards for their quality, and the family report feeling more satisfied with this method of decision-making. A documentary film 'Dancing with Horned Ladies' portrays their journey.

\section{Case Study 2: Partridge Avoids the Pear Tree}

In the Yunnan Province of China, near Kunming, is a farmer who applies Pure Land Buddhist practices in his red pear orchard, in particular playing recorded chantings of Amitābha Buddha's name to the orchard, changing the music with the seasons. He commenced planting the orchard in 2003 and now has 84,000 trees on his 1,300 mu piece of land ( 86.7 ha/214 acres). He applies no synthetic fertilisers, herbicides or pesticides and uses natural farming methods that surpass Chinese organic standards.

Under the guidance of teachers, he also learned to converse and negotiate with insects and small animals 'through will and thoughts' (intention), feeling and seeing the messages that come from nature. He uses 'truth, love and sincerity' to communicate with the plants, birds and insects on his land, treating every living being with equal respect, no matter its size.

Every day, he requests from the birds and insects that they only eat the fruit in the $26 \mathrm{mu}$ area ( $2 \%$ of the total orchard size) that he has designated specifically for them as 'free food', and to leave the rest of the orchard for human consumption. The result is that, in the designated area, the incidence of bird and insect damage on fruit and leaves is now $86 \%$ on average, but in the main part of the orchard, the damage is negligible (usually $<6 \%$ ), yielding an average harvest of $94 \%$ of intact, high-quality pears. Although his yield is about $70 \%$ of what other local pear growers obtain with conventional methods, the quality of his produce is three to four times higher across several

\footnotetext{
${ }^{1}$ https://vimeo.com/ondemand/dancingwithhornedladies.
} 
quality parameters. There are now over 500 species of flora and fauna living cooperatively and 'like a family' in the orchard. The farmer maintains that this makes him feel happy and fulfilled, and for him, it demonstrates that animals have full awareness and consciousness and can communicate with human beings who choose to do so and who treat them with sincerity and love, thereby coexisting in harmony and prosperity.

This success in managing crop damage reported by the farmer in Case Study 2, through designating a portion of the crop's area for other-than-human consumers, is similar to other cases in the study. Overall, the 17 case study farms report similar benefits to those described by Kieft $(2006,2015)$, such as reduced inputs and improved quantitative and qualitative outputs, resulting in greater profit margins, healthier farm systems and a more satisfied feeling regarding their decision-making. Of particular interest is that several farmers noted that they felt the heart played a role when receiving intuitive information.

\section{The Transformation of the Intuitive Farmer}

Regenerative agriculture is knowledge intensive, and transitioning towards this approach requires that the farmer has access not only to more knowledge to aid with analytical thinking, but also to greater sensitivity and better 'knowing' of the systems with which he/she is working. The process of developing intuition offers this access, involving a transformation of both the farmer and his/ her worldview, which, in turn, leads to a deeper, more balanced and harmonious relationship with nature (Cox, 2014; von Diest, 2019; van Eijk, 1998; Kieft, 2006; Paxton et al., 2017).

As we have seen, intuition is not easily articulated, and while it is not emotional per se, it is affected by emotion, which can affect the decision-maker's confidence and thus its accuracy (Hogarth, 2010). For this reason, Nuthall and Old (2018) argue that reflexive processes are required to help refine the reliable and confident application of intuition in decision-making. These processes include managing emotional triggers, observation and feedback with oneself and others, and gaining experience in a particular field of expertise. Nuthall's book, The Intuitive Farmer: Inspiring Management Success (2016), based on extensive research by the author, is the only existing handbook that the author is aware of for developing intuition in management, which is aimed specifically at farmers and farm managers and offers accessible principles and guidelines for reflexive practices.

In a study on what constitutes healthy farm management, involving 79 farmers in Austria, Germany and the UK, Paxton et al. found that

learning to be intuitive meant that farmers had to dare to listen to their intuition regardless of rational explanation and, occasionally, in the face of criticism. The farmers felt they improved their capacities for managing farm health through mindful self-reflection and self-observation, meaning that farm health depends heavily upon personal development.

Paxton et al. (2017: 84)

Sadler-Smith and Shefy (2007) and van Eijk (1998) emphasise the value of meditation and mindfulness for developing intuition, as well as metacognition. Similarly, Erickson (2011) states that calm emotional states are more conducive for not only intuition, but also interspecies communication, and these states may be attained through regulated breathing and meditation practices, as well as other lifestyle changes aimed at stress reduction, including good nutrition, exercise, adequate rest and spending time in nature.

Several authors stress that improving somatic awareness is essential for accessing tacit knowing through intuition (McCraty, 2015; Nonaka and van Krogh, 2009; Sadler-Smith and Shefy, 2007). As Kieft (2015: 183) put it: 'if we learn to better communicate with our body, we are also opening our mind for communicating with nature in a wider sense'. Developing a heightened 
physical sensitivity may involve muscle testing or kinesiology, or using instruments such as a pendulum or dowsing rods (Kieft, 2006). Physical rituals are also important as they reduce the neural signals related to both performance anxiety and the impact of experiencing failure (Hobson et al., 2017).

As well as increasing somatic awareness in general, several authors also concur that the heart plays a central role and more attention should be paid to this aspect (Erickson, 2011; Kieft, 2015; McCraty, 2015). McCraty (2015: 52), in particular, explains how coherence between the heart's rhythm and the brain can be intentionally activated by focusing on positive emotions, thereby bringing intuitive signals of all kinds to the conscious awareness.

Various works by Steiner, including Knowledge of the Higher Worlds (1923 [1904]), provide instructions for developing self-awareness, as well as the capacities of intuition and intuitive communication. Other practical handbooks for developing these capacities include those by Andeweg (2009), MacManaway (2013), Conroy and Alexander (2014), Gurney (2001), Williams (2003) and Raven (2012). All these authors and many others recommend four common critical aspects: (1) to seek the truth through allowing the heart to guide decisions, (2) to meditate as a daily practice, (3) to spend time in nature, silently, and (4) to remain grounded. As Kieft (2015: 184) explains, 'the intuitive or 'sensing' techniques applied by farmers look very much like the way the mystic describes his/her access to deeper information'.

Based on the above, this author proposes that becoming an intuitive farmer is a journey of personal development and transformation, requiring courage and dedication. This may require psycho-social support, which is not currently available from mainstream agricultural organisations. Therefore, attention is required from not only farmers but also farm support services, researchers and policy-makers, to provide the supportive and enabling frameworks for farmers who wish to develop their intuitive capacities and thus become co-creative decision-makers with their farm ecosystems.

\section{CONCLUSIONS}

There is no unifying definition of intuition, but it is clear from the existing research that intuition is fast, is an inevitable part of all decision-making and provides useful and accurate information beyond whatever analytical approaches can access. The small, but growing, evidence base on the practical value of intuition and intuitive communication in farm management decision-making indicates that it deserves more attention from agricultural research and practice.

Some authors have found that intuition may also play a crucial role in intuitive or interspecies communication. Emerging research, such as the two case studies of intuitive farmers presented here, suggests that this co-creative approach to food growing holds the potential to offer farmers more agency, autonomy and confidence, to make better-informed, customised and more environmentally appropriate management decisions, not least because they gather direct feedback from the other-than-human.

Methods for developing intuitive capacities already exist for farmers. All of these methods emphasise the need to willingly and actively self-critique and manage emotional triggers, which may be supported through increased awareness of somatic sensitivity. The process of personal transformation in the development of intuitive capacities may be challenging and lengthy. But perhaps the transformation of the farmer in the search for inner knowing may be what is needed to help transform mainstream agriculture towards more regenerative, harmonious engagement with nature.

\section{ACKNOWLEDGEMENTS}

The Chin Kung Multicultural Education Foundation is acknowledged for acting as intermediary and translator in communications with the farmer in Case Study 2. The research in the case studies presented in this chapter was supported by funding from the Department of Science and 
Technology and the National Research Foundation of South Africa, from the office of the ViceRector of Innovation, Research and Postgraduate Studies at Stellenbosch University, and from Coventry University.

\section{REFERENCES}

Andeweg, H. (2009) In Resonance with Nature: Holistic Healing for Plants and Land. Edinburgh: Floris Books.

Conroy, J., and Alexander, B. (2014) Live and Let Live: How Multidimensional Collaboration Heals Ecosystems. Morris Plains, NJ: Plant Kingdom Communications.

Cox, T. (2014) “Transpersonal Agroecology: The metaphysics of alternative agricultural theory”. The Journal of Transpersonal Psychology 46(1):5-57.

Dane, E., and Pratt, M.G. (2007) "Exploring intuition and its role in managerial decision making". Academy of Management Review 32(1):33-54.

Dutton, D., and Williams, C. (2009) "Clever beasts and faithful pets: A critical review of animal psi research". Journal of Parapsychology 73(Spring):43-68.

Erickson, D.L. (2011) "Intuition, telepathy, and interspecies communication: A multidisciplinary perspective." NeuroQuantology 9(1):145-152.

Erickson, D.L., Fisher, D., Woelk, B., Buckner, W., and Ashley, C. (2016) "A mixed methods study of telepathic interspecies communication with therapeutic riding horses and their recovering wounded veteran partners." NeuroQuantology 14(2):403-425.

Gagliano, M. (2013) "Persons as plants: Ecopsychology and the return to the dream of nature." Landscapes: the Journal of the International Centre for Landscape and Language 5(2). Retrieved from http://ro.ecu. edu.au/landscapes/vol5/iss2/14.

Gagliano, M., and Gimonprez, M. (2015) "Breaking the silence: Language and the making of meaning in plants.” Ecopsychology 7(3):145-152.

Gurney, C. (2001) The Language of Animals: 7 Steps to Communicating with Animals. New York: Dell.

Hobson, N.M., Bonk, D., and Inzlicht, M. (2017) "Rituals decrease the neural response to performance failure." PeerJ 5:e3363. DOI: 10.7717/peerj.3363.

Hodgkinson, G.P., Langan-Fox, J., and Sadler-Smith, E. (2008) "Intuition: A fundamental bridging construct in the behavioural sciences." British Journal of Psychology 99:1-27.

Hogarth, R.M. (2010) "Intuition: A challenge for psychological research on decision making." Psychological Inquiry 21(4):338-353.

Jung, C.G. (1933) Psychological Types. Translated by H. Godwyn Baynes. London: Routledge \& Keegan Paul.

Kahneman, D. (2003) "Maps of bounded rationality: Psychology for behavioral economics." American Economic Review 93:1449-1475.

Keller, J., and Sadler-Smith, E. (2019) "Paradoxes and dual processes: A review and synthesis." International Journal of Management Review 21:162-184.

Khatri, N., and Ng, H.A. (2000) "The role of intuition in strategic decision making." Human Relations 53(1):57-86.

Kieft, H. (2006) “Quantum agriculture: Bridging frontline physics and intuitive knowledge of nature?” In B. Haverkort and C. Reijntjes (eds), Moving Worldviews, Reshaping Sciences, Policies and Practices for Endogenous Sustainable Development, pp. 209-218. Leusden: Compas Leusden.

Kieft, H. (2015) "Intuitive farming: Towards a new vision on nature." In S.A. Park and C. Shoemaker (eds), Proceedings of the XI International People-Plant Symposium on Diversity: Towards a New Vision on Nature. Acta Horticulturae 1093:179-194.

King, L., and Appleton, J.V. (1997) Intuition: A critical review of the research and rhetoric. Journal of Advanced Nursing 26:194-202.

Kulick, D. (2017) “Human-animal communication.” Annual Review of Anthropology 46:357-378.

MacManaway, P. (2013) The Practical Guide to Dowsing: How to Harness the Earth's Energies for Health and Healing. Leicestershire: Lorenz Books.

McCraty, R. (2015) Science of the heart: Exploring the role of the heart in human performance, Vol. 2. An Overview of Research Conducted by the HeartMath Institute. Technical Report, California: HeartMath Institute.

Nonaka, I., and van Krogh, G. (2009) "Tacit knowledge and knowledge conversion: Controversy and advancement in organizational knowledge creation theory." Organization Science 20(3):635-652.

Nuthall, P.L. (2016) The Intuitive Farmer: Inspiring Management Success. Portland, OR: 5M Publishing. 
Nuthall, P.L., and Old, K.M. (2018) "Intuition, the farmers' primary decision process: A review and analysis." Journal of Rural Studies 58:28-38.

Parry, G.A. (2005) "Native wisdom in a quantum world." Shift 9:29-33.

Paxton, R., Klimek, M., Vieweger, A., Döring, T., Bloch, R., Bachinger, J., and Woodward, L. (2017) “The role of intuition in managing organic farm system health." In G. Rahmann et al., (eds), Innovative Research for Organic 3.0-Volume 1: Proceedings of the Scientific Track at the Organic World Congress 2017, November, 2017, Delhi, India, Thünen Report, No. 54,1.

Raven, S. (2012) Nature Spirits, the Remembrance: A Guide to the Elemental Kingdom. Forest Row: Clairview Books.

Sadler-Smith, E., and Shefy, E. (2007) "Developing intuitive awareness in management education". Academy of Management Learning \& Education 6:186-205.

Smuts, J.C. (1926) Holism and Evolution. New York: Macmillan Company.

Steiner, R. (1923) Knowledge of the Higher Worlds and How It Is Achieved. Translated by G. Metaxa. New York: G P Putnam's Sons.

Steiner, R. (1967) The Stages of Higher Knowledge. Translated by L. Monges and F. McKnight. Hudson: Anthroposophic Press.

Tompkins, P. and Bird, C. (1973) The Secret Life of Plants. New York: Harper and Row.

van Eijk, T. (1998) Farming systems research and spirituality. PhD dissertation, Wageningen: Wageningen University.

von Diest, S.G. (2019) "Could biodynamics help bridge the gap in developing farmer intuition?" Open Agriculture 4:391-399.

von Diest, S.G., Wright, J., Samways, M.J., and Kieft, H. (2020) A call to consider farmer intuition for improved management decision making. Outlook on Agriculture 49(4):278-285.

Williams, M. (2003) Learning Their Language: Intuitive Communication with Animals and Nature. Novato, CA: New World Library.

Zylstra, M., Esler, K., Knight, A., and Le Grange, L. (2018) "Integrating multiple perspectives on the humannature relationship: A reply to Fletcher 2016". Journal of Environmental Education 50(1):1-10. 


\title{
22 An Investigation of Sustainable Yogic Agriculture as a Mind- Matter Farming Approach
}

\author{
Janus Bojesen Jensen \\ Coventry University
}

\section{CONTENTS}

Introduction: A Paradigm Shift for Farming Practice? ............................................................. 247

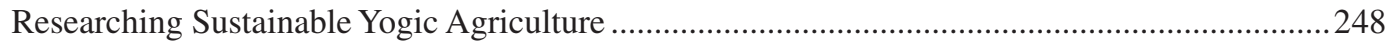

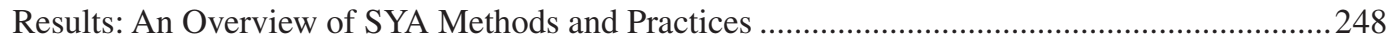

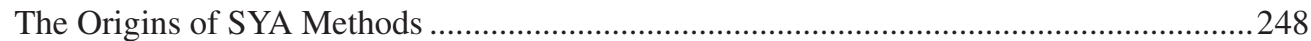

The Metaphysical Component: Practice of Raja Yoga Meditation.....................................249

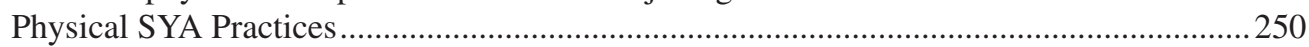

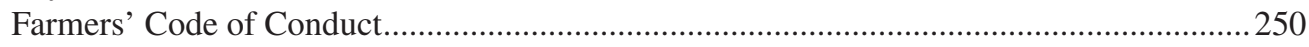

What Are the Impacts of SYA Farming Methods? ...........................................................250

Results of Published Research Trials on the Impacts of SYA .................................250

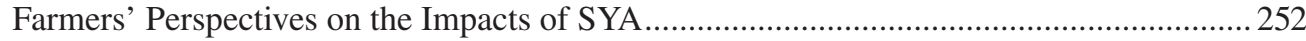

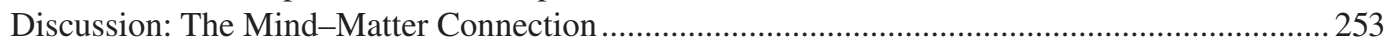

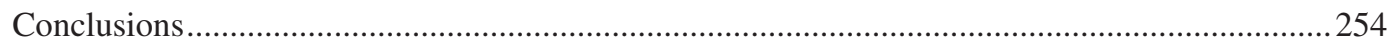

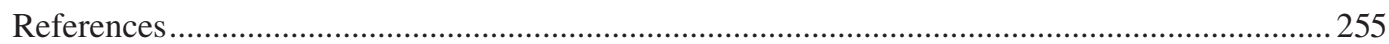

\section{INTRODUCTION: A PARADIGM SHIFT FOR FARMING PRACTICE?}

The global convergence of ecological, political, social and economic crises demands that 'business as usual' cannot continue. The global environmental and human health problems resulting from industrial-chemical agriculture have not gone away and are increasingly apparent in the public domain (IPCC, 2019; IARC, 2015; UNCTAD, 2013; UNCCD, 2011). Proposals from within the dominant paradigm that advocate further techno-fixes are no longer convincing or appropriate; as author Charles Eisenstein states, we are living in a liminal time 'between stories' (Eisenstein, 2013: 6). From an epistemological perspective, Santos (2014: 233) argues that global social justice is impossible without global cognitive justice and that we are in a transition period in which the problems created from the cultural and political confines of Western modernity have no modern solutions.

The alleged universal norms of modern industrial society, with its overriding emphasis on materialist science and technology as a means to subjugate nature, are a lingering Western colonial legacy. The ontological and epistemological premises of materialism continue to be challenged on the periphery by indigenous cultures, for example in the academic literature on decolonisation. Santos (2014: 188) refers to an existing 'sociology of absences' and calls for an 'ecology of knowledges' that enables alternate ways of knowing and scientific knowledge to coexist. The intimate connection between spirit and matter has long been recognised in the spiritual traditions and worldviews of indigenous cultures worldwide (Aikenhead and Michell, 2011; Ramsay, 2012a) and remains so in the world's social majority (Apffel-Marglin, 2012). In recent decades, the growing field of quantum 
mechanics within the Western scientific establishment reveals synergies with indigenous worldviews on the underlying nature of reality (Craven and I'poyi, 2009).

In the farming context, the application of invisible, non-material and spiritual practices is neither a radical nor a new suggestion. For over 10,000 years of farming, such practices were incorporated into agricultural life up until very recent times even in the West (Bellwood, 2005). The proposition of this chapter is that part (at least) of any transition towards a more healthy and regenerative global agriculture will not be found within the confines of the Western industrial worldview and its dogmas need to be overcome so as to include invisible, non-material and spiritual practices to supplement and perhaps alter the existing material ones.

\section{RESEARCHING SUSTAINABLE YOGIC AGRICULTURE}

One farming approach that recognises and works with the invisible, non-material dimension is Sustainable Yogic Agriculture (SYA). This system originates from the Brahma Kumaris spiritual movement, founded in India by Dada Lekhraj Kripalani in 1937, and which now has a global presence with 8,500 centres in 110 countries (Brahma Kumaris, ND). The Brahma Kumaris worldview is derived from Vedic cosmology and holds that all human beings are pure souls inhabiting a physical body. It states that soul consciousness, having traits of purity, bliss and love, is to be considered as one's true nature rather than the more common body consciousness, the latter being the cause of humanity's present afflictions (Ramsay, 2012b). The SYA initiative was launched in 2008 by the Rural Development Wing of the Brahma Kumaris World Spiritual University (RDW, 2009). SYA is premised on the philosophy that 'as the food, so the mind and as the mind, so the body'.

Given that SYA is little known as a farming system, a research study was developed to understand its methods and to ascertain its performance and potential. This was undertaken through a literature review followed by a field trip to SYA farmers in Rajasthan and Gujarat provinces, close to the Headquarters of the Brahma Kumaris at Mount Abu from 8 to 23 November 2017. Permission was necessarily obtained from the headquarters. Taking an inductive approach, the study assessed the findings against existing scientific evidence about the practices being performed.

In terms of scientific literature, only one peer-reviewed paper has been published on SYA (Pandey et al., 2015). Because of this dearth of research, non-peer-reviewed and grey literature is also taken into account in this chapter, including a further 12 publications that were only accessible in hard copy form at the Brahma Kumaris Headquarters.

The field study visit comprised a group interview based on a pre-prepared, semi-structured questionnaire that was conducted with eight farmers practising SYA. A translator was present to enable the discussion. This meeting was organised by the Brahma Kumaris Rural Development Wing, which also selected the participants, all of whom were members of a Gujarat-based SYA group consisting of 30 farmers. All were male and in an age range of between 40 and 60. The area of the farmers' holdings dedicated to SYA was small, averaging 1 acre, and did not cover all of their landholdings.

A field visit was also made to the Brahma Kumaris Demonstration Farm, 'Tapovan', located near the global headquarters at Shantivan, Mount Abu. This 5-acre horticultural farm has been managed as an SYA demonstration farm for the past 3 years, hosting educational visits by thousands of conventional small- and medium-scale farmers from within India and abroad.

Using an ethnographic approach, questions were put to the farm manager and a representative from the Rural Development Wing.

\section{RESULTS: AN OVERVIEW OF SYA METHODS AND PRACTICES}

\section{The Origins of SYA Methods}

SYA came into being as a result of observations by Indian farmers practising meditation in their fields to improve crop health. Their methods were brought to the attention of the Brahma Kumaris 
Rural Development Wing (RDW), which subsequently developed and launched them as an initiative to improve the lives and livelihoods of farmers (Ramsay, 2012a). Ramsay (2012a: 118) defines SYA as 'a unique form of farming that combines thought-based meditative practices with the methods of organic agriculture'. SYA sets its foundation on standard organic principles that prohibit the use of non-organic fertilisers and biocides. The metaphysical or subtle element of meditation is subsequently added as a core component of all farming practices throughout the year.

\section{The Metaphysical Component: Practice of Raja Yoga Meditation}

SYA farmers are firstly trained in the practice of Raja Yoga, a style of open-eyed meditation taught by the Brahma Kumaris that is inspired by ancient Indian practices. The method is described in the SYA Manual (RDW, 2009: 21-22) and summarised as follows:

The first step of Raja Yoga Meditation is to attain the soul-conscious stage. Pure thoughts are the source of pure vibrations, and pure vibrations create a pure atmosphere. After having entered into such a state, if you think positive about any person, animal, or vegetation irrespective of where they are, very far or very close, our vibrations reach them and activate every gene.

The manual also states that the ideal time to perform this meditation is between 4 and 5 am (part of the time period referred to as 'Amrit Vela'). Farmers should also transmit positive intentions outside this time period during specific farming activities. These regular meditation sessions can be conducted remotely or in the field, with focused thought practices and affirmations to support each phase of the crop growth cycle, from sowing, irrigation and growth to harvest and soil rehabilitation (Ramsay, 2012c; RDW, 2009). As well as focused meditation on the field crops, Ramsay (2012c) describes the practice of seeds being taken to local Brahma Kumaris meditation centres where experienced meditators focus thoughts of peace, non-violence, love, strength and resilience on them from between 10 days and 1 month prior to sowing. This is believed to enhance seed germination.

Examples of meditative affirmations for various stages and occurrences over the seasonal farming cycle are provided by Ramsay (2013a) and shown in Table 22.1.

Farmers are also encouraged to play music and sing spiritual songs while working in the fields, both for their own motivation and happiness and in the expectation that this will aid crop growth (RDW, 2009: 44). The ringing of bullocks' bells was also felt to have a beneficial environmental effect (farm group interview, this study). Another cultural practice is the hoisting of red and yellow 'Flag of Shiva' $5 \mathrm{ft}$ above the ground at regular intervals across the fields. This serves multiple purposes, some of which are metaphysical: it is a constant reminder to the farmer that he/she is tending God's land, and that the land is under divine care even when the farmer is not present; and it acts as a reflector of sunlight onto the crops (RDW, 2009: 44).

TABLE 22.1

\section{Affirmations Used by SYA Farmers at Specific Farming Events}

\section{Farming Event}

Amrit Vela (4-5 am every morning)

Ploughing the land

Application of organic inputs

Irrigating

Incidence of disease

Incidence of pests

\section{Affirmation}

I am the form of peace, filling seeds with peace

I am a soul who transforms the world

I bestow fortune on the earth

I am a living river of wisdom

I am the form of silent healing power

I am the form of supreme purity

Source: Ramsay (2013a). 
In the event of pest damage, farmers in the group interview explained that a farmer may enter a state of meditation with the aim of achieving pure soul consciousness. This feeling of soul purity is then vibrated onto the crop as being full of health and divine light and therefore capable of resisting the pests. On Tapovan farm, a case was reported where parrots were causing partial damage to fruits, and the farmer meditated and established a communication with the parrots, inviting them to eat some whole fruits and to leave others intact. This was reportedly successful. SYA was premised on the notion that the farm is not only for human beings but that animals and all other living things should also be accepted and have their rightful place on the farm.

While the SYA farmers in the group interview reported following the astrological calendar as part of their cultural tradition, Tapovan farm respondents explained that meditation rather than external influences was considered the primary force for ensuring crop health. Nevertheless, the SYA farmers felt that performing the meditation and sending love to distressed plants supported the use of traditional remedies, which, according to them, were generally effective.

According to respondents at Tapovan farm, the aim of teaching Raja Yoga meditation is to cultivate in farmers a feeling of connection to God, Self, the Motherland and cows - the holy animal of India, and that this inner transformation of the farmer will in turn transform the farm through right thinking and action. The early morning meditation takes place near the 'Flag of Shiva', which is hoisted in the field, and the visible results of the meditation typically manifest in around 2-3 months.

\section{Physical SYa Practices}

As well as meditation and focused intent, organic farming techniques are applied. These include companion planting and integrated pest management (RDW, 2009). Such techniques were visible on Tapovan farm alongside rotations and the use of green manures. From a physical perspective, the red and yellow 'Flag of Shiva' also acts as a deterrent to grasshoppers, which allegedly lay eggs on the yellow part of the flag and subsequently perish (RDW, 2009: 44).

The production of home-made farm inputs is encouraged, and the SYA Manual provides instructions on how to prepare 11 specific soil, bacterial inoculation, pest management and fungicide preparations based on traditional practices using cow by-products and other local materials (RDW, 2009: 31-24). One such preparation is 'Jeevamrut', an organic liquid fertiliser. Farmers in the group interview concurred that it was vital to have a healthy soil with a good carbon content and microbial population, and this was attained through composted cow manure, cover crops and 'Jeevamrut' that serves as an inoculate of beneficial microbes.

Farmers explained that the use of tractors should be avoided as these compact the soil and that bullocks should be used instead, which are gentler to 'Mother Earth' (farmer group interview). The Brahma Kumaris believe that cows are integral to agriculture. Nevertheless, a tractor was used on the demonstration SYA farm as it was under pressure to produce food for the thousands of visitors to the Mt. Abu Headquarters (Tapovan farm).

\section{Farmers' Code of Conduct}

As well as the metaphysical and physical farming practices, SYA also comprises a specific code of conduct for farmers. This includes adherence to a pure vegetarian diet, the practice of abstinence from carnal desires, the avoidance of drugs and alcohol, goodwill towards others, remembrance of God and the early morning meditations (RDW, 2009: 44).

\section{What Are the Impacts of SYa Farming Methods?}

\section{Results of Published Research Trials on the Impacts of SYA}

According to Ramsay (2012c), the first SYA field trials were launched in India in 2009 by the Brahma Kumaris Spiritual University, involving 400 farmers from the central and northern regions. 
Research trials have since been carried out with the cooperation of scientists from two of India's agricultural universities, Govind Ballabh Pant University of Agriculture and Technology (GBPUAT) and Sardarkrushinagar Dantiwada University of Agriculture and Technology (SDUAT).

In a peer-reviewed paper on SYA, Pandey et al. (2015) wrote up and consolidated the results of several of these trials. One trial by the Directorate of Wheat Research in Karnal focused on the growth, productivity and quality of bread wheat in the growing season 2011-2012, on three adjacent parcels of land in Gagsina village, Karnal, Haryana. This trial compared four treatments: (1) organic farmyard manure plus yogic meditation (SYA), with (2) organic farmyard manure (ORG), (3) non-organic fertiliser (NPK) and (4) a control (CTL). The results are shown in Table 22.2 (Pandey et al., 2015) and have been tested for statistical significance. The results show a difference in performance between the SYA and the other treatments. SYA outperformed the organic and control in the categories of biomass, grain yield and grain weight. It did better than the NPK treatment in terms of grain weight and protein content, matched in terms of grain yield. The NPK treatment outperformed the others for biomass. While a one-season trial is not sufficiently robust, the indications are positive.

Another trial, carried out by SDUAT, focused on yields of wheat grain and stover (leaves and stalks), which were assessed over 3 years (one harvest per year) from 2009 to 2012, under treatments of (1) traditional organic with farmyard manure (ORG), (2) traditional organic + yogic farming (SYA) and (3) non-organic (NPK). In this trial, there was no control. As can be seen in Figure 22.1, for all 3 years and for both grain and stover, the non-organic treatment outperformed the rest. Apart from the first season, SYA outperformed the organic treatment. According to Ramsay (2012c), other results from this same trial showed higher amounts of iron, protein and vitamins in the SYA treatment compared to traditional organic and non-organic methods.

Pandey et al. (2015) summarised another experiment of SDUAT in which the quality (protein and oil contents) and quantity (haulm and oil yields) of groundnut were assessed over three harvest seasons (2009-2010, 2010-2011 and 2011-2012), with treatments of NPK, traditional organic and SYA practices. Although the yields of haulm and oil were significantly higher in the NPK-treated plots than in the traditional organic and SYA for all three harvest seasons, the protein and oil contents in the SYA treatments were higher than for the NPK and organic treatments.

A non-peer-reviewed study by Raval (ND) from Tolani College of Arts and Science in Adipur, India, published on the Brahma Kumaris website, also explores crop quality. This study assessed the protein, carbohydrate and energy values of SYA versus organic treatments of soybean. While the SYA treatments outperformed the organic in all three categories, little other information was provided regarding the details of the trial.

TABLE 22.2

\section{Trial of Bread Wheat over One Season, Comparing (a) SYA, (b) Organic and (c) Non-Organic Methods of Agriculture}

\begin{tabular}{|c|c|c|c|c|}
\hline Treatment & $\begin{array}{l}\text { Biomass } \\
\left(q^{\mathrm{a}} / \mathrm{ha}\right)\end{array}$ & $\begin{array}{c}\text { Grain Yield } \\
\text { ( } q^{\mathrm{a} / \mathrm{ha})}\end{array}$ & $\begin{array}{c}\text { 1,000-Grain Weight } \\
(\mathrm{g})\end{array}$ & $\begin{array}{c}\text { Grain Protein } \\
\text { Content }(\%)\end{array}$ \\
\hline Organic + yogic (SYA) & 81.31 & 31.46 & 44.28 & 9.13 \\
\hline Organic (ORG) & 63.28 & 22.78 & 41.70 & 9.78 \\
\hline Non-organic (NPK) & 94.59 & 31.81 & 41.74 & 8.03 \\
\hline Control (CTL) & 61.89 & 19.76 & 40.92 & 7.75 \\
\hline Results compared with $P=0.05(5 \%)$ & $3.69 \%$ & $2.48 \%$ & $1.49 \%$ & $0.51 \%$ \\
\hline $\begin{array}{l}\text { Source: Pandey et al. (2015). } \\
\text { a } 1 q \text { (quintal) }=100 \mathrm{~kg} \text {. }\end{array}$ & & & & \\
\hline
\end{tabular}




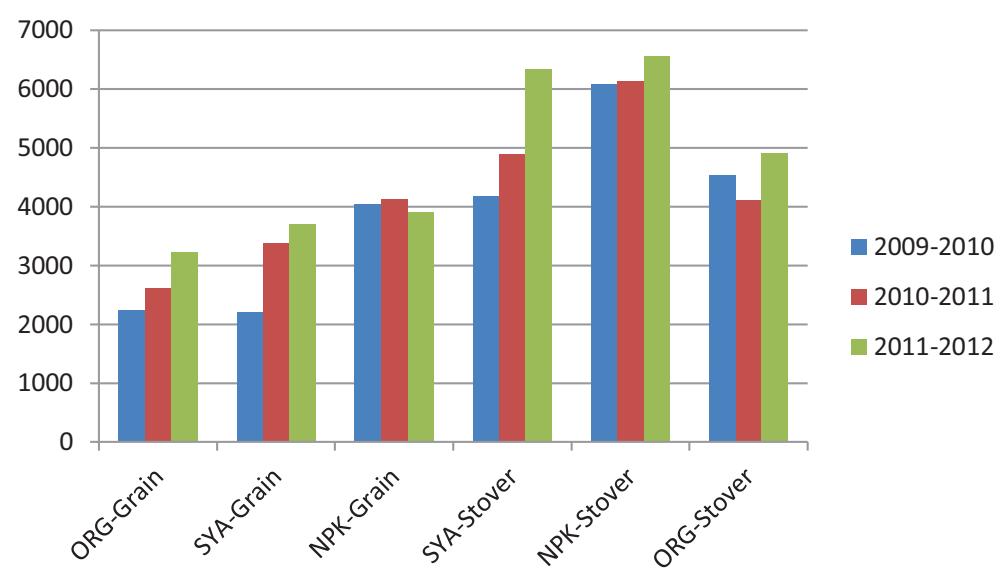

FIGURE 22.1 Bar chart showing yield ( $\mathrm{kg} / \mathrm{ha}$ ) of wheat grain and stover from SYA, organic and non-organic treatments. (Adapted from Pandey et al. (2015).)

\section{Farmers' Perspectives on the Impacts of SYA}

RDW has published at least 38 anecdotal reports of a qualitative nature from farmers on the benefits of adopting SYA, which were collected by Brahma Kumaris members (Ramsay, 2013b) and SDUAT university scientists (Patel et al., 2011). These benefits are summarised in Table 22.3.

Farmers in the group interview also identified improvements in the health and quality of their land and soil after abandoning the use of agrochemicals, including increased microbial load and activity and increased beneficial insect populations. In addition, there were fewer incidences of wild animals and pests causing crop damage. Livestock was reported to be more peaceful following the meditation practice. Customers were willing to pay more for their SYA produce, which they perceived to be of better quality.

The farm environment was reported to be more pleasant, joyful and refreshing, and these changes had also been noted by visitors. They felt their villages had become cleaner, more peaceful and unified politically, especially during elections. Farmers perceived their families as happier because the heads of the household (themselves) were more peaceful. They also noted fewer problems associated with addictions to smoking, alcohol, opium and other substances, since they had to abandon these practices. Fewer doctor's visits were reported, and one farmer claimed to have cured his paralysis problems after adopting SYA and eating more high-quality plant food. Farmers reported improved inner strength and higher self-esteem.

Most farmers planned to expand the SYA techniques to a larger area of their holdings. However, sufficient labour was a limitation, and the farmers were concerned that any labourers could affect the health of the crops if they were drinking and smoking. Some farmers in the group interview felt that the SYA farming was harder work since organic inputs were not always easily available whereas agrochemicals were. For example, the cow urine required as an ingredient for the traditional preparations should come from indigenous breeds, but in Gujarat, $90 \%$ of the cows are cross-bred. Hence, farmers felt they had to be seriously committed to the practices. The SYA farmers reported that 3 years was the transition period required to restore biodiversity to the land and soil. The Tapovan farm respondents noted that many farmers did not believe it possible to farm without agrochemicals and were afraid to try alternative methods as they expected lower yields. At this demonstration farm, the rationale was to explain that the higher quality produce led to higher market prices, and this combined with lower production costs (owing to the savings on agrochemical purchases) made SYA farming more profitable than non-organic farming. To help farmers adopt SYA, the RDW is facilitating a system of farmer-to-farmer networks, 
TABLE 22.3

\section{Key Quantitative and Qualitative Benefits of SYA, as Described by Farmers}

\section{Quantitative Benefits}

Increased crop yield

Increased crop nutritional content

Decreased costs of production

Increase in the price per kilo of product sold

Increased plant resilience

Decreased crop vulnerability to pests

Faster seed germination

Easy incorporation with other methods of sustainable agriculture such as sustainable rice intensification

\section{Qualitative Benefits}

\begin{abstract}
Improved family relations
Increased feeling of connection with livelihood

Increased sense of well-being and purpose

Increased sense of pride as a farmer

Improved relationships among farming communities

Reduction in emotions such as anger and frustration among farmers

Increase in emotions such as patience and forgiveness among farmers

Incorporates cultural and spiritual meaning into work life

Brings together disparate social sectors into a common purpose with wide-ranging benefits
\end{abstract}

Source: Ramsay (2013b) and Patel et al. (2011).

where farmers experiencing difficulties were put into contact via telephone with more experienced farmers.

In terms of spontaneous farmer-to-farmer dissemination, almost all SYA farmers in the group interview explained that their neighbours were sceptical when they initially adopted SYA but after some time would notice improvements in the quality of their produce of farm, which made them more curious to engage in SYA.

Online references show that SYA has also recently received attention at a national level with the Indian agricultural minister advocating that farmers adopt SYA (BBC, 2015). Outside India, SYA has also been adopted by an arable farmer in Italy who claims to have maintained profits and increased grain quality (Kebio EU, 2016).

\section{DISCUSSION: THE MIND-MATTER CONNECTION}

The published literature, farm visit and group interview all concur that the primary emphasis of SYA is positive human intention that is transmitted onto the farm, and this is carried out by trained farmer-meditators. The meditative practice, as well as the use of sound, is superimposed onto a foundation of standard organic practices that include the use of traditional preparations and remedies.

The mind-matter connection in the material realm and the effects of meditation on plant growth are supported by existing studies that attribute some scientific credibility to SYA claims (e.g. Dossey, 1998; Ducharme, 2007; Emoto, 2004; Loehr, 1959; Roney-Dougal and Solfvin, 2002, 2003; Radin and Nelson, 2000). These works are briefly reviewed below.

One of the earliest published experiments was undertaken on seed germination by Presbyterian minister and scientist Franklin Loehr (1959) who conducted two trials involving seeds and water. His results consistently indicated that positive prayer helped speed up germination and produced more vigorous plants, whereas negative prayer actually halted germination in some plants and suppressed growth in others. In another experiment, maize in a container receiving prayer water consistently sprouted a day earlier and had higher germination and growth rates than that in the other that received no prayer.

A meta-analysis by Radin and Nelson (2000) reviewed 40 studies carried out from 1959-2000 showing the impacts of mental intention focused towards a specific number, compared to a dice or random number generator (RNG). From a total of 515 RNG experiments by 91 researchers, the findings showed a statistically highly significant and repeatable mind-matter interaction effect in which 
the intention affected the outcome of the roll of the dice or RNG. The authors concluded from this study that the overall results could not be attributed to chance, selective reporting or variations in design quality. A well-known experiment made by Japanese scientist Masaru Emoto (2004) showed the effects of intent and words on water crystallisation patterns, and this has led to several publications and books which expound the potential implications for living organisms which are primarily composed of water. Ducharme (2007) published a doctoral thesis on an experiment in which positive and negative prayers were sent towards courgette seeds stored in Petri dishes in a greenhouse. The prayers were made by the researcher who was a trained alternative healer. The study found, compared to the control sample, a significant increase and decrease in germination rates and weights above statistical significance on the seeds receiving the positive and negative treatments, respectively. Roney-Dougal and Solfvin $(2002,2003)$ did two double-blind trials on two commercial organic farms in Somerset, UK, in which a trained healer blessed some of the lettuce seeds to test for germination and growth. The results showed that the seeds that were prayed for yielded an $\sim 10 \%$ higher crop yield and had less fungal and slug damage during the growing season than the control.

The many spiritual, physiological, psychological and emotional benefits provided by meditation have also been confirmed in numerous studies as summarised by Erickson (2016), and the practice of meditation itself has moved into the global mainstream culture for personal well-being (Pathath, 2017). SYA takes this further and applies meditative practices to crop growth and farm resilience (Ramsay, 2012a), and similar approaches that include a metaphysical dimension in agriculture have been advocated by Wright et al. (2017), Kieft (2006) and van Eijk (1998).

There are two main challenges with researching SYA. Firstly, in focusing on yield and productivity comparisons, the available research maintains the standard reductionist methodological approach while attempting to assess complex holistic systems that comprise both the physical and metaphysical. Nevertheless, the wider benefits of SYA are captured subjectively through the valuable anecdotal stories and literature of the SYA farmers, and this provides sufficient indication of differences between SYA, organic and conventional practices to encourage further research. Ramsay (2013b) recommends more targeted research on the topics of water absorption and retention, challenges of conversion from non-organic to SYA, the potential for SYA outside of the Brahma Kumaris community and India, differing farm scales and replicability with other forms of meditation.

The second challenge relates to differentiation between organic and SYA farming. It is possible that the reported economic benefits which appeared to be a result of the cost savings through both the non-purchase of agrochemicals and the selling of premium produce could be the result of the organic practices rather than the spiritual practices of SYA farming. Similarly, the environmental benefits could also be a result of switching from chemical to organic farming without the meditative practices having any impact. In addition, farming organically also requires conscious intention to switch from the mainstream approach - which is easier and less labour intensive, and thus, there could be intentional interference in organic as well as with SYA farming. Nevertheless committing to both the additional farm practices and the lifestyle changes of vegetarianism and abstinence (necessary to achieve a higher proficiency in Raja Yoga meditation) can be perceived as additional stringent requirements for the uptake of SYA farming and arguably involve an even stronger intention.

\section{CONCLUSIONS}

This chapter aims to provide an overview of SYA practices and investigate their effects. In order to achieve these objectives, a triangulated approach was deployed through a literature review, group interview and a visit to the SYA demonstration farm. Notwithstanding the lack of empirical verification, this provided rich data for the initial exploration of SYA as a farming system. While neutrality cannot be claimed - the small sample of farmers interviewed for this study had been selected by the Brahma Kumaris who were present during the group interview and who owned the demonstration farm visited - the author encountered what appeared to be a clear moral and spiritual integrity within the SYA movement. 
SYA superimposes a spiritual dimension onto standard organic practices, a dimension on which it places great emphasis. As a meditation-focused farming system, it offers synergies with the alternative agricultural movements, sharing common goals towards healthy food and community well-being. Such movements claim to be holistic, but to date, many of them have avoided or underemphasised the mind-matter dimension that is brought to the fore with SYA. SYA has achieved relatively good results at a local, national and international level in a very short (12 years) time period, and interest could spread further afield with the increased recognition and adoption of meditation practices originating from India. This study also highlights the psycho-social benefits of the meditation practice, which are incurred first by the farmer and then positively impact the entire farming family and community. This increased peace of mind - and fewer suicides ${ }^{1}-$ cannot be overestimated in the context of the plight of small farmers in India and other regions of the world.

\section{REFERENCES}

Aikenhead, G. and Michell, H. (2011) Bridging Cultures: Indigenous and Scientific Ways of Knowing Nature. New York, ON: Pearson Canada Ltd. Don Mills.

Apffel-Marglin, F. (2012) Subversive Spiritualities: How Rituals Enact the World. Oxford Ritual Studies Series. New York: Oxford University Press.

BBC (2015) India minister backs 'yogic' farming to 'empower seeds'. Available at: https://www.bbc.com/ news/world-asia-india-34254964 [accessed September 5th, 2020].

Bellwood, P. (2005) First Farmers: The Origins of Agricultural Societies. Malden, MA: Blackwell Publishing.

Brahma Kumaris (ND). Introducing ourselves. Available at: http://brahmakumaristhane.com/ [accessed August 10th, 2020].

Craven, J. and I'poyi, O. (2009) Indigenous epistemology and scientific method. Presented at the 16th Congress of the IUAES, Kunming, China July 26-31.

Dossey, L. (1998) Be Careful What You Pray for, You Just Might Get It: What We Can Do about the Unintentional Effects of Our Thoughts, Prayers, and Wishes. San Francisco, CA: HarperCollins.

Ducharme, L.J. (2007) The effects of intentional thought in close proximity or at a distance: Demonstrating the relation between mind and matter on seed germination. Ph.D. Thesis, Missouri: Holos University. http://www.holosuniversity.net/pdf/DuCharme_L_PDF\%20(1).pdf.

Eisenstein, C. (2013) The more Beautiful World Our Hearts Know Is Possible. Berkeley: North Atlantic Books.

Emoto, M. (2004) Healing with water. The Journal of Alternative and Complementary Medicine 10(1): 19-24.

Erickson, D.L. (2016) Integrating body, mind and spirit: An essay reviewing the physiological, psychological, and spiritual benefits of meditation. Journal of Transpersonal Research 8(2): 147-159.

IARC (2015) IARC monographs volume 112: Evaluation of five organophosphate insecticides and herbicides. Internal Agency for Research on Cancer (IARC). Rome: World Health Organization.

IPCC (2019) Global warming of $1.5^{\circ} \mathrm{C}$ : The intergovernmental panel on climate change. Available at: https:// www.ipcc.ch/sr15/ [accessed August 8th, 2020].

Kebio EU (2016). Spirituality and organic farming. Available at: https://www.kebio.eu/en/news/yoga-andagriculture.html [accessed August 10th, 2020].

Kieft, H. (2006) Quantum agriculture: Bridging frontline physics and intuitive knowledge of nature. In: Haverkort, B. and Reijntjes, C. (eds), Moving Worldviews, Reshaping Sciences, Policies and Practices for Endogenous Sustainable Development, pp. 209-218. Leusden: ETC/Compas.

Loehr, F. (1959) The Power of Prayer on Plants and People. Garden City, NY: Doubleday.

Pandey, S.T., Verma, O., Kewalanand, Pandey, D.S., Gill, S., Patel, J.C., Patel, G.N., Patel, D.M., Patel, B.T., Patel, B.B., Patel, D.S., Patel, I.S., Patel, R.N., Singh, N.K., and Thakur, D.M. (2015) Yogic farming through Brahma Kumaris Raja yoga meditation: An ancient technique for enhancing crop performance. Asian Agri-History 19(2): 105-122.

Patel, B.T., Patel, I.S., and Patel, M.M. (2011) Visit report for Brahma Kumaris Kolhapur, Maharashtra. SD Agriculture University. Available online: http://www.environment.brahmakumaris.org/images/ resources/Survey\%20Report.pdf.

Pathath, A.W. (2017) Meditation: Techniques and benefits. International Journal of Current Research in Medical Sciences 3(6): 162-168.

\footnotetext{
${ }^{1}$ One Indian farmer commits suicide approximately every 42 minutes (Prasad, 2019).
} 
Prasad, N.R. (2019) A review on the farmer suicides in India: An unsolved problem. Journal of Economic Policy and Research 14(1): 56-67.

Radin, D. and Nelson, R. (2000) Meta-analysis of mind matter interaction experiments: 1959 to 2000. Boundary Institute, Los Altos, California, and Princeton Engineering Anomalies Research, Princeton University, p. 11. Available online: http://citeseerx.ist.psu.edu/viewdoc/download?doi=10.1.1.385.3058\& rep=rep1\&type $=$ pdf [accessed August 10th, 2020].

Ramsay, T. (2012a) Systems approach to agriculture. Combatting Desertification, LEISA India, 14(4): 29-30.

Ramsay, T. (2012b) Awakening biodiversity consciousness. Statement for the Conference of the Parties to the Convention on Biological Diversity. Eleventh Meeting, Andhra Pradesh, Hyderabad, India. October 8-19, 2012. (Unpublished). Available online: https://www.researchgate.net/publication/239672387_ Awakening_Biodiversity_Consciousness (accessed August 10th, 2020).

Ramsay, T. (2012c) Yogic agriculture reaping rewards in India. Rioplus Business Magazine. Produced for: Rio+20, United Nations Conference on Sustainable Development, Rio de Janeiro, June 2012. pp. 118-119. Available online: http://www.academia.edu/1786497/Yogic_Agriculture_Reaping_Rewards_in_India (accessed August 10th, 2020).

Ramsay, T. (2013a) Sustainable yogic farming: Changing the lives and livelihoods of farmers. October 8th 2013. Available online: http://yogickheti.org/researchPapers/SYA_Living_in_Harmony_2013.pdf (accessed October 13th 2020).

Ramsay, T. (2013b) Sustainable yogic farming: Internal report. Tour of Maharashtra and Goa 2013. Brahma Kumaris at the United Nations, New York. Available online: https://www.researchgate.net/ publication/265172643_Informal_Report_-_SYA_Tour_India_September_2013 (accessed August 10th 2020).

Raval, K. (ND) A statistical analysis of the effect of yogic and organic fertilization on the Nutritive values of Soyabean. Department of Home Science, Tolani College of Arts \& Science, Adipur, Gujarat (Unpublished). Available online: http://www.yogickheti.org/researchPapers/Dr_Kiran_Raval_final_ paper.pdf (accessed August 10th, 2020).

RDW (2009) Perpetual yogic agriculture. Rural Development Wing. Rajyoga Education and Research Foundation and Prajapita Brahma Kumaris Ishwariya Vishwa Vidyalaya. Shantivan, Mount Abu: Omshanti Press. Available online: http://yogickheti.org/pdf/Book\%20English.pdf (accessed August 10th, 2020).

Roney-Dougal, S.M. and Solfvin, J. (2002) Field study of enhancement effect on lettuce seeds: Their germination rate, growth and health. Journal of the Society of Psychical Research 66: 129-143.

Roney-Dougal, S.M. and Solfvin, J. (2003) Field study of an enhancement effect on lettuce seeds: Replication study. Journal of Parapsychology 67(2): 279-298.

Santos, B.S. (2014) Epistemologies of the South. London: Routledge.

UNCCD (2011) Desertification: A Visual Synthesis. Bonn: UNCCD Publications.

UNCTAD (2013) Wake up before it is too late: Make agriculture truly sustainable now for food security in a changing climate. Trade and Environment Review. Geneva: United Nations Conference on Trade and Development.

van Eijk, T. (1998) Farming systems research and spirituality: An analysis of the foundations of professionalism in developing sustainable farming systems. Ph.D. Thesis, Wageningen: Wageningen Agricultural University. ISBN 90-5485-980-6.

Wright, J., Kieft, H. and von Diest, S. (2017) Quantum-based agriculture: The final frontier? In: Rahmann, G., Andres, C., Yadav, A.K., Ardakani, R., Babalad, H.B., Devakumar, N., Goel, S.L., Olowe, V., Ravisankar, N., Saini, J.P., Soto, G., and Willer, H. (eds), Innovative Research for Organic 3.0 - Volume 1. Proceedings of the Scientific Track at the Organic World Congress 2017, November 9-11 in Delhi, India. Braunschweig: Johann Heinrich von Thünen-Institut, 549 p., Thünen Rep 54, Vol. 1: 107-111. http://orgprints.org/32350/. 


\section{Section 4}

Voices from the Field 


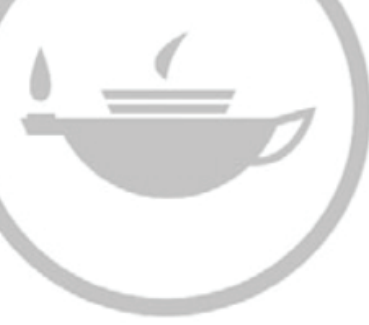

Taylor \& Francis Taylor \& Francis Group http://taylorandfrancis.com 


\title{
23 The Etheric Realms as a Foundation for Exploring the Use of Radionics with the Biodynamic Preparations
}

\author{
Hugh Lovel*
}

\section{CONTENTS}

Introduction.

The Advance of Western Science, from Kant to Goethe............................................................260

Maxwell's Ether and the Etheric Realms...............................................................................260

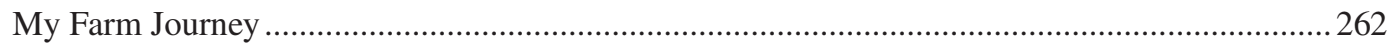

Exploring the Biodynamic Preparations through Radionic Applications .....................................264

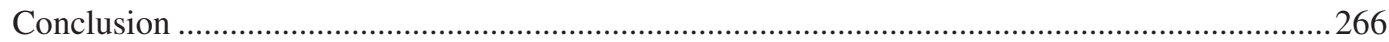

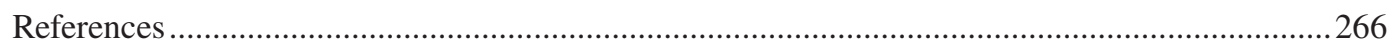

\section{INTRODUCTION}

The more that agriculture explores variables such as the weather, latitude, soil types, planting dates and soil ecologies - to say nothing of human factors - the clearer it becomes that agricultural research has no hope of limiting or controlling most of these variables, and instead we need to update our concepts and methods. One such concept is that of the soil food web - a living result of the earth and the sky interacting with life. Another is organisation as being the basis of life, as life is organic. The soil food web must breathe, and the earth and sky must interact well for life to thrive. We cannot enliven the soil without also organising the atmosphere, and to do that we must awaken life in the soil.

Yet anyone using such terms in relation to agriculture, such as sky, sun, moon and planets, let alone ether and astrality, is apt to be met with rejection and disdain, even though history is replete with lore about studying the stars and delving into the mysteries of nature, such as that of the Rishikas, Zarathustra, Moses or the Magi. Such is to be expected, since western science has for centuries held that intangible phenomena are imponderable and cannot be examined. Meanwhile, truth seekers will realise that these concepts and observations are too consistent and elaborate to be mere imagination, and here lies a rich load of scientific discoveries waiting to be brought to light. At its roots, science is the art or craft of knowing, and the analytical method is not our only means of knowing. Quantum physicist Max Planck famously observed, in mainstream academia, that science advances one funeral at a time. ${ }^{1}$ However, pioneers in science push the boundaries of what we know in order to free themselves of these restraints and explore the vast uncharted territories beyond. For myself as a farmer, teacher and independent researcher, I write from my experiences and knowledge

\footnotetext{
* Deceased.

1 'A new scientific truth does not triumph by convincing its opponents and making them see the light, but rather because its opponents eventually die and a new generation grows up that is familiar with it' (Planck, 1949: 33).
} 
rather than in pure academic form. Much more can be found in my book Quantum Agriculture, Biodynamics and Beyond (Lovel, 2014).

\section{THE ADVANCE OF WESTERN SCIENCE, FROM KANT TO GOETHE}

Western thought has been considerably shaped by the adoption of Emanuel Kant's epistemology the study of how we know what we know. Kant (1724-1804) was an influential German philosopher in the Age of Enlightenment. His most persuasive work was Critique of Pure Reason, written in 1781, and his views continue to influence contemporary philosophy, especially in the fields of epistemology, ethics, political theory and postmodern aesthetics. Kant asserted that we know something is real by seeing, hearing, smelling, tasting or touching it - and that there are no other means. So, we can know the physical corpus of any plant, animal or human, but since we cannot hold its life in our hands and measure its weight and circumference or its will to live, then the fact of its life is not real (Kant, 2017). Excluding the influence of life and values on physical reality may seem strange in the twenty-first century, but in Kant's time, phenomena beyond the five senses were categorised as 'imponderable' and to be avoided. Kant's epistemology coupled neatly with the ideas of Pierre-Simon Laplace (the French polymath who from 1799 to 1825 wrote Mécanique Céleste Celestial Mechanics (Biot, 2009)) that the universe follows a precise calculable path, and the Kant/ Laplace cosmologies were far and away the predominant theories taught in western schools in the late nineteenth and most of the twentieth centuries. This all seemed to make the pursuit of scientific truth so clear and simple that physicists and mathematicians of that time believed they were on the verge of understanding the totality of natural science, or at least the 'hard' sciences like physics and chemistry.

However, physics went from Isaac Newton (who laid the foundations of classical mechanics) and James Maxwell to the twentieth-century figures of Ernest Rutherford (father of nuclear physics) and Einstein, Niels Bohr (who paved the foundations for understanding quantum theory) and Werner Heisenberg (pioneer of quantum mechanics), Paul Dirac (who contributed to both quantum mechanics and electrodynamics) and Erwin Schrödinger (who showed how to calculate the wave function), and things clearly became more complex than they had previously seemed (Becker, 2019). Nevertheless, all efforts to form a 'theory of everything' failed. But there also was Johann Wolfgang von Goethe. Goethe (1749-1822) was a German writer, statesman and scientist of wide acclaim.

In his lifetime, Goethe's scientific writings were often rejected by fellow scientists, though a bit later quantum physicists like Heisenberg and Schrödinger found Goethe to be a rich source of inspiration. Goethe's belief that the observer and the phenomenon were inseparably linked was especially at odds with his contemporaries. To Goethe, it was obvious that perception is limited to and determined by our concepts. What is beyond our conception eludes our perception. Furthermore, the observer chooses what to look at and how. People commonly attract those experiences they look for most, whether out of desire or aversion. Other experiences pass them by unnoticed (Steiner, 1988).

Here, Goethe's thinking flies in the face of the popular Cartesian belief (from René Descartes, founder of modern philosophy) that reality is purely objective and the observer has no influence over phenomena. But quantum theory vindicated Goethe as it found the observer, and his/her measuring instruments, are determining factors of what is actually observed. Observers seeking waves find their non-local patterns, and those seeking particles find their locations. Both are indeterminate until the observer looks. To some as yet unknown extent, we determine the realities we experience.

\section{MAXWELL'S ETHER AND THE ETHERIC REALMS}

In conventional physics, gravity is the first force and electromagnetism is the second. James Clerk Maxwell (1831-1879) was a Scottish physicist, known for his formulation of electromagnetic theory. By combining electricity and magnetism, Maxwell and his colleague Michael Faraday created 
a flow of electromagnetic force along the inner surface of a wire. Around the same time, J. J. Thomson (who is credited with discovering electrons) discovered electrical discharge through gasses. Thomson's subsequent discovery of what he termed the 'electron' launched a new era of atomic theory. This suggested to Maxwell there must be an extremely fine stationary field, which supports the propagation of light and electromagnetic waves in the way air propagates sound. He called this the ether field. Ultimately, this field was not found by Michelson and Morley in their experiment of 1887 when they attempted to detect the existence of the ether, a supposed medium permeating space that was thought to be the carrier of light waves. They found no interaction with any etheric field in any direction, even though the earth travels at great speed. They then built a huge interferometer resting on a bed of mercury to dampen extraneous vibrations, and they still detected no 'etheric wind'. This was taken as proof that there was no ether, which today is still the basic belief (Shankland, 1964). However, though Michelson and Morley's experiments disproved Maxwell's theory of a universal fixed etheric field, this did not disprove any other ether, and Dirac believed mathematics required some kind of organisational activity - which is to say etheric activity - as an inherent property of all physical masses (Pais, 2005).

Prior to this however, Goethe, in his alchemical investigations, studied not only the elements and ethers of Greek philosophy, but also elemental beings or individualities - gnomes, sylphs, undines and salamanders - which he used his imagination to 'see'. The term 'being' refers to their condition of being self-organising and thus alive, but does not mean they organise physical substance. These beings inhabit the ethers corresponding to the four elements of Greek philosophy (fire, air, water and earth), which indicate the effects of their otherwise unexplained activities (Steiner, 1988). This was such a major departure from the western worldview of Kant and modern physics that it triggered the automatic mainstream rejection of Goethe's scientific works for all except Rudolf Steiner.

Steiner (1861-1925), an Austrian philosopher, social reformer, architect, esotericist and clairvoyant, put forward the concept of the fourfold human being as a vessel consisting of a physical body, an ether-body, an astral body and an ego or 'I' (Steiner, 1959). Steiner's concept of the ethers is also tied to the four elements. The four elements are visible, tangible and subject to entropy, while the ether or ethers associated with these elements are invisible, dynamic and syntropic rather than entropic. 'Dynamic' indicates an energetic process that begins and ends over an interval of time, and 'syntropic' means they are organisational, as their order flows from lower concentration to higher concentration. The ethers organise and activate the elements, each element relying on a different sort of ether.

Based on Steiner's teachings, Dr Ernst Marti (1903-1985) took forward the study of the ethers as a lifelong pursuit and proposed bridges between the ancient and medieval worldviews and the present natural and spiritual sciences (Marti, 2017).

Warmth Ether: The initial and most rarefied ether stage, the warmth ether, is one with the fire element, as is characteristic of sulphur. It is a purely temporal and non-spatial oscillation, having no mass or density, only duration.

Light Ether: Following the warmth ether, the light ether creates order, as is characteristic of nitrogen, within the air element. Light ether flows outwards from surfaces, creating space within the fullness of time. With light, we have the first appearance of its opposite - physical density and mass, or the other side of surfaces.

Tone Ether: The next etheric stage is the tone ether, which organises the water element and shows us the characteristics of hydrogen in the way water behaves. Tone adds vorticity or movement to warmth/time and light/space, as is characteristic of water, which spins either left or right as well as in and out, creating nodes, waves, intervals, separation and union, number and periodicity, precipitation and buoyancy.

Life Ether: The last and the most dynamically organised stage is the life ether, which is characteristic of carbon. It contains, permeates and integrates self-organising forms. The life ether provides unity and identity to organisms whose physical structure is made up of what Vedic and Greek philosophies called the earth element. 
If each ether creates the conditions for the next ether to arise, then the life ether depends on the creation of time by warmth, space by light, and movement by tone to create coherence, thus forming living organisms with all four ethers which work together in unity within a boundary. Life ether is the vitalising force of identity, containment and healing that permeates every living organism within its cell wall, skin, bark or its outer integument. When this is lost, the organism dies. Author and biophysical researcher Rupert Sheldrake calls this 'morphic resonance', or the resonant coherence that sustains form and keeps it whole (Sheldrake, 2009). However, Sheldrake's work is more in accord with Goethe's epistemology than Kant's and thus still lacks mainstream acceptance.

So from the Goethean point of view, the four dynamic, syntropic ethers create time, space, motion and coherence, each of which is associated with the elements - fire, air, water and earth. The warmth ether creates nature as an oscillation between past, present and future, just as subatomic particles are found to go both forward and backward in time. All else follows. Critically, the light, tone and life ethers are opposed by the entropic disorganisational forces of electricity, magnetism and radioactivity, which tend to destroy the integrity of living bodies, eliminating their coherence, paralysing their motion and creating an absence of space.

It might seem that Goethe's belief that concepts are required for perception to occur has nothing to do with agriculture. However, agriculture has long been perceived as a battle to wrest a living from nature which fights back with weeds, pests, diseases and inclement weather. Our war with nature has typically depleted its resource base with 'disorganisational' activities. Ploughing led to erosion, and adding nitrogen, phosphorous and potassium salts to soils over the last 100 years has made these soils increasingly less fertile. Even though we started with soils rich in humus and organic life, we ended up with soils so low in carbon that earthworms are now rarely seen. What our farms lack most is vitality or life, or, what can be termed organisational, etheric forces. From the Goethean point of view, the ethers, which are organisational and essential to life, reverse entropy just as living organisms are islands of order amidst a sea of chaos (as Schrödinger pointed out in his biophysics lectures in 1948). This makes a study of the ethers an overdue investigation.

\section{MY FARM JOURNEY}

Since my early childhood in South Louisiana, I was aware of the environmental challenges that were occurring around me. As the oil companies pumped, the tidelands south of us were subsiding. At the dinner table, my parents discussed our house going underwater if Greenland melted. I was aware of the gradual trend towards extreme weather events even in the early 1950s. My family took long summer trips from Louisiana to the Pacific Northwest to visit relatives, back when the roads were almost all two lane and rural. We saw lots of crops - along with flash floods, dust storms, devastating erosion, grasshopper plagues and failed farms. The Oklahoma Dust Bowl was history already, but my geography book had pictures of more recent and quite serious soil erosion in Georgia. Though this was decades ago, even then farming had worn out and used up its most basic resources, particularly soil and water. Weather affected soil loss and soil loss affected weather.

I was a city boy who had just a few summer farm experiences. Still, in 1970 I studied soil microbiology as a biochemistry major, and at the time, I found it odd that there were no agriculture students in our class. When I started farming, I assumed farmers knew what they were doing, so I copied their examples by ploughing and discing my fields edge-to-edge. This didn't work as well as I had hoped; I had some hard lessons to learn.

Trying to farm an eroded and failed farm that held only 1.5\% organic matter, in 1976 I grew a crop of sorghum for syrup using conventional methods of ploughing and chemical fertilisation. The sorghum crop was made into syrup, but the manner in which I grew it had such a negative effect on the soil biology - which already was quite poor - that it obviously could not be farmed further this way. Fortunately, I soon realised that I couldn't afford to grow any crop or use any method that didn't build life back into my soil. I already knew that soil fertility, from the soil microbes on up, was the basis of every farm's vigour. Somehow in the back of my mind, 
I always thought of my farm as having a coherent identity whose various activities fitted together and contributed to each other's success, though at first my farm didn't look as though that was happening.

That first winter after growing the sorghum crop, I humbly and gratefully prayed to find out what I needed to know. That was the first step as the next spring my neighbour, Shabari Bird, gave me two books: Thompson and Bird's best-selling 'Secret Life of Plants' (Thompson and Bird, 1989) and Pfeiffer's 'Biodynamic Farming and Gardening' (Pfeiffer, 1983), and introduced me to Peter Escher who became my mentor in biodynamic farming, a quality, self-sufficient, regenerative system of agriculture based on the insights of Rudolf Steiner. Biodynamics emphasises farming practices intended to achieve balance between the physical and higher, non-physical realms by harnessing both the cosmic and terrestrial forces. In the spirit of scepticism - rather than cynicism - I set about studying the organisational forces identified by Steiner, who gave recipes for making preparations to enhance these forces in order to build organisation into its environment so as to wean itself off outside inputs.

These preparations are one of the fundamental practices in biodynamic agriculture. They consist of mineral, plant or animal manure extracts, usually fermented and applied in small proportions to compost, manures, the soil, or directly onto plants, after dilution and stirring procedures called dynamisations. The original biodynamic (BD) preparations are numbered 500-508. They are intended to help moderate and regulate biological processes as well as to enhance and strengthen the etheric forces on the farm (Diver, 1999).

While setting up the small market garden, I also heard about something called the soil food web. I had studied this microbial community of soil organisms and the name made perfect sense. I could envision the soil food web as a symbiotic community of soil organisms where hundreds of thousands of different life forms worked harmoniously together, sharing all the tasks. I felt certain that this kind of synergistic ecosystem could enliven and unify my entire farm as an entity. I began to encourage it with Dr. Pfeiffer's Field Spray. As a young man, Ehrenfried Pfeiffer (1899-1961) was guided in his studies by Steiner. He came to America and, with the help of Peter Escher, set up laboratories in Spring Valley, New York. Pfeiffer looked at the task ahead: Steiner had said that the most important thing was to apply the benefits of the agricultural preparations from his Agriculture Course to the widest possible areas of the entire earth for its healing and the improvement of its produce in every respect. This led Pfeiffer to produce his Field Spray, which contained all of the biodynamic preparations except the horn silica. So I used this spray around the house, up the driveway to the highway, along the creek, fences, tracks and boundaries - and over the fields too. The thistles disappeared except for a scattered few. Clover started to grow abundantly. The grass burst forth earlier in spring and stayed green longer in autumn. The interplay became increasingly dynamic between what went on above ground by day and what went on below ground by night.

Having studied biochemistry, what the biodynamic literature said about lime and silica and what Peter showed me made good sense; I had known almost nothing about Steiner, but at least he was precise enough about chemical nomenclature to mean calcium oxide when he said lime and silicon dioxide when he said silica.

Strangely, biodynamics was the only form of agriculture I knew of that thought silica was important, even though silica comprises more than half of the earth's crust. I also knew silica is structural like carbon. It forms strong cell walls, connective tissues and transport vessels. Insect exoskeletons are rich in silica. It creates the chalice that contains and circulates the mineral/protein protoplasm in living organisms.

It became my daily meditation to ask myself: what could I do to establish, grow and enhance this biological reservoir and well of life so that it permeated every corner of my farm? When I listened with an ear to the soil, I imagined I could faintly hear the soil food web humming, breathing, spinning, weaving, chirping, moaning, sighing, sleeping and, especially in winter, waking up and renewing itself. I was growing an ecosystem, a teeming, diverse metropolis of soil organisms whose complexity made a city like Tokyo look like a country village. 


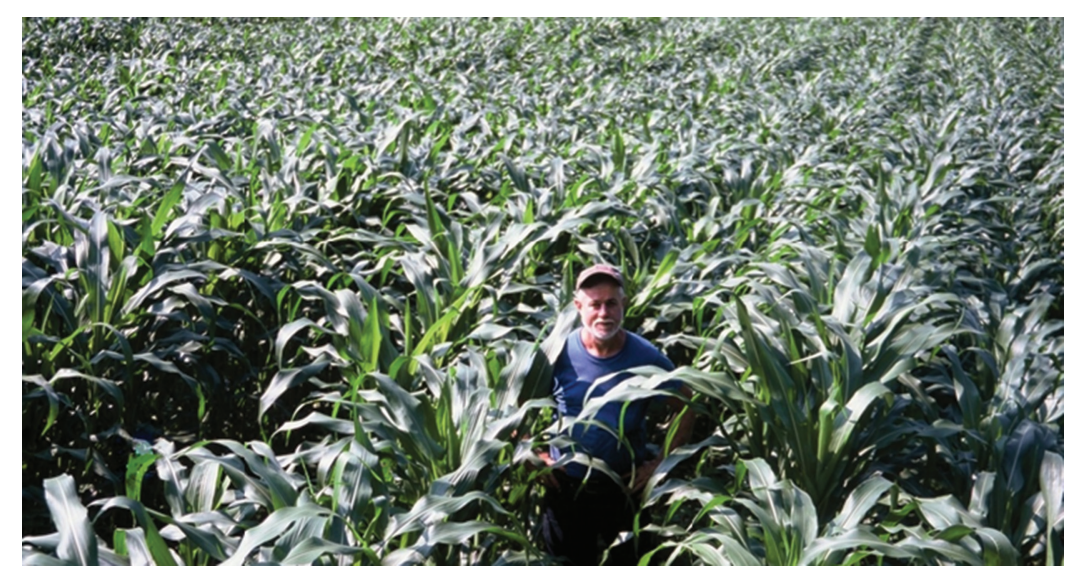

FIGURE 23.1 The author in a field of maize undersown with soybeans with radionically applied biodynamic preparations and no other fertility inputs, in metre wide beds spaded into the soil food web. (Photo credit: Hugh Lovel.)

The benefits of feeding and improving the soil food web kept adding up. I'd heard about chaos theory's discovery that organisation arises at boundaries, and I learned to nurture my boundaries so that they fed organisation to my beds and fields. My best veggies grew on the edges of the beds. I found I could spread my natural inputs everywhere, feeding paths, fence rows and boundaries as well as my crops. Always the paths and boundaries fed the beds. I was growing maize along with soybeans as a soil improvement crop to add carbon and organic life to the soil without the need for external inputs (Figure 23.1).

It took me 8 years to realise what should have been obvious. Ploughing, cultivating and leaving entire fields bare for weeks and months on end don't just kill the earthworms. These actions stunt, starve, shred and kill the entire soil food web. On the other hand, strip tilling beds in an otherwise undisturbed soil food web creates miles of boundaries between cultivated beds and the surrounding sod. After all, organisation arises at boundaries. Then the delicate influences of starlight and moonlight could engage the atmosphere with the soil for nitrogen fixation and protein chemistry. As life in the soil food web grew, the soil's animal sense-and-desire life became well-fed and thriving. Throughout the animal kingdom, digestion develops hand-in-hand with animal awareness. With abundant animal life in the soil, the market garden and soil food web became sentient, even though these animals do not have a brain isolated in dense bone like the human skull. I think if anyone experienced such living, sentient food, they would want a steady diet of it.

\section{EXPLORING THE BIODYNAMIC PREPARATIONS THROUGH RADIONIC APPLICATIONS}

As well as biodynamic agriculture and the soil food web, I have experimented with specific applications of quantum physics and in particular with radionics. Radionics is a technology based on the wave or etheric aspect of nature rather than the particle aspect and is all about copying and transferring patterns (Young, 1976). It was discovered and developed at the turn of the twentieth century before quantum physics showed that while particles are local, wave patterns are non-local. A medical doctor in the USA, Albert Abrams, was experimenting with various tunable resistance devices and discovered that everything he experimented with radiated an emanation or frequency and that this could be used to treat disease. At first, radionics met with intense scepticism and, with only superficial examination, was frequently dismissed as bunk. However, according to my understanding, non-local waves are the etheric forces that organise physical materials, and my investigations 
into influencing the farm biosystem's patterns of activity showed me the ease and efficiency of applying the wave patterns of the biodynamic preparations through radionics. My studies in physics made it clear that radionics worked with quantum non-locality and entanglement as it transferred patterns of activity over any distance instantaneously with no loss of signal (Lovel, 2014).

Prior to my use of radionics, my customary method of applying biodynamic preparations involved intensive stirring in water with alternating vortexes from clockwise to anticlockwise - then spraying the water on soil, plants, animals and/or over the atmosphere. Despite its meditative charm, this was time consuming as each application took more than 2 hours, and most farmers don't need extra jobs to do. Being able to impart biodynamic preparation patterns from a kitchen alcove or farm office in just a few minutes greatly extended my capacity to adjust the farm's biosystem with these patterns, especially during rain but even when I was off the farm. To assist with this and based on the work of T. Galen Hieronymus 2 , I designed and manufactured a simple, self-powered device similar to a crystal radio set, which I called a Field Broadcaster.

I use this to broadcast all the biodynamic preparation patterns to the entire farm in any weather, all year round. I also use a radionic instrument of my own design to impart patterns to my brews, soil drenches, irrigations and foliar sprays before applying them (see Figure 23.2). Because it uses cards that hold the preparation patterns, this allows uniform applications without using up any physical substances. This allows me to target different crops and fields with the individual activities that each needs in order to stay balanced and on track. When the sun is near the horizon (before breakfast and before supper), I compose and set in progress radionic programmes to impart appropriate preparation patterns via an aerial map of the farm with its boundaries marked. This allows me to respond to environmental conditions such as weather, seasons, daily cycles and lunar cycles, in order to keep the farm healthy. These morning and evening programmes help me to integrate and balance the activities in the farm biosystem as a coherent entity.

This is a general overview of how I apply radionics, and I have found that the radionic application of the biodynamic preparation patterns and observation of the results have revealed characteristics that have not been recorded elsewhere. Here, I describe just two of the preparations that I use.

$B D$ Soil Activator (1000): This is a complex compost made with all the biodynamic preparations including horn silica, horn clay and horsetail decoction in a cow manure base with the addition of rock powder (usually basalt) and lime (usually eggshell powder). All the ingredients are intensively
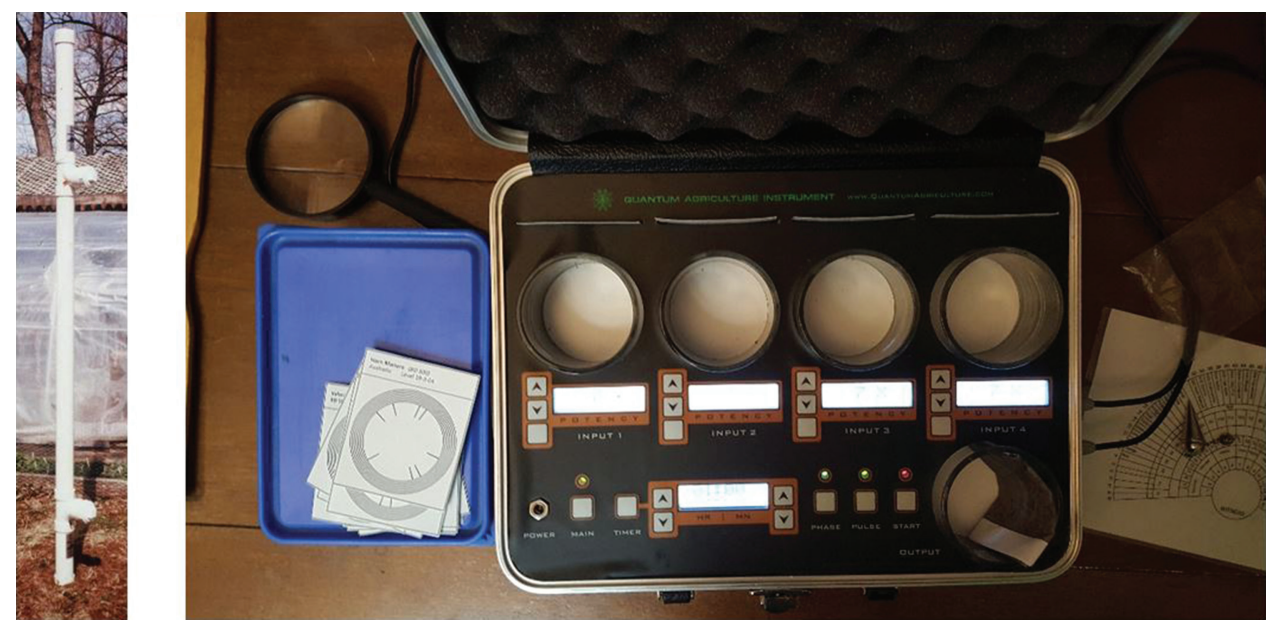

FIGURE 23.2 Field Broadcaster (left) and radionic instrument with cards (right). (Photo credit: Hugh Lovel.)

${ }^{2}$ T. Galen Hieronymus (1895-1988). One of the early radio engineers and radionics pioneers, who obtained the only US patent on a radionic instrument. 
mixed in a potentising process. Because the chemistry of these patterns works like music with its resonances and dissonances, this preparation acts like an orchestral ensemble, as compared to using each preparation as a solo instrument. The BD Soil Activator establishes and strengthens the full array of organic processes of the farm's biosystem and, with all its systems going, the integrity of the farm organism is on track.

$B D$ Yarrow (502): This preparation is made by stuffing the bladder of a male stag, deer, elk, caribou or other related species with the florets from yarrow (Achillea millefolium), hanging it overhead in the warmth and light ethers over summer, and then burying it in the soil's chemistry and life ethers over winter. A teaspoonful moulded into a ball with a little clay or manure can be dropped in a hole in a compost pile, where its vibratory resonance imparts the kidney/bladder process to a mass of material as big as a small house. Yarrow, with its lacy foliage and umbels of flowers, reaches out to the widest expanses of the universe and brings in the astral chatter of informational beauty and affinity. The male deer's bladder receives, collects and integrates this information and the nitrogenous substances associated with it. This provides the patterns of purification and refinement associated with the kidneys and bladder and the planet closest to the earth, Venus.

Farming with radionics, these biodynamic preparations are commonly used purely as patterns. Though the effects evoked are much the same as using the preparation materials by stirring and spraying, the ease of radionic application allows the farmer to use them far more frequently without using up any materials. This not only gives the farmer the opportunity for the timely application of patterns that can ensure the abundant production of quality crops, but it also enables the farmer to explore and discover how useful the biodynamic preparations can be.

\section{CONCLUSION}

I think of a farm as a living organism that breathes and grows in cycles to become increasingly alive and coherent within its boundaries. It's also a cell in the body of the living earth. Its processes are reflected in human body processes where the human diaphragm is like the soil's surface, while the activities going on in our heads are similar to what goes on in the soil, and the activities going on in our guts are similar to what goes on in the canopy. A farm and its food then become organised as a reflection of the surrounding solar system and cosmos. In this way, the context is able to inform the content.

\section{REFERENCES}

Becker, A. (2019) What Is Real? The Unfinished Quest for the Meaning of Quantum Physics. London: John Murray.

Biot, J.P. (2009) Analyse du Traité de Mécanique Céleste de P S Laplace. Ann Arbor, MI: University of Michigan Library.

Diver, S. (1999) Biodynamic Farming and Compost Preparation: Alternative Farming Systems Guide. Arkansas: ATTRA, National Center for Appropriate Technology, p. 20.

Kant, I. (2017) The Critique of Pure Reason: Original Classic Version of 1781. Scotts Valley, CA: CreateSpace Independent Publishing Platform.

Lovel, H. (2014) Quantum Agriculture, Biodynamics and Beyond. Blairsville: Quantum Agriculture Publishers.

Marti, E. (2017) The Etheric: The World of the Ethers Volume 1: Broadening Science through Anthroposophy. Sussex: Temple Lodge Publishing.

Pais, A. (2005) Paul Dirac: The Man and His Work. Cambridge: Cambridge University Press.

Pfeiffer, E. (1983) Biodynamic Farming and Gardening: Complete Set of 3 Volumes. New York: Mercury Press.

Planck, M. (1949) Scientific Autobiography and Other Papers. New York: Philosophical Library.

Schrödinger, E. (1948) Statistical thermodynamics. A Course of Seminar Lectures delivered in JanuaryMarch 1944, at the School of Theoretical Physics. Dublin: Institute for Advanced Studies, 1944. Reprint: Cambridge: Cambridge University Press. 
Shankland, R.S. (1964) Michelson-Morley experiment. American Journal of Physics 31(1):16-35.

Sheldrake, R. (2009) Morphic Resonance: The Nature of Formative Causation. Randolph, VT: Park Street Press.

Steiner, R. (1959) Cosmic Memory, Prehistory of Earth and Man. Sussex: Rudolf Steiner Press.

Steiner, R. (1988) Goethean Science. New York: Mercury Press.

Thompson, P. and Bird, C. (1989) The Secret Life of Plants: A Fascinating Account of the Physical, Emotional, and Spiritual Relations between Plants and Man. New York: HarperPerennial.

Young, A.M. (1976) The Reflexive Universe: Evolution of Consciousness. New York: Delacorte Press. 


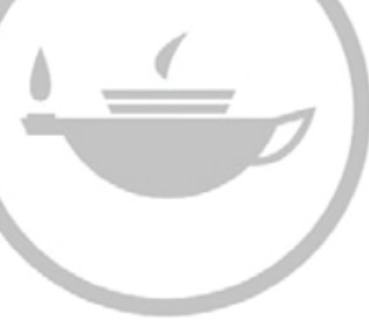

Taylor \& Francis Taylor \& Francis Group http://taylorandfrancis.com 


\title{
24 The Subtle Life of the Bee and Its Importance for Humanity
}

\author{
Sabrina Menestrina \\ Anthroposophical Veterinary Medicine, \\ Medical Section, the Goetheanum
}

\section{CONTENTS}

The Demise of the Bee?

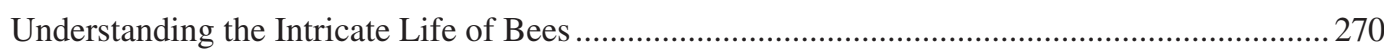

Evidence on the Physical and Metaphysical Characteristics of Bees ........................................ 272

Colony Collapse Disorder and the Impacts of Electromagnetism ............................................2 273

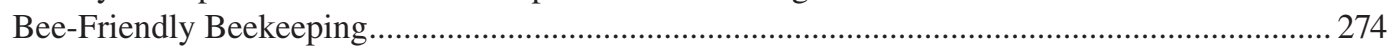

Conclusion: The Importance of Flower Power ...................................................................... 275

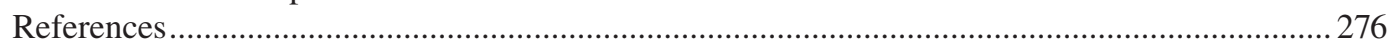

In this holy hum of bees,

Wing song of pollen hunt and honey,

Can you hear a rhythm

Running through the birth of stars,

And towards our destination, returning towards

An ever awakening ground?

Fragment - Anonymous

\section{THE DEMISE OF THE BEE?}

There is an important beehive death going on, for several reasons, first of all environmental pollution, in all its forms. This is a situation of great danger but there is something we can all do with great ease. All you need is a balcony, a flower bed, a piece of land or a vase of flowers that will allow our bees to survive. Bees are hungry because of monocultures and extreme weather conditions.

Find out which essences the bees prefer, from seeds and seedlings that can be found in agricultural stores, in nurseries and in the numerous exhibitions of rare and horticultural plants that adorn the Italian spring with colour, beauty and delicacy, in cities, in villas, parks and castles. Spread the word, share this joyful activity with friends and children! Set a good example and weave new relationships in the name of the good that you do by paying attention to nature and therefore to yourself.

This was the rallying cry at the inception of the 'We sow flowers for the Italian bees' campaign initially broadcast by the ApiSophia Association ('we love and save the bees') of Italy, in the spring-summer of 2018, which continues to be promoted.

Bees have accompanied us in our evolution and are an example of life, of gift and sacrifice, for humanity an example of a totally different social organisation. Wandering around the flowers, sucking the nectar, the bees are covered with an impalpable powder that pollinates most of the plants that humanity feeds on. Honeybees are essential partners for the success of agriculture. Like us, bees also live in a polluted and impoverished environmental context.

\footnotetext{
${ }^{1}$ apisophia.it.
} 
Thirty or 40 years ago, every refuelling at the service station necessitated a washing of the car windshield that had become smeared with hundreds of squashed insects. Today, we travel thousands of miles often without even finding one small insect corpse to remove. This personal experience does not need sophisticated scientific investigations and evidence to effectively describe the current condition faced by the insect world (Selg and Wirz, 2015).

All insects, including bees, are exposed to the destruction of their natural environments, impacted by agricultural practices, environmental pollution and diseases. If we pay attention for a moment, we can see Nature in agony, a dying world, and mankind is the cause. In the early months of 2019, some researchers again raised the alarm and highlighted how the rate of extinction of insects was eight times greater than that of mammals: overall insect species have decreased by $41 \%$, the bees by $46 \%$, and the planet is on the threshold of a mass insect extinction, with losses greater than those reported for large animals (Sanchez-Bayo and Wyckhuys, 2019).

Insects are fundamental for the proper functioning of all ecosystems, and bees in particular have suffered from breeding practices that have weakened their nature: the extraordinary increase in the production of honey for commercial purposes, resulting in the exploitation of hives, is in stark contrast to the essential needs of bees and reflects the similar treatment of livestock species in intensive farming. It is important to be aware that, just like other domestic animal species, bees have undergone intensive breeding. The world must change the way food is produced, to recreate an environment with organic and biodynamic farming rich in biodiversity, which is healthy and welcoming to insects and humans (Menestrina, 2019). In his cycle of lectures on The Bees, Rudolf Steiner indicated clearly to the workers of the Goetheanum, Switzerland, the implications of modern beekeeping techniques, including the introduction of new prismatic rather than rounded beehives, of man-made, pre-constructed wax honeycombs instead of the combs built by the bees themselves, of the artificial breeding of queen bees and the feeding of sugar-based products instead of honey. He said, 'We'll see it in one hundred years' (Steiner, 1998: 75).

Today, this prediction can be both seen and heard: the silence around trees and bushes in bloom is symptomatic, it is a deafening silence. Bees are dying, and this topic cyclically resurfaces in newspapers or in popular action, or as a personal protest because of the deep worries of beekeepers (Menestrina, 2016).

The concern for pollination and therefore for the bees' food supply adds to this picture, but in a broader sense, it must be recognised that bees touch deeper layers in humans than any other living being on Earth. The most worrying aspect of the aforementioned factors is precisely this lack of relationship between human and bee, because the strength and depth of this connection are only partially understood, whereas bees and their social organisation provide a model for future human organisation. As an example, and contrary to popular assumption, bees are not hierarchical. In the hive, everything is done through the bees' dedication to work and to each one's specific task. The queen does not reign in the normal sense of the word, but instead is an exceptional mother, laying eggs her whole life long. The bee community, meanwhile, makes common decisions, as in the case of swarming or through taking stock of family developments. Thus, the hive organism is a wonderful example of creatures working together in perfect harmony for their best common interests (Menestrina, 2016).

\section{UNDERSTANDING THE INTRICATE LIFE OF BEES}

The majority of people do not know very much about the wonderful world of bees and the wisdom and perfection that is contained in the hive. By getting to know the bee better, they may develop more respect, love and reverence for it.

The inhabitants of the hive are divided into three castes: the queen, the workers and the drones. The worker bees (female) and the drones (male) develop in hexagonal structures that resemble silica crystals, while the queen develops into a round cell that has no relation to the surrounding hexagonal environment. Silica is known to have a very close relationship with light, and for this reason, we 
can say that worker bees and drones develop inside 'light cells'. The queen needs only 16 days after her egg is laid to develop fully. A worker bee takes about 21 days, and thus, it may be deduced that nature takes much more care in procreating the workers than the queen, while the male drones take longer to mature, between 24 and 25 days.

In his cycle of lectures on The Bees, Rudolf Steiner provides an interesting picture of how the cosmos is involved in this gestation. He explains,

The Sun turns on its axis once in twenty-one days. Then it will arrive again at this point and begin repeating this movement. The worker uses from the Sun just what she needs to achieve its full development. If the worker were to continue in her development beyond this point, she would leave the Sun development and come into the sphere of influence that the Earth would exert upon her development. (...) The worker enters into Earth development and experiences it only as an already completely developed animal, having achieved its full maturity at twenty-one days. (...) Now consider the drone. It doesn't "feel," as I would put it, that it is completed at twenty-one days and wants to continue into the Earth development phase before it is finished maturing. It is definitely an Earth animal, while the worker is a Sun child, complete within herself. And what about the queen bee? She doesn't even finish the entire Sun cycle of twenty-one days. She lags behind and remains forever a Sun child. (...) With bees, you can really see what it means to be under the influence of the Earth or of the Sun: depending upon whether a bee waits to complete the Sun development phase, it will turn out to be a queen, a worker, or a drone.

Steiner (1998: 8-9)

So, based on Steiner's intuition, the queen and worker bees are united by the same solar cycle. This connection has been confirmed by the presence of the queen's pheromones (Fontana, 2017), by research on language and communication within the hive (von Frisch, 1976) and by the ability of bees to process information and develop group strategies (Celli, 2008).

Being the only fertile female in the community, the queen is the mother of all the workers, comprising the future queens and sisters of the drones. Her ability to produce eggs is staggering, often more than 1,500 per day, which is similar in total weight to that of her own body. The queen is very different from the drones and the workers: her body is elongated, and her jaws are armed with sharp teeth, whereas those of her daughters - the workers - are toothless. Also unlike the workers who, when they sting, can no longer remove the serrated barb and die by being gutted, the queen has a curved and smooth sting, which is used to destroy premature pretenders to the throne. She lacks the 'work tools' supplied to the workers, such as the pollen baskets, the wax glands and the honey bag. Unable to feed herself, her diet is exclusively based on the secretions of royal jelly from the hypopharyngeal glands on the heads of the workers. Queen bees may live for up to 5 or even 7 years.

Worker bees are sterile because they are fed with royal jelly only for the first 3 days and then with nectar and honey. If the queen has enough space (in an enlarged and rounded cell) and if she is fed with royal jelly, she develops her sexual organs. Therefore, as with other animals and partly in humans, the environment and food to some extent determine the faculties of the subject and what will be its external work.

Then, there is the drone. The drone is helpless and without a sting. Like the queen, it has no pollen baskets or wax glands and does not secrete royal jelly: its only function is to mate with the queen and contribute modestly to the ventilation of the hive. It is also not able to feed itself, the workers feed him. Worker bees are more numerous than drones, and, in a hive in a temperate climate region, the number of workers varies between 8,000 and 15,000 in springtime and up to 80,000 in early summer. For the first 3 weeks of their life, they carry out tasks within the hive: in the first 3 days during which they too are fed with royal jelly - they clean the cells. From days 5-14, they feed on pollen while producing royal jelly to feed the queen bee and the newborn worker bees. From days 10-16, they are 'wax bees', and with their epidermal glands positioned on the abdomen between the sternites (hard plates forming the sternum), they produce wax, a fatty substance of entirely animal origin used as a building material. They spend the last few days of their puberty inside the hive 
sweeping (sweeper bees), keeping watch (guard bees) and ventilating the hive to keep its internal temperature constant at around $35^{\circ} \mathrm{C}-36^{\circ} \mathrm{C}$. Finally, from the 21 st day, the worker bee takes flight and becomes a bee foraging for water, pollen, nectar and propolis. We can thus observe how the worker bee begins its industrious life with a sort of training period and that, in a crescendo of experience and responsibility, reaches the apotheosis, or highest point, of its life at the 21st day, from when on it exteriorises its work for the hive. The lifespan of the foraging worker bee is variable depending on the season and external conditions and may be up to 6 months in the winter period (Menestrina, 2017).

Now, let's discover the virgin queen who makes a nuptial flight at 3 days of life: on the running board of the hive, we see a 'ping-pong ball' that darts vertically towards the sky: it is the queen surrounded by the drones, coming from up to $15 \mathrm{~km}$ away. Once it was supposed that only a maximum of 3 drones would fertilise her, but today, we know that it can be up to 24, and this ensures a very important genetic variability as she takes from all of them the seed that will serve for the rest of her life (Fontana, 2017). The bee family regenerates itself through swarming: the old queen ages and moves away making room for the newborn virgin queen and along with all the bees who are able to fly creates a new family in another hospitable place. It is thus that from a first colony, we now have two, less numerous ones, both of which have to work hard to recreate winter stocks.

Awareness of the needs of bees may bring us to better understand the needs of the environment in relation to human activities (Menestrina, 2019). Further, we may take bees as an example of community, and for the 'ancients', the practice of beekeeping was considered a gateway to the inner journey, so much so that it was recommended to all novices (Thun, 2000).

\section{EVIDENCE ON THE PHYSICAL AND METAPHYSICAL CHARACTERISTICS OF BEES}

Research has enabled us to understand more about the complex relationship of the bee with the rest of nature. The bee (along with the ant) produces formic acid as part of its venom. Flying from flower to flower, the bee scatters this formic acid and in doing so makes it available to nature, so that, according to Steiner (in his 1923 lectures The Bees, nos. 7 and 8 (Steiner, 1998)), the soil does not rot or become desertified and so that plants are revitalised. A testimony from biodynamic winemakers explains that in a clean and healthy environment, the bees do their utmost to repair individual grapes damaged by hail, thus avoiding the rotting of the whole bunch (Magrini, 2014).

Recent studies (Khait et al., 2019) have discovered that stressed plants emit airborne sounds that can be recorded remotely, in acoustic chambers and in greenhouses, and that plants possess a faculty akin to hearing, which allows them to hear the buzzing of bees nearby and consequently produce a sweeter nectar to attract the insects to them (Veits et al., 2019). The researchers found that the plants' flowers vibrated mechanically in response to these sounds, suggesting a plausible mechanism whereby the flower serves as the plant's auditory sensory organ. Both the vibration and the nectar response were frequency-specific: the flowers responded to pollinator sounds, but not to other frequency sounds.

Heat plays an important role in their organisation, and in winter, the hive is maintained at a constant temperature, the only example among insects of living in homeotherms, which is otherwise peculiar to mammals (S.I.M.A, 2015). The nectar from different origins is accumulated by the single bee in its stomach, regurgitated and eaten by the next bee. It is sometimes said that the bee is the smallest ruminant on Earth. The honey forms in this way, passing through about 30 individual animals, and finally matures in the cells of the comb in the warmest place of the hive. A universal food is thus born for the whole swarm, which provides them all with the energy they need to maintain a uniform temperature. In homeopathic medicine, Apis is an excellent remedy for acute and subacute inflammations of the skin, mucous membranes and joints, reflecting its relationship with heat (S.I.M.A, 2015). 


\section{COLONY COLLAPSE DISORDER AND THE IMPACTS OF ELECTROMAGNETISM}

Bee losses have increased over the decades, and scientists suspect that many factors could be responsible for their decline. The Varroa mite, pesticides, viruses, monocultures, poor hygiene in the hive and climatic factors are the most widely cited possibilities (Fabre, 2011). Commencing in 2003-2004, bee colonies worldwide suddenly began to show symptoms of what was termed colony collapse disorder (CCD). CCD initially affects the worker bees, which desert the hive. One of the causal factors is likely to be the constant erosion of the genetic heritage of the species Apis mellifera. The extraordinary reshuffling of the subspecies, the selection towards pure breeds - which makes no sense in a non-domesticated animal, and the enormous loss of genetic variability caused by the artificial breeding of queens would logically lead to a 'disease' of the superorganism of the beehive (Contessi, 2016).

Recent efforts have been made to study another potential cause of the bee losses: man-made electromagnetic fields. To understand the potential effects of electromagnetic fields on bees, some context is necessary. Magneto-reception, the perception of the geomagnetic or electromagnetic fields, is a sensory modality well-established across all major groups of vertebrates and some invertebrates, although its presence in humans has rarely been tested and has yielded inconclusive results (Del Bene et al., 2008). Although many migrating and homing animals are sensitive to the Earth's magnetic field, most humans are not consciously aware of the magnetic stimuli that we encounter in everyday life. Either we have lost a shared, ancestral magneto-sensory system, or our system lacks a conscious component with detectable neural activity, meaning that there is no apparent perceptual awareness by us (Wang et al., 2019).

When a biological organism is in an electric and/or magnetic field, an interaction inevitably takes place between the forces of the fields and the electric currents present in the tissues of the organism, which are generally good conductors, in particular at low frequencies. The result is always a 'deviation of the conditions of the tissues from the previous condition of equilibrium', which can be indifferent or manifest as advantageous or harmful, and temporary or permanent (Del Bene et al., 2008).

As already mentioned, flowers vibrate mechanically in response to the buzzing sounds of bees and emit electrical signals, and it has been hypothesised that these weak electric fields, together with other chemical and visual signals, increase the flower's ability to attract pollinating insects. Studying bumblebees has shown that they are able to better distinguish the colours of flowers when they are electrically charged. In addition, insects acquire a positive electric charge during flight, while flowers produce a weak negative charge. When a bumblebee touches a flower, the electric potential of the plant changes and remains thus for a few minutes. This change allows other bumblebees to understand that the flower has been visited recently. Most of the surface of the bee's body has a low potential electric charge. Normally, the antennae carry electric charges opposite to each other, and this polarity can be inverted, apparently at will, within a second. Bees are sensitive to electromagnetic fields: low-frequency fields increase their metabolism, while high-frequency fields cause them to flee. Variations of electromagnetic fields due to anthropogenic interferences can interact negatively with bees, and these interferences can confuse them and prevent them from returning to the hive. Similarly, bees are also sensitive to geomagnetic perturbations caused by solar flares. These flares interfere with their orientation and significantly increase the number of bees that do not return to their hive (Contessi, 2017).

In the $1950 \mathrm{~s}$, only $10 \mathrm{pW} / \mathrm{cm}^{2}$ (Pico-Watts per square centimetre) was found on the ground in the radiofrequency electromagnetic field spectrum from $100 \mathrm{kHz}$ to $300 \mathrm{GHz}$, whereas current values measure from a million to a billion times higher, owing to the rapid development of telecommunications (Del Bene et al., 2008).

Daniel Fabre published a study in 2011 where he linked the massive disappearance of bees that have been witnessed for almost a decade and especially in Northern Europe and North America, to 
massive electromagnetic wave pollution that also mainly affected developed countries as a result of the spread of mobile phones. Fabre noted that the electromagnetic waves of a cell phone in activity near a hive disturbed the activity of bees. In particular, the worker bees responded to the frequencies emitted by the cellular phone placed under the hive, producing a typical hum ('piping') normally associated with the intrusion of strangers in the hive or with swarming (the abandonment of the hive to found a new colony), while under the control conditions, this hum (in Fabre's experimental sessions) was completely absent. According to Fabre, the bees' sensitivity to electromagnetic radiation could be explained by the presence of magnetite crystals in the animal's body fat (Sgorbissa, 2011). Back in 1978, Gould et al. have shown how the abdomen of adult bees contained very fine granules of a kind of 'magnetic memory' that could produce sensitivity to magnetic fields. Subsequent investigations showed that this magnetite iron was derived mostly from pollen, with higher levels found in the trophocytes or fat storage cells of foragers, up to levels of about $2.2 \mu \mathrm{g} \mathrm{Fe} / \mathrm{mg}$ (Kuterbach, 1985). Scholars have since found that honey bees undergo iron biomineralisation, providing the basis for such a magneto-receptor located in the abdomen. This magneto-reception of honeybees has also been proposed on the basis of much behavioural evidence: the behavioural changes in comb building, the strength of the hive, the weight and quantity of bees, and the homing orientation when an extra magnetic field is added (Lambinet et al., 2017).

Therefore, there is clear evidence that electromagnetic frequencies are damaging to the health and behaviour of the bee, and, along with chemical pollution, there is little that the individual beekeeper can do except refrain from siting his/her beehives near a mobile phone mast or industrial farmscapes.

\section{BEE-FRIENDLY BEEKEEPING}

We know that environment and nutrition are key determinants of animal welfare and that animal health is ensured by a correct relationship between metabolism and internal homeostasis through the polarity of the transformation and maintenance - given by the constant relationship over time of the $\mathrm{pH}$ of gastric juice to the $\mathrm{pH}$ of blood at optimal values. Crucially, bees must eat nectar, pollen and honey, and not sugar and syrup.

Regarding hive conditions, ApiSophia, inspired by Kozak and Curries' study on the effects of temperature and ventilation on Varroa (2011), has been conducting field surveys aimed at identifying more suitable housing solutions that would facilitate - rather than counteract - the bees' metabolic processes, and checking whether, in certain beehives, optimal environmental conditions could be found that are unconducive to Varroa infestation. Monitoring has confirmed substantial and very interesting differences in temperature as well as carbon dioxide concentration, between hives with a closed wooden bottom (which were used before the 1980s and prior to the advent of the Varroa mite) and those with a net bottom and tray below. In addition, hives with a closed bottom show to allow bees to ensure the cleanliness of the hive. Sun hives ${ }^{2}$ have also been examined and are showing excellent performance, their ovoid structure allowing for the movement of gases. Particularly detrimental however is the use of sheet metal rooves, because these can produce too much heat. This research is ongoing and will, when finalised, be available on the ApiSophia website.

It is essential for the life of the colony that the combs are made of 'pure' beeswax. In nature, bees are perfectly capable of building honeycombs without the beekeeper's intervention, but to facilitate their work (and reduce honey consumption by the bees), waxy sheets are used. Extreme care must be taken with the wax used for the preparation of the waxy sheets, as the wax, being a fatty substance, absorbs and retains fat-soluble pollutants including most pesticides. Moreover, owing to its

\footnotetext{
2 The Sun Hive is an alternative beehive made of straw and designed by Günther Mancke (German beekeeper and sculptor;
} 1925-2020) to mimic the form of wild beehives. 
high cost and scarcity, wax lends itself to tampering, and some producers add paraffin. Both the choice of location and the level of permanence of the apiaries can reduce problems of environmental contamination of the wax, which is itself a fatty substance that absorbs and holds toxic substances. The use of old combs is recommended, because they are rich in propolis that makes the wax more rigid, which can then better transmit the vibrations that bees produce, in particular the dance of the explorer bees as they communicate the location of the flower fields (Contessi, 2017).

Conventional beekeepers oppose swarming in order to maintain families rich in foraging bees, gaining an abundance of honey by artificially preventing the family from separating. Other beekeepers, more sensitive to the species' requirements, allow swarming and thus enable the only form of natural evolution possible for the hive organism. It can be said that conventional beekeepers violently enter the hive to profit from their forced overproduction and unfortunately ignore good management maxims such as 'Bees must eat honey and not sugar', or 'Let them swarm, it is their only form of regeneration'. Moreover, some beekeepers change the queen every year in the belief that she lays more eggs, but in fact, queens live 5 or more years and, like cows, they improve their performance with age.

Enlightened beekeepers should be universally recognised for the dedication they offer for all of humanity. Honey, wax, pollen and propolis can be seen as a gift from bees for humanity, and even their poison - painful for us if stung, becomes a medicine, a therapy. Beekeeping and agriculture are sisters, as they were when every farmer had his/her own hive, with honey being a by-product of little interest compared to the bees' role among the flowers, the trees and around the farmhouse, for the sake of the environment and the family.

\section{CONCLUSION: THE IMPORTANCE OF FLOWER POWER}

In many respects, we should consider the beehive as not just the hive itself but as the whole 3-km foraging radius or territory of the worker bees. This is the organism of which bees are the cells that nourish and feed on the flowers. In this way, everyone can help to create a bee-friendly world, a natural setting with wonderful flowered pastures seeded specifically for bees. We are thus all encouraged to guard the spontaneous borders of the fields, to plant and care for flowering meadows, to sow strips of wild flowers in urban and residential areas, in our gardens and on our balconies. Bees need pollen and nectar plants, and we can plan sowing and planting for next spring-summer, because it is precisely in summer that bees are more hungry. We can sow perennial mint (Labiata), scalar seedlings of purple tansy (Phacelia), borage and black mustard, flower beds destined for the annual sowing of garlic, poppies, sunflowers, celery, sweet clover (Melilotus). Bees will also enjoy the Japanese medlar, the viburnum, the snowdrops, the first hazelnuts, the veronica, the first dandelion, the willow, the minor ash, the cornelian cherry tree (Cornus mas). We find them on the catkins of the alder and the winter honeysuckle (Lonicera fragrantissima) and then again on the now more frequent dandelion and so gradually in a continuous and more intense dance. In this way, the desire to give bees a great wealth of flowers, including ornamental and aromatic, will be born, to realise for them what we call the bee pharmacy, because biodynamic beekeepers believe that if bees have the possibility, they will choose the plants and flowers that for them are curatives, similar to grazing cows, which choose the right herbs that, during their milk cycle, help their calves to recover from juvenile diseases (Menestrina, 2019).

In his cycle of lectures on The Bees, Rudolf Steiner said: 'Actually, every human being should show the greatest interest in this subject, because, much more than you can imagine, our lives depend upon beekeeping' (1998: 5). So, what we now consider to be the need of bees is increasingly being seen as our need, because a world in which bees can no longer live is a world that lacks what is essential for man. In this sense, bee health is a responsibility of all human beings (Menestrina, 2016) (Figure 24.1). 


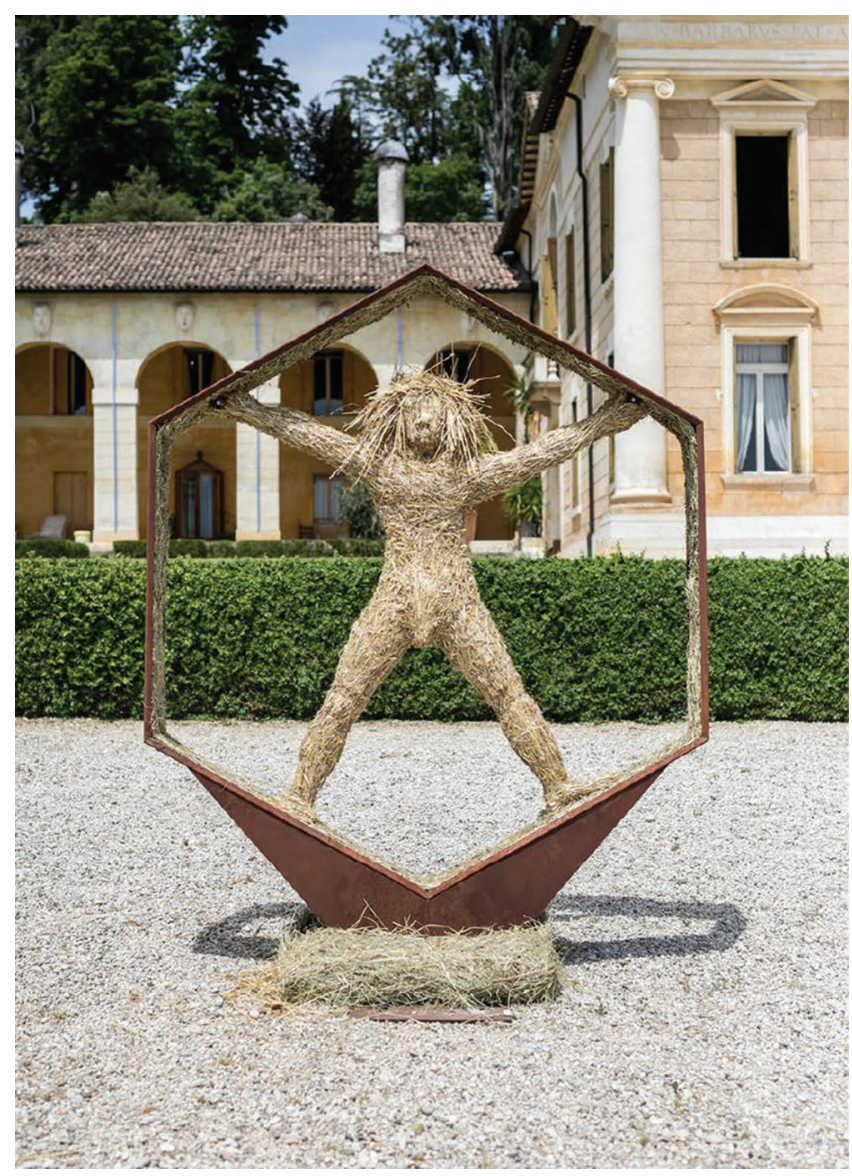

FIGURE 24.1 'VITA NOVA' (New Life) by Julia Artico, Villa Maser, Treviso, Italy.

Bees Humankind Hexagon Crystal Light: This pentad, born from the encounter with a lecture by Rudolf Steiner on bees, generated the form of VITA NOVA. In a spiritual dialogue with the iconographic pathway enshrined in Villa Maser, the Vitruvian Man unexpectedly finds himself inscribed in a hexagon, evoking a bright future in harmony with every kingdom of nature. The life of bees and healthy beekeeping form an authentic image of this future (with permission from Julia Artico, JULIAARTICO.IT).

\section{REFERENCES}

Celli, G. (2008) La mente dell'ape: Considerazioni tra etologia e filosofia. Bologna: Editrice Compositori.

Contessi, A. (2016) Le api: Biologia, allevamento, prodotti. Bologna: Edagricole.

Contessi, A. (2017) Nuove acquisizioni nel mondo delle api. Rivista Nazionale di Apicoltura, Apinsieme Ambiente Sociale, 4: 32-39.

Del Bene, G., Tesoriero, D. and Sabatini, A.G. (2008). Approccio alla individuazione delle cause della sindrome dello spopolamento degli alveari (CCD Colony Collapse Disorder) con riferimento alle onde elettromagnetiche. APOidea, 5: 70-77.

Fabre, D. (2011) Mobile phone-induced honeybee worker piping. Apidologie, 42(3): 270-279.

Fontana, P. (2017) Il Piacere Delle Api - Le Api Come Modello di Sostenibilità e l'Apicoltura Come Esperienza Della Natura e Della Storia Dell'Uomo. Verona: WBA (World Biodiversity Association) Project, pp. 74-76. 
Gould, J.L., Kirschwink, J.L. and Deffeyes, K.S. (1978) Bees have magnetic remanence. Science, 201(4360): 1026-1028.

Khait, I., Lewin-Epstein, O., Sharon, R., Saban, K., Perelman, R., Boonman, A., Yovel, Y. and Hadany L. (2019) Plants emit informative airborne sounds under stress. bioRxiv 507590. doi: 10.1101/507590.

Kozak, P.R. and Currie, R.W. (2011) Laboratory study of the effects of temperature and three ventilation rates on the Varroa destructor in clusters of honey bees (Hymenoptera: Apidae). Journal of Economic Entomology, 104(6): 1774-1782.

Kuterbach, D.A. (1985) The Anatomy, Physiology and Development of Iron-Containing Cells in the Worker Honey Bee (Apis Mellifera). Stony Brook, NY: University of New York, 188 p.

Lambinet, V., Hayden, M.E., Reigl, K., Gomis, S. and Gries, G. (2017) Linking magnetite in the abdomen of honey bees to a magnetoreceptive function. Proceedings: Biological Sciences, 284(1851): 2016-2873.

Magrini, F. (2014) Verso la biodinamica: Vignai da Duline, Terzo Notiziario. Italian Biodynamic Association, pp. 19-22.

Menestrina, S. (2016) Le Api e l'Umanità. Un destino comune. Antroposofia. Milano: Editrice Antroposofica, vol. 6, pp. 51-64.

Menestrina, S. (2017) Le Api e l'Umanità. Unla Biografia comune? Antroposofia. Milano: Editrice Antroposofica, vol. 1: pp. 55-64.

Menestrina, S. (2019) Seminiamo Fiori Per le Api Friulane. La Panarie, 200: 53-62.

Sanchez-Bayo, F. and Wyckhuys, K.A.G. (2019) Worldwide decline of the entomofauna: A review of its drivers. Biological Conservation, 232: 8-27.

Selg, P. and Wirz, J. (2015) Der Mensch und die Bienen. Stuttgart: Verlag des Ita Wegmann Instituts.

Sgorbissa, F. (2011) Il ronzio (elettromagnetico) che disturba l'ape. OggiScienza, May 13th 2011.

Società Italiana Medicina Antroposofica (S.I.M.A.) (2015) Vademecum dei Medicinali Antroposofici. Milano: Editrice Antroposofica, pp. 51-52.

Steiner, R. (1998) The Bees - Eight Lectures 1923. Hudson: Anthroposophic Press.

Thun, M.K. (2000) Die Biene - Haltung und Pflege. Biedenkopf: M. Thun Verlag.

Veits, M., Khait, I., Obolski, U., Zinger, E., Boonman, A., Goldshtein, A., Saban, K., Seltzer, R., Ben-Dor, U., Estlein, P., Kabat, A., Peretz, D., Ratzersdorfer, I., Krylov, S., Chamovitz, D., Sapir, Y., Yovel, Y. and Hadany, L. (2019). Flowers respond to pollinator sound within minutes by increasing nectar sugar concentration. Ecology Letters 22(0): 1483-1492.

von Frisch, K. (1976) Il Linguaggio Delle Api. Torino: Universale Scientifica Boringhieri.

Wang, C.X., Hilburn, I.A., Wu, D-A., Mizuhara, Y., Couste, C.P., Abrahams, J.N.H., Bernstein, S.E., Matani, A., Shimojo, S. and Kirschvink, J.L. (2019) Transduction of the geomagnetic field as evidenced from alpha-band activity in the human brain. eNeuro, 6(2): 0483-18.2019. 


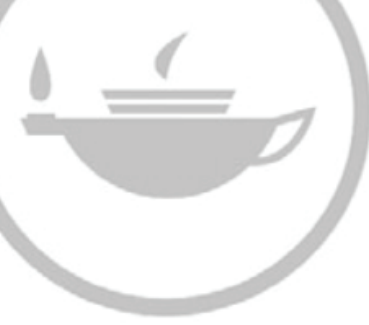

Taylor \& Francis Taylor \& Francis Group http://taylorandfrancis.com 


\title{
25 Exploring a Dynamic Role for Water in Agriculture
}

\author{
Simon Charter \\ UK branch of the Natural Science Section at the Goetheanum, Switzerland \\ Ebb and Flow Ltd, UK
}

\section{CONTENTS}

Introduction.

Phenomenological and Epistemological Background: The Union of Sense Experience

(Percepts) and Ideas (Concepts) as the Basis of Knowledge.

Geometry and Gestures in Flow: Spiral and Ring Vortices

Rhythm - Another Gesture of Flow

The Dynamisation of Water ......

Flowform Movement: An Alternative Method of Dynamisation ............................................ 287

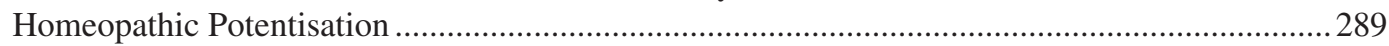

Concluding Discussion: Research with the Life-Forming Forces ............................................290

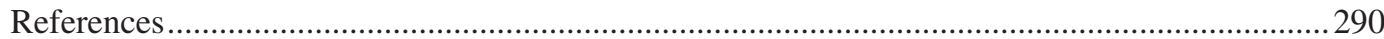

\section{INTRODUCTION}

This chapter is concerned with the healthy 'forming' of living organisms (their form development to maturity) and the ways this may be enhanced with methods that involve water. Few can really claim to have the full picture when it comes to understanding how plants and animals emerge into life, form themselves, grow and develop healthily. Within many traditional worldviews as well as some modern ones, there are believed to be subtle forces at work which organise life's functions, and these are variously termed pranha, chi or the etheric. In my own practice with reed bed systems, water cleaning ecologies and landscapes with moving water, I noticed plants, and especially, flowers have better-developed forms when growing in certain situations rather than others. Having heard about life's formative forces through working on a biodynamic farm and having learnt how projective geometry reveals principles found in natural forms, I found myself researching the relationships between qualities of form in water flow and the forming of life. Such work was pioneered by Theodor Schwenk (2014) in the 1950s. This chapter provides aspects of the results of that research, much of which has been collaborative.

The chapter explores the principles of form that are found in geometry, in the realm of pure idea and relates these to the observed flow movements, or gestures, in the realm of pure perception. It does not seek to justify any particular worldview, but the intention is to allow the relationships between the ideas and the observations to reveal what is at work.

Biodynamic agriculturalists and others are interested in strengthening the working of the forming principles, the formative forces within living organisms, in order to engender health in the farm ecology. Such forces are associated with the moon, the sun and the planets, and their positions and movements in relation to the earth and the stars. Water is seen to mediate these forces and influences, so one may enhance them by working with water. This chapter aims to build an understanding of water by examining the way water flows naturally and seeking the inherent principles in this. It begins by discussing the epistemological basis for this work, how, through taking a Goethean 
approach, we can become more confident in our understanding. It then builds a picture of water flow by showing three distinct 'movement gestures' which interplay and can also be seen in life forms. These gestures can be experienced in a qualitative, artistic way, as with dramatic or sculptural gestures, but can also be defined geometrically and drawn simply but precisely through the interplay of points and lines. This provides a background to then look at the practice of 'dynamisation', the 'enlivening' of water by inducing particular movements, as well as other ways of moving water used in some agricultural practice. It examines the water movements in specifically designed vessels (Flowforms) as well as those in potentisation. The chapter concludes with a consideration of possible connections between the researcher and research results when investigating organic life.

\section{PHENOMENOLOGICAL AND EPISTEMOLOGICAL BACKGROUND: THE UNION OF SENSE EXPERIENCE (PERCEPTS) AND IDEAS (CONCEPTS) AS THE BASIS OF KNOWLEDGE}

If we wish to develop any clear and useful knowledge, we need to find appropriate concepts with which to meet the things we can experience with our senses. We judge our understanding by the degree to which the concepts make sense of the perceived phenomena, by the degree they create a satisfying meaning of our experience. Some concepts make meaning for a single occurrence only, while others, we realise, apply widely. If we can see an active principle to be at work in all instances, we may call it an archetypal idea. These archetypal ideas give us the greatest meaning, since we see the instances related to a wholeness, we see the principles of the whole at work in the parts.

Taking a monistic perspective, I see both our ideas and the sense percept as being united within the world we encounter. It is only in our minds that they are separate. This view comes to light in the works of J. W. von Goethe and was clarified by Rudolf Steiner (Seamon and Zajonc, 1998; Steiner, 1988). It has been expressed more recently by Gregory Bateson and Henri Bortoft (Bateson, 2002; Bortoft, 1996, 2012). Through the practice of science stemming from Goethe (termed Goethean inquiry, or Goethean phenomenology), we can gain moments of direct understanding, when it is possible to 'see' that the idea is one with the percept, to 'realise' an organising principle at work in the object of study as one perceives it (Colquhoun and Ewald, 1996; Hoffman, 2007; Holdrege, 2013). Once this has happened, the idea is always there, and it can be shared with others who may take it on intellectually or 'realise' the truth of it themselves. It is this quality of understanding which occurs in 'A-ha moments' or 'Eureka' experiences, which are the subject of neurological research (Danek and Salvi, 2020).

With water in flow, however, the organising principles are found to be flexible ideas that we can grasp but never entirely possess (Holdrege, 2013; Seamon and Zajonc, 1998). The archetypal ideas at work are manifold; they do provide a sense of reality, of certainty, but they interplay according to the context. This means that it would be inappropriate to state what is best practice for all situations. What we can do is build up a conceptual picture in connection with the phenomena we perceive, which helps to make meaning of one's own practice.

The following section explores the forms that water takes up in non-turbulent flow, their appearance and their lawfulness. In particular, it explores how water can be sensitive. This will provide us with some ideas with which to look at the practice of dynamisation.

\section{GEOMETRY AND GESTURES IN FLOW: SPIRAL AND RING VORTICES}

Geometry gives us the clarity of precisely defined concepts. In this chapter, I search for some commonality between these concepts and gestures in the study of flow. In our standard school Euclidian $^{1}$ geometry, concepts are generally fixed as rigid measurements, including distances and

${ }^{1}$ Euclid of Alexandria, Greek mathematician and founder of classical geometry, b.300 BC. 
angles. Projective geometry, developed mainly in the nineteenth and twentieth centuries, encompasses the Euclidian while also including the infinite, which is brought in from the far distance, such as through perspective drawings with vanishing points on the horizon line. This enables us to work with new spaces, in which the familiar Euclidian geometrical ideas are seen to be more restrictive cases of flexible thinking and universal ideas (Whicher, 2013).

Lawrence Edwards' work with projective geometry and natural form (2006) gives the defining geometrical idea of the spiral vortex in its pure form, which we see when water is being drawn towards a single distant point (under gravity this point is the earth's centre). We see this vortex every day as water goes down a plughole of a bath or sink. Edwards called this the watery vortex; I will call it the spiral vortex for reasons which will become clear later (see Figure 25.1). The geometry is what is known as a path-curve surface, composed of curved lines (Edwards, 2006). There are many such surfaces in natural forms, including eggs, buds, seed-bearing cones and the left ventricle of the heart. The lines are defined paths of movement in relation to four points, and one may choose any four points to create a path-curve. These points are named the invariant points and are unreachable or infinity points in terms of the movement.

In the case of the spiral vortex, shown in Figures 25.1 and 25.2, the lines of movement come from peripheral points in the infinitely distant line in the plane of the water surface, which may be easiest to think of as the horizon line, and they run to an infinitely distant point on the central axis. In the spiral vortex, unlike most path-curves, we can actually see the path of movement if we follow a suspended particle moving in the funnel surface. The movement runs spiralling down the funnel surface towards the infinitely distant point on the axis. For water flowing primarily under the draw of gravity, this axis tends to the vertical. Note that the spiral ripples that one sees in the photo do not show the path of movement, i.e. the flow, but are a structure in the flow, like standing waves in a stream.

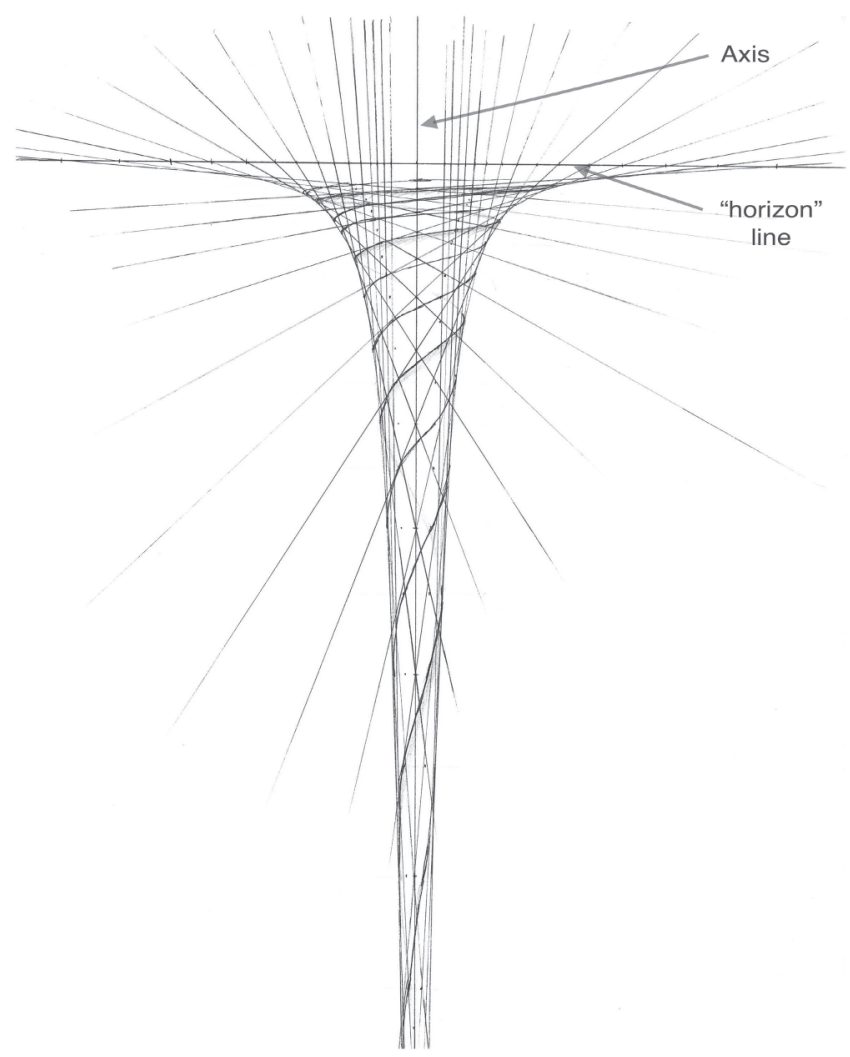

FIGURE 25.1 Spiral vortex geometry. (After Edwards, 2006.) 


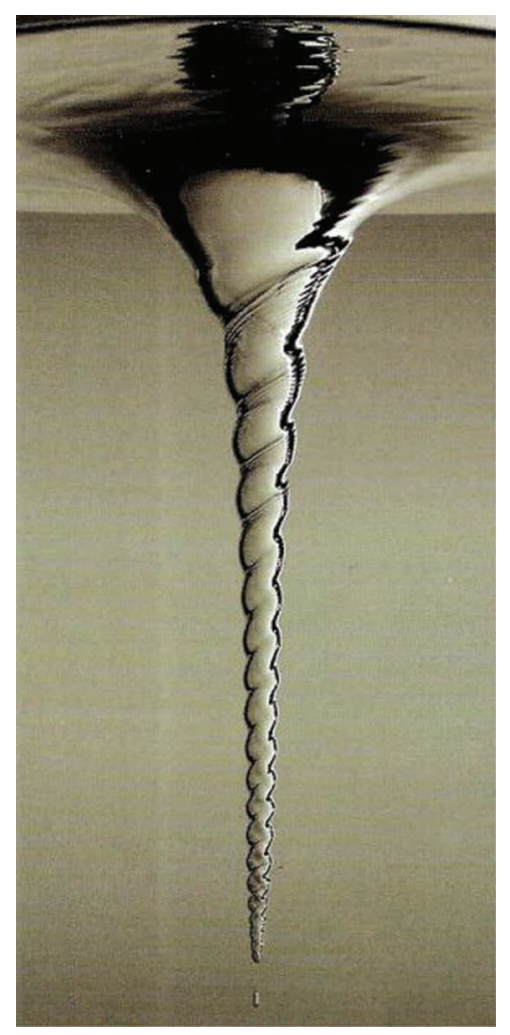

FIGURE 25.2 Spiral vortex. (Photo courtesy of Institute of Flow Science, Wilkens et al., 2005.)

Qualitatively, this vortex form can be experienced as very open, the surface stretching widely and also as having a contractive gesture, so that when we watch the form in flow, it draws suspended and floating matter towards the centre. It creates a concavity which, under the right conditions, can be many metres deep. This can be seen in Figure 25.3, both in the reflections on the surface and below it as the rope-like tube seen through the water.

This spiral vortex gesture is only part of the full picture. There is another form of fluid movement also called a vortex, the toroidal ring vortex. This is seen in air as smoke rings, often created by smokers and less often by volcanos. It can also be generated in water. It arises not when the fluid is being drawn under suction but when it is pushed, when it is under pressure from somewhere else. Figure 25.4 shows such a ring vortex.

This type of vortex can also be made quite easily in a still body of water by using a short discharge from a tube, as in Figure 25.5, which reveals both its form and its inherent layered structure.

The ring vortex also has a path-curve geometry, but with a transformed construction that embodies asymmetric spirals. These have been termed spiroids (Blackwood, 2012). Of significance here is that this ring vortex form does not have the same relation to the periphery; the movement relates to local, not peripheral, infinity points which are in the ring and on the axis. The movement in the form is more enclosing and relates more to itself, in that it rolls around its core. Qualitatively, we can experience it as having an expansive gesture, both when we observe its initial appearing (mushrooming out) and again at the end of its appearance when it meets resistance and deforms itself. It is very convex in its inherent surfaces. Thus, we can see the toroidal ring vortex, created with a push or a puff, as polar opposite in nature to the spiral vortex described above which was created with a draw or a suck. 


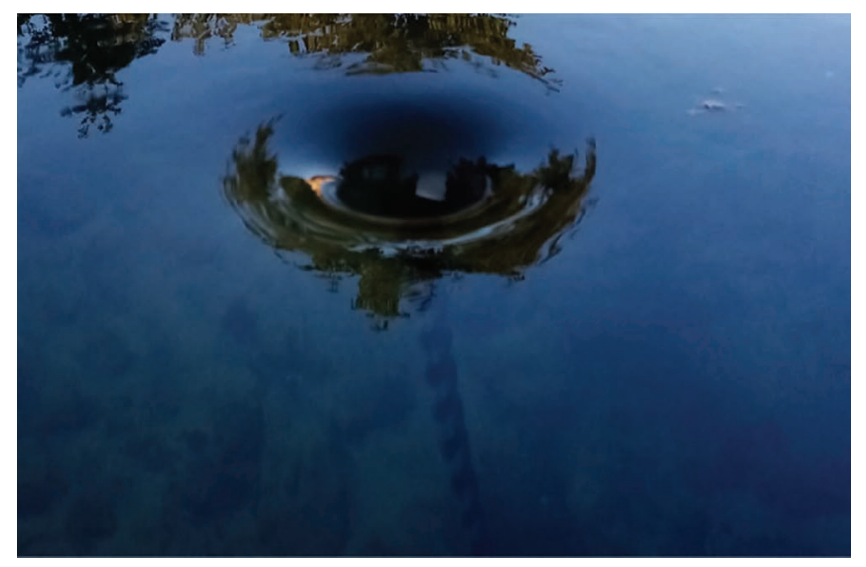

FIGURE 25.3 Spiral vortex in free water, viewed from above. (Photo credit: Simon Charter.)

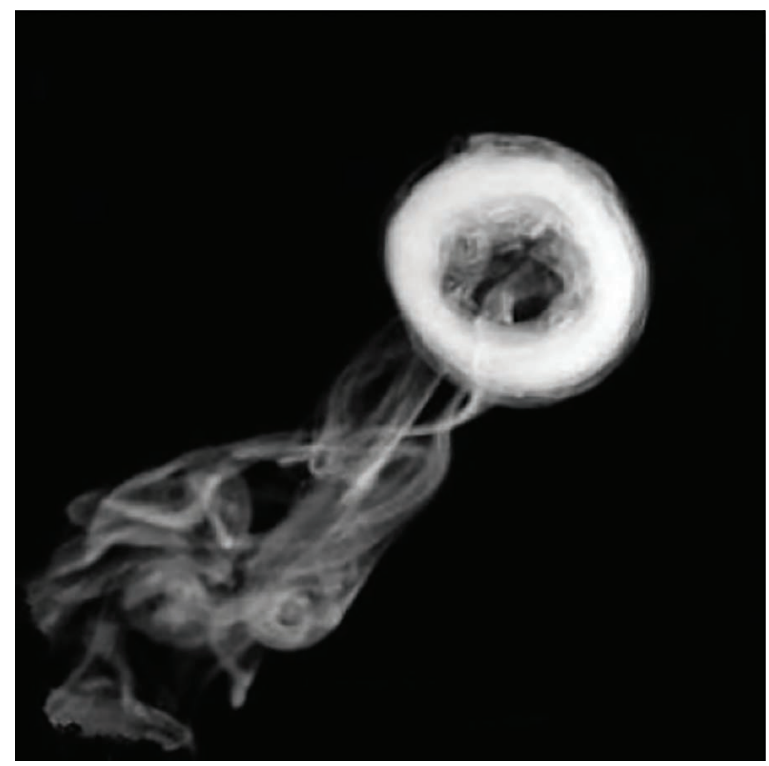

FIGURE 25.4 Ring vortex, smoke in air. (Photo credit: stock image from pinterest.com.)

Leonardo da Vinci, often seen as a forerunner of modern natural scientists, appears to have been aware of both these gestures. He made a close study of flow in water and is known to have used sawdust as a marker to observe the streaming of the liquid. He illustrated both of these gestures in a drawing (see Figure 25.6). The rings rising in the centre he called welling, and the spiral vortices around them he called eddying.

Da Vinci did not draw the way the surface looks, but rather his pen followed the paths of movement, and in doing, so he drew out the curved path of the water to find the gestures that the flow is making. For him, the drawing may have been a research methodology; he was looking for the lawfulness in nature as an aspect of the divinity (Kemp, referring to Leonardo's Codex Madrid II, 1989: 13). 


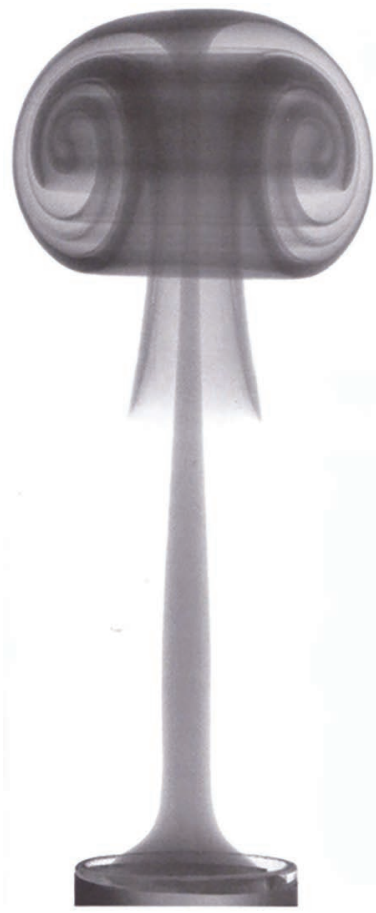

FIGURE 25.5 Ring vortex viewed from the side, made using marker dye in water, pushed in a slow pulse from the tube below. (Photo credit: by kind permission Andreas Wilkens, Institute of Flow Sciences, Herrischried, Germany, www.stroemungsinstitut.de.)

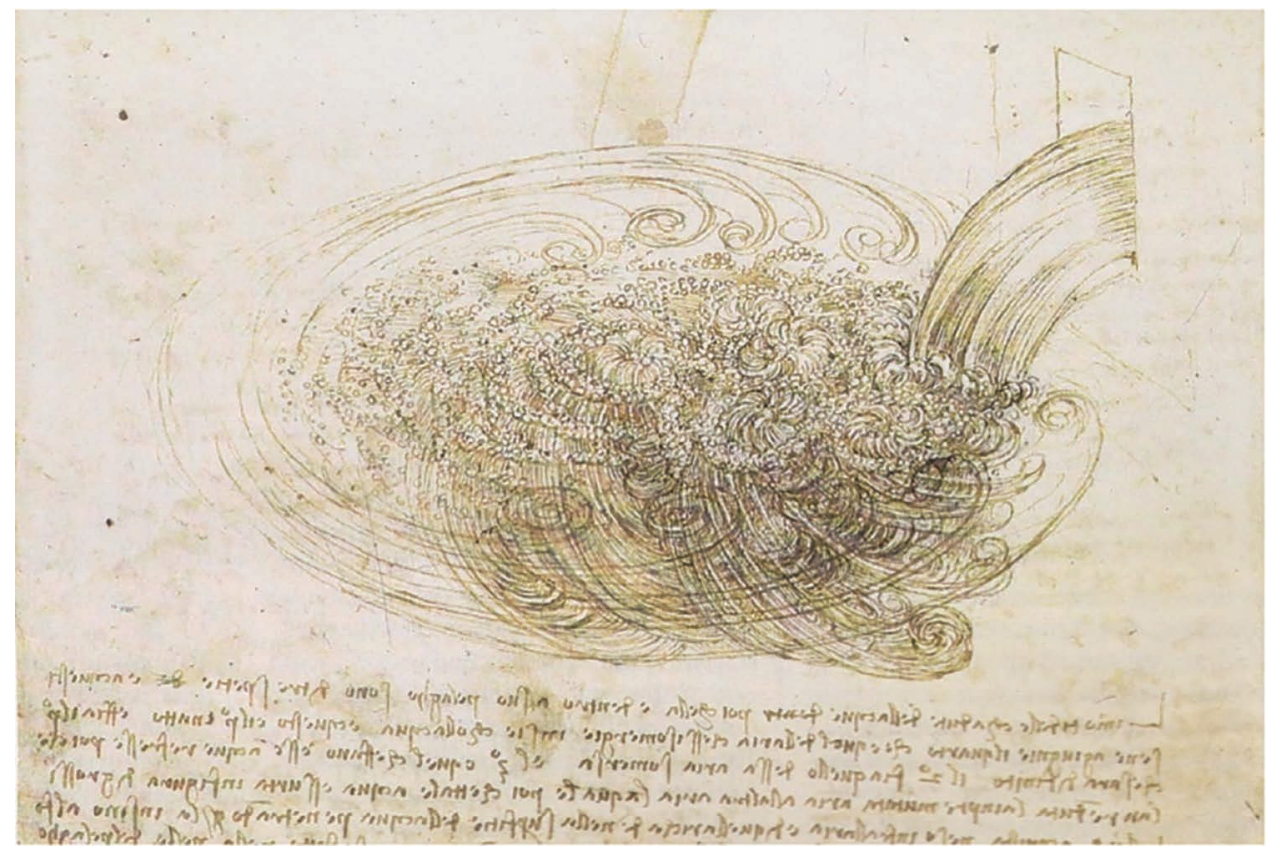

FIGURE 25.6 Water falling into a pool by Leonardo da Vinci, circa 1511. Original drawing held in the Royal Library Windsor (no 12660). (Reproduction courtesy Royal Collection Trust/@ Her Majesty Queen Elizabeth II 2020.) 
If one observes gently flowing water in a river with these two archetypal gestures in mind, one can see there is always a play between the two in the way it moves, with underwater obstructions pushing into the flow and expansive welling up occurring in front. Then behind an obstruction, little contracting eddies can be seen, associated with the drawing down of the water. The water, under push or draw, acts accordingly with either the expansive gesture (towards the ring vortex) or the contractive one (towards the spiral vortex).

In conclusion to this discussion of the phenomena, it is clear that that water is sensitive to the forces of pressure and suction. These are invisible forming forces of which we do have a direct experience.

\section{RHYTHM - ANOTHER GESTURE OF FLOW}

Neither of these two archetypal movement forms seem totally stable in the real world. The spiral vortex will often collapse in an expansive swelling out, especially when its connection to the source of the draw is disturbed, and when the ring vortex encounters resistance it can form a rhythmic pattern as it dissipates, as shown in Figure 25.7.

Another phenomena seen at the surface of a body of water is a marriage of the two vortex gestures, which is called the twin eddy or half-ring vortex (Cowern, 2014). It can be reproduced fairly easily at the surface of still water or on a gently moving water body, by dipping in a rounded flat paddle vertically, giving it a little push and pulling it out again. At each side of the paddle, we see what appears to be two separate spiral vortices (eddies), but a marker in the water (such as ink or milk) reveals their underwater linkage in a half-ring. Careful observation shows that its form also changes in a rhythmic way, and it oscillates slowly around a mean semicircular form. It is interesting that we have both pushed the water in front and pulled the water behind the paddle, and the result is a combination of both gestures. I call both this and the full-ring vortex 'movement organisms' as

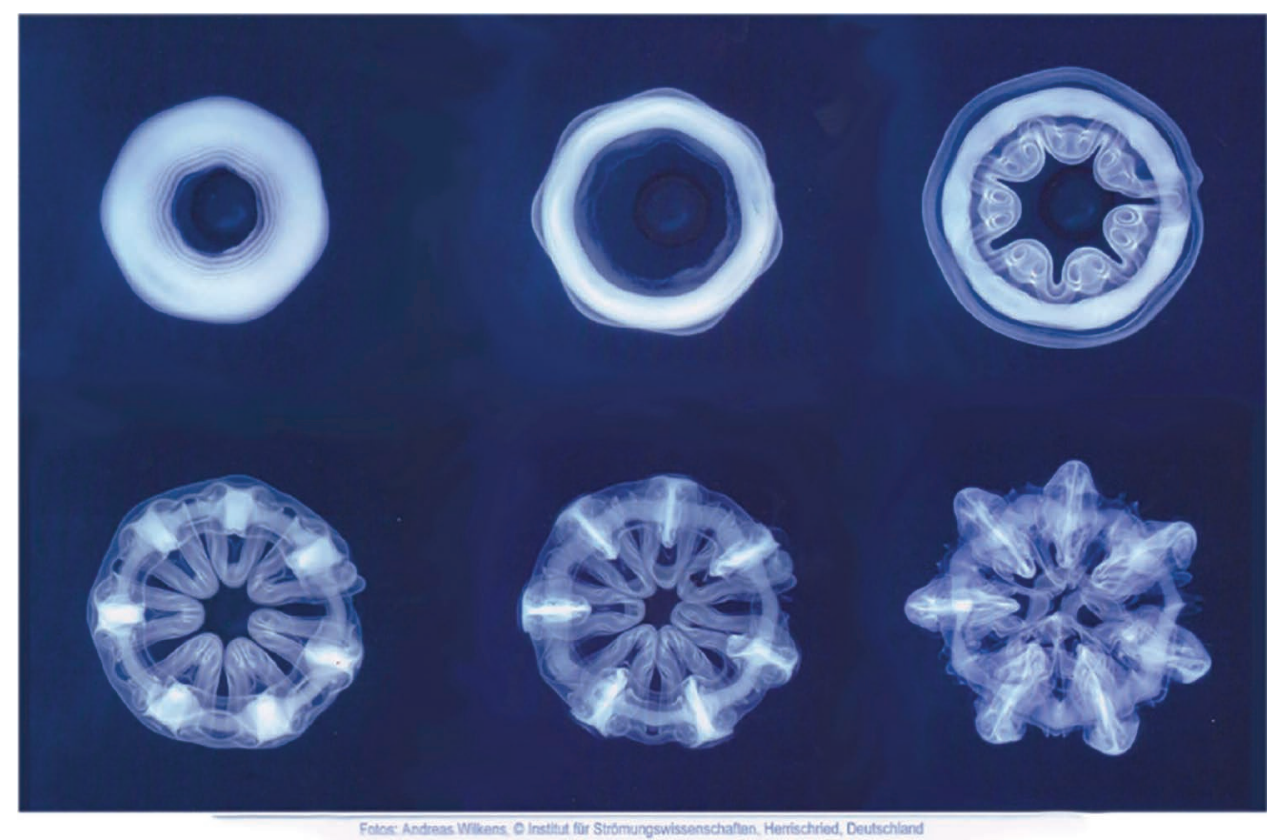

FIGURE 25.7 Collapsing ring vortex in water, seen end-on, as it slowly encounters a perpendicular glass wall. Top left shows the almost undisturbed toroidal ring, which changes through the forms to the bottom right where the form is beginning to disperse. (Photo credit: by kind permission of the Institute of Flow Science. Wilkens et al., 2005.) 
they have a 'birth', a rhythmic 'life' and eventually a 'death', a dissolution of the form. The spiral vortex might also be referred to in the same way, but its form extends into the whole body of fluid so it does not have the same self-maintaining, independent existence we usually associate with the term 'organism'.

If we introduce movement with a straight brushstroke through a suitable shallow layer of water, the brush pushes the water in front and draws in the water behind, and we see a wonderful rhythmic play involving the two polar movement gestures, as seen in Figure 25.8.

The phenomena appearing in Figure 25.8 is one of many rhythmic phenomena seen in fluid flow. There are the meanders, ripples and standing waves as seen in water but also in certain cloud formations. All of these can be seen as a play between the two polar gestures.

Illustrated here is the way that water in non-turbulent flow (also known as a harmonic laminar flow) has a tendency to form itself in a rhythmic play between the polar gestures of the two archetypal vortex forms, the spiral vortex and the ring vortex. I suggest therefore that there is actually a threefold archetype working in this flow, having an expansive pole, a contractive pole and a rhythmic aspect between these polar aspects.

I have tried to elucidate these three active forming ideas in water's laminar flow. The half-ring vortex shows to my mind that it is possible to see them as one transformable idea, so we might call this the archetypal gesture of water, just as Goethe saw the archetypal gesture of plant development in the transformable leaf idea (von Goethe, 2009). We will now see how this threefold gesture is present in dynamisation.

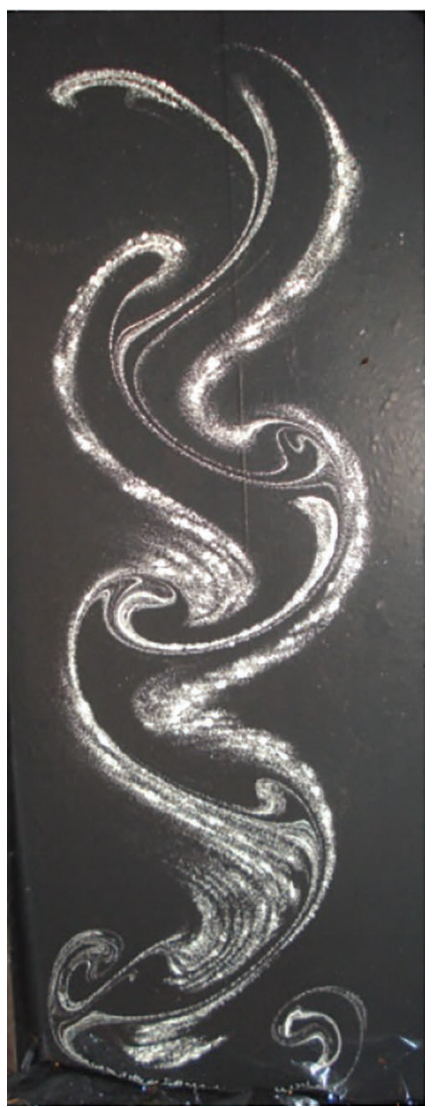

FIGURE 25.8 Rhythmic pattern of alternating vortices (also known as the Kármán vortex street). (Photo credit: Simon Charter.) 


\section{THE DYNAMISATION OF WATER}

Through studying the unfolding of life forms in the way proposed by Goethe, one can see particular species-specific forming influences and one can also see archetypal form gestures. These both work in a coherent way within the constraints of each spatial and temporal situation, such that we can recognise a specimen of a given species at all stages of its development. For instance, a nettle seedling with only two leaves can be recognised as the same species as an older specimen in full flower. In its growth, each organism can be seen to strive towards its specific, qualitatively recognisable form, but this is a fluid form which has a temporal dimension to it. There is no final, fixed form (blueprint or template) imprinted onto the organism in a mechanical way. Methods of achieving such an understanding of natural form are well described by Hoffman (2007), and Colquhoun and Ewald (1996). The observation of the forms of the "movement organisms' in fluid flow, as previously described, can help us to grasp this aspect of life. These forming influences belong to the whole, and they permeate all the parts. In biodynamic agriculture, they are thought to originate in the peripheral entities of the moon, the planets and the stars (Daath, 2006; Thornton Smith, 2009). This is supported by a body of evidence for the effect of the moon on living organisms (e.g. Barlow, 2012; Endres and Shad, 2002), as well as by extensive correlation of tree-bud shape changes with planetary alignments (Edwards, 2006: 213-248). Working with these cosmic influences has shown positive results for many farmers and gardeners (Thun, 2003). When seeking to develop healthier plant life, one works to strengthen the working of such cosmic influences. To do this, one can choose appropriate planting and sowing times according to the positions of planets, and one can also apply biodynamic preparations which are carefully prepared, natural materials that bring specific benefits to the growing plants (von Wistingshausen et al., 2000).

These are enhanced through the mediation of water. One can work with movements in the water to both open the water to be sensitive and then to hold these influences within the water. One way to do this is through dynamisation, which can involve stirring up a container of water, by hand or by another mechanism. Before applying the biodynamic preparations, they are mixed in water in a barrel and stirred in a particular way, usually for an hour. A vortex is created and then broken, and then created again. The vortex opens out the surface and draws the funnel form down into the depth of the barrel which can be experienced as a contractive gesture. To break this form, one must exert pressure against the flow; the resulting movements are more chaotic and expansive but can be experienced as closing in the flow. The water is then stirred in the opposite direction to establish a vortex again, and this is then broken again. This is repeated continuously. The rhythmic stirring movement is not a simple repetition but a varying rhythm as it is in the heartbeat, in breathing and in other rhythmic functions of living organisms. The human being is present, with his/her consciousness accompanying the stirring process.

This dynamisation of the biodynamic preparation may be seen to embody the rhythmic play between the two movement gestures we have identified already: a contractive, well-formed gesture open to the surroundings (reaching out to the periphery) and an expansive, more chaotic gesture closing up within itself. This qualitative exploration of the flow can help us begin to see why dynamisation was originally indicated by Rudolf Steiner as a life-supporting process (Steiner, 2004), and why many farmers continue the practice (von Wistingshausen et al., 2000).

The biodynamic preparations are usually applied to the whole farm or garden rather than one part, and this reflects the holistic approach inherent in biodynamics (Osthaus, 2010). Such dynamised liquid stimulates particular processes in the soil and plant life, for instance the vegetative growth, the flowering or the fruit ripening process (Thun, 2003). If we think of dynamisation as the establishment of a movement organism in the water body, which has a spatial form and is also formed in time, this may indicate why the dynamised liquid may be resonant with forces for only a limited time period and needs to be applied soon after stirring has finished. For preparations to be used over large areas, dynamisation has been undertaken by machine, stirring with a motor and 
suitable gearings, but this will have a more mechanical rhythm. Since the 1980s, dynamisation has also been undertaken in various countries using Flowform water sculptures. We will now look into what happens in this method of engendering movement in water.

\section{FLOWFORM MOVEMENT: AN ALTERNATIVE METHOD OF DYNAMISATION}

Flowforms are vessels specifically designed for water to embody rhythmic flow patterns. They are usually designed in clay with water flowing through them in an interactive way. The potential for such resonant water movements was discovered by John Wilkes while working with Theodor Schwenk in 1970 (Wilkes, 2003). They have been used for dynamisation among many other uses.

When water flows into a Flowform water sculpture (see Figure 25.9), it is channelled into a bowl where it meets resistance before it can flow out. If the space is appropriately formed and if the resistance at the outflow is not too much or too little for the incoming velocity of flow, then some water builds up in the bowl to meet the inflow, and the movement becomes unstable. The conditions for this instability are essential as the water needs to meet itself in a free and conducive space, and it is often seen to move in an unpredictable way until a resonant recurrent flow pattern asserts itself. In this way, the water is able to establish a stable rhythmic flow condition. When this first happens in a Flowform, the strength and vigour of the movement build up and one feels it 'come to life'. The water reaches up further and reaches out further than previously. Even though it has an average frequency and reach, the rhythmic flow varies, just as a healthy human heart also has variability in its beat even while at rest (Campos, 2017).

The flow pattern in the Flowform vessel can be characterised in many ways; it can be regarded as a wave moving around the vessel, and in some designs, the wave moves in a clearly defined lemniscate. This 'figure of 8 ' form can also be seen as the path of an imagined particle in the water. In contrast to this observation of a part, we can try to observe and experience the movement of the whole body of water. We can then experience the water in a play between the rising expansive gesture (or the beginnings of it), as the water is being pushed up in one side of the vessel, and the contracting spiralling gesture (or the beginnings of it) as it is drawn out. The forms can also be seen to embody rhythm as expressed in all living organisms, an alternating play of expansion and contraction (Figure 25.10).

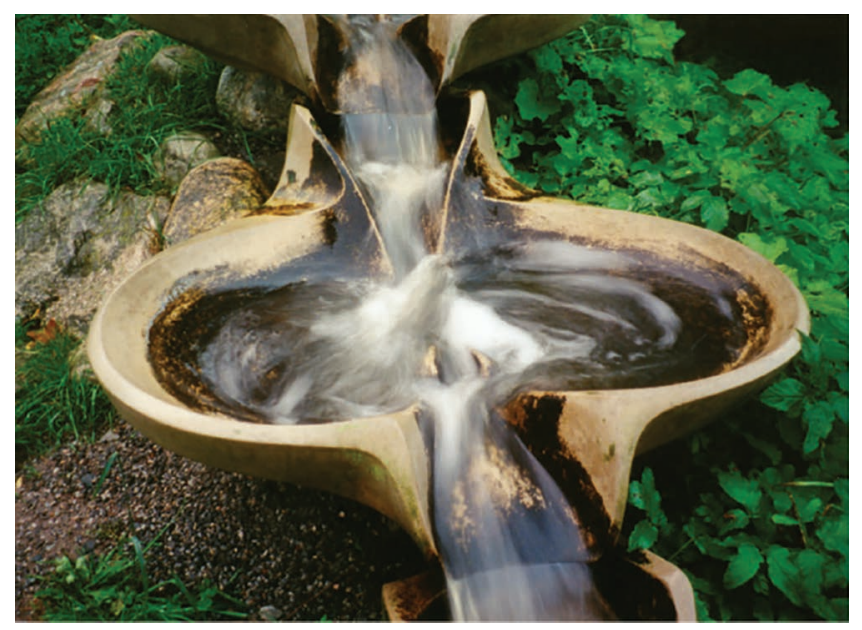

FIGURE 25.9 'Malmo' Flowform Design by John Wilkes, Nigel Wells and Nick Weidmann. (Photo credit: Imke Naudascher.) 


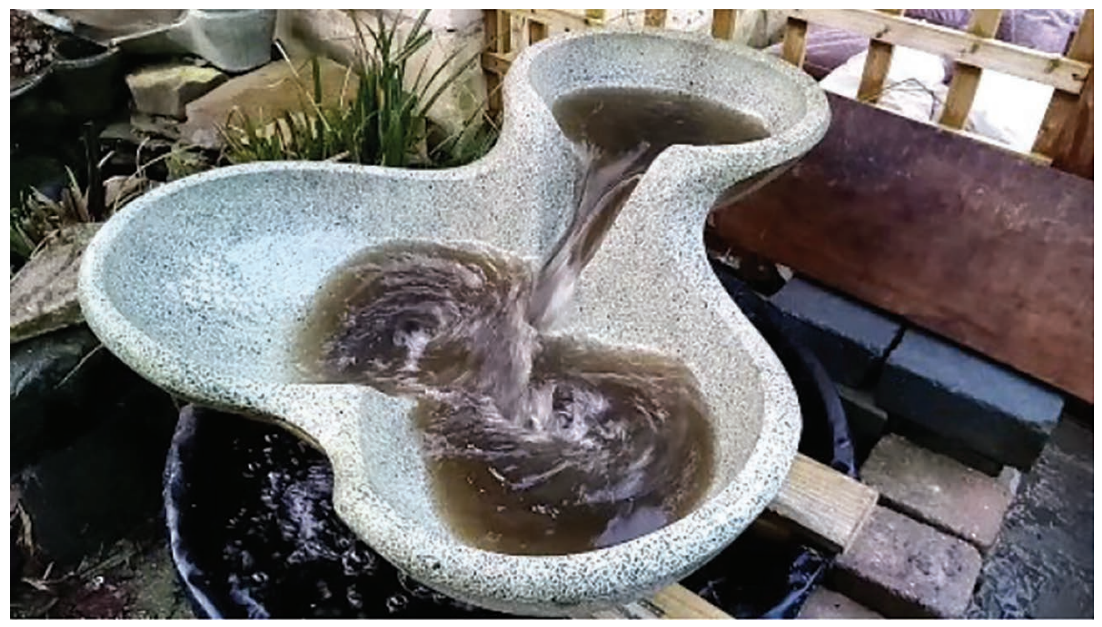

FIGURE 25.10 'Vortex’ Flowform Design, by John Wilkes, Nick Weidmann and Michael Monzies. (Photo credit: Simon Charter.)

Thus, the flow pattern can also be seen as having the same gestures of dynamisation as when done by hand in a barrel. However, Flowforms embody these principles in a variety of ways according to their design, and different types may be chosen to suit different purposes.

In agriculture, Flowforms have also been used to dynamise irrigation water. Based on my experiences and reports from others, this can result in statistically significant crop improvements (both quantitative and qualitative) over controls. However, as these results are seldom repeatable, they have not generally been published. This does, however, suggest that a non-mechanistic process is at work. For example, in 2004, a trial was performed with lettuce whereby the irrigation water was dynamised with Flowforms (Schwuckow et al., 2010: 77-83). Significant increases in total plant weight of between $25 \%$ and $32 \%$ over the control, as well as improvements in colour, form and flavour, were found. However, the following year, a more extensive trial with more crops showed no significant differences. A horticulturalist involved in the second trial was still convinced of improvements in overall crop health and especially initial root growth and went to great lengths to dynamise all his greenhouse irrigation water over future seasons. He and I both observed that his crops became crisper in form and texture and less susceptible to mould.

Another application of moving water in agriculture is in the production and use of aerated compost tea, and studies show the benefits of using this as a liquid nutrient fertiliser in a variety of crops (Min et al., 2015). A comparative trial of the performance of Flowforms compared to mechanical aeration has been undertaken in a soil-food-web laboratory on a biodynamic farm in the UK. The comparison was between aeration using an air pump that pushed bubbles into the liquid, and a Flowform cascade. With the Flowform, dissolved oxygen levels were higher for many days after aeration had ceased, but in the case of the air pump, as soon as the device was turned off, the oxygen levels dropped to the base level (Personal Communication, J. Williams, November 2017). More systematic research is required.

\section{HOMEOPATHIC POTENTISATION}

A final, but important, rhythmic process that is distinct from dynamisation but also done with water is homeopathic potentisation. Here, a specifically chosen substance is diluted repeatedly, as well as subjected to rhythmic movements (succussion) between dilutions. The method of succussion as originally advocated by Samuel Hahnemann - the father of homeopathy - involves raising the bottle of remedy and thumping it down on a thick book or similar soft but solid surface. For the water, this 
technique involves a rhythmic play of more pressure (on the thump down) and less pressure (when lifted up). This is done in order to create a remedy, which can have specific healing effects on an organism, usually human or animal. It can also be used for a crop or a whole farm or garden ecology.

According to homeopathic practice, this potentisation process provides a more time-stable remedy whose influence can be brought into play in an organism many years after it has been made, and for this reason, remedies are not usually given a shelf life. Homeopathy in agriculture is a fast-developing area of research and practice in both India and South America (Sen et al., 2018), and some dramatic results have been achieved with certain plant illnesses (Kaviraj, 2012).

\section{CONCLUDING DISCUSSION: RESEARCH WITH THE LIFE-FORMING FORCES}

When researching with living organisms and subtle influences, one factor is seldom taken into account: the influence of the researcher on the research. In my experience over the last 30 years, experiments in this field that attempt to establish reproducibility and to prove a cause and effect in a reductionist way invariably fail. Often then the work is not published. French immunologist Jaques Benveniste was famously dogged by this issue of reproducibility after sceptics questioned the results of his research into high dilution effects on living tissue which he had published in the journal Nature (Davenas et al., 1988). Eventually, Benveniste found that reproducible results were possible for certain experimenters and not others. Experiments undertaken robotically also failed, unless a connection with an effective experimenter was established, and this was undertaken through using a sample of water (Personal Communication, J. Benveniste, December 1998).

Most subtle forming influences in living things are not physical or chemical in origin, but they can still be grasped clearly. These organising principles in life, these active ideas, can be considered aspects of the spiritual working in the physical world. If the influenced phenomena were predictable in a mechanistic way, we would feel obliged to take up a subservient position in relationship to this spiritual realm and become mechanistic in our own dealings with the living world. This would run counter to our ability to be free and independent, to work out of our own sense of responsibility in any given situation and to seek what we find to be true, beautiful and good. The more we get to know the qualities of these active influences at work in the natural world, the more these influences also become creative, artistic tendencies in us, and we willingly work in tune with them.

Many influences in the environment are working on plants, yet overarching these are subtle forming forces that may be mediated by the water in and around the organism. These work as a whole on the whole plant and involve the surrounding rocks, plants, animals, humans and astronomical events. Based on my work with water, there seem to be forces working both from within outward and from the periphery inward, and these work to achieve the time-variable but characteristic form of the organism.

The scientific challenge is to be open to these subtle factors and also to become clearer as to what is going on with both the sense-perceptible world and ideas working in the perceived phenomena (i.e. natural laws and identifiable gestures). We are looking for the satisfying marriage of percept and concept, of phenomena and idea. If we can educate ourselves to read the ideas within what we perceive, then the meaning of the workings of the natural world can increasingly unfold. One of the roles of water claimed by Theodor Schwenk is that it can help us to read this world of living beings. Through observation of its fluidity, 'our way of thinking becomes changed and more suited to the understanding of what is alive' (2014: 11). This need is far greater now than when Schwenk originally suggested this in 1961, and it may be an essential step if we wish to free ourselves from trying to manipulate nature and learn to work and play responsibly with her.

\section{REFERENCES}

Barlow, P.W. (2012) Moon and cosmos: Plant growth and plant bioelectricity. In Volkov, A. (ed), Plant Electrophysiology. Berlin/Heidelberg: Springer, pp. 249-280. 
Bateson, G. (2002) Mind and Nature, a Necessary Unity. Cresskill, NJ: Hampton Press.

Blackwood, J. (2012) Geometry in Nature. Edinburgh: Floris Books, pp. 87-89.

Bortoft, H. (1996) The Wholeness of Nature. Edinburgh: Lindisfarne Books/Floris Books.

Bortoft, H. (2012) Taking Appearance Seriously. Edinburgh: Floris Books.

Campos, M. (2017) Heart rate variability, a new way to track wellbeing. Harvard Health Blog. https:// www.health.harvard.edu/blog/heart-rate-variability-new-way-track-well-2017112212789 (accessed September 10th, 2020).

Colquhoun, M. and Ewald, A. (1996) New Eyes for Plants, a Workbook for Observing and Drawing Plants. Stroud: Hawthorn Press.

Cowern, D. (2014) Fun with vortex rings in the pool. Physics Girl. https://www.youtube.com/ watch? $\mathrm{v}=72 \mathrm{LWr} 7 \mathrm{BU} 8 \mathrm{Ao} \& \mathrm{t}=1 \mathrm{~s}$ (accessed September 11th 2020).

Daath, H. (2006) The Biodynamic Action of Planets. Whitefish, MI: Kessinger Publishing.

Danek, A.H. and Salvi, C. (2020) Moment of truth: Why Aha! Experiences are correct. Journal of Creative Behaviour, 54(2):484-448.

Davenas, E., Beauvais, F., Amara, J., Oberbaum, M., Robinzon, B., Miadonna, A., Tedeschi, A., Pomeranz, B., Fortner, P., Belon, P., Sainte-Laudy, J., Poitevin, B. and Benveniste, J. (1988) Human basophil degranulation triggered by very dilute antiserum against IgE. Nature 333:816-818.

Edwards, L. (2006) The Vortex of Life. Edinburgh: Floris Books.

Endres, K.-P. and Shad, W. (2002) Moon Rhythms in Nature, How Lunar Cycles Affect Living Organisms. Edinburgh: Floris Books.

Hoffman, N. (2007) Goethe's Science of Living Form: The Artistic Stages. Hillsdale, MI and New York: Adonis Press.

Holdrege, C. (2013) Thinking Like a Plant, a Living Science for Life. Great Barrington, MA: Lindisfarne Books.

Kaviraj, V.D. (2012) Homeopathy for Farm and Garden: Homeopathic Treatment of Plants. Kandern: Narayana Verlag.

Kemp, M. (1989) The Disciple of Experience, Leonardo da Vinci. London: Yale University Press for The South Bank Centre.

Min, J.K., Chang, K.S., Yong, K.K., Sung, J.H., Jong, H.P., Eun, J.H., Jin, H.K. and Suk, C.K. (2015) Effect of aerated compost tea on the growth promotion of lettuce, soybean, and sweet corn in organic cultivation. Plant Pathology Journal, 31(3):259-268.

Osthaus, K.E. (2010) The Biodynamic Farm, Developing a Holistic Organism. Edinburgh: Floris Books.

Schwenk, T. (2014) Sensitive Chaos, the Creation of Flowing Forms in Water and Air. Forest Row: Sophia Books.

Schwuckow, J., Wilkes, J. and Trousdell, I. (2010) Energizing Water, Flowform Technology and the Power of Water. Forest Row: Sophia Books.

Seamon, D. and Zajonc, A. (1998) Goethe's Way of Science, a Phenomenology of Nature. New York: SUNY Press.

Sen, S., Chandra, I., Khatun, A., Chaterjee, S. and Das, S. (2018) Agrohomeopathy, an emerging field of agriculture for higher crop productivity and protection of plants against various stress conditions. IJRAR, 5(4):52-56.

Steiner, R. (1988) Goethean Science. Rochester, NY: Mercury Press.

Steiner, R. (2004) Agriculture. Forest Row: Rudolf Steiner Press.

Thornton Smith, R. (2009) Cosmos, Earth and Nutrition, the Biodynamic Approach to Agriculture. Forest Row: Rudolf Steiner Press.

Thun, M. (2003) Results from the Biodynamic Sowing and Planting Calendar. Edinburgh: Floris Books.

von Goethe, J.W. (2009) The Metamorphosis of the Plant. Cambridge, MA: MIT Press.

von Wistingshausen, C., Scheibe, W. and König, U.J. (2000) The Biodynamic Spray and Compost Preparations Production Methods. Stroud: Biodynamic Agricultural Association.

Whicher, O. (2013) Projective Geometry, Creative Polarities in Space and Time. Forest Row: Sophia Books.

Wilkens, A., Schwenk, W. and Jacobi, M. (2005) Understanding Water: Developments from the Work of Theodor Schwenk. Edinburgh: Floris Books.

Wilkes, A.J. (2003) Flowforms: The Rhythmic Power of Water. Edinburgh: Floris Books. 


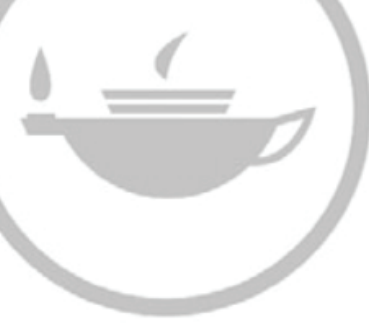

Taylor \& Francis Taylor \& Francis Group http://taylorandfrancis.com 


\title{
26 Land Whispering Practical Applications of Consciousness and Subtle Energy Awareness in Agriculture
}

\author{
Patrick MacManaway
}

\section{CONTENTS}

Land Whispering

Communication with the 'Spirit Realms': From Human and Angelic to Elemental and

Nature Spirits

Understanding Dragons/Earth Meridians .....

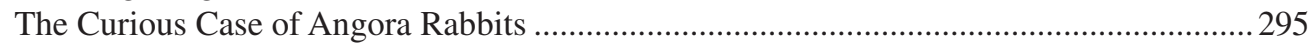

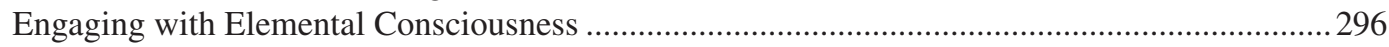

Engaging with Nature Spirit Consciousness ............................................................................ 300

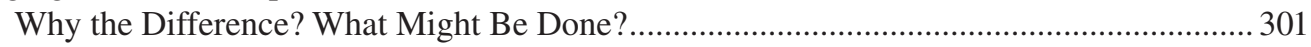

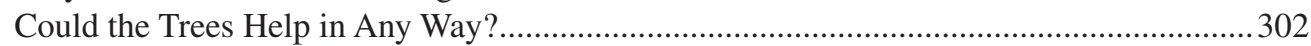

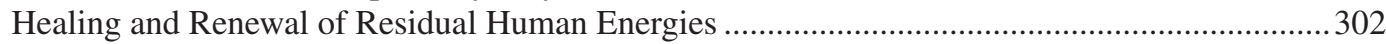

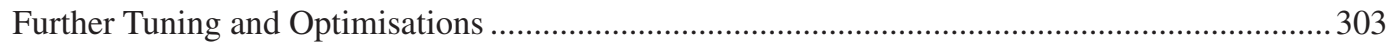

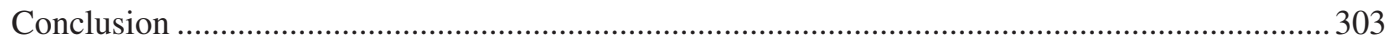

\section{LAND WHISPERING}

This chapter is an account of experiences of land whispering applied - quite literally - in the field. Due to client confidentiality, these can stand only as anecdotal stories.

After 25 years of full-time practice, with experience and awareness developed over work on thousands of properties, domestic and commercial as well as agricultural, my main aim is to inspire, inform and invite readers to 'try this at home and on the farm' and to come to their own conclusions regarding what I can share from the harvest of my own experience and reflections.

My background and the perspective that I hold stems from being born and raised into a family of traditional spiritual healers, psychics, mediums and dowsers running a healing and teaching centre in rural Scotland.

A fundamental principle in the understandings and teachings that occurred in both the classroom and around the kitchen table was to understand that the tone, quality and content of our mind and spirit, our attention and intentions, were defining of our physical circumstance and health.

My parents' enterprise was supported by six acres of garden and pastures - mum was green-fingered - everything seemed to grow effortlessly and extraordinarily - nature spirits were clearly 'on team', and showing off the best of what was possible through close communication and cooperation arising from her sensitivity, awareness and ability to communicate directly with them.

Rabbits and moles dared not enter her garden and were rapidly and fiercely admonished if boundaries were transgressed. Birds were advised season by season which trees in the orchard were theirs to take fruit from, leaving the rest for the people - their compliance was amazing and consistent. 
I was raised therefore with an understanding that all of nature is, at source, a vibrational, interactive intelligence, with our physical, experiential world being a reflection and expression of that vibrational content and tone. My own subsequent experiences, experimentation and observations have, to date, been consistent with that premise.

This fundamental awareness - of the impact and interaction of our own consciousness, heart and mind, with the surrounding intelligence of our landscape and environment, has underpinned human understanding, attitudes and practices in agriculture during 6,500 years of land management.

It seems wise to bring our awareness and focus to a fully contemporary engagement with the sustaining, benevolent and extraordinarily generous intelligences and life forces that we are in daily contact and communication with, and on which we rely and depend upon absolutely.

The quantum model includes the inevitable effects of our human observation, attention and intentions on any given outcome, and so is a good basis for analysing and interpreting the observations of the effects that our ability to interact that our consciousness allows us. Perhaps simple electromagnetism and wave physics, which includes the wave frequencies and waveforms of our own thoughts and feelings and their effects on other electromagnetic fields, is also richly informative.

Our honest science is tasked with the creation of evolving hypotheses to accommodate all observable phenomena. Perhaps if we can understand the core processes and translate the language of our traditional agricultural spiritual traditions as being simple and effective applications of consciousness, then we can bridge the span of time, language and belief, and bring the best of all things into our own contemporary present.

\section{COMMUNICATION WITH THE 'SPIRIT REALMS': FROM HUMAN AND ANGELIC TO ELEMENTAL AND NATURE SPIRITS}

Plato tells us that 'the Gods are Numbers'.

Number expressed in time is music, frequency, wavelength and waveform - number expressed in space is structure, architecture, physiology.

Each level of intelligence has its own frequency or band of frequencies - in traditional understanding, the deepest are the dragons - the earth meridians - pathways of energy, chi, electromagnetism telluric currents. ${ }^{1}$

These perhaps are the pathways of current and flow in the sustaining and surrounding planetary toroidal field ${ }^{2}$ - analogous to the meridians of the human acupuncture system, and traditionally worked with on the earth using needles of stone, wood and metals alongside many other techniques and practices.

Within the stable toroidal magnetic field, elemental consciousness can establish an experiential, 3D world of elemental form - substance within the realms of earth, water, air and fire - each with their own dynamic and interactive intelligence.

Within that elemental world, a population of nature spirits fills the environment with spectacular diversity, creativity and adaptation - shared by we humans, as one of the natural spirits of the ecosystem.

In addressing landscape, it is good to consider the health and vitality, awareness and engagement of each of these levels of vibration intelligence, and of our connection and engagement with them as present members of an interactive system.

The stories and reflections that follow explore each of these vibrational realms.

\section{UNDERSTANDING DRAGONS/EARTH MERIDIANS}

My engagement with holistic environmental practices started with an awareness of geopathic stress - always perhaps recognised, but brought back to contemporary awareness by the work of Bavarian water dowser, Baron Gustav Freiherr von Pohl, who published his observations in 1928,

\footnotetext{
${ }^{1}$ A telluric current is an electric current which moves underground or through the sea.

${ }^{2}$ In mathematics, a toroid is a surface of revolution with a hole in the middle, like a doughnut.
} 
which were subsequently translated into English and published as 'Earth Currents - Causative Factor of Cancer and Other Diseases'.

Von Pohl observed and documented that all life seemed to be aware of and responsive to the electromagnetism transmitted to the surface along and through pathways of underground water. He documented that lightning strikes occurred where underground streams crossed the points of greatest electromagnetic conductivity in the local landscape and that a wide variety of plants, birds and animals were either tolerant, strongly attracted to, or assiduous avoiders of such energetic fields in their environment:

- Birds and mammals absolutely avoided them for nesting, burrowing or sleeping space or extended periods;

- Fruit trees showed poor health, blossom and fruiting when planted over them;

- Insects, including honeybees, thrived and preferred to nest over them, fungi generally, beans and lentils also seemed to prefer them.

A whole range of species preferences and tolerance windows of the baseline electromagnetism, landscape energy or chi emerges in relation to its conductive capacity. The traditional categorisation of Feng Shui practitioners refers to this as yin chi or yang chi-which alone can helpfully guide the placement of structures and planting...

When out of balance or out of phase with the use of space, geopathic stress can arise, which is classically associated with a disturbance of the pineal and adrenal glands, that can have widespread and far-reaching effects, including on sleep and fertility cycles.

\section{The Curious Case of Angora Rabbits}

Friends of ours in Fife, Scotland, engaged their teenage daughter in a project to raise Angora rabbits for cuddly fun and pocket money profit. An L-shaped shed with five identical rabbit hutches was constructed for the purpose, each identical in construction, each identical to the eye.

After a year of breeding, I was asked to see if I could identify the source of a mystery.

Every single litter bred and born in hutch \#3 either miscarried or was stillborn, regardless of the doe currently resident there. Two post-mortems conducted by the local veterinarian on the stillborn babies revealed no apparent cause of death.

Once on site, dowsing for underground water revealed a substantial flow in a narrow rock fissure that ran directly, but only, below hutch \#3.

Classically, for species depleted and stressed by their influence, such energies are remedially grounded and dispersed by either placing highly paramagnetic rock or inserting iron or steel on the energy pathway upstream of the area of concern.

A steel rod was inserted into a convenient area of lawn upstream of the breeding area, dowsed for length and diameter, and countersunk four inches to make it safe for bare feet.

The pregnant doe in hutch \#3, that was already halfway through her term, had stillbirths at the end of that cycle, so the effect seems to have been in the first or early second trimester. Following this, no further stillbirths occurred ever again in hutch \#3, which became as healthy for the rabbits as all the other hutches.

This is a very classic illustration of one of the most fundamental awarenesses in land whispering, of the direct effects of local vibration resonance through pathways of energy in the landscape. Sometimes this can be too yin - receptive, ultimately draining and depleting, and sometimes too yang - stimulating, ultimately over-stimulating and leading to exhaustion and burnout.

A dairy herd in Northern Scotland plagued with mastitis in their indoor barn were found to have seven strong underground streams running underneath the structure. Through a similar process of earth acupuncture, steel rods were inserted upstream of the barn to disperse the incompatible magnetic energies, resulting in a $60 \%$ drop of mastitis within 10 days. 


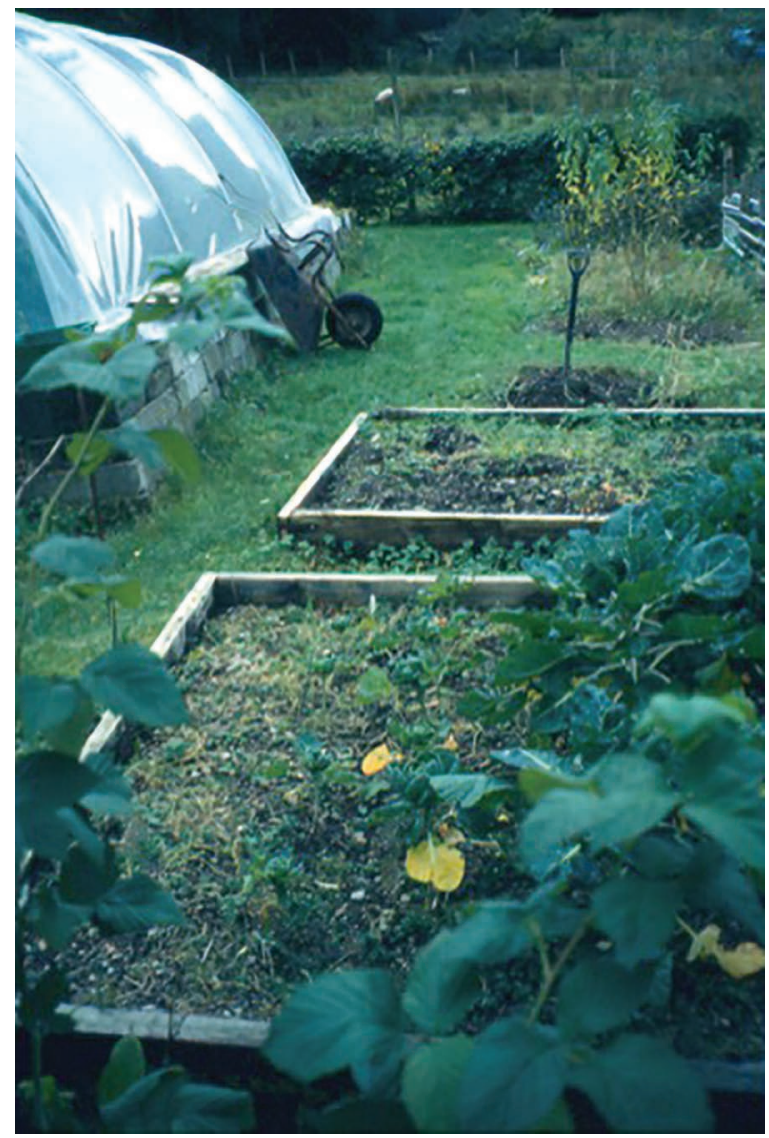

FIGURE 26.1 Brussels sprouts eaten by dragon in Scotland.

Plants, animal and people in the wrong growing environment fail to thrive - von Pohl documented that every single one of 52 people dying over a 10-year period from cancer in the town of Vilsbiburg was sleeping over an underground stream - Brussels sprouts don't like them and neither do spruce trees (Figures 26.1 and 26.2).

Traditionally, we have observed and followed the plants that volunteer in an area and how wildlife prefers or avoids different places in order to site our own homes and infrastructure. In Scotland, the croft house was built where the cattle, sheep and dogs chose to lie down to sleep.

It is good to pay attention to the dragons in our landscape.

\section{ENGAGING WITH ELEMENTAL CONSCIOUSNESS}

Next up from dragons on the fretboard scale are the elementals - the vibrational intelligence of the tangible elemental states of earth, air, fire and water. Each of these tangible states of matter has a vibrational and governing intelligence within them, directing and guiding the physical, particle state.

Traditionally, in Northern Europe, the intelligence of earth is that of gnome, of water undine or sprite, of air the sylphs, and in fire the salamander.

In my experience, the elemental consciousness is entirely focused on channelling energy into the world in whatever form or vibrational tone is required or asked for, without judgement or prejudice. When lovingly and respectfully communicated with, and given clarity of our needs, either for 


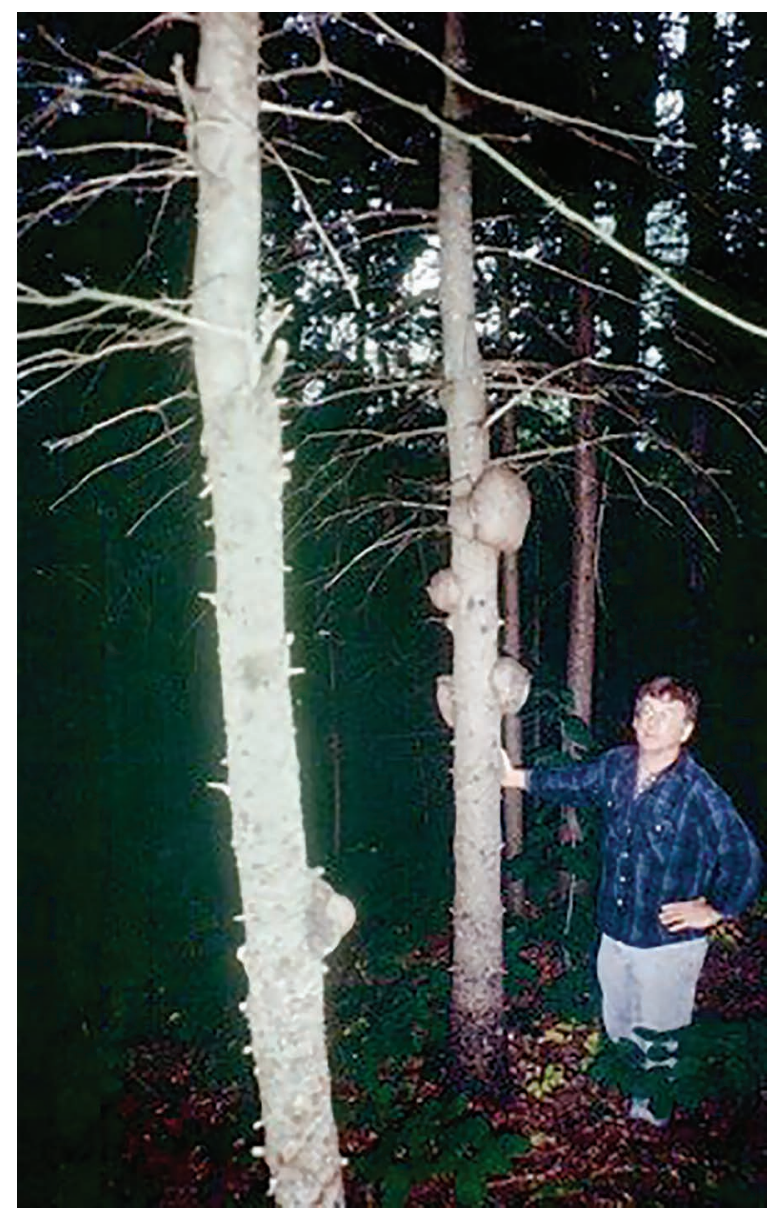

FIGURE 26.2 Cancerous burls on spruce trees in Vermont.

ourselves, plants or animals, they seem extraordinarily able to direct their energy to support those processes or purposes.

I can share some stories of working with the vibrational consciousness of water which is so critical and central to all life, at home as in the garden and on the farm.

During a drought year where I lived in Vermont, many shallow springs went dry, dowsers and drillers were busy finding deeper streams and aquifers for alternative supply, but it was difficult for drilling equipment to access some of the more remote rural properties.

I was asked to look at one such, where a three-foot-deep woodland spring had supplied a family home with sweet freshwater year-round for over 20 years. Accompanied by a colleague and friend, we walked up into the woods to what was now a dry hole. Tuning in to the vibrational presence however, the 'spirit' or guiding intelligence was still strongly present, although no water was there. Through a process of telepathic communication and dowsing, we established that the spring was able to restore itself, that it was willing to restore itself to meet the human need, and that to help and support the process it would like us to sing to it.

So we sang:

And within 48 hours and in the absence of any rain, it was brim-full with water again and remained so for seasons after.

I had an almost identical experience on another property 2 weeks later, which asked for singing and restored itself within 48 hours. 
And then, a client for whom I was doing other work told me her own story of her spring going dry, being inspired to sing to it and then seeing it come back to life.

It turns out that there are many deep and old traditions everywhere of water blessings, especially directed to springs, wells and rivers and which are typically renewed on at least an annual basis.

During a farm field day in New South Wales for interested farmers in the area, we as a group blessed the farm borehole, which supplied water to troughs for sheep in approximately half of the 120 paddocks, the other paddocks having ponds for stock water instead. In tasting the water directly from the bore before and after blessing, we were amazed and delighted in the enhancement of palatability, sweetness and the sense of a refreshing, thirst-quenching drink.

I received a communication 2 weeks later from the hosting farmer letting me know that since the water blessing, the sheep, who hitherto had shown a mild but not substantial preference for the trough water over that in the ponds, now when released through rotation from a pond field to a trough field, were galloping as a flock up to $1.4 \mathrm{~km}$ to the trough and staying there until all had drunk their fill.

I revisited the farm 6 months later, at which point the behaviour was still continuing, and extended our work and experiment by blessing all of the ponds. The sheep immediately became equally happy with both trough and pond water and stopped galloping uphill.

I have subsequently accrued many stories of water quality improving in both palatability and even sometimes mineral and salt content with loving connection and a communicated request boreholes restoring their standing level and volume - on one occasion a creek that had been dry for 8 years bringing its deep gravel-based water up to the surface after a blessing - but only on the property in question and not upstream or downstream on their neighbours' properties (Figures 26.3 and 26.4).

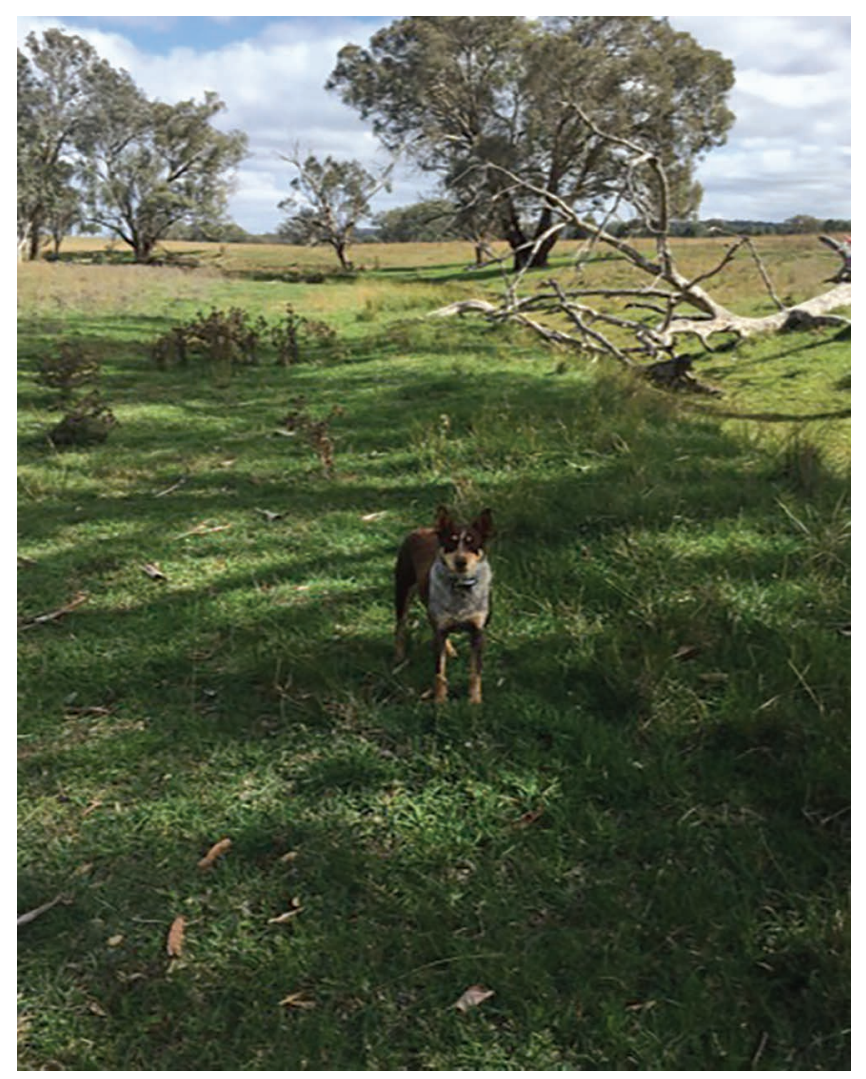

FIGURE 26.3 Dry creek before. 


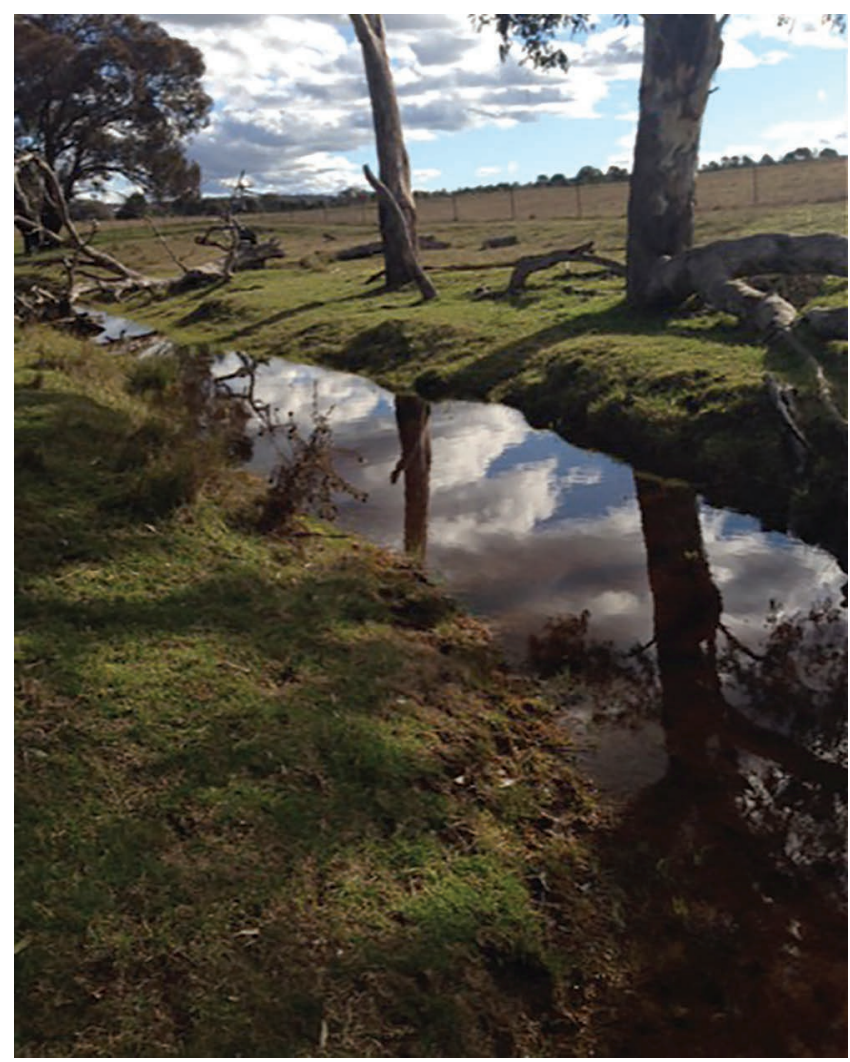

FIGURE 26.4 Wet creek after.

Apparently, the response received is very particular and specific to our requests.

I have a particularly treasured memory of an early morning visit to a farm in Coastal Queensland, which I had previously visited 6 months before. One of the tasks on the list of work initially had been to dowse for, and site, a new borehole, as the existing bore was excessively saline and unpalatable for humans, stock or indeed the garden.

During our work of clearing, balancing and blessing all levels of intelligence in the landscape, and clearly communicating current human needs in relation to the use of this space, the borehole miraculously became sweet and salt free - we were amazed and delighted. This lasted for about 3 months, after which the salinity gradually increased back to its previous un-useable level. So we came back to check in and chat with the spirit of the bore and the local water deva governing all such matters.

Love and appreciation and singing were asked for and inspired, and one of my colleagues and friends present on that day has a highly trained and beautiful singing voice - the rest of us were moved to tears - the singing concluded after maybe 4 minutes - we felt a sense of conclusion - took and tasted freshwater from the bore - and found its bottle quality sweet and delicious. Sustaining and maintaining the relationship seems essential and very deeply rewarding.

Beautiful pictures of the effects of our attention on water can be seen in the work of Dr Masaru Emoto - if you haven't seen them, they truly speak the 'thousand words' more than I can write them.

Similarly to working with the elemental water intelligence, we can work with the gnomes of the earth - all about soil structure and everything to do with supporting the entirety of soil ecology they seem very able to work to create the ideal conditions for specific plants or indeed for specific animals grazing or ourselves harvesting those plants - as with the water spirit, they need only be to 
lovingly asked for clear and specific help and support, and an open dialogue held to hear anything needed from us to further the process - whether that might be love, song, weeding or good compost.

I find that taking time to clearly communicate to the elemental intelligence of growing spaces before, and as seed is sown or plants introduced, as well as clear communication with the nature spirits - covered next - helps set the vibrational tone of the space to the optimum for the desired harvest.

Establishing a loving rapport with the spirit of air allows us the capacity to influence our local weather to small or large degrees, depending on their ability to accommodate. Connecting our hearts and minds to our needs and requesting and having respectful and heart-felt communication can help to support favourable micro-climate conditions and also benevolent timing and intensity of weather events.

Some of my clients are skilled in intentionally establishing and holding a 'weather bubble' over their farm - one dairy farming couple in Vermont can keep rain storms away - splitting and passing to each side of the farm as they pass through - for the critical 2 weeks of haying, after which they take it down and let all do its own thing again - other clients seem able to keep hail from fruit trees - others to be able to take best advantage of any rain available and increase rainfall above regional average.

One of my Australian clients informed me of a whimsical and envious complaint from a friend and neighbour $30 \mathrm{~km}$ away on the next ridge of hills, who called her on the phone one morning during a dry season to let her know that the only visible cloud in the sky was over her farm and dropping rain.

Elemental fire is also in my experience interactive and mutable by connection and communicationI have experienced fire-walking many times over 24 years and occasionally led fire-walks myself, the most extraordinary miracle is that such an intense element can, in the right state of mind and consciousness, be amenable to sustained direct contact and energise without harming.

There are many connections available to working with fire, in so many ways, in our daily homes, work and lives - it is good to remember that these should be engaged with through direct consciousness, and respectfully and lovingly asking for help to support our needs and endeavours.

\section{ENGAGING WITH NATURE SPIRIT CONSCIOUSNESS}

The world created, held and nurtured with life energy by the elementals, is populated by the rest of us - including the very many and various vibrational intelligences of the spirits of nature.

There are nature spirits associated with every natural process, fungi, bacteria, insects, plants, birds, animals - they are sometimes considered as the vibrational intelligence within or of the process, sometimes as companion helpers to the process.

Some, like wildlife, avoid human company or interaction, and choose to inhabit the wilder places, of which we should be sure that there are always plenty, otherwise trouble tends to arise.

Others are comfortable and enjoy working with humans in the landscape, and perhaps find their own fulfilment enhanced within a cooperative working environment in exactly the same way that we ourselves do.

We can consider the individual and collective intelligence of oats and potatoes, of broccoli and kale and their companion deva or fairy - the host of nature spirits is already in community, in our growing spaces, coming from native plants and previous management, and ensures that the spirit of the current crop is welcomed and hosted and supported by all already there.

I have clients in rural England who pay me in cheese. On one occasion, I was called with great urgency to look at a field of alfalfa/lucerne which the cows had just that day been moved onto, and within just a few hours, several were showing signs of life-threatening bloat. Identified early, the cows had been drenched with vegetable oil and all were well - however, this field was the last green forage for that season on the farm, and losing it for grazing would leave a large hole in the supply of dry winter feed. 
On getting further details once on site, I was told that the crop had been planted on the same day with the same seed, equipment and operator, as an immediately adjacent field, separated only by a stone wall, which had been successfully grazed until just the previous day.

\section{Why the Difference? What Might Be Done?}

Plants have a catalogue of secondary metabolites that they can rapidly create to make themselves unpalatable, indigestible and unattractive to pests and predators, as well as for adaptation to temperature and moisture variations. Giraffes in Africa must stalk acacia trees from downwind to enable them to achieve at least a short browse before the trees mobilise tannins to render their leaves unpalatable. A ground cherry in the American West also must by stalked from downwind - if it detects the presence of the human gatherer, its delicious sweetness turns almost instantly sour.

Apparently, this field of alfalfa, unlike its neighbour over the wall, had mobilised a hostile, self-defensive response to the grazing cattle, perceiving itself to be threatened and besieged, whereas the intelligences at play in the adjacent field had apparently understood and cooperatively participated in the agricultural process and purpose, aligning themselves to providing high-quality nutrition for the cattle, after which they would be planted and grown again in the same process in the seasons to follow.

I find that engaging with vibrational intelligence telepathically is a little like a lucid dream, where one has self-awareness and volitional control, or perhaps like an interactive video game. Perceptions are visual, imaginal, sensations are felt, ideas and understandings are perceived - a complex of multi-sensory awareness, connection and communication is available if we align our hearts and minds to those wavelengths by holding in our heart-mind the image or idea of those intelligences with which we wish to be in communication.

Rather like a large family round a kitchen table. It can be chaotic and raucous - this case was.

Through quiet meditative communication in this way, I was able to create a full and clear understanding of circumstance, activity and purpose, between the spirit or intelligence of the farm, the field, the soil, the plants, the devic or fairy community, the collective intelligence of the cattle there and for good measure Bridget - Celtic Goddess and saint of domesticated animals. With clarity of understanding achieved, all went peacefully happy and harmonious in my perceptions. We waited 12 hours and then let the cattle back into the first grazing strip of the field. All was well and the whole field was subsequently fully grazed with no further problem or incident.

This experience is one that continues to both amaze and humble me - apparently, the communication between myself and the guiding and governing intelligence was real and actual - apparently, the plants had the capacity, at their discretion, to adjust their metabolic profile to the advantage of the cattle, and the human enterprise - and clearly chose to do so - and went ahead and did so.

I live in awe of the capacity and generosity of the environment around us to support us in perhaps currently unimaginable ways, with loving communication established between the vibrational community of which we are a part.

I also offer the subsequent reflection on the small extent to which our food is grown where this level of communication is established, compared to the potential consequence when, as with the alfalfa, our food is grown under circumstances where it mobilises secondary metabolites against its predator - in this case ourselves - in order to render itself indigestible and toxic in order to protect itself.

It's a sobering thought, and best to bless everything always. There are many long traditions of that.

Another story to share, that opens us to what can be possible, comes from an apple grower who attended my land whispering workshops for farmers. Already skilled with hail-related weather control, she learned to use telepathy, dowsing and muscle testing to communicate daily with her trees, to establish how best to serve their needs regarding water, compost, nutritional amendments and pruning. 
After several weeks of deepening rapport, she had raised with them the issue that supermarket specifications required her to harvest the apples in a small and specific size range, for which reason the orchard historically had been harvested three times per season with associated time and labour costs.

\section{Could the Trees Help in Any Way?}

When she returned to the next workshop, with bags of delicious apples with Brix readings ${ }^{3}$ in mid to high teens, she informed us that the whole orchard had matured to harvest at uniform size, all the branches of all the trees together, and that only one picking had been required that year.

Again, with further amazement and ever-deepening humility, we are shown that the communication is real, that the capacity is available, and that cooperation and help can be gifted in response to loving gratitude and simple request.

What an amazing and wonderful planet to live on!

There are many more stories of nature spirit communication and cooperation, but if you simply open your heart to them, you will find them in the garden and on the farm and will soon start telling your own stories...

\section{HEALING AND RENEWAL OF RESIDUAL HUMAN ENERGIES}

Landscape holds the memories and resonance of things past as well as present, and while we all enjoy those places full of the resonance of love and laughter, sometimes those place memories, or patterns of 'predecessor chi', are ill at ease and disquieting, leaving a sense of restless uneasiness, emptiness, coldness and sterility.

Such causes are classically associated with battlefields, sites of massacre or murder or suicide, critical points of conflict between indigenous and colonial peoples, sites of bankruptcy, disappointment or despair - the various lists of human stress and trauma in small and large degrees and scales.

Practitioners addressing healing work of this nature consider stress patterns in the earth meridians, the elemental and nature spirit realms, and also the resonant energies of ghosts or 'earthbound souls', curses on the property, and residual human emotional and psychological stress patterns that have become embedded or ingrained in the resonant matrix of the place.

Addressing these resonances with healing intention can, with patience, bring renewal and refreshment, allowing the life forces of elemental and nature spirit to return to engaged present activity rather than being caught up in, and compromised by, residual dissonance and frozen life force. Renewed and refreshed, like the patterns in the sand washed away by the incoming and outgoing tide, leaving all clear and fresh over again.

I worked on one farm in New South Wales that had been the site of a massacre of indigenous aboriginal people during the colonial period. The farmers there described it to me as being 'Rolls Royce property with no spark plugs'. For many years, they had applied regenerative agriculture techniques of grazing and crop rotation and had set up radionics emitters through which biodynamic preparations were being broadcast - nearly always with disappointing results. I engaged in a deep, quiet meditative healing process on the landscape to bring all to peace, and when I felt it had arrived, advised the elemental and nature spirits of current agricultural practices and the human needs there.

Two weeks after my work, a crop of sorghum was planted, which yielded 2.3 tonnes per acre, which compared favourably with their long-term average of 1 tonne/acre and their previous best yield of 1.6 tonne/acre. Almost more excitingly, they reported that the crop had been so full of

\footnotetext{
${ }^{3}$ Brix is a scale based on the amount that light bends when it passes through a liquid, and measures the percent solids in a given weight of plant juice. It is used to determine quality.
} 
spiders and wasps - natural predators to the troublesome Heliothis grub - that they alone out of ten similar neighbours had not needed to treat the Heliothis with sprays of any kind.

The response of landscape to the healing and release of residual stresses and traumas can be dramatic, as in this case, or may be slight and subtle - not all place memory patterns are stressful, and some perhaps are only a little so; therefore, the degree of lifting is proportional to the degree of previous burden - but it would appear that up to $30 \%$ of the growing capacity or life force of landscape can be compromised through trauma and subsequently restored through loving attention.

\section{FURTHER TUNING AND OPTIMISATIONS}

Once a growing area is clear of all residual hangover, balanced and clear in its earth meridians, engaged and communed with at the elemental and nature spirit levels, there is a wide range of further enhancements that we can bring to support those natural processes, with loving respect and inviting cooperation rather than trying to drive or exploit the system through depleting over-exertion. Much like balancing soil $\mathrm{pH}$, moisture and shade/sunlight conditions, we can increase and enhance the most helpful and beneficial vibrational resonances for the plants and animals under our care.

Sound can be used - recorded or live voice or instrument - vibrational technologies such as radionics - homeopathy - standing stones and stone circles - the list is as long as our imagination.

Researchers Burke and Halberg 4 documented a 300\% increase in yield of indigenous South American corn after leaving the seeds for a period in a Mayan pyramid before planting.

A small, simply constructed stone circle on a farm in Vermont achieved a 100\% germination on a rice crop when four other farms in the same regional trial achieved a germination rate of only $25 \%$.

Clearly, there is a world of exploration available to us to sing the vibrational songs to the plants and animals and landscapes in our care that they most love and enjoy to hear.

\section{CONCLUSION}

I hope that these stories and reflections are of help in guiding and inspiring us all to ask ourselves and our landscapes - what is possible, and what is most synergistic and helpful and healthy.

The journey into this work seems to lead us through a progressive sequence of questions for the enquiring mind.

First - is this real? does this work?

After which - its real! it works! Can I do it?

And finally - I can do it! how can I do it better and more?

I hope you will choose to share that lifelong journey with the ever-widening community of like-minded friends.

\footnotetext{
${ }^{4}$ Burke, J. and Halberg, J. (2005) Seed of Knowledge, Stone of Plenty: Understanding the Lost Technology of the Ancient Megalith-Builders. San Francisco, CA: Council Oak Books.
} 


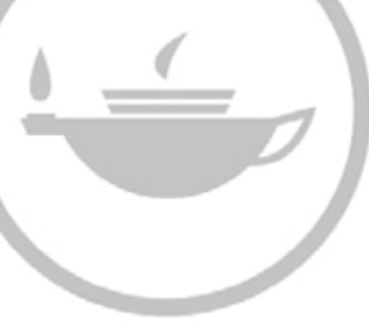

Taylor \& Francis Taylor \& Francis Group http://taylorandfrancis.com 


\title{
27 Rediscovering Ancient Pathways for Regenerative Agriculture
}

\author{
Charles Massy \\ Australian National University
}

\section{CONTENTS}

Subtle Energy as the Next Big 'Freebie' in Agriculture ........................................................... 305

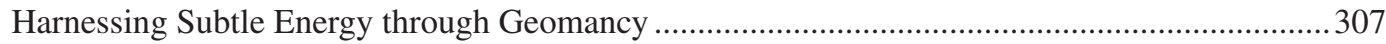

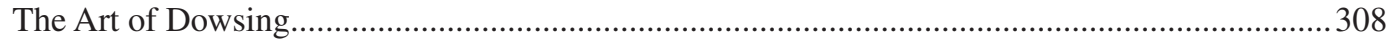

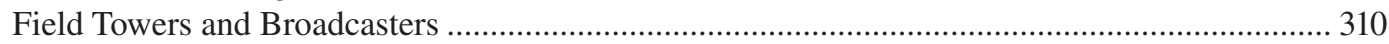

Indigenous Totems and Nature Spirits ............................................................................... 311

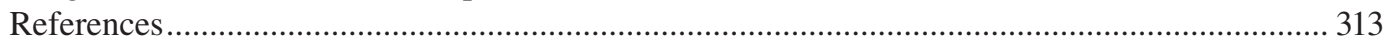

...water from plants, fire, clouds, rain, sun, moon, stars, stories and sites, songs, paintings, dancing... looking after country involves all of these things together - you can't have one without the other. Maintaining language and culture is a tool for relating to country and looking after everything that is on it.

Veronica Dobson, Arrernte Elder of Northern Australia, defining indigenous knowledge.

NAILSMA (2006: 3)

\section{SUBTLE ENERGY AS THE NEXT BIG 'FREEBIE' IN AGRICULTURE}

It is an early winter's day, 2013, in the inland city of Dubbo in Central West NSW. I am 1 of 20 or so farmers walking around a city park with two bent wire rods in my hands. They sit like giant revolvers, held out in front of us and pointing forward. We are learning to divine (or dowse), first for underground water streams and later for cosmic energy flows in the landscape. To my surprise, I find I can do this after only a brief lesson. I know because my two wires suddenly and violently cross onto my chest as I pass across either the stream or energy flow. The accurate locations of both water and energy streams are confirmed by others in the group, and particularly by our teacher, Dr. Patrick MacManaway. What I find even more remarkable is that I can dowse for a water stream, and not the energy stream, simply by focussing my thought-patterns - or my mental 'intent'. Though I had read about such mental power, for me this is the first confirmation. It had a deep impact.

What made me undertake the 7-hour drive to Dubbo for 3 days of workshops on 'subtle energies' is the increasing number of regenerative farmers I have met who have begun working with these energies. They are leading, practical, professional and profitable farmers and have come to this practice from different directions. Despite my initial scepticism, my increasing encounters with this issue meant that, in all integrity, I could no longer ignore it.

Patrick MacManaway is a Scot who gained a medical degree at the prestigious faculty of the University of Edinburgh. In 1994, he moved full time into working in the field of 'geomancy' and as a subtle energy expert, whereby he concentrates on enhancing the positive influences of subtle 
energy in our landscapes, infrastructure and animals - and specifically in regenerative agriculture. Today, he is internationally recognised and respected in his field.

MacManaway calls himself a holistic therapist. He helps farming landscapes and soils perform better, relieves 'geopathic' stress in landscapes (i.e. negative energy fields or flows) and is specifically skilled in using earth acupuncture to do so. His father, also a medically trained doctor, discovered he had a gift of healing when he was stranded with a battalion of soldiers and no medical supplies on the beach of Dunkirk in World War II. While they were being strafed by Messerschmitt, and as casualties mounted, his father's only tools were the physical laying-on of hands and providing kind words to his troops. And it worked, often in seemingly miraculous fashion. Patrick discovered he also had the 'gift', and so he switched to using the special sensitivities he had been endowed with to heal landscapes, people and animals via this different pathway.

Patrick MacManaway was first brought to Australia in 2010 by Terry McCosker and his Resource Consulting Services. McCosker had already introduced Australian farmers to the concept of subtle energies when he brought out the American expert Dr. Phil Wheeler to run workshops on dowsing in 2001. As more regenerative farmers experienced positive results from this programme, McCosker next invited MacManaway to broaden the implications of the positive use of subtle energies in farming and human health. Says McCosker, 'Sunlight and rainfall are natural assets which are seen as "freebies" in your production system that you can manage profit from. With the right knowledge and techniques, subtle energy is another natural asset that you can benefit from'. This leads McCosker to conclude that 'Subtle energy is the next big "freebie" in agriculture'.

From an exploration of the origins of biodynamics, it is clear that certain elements of Rudolf Steiner's work came from medieval European peasants. Such farmers could detect and work with ancient earth and cosmic energies and were connected to nature spirits, or what is called 'animism' - a trope for beliefs that the natural world is 'inspirited' - that is, inhabited by nature spirits, that a sacred reality exists and is different from everyday profane realities, and is manifested at special times and places, usually through natural entities and places (Taylor, 2005: xiii.). Yet it is the 'mechanical' mind that reigns supreme today. Thus, the world is now seen as a machine, deemed fully comprehensible by Western humanistic, rationalistic thought, and is regarded as without value or sensibility. This in turn renders it totally available for human control, domination and exploitation for profit. Here resides the great divorce, for we are no longer bonded to Mother Earth and have therefore lost some of our organic senses. The psychological consequence of this break of the human-Mother Earth bond - a fatal divorce - is what I believe has precipitated us into the Anthropocene era.

Anthropologist-philosopher Mircea Eliade says that 'the completely profane world, the wholly desacralised cosmos, is a recent discovery in the history of the human spirit' (Eliade, 1961: 13). I believe he is right. This makes it hard for those of our generation imbued with a post-Enlightenment, reductionist, mechanistic-minded, modern humanism - and increasingly moored in a 'rational' and profane or desacralised world - to comprehend, let alone identify, with those of other times and other minds who were - and still are - immersed in a sacred world. ${ }^{2}$ Such an 'organic' mind varied from culture to culture over time, but generally, in most eras, things such as place, space and time could assume sacred significance, as did natural, organic, geological and other elements. Even basic physiological acts such as eating, sex and so on were never just simply 'physiological', as Eliade says, they were or could become 'a sacrament... a communion with the sacred' (Eliade, 1961: 14).

As a student of this ancient organic mind, Mircea Eliade captured the almost intangible elements of the pre-mechanistic mind. The existential situation of people of such a mindset, says Eliade, is where 'life has an additional dimension; it is not merely human, it is at the same time cosmic, since

\footnotetext{
${ }^{1}$ McCosker in RCS promotional flyer for Patrick MacManaway's course, 2014.

2 Eliade used the word sacred to mean: beyond 'natural' realities; something that goes beyond the natural experience of humans; the opposite of the profane; the manifestation of something of a wholly different order, a reality that doesn't belong to our world, and can be in objects that are an integral part of our natural 'profane' world (Eliade, 1961: 10-11).
} 
it has a trans-human structure...not strictly confined to man's mode of being...' This is because, he says, 'in living, religious [i.e. spiritual] man is never alone, part of the world lives in him' as 'cosmic symbolism adds a new value to an object or action, without affecting their peculiar and immediate values'. Eliade concludes that

Openness to the world enables religious [spiritual] man to know himself in the world." This means that "the whole of life is capable of being sanctified ...thus life is lived on a two-fold plane; it takes its course as human existence and, at the same time, shares in a trans-human life, that of the cosmos or the gods.

Eliade (1961: 166-167)

Such an 'organic' mindset allowed people the capacity to listen to, feel strongly and empathically with, and identify the organic world around them, in all its manifestations. A crucial aspect of this was a sensitivity to 'subtle energies' (such as those emanating from flowing water or cosmic energy flows). In time, and in certain cultures, a very sophisticated series of practices - if you like a 'science' - was built up around detecting, concentrating and using these energies to good effect for human health, harmonious living and agricultural performance.

Is it any wonder, therefore, that while an extraordinary regenerative agriculture revolution unfolds across our nation and other countries and landscapes, such farmers and others who empathically reconnect to Mother Earth are now discovering, developing or unexpectedly encountering elements of the old organic mind? For this is what is surely occurring. I see it as part of the transformative shift to a third mind for this new era of human existence on Earth: the Emergent Mind. This mind combines elements of the old 'organic' (through an indivisible 'oneness' with the Earth and nature and a capacity to rediscover intuition, Earth-empathy and a mental freedom to be open to other outside and non-rational or spiritual influences) with the best of the modern 'mechanical' mind (such as research about our bio-geochemical world, ecological systems, and complex adaptive systems thinking and so on). The result is this new mind, the 'emergent', equipped with the best of the old and the new. It is thus capable of forging a new agriculture and a new urban-rural connection that regenerates, and doesn't destroy, the Earth.

In order to understand the potential of a new regeneration of agriculture, we need to at least open up and discuss some of the things that are emerging as modern regenerative farmers take steps that end up - intentionally or otherwise - connecting them to some long-lost or neglected ancient pathway.

\section{HARNESSING SUBTLE ENERGY THROUGH GEOMANCY}

In tracing the emergence of a regenerative agriculture and of the innovative farmers behind it, we see that the management approaches leading to ecological regeneration stem from a regeneration of degraded landscape functions. Such regeneration hinges on solar energy and the solar cycle and then flows into the soil-mineral, water and other cycles, and into that of dynamic ecosystem communities. Intersecting with, and indivisible from, these landscape functions is the human-social landscape element. But without solar energy, we humans would be immediately exterminated.

Nevertheless, there is another and complementary energy source that impacts the Earth and its organisms (including humans). Forgotten, over-looked or even repressed, this consists of the wider cosmic energy forces from further out in the solar system (including planetary and lunar influences) and beyond - from the broader galaxy. ${ }^{3}$ There are also energies generated from within the Earth, from processes relating to deep geological fault-lines to radioactivity. Though seemingly not as powerful nor obvious as solar energy, ancient people with an organic mindset recognised these additional energies and used them to maintain harmony with Earth's living patterns, for living and healing in general, particularly for agriculture, as well as for spiritual purposes.

${ }^{3}$ Much academic literature exists on cosmic rays and cosmic energies. See, for example, Dorman and Dorman, 2014. 
Such energies go under the general description of 'subtle energies'. It is no accident that modern regenerative farmers - in moving to a post-mechanical mindset - have discovered and recognised these and increasingly begun to use them to regenerative effect.

Subtle energies come in different forms and expressions, but quite simply, they are those energies present within and around us, which are beyond perceiving by our standard five senses. Moreover, conventional instrumentation can't measure these energy frequencies. However, importantly, they affect living systems at the cellular level, and this is dependent upon both the perception of the quality and character of the energy, and the sensitivity of living systems to the energy. In the modern scientific era, Albert Einstein first mooted some of these energies, which later led to the field of quantum physics: things too small to be seen but which are a basic part of our world, matter and the universe.

Our restricted modern worldview recognises just five main descriptions of subtle energies in our environment: electricity, magnetism, gravity, and weak and strong nuclear forces. Yet our living systems themselves are bio-electromagnetic (Malmivuo and Plonsey, 1995), and we can only see, hear and touch a narrow range of these frequencies. There is a good reason for our restricted perceptions: if we were able to perceive, feel, hear, etcetera everything out there, then we would be in a constant state of sensory overload.

The detection of magnetic energy lines and energy flows, patterns, auras or force fields is a skill that can be developed - as I found out in that park in Dubbo. In everyday language, such detection is called divining or dowsing, and in the case of treating animals or humans has various names, such as radionics and kinesiology. Ancient people with an organic mindset were incredibly sophisticated at detecting and experiencing subtle earth energies. That is why they attributed them to the activity of the Earth Spirit or nature spirits. The purpose of applying these skills was to connect themselves to special places, times, cosmic positions and to purpose. The age-old science of doing this is called 'geomancy'. ${ }^{4}$

Because their minds were totally trusting of their indivisibility with Mother Earth and her cosmic forces, such peoples were able to enter more directly into the spiritual realm: much of which is a realm of energy and mind and includes the physical power of human thought. This, as a researcher in the field, Nigel Pennick, says, led to people of an organic mindset revering 'stream and fountain, rock and grove, not as gods in themselves...but as inherent sources of the spirits of the earth such as the Yarthlings and Hyter Sprites, still talked of in East Anglian folklore' (Pennick 1979: 7-9).

Places of geographical interest were aligned on identified or dowsed energy lines called leylines. Sacred monuments and megalithic arrangements were erected on these lines at key nodal points, which were deemed to resonate with special psychic energy.

In short, there was an ancient geomantic and geophysical knowledge which underpinned most of the major religions of the world and which was largely lost as the organic mindset morphed into the rationalist, sceptical mechanical mind. This knowledge is now being put to constructive applied use by human healers, geomantic earth healers and regenerative farmers who in many other respects have moved into the post-mechanical or emergent mindset.

\section{THE ART OF DOWSING}

As I wandered around the city park in Dubbo, refining my dowsing skills, I reflected on how, over my life, I had met various water diviners or dowsers. A now deceased friend of the family, not far from our home, had an English aunt who used to come out to walk his farm and, through water divining, would accurately map his underground streams. During World War II, this lady was called in by the Ministry of Defence to divine the whereabouts of German U-boats. She used a pendulum over a map to do so. ${ }^{5}$

\footnotetext{
4 "Geomancy: or "earth divination", is the subtle relation between humans and their natural surroundings. It is the science of putting human habitats and activities into harmony with the visible and invisible world around us' (Pennick, 1980: 7).

${ }^{5}$ In the UK in 2017, 10 out of the 12 main private water companies were using dowsing to locate water (Le Page, 2017).
} 
But now I know people of all sorts and persuasions who, in an unencumbered way, have developed or discovered dowsing skills. Key to all these examples is people putting their 'mind' to the task. This word 'mind' is the secret because, as I soon discovered at Dubbo, successful dowsing is all about a concentrated focus of the human mind - or the use of what is termed mental 'intent'.

Mental thought is a basic physiological manifestation - that is, a concentrated stream, focussing and use of physical energy. As such, this different form of 'energy' focus may have physical and chemical effects across distance and even time. In spiritual matters, this is a component of prayer. The physical and/or chemical manifestation of the directed focus of human intention has also been written about as 'psycho-energetics' (Krippner, 1979), a term developed by Czech physicist František Kahuda (1911-1987). ${ }^{6}$ Similar concepts have also been expounded by Lipton (2011). One example is the remarkable quantified and photographed effects of Japanese scientist Dr. Masaru Emoto who, through powerful concentrated positive thought and even music, has shown that it is possible to change the shape of water molecules and crystalline structures (Radin et al., 2006).

From a farmer's perspective, a healthy water cycle is a key landscape function, and we all know water is the lifeblood of the living (especially in my dry continent of Australia). People like Patrick MacManaway hold water in the highest esteem. 'It is the consciousness of the earth, planet and soils', he said in his course. 'It is the matrix that holds the quality of consciousness, and beautiful, patterned, bright water crystals are vital for human and landscape health'. Water can be divined not just because its movement creates an electromagnetic force but also because even deep water underground has an energetic effect on the surface. Moreover, other subtle energies in or below our landscapes can also be divined.

So at Dubbo, I learnt to detect various underground streams by focussing clearly on finding water. When found, my divining rods suddenly and vigorously swung inwards and crossed on my chest. My divining also included finding a major health energy point where streams intersected. It is no accident that such nodes were ancient sacred sites or the location of temples and then churches. But once found, and again through mental focus and use of a binary 'yes/no' series of questions, I could then determine the approximate depth of the water below the surface. Experienced diviners/ dowsers and experts in subtle energy can do this with considerable accuracy.

Patrick MacManaway makes an important distinction between 'dowsing' and other 'divinatory approaches'. Dowsing (or the art of divining for something that is desired), as I learnt with wire rods, is straightforward. You clear your mind and focus thought 'intent' and use a simple and specific binary approach of 'yes' or 'no'. Such dowsing is not new. Moses divined water in the desert with a rod over 3,500 years ago, and indeed evidence of dowsing dates back to at least 8,000 years (Webster, 2008).

All sorts of dowsing tools can be used, but predominantly bent wire rods or wooden forked sticks and wands. A few people dowse with their hands, and some use a simple pendulum: usually a small piece of pottery, wood, plastic, metal or a piece of jewellery. One calibrates the tool by determining the response to 'yes' or 'no' via the way the pendulum moves, and then proceeds to ask a series of binary questions. Such questions, as I found among leading regenerative farmers, can apply to any field of activity.

In that Dubbo park, I then switched from water and focussed on detecting positive energy flows in the landscape and I was also able to find these, and in different places to the underground water streams. Again, it was because I had focussed my mental 'intent'. However, there are also negative energies that can cause illnesses, sleeplessness and such. Geopathic stress is caused by detrimental energy zones that can arise from underground sources. These can be due to geological faults and fractures, or from water flowing through such fault-line cracks in the underlying rock

\footnotetext{
${ }^{6}$ The term psycho-energetics also features in a draft proposal published by the CIA to investigate psycho-energetic phenomena, which defines this term as 'remote viewing/extra sensory perception' (ESP), or psychokinesis. Draft Proposal: DoD Psychoenergetics Program. Released 2008/08/08. https://www.cia.gov/library/readingroom/docs/CIA-RDP9600789R002100230001-3.pdf.
} 
strata. This field has been scientifically studied since the 1920s, particularly in Germany, under the rubric of geo-biology, and more recently has been researched in various other locations (see, e.g., Dharmadhikari et al., 2010; Freshwater, 1997; Hacker et al., 2005; Klimentov et al., 2015; Saunders, 2003; Wojtkun, 2017). Part of Patrick MacManaway's work is to diagnose such 'geopathic stress' and to heal or deflect the negative and pathological flows, through earth acupuncture or other mechanisms.

The ancient tradition of using earth acupuncture to address such negative subtle energies goes back to Neolithic and early Egyptian and Greek times (Comerford, 2012; Keen, 2018). MacManaway uses copper rods to deflect or divert the negative energies, which he finds resolves problematic situations for humans, animals and agricultural crops. That is why Terry McCosker calls this use of subtle energies 'the next big "freebie" in agriculture'. According to them, farms that have employed these methods have seen improvements such as increased crop production, conversion of standard bulk wheat grades to higher 'prime-hard' Australian Standard Wheat (ASW) grades, reduced pest and disease incidence in crops and animals, increased germination levels, more uniform growth, increased pollination levels, improved quality of produce (such as in nutrient levels and consequently taste), in energy or plant sugars (as measured by Brix levels), and of course underlying these changes, improvements in soil health and water quality.

\section{FIELD TOWERS AND BROADCASTERS}

The other device that is increasingly used by regenerative farmers is an adaptation of another ancient tradition. During World War II, biophysics scientist Dr Philip Callahan ${ }^{7}$ found himself stationed in Ireland as a radio technician, where he came across round towers dating back to the ninth century (of which there is a network of $~ 50$ ). After studying these in combination with his specialist knowledge of insect sensilla (receptors which gather information about the environment), Callahan postulated that they 'were constructed at ancient Christian monasteries where the Celtic monks practiced a form of eco-agriculture dependent upon crop and pastoral animal rotation' (Callahan, 1984: 26).

Callahan had described and measured the two magnetic forces of paramagnetism and diamagnetism, and he saw that monks could have used these towers - that were constructed of paramagnetic stone - to focus, collect and concentrate cosmic and earth paramagnetic energies, which then radiated (antennae-like) from the tower base to 'dope' their cropping soils and fields with a subtle energy that increased the paramagnetic properties of the surrounding soil and fields. This, he concluded, stimulated growth, health and well-being in plants, animals and thus humans (Callahan, 1995). ${ }^{8}$ Callahan went on to call these ancient monks 'the forefathers of good, modern, biological farming'. To recreate on a small scale the equivalent of the monk's giant magnetic antennae used for concentrating paramagnetic energy, Callahan's work inspired regenerative farmers to build smaller versions of these towers that are now being used around the world to generate good 'growth forces'.

As I drove around Australia, visiting regenerative farmers who have made the mind-shift to a post-mechanical mindset, I encountered a wide variety of these 'power towers', the first of which were constructed in the late 1980s. Most of these farmers would, a few years previously, have ridiculed such 'way-out', 'new-ageist' devices which they would most likely associate with some pot-smoking group of hippies. Today, one can see a plethora of tower designs, ranging from sculpture-like layered terracotta pipes, to PVC pipes of varying diameters and heights. When properly dowsed and sited, one can see visible, wave-like energy radiating from the top of the pipes - similar to the waves of energy that reflect off hot surfaces in summer (Moore, 2001: 166).

\footnotetext{
${ }^{7}$ Dr Philip Callahan (1924-2017), entomologist, ornithologist, explorer, photographer and philosopher, whose research involved the utilisation of non-linear far infrared radiation by biological systems and its applications to insect control and medicine. His work in biophysics focussed on insect molecular bioelectronics.

${ }^{8}$ There is little research so far on the relationship between paramagnetic properties and horticulture or agriculture (though, see Teixeira da Silva and Dobránszki, 2016), although rock dust is used as a soil amendment (Anon, 2012).
} 
Farm-emitters or broadcasters are a more sophisticated version of power towers. They are sited and built on the same principles, but with the added purpose of transmitting, for example, biodynamic preparations and other mixtures or ingredients, sometimes over hundreds, even thousands of acres. Such towers involve a strong degree of mental 'intent' or concentrated positive mental energy, so their users usually place a map of the desired area of influence and even a written statement of intent in the tower along with the biodynamic preps or other substances.

Interestingly, through the use of mental 'intent', many dowsers can map-dowse with a pendulum. Time and again, I have seen cases where the location of towers, over the confluence of underground streams or leylines, was first marked on a map in the homestead kitchen, or even hundreds of kilometres away in an office. When the physical dowsing was done in situ, the map-dowsed locations were accurate to within metres.

As Dr Phillip Callahan summarised the issue: because the majority of American (and Australian) farmers 'no longer farm according to the laws of nature (eco-agriculture), but rather according to the quick fix - whereby we have become drug the soil addicts' (Callahan, 1984: 117). But, 'no amount of nitrogen, phosphorous and potassium can replace the rock-generated paramagnetic force that is eroded from our soils by the sheer stupidity of our modern agricultural practices' (ibid). Conversely, if we work with nature, 'then insects and disease problems will take care of themselves. Healthy plants, properly nourished, will fight off attacks from outside, the same way healthy people do' (ibid).

\section{INDIGENOUS TOTEMS AND NATURE SPIRITS}

On my drive back from Dubbo Park, my mind was so full of ideas and information that the trip seemed like 5 minutes. Everything 'old' seemed 'new' again, I reflected and then remembered another incident when I was sitting around a campfire with local Aboriginal Ngarigo Elder, Rod Mason. We were near my home, up on a thickly timbered hill with giant granite boulders, where there had once been a major Aboriginal camp. In the course of a long conversation, in which I felt I was back in kindergarten, Rod (who is a highly respected man) told me that in his early training, he was taught how to use and integrate both brain hemispheres.

I wondered then whether this physiological development had been part of the cognitive-symbolic evolutionary step that had differentiated us from all other creatures, yet had been somewhat lost since the Age of Enlightenment.

Elders of the Wolgal-Bemmerangal clan of our local Aboriginal Ngarigo people are 'water people': rainmakers. According to Rod Mason, the spirits of the Wolgal-Bemmerangal return first to the water and not the sky, as is the case with members of other clans. As a consequence, Rod's people have a particular responsibility for water, as well as for animals and for their management.

The central grassland and woodland area of the Monaro where I live comprises a broad tableland - the 'big grass country' or Narrawallee. Our Narrawallee country (today recognised as a rich, highly mineralised and paramagnetic country) was also called the 'healing grounds' by the Ngarigo people. In springtime, they would dally there on their way to the ceremonial country in the mountains and the Bogong moth feasts and once again on their return home in the autumn.

Rod Mason told me that there are many spirits alive across our big grass and granite boulder country. These can be ancestors' spirits or nature spirits. The Ngarigo believe that the extraordinarily varied and beautiful boulders on our land are Elders who have passed on. They keep watch over the land and must be respected: the bigger the boulder, the more powerful the spirit. In every landscape, there is one very large and special rock - the Gurrubung: the caretaker rock. This contains a powerful spirit watching over the land, and people often go to sit at its base to seek comfort and imbibe spiritual benefits.

A kilometre from our house, and its sacred kurrajong tree, we have our own Gurrubung: two conjoined giant granite rocks we call 'bull rock', because (intriguingly, in retrospect) a bull died there decades ago. Its bones are still there and both our children and grandchildren have played 
with them. These two rocks are $80 \mathrm{~m}$ long and $15 \mathrm{~m}$ high and have been weathered over hundreds of millions of years. Partly submerged in the soil, they curve like a pair of giant blue whales breaching, replete with deep eye-sockets and blowholes. It is perhaps no coincidence that a pair of regal wedge-tail eagles nest in a large ribbon-gum tree overlooking this Gurrubung.

There are other spirits out in the grasslands: nature spirits such as the Mirrakarbalee, the ancient bird people. Children around campfires are told of these bird people, with their long, curved beaks and strange legs, who dwell in Narrawallee ready to pounce on and steal any child who wanders off alone.

Central to this story is that most Australian indigenous people (who are animists) have evolved a worldview called 'totemism', in which they form what seems to 'Westerners' to be mystical associations with plants, animals, natural features or phenomena, and even created objects. This runs parallel with uni-lineally related human groups (such as lineages, clans and tribes). A person's totem can thus determine their name or group and can involve totemistic symbols and emblems, taboos and prohibitions applied to their totem animal, plant and such. This connects them with a large number of animals and natural objects. Again, living in the spiritual world is the basis of their animistic existence and their close association with, and indivisibility from, nature.

The depth and complexity of the Australian Aboriginal worldview and its longevity in sustaining and managing Australia's varied ecosystems are due to evolved, interconnected and diverse features such as The Dreaming, The Law or Tjukurpa, Dreaming Tracks, Songlines, and their associated kinship arrangements that are linked to totems. All these are enmeshed in reinforcing Aboriginal myth, story, song, dance and art.

This Aboriginal knowledge and its associated beliefs organised the management and nurturance of 'country'. In a brilliant speech at the National Library in 2013, historian and scholar Bill Gammage pointed out that the knowledge that guided Australian Aboriginals' sustainable and regenerative management of 'country' was gained both physically and mentally over millennia, but also was a fusion with the spiritual in the land - with the religious. He said that the extraordinary indigenous knowledge and understanding of country - this "mighty intellectual achievement...a fusion of ecology and religions' (Gammage, 2013: 2) - was because the Dreaming

Is grounded on ecological realities, whatever its social applications. It taught why the world must be maintained; the land taught how. One made land care compulsory, the other made it rewarding. One was spiritual and universal, the other practical and local. In their country, people lived the World of the Dreaming, thronged with plants, animals and elements, each in their appointed localities. Not only obvious features which Europeans named, but every pebble and ripple disclosed both the ecological logic of its existence and the Dreaming's presence.

Gammage (2013)

'Dreaming site and ecological niche alike proved the need and reward in caring for country' continued Gammage. He further explained that

Totems expressed this. In English 'totem' can mean just a badge, for Aboriginals it is a life force stemming from and part of a creator ancestor - the soul a person shares with that ancestor's plant or animal and its places and ceremonies. An emu man does not have emu as a mere badge: he is emu, of the same soul and the same flesh. He is of its totem, not the reverse, and he must care for emu and its habitat, and they must care for him. A man "born along the track of the wallaby" might say, when seeing a wallaby, "that is me, that wallaby, that is me", or "that is my father".

\section{Quote from a 1984 manuscript "Nintirringu" in Bradley (2001) $)^{9}$}

We modern Westerners may scoff at the idea of nature spirits and people's ability to communicate with and, even, encounter them. We may even dismiss indigenous people as primitive, superstitious

${ }_{9}^{9}$ M de Graaf, 'Nintirringu', ms 1984; John Bradley 11 July 2001, cited by Gammage, 2013. 
or over-imaginative, but to them, the spirit world is real. The key point is that indigenous people have not lost connection to Mother Earth and Nature. They are truly organic in as much as they see themselves as a small, indivisible part of her. This leaves them open to experiencing and recognising natural energies, features and entities that the modern Western mind has become totally blind to.

In some respects, nature spirits are a manifestation of subtle energies in our landscape that we, modern, mechanically minded humans have lost the art of detecting. So it didn't come as a surprise to me when Patrick MacManaway, on that subtle energy course in Dubbo, quite naturally began to discuss the issue of nature spirits. This came about when he began to explain the various forms and uses of subtle energy.

According to Patrick, not only does this nature spirit world exist, but it is different in different lands and landscapes. Fairy tales are instructive on how to treat nature spirits; in Scotland, the Fairy Queen Sidhe, who lives in a sacred mountain, is the boss of nature. People maintaining the surviving Celtic worldview still see nature sprites and faeries, as real and active, and elsewhere in Europe, there are elves, gnomes, trolls, wights, pixies, gremlins, gronkydoodles and such that live in and around rocks, forests, streams, glades and other places. Today, in Norway, for example, there are still troll-catchers and stories abound of trolls' visible presence. Ancient people respected these nature spirits and worked with, or placated, them.

However, Australia is different to Europe and its diverse cultures. After 60,000-plus years of Australian nature - and spirit - empathic indigenous land management and living, it was inevitable that the establishment of the first incomers' settlement in 1788 would lead to a violent clash of cultures or hemispheres. A modern Western approach characterised by being rational, cruel, and exploitative and destructive of the land was imposed virtually overnight. As a result, the ancient human custodians of the land and their connection to a nature spirit reality suffered displacement and widespread destruction. In the process, a sacred human-earth bond was broken and displaced by a destructive, dominating, agriculture which the land had never seen before.

Patrick taught us that the connection to a nature spirit reality needs to be rebuilt and that the elemental spirits are still available. He explained, 'a landscape that doesn't yet recognise agriculture cannot help it'. We can learn from ancient medieval farmers in the UK and Europe who once communicated with nature spirits and the Earth, once showered them in blessings and, in turn, received their support. The clear implication is that, first of all, we need to work empathically with the landscape to regenerate it by harmoniously and lovingly using its functions. Then, we can work with the various nature spirits to free up the different earth, soil and other natural energies and elemental associated spirits.

On the long drive home, I had much time to ponder over our three packed and mind-bending days of lectures, discussion, dowsing and other energetic practices and found myself recalling a line from Fritjof Capra in The Web of Life: 'Ultimately, deep ecological awareness is spiritual or religious awareness' (Capra, 1997: 7)

\section{REFERENCES}

Anon (2012) Volcanic soil improver goes on sale at B\&Q. Horticulture Week, June 22, p. 15.

Bradley, J. (2001) Landscapes of the mind, landscapes of the spirit: Negotiating a sentient landscape. In R. Baker, J. Davies and E. Young (eds), Working on Country: Contemporary Indigenous Management of Australia's Lands and Coastal Regions, pp. 2295-2307. Oxford: Oxford University Press.

Callahan, P.S. (1984) Ancient Mysteries, Modern Visions: The Magnetic Life of Agriculture. Metairie, LA: Acres USA, 148 p.

Callahan, P.S. (1995) Paramagnetism: Rediscovering Nature's Secret Force of Growth. Metairie, LA: Acres USA, $128 \mathrm{p}$.

Capra, F. (1997) The Web of Life: A New Synthesis of Mind and Matter. New York: Harper Collins.

Comerford, K. (2012) Newgrange and the New Science: Exploring the Subtle Energies of Ireland's Ancient Neolithic Monuments. Dublin: CTM Books.

Dharmadhikari, N., Rao, A., Pimplikar, S., Kharat, A., Aghav, S., Meshram, D., Kulkarni, S. and Jain, B. (2010) Effect of geopathic stress on human heart rate and blood pressure. Indian Journal of Science and Technology, 3(1): 54 . 
Dorman, L.I. and Dorman, I.V. (2014) Cosmic Ray History: Space Science, Exploration and Policies Series. New York: Nova Publishers.

Eliade, M. (1961) The Sacred and the Profane: The Nature of Religion. New York: Harper Torchbooks.

Freshwater, D. (1997) Geopathic stress. Complementary Therapies in Nursing and Midwifery, 3(6): 160-116. Gammage,W.(2013)ThebiggestestateonEarth. Writing the AustralianLandscape Conference, 3-4 August 2013. Canberra: National Library of Australia. https://www.nla.gov.au/content/the-biggest-estate-on-earth.

Hacker, G.W., Pawlak, E., Pauser, G., Tichy, G., Jell, H., Posch, G., Kraibacher, G., Aigner, A. and Hutter, J. (2005) Biomedical evidence of influence of geopathic zones on the human body: Scientifically traceable effects and ways of harmonization. Forschende Komplementärmedizin und klassische Naturheilkunde. Karger, 12: 315-327.

Keen, G. (2018) The Mind's Interaction with the Laws of Physics and Cosmology. Newcastle-upon-Tyne: Cambridge Scholars Publishing.

Klimentov, V.V., Prohorov, G.V., Gozhenko, S.A. and Zukow, W. (2015) New aspects of solving the problem indication and measurements and geopathogenic anomalous zones. Journal of Education, Health and Sport, 5(4): 109-116.

Krippner, S. (1979) Psychoenergetic Systems: The Interaction of Consciousness, Energy, and Matter. London: Gordon \& Breach Science Publishing (Taylor \& Francis Group).

Le Page, S. (2017) In 2017, UK water companies still rely on "magic". November 20, 2017. Medium online news platform. https://medium.com/@sallylepage/in-2017-uk-water-companies-still-rely-on-magic6eb62e036b02 (accessed October 13th 2020)

Lipton, B. (2011) The Biology of Belief: Unleashing the Power of Consciousness, Matter and Miracles. London: Hay House.

Malmivuo, J. and Plonsey, R. (1995) Bioelectromagnetism: Principles and Applications of Bioelectric and Biomagnetic Fields. Oxford: Oxford University Press.

Moore, A. (2001) Stone Age Farming: Eco-Agriculture for the 21st Century. Castlemaine: Python Press.

NAILSMA (2006) Indigenous ecological knowledge: A Northern Territory scoping study. Prepared by the North Australian Indigenous Land and Sea Management Alliance (NAILSMA) for the Natural Resource Management Board, Northern Territory, April 2006.

Pennick, N. (1979) The Ancient Science of Geomancy: Man in Harmony with the Earth. London: Thames \& Hudson.

Pennick, N. (1980) Sacred Geometry: Symbolism and Purpose in Religious Structures. Wellingborough: Turnstone Press.

Radin, D., Hayssen, G., Emoto, M. and Kizu, T. (2006) Double-blind test of the effects of distant intention on water crystal formation. Explore, 2(5): 408-411.

Saunders, T. (2003) Health hazards and electromagnetic fields. Complementary Therapies in Nursing and Midwifery, 9(4): 191-197.

Taylor, B. (ed) (2005). Encyclopedia of Religion and Nature. London/New York: Continuum.

Teixeira da Silva, J. and Dobránszki, J. (2016) Magnetic fields: How is plant growth and development impacted? Protoplasma, 253(2): 231-248.

Webster, R. (2008) Dowsing for Beginners. Woodbury, MN: Llewellyn Publications.

Wojtkun, G. (2017) Human residential environment and radiesthesia. Surveying Geology \& Mining Ecology Management (SGEM) International Multidisciplinary Scientific GeoConference: SGEM, 17: 469-475. 


\title{
$28 \begin{aligned} & \text { Experiences with the } \\ & \text { Metaphysics of Nature }\end{aligned}$
}

\author{
Michael J. Roads
}

\section{CONTENTS}

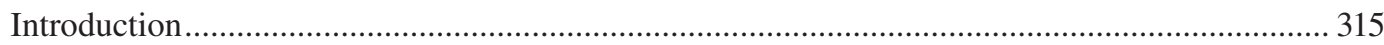

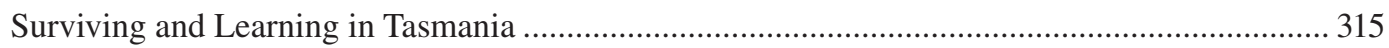

Goodbye Tasmania ... Hello Organic Farming Consultancy.................................................... 320

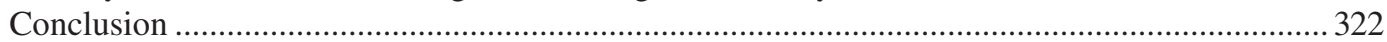

\section{INTRODUCTION}

I grew up in a farming family in East Anglia, UK, working with my father until his untimely death in the early 1960s. With my wife and I in our mid-twenties, and with two young children, we then emigrated to Tasmania, the island state of Australia. It was there that I experienced many of the deeper insights of Nature that I share with you now.

I will begin by explaining about energy. My early years of working with the metaphysics of Nature were by trial and error, interlaced with a fair degree of common sense. What I have learned is that everything is energy. All space and matter is energy and all energy is information. Another name for this energy is consciousness. So, here, we have a vast reservoir of information that is not physically visible or available and is thus ignored, despite being metaphysically obtainable.

Over my many years of experience and study, I have learnt that the metaphysical precedes the physical. That we are unaware of this makes no difference to reality. However, if you accept this higher reality and work with it, life as a farmer becomes very different, very interesting. You accept what you can physically see, but you acknowledge that if you learn to work with the unseen, then the results will be far greater than before. It follows that, just as Nature is far more than we can see, so also are you. I have written several books on this topic of the metaphysical world of Nature and have lectured internationally on this subject. My books, Talking with Nature (1985) and Journey into Nature (1990), both best-sellers, are still in publication under a single cover. In addition, Conscious Gardening (2008) has been well received, and I have also explored the astral worlds of Nature in my book, Stepping between Realities, published in 2014. My latest book is Entering the Secret World of Nature.

\section{SURVIVING AND LEARNING IN TASMANIA}

When I emigrated at aged 26 with my late wife and 2 young children, I went from an arable farm in Cambridgeshire, England, to a beef farm in Tasmania, the island state of Australia. This was in November 1963. There is of course a huge difference between these two types of farming, in two very different countries with very different climates, but we were young and full of confidence, and the scale of this challenge was easy to dismiss at the start. This was our choice. What I did not choose was a plague of armyworm caterpillars that, like a swarm of locusts, crawled across my 354 acres on the foothills of Mt Arthur and devastated my pasture. My cows drank from waterholes that were so full of dead caterpillars that the living ones could crawl over the surface. Within 
2 weeks, I was walking around my farm shooting my very sick, poisoned and starving herd of beef cattle. Quite a shocking and very sobering introduction to farming in Tasmania!

For economic survival, I became a reluctant dairy farmer. I will skip the many trials and tribulations I endured during the worst decade of farming of the twentieth century in Tasmania. But it was under this constant pressure that my new relationship with Nature and agriculture was born ... and grew.

What gradually hit me so powerfully was how poorly equipped and uneducated I was to change both my country and my farming practice in one move. And yet, it was this sheer lack of knowledge that pushed me in a very different direction. Realising how much I did not know, I turned towards my hitherto unexplored intuition. Intuition said that if I wanted to learn about pastures and cows, then I should ask them. Initially, I had trouble with this ... but I did it. I walked out into the middle of a 30-acre paddock and, sitting down, I did my best to attune with the land. I had little idea of what I was doing, so I focused on my farm, my cows and myself. In those distant days, I had no idea of a simple universal principle: Where you focus energy flows, and connects, and creates.

It took me a while to find a measure of inner quiet, but over a period of maybe a couple of hours or so, I suddenly became aware of having answers to my varied questions. This shook me. They seemed to come from nowhere, but the answers carried a fair degree of certainty. How was this possible? However, in good faith, I applied all that I had apparently learned to the problems I had ... and it all worked. All the deep insights proved to be valid and invaluable. And so a whole new education began.

My cows became my main teachers, beginning with one particular young cow. One of my dairy heifers had become paralysed as the result of birthing her first, rather overlarge calf. In the early 1970s, generally, if a cow was 'down' for more than 2 or 3 days, she would die. However, I noticed that no crows hung around her. My observations indicated that if the local crows attended a cow, she would almost always die, no matter how you treated her. So morning and night, every day for 10 days, I fed and hand-milked her, rolling her from one side to the other. On the tenth day, she struggled to get to her feet and, with my help, she managed. During this struggle for her life, we bonded, and she became my 'cow teacher'.

'Awkward' - as I named her because she now had an awkward walking gait - and I spent many odd hours as companions while she grazed. We would walk together, and when she lay down, I would sit leaning against her side. It was she who taught me most about the varying energies of the land. There were areas in a 50-acre paddock where my 100 milking cows would never lie down. Never. Based on no reasons that were visible, there were other areas they would congregate in. When I lay down where cows would not, I sensed a feeling of discord, out of harmony with the land. Not good or bad, or right or wrong, just a strange unsettling feeling of disquiet. When I lay carefully - where the cows congregated, I felt fully at ease, in harmony with the land. Conclusion: never build a house where the cows will not lie down!

I was not able to talk with my farming friends about learning the varying energies of the land from a cow. I was already 'the Mad Englishman on the hill!' Nevertheless, when I sat with Awkward while she chewed her cud, I would go into a dreamy, half-meditative state of deeper consciousness and emerge into a very different world of energy. In this world, I was told that the paralysis of Awkward was not an accident. It was a test to see how I would respond to her situation.

I confess, many times during the 10 days of attending her I wondered why I was doing this. Every farmer knew that 2 or 3 days was the limit. Despite this, I persisted and I was rather proud of getting the cow back onto her feet. Now, I was learning that farming was all about the qualities I expressed as a farmer and the patience and compassion I had towards both the land and my livestock.

Under the tuition of this metaphysical aspect of Awkward, I learned more about cows than any book ever written could teach me. Certainly, books could and did teach me about the physical anatomy of a cow, but just as humans are not mortal body/personalities, they are immortal souls, so also a cow is far more than the physical anatomy. I learned to interpret the body language of all my cows from an intuitive perspective. I learned to know what it is to be a cow. I learned how the 
herd is a group soul, with each individual cow an aspect of that. I learned that each soul as a part also held the blueprint of the whole ... and that separation is an illusion created by our intellectual beliefs. We do not think holistically.

Awkward showed me the energies of the land. To most farmers, soil is just soil, land is just land, good, bad, or indifferent. This is not so. Just as with all life, soil is living. By this, I do not mean only the micro- and macro-life teeming within the soil, I also include the mineral aspects of the soil as particulates. Everything is energy. If I viewed the soil as dead or half-dead, as a substrate that I had to somehow grow living pasture upon, then I would create my own opposition to this growth. Not only this, but I would unwittingly create the conditions that would support my belief that the soil is dead rather than living. Conditions such as drought, or excessive rain, or subsoil hardpans may all be collectively created by unwitting farmers. As I said earlier, it is all about energy.

Farming is more about the wielding of consciousness than almost anything else. We have not even begun to farm the land, we only think we do. Most farmers are like people attempting to follow a path with their eyes closed. This does not make them bad or wrong, but we do need to awaken to a new and vital era of more enlightened agriculture. I concede, however, that it is a huge leap forward. Bio- or organic farming was and is a wonderful first step, but this next quantum step is long overdue.

As a dairy farmer, I had a serious problem. I feel a touch of embarrassment to admit that even though I truly liked my cows ... I hated milking. It took me only 8 weeks to learn how much I detested the regular, monotonous work of milking twice a day, every day. Fortunately, I had no idea that I would spend the next 8 years milking them, but in hindsight, I realise that this was the perfect way to teach a person completely lacking in self-discipline, and this was something that I greatly needed in my life. My hate of milking meant that I was mostly bad-tempered in the milking shed. The cows picked up on my energy and liberally doused the whole milking shed in hot, green, liquid poo! They kicked and were continually agitated, making the process of milking far more laborious than it needed to be. As far as I was concerned, however, it was all their fault, not mine!

Only a few weeks after my association with Awkward started to deepen and develop, an incident happened in the milking shed that began a major change my life.

I brought the cows in as usual with my trained cattle dogs, and in a particularly bad mood, I commenced milking. One of my skittish, long-legged Friesians came towards the milking stall, and just as she entered, she kicked out at me. She caught me a heavy whack on the quad muscle of my thigh, the leg going instantly numb. As I struggled not to fall over, my rage boiled and I did something I had never done before. Picking up the leg-chain, I swung it in an arc around my head, before bringing it down towards her ribs as hard as I could.

It all went horribly wrong ... or perhaps I should say, it all went perfectly right!

As the leg-chain approached her ribs, she danced out the way and again kicked out. The leg-chain caught on her ankle, and she kicked again. Now, in a blur of speed, the leg-chain did a double arc and was hurtling towards my head. I automatically put up my arm to stop it. The next thing I knew was a terrible, agonising pain as the leg-chain wrapped around my arm. The pain was so bad I did not know whether to vomit or faint, but I managed to do neither. However, in that moment of intense pain, powerful words were forcibly and indelibly imprinted into my consciousness: 'I did this to myself'.

In that moment of agony, I knew that I was the cause of all the chaos and turmoil in the dairy. I knew that I was the author of my pain ... and in that moment, my consciousness changed. In what way exactly, I had no idea, but I knew I was changed. It was 4 days before I could milk again. My arm was black-blue and purple. It was 4 months before the bruise finally left the bone in my forearm and I was without pain. But the results were remarkable. I had changed.

Within myself, I knew I had changed. When I was able to recommence milking, every cow was quiet, no agitation, no chaos, no hot green poo all over the place. My frustration at milking, my anger, had vanished. It gradually dawned on me that every one of my hundred milking cows knew that I had changed. From then onwards, the mayhem of the previous 2 years in the milking shed ended because my anger had disappeared. The cows were aware of my changed state of 
consciousness. Our shared consciousnesses, although very different as man and cows, were as One. It took me a while to embrace this.

However, among all my friends and even my family, only my wife knew that I had changed - not a single other person I knew. I mentioned the change to a couple of very close friends, and they even laughed at me. It was very sobering to know that humans with whom I shared consciousness were, in fact, far less conscious of this change than my cows. Eventually, I was to learn that humanity lives largely subconsciously, while all animals live fully in a conscious state. This is a huge subject that I will not pursue in these pages.

I later asked the metaphysical aspect of Awkward if she had anything to do with what had happened. What she told me was a shock. 'It is all about timing. Eggs hatch at the perfect time, and so do buds unfold. The bud of your potential needed a great shock to bring you to a higher level of consciousness'. I asked why. 'Because like so many humans you are into trauma and drama as a stimulant for inner growth. Pain is the usual supplier for this'. (I should add that I no longer use such techniques for inner growth!)

Most people are unaware of the energies of life. As I developed my ability to go ever deeper into the metaphysical world, so I learned that Chaos - the engine that drives, Order - the stability of structure, and Balance - the place of highest potential, are the energies that govern all life. For me, Chaos is a range of about a thousand shades of red. Each shade has a different energetic expression, ranging from a red of extraordinary grace to a red of extreme rage and on to pure wordlessness. I struggle to explain this as it is purely metaphysical, and for this, we have no language. Order, for me, is in the range of the colour black and also has a vast diversity of meanings. Balance is a flickering pure white, which has the greatest energy of all. I have named these energies Chaos, Order and Balance with capitals simply because these words are the best fit. I need to say that I experience these all on an emotional, not intellectual, level. They suggest to me that we are on the cusp of developing an emotional language that far exceeds our mental one, but this is all tied to our state of consciousness. Imagine you have a thick rope. You are twisting it to the right, Chaos, and your friend is twisting it to the left, Order. This twisting in opposite directions creates torsion in the rope. Too much either way and the torsion is out of balance. However, if the twisting is equalised, the torsion moves into Balance. In a way, Chaos and Order are in direct opposition with each other, yet from this comes Balance. As an example, a wildfire is pure Chaos with no Order, while a rock is pure Order with no Chaos. In a sick person, either Chaos or Order is dominant, depending on their condition. In a vital, healthy person, they are in Balance.

As you follow this, you may realise that this principle applies to every living organism, from the tiniest micro to the largest macro forms of life. As an ex-dairy farmer, let me give an example. A human crowd is utter Chaos. Not so in animal herds. Every cow in the herd has the Chaos/ Order dynamic within her. Generally, the more Chaos, the more dominant the cow. This creates the 'pecking' order. The cows are quietly grazing in the paddock. Each cow is always standing in perfect proximity to every other cow in the herd. My cattle dogs move in and hurry all the cows towards the milking shed. The dogs are enthusiastic and the cows are being rushed. All is now Chaos in the herd. They reach the holding yard with the swinging gate, and every cow is in the wrong position with regard to the others. To the degree that they can, they head-knock each other into the right pecking order, but this is hampered by the gate and the cows being steadily taken into the milking stalls.

With the milking finished, the cows congregate either outside the milking shed, or wherever the farmer takes them. They lay down long enough to find their own Chaos/Order/Balance equilibrium before eventually moving away to graze once more in the proper order of dominance. A wise farmer allows time for the cows to rebalance their energy. It is essential for the well-being of the herd.

After completing my 8-year apprenticeship with the cows in the dairy, I reached a turning point. All my milk had until then been separated and some sold as cream. Then, the butter factory said it would only take whole milk to process themselves. So it was either 'get in deeper, or get out'. An easy choice for me! I had been breeding my own beef herd with Hereford bulls over my Frisian 
cows. My bucket-reared heifers were put to the bull in their second year, not the first, so they were beautiful large animals ... and I really loved them. This was also a turning point in my whole relationship with the land and cattle, it was when I truly realised that ... I loved them. It was a time when my connection with the cattle moved to a new level.

I will share an incident involving my developing beef herd. All my ex-dairy cows now ran with my beef cows in one large herd of about 140 cows. I would walk among them almost every day, talking to them, stroking their backs and consciously connecting with them. And I use the words consciously with deliberation. I was not thinking of other things, my whole focus and attention was on the cow herd, and on each cow as I touched her. As I did this, I noticed that one of my large tame heifers was not energetically right. She looked perfect, but her Chaos/Order energy was out of Balance. As I focused on her, my intuition told me that her calf was dead inside her and that she had peritonitis.

Talking to her all the time, I walked her out of the herd and down the steep roadway to the creek. The idea was to cross the creek bridge and up the roadway on the other side to the farm buildings, where I would keep her and phone for the vet. Unfortunately, this did not happen. When we reached the creek, she turned off the roadway and followed the creek. Despite my efforts, I could not stop her. When she reached a narrowing of the creek, she deliberately laid down, effectively damming the flow of the water so that it flowed around and over her. For half an hour, I tried everything to get her out of the freezing cold creek, but she would not budge. Finally, I put a halter on her, and with my Landrover, I dragged her onto the bank. Then leaving her haltered to the vehicle, I walked to my house to phone the vet.

Returning to her immediately, I found she had broken the rope and was back in exactly the same position. I sat down in tears. Cows have their eyes in the sides of their head, so are unable to fully see you. Yet she fully looked at me, an invitation in her eyes. She then swung her head along her back and immersed her head under the deeper water caused by her body. As I watched this through eyes blurred with my tears, I knew, I even felt the pain she was in. Her calf was dead and rotting, and she was suiciding. Every book I have ever read about such topics says that only humans suicide, never animals. I knew and felt that the icy water was numbing her pain and that she was inviting me to metaphysically join with her in this conscious and deliberate process. Sadly, all I could do was cry as I helplessly watch a heifer I loved drown herself.

Metaphysically, all linear time occupies the same moment. Years later when I had grown in consciousness, I visited that moment again, and this time, I accompanied her as she transitioned from a herd-soul on a physical plane to a far greater and more wondrous herd-soul on a higher plane of consciousness. That was when I learned how our conscious human love can raise the consciousness of all animals. Even the farmer using animals for milk or meat can, by conscious love for his or her livestock, raise their consciousness. I will go as far to say that this is what it is to be a true custodian of livestock or of the land. By our good use or misuse, we raise or lower their or its consciousness.

My own personal evolution of consciousness took me away from farming in a way that I did not expect. My relationship with my cattle had been a very close one. One wild and wet night, I had been walking the herd because I knew that this was the weather they preferred for calving, and the old deep instinct of rain washing away the birthing smells from predators was still with them. Every cow so far had calved with no problems, but I knew there was one more to check on. When I found her around $5 \mathrm{am}$, there was enough light for me to see she had licked away and eaten all the afterbirth except for one thick piece on the face of the calf, covering its mouth and nostrils. I cleaned it away, but he was dead. Because he was still warm, I positioned him so that I could push onto his lungs while giving him mouth-to-mouth resuscitation. Just as I was about to give up, he took a deep shuddering breath and was alive! In that moment, I felt an incredible elation, joy, victory, a soaring of my spirit ... which came crashing down as I realised that in 10 months I would be sending him to the slaughterhouse.

That moment finished my beef career. I knew that I could not do this to animal Beings that I loved. If this sounds stupid or emotional, so be it. For me to continue growing in consciousness required that I follow a different path in my physical life. 


\section{GOODBYE TASMANIA ... HELLO ORGANIC FARMING CONSULTANCY}

We sold the farm, and for a year, we travelled with our four children in a caravan on a glorious adventure. Settling temporarily in the Bellingen Valley in NSW, I spent the next several years as an organic farming consultant. I named my business Soil Sense Associates. My practical approach was to have the farmer-clients' soil tested in a laboratory, and the results I would then reconfigure away from the chemical recommendations into organic fertiliser terms. To fertilise means 'to enrich', not to chemically stimulate; a true fertiliser fills the soil pantry, rather than emptying it.

My all-important metaphysical focus was to be conscious of the Spirit of the Land and to communicate with it. In this way, I had a double-barrelled approach, with one foot in the physical and the other in the metaphysical, which proved to be very effective. It all really took off when, in the early 1980s, I gave a public talk in the Darling Downs grain growing area of Queensland. Billed in the local newspaper as the 'Prophet of Natural Farming', the local farmers were shocked to find their meeting hall full with 90 or so people, instead of the regular10-15 farmers. I was no longer a joke.

It so happened that the Darling Downs was an area of very complex soils. Magnesium levels in the soil were higher than the calcium, which caused conditions of concrete-hard soil as it dried out, and clinging mud when wet. Local farming techniques were compounding the problem, which worsened each year. In the talk, I expanded on their problem using terminology that they understood, and even managed to get across some of the metaphysics of the situation.

I won a small number of clients from my talk. A few days later, I was with one of these clients, walking across a fallow field. He was a good farmer, progressive and open to change. He was also very talkative. I had tested his soil, but now I wanted to communicate with the Spirit of the Land. For that, I needed silence and preferably to be alone. Just as I was wondering how I could achieve this, his wife appeared in the distance ahead of us and waved. 'I'm wanted on the phone. I'll be back in about an hour', he said as he walked off. No cell phones in those days!

I smiled, I could now make the connection while he chatted and sipped his coffee.

As I continued across the loose fallow soil, it very strongly came to me that the $\mathrm{pH}$ was changing almost with each of my footsteps. I stopped, puzzled, but all I got was a stronger affirmation of this. I had with me a very sophisticated $\mathrm{pH}$ meter, worth about $\$ 400$, not your local store $\$ 10$ type. I knew it was very reliable. My footsteps were very obvious in the loose dry soil, so I retraced my path taking samples from the soil in my footprints. Sceptical and rather disbelieving, I also took samples 5 metres away from my footprints, and at $10 \mathrm{~m}$ away.

The results gave me a considerable shock. The overall soil in this field was $\mathrm{pH} 9.5$, very alkaline. In my footsteps, it dropped to $\mathrm{pH} 8.3$, an absolutely huge and almost impossible drop. At $5 \mathrm{~m}$ out, it was $\mathrm{pH} 8.9$ and at $10 \mathrm{~m} \mathrm{pH} \mathrm{9.4.} \mathrm{I} \mathrm{rechecked} \mathrm{this} \mathrm{twice,} \mathrm{it} \mathrm{seemed} \mathrm{unreal,} \mathrm{but} \mathrm{the} \mathrm{results} \mathrm{remained.}$

From this, I learned much. Today, I know that the farmer is the very matrix of the farm. What affects the farmer, male or female, affects all the land. There is no exception to this. You may not see, or realise this, but it will be there. The farmers' mood, their anger or inner peace, their depression or happiness, their thinking, their positive or negative energy, their stress, their greed or generosity and their love of farming affected the whole farm. The farmer who truly loves their land and their farming, whether it be horticulture, arable or livestock, is the farmer who is leading the way in consciousness. To these people come the insights and intuitive leaps that most of them have the courage to follow. If you are in the most menial of work, and love what you are doing, love who you are with, and love where you are in life ... then you are a giant in consciousness among humanity.

If you love your farm and the act of farming, you affect the whole because you are the whole. This includes the billions of micro and macro soil life, the livestock, the pastures, the crops, all of it. Just as you are the One, so you are the All. Love reveals this.

I can assure you that no matter how this may not fit in with the rather restrictive beliefs of our current agricultural science ... it remains true. It is also true for a real gardener. By 'real', I mean this does not necessarily apply to the landowner who lets or leases his or her house and garden, or farm and farmland; it applies to the gardener or farmer who is intimately involved with the land itself. 
During my few years as an organic farming consultant, I became aware that if the farmer, or whole family, were constantly sick, the land and livestock struggled to be healthy. Always, the farmer and his or her family were the hinge-pin of the conditions of the soil and the livestock. I also noted that so many farmers battled with Nature on a daily basis. For many, farming was about battling the weeds, the insects and the weather, along with the various political issues over which they held great anger, but could do nothing to control, other than verbally vent their wrath. With this negative energy, their troubles grew and multiplied.

My decade on the foothills of Mt Arthur had taught me that the farm was my meeting place with Nature. I took this very seriously. I considered myself as the student, with the Spirit of the Land as my teacher. This served me very well. I agree that knowledge from other sources has a strong place in agriculture, but I strongly contend that it should not be considered infallible.

When we regard the farm as a complex of energies, with the most complex - the farmer - as the matrix of the energies, we would be wise to understand and integrate these many energies into a compatible amalgam. Agriculture is always going to be a matter of forcing growth if we are unable to comprehend that the $99 \%$ of life that we cannot see is very deeply involved within our methods of farming.

I will share one last aspect of the metaphysics of Nature. I had given a talk in a country town in Victoria, Australia, when I was approached by a farmer. He told me that he had 1,000 sheep and 5 sheepdogs. His problem was the dogs. If let loose, they wandered off the property, and/or would work the sheep, so they were fastened on running chains next to their kennels where they would bark incessantly, driving him and his family crazy. What would I suggest?

I made the usual suggestions, and he had tried them all to no avail. Then, I asked him if his dogs were educated. He replied that yes, they were trained sheepdogs. I asked again if they were educated. This time he asked me what I meant. I asked him if he had ever actually told the dogs what he wanted of them, what they could, and should not, do? He had never even thought of such things. 'They're just dogs', he said.

Because he was obviously full of anxiety and turbulent thoughts, I told him first of all to wait until he was quiet and calm in his head. When he was internally quiet, he should let the dogs off the chains and allow them to first run off their energy. Then, calling them to him, he should walk slowly around the boundary of his farm. All the time he should be focused, consciously telling his dogs that this is their boundary and they do 'not' cross without his permission. Next, he should tell the dogs that he does 'not' want them to work the sheep without his permission. As he walks the boundary with no stray thoughts at all, he should tell them that in return for obeying these requirements, they would no longer be kept on chains. They would be free, so long as they followed his rules. This, I told him, is yours and their education.

I told him that he was the creator on his farm, and it was his choice to make. He huffed a bit and puffed a bit, but we parted on friendly terms. About 8 weeks later, I received a letter from him. No email in those days! He explained that he had thought I was crazy, but he had nothing to lose by giving it a try. To be fair to him, he said it took 4 weeks to quieten his mind, but he managed it. He did as I had told him with the dogs, and with great trepidation did not chain them during the day. Only at night. He was stunned that during those 4 weeks, the dogs had not once strayed or worked the sheep ... and they had stopped the endless barking. Needless to say, he was very grateful.

Under my prompting, he changed his relationship with the dogs to a greater and more accepting one. By doing this, he changed the behaviour of the dogs to a partnership with him, rather than in opposition to him. In other words, he moved their energy from Chaos to a Balance with both him and the farm.

\section{CONCLUSION}

Every farmer has choices. It is far too easy to follow the crowd. Nature speaks to us, we are one energy, one consciousness, something which is outside of conventional thinking. Humanity has 
forgotten how to listen to the world of energy. If agriculture is to have a viable future where farmers return to being custodians of the land, then abusive modern conventional farming has to end. The chemical approach is similar to beating a tired horse with a stick. It may well get a result, but it will only be a short-term one, and that term is now ending: our agribusiness land is in the final stages of erosion and death!

Agribusiness has no heart, no soul, no future. This world is right now going through major shifts, and the metaphysics of farming is in harmony with this change. It is timely now for a more enlightened approach to farming our precious land.

If you, as the reader/farmer, can embrace the reality that you are the very matrix of the land that you farm, you have a future. If you realise that your every thought and emotion stirs the holistic energy of the farm, affecting everything from the micro-organic life in the soil, every plant that grows, all the livestock, the whole caboodle, then you may one day be teaching other people how to manage the land. It is all about conscious connection. You need to know that farmers have the greatest responsibility of anyone; they are the caretakers of the land, of the living soil.

We are moving into new times. All that I have learned in my lifelong connection with Nature indicates that we have to lift our game. Or, it will be game over! Our perception of Nature is a stunted mockery compared with those living in Palaeolithic times. We have become lost in our clever, but stupid, intellects. It is time to return to the wisdom of conscious intelligence. To be innovators: to trust our intuition: to connect with Nature and to once again experience the Oneness of all life.

I am delighted that in our rapidly changing world of today, there are farmers who do see this new way ahead. It is ironic that the new way is a revival of the old way, yet it is a revival with new knowledge and a far deeper insight into the real quantum world of agriculture, offering all the many possibilities of this new perspective. In this quantum world, we should always be aware that the frequency of physical life is low and slow. Your thoughts and emotions are fast, on a far higher frequency, and despite a linear time lag, they will inevitably impact your land and all that lives on it. With this in mind, know that there is no higher energy or greater transformative influence than your ability to use the Power of Love. 


\title{
Biography of Contributors
}

\begin{abstract}
Alexander Álvarez Fonseca
Born on 21 November 1976, Alexander graduated as an agricultural engineer from Granma University in 2010. Gaining a Master's in Agricultural Sciences in 2016, he works at Jorge Dimitrov Agricultural Research Institute, Bayamo, Granma, Cuba, carrying out investigations on the laser and ionising radiation effects on seeds, with several scientific articles published in refereed reviews. He participates in the Local Agricultural Innovation Program, leading the participatory plant breeding studies in the eastern region of Cuba, which is involved with many research and technological innovation projects.
\end{abstract}

\section{Luis Enrique Arias Basulto}

Luis Enrique Arias Basulto graduated as an agricultural engineer from the Higher Institute of Agricultural Sciences of Bayamo (ISCAB) in 1984 (today Granma University). An auxiliary researcher in 2002, he gained a Master's in Agricultural Sciences in 2003. From 1985 to 2006, he was a researcher at the Jorge Dimitrov Agricultural Research Institute, conducting research such as the establishment of the institution's fruit tree germplasm bank, setting up and conducting experiments in coffee cultivation related to the management of new plantations and established plantations, considering pruning, shade regulation and planting density, as well as the study of different coffee genotypes resistant to rust. He became Assistant Professor in 2007 at the University of Granma. He has undertaken more than 40 postgraduate courses and is author and co-author of 17 scientific publications. He has been the tutor of several undergraduate theses and taught seven postgraduate courses.

\section{Pedro Boff}

Pedro Boff is the great-grandson of Italian immigrants in southern Brazil, where he helped out on his family farm. He graduated in agronomy (1983), followed by a Master's degree in phytopathology, joining EPAGRI-Agriculture Research and Extension Rural Service of Santa Catarina, southern Brazil, in 1988, where he works as a researcher linked to the Lab of Homeopathy and Plant Health until today. After 4 years of direct contact with farmers, he realised that the industrial technologies were leaving farmers more dependent than ever on pesticides. So he returned to study, first, agroecology (1992), and then to gain a doctorate in biological control from Wageningen University (1997-2001). Soon after, he realised that the widespread application of biological controls could be as dangerous as chemicals and that farmers needed inputs that were easy to access and of low cost. He came across biodynamic farming, and from there agricultural homeopathy, to which he has been dedicated since 2005 to the present, chiefly through research and supervising MSc and $\mathrm{PhD}$ theses students. Pedro collaborates in disciplines of integrative homeopathy at UDESC and UNIPLAC universities in Santa Catarina State, Brazil. He coordinates courses of integrative and popular homeopathy for farmers, technicians, researchers, students and the public in Brazil. His commitment to homeopathy is to guarantee free access to farmers, without it being appropriated exclusively by corporations and/or professional classes. Parallel with this, he also runs an organic viticulture farm in his own area (https://www.epagri.sc.gov.br/).

\section{Janus Bojesen Jensen}

Already holding an MSc in Organic Farming, Janus's current research topic is 'An Exploration of Subtle Agroecological Practices for the Decolonisation of Agriculture', and he investigates the potential of non-material, energetic practices to enhance organic and agroecological farming systems worldwide. Janus has previously conducted research in India with the Brahma Kumaris Rural Development Wing and is keenly interested in exploring the links between spirituality, ecology and 
agriculture. He lives in London, UK, and in his free time enjoys natural beekeeping, learning rural skills and horticulture, building on his certification in permaculture design. He is also restoring a seventeenth-century farm on Bornholm Island, Denmark, with the intention of transforming it into a demonstration ahimsa (sacred) farm and teaching centre for Subtle Agroecology.

\section{Isis Brook}

Isis Brook completed a $\mathrm{PhD}$ on Goethean science following training with the Life Science Trust in the UK in the early 1990s. She has been a university lecturer for over 25 years, mainly teaching environmental philosophy and aesthetics, and is author of numerous research papers in these areas. Her most recent post was with Crossfields Institute, in Stroud, UK, where she was involved in designing and teaching on their innovative Masters programme 'Researching Holistic Approaches to Agroecology'. Isis is now semi-retired and as a Research Fellow continues to write on phenomenology, plants, landscapes and Goethe's approach to nature. However, a lot of her time is now spent in the garden and on her allotment.

\section{Simon Charter}

After obtaining a degree in Applied Physics, expeditions to Norway, Africa and India, and voluntary work, Simon spent 4 years working in biodynamic farming and social education in Botton Village Camphill Community in the UK. After further training in art therapy, he started working with water in the environment, where his artistic, ecological and practical interests flowed together. For 30 years, this has focused on landscape projects with Flowform water sculptures as pioneered by John Wilkes. Through the company Ebb \& Flow Ltd, these projects have included sewage treatment systems and work in agriculture, therapeutic and educational environments and in gardens. Interest in the challenge of the single-bowl Flowform idea, as discovered by Philip Kilner, led Simon to develop his own Flowform designs which are being made in glass, ceramic, cast stone and metal. Simon completed a Master's in education in 2014, researching the way people develop through engaging creatively with the element of water. He undertakes independent and collaborative research into flow phenomena and runs Goethean science workshops that explore the nature of water (following Theodor Schwenk's approach). He organises courses on basic Projective Geometry and on the path curves found in natural form (as revealed by Lawrence Edwards). Simon and his wife Cate also take guests in their house on an old mill site with much clear flowing water, its own hydropower and a water-driven heat pump (flowoflife.org; ebbandflowltd.co.uk).

\section{Mike Zeddy Chikukwa}

Zeddy Chikukwa grew up in Chikukwa, Zimbabwe, always needing to be in nature, exploring the connections between our natural world and village life. He started as a community volunteer in 2005 and, since 2009, has worked for the Chikukwa Ecological Land Use Trust as a youth activist and advocate, initiating environmental management action groups. His interests are rooted in his cultural traditions, which led him to establish the Culture Group consisting of spirit mediums, traditional healers, herbalists and other knowledge holders, learning together about his cultural heritage that has been lost since colonial times. Being the youngest in the group, he noticed that the elders needed a listening ear, to preserve and revive their rituals and practices, and investigate how these can help them to become more resilient in these changing times - from what and how they grow the crops they eat, to the way they harvest, process and store. Over time, he has been motivated to learn about our natural laws and spirit connections, and work towards the preservation of his lands and sacred sites. His dreams and hopes are that through a better understanding of spirituality and place, everyone might heal the wounds of Mother Earth.

\section{Travis Cox}

Dr Cox's interests and research are about the intersections of social movements and social justice, education, metaphysics, psychedelics, environmental philosophy, agriculture and deep sustainability. 
He is currently an Associate Professor in the undergraduate school and in the Ecopsychology MA (where he was former chair) at Naropa University - a Buddhist-inspired fully accredited university in Boulder, Colorado. He has taught environmental humanities in the BA and MA programmes in Sustainable Living at Maharishi University of Management in Fairfield, Iowa, and was codirector of the BA for 2 years. Dr Cox earned his $\mathrm{PhD}$ in Sustainable Agriculture at Iowa State University; a Master's in Philosophy and Religion, with an emphasis in Philosophy, Cosmology and Consciousness, from the California Institute of Integral Studies; and a Bachelor's in Philosophy from Central College in Pella, Iowa.

\section{Jude Currivan}

Dr Jude Currivan is a cosmologist, planetary healer, author, previously one of the most senior business women in the UK and co-founder of WholeWorld-View. She has experienced multidimensional realities since early childhood, travelled to over eighty countries and worked with wisdom keepers of many traditions. She integrates leading-edge science, consciousness research and universal wisdom teachings into a wholistic worldview, underpinning her work to enable transformational and emergent resolutions to our collective planetary issues. She holds a $\mathrm{PhD}$ in Archaeology from the University of Reading in the UK researching ancient cosmologies and a Master's Degree in Physics from Oxford University specialising in cosmology and quantum physics. International author of six non-fiction books, her latest is Nautilus award-winning The Cosmic Hologram: In-formation at the Center of Creation, the first book of the Transformation trilogy. She is currently writing book two Gaia: Her-Story. In 2010, she was presented with a CIRCLE Award by WON Buddhism International for her 'outstanding contribution towards planetary healing and expanding new forms of consciousness'. She is a member of the Evolutionary Leaders Circle (www.evolutionaryleaders. net) and in 2017 co-founded WholeWorld-View (www.wholeworld-view.org) to empower the understanding, experiencing and embodying of unity awareness in service to conscious evolution (www. judecurrivan.com).

\section{Saskia G. von Diest}

Saskia von Diest is a facilitator, educator, consultant and researcher of 'ecofluency' - intuitive, interspecies communication with the rest of Nature, as a vital way of knowing and a resource for harmonious relationship with all life - https://www.ecofluency.org/. After completing her PhD in plant pathology (2013), she held a postdoctoral fellowship (2014-2017) at Stellenbosch University, South Africa, to investigate quantum-based agricultural techniques and technologies that use sound, electromagnetics and intuitive abilities in management decision-making. Her passion for knowledge extension inspired her to bring various international experts to host workshops in South Africa, and to help build an international network of farmers, technical advisors and researchers for this emerging field of research. Saskia further explored intuitive farming in a collaborative postdoctoral project (2018-2020), between the Centre for Complex Systems in Transition (CST) and the Department of Conservation Ecology and Entomology at Stellenbosch University, and the Centre for Agroecology, Water and Resilience (CAWR) at Coventry University, UK. She presents her work in various forms on numerous international platforms, and facilitates embodied experiences of how dialogue with the rest of nature can practically benefit decisions, from food growing to personal development (https://www.ecofluency.org/).

\section{Paul Doesburg}

Paul Doesburg holds a BSc in medical biotechnology. Paul became acquainted with the copper chloride crystallisation method during his employment at the Louis Bolk Institute where he worked from 2001 to 2009 on the standardisation, validation and application of this method within a European context. In 2010, he started a private company, Crystal Lab, to continue this work. Since 2010, he has been a member of the board of the King Fisher Foundation, a Dutch foundation for phenomenology and Goethean science. Paul's vision is a world in which wholeness and resilience 
are leading principles in healthcare and nutrition. To this end, he co-authored the book Barstensvol leven: een pleidooi voor vitale voeding ('Full of Life: a Plea for Vital Food'), which focuses on a systemic perspective towards food quality; its relation to resilience; new research methodologies that address this aspect; a new concept of health which emphasises resilience and makes a direct link feasible between vital food and health; and the policy implications with respect to the production of vital food and the development of (high-tech) sustainable agriculture. Paul is a $\mathrm{PhD}$ candidate at since 2017 the Witten/Herdecke University, Germany, focusing on fundamental homeopathic research in combination with the crystallisation method. Since 2020 he has been working at the Society for Cancer Research at the Hiscia Research Institute in Arlesheim, Switzerland (https:// www.crystal-lab.nl/ and https://www.iscador.com/en/).

\section{Michel Duhamel}

Michel Duhamel was educated in mechanical engineering (Supmeca Institute, Paris) and graduated in social psychology (Paris-X University). He has a diversified experience in the development of new activities, which he practised during 14 years at Bossard Consultants (1971-1985), was then the first French group of management consultants; subsequently 6 years at Nodal Consultants (business development strategies through innovation and partnership) (1991-1996); and 5 years at Erdyn Consultants (scientific and technical consulting) (1997-2001). He is co-founder and chairman of Genodics SAS, since May 2008, and Multinno SARL (Paris; 2010). He has also strategically contributed to the establishment of the European Association for the Transfer of Technologies, Innovation and Industrial Information (T.I.I., Luxembourg), of which he was Secretary General from 1986 to 1990 and President from 2006 to 2009. His main areas of expertise are the creation of new businesses, innovation management, economic development policies, industrial and administrative management, human relations and change management, the development of genodics - a new approach to biology through protein music - and the production of scientific publications.

\section{Miche Fabre Lewin and Flora Gathorne-Hardy}

Dr Miche Fabre Lewin and Dr Flora Gathorne-Hardy are co-founders of Touchstones Earth ecological arts and research practice. Their work comprises multimedia rituals, choreographies, installations, artworks and forums to engage the senses and amplify our capacities for thinking-feeling with each other and Earthly sentience. These emergent encounters open us to experiences of life as a connecting force, inspiring refreshed narratives and cooperative partnerships for responsible and liberatory action in the world. Within her research, Miche Fabre Lewin has evolved sympoiethics as the conjoining of sympoiesis and ethics, where sympoiesis defines life as a process of 'makingwith' between human cultures and an animate world. Sympoiethics is a responsive, life-affirming orientation that attends to the multiplicity of bodymind experiences, the diversity of human bodies of culture, and the multifold 'voices' of the planetary body. Touchstones Earth is in alliance with the transdisciplinary research Centre for Agroecology, Water and Resilience (CAWR) at Coventry University, the Sustainability Institute, Lynedoch, South Africa and the Centre for Complex Systems in Transition, Stellenbosch University, where both Miche and Flora are Artist Research Associates (www.touchstones.earth).

\section{Leonardo Felipe Faedo}

Leo is Brazilian, graduating in agronomy from the Santa Catrina State University (UDESC) in the Agroveterinarian Science Centre (CAV), in 2012, with a specialism in Agribusiness Administration from the Federal University of Paraná (UFPR) in 2015. He then worked with conventional horticulture, fruticulture and cereal crops, and this experience made him change his perspective on agriculture since which he has focused on agroecology. This led to a Master's in Plant Production focusing on homeopathy and biological control of plant diseases on the strawberry crop (UDESC), in 2018, and he is currently a Co-tutelle PhD student on Plant Production at both the Santa Catarina State 
University (UDESC) and the Centre for Agroecology, Water and Resilience (CAWR), Coventry University, UK, where he is focusing on homeopathy applied to plants and biodynamic farming methods to increase the vitality of farming systems. Leo is a member of the Laboratories of Fruticulture at the CAV/UDESC, focusing on strawberry crops, and the Laboratory of Homeopathy and Plant Health at the Institute for Research and Rural Extension of Santa Catarina State (EPAGRI). $\mathrm{He}$ is also a permaculture designer; organic farming advisor; homeopathic agronomist; biodynamic agronomist; and editor of the Brazilian Agroecology Journal. His intention is to promote agroecological food systems worldwide, to help to build green agriculture and make healthy, nutritional food available for all.

\section{Pedro Ferrandiz}

Pedro Ferrandiz gained engineering qualifications at the Pierre and Marie Curie University (UPMC), Paris, in 1993. Prior to that, in 1991, he had started undertaking independent research in genodics, supervised by Joël Sternheimer, inventor of this discipline. The first experiments were on plants and in bread-making, resulting in the article: Process of epigenetic regulation of protein synthesis - trial in bread-making, Industrie des Céréales, No. 85, December 1993, p. 40, https://aemic.com/blog/ article/procede-de-regulation-epigenetique-de-la-synthese-proteique-essai-en-panification.html. From 1994 to 2008, he worked as Production Engineer, Group Industrial Controller and Group Supply Chain Manager at the Evry site of the Jacquet Group (France). In 1999, he was a founding member of the R.A.Ch.I (Réseau Associatif de Chercheurs Indépendants), undertaking research work, the development of applications and conferences and publications on genodics. In 2008, he became Executive Director of Genodics SAS (Paris), with the objective of providing evidence of genodics through concrete applications in the field, particularly in agriculture. In 2020, 170 farmers used this process, over 2,500 ha, with around 40 applications. He leads on the research, distribution, installation and monitoring of applications as well as partnerships with research teams.

\section{Bertus Haverkort}

Bertus Haverkort has worked for several decades in agricultural and rural development programmes in Colombia, Bolivia, Ghana and India. He has been Manager of ILEIA (www.ileia.org) and has worked in the ETC Foundation. More recently, he has been Visiting Professor at the University for Developing Studies in Ghana. Bertus is author/co-author of several books including the following: Towards Co-Creation of Sciences: Building on the Plurality of Worldviews, Values and Methods in Different Knowledge Communities (2012); Ancient Roots, New Shoots: Endogenous Development in Practice (2003); Food for Thought: Ancient Visions and New Experiments of Rural People (1999); Linking with Farmers: Networking for Low-External-Input and Sustainable Agriculture (1993); Farming for the Future: An Introduction to Low-External-Input and Sustainable Agriculture (1992); and Joining Farmer's Experiments: Experiences in Participatory Technology Development (1991).

\section{Pedro Jovchelevich}

Pedro Jovchelevich is an agronomist with a Master's degree (moon rhythms in biodynamic horticulture) and a $\mathrm{PhD}$ in biodynamic plant breeding. Pedro is General Manager of the Brazilian Association of Biodynamic Agriculture (ABD), teacher of the Brazilian biodynamic course and coordinator of ABD's Participatory Guarantee System and the biodynamic seed network. He is 52 years old and married and has three children. He lives in the countryside in Botucatu, SP, Brazil (www.biodinamica.org.br).

\section{Eline Kieft}

Eline Kieft has danced from a young age, including rigorous classical and contemporary training to become a professional dancer. She explored indigenous ways of knowing through her studies in anthropology (BA, MA). During her PhD in Dance at Roehampton University, London, she 
looked at dance as a modality for healing and spirituality, including embodied epistemologies and shamanic techniques. From 2015 to 2020, she worked at the Centre for Dance Research (C-DaRE) at Coventry University where she designed a Somatics Toolkit for Ethnographers to use the body within the research cycle. She is a long-term shamanic practitioner and student of Jonathan Horwitz, as well as a qualified teacher of Movement Medicine, an approach for contemporary shamanic improvised dance. Finally, Eline is a certified Holden Qi Gong instructor. All these experiences are woven into her freelance company Clover Trail, a place where people can reconnect with what helps them thrive in life. This includes various movement practices, nature immersion, shamanic and lucid-dreaming techniques, tools for embodied knowing, sacred art-making, ceremony and transformation (http://www.clover-trail.com).

\section{Hugh Lovel}

Hugh Lovel (1947-2020) was a farmer and an international consultant to dairy farms, graziers, broadacre grain growers and fruit and vegetable producers. As a multidisciplinary scientist, Hugh introduced comprehensive soil testing using both the Albrecht approach and a total acid digest test that more clearly revealed what is actually present in soils. Above all, he was a leading pioneer of the new science of Quantum Agriculture. Hugh Lovel authored A Biodynamic Farm, for Growing Wholesome Food and Quantum Agriculture: Biodynamics and Beyond. He was the original designer of the Field Broadcaster quantum technology and the Quantum Radionic Analyser. His articles have appeared in Acres USA and related organic farming periodicals such as Acres Australia and biodynamic journals around the world. Hugh's work and legacy are being continued in the capable hands of his widow, Shabari Bird Lovel (www.quantumagriculture.com).

\section{Patrick MacManaway}

Dr Patrick MacManaway is a third-generation practitioner of psychic and healing arts. A graduate of Edinburgh University Medical School, he is a former President of the British Society of Dowsers and the author of several books and CDs. He consults and teaches land whispering in the UK, the USA and Australia (www.patrickmacmanaway.com).

\section{Charles Massy}

Charles Massy gained a BSc (Zoology, Human Ecology) at the Australian National University (ANU, 1976), before going into farming for over 40 years. This included the development of a prominent Merino sheep genetics business ('Severn Park'). Concern over ongoing land degradation and humanity's sustainability challenge led him to return to ANU to undertake a PhD in Human Ecology, completed in 2013. Charles has chaired and served as a director on a number of national and international businesses, research organisations, review panels and statutory wool boards, involving garment manufacture, wool marketing, R\&D, molecular genetics and genomics. Charles has had five books published, including two on Merino history (Penguin and Random House) and one on the political destruction of the Australian wool industry (Breaking the Sheep's Back 2011, UQP), and in 2017, he published the best-selling Call of the Reed Warbler: A New Agriculture, a New Earth (UQP and Chelsea Green). This book has become a talisman for the regenerative agriculture movement and has won and been shortlisted for a number of literary awards. Massy has also engaged in freelance journalism since 1977 across a range of subjects from mountaineering, ecology, history, sheep and wool, research management, plus fiction short stories and poetry. He continues to manage a sheep and cattle grazing property, while consulting widely in the fields of Merino breeding, transformative change in agriculture, and in landscape design.

\section{Georgina McAllister}

With an NGO background since the early 1990s, George's experience spans both the humanitarian and development sectors in Europe, the Middle East, South-East Asia, Pacific and sub-Saharan 
Africa. It was this engagement with the on-the-ground realities of those affected by ongoing political instability, social division and shattered infrastructure that first drew her to agroecology. Now as assistant professor in Stabilisation Agriculture at the Centre for Agroecology, Water and Resilience, George applies a regenerative lens to food and farming systems in disaster-prone and conflict-affected environments, with a specific interest in the transformation of social-ecological relationships rooted in social farming. This work explores the extent to which small 'non-movements' employ non-threatening, practice-based co-learning processes not only to shape physical landscapes, but to negotiate social change by re-forging networks based on principles of reciprocity and trust.

\section{Gudrun Mende}

Gudrun Mende (Dipl.Chem) has been working at KWALIS since 1997. She was introduced by Jürgen Strube to the measuring technology of fluorescence excitation spectroscopy (FES) and is involved with the dependencies of the measurement methodology, the scientific documentation and the development of the evaluation principle of FES (https://www.kwalis.de/).

\section{Sabrina Menestrina}

Sabrina was born in 1962 in Italy, where she lives and works as a veterinary doctor for the Italian healthcare service in central Friuli region. Among her various roles, she is responsible for health in beekeeping. In 2013, she founded, with Enrico Zagnoli, the biodynamic beekeeping section within the Italian Biodynamic Agriculture Association, for which she was General Secretary from 2011 to 2017. Since 2014, she has served on the board of the Italian Association of Anthroposophical Medicine, of which she is the Vice President. With friends and beekeepers, in 2016 she founded the Italian association ApiSophia to promote bees. In 2017, she co-founded the Anthroposophical Veterinary Medicine section within the Medical Section of the Goetheanum, in Dornach, Switzerland, of which she is the International Coordinator. She is also a board member of the new Biodynamic Federation Demeter International in Germany. She has presented many conferences on the health and dignity of bees and other animals.

\section{Joseph Milne}

Dr Joseph Milne is an Honorary Lecturer at the University of Kent where he taught on the MA course in Mysticism and Religious Experience until his retirement in 2013. His interests range from Platonism to medieval mysticism and theology, and in particular the transformations of metaphysical thought that have occurred at different times in Western civilisation. His current research is into the classical and medieval understanding of Natural Law. He is Editor of Land \& Liberty, the journal of the Henry George Foundation, and also a member of the team editing The Annotated Works of Henry George. He is the author of the Temenos Academy Papers: The Ground of Being: Foundations of Christian Mysticism (2004); Metaphysics and the Cosmic Order (2008); The Mystical Cosmos (2013); and The Lost Vision of Nature (2018). He is contributor of chapters to Mystical Theology and Continental Philosophy (ed. D. Lewin et al.; Routledge, 2017); to Peacefulness: Being Peace and Making Peace (eds. D. Cadman and S. Gill; Spirit of Humanity Press, 2017); and to The Harmony Debates: Exploring a Practical Philosophy for a Sustainable Future (edited by Nicholas Campion, University of Wales Trinity Saint David, 2020). He is a Trustee of The Eckhart Society and a Fellow of the Temenos Academy.

\section{Ed Moerman}

Ed Moerman was born the oldest of two children into a Dutch greenhouse grower's family. As a teenager, helping out his father with cucumber crops influenced his career plans and he changed his studies from electrical engineering to horticulture. After graduation (with a BSc in Horticulture), Ed started advising greenhouse growers (1980-1987) as a government consultant, and in 1988, he moved to Koppert Biological Systems and worked in various positions, including advising growers 
on integrated pest management, pioneering the development of new export markets in Mediterranean and African countries, developing packaging methods for the global transport of living beneficial insects, and acting as knowledge manager in various domains. In many of the roles at Koppert, Ed has worked on developing simple ways to support growers and advisors to better measure, understand and manage their (visible and invisible) biological systems. The challenge of making plant resilience measurable started Ed's search in the domain of bio-electronics. In 2017, the Koppert Foundation was established, for which Ed works (part-time) as Executive Manager. This foundation supports smallholder farmers with some resources and sharing the treasure of Koppert's practical knowledge. Ed is convinced that sharing knowledge and developing skills, including around agroecology, are essential on this journey for all stakeholders, and this will help farming as a business to gain popularity, not the least for young people (www.koppert.com).

\section{Eduardo Ortega Delgado}

Eduardo Ortega Delgado graduated from the University of Havana with a Bachelor's in Chemistry in 1969, a Master's in Agricultural Sciences in 1975 and a PhD in Biological Sciences in 1979. Since 1981, he has been Professor of Plant Physiology. He is author or co-author of 120 published papers in national and international journals, and author of two educational books, two scientific books and contributions to book chapters. Leader of national and international scientific projects, Eduardo has supervised 70 undergraduate, Master's and $\mathrm{PhD}$ theses. He has been an Invited Professor at universities in Angola, Argentina, Austria, Brazil, Canada, Germany, Mexico, Spain, the USA and Venezuela and is a member of Scientific Councils at the University of Havana and two other Cuban institutes. He received the National Award in Biochemistry in 2014 as well as other awards. His main scientific interests are physiology of plant microorganisms' interactions, abiotic stress and plant productivity.

\section{Victor Prévost}

Victor Prévost was educated in Biology at the University of Cergy-Pontoise, graduating as an Environmental Engineer from the Institut Supérieur de l'Environnement, and then gained a Master's Degree in Biology of Tropical Ecosystems at the University of Guadeloupe, French West Indies. Victor practised as an Environmental Engineering Consultant in Caraïbes Environnement, Guadeloupe. In 2010, he joined the activity of Genodics as a research partner affiliated with ERRMECe laboratory in the University of Cergy-Pontoise and started developing the hydric stress resistance in pea experimental model to investigate the effect of Genodics technology on peas. He joined the National Centre for Scientific Research (CNRS) as a Biology Engineer and developed a dynamic fluidic system designed to observe the interaction between human bone cells and pathogenic bacteria in real time under a confocal microscope (results published in 2019). With Genodics, he then consolidated the R\&D function of the company and developed research partnerships and scientific communications. In partnership with ERRMECe laboratory, he continued the experimentations on hydric stress in pea regulated by genodic effect (results published in September 2020).

\section{Michael J. Roads}

Michael Roads was born a farmer's son in Cambridgeshire, England, in 1937. From an early age, he discovered that he had a natural ability to communicate with the mineral, plant and animal kingdoms, and to travel beyond linear time and space. Over the last 60 years, he has actively continued to develop these abilities. Emigrating to Australia in the 1960s, he farmed for 12 years in Tasmania and then pulled up all roots and, with his family, travelled around the mainland. Following this, he spent 6 years as an organic farming consultant during which time he published books on organic gardening. Michael has since written 23 books on his experiences and explorations of metaphysical realities and higher dimensions, and 2019 marked his 30th year of travelling over five continents presenting inspirational events that enable many participants to experience profound shifts in 
consciousness. While he still occasionally speaks to farming audiences, he continues to write and speak prolifically on the 'Metaphysical World of Nature' and on 'Growing in Consciousness' (www. michaelroads.com).

\section{Sergio Rodríguez Rodríguez}

Sergio Florentino Rodríguez Rodríguez graduated as an agronomist in 1987 from the University of Matanzas, Cuba. Head of the Department of Genetic Improvement of the Sugar Cane Research Stations in the provinces of Granma and Ciego de Ávila, he gained a Master's in Agricultural Sciences in 1999 from the University of Granma and a Doctorate in Agricultural Sciences in 2008 from the same university. He became Professor at the University of Granma in 2013 and Director of International Relations from 2008 to 2017. He has published more than 25 scientific articles as author or co-author, and two book chapters. He has directed undergraduate, masters' and doctoral theses. Coordinator of several international projects, he has carried out research stays in Belgium, China, Spain and Argentina. His field of research and teaching is genetics, plant physiology and the use of statistics in research, and on the topics of stress due to soil flooding, physical and chemical treatments for seed priming in sugarcane, mulberry, rice and papaya crops. He is a reviewer of scientific journals including the HOLOS journal (web of science, http://www2.ifrn.edu. br), a member of scientific editorial committees, and coordinator of the Environment Management Master's at the University of Granma.

\section{Melissa Roussopoulos}

Since 2005, Melissa Roussopoulos has been pioneering, researching and running Nature Constellations, an experiential group methodology that provides insights and solutions for questions about human interactions with ecological systems. Clients have included farmers, landowners, agronomists, environmental groups and university agricultural departments, bringing issues from difficulties with domestic animals to planning complex agricultural projects to concerns about global environmental problems.

Melissa's Nature Constellations work draws on her training in Organisational and Family Constellations, both well-established methods, as well as her experience in a post with the nowhere foundation researching the application of Constellations into different professional fields. It is also informed by her interdisciplinary research into interspecies communication.

Her background is as an environmentalist, and she worked on multi-stakeholder approaches to sustainability issues at The Environment Council, a UK-based charity, as well as undertaking research projects for international NGOs and the Austrian government. She has an MSc in Natural Resource Management (University of Leicester) and a BA in History and Philosophy of Science (University of Cambridge) (www.forgottenconnections.org).

\section{Juan José Silva Pupo}

Graduating as an agronomist in 1989 at the Higher Institute of Agricultural Sciences of Bayamo (ISCAB), current University of Granma, Juan has 30 years of teaching experience. He gained his $\mathrm{PhD}$ in Agricultural Sciences from the University of Granma in 2006 and became Professor in 2008. He has since held the posts of Dean of the Faculty of Agricultural Sciences (2010-2012), Vice-rector for Research and Postgraduate Studies at the University of Granma (2012-2015), and Director of the Center for Plant Biotechnology Studies (2007-2010 and 2015-present). He is Coordinator of national and international projects, including Coordinator of the Master's Degree in Agricultural Biotechnology (2017-2020) and Coordinator of the UNESCO Chair in Agricultural Biotechnology for Local Development, approved in 2014 jointly by UNESCO and the University of Granma. He has given courses and conferences on agricultural biotechnology and project management in Ecuador, Colombia, Venezuela and Guatemala. A tutor of diploma, master's and doctorate research, he has participated in numerous symposia and congresses in Portugal, the Netherlands and Cuba. He is the coordinator of the International Workshop on Sustainable Agriculture and Plant 
Biotechnology, which is part of the Cuban Congress on Local Development and is held every 2 years at the University of Granma. He has published more than 40 articles as lead author and co-author.

\section{Anneloes Smitsman}

Anneloes is a visionary scientist, published author, futurist, system architect and global catalyst. She holds a Master's degree in Law and Judicial Political Sciences from Leiden University and received a degree of Doctor from Maastricht University, the Netherlands. Her research 'Into the Heart of Systems Change' addresses how to transform the dualistic systemic barriers via a 'Transition Plan to a Thrivability Civilisation'. Anneloes has a unique vision and understanding of the Cosmic architecture of life, which she applies in all of her initiatives. She is the author of the Amazon Bestseller Love Letters from Mother Earth - The Promise of a New Beginning, and a forthcoming book 'Future Humans' with Dr Jean Houston. Anneloes is passionate about empowering people in developing the future systems, capabilities and living vision for an evolutionary civilisation. She is the lead architect of the EARTHwise Tipping Point System and a powerful teacher of Evolutionary Leadership, Social Innovation and Transformational Change. Her unique programmes have empowered thousands of people and organisations from around the world. She is a member of the Evolutionary Leaders Circle (www.earthwisecentre.org).

\section{Angel De Souza-Torres}

Angel Rafael De Souza Torres was born on 1 August 1967 in Bayamo, Granma, Cuba. Prof De Souza-Torres obtained his MSc in Physics from the Faculty of Physics and Mathematics, University of Oriente, Santiago of Cuba, in 1990. Presently, Prof De Souza-Torres is working as Professor of Physics in Department of Physics and Mathematics, Faculty of Technical Sciences, Granma University, Bayamo, Granma. Prof De Souza-Torres' main area of research includes bioelectromagnetism and the effects of extremely low-frequency non-uniform magnetic fields (MFs) on seed vigour, plant growth, water relations, photosynthesis and yield of crops grown under abiotic, biotic and non-stress conditions. He also is investigating the tracking of iron oxide nanoparticles in plant organs using magnetic measurements and the impact of $\mathrm{Fe}_{3} \mathrm{O}_{4}$ nanoparticles on nutrient accumulation in common bean plants in collaboration with Institute of Physics, University of Sao Paulo, Brazil. He has been awarded a grant by Soleil Synchrotron, Paris, for a research cooperation project in collaboration with the European Synchrotron Radiation Facility, Grenoble, France. He has made major contributions in the field of bioelectromagnetism, especially in the improvement of germination, plant growth, water relations, photosynthesis, yield of tomato and onion crops and the protection of plants against heat stress and pathogens by MFs under field conditions. He has published several papers in high-impact journals and is a regular reviewer of 15 international journals. He was awarded the National Award of the Cuban Academy of Sciences in 2008 (www.udg.co.cu).

\section{Joël Sternheimer}

Joël Sternheimer holds a degree in Mathematics (Paris, 1964) and a PhD in Theoretical Physics (Lyon, 1966). His early research in theoretical physics was supported by income from his singersongwriting royalties, and he then undertook independent research on the masses of elementary particles, supervised by mathematical physicist André Lichnerowicz, a member of the Academy of Sciences. He has been involved in the development of various publications and patents, as well as giving seminars at the Collège de France. Since 1984, he has been scientific advisor on patent licensing to the Cité des Sciences et de l'Industrie, Paris, and from August 1985, has been working on applications related to the decoding of proteodies according to the method described in patent No. FR 92 06765 (filed in 1992), WO 1993/024645, which was published on 29 August 2007. From 1986 to 1988, he was Director of Seminars at the Collège International de Philosophie, Paris, co-organising the Colloquium 'Louis de Broglie, physicist and thinker', and since 1994 in a similar role at the European Research University, Paris. In 1999, he became Founding President of the Associative Network of Independent Researchers, and in the same year, he received the Philips-Science Front 
Award. He has implemented various agronomic applications, at the Nagata Agric. Research Institute, Japan, 2000-2003, and after that in France, in particular in viticulture, market gardening and oyster farming.

\section{Peter Stolz}

As an analytical chemist, Dr Peter Stolz is leading the institute KWALIS Qualitätsforschung, in Dipperz, Germany. He studied chemistry at the University of Bielefeld, Germany, from 1978 to 1986, and obtained his $\mathrm{PhD}$ (Dr. rer. nat.) from the chemistry department of the University of Oldenburg, Germany, in 1989. He worked at the Bremer Umweltinstitut, Germany, where his scientific and financial chairmanship lasted for 9 years. His cooperation and collaboration in the years 1998-2010 with Dr Jürgen Strube, who established the institute KWALIS, empowered him to continue the scientific work of Jürgen Strube and combine it with the knowledge of chemistry and the competence to work with modern analytical techniques. His concern to view food not only as the sum of single chemical substances, but as a whole that is integrated into life processes, has resulted in, among other things, the book Food Mediates Life (German: Lebensmittel vermitteln Leben), and this interest is present in all of his scientific activities (https://www.kwalis.de/).

\section{Jack Tuszyński}

Prof Tuszyński obtained his $\mathrm{PhD}$ in condensed matter physics in 1983 from the University of Calgary. From 1983 to 1988, he was a faculty member at the Department of Physics of the Memorial University of Newfoundland. He moved to the University of Alberta in 1988 as an assistant professor; between 1990 and 1993, he was an associate professor, and then full professor at the Department of Physics until now. Between 2005 and 2020, he held the prestigious Allard Chair in Experimental Oncology at the Cross Cancer Institute. He was also a Fellow of the National Institute for Nanotechnology of Canada. Dr Tuszyński held visiting professorship and research positions in China, Germany, France, Israel, Denmark, Belgium and Switzerland. He has published over 500 peer-reviewed journal papers and 12 books. He delivered almost 400 scientific talks at conferences on five continents, half of which were invited presentations. He submitted 21 patent applications and obtained 4 patents in the USA, South Korea, Japan and Singapore. His research has been supported by over 100 research grants from Canadian, US and European funding agencies. He is on the editorial board of almost 30 international journals including the Journal of Biological Physics. He is an Associate Editor of The Frontiers Collection at Springer-Verlag, Heidelberg. The major thrust of his computational biophysics group is in silico drug design for cancer chemotherapy applications.

\section{Medardo Ángel Ulloa Enríquez}

Medardo Ulloa Enríquez is a works engineer at the Equinoccial Technology University, Ecuador. He holds a Master's in Production Management and a Diploma in Didactics of Higher Education both from the Technical University of Cotopaxi, Ecuador. He also has a $\mathrm{PhD}$ in Technical Sciences from Oscar Lucero Moya, Holguín, Cuba. Director of productive projects at the Technical University of Cotopaxi (Ecuador), he has published more than 15 scientific articles and has tutored undergraduate and masters' theses. His research is based on the risks of work, quality systems and environmental aspects in different areas of research and production.

\section{Rovier Verdi}

As a rice grower's son, Rovier Verdi has worked his whole life with agriculture. After his graduation in agronomy, from 2010 to 2015 at the Catarinense Federal Institute of Education, Science and Technology, Rio do Sul, Brazil, he became interested in agroecology and got in contact for the first time with homeopathy for plants. There he studied homeopathy applied to medicinal plants. During 2016 and 2018, he did a master's degree in plant production at the Agroveterinary Science Centre of the Santa Catarina State University, Brazil (CAV/UDESC), working with the propagation of a Brazilian native medicinal plant (Poiretia latifolia) and homeopathy. Since then, he has been a member of the Laboratory 
of Homeopathy and Plant Health/Lages Experimental Station of EPAGRI, Brazil. During the same period, he took a specialisation on agroecology at the Santa Catarina Federal Institute of Education, Science and Technology, Lages, Brazil, working with homeopathy in rice crops. Nowadays he is doing a PhD in Plant Production at the CAV-UDESC and in Interdisciplinary Studies in Agroecology, Water and Resilience at the Centre for Agroecology, Water and Resilience of Coventry University, UK. He is working with eco-intensification of irrigated rice production where he is examining mainly the practices supported by the System of Rice Intensification method, innovative technologies such as homeopathy and biodynamics and a knowledge-intensive research methodology, based on a researcher-farmer participatory approach to improve the state of knowledge on sustainable rice production in Brazil. He is the Santa Catarina State representative for the Brazilian Association of Homeopathy for Agriculture, Livestock and Environment, as well as Editor of Brazilian Journal of Agroecology.

\section{Jenifer Wohlers}

The research focus of Jenifer Wohlers is on organic and biodynamic farming practice and agricultural scientific knowledge, commencing when she studied organic agriculture and undertook her $\mathrm{PhD}$ from the University of Kassel-Witzenhausen in Germany. Since 2011, she has been working as a scientist at the research institute KWALIS in Dipperz, Germany.

An important topic of her research is the evaluation of food quality from analytical as well as holistic quality aspects, in relation to both farming-relevant factors in organic agriculture and processing-relevant factors in food excellence, with the aim to develop food quality parameters which complement the established analytical parameters and may point to health and welfare aspects in food production situations (for both plants and animals), or point to improvements in consumer well-being (https://www.kwalis.de/). 


\section{Index}

Note: Bold page numbers refer to tables; italic page numbers refer to figures and page numbers followed by " $n$ " denote endnotes.

abiotic stress 101

effects of MFs on 102-103, 102-105

Abram, D. 191

Abrams, A. 264

acoustic diffusion system 112

action potentials 131

Afonso, G. 124

Africa

ancestral support in 29,30

reality 24

age-old practice, intuitive communication as 239-240

Agnihotra in India 29, 29

agricultural method, influence of 183-185, 184, 185

agricultural practices $27-31$

Agnihotra in India 29, 29

ancestral support in Africa 29, 30

from different worldviews 23-27

harmonising the Earth and cosmic forces in Europe 29

sacrifices and festivals in Andes 29

Sri Lanka: Mantras, Yantras and Kems 28, 28

agriculture

astronomical rhythms in biodynamic 126-130

biodynamic 75, 263

'freebie' in 305-307

homeopathic therapy in 148-149

homeopathy in 149-151

organic/biodynamic 183

regenerative 243

Sustainable Yogic Agriculture 248-255

agroecology

appropriateness of homeopathy for 151

movement 10

agroforestry (AF) systems, cocoa beans growth in 173,

$$
\text { AGRUCO } 24
$$

$$
\text { 173-174, } 174
$$

airborne sounds 272

Akasha 24

Akay, A. 138

Albrecht-Buehler, G. 83

Alexander, B. 244

alternating current (AC) 132

Altieri, M. 10

'Amrit Vela' 249

ancestral support, in Africa 29

Andes

Pacha Mama ritual in 30

sacrifices and festivals in 29

Andeweg, H. 192, 244

Anglo-Portuguese Treaty of 189140

Angora rabbits 295-296

animals and plants, influence of moon on 124-126

animism 306

Apis mellifera 273
Aristotelianism 51

Aristotle 52, 57

Metaphysics 53

artistic and spiritual techniques 198

astronomical rhythms, in biodynamic agriculture 126-130

Australian Standard Wheat (ASW) grades 310

Bacon, C. 22

Bacon, F. 7n2

The New Atlantis 51

Bailey, L.H. 64

Balfour, E. 62

'bare awakening food' 210

Baring, A.

The Dream of the Cosmos: a Quest for the Soul 7

Barratt, M.J. 223

Bateson, G. 193, 280

Steps to an Ecology of Mind 61

BD Soil Activator 266

Beck-Eccles model 84

Beck, F. 84

bee-friendly beekeeping 274-275

bees

demise of 269-270

evidence on physical and metaphysical characteristics of 272

intricate life of 270-272

sounds of 273

behaviours, evolutionary coherent 95

de la Bellacasa, M.P. 204

Benada, J. 137

Benveniste, J. 296

Berman, M. 15

Berry, W. 65

Beuys, J. 205

biodynamic agriculture 75, 263

astronomical rhythms in 126-130

biodynamic farmers 12

biodynamic farming 10

biodynamic management 126-129, 127, 128, 128

biodynamic movement, international 123

biodynamic preparations, through radionic applications 264-266

biological systems 83

biophotonics 87

biophotons 167

biotic stress 101

effects of MFs on biotic stress 105-106, 106

Bird, C. 241, 263

Blackman, V.H. 139

Bloksma, J. 170

Bockemuhl, J. 75, 232-235 
body

deeper familiarisation with 196-197

and environment, broadcasting between 194-195

mind and 196

Boff, P. 148

Bohm, D. 193-195

Bohr, N. 82, 260

Bonamin, L.V. 151

Bortoft, H. 280

Bose-Einstein condensation 85

Brahma Kumaris 250, 251, 254

Brahma Kumaris Rural Development Wing 248-249

meditation centres 249

spiritual movement 248

Brix 302, 302n 3

broadcasted programmes 111-112

broadcasters, field towers and 310-311

Brundtland Commission of 198790

Buddhism 66

buddhist $66-67$

Burke, J. 13

Bushmen, K. 56

Cajete, G. 67

Callahan, P. 14, 310, 310n7, 311

Callicott, J.B. 5

Camara, F.L.A. 126

Canadian Prairies, agriculture in 6

capacitance 132,133

capacitor 132-133

CAPTURED programmes 27

Cartesian science 23

CCD see colony collapse disorder (CCD)

Chikramane, P.S. 147

Chikukwa Ecological Land Use Community Trust 42

Christian-Traditionalist relationships and practices 45

chromophores 83

chronobiology 126

Cicero, D. 54, 55

Clark, D. 133

cocoa beans, growth in monocultures or agroforestry systems $173,173-174,174$

code of conduct, farmers 250

cognitive factors, behind the industrial worldview $6-8$

collective excitations 82

Collingwood, R.G.

The Idea of Nature 51

colony collapse disorder (CCD) 273

Colquhoun, M. 229, 287

combined heat and power (CHP) system 132

commodification of nature 57

communication

intuitive 240-241

intuitive or interspecies 241

with 'spirit realms' 294

COMPAS programmes 27

computational biology 81

conductivity 132

Conroy, J. 244

consciousness

engaging with elemental 296-300

engaging with nature spirit 300-302

quantum 84-86

consciousness-actualising affordances 95 constellations

'Family Constellations' 220

Nature Constellations 220-223, 227

organisational 220

conventional progress, cost of 90-91

Copenhagen interpretation of quantum mechanics 82

coronavirus crisis 91

cosmic forces, in Europe 29

cosmic influences 26

cosmic sense 50

cosmos 7, 52, 53, 271, 306

cosmovisions, traditional 27

Courtney, H.J. 11

Cox, T.E.B. 14,65

crop 76, 102, 104, 131-132, 158-161

development 184

diversification 8

and livestock yields 16

materia medica for some farm $\mathbf{1 5 0}$

production 101, 105, 266, 310

protection 135

Cryan, J. 64, 65

crystallisation method 180-183, 181-183

Cseresnyes, I. 135, 136

Cuba

agricultural strategy 4-5

economic vulnerability 4-5

Cucumis sativus $\mathbf{1 0 3}$

Cullen, W. 146

cultivating right-brain abilities, and expanding consciousness 198-199

cultivating sympoiethics 215-217

culture laced with power 42

Currivan, J. 92, 93

Cyclone Idai 40, 44

Darwin, Charles 22

Daucus carota L. 126-129, 127, 128, 128

Deboni, T.C. 150

Deep, K. 125

'delicate empiricism' 74

Dempster, B. 203

Descartes, R. 22, 23

Deutsche National-Literatur (Goethe) 75

von Diest, S.G. 239

Dietrich, R.C. 135,136

diffusion system, acoustic 112

Dirac, P. 260

direct current (DC) 132

discontinuous metamorphosis 233

'DOC-trial' field experiment 169-170, 170

Dokuchaev, V.V. 62

Doussan, C. 137

The Dream of the Cosmos: a Quest for the Soul (Baring) 7

dry root mass 127

Ducharme, L.J. 254

Dutton, D. 241

dynamisation

alternative method of 288-289

of water 287-288

Earth and cosmic forces in Europe 29

earth meridians 294-295 

The Earth's Blanket: Traditional Teachings for
Sustainable Living (Turner) 67

Eccles, J.C. 84

eco-feminism 66

eco-feminist and indigenous 66-67

EcoIntention 191, 192

ecological farming 4

ecological systems, human systems interacting with 225-226

economic domains, growth in 89

eco-psychology 60

look at human/soil relationships

non-dual aspects of 64

non-dual form 59

ecosystems 224-225

EcoTherapy 192n1

Edmunds, F. 12

Edwards, L. 281

van Eijk, T. 243, 254

Einstein, A. 12, 308

Eisenstein, C. 247

electrical capacitance (EC) $135 \mathrm{n} 4$

electrical impedance (EI) 133, 135n4

electrical parameters 139

and monitor plants' status, development and process 134-138, 135, 136

electrical potentials 131

electric current 132

electric phenomena inside plant 133-134, 134

electroculture 140

electromagnetic fields (EMFs) 101

electromagnetism 132

colony collapse disorder and impacts of 273-274

electrophysiology, plant 131

elemental consciousness, engaging with 296-300

Eliade, M. 306, 306n2, 307

Elliott, J. 125

EMFs see electromagnetic fields (EMFs)

emotional literacy 197-198

Emoto, M. 254, 299, 309

empiricism 22

endogenous development 28

energy

harnessing subtle energy through geomancy 307-308

signals, radio frequency 140

subtle energy

as next big 'freebie' in agriculture 305-307

through geomancy $307-308$

Engel, G.S. 83

environmental humanities 59

environmental stress 101

Erickson, D.L. 241, 243, 254

Escher, P. 263

ESP see extrasensory perception (ESP)

ether 260-262

ethical relation with nature 51-52

ethno-astronomy, importance of 123-124

Eucalyptus globulus $\mathbf{1 0 3}$

Europe, harmonising the Earth and cosmic forces in 29

evolutionary coherent behaviours 95

Ewald, A. 287

extrasensory perception (ESP) 241
Fabian, S.M. 124

Fabre, D. 273-274

'Family Constellations' 220

Faraday, M. 260-261

farm-emitters 311

farmers

code of conduct 250

perspectives on impacts of SYA 252-253

SYA farmers at specific farming events $\mathbf{2 4 9}$ transformation of intuitive 243-244

farming

applying intuition in 241-244

with hidden half of nature $12-16$

intuitive communication in 241-243

with radionics 266

farming communities, cosmovisions of indigenous 25

farming of tomorrow 95

farming practice, paradigm shift for 247-248

farming system

contemporary, ecologically based 8-12

ecologically based 9-12, 12

meditation-focused 255

farming techniques 47,320

organic 250

'unconventional' 14

A Feeling for the Organism 76

Feller, C.

Soil and Culture 59-60

FES see fluorescence excitation spectroscopy (FES)

FieldTable, food ritual 206-208, 208-215, 215-217

field towers and broadcasters 310-311

Fink, K. 75

Fleming, G.R. 83, 84

flooded plants, gas exchanges in organs of 156

flooding, soil 156

flower power, importance of 275-276

flowform movement 288-289

flowform water sculpture 288, 288

fluorescence excitation spectroscopy (FES) 167, 168

apple quality: maturation and growing conditions 170-171, 171, 172

cocoa beans grown in monocultures or in agroforestry systems $173,173-174,174$

'DOC-trial' field experiment 169-170, 170

effects of farming systems on food quality $168-174$

emission spectrums as dependent on type of sample 171-173, 172

measurement method 168

'focussing' $197 \mathrm{n} 12$

food production 14, 23, 180, 207

in home gardens 40

organic 151

raw materials for 156

food quality 185

food ritual, FieldTable 206-208, 208-215, 215-217

food rituals, knowing through 205-206

food web, soil 59, 259

Fouke, D. 60, 61

Fox, M. 205

'freebie,' in agriculture 305-307

Fusarium sp. 105

'future creative' 94 
Galeazzi, B. 148

Gardner, H. 193

gas exchanges, in organs of flooded plants 156

Gasner, W.G. 139

Geertz, C. 205

Gendlin, E. 197n12

Genodics 111, 112

case study $112-120, \mathbf{1 1 3}, 115-119$

on plant production 120

geomancy $308 \mathrm{n} 4$

harnessing subtle energy through 307-308

geometry and gestures in flow 280-285

geopathic stress 294

gestures

in flow 280-285

of flow 285-286

Giesel, A. 150

Global Reporting Initiative (GRI) 91

Global System for Mobile Communications (GSM) 111

Glycine max L. 102, 103

Goethean approach 229-237, 236, 279-280

being one with object 235-236

clearing the workspace 230-231

exact sense perception 231-232

exact sensorial imagination 233-234

seeing-in-beholding 234-235

selection of study 230

von Goethe, J.W. 71-75, 260, 261, 280, 287

and biodynamic agriculture 75

Deutsche National-Literatur 75

The Metamorphosis of Plants 73

Theory of Colours 75

Golden Age 49, 55

Goldstein, W. 123, 125, 128

Gould, J.L. 274

Goulding, K.W.T. 5

The Great Transformation (Polanyi) 57

Greening the Paranormal (Hunter) 14

Green Revolution

models 4

technological packages 5

Greenway, R. 63, 64

GRI see Global Reporting Initiative (GRI)

Griffin, D.R. 61

Griffin-Pierce, T. 67

Grimes, R. 204

GSM see Global System for Mobile Communications (GSM)

Gurney, C. 244

Gurwitsch, A. 167

Hahnemann, C.F. 145-147, 152

Halberg, L. 13

Hanh, T.H. 66

Haraway, D. 203-204

harmony, recollecting primordial 57-58

Harvey, G. 192n3

healthy living systems, infodynamics of 92-95

Heisenberg, W. 82, 260

Hellinger, B. 219, 220

Hieronymus, T.G. 265n2

Hillman, J. 63

Hobbes, T. 52

Hoffman, N. 287
Hoffmann, M. 138, 139

von Hohenheim, B. 146

holarchic complex developmental patterns 95

Holdrege, C. 75

home gardens, food production in 40

Homeopathic Materia Medica 146, 149, 150

homeopathic potentisation 289-290

homeopathic therapy, in agriculture 148-149

homeopathy

in agriculture 149-151

for agroecology 151

historical overview 145-147

integrative 148-149

applying the concept of 148-149

mechanisms behind the concept of 147-148

Horwitz, J. 192n4

hot tent, in Telangana 3-4

Howard, A. 8, 9-10

Huambachano, M.A. 9, 15

human being, role of 74-75

human energies, healing and renewal of residual 302-303

human interactions, role of more-than-human interactions in generating change $42-44$

humanities, environmental 59

humans as humus 63-65

human/soil relationships, eco-psychological look at 63-65

human systems, interacting with ecological systems 225-226

human traits 23

humus, humans as 63-65

idealism 22

The Idea of Nature (Collingwood) 51

India, Agnihotra in 29, 29

indigenous communities 26

indigenous cultures 240

indigenous farming communities, cosmovisions of 25

indigenous ontologies, farming practice based on 13

indigenous relationship of people, land and nature 8-9, 9

indigenous sciences, and interactions 25,26

indigenous totems, and nature spirits $311-313$

inductance 132

industrial farming 156

industrial models 4

industrial worldview

cognitive factors behind the $6-8$

stranglehold of 4-5

Infeld, L. 12

infodynamics 93

of healthy living systems 92-95

Ingold, T. 193-195

inhabiting sympoiesis 203-204

Inner Quality Concept 170n2

integrated farming 93

Integrated Reporting (IR) 91

integrative homeopathy 148-149

international biodynamic movement 123

International Forum for System Constellations in Organisations 220

International Permaculture Conference (India) 3

interspecies communication 241 reflections on 223

intuition

applying intuition in farming 241-244 
defining and understanding 240-241

intuitive communication 240-241

as age-old practice $239-240$

in farming 241-243

The Intuitive Farmer: Inspiring Management Success (Nuthall) 243

intuitive farmer, transformation of 243-244

intuitive interspecies communication 241

IR see Integrated Reporting (IR)

Jackson, W. 65

Jacobs, D. 216

Japanese fermentation method 213

Jenny 62

Jewish culture 206

Jovchelevich, P. 124, 126

Jung, C. 240

justice and nature 52

Kahuda, F. 309

Kant, E. 260

Kara, Z. 138

Keller, E.F. 76, 77

Kertz, M.G. 140

Kieft, H. 14, 15, 241-244, 254

Kimmerer, R.W. 61

Kirschenmann, F. 61, 62

knowing and learning 195-196

Knowledge of the Higher Worlds (Steiner) 244

Koestler, A. 91

Kokornaczyka, M.O. 148

Koppert Biological Systems 134, 136, 141

Kornfield, J. 66

Kripalani, D.L. 248

Kruskal-Wallis test 160

Landa, E.R.

Soil and Culture 59-60

landscape

changing relationships with 41-42

and people 40

land whispering 293-294

Laplace, P-S. 260

laser biotechnology pretreatment 157-158

laser treatment 156, 157

Latin America: The Andes 24

Law, Natural 54-56

learning and ways of knowing 24-25

learning, knowing and 195-196

Lemke, H. 205

Leopold, A. 65

Lepidium sativum L. (garden cress) 124-125

Levy, P. 6

life ether 261

life-forming forces 290

Life Science Trust 230n1

light ether 261

livestock 11, 16, 91, 149, 151, 270, 319-321

Lobreiro, J.C.T. 125

Loehr, F. 253

love 23, 248, 249, 319

Lovel, H. 14

Lowenstein, W. 84

low-power laser biotechnology pretreatment under flooding stress in mulberry and sugarcane 158-162, 159, 160, 161, 161

on shooting and initial growth of mulberry and sugarcane $157-158$

lycopene 179

MacManaway, P. 244, 305, 306, 309, 310, 313

macroscopic quantum phenomena 86

magnetic fields (MFs) 101

effects on abiotic stress 102-103, 102-105

effects on biotic stress 105-106, 106

magnetic treatment 105

Manzalini, A. 148

Marsden, M. 9

Marti, E. 261

Mason Boring, F. 224, 226

Mason, R. 311

The Master and his Emissary: the Divided Brain and the Making of the Western World (McGilchrist) 6 materialism 22, 25

Materia Medica, Homeopathic 149, 150

Matopos Hills 41

matter, mind and 22-23

matter-wave equation of de Broglie 111

Mawere, A. 45

Maxwell, J.S.

ether and etheric realms 260-262

McClintock, B. 71

understanding of organisms 76-78

McCosker, T. 306, 310

McCraty, R. 241

McGilchrist, I. 6-8, 12

The Master and his Emissary: the Divided Brain and the Making of the Western World 6

McTaggart, L. 193

meditation

focused farming system 255

Raja Yoga Meditation 249, 249-250

meditative techniques 24

Menaken, R. 207

mental thought 309

metamorphosis, discontinuous 233

The Metamorphosis of Plants (Goethe) 73

Metaphysics (Aristotle) 53

metaphysics of nature 315-322

methodology 32, 168, 219, 220, 227, 283, 329, 331, 334

Metzner, R. 65

MFs see magnetic fields (MFs)

Miche, F.L. 206, 207, 216, 217

Michelson and Morley's experiment 261

microbiome, root 140-141

microtubules (MTs) 83

mind

and body 196

and matter 22-23

mind-matter connection, Sustainable Yogic Agriculture 253-254

Mittal, R. 125

mobility, time and sense of 73-74

modernist

with indigenous worldviews of nature and of farming 9,9

societies 12,15

modern proprietorial relationship 57 
modern sciences 21,22

modern technology, advancements in 23

Mollison, B. 3, 10, 11

monocultures, cocoa beans growth in $173,173-174,174$

Moore, D. 42

'Mother Earth' 62

'movement gestures' 279-280

Movement Medicine 191, 192

MT-associated protein (MAP2) 86

mulberry (Morus alba)

laser biotechnology pretreatment on the shooting and initial growth of 157-158

low-power laser biotechnology pretreatment under flooding stress in 158-162, 159, 160, 161, 161

Musapa River 40

'mythic consciousness' 50

Narby, J. 193

narrative consciousness, and teleology 50-51

National Soil Tilth Lab 59

natural inclination, to responsible knowledge 53-54

Natural Law 54-56

natural virtues 54

nature

commodification of 57

ethical relation with $51-52$

and of farming, indigenous worldviews of 9

as intelligent 52-53

nature communication 9

Nature Constellations (NCs) 221-223, 227

development of 220-221

nature immersion 199

nature spirits

angelic to elemental and 294

consciousness, engaging with 300-302

indigenous totems and 311-313

NCs see Nature Constellations (NCs)

Nelson, R. 253

neurotransmitter system 84

The New Atlantis (Bacon) 51

Newton, I. 22, 260

'noetic ecology' 241

non-duality 66

non-dual perspectives, buddhist, eco-feminist and indigenous 66-67

Northolt, M. 138

Nuthall, P.L.

The Intuitive Farmer: Inspiring Management Success 243

objective dimension 50

obligate parasite $138 \mathrm{n} 6$

Old, K.M. 243

Olyslaegers, S. 140

oomycetes $138 \mathrm{n} 7$

Orch OR hypothesis $85-86$

orders of truth 50

organic/biodynamic agriculture 183

organic farming consultancy 320-321

Organisational and Family Constellations 220

Organisational Constellation 220

Orr, D. 6 "other-than-human-beings" 191-193

over-reliance on theory, rejection of 72-73

Ovid 55

ownership and right use 55-56

Pacha Mama 24, 29, 92

ritual in Andes 30

Palmer, J.D. 124

Pandey, S.T. 251

Paracelsus 146

Patzel, N. 62-63

Peat, D. 14

Pennick, N. 308

Penrose-Hameroff orchestrated objective reduction (Orch OR) theory 85-86

Penrose, R. 85

people, land and nature, indigenous relationship of 8-9

permaculture 3, 8-11, 42

Pfeiffer, E. 180, 263

Pfeiffer, T. 12

phase angle 133, 133

philosophy $52,151,205,248,260$

environmental 59, 324

Greek 50, 261

photons 167

generation of 87

photosynthesis 133

physical rituals 244

Pimbert, M. 11

Planck, M. 81, 259

plant

electric phenomena inside 133-134, 134

electrophysiology 131

growth regulators 157

plant production, genodics on 120

plants and animals, influence of moon on 124-126

plant stress 101

Plato 52, 57

von Pohl, B.G.F. 294-296

Polanyi, K.

The Great Transformation 57

political ecology 39

pollinators 133

Popp, F.A. 167, 168

POR method (Procedure, Observation, Report) 195n11

Portales, M.F. 150

Posey, D.A. 9

Postic, F. 137

potential drop 132

power, culture laced with 42

primordial harmony, recollecting 57-58

primordial sense of order $49-50$

production

crop 101, 105, 266, 310

food $14,23,40,156,180,207$

plant 120

proprietorial relationship, modern 57

proprietorial self, rise of 56-57

proteodies 111

psycho-energetics 309n6

pulsed electromagnetic fields (PEMFs) 101, 102

Pythagoras 194n9 
quality

food 185

effects of farming systems on 168-174

Inner Quality Concept 170n2

'quantum beating' effect 84

quantum biology 81

quantum chemistry to $82-84$

quantum chemistry, to quantum biology $82-84$

quantum coherence 83

quantum consciousness $84-86$

quantum-informed agriculture (Q(I)A) 191

quantum mechanics 82

Quantum theory 147

'Quilombola' agricultural management 124

de Quincey, C. 192-194, 194n9, 195

'radical knowing' 195n10

Radin, D. 253

radio frequency (RF) energy signals 140

radionic applications, biodynamic preparations through

$$
\text { 264-266 }
$$

radionics 264

farming with 266

Raja Yoga meditation 249, 249-250

Rajda, V. 134, 139

Ramprasad, V. 13

Ramsay, T. 249-251

Ramthun, A. 133, 134

Rao, P. 29

'rational' political ecology 39

Raval, K. 251

Raven, S. 244

raw materials, for food production 156

reactive oxygen species (ROS) 105

reality 24

African 24

re-cognising ritual 204-205

regenerative agriculture 243

resistance 132,133

resistance-capacitance (RC) circuits 136

responsible knowledge, natural inclination to 53-54

rhythm 285-286, 286

Ricciardi, L.M. 85

Rickard, S. 5

Ricoeur, P. 49, 58

right use, ownership and 55-56

ring vortex 282, 283, 284

rituals

food, knowing through 205-206

physical 244

re-cognising 204-205

Roney-Dougal, S.M. 254

root microbiome 140-141

ROS see reactive oxygen species (ROS)

Roszak, T. 6, 64

Roussopoulos, M. 226

Rusch, H-P. 62

sacred sites 92, 309

Sadler-Smith, E., 243

Salami, M. 204

Sanches, R.A. 124
Schrodinger, E. 82, 260

Schroer, K.J. 75

Schwenk, T. 279

science

Cartesian 23

indigenous sciences and interactions 25, 26

modern 21, 22

Western-based science 21, 23, 26, 260

scientific laws 92-93

secular-material frameworks 11

secular-materialist mind 15

secular-materialist worldview 8,15

self-regulation $179 \mathrm{n} 1$

Seneca 55

Sewall, L. 65

Shapiro-Wilk test 160

Shefy, E. 243

Sheldrake, R. 193, 262

Silva, W.R.G. 147, 148

Simao, S. 124

Sloan, K.E. 226

Smith, A. 22

Smitsman, A. 90, 94

socio-political landscape, Zimbabwe 41 soil

from 'inner soil' to being soil 62-63

western concerns for 60-62

Soil and Culture (Landa and Feller) 59-60

soil flooding 156

soil food web 59, 259

soil shrine making 213

Solfvin, J. 254

Somatics Toolkit 199n15

sounds

airborne 272

of bees 273

waves 111, 191, 194

Spiess, H. 123, 125

spiral vortex gesture 282, 282

spirit

indigenous totems and nature $311-313$

nature spirit consciousness 300-302

'spirit realms,' communication with 294

Spiritual Foundations for a Renewal of

Spretnak, C. 66

Agriculture: A Series of Lectures

(Steiner) 11

Steel, C. 205

Steiner, R. 10-13, 71, 75, 123, 126, 147, 195, 206, 240, 244, 261, 263, 270-272, 275, 280,287

and biodynamic agriculture 75

Spiritual Foundations for a Renewal of Agriculture: A Series of Lectures 11

Steps to an Ecology of Mind (Bateson) 61

Sternheimer, J. 111

Stolz, P. 168, 170, 172

Stoneham, M. 84

Strube, J. 167, 170, 172

subtle agroecologies

definition of 15-16

state-of-the art of 13-15 
subtle energy 308

as next big 'freebie' in agriculture 305-307

through geomancy 307-308

sugarcane (Saccharum spp.)

laser biotechnology pretreatment on the shooting and initial growth of 157

low-power laser biotechnology pretreatment under

Sun, T. 141 flooding stress in 158-162, 159, 160, 161, 161

'survival of the fittest' 23

sustainable development 90

Sustainable Yogic Agriculture (SYA) 248, 254-255

farmers' code of conduct 250

impacts of

farmers' perspectives on 252-253

results of published research trials on 250-253, 251, 252

metaphysical component: practice of Raja Yoga Meditation 249, 249-250

mind-matter connection 253-254

origins of SYA methods 248-249

physical SYA practices 250

quantitative and qualitative benefits of $\mathbf{2 5 3}$

SYA see Sustainable Yogic Agriculture (SYA)

sympoiesis, inhabiting 203-204

sympoiethics, cultivating 215-217

syncretic relationship 24

synderesis 52

systemic constellations method 219

case study 221-226

evolution of 219-220

general reflections 226

human systems interacting with ecological systems 225-226

information from and about ecosystems 224-225

reflections on interspecies communication 223

reflections on representative perception 222-223

systems theory 148

Tansley, A. 65

Tasmania, surviving and learning in 315-319

Telangana, hot tent in 3-4

terra incognita 23

Terra Preta soils 92

terrestrial plants 156

Theory of Colours (Goethe) 75

Thompson, P. 263

Thomson, J.J. 261

Thun, M. 123

Tichavsky, R. 149

time and sense of mobility 73-74

Todres, L. 195

Tompkins, P. 241

tone ether 261

traditional cosmovisions 27

traditionalism 39

Trichoderma harzianum 141

Triticum aestivum $\mathbf{1 0 3}$

Turin, L. 84
Turner, N.J.

The Earth's Blanket: Traditional Teachings for

Turner, V. 205 Sustainable Living 67

ultra-low photon emission (ULPE) 167

ultra-weak photon emission (UWPE) 167

Umezawa, H. 85

'unconventional' farming techniques 14

United Nations Declaration on the Rights of Indigenous Peoples 8-9

vedic knowledge 24

Vilela, G.F. 124

Vincent's bioelectronic method (BEV) 138

da Vinci, L. 283, 284

vitalism $71 \mathrm{n} 1$

vitality $179 \mathrm{n} 1$

Volkov, A.G. 131

voltage (potential difference) 132

Voss, A. 14

warmth ether 261

water, dynamisation of 287-288

water moulds $138 \mathrm{n} 7$

Wawrecki, W. 139

Weber, M. 15

Weidmann, N. 288, 289

Wells, N. 288, 289

Western-based science 21, 23, 26, 260

Western colonial legacy 247

western concerns, for soil 60-62

Western dualism 67

van West, P. 138

Whispering, land 293-294

wholeworld-view $91 \mathrm{n} 1$

Wigner, E. 82

Wilkes, J. 288, 289

Williams, C. 241

Williams, M. 244

Wilson, K. 42, 45

Wilson, S. 14

Witchcraft Act of 17357

Wohlers, J. 168

worldviews, agricultural practices from different 23-27

Worster, D. 65

Wright, J. 254

yoga 24

yoga meditation, raja 249, 249-250

yogic see Sustainable Yogic Agriculture (SYA)

Zagorska-Marek, B. 139

Zajonc A. 75

Zanco, J.J. 148

Zeno 54

Zimbabwe, socio-political landscape 41

Zurcher 125

van Zyl, P.J.J. 140 